\title{
RESIDUE EVALUATION \\ OF CERTAIN \\ VETERINARY DRUGS
}

Joint FAO/WHO Expert Committee on Food Additives

78th meeting 2013

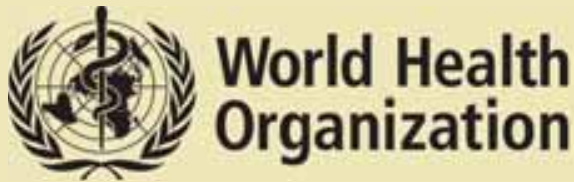




\section{RESIDUE EVALUATION OF CERTAIN VETERINARY DRUGS}

Joint FAO/WHO Expert Committee on Food Additives

78th Meeting 2013 
The designations employed and the presentation of material in this information product do not imply the expression of any opinion whatsoever on the part of the Food and Agriculture Organization of the United Nations (FAO) or of the World Health Organization (WHO) concerning the legal status of any country, territory, city or area or of its authorities, or concerning the delimitation of its frontiers or boundaries. The mention of specific companies or products of manufacturers, whether or not these have been patented, does not imply that these are or have been endorsed or recommended by FAO or WHO in preference to others of a similar nature that are not mentioned. All reasonable precautions have been taken by FAO and WHO to verify the information contained in this publication. However, the published material is being distributed without warranty of any kind, either expressed or implied. The responsibility for the interpretation and use of the material lies with the reader. In no event shall FAO and WHO be liable for damages arising from its use.

ISBN 978-92-5-108300-0 (print)

E-ISBN 978-92-5-108301-7 (PDF)

\section{(c) FAONHO 2014}

FAO and WHO encourage the use, reproduction and dissemination of material in this information product. Except where otherwise indicated, material may be copied, downloaded and printed for private study, research and teaching purposes, or for use in non-commercial products or services, provided that appropriate acknowledgement of FAO and WHO as the source and copyright holder is given and that their endorsement of users' views, products or services is not implied in any way.

All requests for translation and adaptation rights, and for resale and other commercial use rights should be made via www.fao.org/contact-us/licencerequest or addressed to copyright@fao.org.

FAO information products are available on the FAO website (www.fao.org/ publications) and can be purchased through publications-sales@fao.org. 


\section{CONTENTS}

List of participants iv

Abbreviations used vi

1. Introduction 1

2. General considerations 5

3. Derquantel 13

4. Emamectin Benzoate $\quad 23$

5. Gentian violet 39

6. Ivermectin 61

7. Lasalocid sodium $\quad 65$

8. Monepantel 89

9. Recombinant bovine somatotrophins 93

10. Zilpaterol hydrochloride 133

Annex 1 - Summary of JECFA evaluations of veterinary drug residues $\begin{array}{ll}\text { from the 32nd Meeting to the present } & 161\end{array}$

Annex 2 - Summary of Recommendations from the 78th JECFA on Compounds on the Agenda and Further Information Required 171

Annex 3 - Pilot of new approaches to estimate dietary exposure to $\begin{array}{ll}\text { veterinary drug residues } & 175\end{array}$

Annex 4 - Response from JECFA to nine questions posed by CCRVDF $20 \quad 205$

Annex 5 - JECFA Guidelines for the Extrapolation of MRLs to Minor Species 211

Annex 6 - JECFA guidance for the establishment of MRLs in honey 229

Use of JECFA reports and evaluations by registration authorities

Most of the evaluations and summaries contained in this publication are based on unpublished proprietary data submitted to JECFA for use when making its assessment. A registration authority should not consider granting a registration based on an evaluation published herein unless it has first received authorization for such use from the owner of the data or any second party that has received permission from the owner for using the data. 


\title{
LIST OF PARTICIPANTS
}

\author{
Seventy-eighth Meeting of the \\ Joint FAO/WHO Expert Committee on Food Additives \\ Geneva, 5-14 November 2013
}

\section{Members}

Professor A. Anadón, Department of Toxicology and Pharmacology, Faculty of Veterinary Medicine, Universidad Complutense de Madrid, Madrid, Spain (Joint Rapporteur)

Dr S. Barlow, Toxicologist, Brighton, East Sussex, England, United Kingdom

Dr J.O. Boison, Centre for Veterinary Drug Residues, Canadian Food Inspection Agency, Saskatoon, Saskatchewan, Canada

Professor A.R. Boobis, Centre for Pharmacology \& Therapeutics, Department of Experimental Medicine, Division of Medicine, Faculty of Medicine, Imperial College London, London, England, United Kingdom (Chair)

Dr L.G. Friedlander, Residue Chemistry Team, Division of Human Food Safety, Center for Veterinary Medicine, Food and Drug Administration, Department of Health and Human Services, Rockville, MD, USA (Joint Rapporteur)

Professor S.H. Jeong, Department of Applied Biotoxicology, Hoseo University, Hoseo Toxicology Research Centre, Asan City, Chungnam, Republic of Korea

Professor J. Palermo-Neto, Department of Pathology, Faculty of Veterinary Medicine, University of São Paulo, São Paulo, Brazil

Professor Emeritus L. Ritter, University of Guelph, Guelph, Ontario, Canada

Dr P. Sanders, National Reference Laboratory for Veterinary Drug Residues and Antimicrobial Resistance, Agence nationale de sécurité sanitaire de l'alimentation, de l'environnement et du travail (ANSES), Fougères, France (Vice-Chair)

Professor G.E. Swan, Faculty of Veterinary Science, University of Pretoria, Onderstepoort, South Africa

\section{Secretariat}

Ms A. Bruno, Joint FAO/WHO Food Standards Programme, Food and Agriculture Organization of the United Nations, Rome, Italy (Codex Secretariat)

Dr C.E. Cerniglia, Division of Microbiology, National Center for Toxicological Research, Food and Drug Administration, Department of Health and Human Services, Jefferson, AR, USA (WHO Expert)

Mr S.J. Crossley, Provision of Scientific Advice, Agriculture and Consumer Protection Department, Food and Agriculture Organization of the United Nations, Rome, Italy (FAO Joint Secretary)

Dr H. Erdely, Residue Chemistry Team, Division of Human Food Safety, Center for Veterinary Medicine, Food and Drug Administration, Department of Health and Human Services, Rockville, MD, USA (FAO Expert)

Dr V. Fattori, Food and Agriculture Organization of the United Nations, Rome, Italy (FAO Secretariat)

Dr S. Ghimire, Veterinary Drugs Directorate, Health Canada, Ottawa, Ontario, Canada (WHO Expert) 
Dr N. Jarrett, European Medicines Agency, London, England, United Kingdom (WHO Expert)

Dr K.M. Kang, Joint FAO/WHO Food Standards Programme, Food and Agriculture Organization of the United Nations, Rome, Italy (Codex Secretariat)

Mr J. Kim, Risk Assessment and Risk Management, Department of Food Safety and Zoonoses, World Health Organization, Geneva, Switzerland (WHO Secretariat)

Professor B. Le Bizec, Laboratoire d'Étude des Résidus et des contaminants dans les aliments (LABERCA), École Nationale Vétérinaire, Agroalimentaire et de l'Alimentation Nantes Atlantique (ONIRIS), Nantes, France (FAO Expert)

Dr J. MacNeil, Consultant, Food and Agriculture Organization of the United Nations, Rome, Italy (FAO Secretariat)

Dr K. Ogawa, Division of Pathology, Biological Safety Research Center, National Institute of Health Sciences, Tokyo, Japan (WHO Expert)

Professor F. Ramos, Bromatology, Pharmacognosy and Analytical Sciences Group, Pharmacy Faculty, Coimbra University, Coimbra, Portugal (FAO Expert)

Mr J. Reeve, Science and Risk Assessment Directorate, Standards Branch, Ministry for Primary Industries, Wellington, New Zealand (WHO Expert)

Dr R. Reuss, Food Standards Australia New Zealand, Barton, ACT, Australia (FAO Expert)

Ms M. Sheffer, Orleans, Ontario, Canada (WHO Editor)

Dr A. Tritscher, Risk Assessment and Management, Department of Food Safety and Zoonoses, World Health Organization, Geneva, Switzerland (WHO Joint Secretary)

Dr S. Vaughn, Chair, Codex Committee on Residues of Veterinary Drugs in Foods (CCRVDF), Office of New Animal Drug Evaluation, Center for Veterinary Medicine, Food and Drug Administration, Department of Health and Human Services, Rockville, MD, USA (CCRVDF)

Dr P. Verger, Department of Food Safety and Zoonoses, World Health Organization, Geneva, Switzerland (WHO Joint Secretary to JMPR)

Dr Z. Yuan, Department of Veterinary Basic Medicine, College of Veterinary Medicine, Huazhong Agricultural University, Hubei, China (FAO Expert)

Dr T. Zhou, Office of New Animal Drug Evaluation, Center for Veterinary Medicine, Food and Drug Administration, Department of Health and Human Services, Rockville, MD, USA (WHO Expert) 


\section{Abbreviations}

ADI Acceptable daily intake

ADME Absorption, distribution, metabolism and excretion

APCI atmospheric pressure chemical ionization [in LC/MS and LC-MS/MS]

ARfD acute reference dose

AUC area under the curve

bST bovine somatotrophin

bw bodyweight

CAC Codex Alimentarius Commission

CAS Chemical Abstracts Service

CCRVDF Codex Committee on Residues of Veterinary Drugs in Foods

$\mathrm{Cl}_{\mathrm{T}} \quad$ total body clearance

$\mathrm{C}_{\max } \quad$ maximum concentration (plasma)

$C_{R} \quad$ clearance (renal)

$\mathrm{CV} \quad$ coefficient of variation

CVMP Committee for Medicinal Products for Veterinary Use [of EMEA]

DAD diode array detector [in HPLC]

EC electrochemical detection [in liquid chromatography]

ECLIA electrochemiluminescent immunoassay

EDI estimated daily intake

EHC Environmental Health Criteria

EINECS European Inventory of Existing Commercial Chemical Substances

ELISA enzyme-linked immunosorbent assay

EMEA European Agency for the Evaluation of Medicinal Products

ESI electrospray interface [in LC/MS and LC-MS/MS]

FAO Food and Agriculture Organization of the United Nations

GC gas chromatography

GC/MS gas chromatography/mass spectrometry

GEADE global estimate of acute dietary exposure

GECDE global estimate of chronic dietary exposure

GLP Good Laboratory Practice

GV gentian violet

GVP Good Veterinary Practice

h hour(s)

HBGV health-based guidance value

HPLC/FL high performance liquid chromatography with fluorescence detection

IGF-I insulin-like growth factor-I

i.m. intramuscular [injection] 
INN International Non-proprietary Name

IR infrared

IUPAC International Union of Pure and Applied Chemistry

i.v. intravenous [injection]

JECFA Joint FAO/WHO Expert Committee on Food Additives

JMPR Joint FAO/WHO Meeting on Pesticide Residues

$\mathrm{kg} \quad$ kilogram $\left(10^{3} \mathrm{~g}\right)$

L litre

LC liquid chromatography

LC/MS high performance liquid chromatography/mass spectrometry

LC-MS/M high performance liquid chromatography/tandem mass spectrometry

LGV leucogentian violet

LOAEL lowest observed adverse effect level

LOD limit of detection

LOQ limit of quantification

LSC liquid scintillation counting

$\mu \mathrm{g} \quad \operatorname{microgram}\left(10^{-6} \mathrm{~g}\right)$

mg milligram $\left(10^{-3} \mathrm{~g}\right)$

min minimum or minute

MR marker residue

MRL Maximum Residue Limit

MRT mean residence time

MS mass spectrometry

MW molecular weight

NA not analysed

ND not detectable

ng nanogram $\left(10^{-9} \mathrm{~g}\right)$

NOAEL no observed adverse effect level

NQ non-quantifiable

PBPK physiologically based pharmacokinetic [models]

PR perirenal

QA quality assurance

QC quality control

rbST recombinant bovine somatotrophin

RP reverse phase

RSD repeatability standard deviation

$\mathrm{R}_{\mathrm{t}} \quad$ retention time

$R_{\mathrm{tp}} \quad$ ratio of tissue radioactivity concentration to that of plasma 


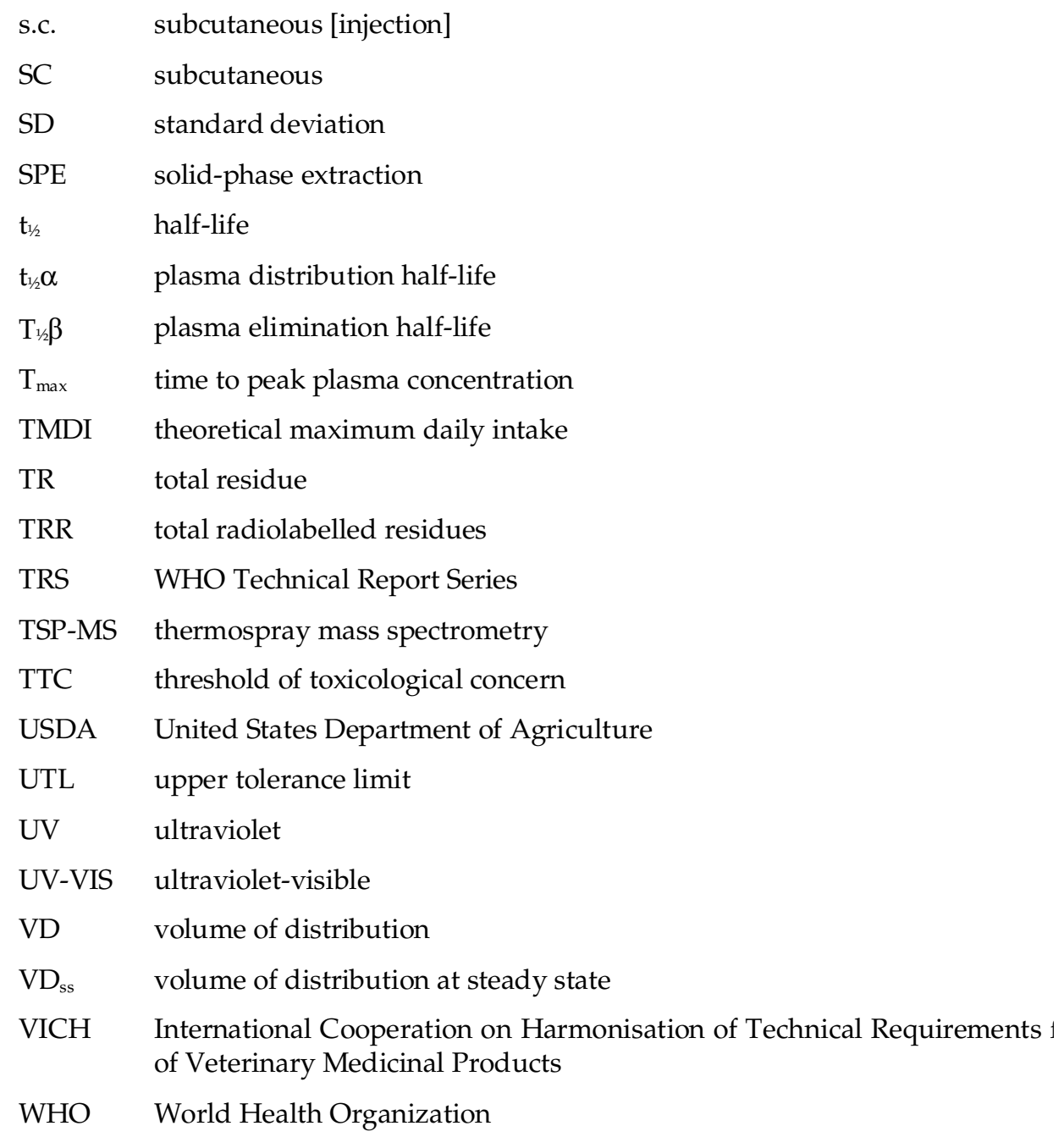

WHO World Health Organization 


\section{Introduction}

This volume of FAO JECFA Monographs contains residue evaluations of certain veterinary drugs prepared at the 78th Meeting of the Joint FAO/WHO Expert Committee on Food Additives (JECFA), held in Geneva, Switzerland, 5-14 November 2013. This was the twentythird meeting of JECFA convened specifically to consider residues of veterinary drugs in food-producing animal species. The tasks for the Committee were to further elaborate principles for evaluating the safety of residues of veterinary drugs in food and for establishing acceptable daily intakes (ADIs), and recommend maximum residue limits (MRLs) for substances on the agenda when they are administered to food-producing animals in accordance with good veterinary practice in the use of veterinary drugs. The enclosed monographs provided the scientific basis for the recommendations of MRLs.

\section{Background}

In response to the growing use of veterinary medicines in food animal production systems internationally and the potential implications for human health and fair trading practices, a Joint FAO/WHO Expert Consultation on Residues of Veterinary Drugs was convened in Rome in November 1984. One of the major recommendations of this consultation was the establishment of the Codex Committee on Residues of Veterinary Drugs in Foods (CCRVDF) and the periodic convening of an appropriate expert body to provide independent scientific advice to this Committee and to member countries of FAO and WHO. At its first session, in Washington, DC, in November 1986, the CCRVDF re-affirmed the need for such a scientific body and made a number of recommendations and suggestions to be considered by JECFA. In response to these recommendations, the 32nd JECFA meeting was devoted entirely to the evaluation of residues of veterinary drugs in food-a new responsibility for the Joint FAO/WHO Expert Committee on Food Additives.

\section{8th Meeting of JECFA}

The present volume contains monographs on the residue data of eight substances scheduled for evaluation at the 78th Meeting of the Committee. Of the substances on the original agenda, no data were submitted by the sponsors for apramycin (residues only) and sisapronil (phenylpyrazole), so these substances were not evaluated. The agenda was modified to include ivermectin (recommendation of MRLs in bovine muscle), as requested by the 21st Session of CCRVDF. Four substances on the agenda were new evaluations (emamectin, gentian violet, lasalocid and zilpaterol hydrochloride) and four were reevaluations (derquantel, ivermectin, monepantel and recombinant bovine somatotrophins (rbSTs)). The re-evaluation of rbSTs was in response to a request from the 35th Session of the Codex Alimentarius Commission that the Committee update the evaluation of rbSTs on the basis of new data and information and to consider the need to revise or maintain the ADI and MRLs. It was agreed that aspects of human antimicrobial resistance could be considered in the evaluation, as appropriate. For derquantel, the 20th session of CCRVDF had requested that JECFA (i) review the ADI in light of a possible different interpretation of the toxicological data, (ii) review the calculation of the marker to total radiolabelled residue, and (iii) revise the recommended MRLs, if appropriate. The 20th session of CCRVDF also noted that the MRLs previously recommended by JECFA for monepantel were significantly lower than those already established in some countries, and that this could present problems in trade. The CCRVDF also noted that the recommended MRLs were not consistent with the withdrawal times in some countries, and therefore requested that JECFA re-evaluate the MRLs in the light of this information. 
The monographs are prepared in a uniform format consistent with the data provided and the specific request for risk assessment by CCRVDF. The format includes identity of substance, residues in food and their evaluation, metabolism studies, tissue residue depletion studies, methods of residue analysis, a final appraisal of the study results, and, if appropriate, recommendations on MRLs.

A summary of the recommendations on compounds on the agenda and further information required is included in Annex 2. In addition, a summary of JECFA evaluations of residues of veterinary drugs in foods from the 32nd to the present 78th Meeting can be found in Annex 1.

The Committee continued to implement some of the more significant recommendations from the workshop to update the principles and methods of risk assessment for MRLs for pesticides and veterinary drugs, held jointly by FAO/RIVM/WHO, in Bilthoven, The Netherlands, 7-11 November 2005. In particular the concept of using median residue values to estimate daily intakes of residues of veterinary drugs in food for chronic exposure intake estimates, further development of guidance on the extrapolation of MRLs between species (Annex 5) and the further development of guidance for the recommendation of MRLs for honey (Annex 6). A pilot project was conducted to evaluate alternative approaches to estimate daily intakes of residues of veterinary drugs in food for chronic and acute exposure intake estimates (Annex 3), based on the recommendations of the Joint FAO/WHO Expert Meeting on Dietary Exposure Assessment Methodologies for Residues of Veterinary Drugs, 7-11 November 2011, Rome, Italy (FAO/WHO, 2012b).

The monographs and general considerations on risk assessment principles of this volume must be considered in the context of the full report of the meeting, which will be published in the WHO Technical Report Series.

On-line editions of Residues of some veterinary drugs in animals and foods (from FAO JECFA Monographs and FAO Food and Nutrition Paper, No. 41) are available online at http://www.fao.org/food/food-safety-quality/scientific-advice/jecfa/jecfa-vetdrugs/en/. The search interface is available in five languages (Arabic, Chinese, English, French and Spanish) and allows searching for compounds, functional classes, ADI and MRL status.

\section{Contact and feedback}

More information on the work of the Committee is available from FAO at http://www.fao.org/food/food-safety-quality/scientific-advice/jecfa/en/

Please send questions and feedback to jecfa@fao.org.

\section{References and other sources}

FAO/WHO. 1985. Residues of Veterinary Drugs in Foods. Report of a Joint FAO/WHO Consultation, Rome, 29 October-5 November 1984. FAO Food and Nutrition Paper, No. 32.

FAO/WHO. 1986. Report of the First Session of the Codex Committee on Residues of Veterinary Drugs in Foods (ALINORM 87/31). Washington, D.C., 27-31 October 1986.

FAO/WHO. 2006. Updating the Principles and Methods of Risk Assessment: MRLs for Pesticides and Veterinary Drugs. Report of the FAO/RIVM/WHO Workshop: "Updating the Principles and Methods of Risk Assessment: Maximum Residue Levels (MRLs) for Pesticides and Veterinary Drugs" held in Bilthoven, the Netherlands, 7-10 November 2005. FAO/WHO, Rome.

FAO/WHO. 2012a. Report of the Twentieth Session of the Codex Committee on Residues of Veterinary Drugs in Foods (REP12/RVDF), San Juan, Puerto Rico, 7-11 May 2012.

FAO/WHO. 2012b. Joint FAO/WHO Expert Meeting on Dietary Exposure Assessment Methodologies for Residues of Veterinary Drugs. Final report including report of stakeholder meeting. Available at http://www.who.int/foodsafety/chem/jecfa/FAO-WHO_exposure_report.pdf Accessed 201405-29. 
FAO/WHO. 2012c. Thirty-fifth Session of the Codex Alimentarius Commission. Rome, Italy, 2-7 July 2012. Food and Agriculture Organization of the United Nations and World Health Organization, Joint FAO/WHO Food Standards Programme, Codex Alimentarius Commission. (REP12/CAC).

FAO/WHO. 2013. Report of the Twenty-first Session of the Codex Committee on Residues of Veterinary Drugs in Foods, Minneapolis, USA, 26-30 August 2013. (REP14/RVDF)

JECFA [Joint Expert Committee on Food Additives]. 1969. Specifications for the Identity and Purity of Food Additives and their Toxicological Evaluation: Some antibiotics (Twelfth Report of the Joint FAO/WHO Expert Committee on Food Additives). FAO Nutrition Meetings Report Series, No. 45; WHO Technical Report Series, No. 430.

JECFA. 1982. Evaluation of Certain Food Additives and Contaminants (Twenty-sixth Report of the Joint FAO/WHO Expert Committee on Food Additives). WHO Technical Report Series, No. 683.

JECFA. 1983. Evaluation of Certain Food Additives and Contaminants (Twenty-seventh Report of the Joint FAO/WHO Expert Committee on Food Additives). WHO Technical Report Series, No. 696.

JECFA. 1988. Evaluation of Certain Veterinary Drug Residues in Foods (Thirty-second Report of the Joint FAO/WHO Expert Committee on Food Additives). WHO Technical Report Series, No. 763.

JECFA. 1989. Evaluation of Certain Veterinary Drug Residues in Foods (Thirty-fourth Report of the Joint FAO/WHO Expert Committee on Food Additives). WHO Technical Report Series, No. 788.

JECFA. 1990. Evaluation of Certain Veterinary Drug Residues in Foods (Thirty-sixth Report of the Joint FAO/WHO Expert Committee on Food Additives). WHO Technical Report Series, No. 799.

JECFA. 1991. Evaluation of Certain Veterinary Drug Residues in Foods (Thirty-eighth Report of the Joint FAO/WHO Expert Committee on Food Additives). WHO Technical Report Series, No. 815.

JECFA. 1993. Evaluation of Certain Veterinary Drug Residues in Foods (Fortieth Report of the Joint FAO/WHO Expert Committee on Food Additives). WHO Technical Report Series, No. 832.

JECFA. 1995. Evaluation of Certain Veterinary Drug Residues in Foods (Forty-second Report of the Joint FAO/WHO Expert Committee on Food Additives). WHO Technical Report Series, No. 851

JECFA. 1995. Evaluation of Certain Veterinary Drug Residues in Foods (Forty-third Report of the Joint FAO/WHO Expert Committee on Food Additives). WHO Technical Report Series, No. 855.

JECFA. 1996. Evaluation of Certain Veterinary Drug Residues in Foods (Forty-fifth Report of the Joint FAO/WHO Expert Committee on Food Additives). WHO Technical Report Series, No. 864.

JECFA. 1998. Evaluation of Certain Veterinary Drug Residues in Foods (Forty-seventh Report of the Joint FAO/WHO Expert Committee on Food Additives). WHO Technical Report Series, No. 876.

JECFA. 1998. Evaluation of Certain Veterinary Drug Residues in Foods (Forty-eighth Report of the Joint FAO/WHO Expert Committee on Food Additives). WHO Technical Report Series, No. 879.

JECFA. 1999. Evaluation of Certain Veterinary Drug Residues in Foods (Fiftieth Report of the Joint FAO/WHO Expert Committee on Food Additives). WHO Technical Report Series, No. 888.

JECFA. 2000. Evaluation of Certain Veterinary Drug Residues in Foods (Fifty-second Report of the Joint FAO/WHO Expert Committee on Food Additives). WHO Technical Report Series, No. 893.

JECFA. 2001. Evaluation of Certain Veterinary Drug Residues in Foods (Fifty-fourth Report of the Joint FAO/WHO Expert Committee on Food Additives). WHO Technical Report Series, No. 900.

JECFA. 2002. Evaluation of Certain Veterinary Drug Residues in Foods Fifty-eighth Report of the Joint FAO/WHO Expert Committee on Food Additives. WHO Technical Report Series, No. 911.

JECFA. 2003. Evaluation of Certain Veterinary Drug Residues in Foods (Sixtieth Report of the Joint FAO/WHO Expert Committee on Food Additives). WHO Technical Report Series, No. 918.

JECFA. 2004. Evaluation of Certain Veterinary Drug Residues in Animals and Foods (Sixty-second Report of the Joint FAO/WHO Expert Committee on Food Additives). WHO Technical Report Series, No. 925.

JECFA. 2006. Evaluation of Certain Veterinary Drug Residues in Animals and Foods (Sixty-sixth Report of the Joint FAO/WHO Expert Committee on Food Additives). WHO Technical Report Series, No. 939.

JECFA. 2009. Residue Evaluation of Certain Veterinary Drugs in Animals and Foods (Seventieth Report of the Joint FAO/WHO Expert Committee on Food Additives). WHO Technical Report Series, No. 954.

JECFA. 2010. Residue Evaluation of Certain Veterinary Drugs. Meeting 2010 - Evaluation of data on ractopamine residues in pig tissues. FAO JECFA Monographs, No. 9. 
JECFA. 2012. Residue Evaluation of Certain Veterinary Drugs (Seventy-fifth Report of the Joint FAO/WHO Expert Committee on Food Additives). FAO JECFA Monographs, No. 12. 


\section{General considerations}

Note: Only the general considerations pertinent for the reading of the monographs and for future assessments of veterinary drug residues are provided here.

\section{Dietary exposure to veterinary drug residues}

\section{Explanation}

Dietary exposure assessment plays an essential part in quantifying risk and is central to the work of JECFA. There has been an ongoing need to improve the approaches used to estimate dietary exposure to veterinary drug residues in foods. The 70th Meeting of the Committee (JECFA, 2009 [TRS 954]) identified further work on new approaches in this area, considering methods for chronic and acute dietary exposure assessment. In response, CCRVDF requested FAO and WHO to convene an expert meeting on dietary exposure assessment methodologies for residues of veterinary drugs.

The expert meeting, held in November 2011, proposed new methods for acute and chronic dietary exposure assessment for veterinary drug residues, taking the key findings, concerns and recommendations of stakeholders into consideration (FAO/WHO, 2012b). Subsequently, it was recommended that the new approaches should be piloted at the 78th Meeting of JECFA.

The purpose of the pilot study was to explore the new calculations for dietary exposure assessment, compare them with estimates calculated using the model diet approach, identify the practical impact of using the new methods and make recommendations for dietary exposure assessment at future meetings. As summarized below, dietary exposures were calculated for four veterinary drug residues using the model diet approach, as well as the new methods for chronic and acute dietary exposure estimation.

\section{Dietary exposure assessment approaches}

The current model diet used for veterinary drug residues is intended to cover chronic high consumers of animal products. The model assumes that the food consumption applies to an average adult bodyweight (bw) of $60 \mathrm{~kg}$ and is intended to also cover the consumption of all processed foods with these foods as ingredients. All muscle tissues are equivalent, so meat and fish consumed are considered as equivalent in the calculations.

For estimating chronic dietary exposures to veterinary drug residues, JECFA uses the median of the residue depletion to derive the estimated daily intake (EDI). The contribution to the EDI from consumption of individual tissues is calculated by multiplying the amount of tissue in the model diet by the median concentration of marker residue corresponding to the Maximum Residue Limit (MRL). The EDI itself is the sum of the individual intakes resulting from all tissues. Where a median residue cannot be derived, the MRL may be substituted for the median residue to calculate the theoretical maximum daily intake (TMDI).

The two new methods for estimating dietary exposure are the global estimate of acute dietary exposure (GEADE) and the global estimate of chronic dietary exposure (GECDE). Both methods differ from the EDI by having the capacity to estimate specific dietary exposure for additional population groups (children aged 12 months and older, and infants younger than 12 months) and by using more realistic global consumption amounts as inputs into the calculations. Consumption data used are based on surveys and can be expressed per person, to be compared with the current approach, or per kilogram bodyweight, based on values reported in food consumption surveys. Instead of the set amounts of food in the model diet, more detailed food consumption data are used where available. For example, muscle tissue is differentiated by species, and finfish are considered separately from molluscs and crustaceans. 
It should be noted that consumption amounts for infants are not reported for some categories (e.g. mammalian fat; poultry fat and skin) and therefore are not included in estimates. Other categories were not reported separately as consumed according to the surveys used to derive consumption amounts. In such cases, the broader categories have been used, with the highest residue concentration used as the input. For example, "mammalian kidney" consumption is not reported for infants; therefore, the residue found in kidney would be assigned to "All mammalian offal", which is the best available match for kidney consumption in this population.

The current approach to estimating dietary exposure does not adequately estimate acute dietary exposure, which should be based on the highest probable exposure from a single commodity on a single day. The GEADE is an explicit estimate of acute dietary exposure, combining consumption at the 97.5th percentile with the 95th percentile residue concentration. Unlike the EDI, estimates can be derived specifically for children as well as for the general population, following the principle that dietary exposure assessments should cover the whole population, including children.

The GECDE uses median residues combined with two different types of consumption data to estimate chronic dietary exposure. Firstly, the highest exposure at the 97.5th percentile of consumption is selected from all the foods relevant to exposure. This value is derived from chronic consumers of the food; that is, the percentile consumption is calculated from consumers of the food only and is different from the 97.5th percentile of consumption used in acute exposure, which reflects a single eating occasion (acute). Secondly, the mean dietary exposures from all the other relevant foods are then added to estimate total exposure. The mean dietary exposure is derived from the total population; in other words, nonconsumers of the food are included in the mean calculation. In addition to the general population and children, dietary exposure of infants can also be estimated.

\section{Pilot study results}

The results of the pilot study and the scientific basis of the new approaches to the estimation of dietary exposure are described in Annex 3.

\section{Extrapolation of MRLs to minor species}

\section{CCRVDF request for additional considerations concerning extrapolation of MRLs to minor species}

The 20th Session of CCRVDF in 2012 posed questions to JECFA concerning the extrapolation of MRLs from major to minor species (FAO/WHO, 2012a). The JECFA Secretariat engaged a consultant to prepare a draft working paper to review the background and JECFA practices regarding extrapolation of MRLs from major to minor species, to review available guidance from other sources, and to prepare responses to each of the questions forwarded from the 20th Session of CCRDVF. The working paper was then circulated to members of an electronic working group of JECFA residue experts ${ }^{1}$ for comment and discussion. Responses to the questions were finalized by the electronic working group and were presented to the 21st Session of CCRVDF, in 2013 (Annex 4).

The 21st Session of CCRVDF then addressed additional comments and questions to JECFA concerning the extrapolation of MRLs to additional (minor) species (FAO/WHO, 2013). JECFA's responses are provided below.

\footnotetext{
${ }^{1}$ The electronic working group consisted of Drs Joe Boison, Alan Chicoine, Holly Erdely, Lynn Friedlander, Fernando Ramos, Pascal Sanders, Stefan Scheid and Zonghui Yuan.
} 
1. While JECFA's position is scientifically sound, in practice "compounds should be present in quantitatively similar proportions" could be unnecessarily restrictive for MRL extrapolation.

Many jurisdictions do not require radiolabel studies (and hence MR:TR) in extrapolated species.

JECFA response: JECFA does not generally require data from a radiolabel study when considering a request for extrapolation of MRLs. Such data are requested only when available data do not enable JECFA to make a determination that the distribution and depletion of the drug residues in a minor species are comparable to those observed in a representative major species. This can apply particularly when the calculated exposure approaches the ADI and there is evidence of variability in marker residue to total residue (MR:TR) adjustment factors used in the dietary exposure calculations. JECFA has been reluctant to place quantitative limits on the "similar proportions" so as not to be unnecessarily restrictive when considering extrapolation. However, if there are large differences in the pattern of metabolites observed in two species, this may have a significant impact on the relationships between the marker residue and total residues, and therefore also a significant impact on the dietary exposure calculations. These concerns must be reflected in advice provided by JECFA.

2. For comparative metabolism data assessment in a major species, JECFA does not consider that metabolites in target animals should be present in "quantitatively similar proportions" to those observed in laboratory animals (from which the ADI is derived); rather, the compounds are required to be qualitatively similar (i.e. the same major metabolites should appear in the metabolite profile). Also, in many cases, estimated exposure to residues at the MRL represents only a fraction of the ADI. Consequently, the extrapolated MRLs would not exceed the ADI even if the MR:TR ratio is several-fold different.

JECFA response: Only metabolites of toxicological concern identified in studies in food animals are considered by JECFA when comparing metabolism in laboratory animals and food animal species for the recommendation of MRLs. It is correct that JECFA does not consider the quantitative relationships between metabolites observed in laboratory animals and those observed in food animal species, as the focus for recommendation of MRLs is on the behaviour of the residues in food animal species. Although it is also correct that there are instances in which only a small fraction of the ADI is represented in the dietary exposure calculation, there are also instances in which the estimated dietary exposure approaches the ADI. The Committee would have to be satisfied that there was adequate exposure of toxicological species to metabolites of toxicological concern observed in food animal species. This is one reason why JECFA has taken a case-by-case approach in responding to requests for recommendations on extrapolation. When the dietary exposure calculation represents only a small fraction of the ADI, there is less risk that estimated exposure will exceed the ADI when MRLs are extrapolated to a minor species, and therefore fewer data for the minor species should suffice. When the calculated exposure approaches the ADI, more information on residues that occur in foods derived from the minor species may be required to ensure that dietary exposure through consumption of edible tissues, milk or eggs from the minor species does not exceed the ADI. When the marker residue is the only residue of toxicological concern, then extrapolation of MRLs to a minor species should result in the same calculated dietary exposure.

3. JECFA may consider being flexible in defining the "reasonable limits" to define the comparative metabolic profile and in metabolism data requirements in extrapolated species based on the overall safety profile of the drug (e.g. proportion of ADI used). Alternatively, the MR:TR ratio from physiologically related species could be used for MRL extrapolation.

JECFA response: JECFA follows the procedures for assessment of metabolites as described in VICH guidance documents (VICH, 2011a,b,c,d). As stated in response to a previous point, JECFA considers that it may at this point be unwise to specify "reasonable limits" in concise numerical terms. Given the variability in the quantity and quality of data available to 
support requests for extrapolation, it is better to assess each case based on the available data, taking into account the uncertainties in the data provided. A review of past JECFA recommendations of MRLs for the "related" species cattle and sheep reveals several instances in which differences in residue concentrations in tissues have resulted in differences in the MRLs recommended for one or more tissues from these species. In such cases, there may be a concern about using the MR:TR ratio from one major species for extrapolation.

4. We note that the EU has extensively extrapolated MRLs of veterinary drugs to all foodproducing species. No serious public health issues have been reported because of public exposure to residues of veterinary drugs in extrapolated species.

JECFA response: While JECFA is aware of the practices followed in the European Union (EU) for extrapolation of MRLs, the situations are not necessarily directly comparable. JECFA follows principles established within CCRVDF and JECFA, consistent with principles and methods for the risk assessment of chemicals in food given in EHC 240 (FAO/WHO publication Environmental Health Criteria, No. 240 - see FAO/WHO, 2009). The species that are defined as minor within the regulatory context in the EU may not reflect the consumption patterns and potential exposure to veterinary drug residues within the global context. It is a requirement under current procedures followed by both CCRVDF and JECFA that there is evidence of an approved use of a drug (Good Veterinary Practice - GVP) in a Member State before MRLs can be considered. JECFA risk assessments consider potential effects following established risk assessment principles. JECFA considers that a review based on a lack of reported health problems would be an insufficient means of ensuring public health protection and would be inconsistent with practices followed by the Codex Alimentarius Commission and JECFA to ensure protection of consumer health.

5. Absence of metabolites or residues of toxicological concern in extrapolated species can generally be substantiated by data from a radiolabel study. In practice, if radiolabel studies are available, MRLs can be established by routine procedure (i.e. extrapolation is not required).

JECFA response: The metabolites found in a major species are typically determined from radiolabel studies, where fractions are chromatographically separated from tissue extracts and then further characterized using spectroscopic and mass spectrometric techniques. Once such studies have been completed in a major species, the same metabolites, if present, may be identified in extracts of tissues from minor species that have been treated with the unlabelled drug using chromatographic separation combined with spectrometric techniques. The same approach may be taken to identify the metabolites formed in in vitro experiments. As noted in the CCRVDF comment, MRLs can be established following the routine procedures used for major species when complete radiolabel studies are available for the minor species. In such cases, extrapolation is not required. In addition, as noted in JECFA's response to the questions posed to JECFA by the 20th Session of CCRVDF and provided to the 21st Session of CCRVDF (Annex 4 to this report), MRLs can be and have been recommended for minor species when there are no or very limited data from radiolabel studies conducted in the minor species, but data from a depletion study with unlabelled drug are available. In such cases, JECFA will usually apply MR:TR ratios from a physiologically related major species, if required, in the intake calculation. For example, the 70th Meeting of JECFA (JECFA, 2009 [TRS 954]) used MR:TR ratios for chicken to recommend common MRLs for chicken and turkey. 
6. Radiolabel studies are generally not available when extrapolation is requested. Rather than asking to demonstrate the absence of metabolites of toxicological concern, could a practical approach be taken to ascertain, based on available data and public literature, whether there is any evidence suggesting that metabolites or residues of toxicological concern occur in extrapolated species (i.e. absence of evidence, rather than evidence of absence)?

JECFA response: The information available on residues of a drug in a minor species typically includes either no data from a radiolabel study or else very limited data from a study that is not compliant with good laboratory practice (GLP). In these situations, JECFA considers other information on metabolism that may be available, such as the identification of known metabolites found in the major species in tissues from the minor species by chemical analysis techniques, the body of information available on the metabolism of the drug in other laboratory and food animal species, and data from in vitro studies, if available. Information on the metabolism of chemically related drugs or on common metabolic pathways may also be considered. It is difficult to prove a negative (no novel unknown metabolites of potential toxicological concern in tissues of the minor species), so JECFA will consider the available information and assess the potential for the occurrence of a previously unknown metabolite to occur in the minor species. This has not typically been a major source of uncertainty when JECFA has considered requests for extrapolation. The key issues are commonly lack of information on distribution profiles, depletion profiles and/or MR:TR ratios in the minor species. Lack of such information means that there is a greater level of uncertainty associated with the MRL recommendations, and this uncertainty will be outlined in the JECFA evaluations.

\section{Could a well designed marker residue depletion study further substantiate this?}

JECFA response: A review of past JECFA decisions indicates that JECFA has been more likely to recommend the extrapolation (extension) of MRLs from a major to a minor species when data from a residue depletion trial with unlabelled drug are available for the minor species. For example, the extrapolation of MRLs for moxidectin from cattle to deer was based on in vitro comparative metabolism data and a residue depletion study with unlabelled drug in deer (JECFA, 1999 [TRS 888]). MRLs for phoxim were extrapolated from cattle and sheep to goats, based on metabolic data for cattle and sheep and a residue depletion study with unlabelled drug in goats (JECFA, 2004 [TRS 925]). MRLs for other drugs, such as colistin and erythromycin, were extrapolated from chicken to turkey based on metabolic data for chicken and evidence of a common marker residue and a validated analytical method for turkey tissues (JECFA, 2006 [TRS 939]). MRLs for deltamethrin in salmon have been recommended by JECFA based primarily on data from pharmacokinetic and depletion studies with unlabelled drug, using information from metabolic, pharmacokinetic and depletion studies in major food animal species to supplement the information (JECFA, 2000 [TRS 893]). The problems faced by JECFA, when asked to recommend extrapolation, typically involve an absence of data from "well designed" studies.

8. Could JECFA consider extrapolation to all aquatic animals instead of just finfish, provided minimum criteria are met?

JECFA response: In principle, the extrapolation of MRLs to all food-producing animals once similar MRLs have been established in a major species representative of each class seems a practical solution. However, current procedures within CCRVDF and JECFA require that evidence of an approved use of the drug in a Member State (as GVP) must be provided for any food-producing species for which extrapolation of MRLs is requested. JECFA will consider whether the extrapolation of the MRL is valid, taking into consideration all the data available to the Committee in the classes of animals exposed to the treatment, including the existence of MRLs in a species considered as physiologically related to the species to which extrapolation of MRLs has been requested. A future JECFA might, for example, consider recommending extension of MRLs from one species of fish to related species of fish. 
However, this will be considered only when there is evidence of approved usage of the drug in multiple species and GVP conditions are available for review.

9. JECFA may also wish to consider other in-built safety (e.g. human exposure to residues at MRL level in species in which MRLs are established often represents only a fraction of the ADI, which could compensate for any differences in MR:TR ratio) inherent in the MRL establishment procedure in future extrapolation work.

JECFA response: Under current procedures, when data to establish an MR:TR ratio in tissues of a minor species to which extrapolation of MRLs has been requested are not available, JECFA will consider assigning surrogate values based on the most conservative MR:TR ratios determined for other species to which MRLs have been assigned. The new GECDE calculations assessed in the pilot study of alternative approaches to dietary exposure assessment by the current Committee may also provide additional flexibility in the consideration of future requests for the extrapolation of MRLs.

\section{JECFA guidance for the extrapolation of MRLs to minor species}

Guidance on the extrapolation of MRLs from major species to minor species approved at the present meeting of the Committee is provided in Annex 5.

\section{MRLs for veterinary drug residues in honey \\ CCRVDF request to JECFA for additional considerations concerning the establishment of MRLS in honey}

Is it possible to establish MRLs for honey using monitoring data from national authorities, similar to the approaches used by JMPR for setting MRLs for spices?

JECFA response: Alternative approaches to obtaining residue data to support MRLs for honey other than the traditional dose administration under controlled situations were discussed by the 70th Meeting of the Committee (see JECFA, 2009 [TRS 954]) and also by the electronic working group of $\mathrm{JECFA}^{2}$, which provided responses to the 21st Session of CCRVDF (Annex 4) in answer to questions posed to JECFA by the 20th Session of CCRVDF (FAO/WHO, 2012a). Given the difficulty in obtaining reliable residue depletion data from a limited study (i.e. it appears that multiple hives at multiple locations and times may be required to derive a representative picture), JECFA agrees that the consideration of alternative approaches to the standard dose administration trials conducted for most uses of veterinary drugs is indicated.

JECFA is aware that JMPR has used information from surveys (monitoring data) in the recommendation of MRLs for spices and that monitoring data are also used in establishing maximum limits for some contaminants. An approach using data from statistically based surveys of product in the marketplace could provide some assurance that the MRLs established in this manner for veterinary drug residues in honey are consistent with GVP and provide appropriate protection to consumers.

As an alternative, a supervised field trial approach, such as that taken by JMPR for residue evaluation of pesticides, may be more appropriate for the establishment of MRLs for veterinary drug residues in honey than the conventional residue study approach used in the evaluation of veterinary drug residues in animal tissues, milk and eggs. This could perhaps be achieved by structuring residue studies so that composite samples taken at each of four or five geographically separated locations are analysed to provide a representative set of data for typical field conditions. Further guidance on the design of residue studies for veterinary drugs used in honey is being developed by $\mathrm{VICH}$ and will be considered as guidance by

2 The electronic working group consisted of Drs Joe Boison, Alan Chicoine, Holly Erdely, Lynn Friedlander, Fernando Ramos, Pascal Sanders, Stefan Scheid and Zonghui Yuan. 
JECFA when it is complete.

\section{JECFA guidance for the establishment of MRLs in honey}

Guidance on the establishment of MRLs in honey approved at the present meeting of the Committee is contained in Annex 6.

\section{Scope of MRLs established by JECFA relating to fish and fish species}

The Committee noted that some previous recommendations for MRLs have been for specific species of fish, such as salmon and trout, whereas others have been for "fish", which could be interpreted to include shellfish. To more accurately reflect the species for which MRL recommendations are made, the Committee recommends, consistent with the terminology used in the report of the Joint FAO/WHO Expert Meeting on Dietary Exposure Assessment Methodologies for Residues of Veterinary Drugs (FAO/WHO, 2012b), that the term "fish" should be used when an MRL recommendation applies to multiple species of finfish. For other "seafood", the term "mollusc" should be used for species such as clams, oysters and scallops, and the term "crustacean" should be used when MRLs are recommended for species such as shrimp, prawn and crayfish. When the recommendation of an MRL is for a specific species of fish or seafood, this will be reflected in the MRL recommendation. In this regard, the Committee considered that it may be appropriate to also identify some representative species of fish, such as salmon, and of seafood, such as shrimp (crustacean), as "major species" of fish and seafood. It is recommended that this matter should be further discussed at a future meeting of the Committee.

\section{JECFA analytical method validation requirements}

Current JECFA guidelines for the validation of analytical methods were adopted at the 52nd Meeting of the Committee in 1999 (JECFA, 2000 [TRS 893]) and subsequently published as Annex 3 of FAO Food \& Nutrition Paper, No. 41/14 (FAO, 2002). The present Committee noted that a new Codex guideline, Guidelines for the design and implementation of national regulatory food safety assurance programme associated with the use of veterinary drugs in food producing animals (CAC/GL 71-2009), includes detailed updated information on criteria for the selection and validation of analytical methods suitable for use in regulatory programmes for the control of veterinary drug residues in foods (FAO/WHO, 2012c). The Committee agreed that the method selection and validation criteria contained in CAC/GL 71-2009 and subsequent revisions to these guidelines will be applied when assessing the suitability of methods proposed to JECFA as regulatory methods to support recommended MRLs. The Committee also agreed that in view of developments in method validation criteria that have occurred since the adoption of the current JECFA method validation requirements in 1999, the criteria for validation of methods used in the pharmacokinetic, metabolism and depletion studies submitted to the Committee should be reviewed and updated at a future meeting of the Committee.

\section{References}

FAO. 2002. Residues of some veterinary drugs in animals and foods FAO Food and Nutrition Paper, No. 41/14, Annex 3.

FAO/WHO. 2009. Principles and methods for the risk assessment of chemicals in food. Environmental Health Criteria, 240. World Health Organization, Geneva. Available at: http://www.who.int/foodsafety/chem/principles/en/index1.html Accessed 2014-05-14.

FAO/WHO. 2012a. Report of the Twentieth Session of the Codex Committee on Residues of Veterinary Drugs in Foods. REP12/RVDF. San Juan, Puerto Rico, 7-11 May 2012. Available at: http://www.codexalimentarius.org/download/report/778/rv20_01e.pdf Accessed 2014-05-10. 
FAO/WHO. 2012b. Joint FAO/WHO Expert Meeting on Dietary Exposure Assessment Methodologies for Residues of Veterinary Drugs. Final report including report of stakeholder meeting. Available at http://www.who.int/foodsafety/chem/jecfa/FAO-WHO_exposure_report.pdf Accessed 201405-29.

FAO/WHO. 2012c. [Codex Alimentarius Commission] Guidelines for the design and implementation of national regulatory food safety. No. 12 - Assurance programmes associated with the use of veterinary drugs in food producing animals. Doc. 13 CAC/GL 71-2009, rev. 2012. Available at: http://www.codexalimentarius.org/ download/standards/11252/CXG_071e.pdf Accessed 201405-29.

FAO/WHO. 2013. Report of the Twenty-first Session of the Codex Committee on Residues of Veterinary Drugs in Foods, Minneapolis, United States of America, 26-30 August 2013. CAC doc. REP14/RVDF. Available at: http:/ / www.codexalimentarius.org/download / report/802/REP14_RVe.pdf Accessed 2014-05-29.

JECFA. 1999. Evaluation of certain veterinary drug residues in food (Fiftieth report of the Joint FAO/WHO Expert Committee on Food Additives). WHO Technical Report Series, No. 888. Available at http://whqlibdoc.who.int/trs/WHO_TRS_888.pdf?ua=1 Accessed 2014-05-29.

JECFA. 2000. Evaluation of certain veterinary drug residues in food (Fifty-second report of the Joint FAO/WHO Expert Committee on Food Additives). WHO Technical Report Series, No. 893. WHO, Geneva. Available at: http:/ / whqlibdoc.who.int/trs/WHO_TRS_893.pdf?ua=1 Accessed 2014-0515.

JECFA. 2004. Evaluation of certain veterinary drug residues in animals and foods (Sixty-second Report of the Joint FAO/WHO Expert Committee on Food Additives). WHO Technical Report Series, No. 925. Available at http://whqlibdoc.who.int/trs/WHO_TRS_925.pdf?ua=1 Accessed 2014-0529.

JECFA. 2006. 2006. Evaluation of certain veterinary drug residues in food (Sixty-sixth report of the Joint FAO/WHO Expert Committee on Food Additives). WHO Technical Report Series, No. 939. WHO, Geneva. Available at: http://whqlibdoc.who.int/publications/2006/9241209399_eng.pdf?ua=1 Accessed 2014-05-15.

JECFA. 2009. Evaluation of certain veterinary drug residues in food (Seventieth report of the Joint FAO/WHO Expert Committee on Food Additives). WHO Technical Report Series, No. 954. Available at: http:/ / whqlibdoc.who.int/trs/WHO_TRS_954_eng.pdf?ua=1 Accessed 2014-05-15.

VICH. 2011. Studies to evaluate the metabolism and residue kinetics of veterinary drugs in foodproducing animals: Metabolism study to determine the quantity and identify the nature of residues. Report VICH GL46 (MRK). Available at http://www.vichsec.org/component/ attachments / attachments/312.html?task=download Accessed 2014-05-29.

VICH. 2011b. Studies to evaluate the metabolism and residue kinetics of veterinary drugs in foodproducing animals: Comparative metabolism studies in laboratory animals. Report VICH GL47 (MRK). Available at http://www.vichsec.org/component/ attachments/attachments/313.html?task=download Accessed 2014-05-29.

VICH. 2011c. Studies to evaluate the metabolism and residue kinetics of veterinary drugs in foodproducing animals: Marker residue depletion studies to establish product withdrawal periods. Report VICH GL48 (MRK). Available at http:/ / www.vichsec.org/component/attachments/ attachments /314.html?task=download Accessed 2014-05-29.

VICH. 2011d. Guidelines for the validation of analytical methods used in residue depletion studies. Report VICH GL49 (MRK). Available at http:/ /www.vichsec.org/component/ attachments / attachments/315.html?task=download Accessed 2014-05-29. 


\section{Derquantel}

First draft prepared by

Lynn G. Friedlander, Rockville, MD, USA

Bruno LeBizec, Nantes, France

and

Gerry Swan, Pretoria, Republic of South Africa

Addendum to the monograph prepared by the 75th Meeting of the Committee and published in FAO JECFA Monographs, No. 12

\section{Identity}

International Non-proprietary Name (INN): derquantel

Synonyms: PF-00520904, PNU-141962, 2-DOPH, 2-desoxyparaherquamide,

2-deoxyparaherquamide, Startect ${ }^{\circledR}$ (derquantel + abamectin)

IUPAC Name: $(1 R, 3 S, 5 R, 7 S, 12 R)$-12-Hydroxy-4,4,4',4',12,14-hexamethyl-9',10'-dihydro4'Hspiro[9,14-diazatetracyclo [5.5.2.01,9.03,7]tetradecane-5,8'-[1,4]dioxepino[2,3g]indol]-13-one

Chemical Abstract Service Number: 187865-22-1

Molecular formula: $\mathrm{C}_{28} \mathrm{H}_{37} \mathrm{~N}_{3} \mathrm{O}_{4}$

Molecular weight: 479.6

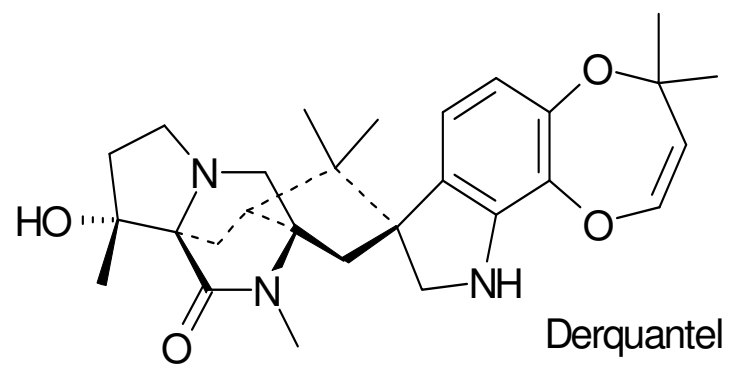

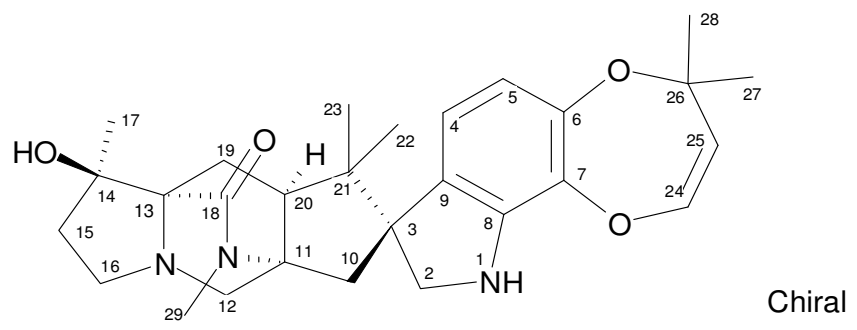




\section{Background}

Derquantel, a spiroindole, is an oral anthelmintic registered for use, in combination with abamectin, to treat and control a broad range of adult and immature gastrointestinal nematodes of sheep. Derquantel is available only as a combination product with abamectin.

Derquantel was previously reviewed by the Committee at its 75th meeting (FAO, 2012), which assigned an ADI of $0-0.3 \mu \mathrm{g} / \mathrm{kg}$ corresponding to an upper bound of acceptable intakes of $18 \mu \mathrm{g} /$ day for a $60 \mathrm{~kg}$ person. Although deficiencies were identified in the residue dossier, MRLs were recommended, expressed as derquantel parent compound, in sheep tissue at $0.2 \mu \mathrm{g} / \mathrm{kg}$ in muscle, $0.2 \mu \mathrm{g} / \mathrm{kg}$ in kidney and $0.7 \mu \mathrm{g} / \mathrm{kg}$ in fat. In addition, a MRL of $0.2 \mu \mathrm{g} / \mathrm{kg}$ in liver was estimated by the Committee; however, due to an error, this MRL was presented in the report as $2 \mu \mathrm{g} / \mathrm{kg}$. There were not sufficient data to calculate an estimated daily intake (EDI). Using the model diet and mean marker to total ratios of $6 \%$ for muscle, $3 \%$ for liver, $7 \%$ for kidney and $15 \%$ for fat, a theoretical maximum daily intake (TMDI) was calculated of $8 \mu \mathrm{g} /$ person per day, which represents $45 \%$ of the upper bound of the ADI.

At the 20th meeting of the Codex Committee for Residues of Veterinary Drugs in Food (CCRVDF), concern was expressed regarding the basis for the ADI assignment (FAO/WHO, 2013). One Observer proposed an alternative approach to the derivation of the MRLs. A Member State expressed concern as to the ratio of the marker residue to total radioactive residues used by JECFA in the calculation of the dietary intake, specifically that the ratio involved time-points for the marker residue and total residue that differed from the timepoint used for assignment of MRLs. The Member State and an Observer proposed that the CCRVDF consider lower MRLs for derquantel.

In the light of the above discussion, the CCRVDF agreed to include derquantel on the priority list for re-evaluation by JECFA to: (i) review the ADI in the light of a possible different interpretation of the toxicological database; (ii) review the calculation of the marker to total radiolabel residue ratio; and (iii) revise the recommended MRLs, if appropriate.

\section{Current evaluation}

No new data or studies were provided for the current evaluation. A Member State provided written concerns, including exposure scenarios, associated with the concerns that had been expressed during the 20th Meeting of the CCRVDF (Concerns from a Member State, 2012). Additionally, an alternative approach to determining the ratio of marker residue to total radioactive residues was presented by the sponsor (Zoetis, 2013).

\section{Concern from Member State}

The concern identified by the Member State was that the ratios of marker residue to total radioactive residue (MR:TRR ${ }^{3}$ ) used by JECFA were not appropriate, given the time-point selected for recommending MRLs. As a result, the selected MR:TRR ratios may lead to an underestimation of exposure. The request for clarification by the Member State included an outline of concerns over the interpretation of the MR:TRR ratios used in the risk assessment and an interpretation of the total radioresidue data. The conclusion reached in the suggested exposure scenarios is that the JECFA MRL proposals would lead to a TMDI estimate that exceeds the assigned ADI. Two questions were posed to JECFA:

3 MR:TRR as used in this monograph is consistent with the terminology used by the Member State and the sponsor, where MR is marker residue and TRR is total radioactive (radiolabelled) residues. In the Appraisal and Maximum Residue Limits sections of this monograph, the preferred JECFA terminology, MR:TR, is used, where TR is total residues. 
Question 1. Did JECFA take into consideration the fact that the only MR:TRR data available are for the rapid phase of elimination ( $\leq 6$ days) and that no data are available for MR:TRR for the terminal slow phase of elimination, the period relevant to the MRL proposals?

Question 2. Did JECFA look at other evidence, such as TRR studies, to determine whether or not exposure would be acceptable for the proposed MRLs?

The concern identified by the Member State also suggested that these MR:TRR ratios will be much lower during the slow terminal phase of elimination. Supporting scenarios for MR:TRR ratio interpretation were provided.

Using the data in Table 3.19 of JECFA Monograph 12 (FAO, 2012), the Member State noted that there is a clear decline in MR:TRR ratios over time post-dosing, especially for liver, moving from the fast rate of elimination phase to the slow rate of elimination phase (Figure 3.1).

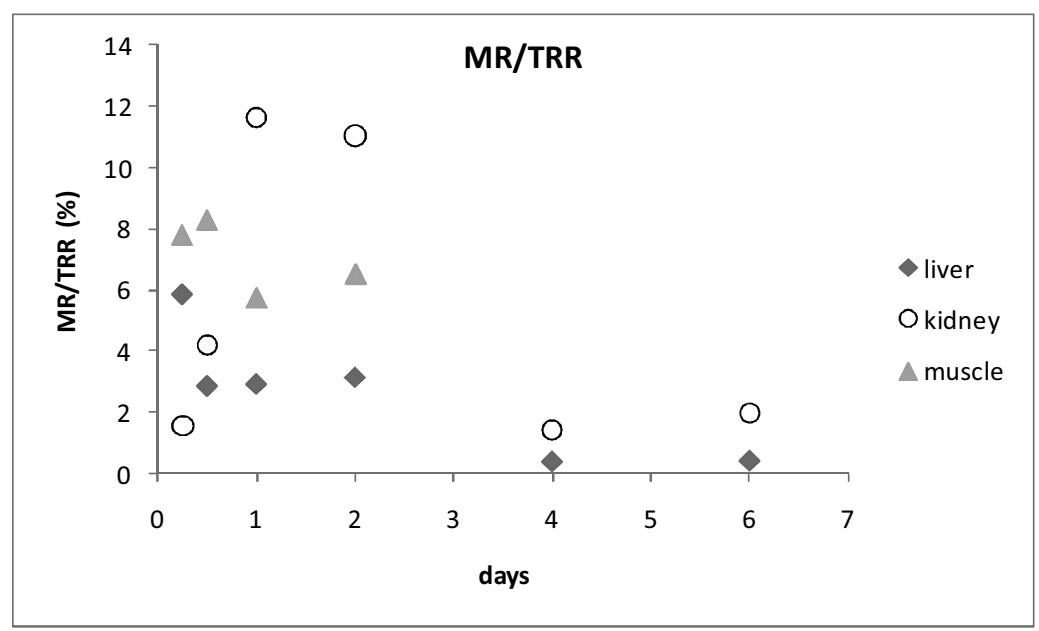

Figure 3.1. Summary of MR:TRR data reported by JECFA for liver, kidney and muscle

The Member State noted that the change in MR:TRR ratios was illustrated also in the marker residue study (Chambers, 2009) and the TRR study of Byrd and Liu (2008) (Figure 3.2). The Member State suggested that the study of Byrd and Liu (2008) (TRR; not commercial formulation) might reflect the expected TRR when using the commercial formulation, i.e. same kinetics. The Member State provided plots of the ratios of derquantel from Chambers (2009) and TRR from Byrd and Liu (2008) and noted that the ratio of mean MR and TRR concentrations (with data corrected to same dose rates) are similar to those derived using MR reported by Byrd and Liu (2008). The Member State noted that the presentations were intended to illustrate the decline and were not suggested to be used for MRL estimation or dietary exposure calculation. They were intended to illustrate the trend with time post-dosing.

Additionally, the concern identified by the Member State noted that the samples may have been stored at $-20^{\circ} \mathrm{C}$ for differing periods, which could have resulted in a $50 \%$ reduction in derquantel residues (Table 3.1). Even if this were the case, the MR:TRR ratio at 6 days (144 hours) corrected for reduction on storage would be less than $0.01(<1 \%)$ and would be expected to be even lower by 8 days, the time-point relevant to the JECFA MRL recommendations. 
Table 3.1. Ratio of marker residue to total radioactive residues (\%) for liver

\begin{tabular}{|c|c|c|c|}
\hline Slaughter interval post-dosing & Byrd and Liu, $2006^{(2)}$ & Byrd and Liu, 2008 ${ }^{(2)}$ & Byrd, $20 C$ \\
\hline 3 & $19.9(26.2)$ & & \\
\hline 6 & - & 5.86 & \\
\hline 12 & $7.32(9.21)$ & 2.09 & 4.36 \\
\hline 24 & $1.07(1.83)$ & 3.25 & 2.23 \\
\hline 48 & & 4.43 & 0.73 \\
\hline 96 & & & 0.44 \\
\hline 144 & & $0.2^{(1)}$ & \\
\hline
\end{tabular}

NOTES: (1) derquantel reported as $0 \mu \mathrm{g} / \mathrm{kg}$ is assumed to be present at $1 / 2 \mathrm{LOD}$ of $0.5 \mu \mathrm{g} / \mathrm{kg}$; (2) samples stored at $\leq-10^{\circ} \mathrm{C}$ prior to analysis; (3) samples stored at -20 and $-70^{\circ} \mathrm{C}$ prior to analysis; (3) samples stored at $-20^{\circ} \mathrm{C}$ prior to analysis.

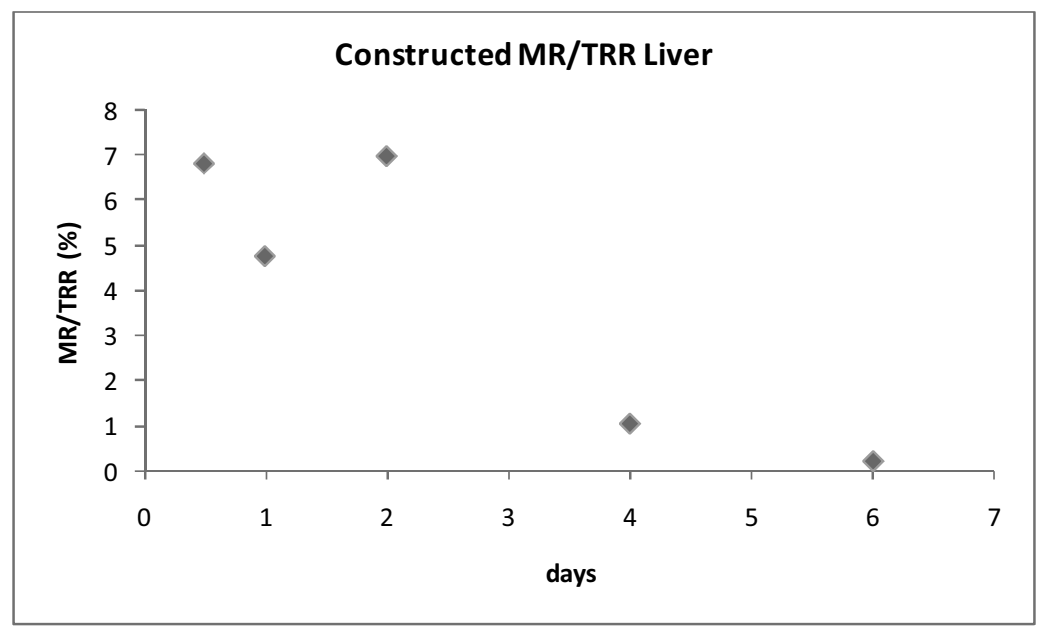

Figure 3.2. Summary of MR:TRR ratios constructed using data reported in Chambers (2009) for MR and Byrd and Liu (2008) for TRR

The conclusion from the Member State was that the MR:TRR ratio for liver exhibited a significant decline of the MR:TRR ratio with time after dosing. The MR:TRR ratio for liver relevant to the MRL proposal (8 days) is much lower than the 0.03 (or 3\%) used by JECFA for liver and is likely to be $<0.3(0.003 \%)$. The plot of the data from Chambers (2009) showed an initial rapid decline phase followed by a longer slow terminal elimination phase (Figure 3.3).

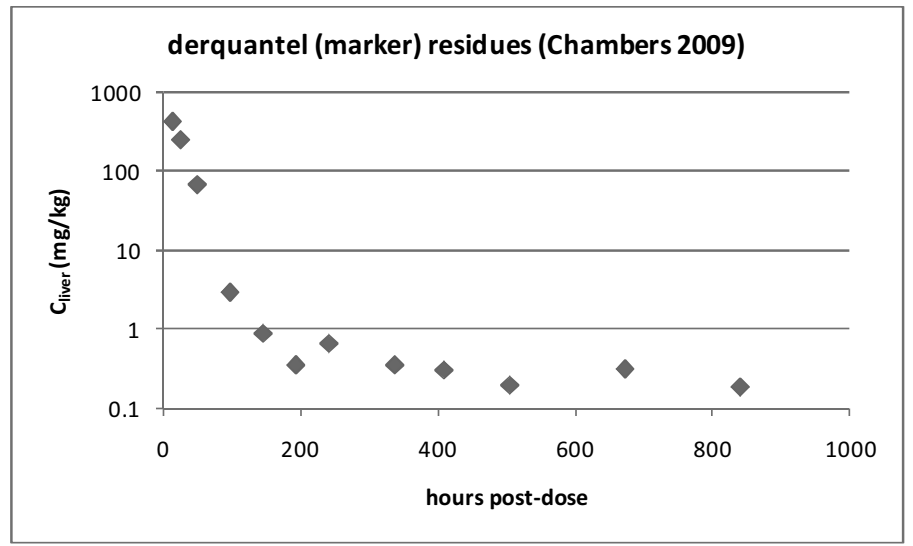

Figure 3.3. Plot of Marker residue (derquantel) residues with time after dosing 
The Member State noted that the choice of MR:TRR ratio has a large impact on the resulting exposure assessment using the standard food basket and, if the MR:TRR ratio for liver is 0.003 , this would give rise to a TMDI (liver only) that is 370\% of the upper bound of the ADI established by JECFA. The Member State therefore proposed that an appropriate MR:TRR ratio for liver was less than $0.03(3 \%)$ but more likely greater than $0.003(0.3 \%)$. TRR in a single animal dosed at $2 \mathrm{mg} / \mathrm{kg}$ bw were $17.4 \mu \mathrm{g} / \mathrm{kg}$ at 28 days after dosing (Byrd, 2008, as stated in FAO JECFA Monographs 12, Table 3.16 (FAO, 2012), while derquantel residues at 28 days reported by Chambers (2009) were $0.32 \pm 0.19 \mu \mathrm{g} / \mathrm{kg}$ (or $0.21 \pm 0.13 \mu \mathrm{g} / \mathrm{kg}$ when corrected to the same dose). Overall TRR (single animal per time) in Byrd (2008) were lower than those in Byrd and Liu (2008), also suggesting lower MR concentrations. The Member State concluded that the liver MR:TRR ratio was anticipated to be about $(0.21 \pm 0.13) / 17.4=$ $0.005-0.02$.

\section{Alternative approach proposed by the sponsor to determine the M:T ratio}

The alternative approach proposed by the sponsor (Zoetis, 2013) utilized the residue depletion data determined by Chambers (2009) and the combined TRR data of Byrd and Liu (2008) and Byrd (2008). The focus was on residues from Day 4 and Day 6. To facilitate the comparison of residue concentrations from disparate studies, the TRR concentrations (dose of $2 \mathrm{mg} / \mathrm{kg}$ ) were "arithmetically normalized" to the higher dose employed in the Chambers study (dose of $3 \mathrm{mg} / \mathrm{kg}$ ) (i.e. the residue values from the $2 \mathrm{mg} / \mathrm{kg}$ TRR study dosing were multiplied by 1.5 to correspond to a $3 \mathrm{mg} / \mathrm{kg}$ residue depletion study dosing). The combined TRR data, including "arithmetically normalized" values, are shown in Tables 3.2-3.5.

Table 3.2. Total radioactive residue data - Day 4.

\begin{tabular}{|c|c|c|c|c|c|c|}
\hline Tissue & $\begin{array}{c}\text { TRR Data at } \\
4 \text { days (Studies } \\
171+186)\end{array}$ & $\begin{array}{l}\text { Adjust for } \\
3 / 2 \times \text { dose }\end{array}$ & $\begin{array}{c}\text { Mean } \\
\text { TRR }(\mu \mathrm{g} / \mathrm{kg})\end{array}$ & $\begin{array}{l}\text { Std Dev } \\
\text { Std Error }\end{array}$ & $\begin{array}{c}\text { T Value (97.5\%; } \\
0.05 / 2.3)\end{array}$ & $\begin{array}{c}\text { Upper } 95 \% \text { CI } \\
\text { Mean + T*SE } \\
(\mu \mathrm{g} / \mathrm{kg})\end{array}$ \\
\hline \multirow{4}{*}{ Liver } & 122.1 & 183.15 & \multirow{4}{*}{292.05} & & \multirow{4}{*}{3.1825} & \multirow{4}{*}{427.8} \\
\hline & 178.3 & 267.45 & & 85.3 & & \\
\hline & 249.3 & 373.95 & & 42.7 & & \\
\hline & 229.1 & 343.65 & & & & \\
\hline \multirow{4}{*}{ Kidney } & 20.5 & 30.75 & \multirow{4}{*}{58.725} & & \multirow{4}{*}{3.1825} & \multirow{4}{*}{98.9} \\
\hline & 29.3 & 43.95 & & 25.3 & & \\
\hline & 53.1 & 79.65 & & 12.6 & & \\
\hline & 53.7 & 80.55 & & & & \\
\hline \multirow{4}{*}{ Muscle } & 1.7 & 2.55 & \multirow{4}{*}{4.6875} & & \multirow{4}{*}{3.1825} & \multirow{4}{*}{7.4} \\
\hline & 3.0 & 4.5 & & 1.68 & & \\
\hline & 4.4 & 6.6 & & 0.838 & & \\
\hline & 3.4 & 5.1 & & & & \\
\hline \multirow{4}{*}{ Fat } & 1.8 & 2.7 & \multirow{4}{*}{9.525} & & \multirow{4}{*}{3.1825} & \multirow{4}{*}{21.4} \\
\hline & 6.1 & 9.15 & & 7.43 & & \\
\hline & 4.2 & 6.3 & & 3.72 & & \\
\hline & 13.3 & 19.95 & & & & \\
\hline
\end{tabular}

NOTES: $\mathrm{Cl}=$ Confidence interval; $\mathrm{T}=$ total residue; $\mathrm{T}^{\star} \mathrm{SE}=\mathrm{T}$-value $\times$ standard error of the mean. Studies 171 and 186 are sponsor study numbers and correspond to the combined TRR data of Bird and Liu, 2008, and Bird, 2008. 
Table 3.3 Derquantel Marker Residue data - Day 4

\begin{tabular}{|c|c|c|c|c|c|c|c|}
\hline \multicolumn{5}{|c|}{ Marker Residues (Chambers, 2009) ( $\mu \mathrm{g} / \mathrm{kg})$} & \multirow{2}{*}{$\begin{array}{c}\text { Marker to } \\
\text { Total } \\
\text { Ratio }^{(1)}\end{array}$} & \multicolumn{2}{|c|}{ Exposure at 4 Days } \\
\hline Tissue & VHR $^{(3)}$ & $\mathbf{P A H}^{(4)}$ & Mean & $\begin{array}{l}\text { Group } \\
\text { Mean }\end{array}$ & & $\begin{array}{c}\text { Consumption } \\
\text { (kg) }\end{array}$ & $\begin{array}{c}\text { Total (2) Intake } \\
(\mu \mathrm{g})\end{array}$ \\
\hline \multirow{6}{*}{ Liver } & 3.51 & 2.94 & 3.225 & \multirow{6}{*}{2.806} & \multirow{6}{*}{$1.0 \%$} & \multirow{6}{*}{0.1} & \multirow{6}{*}{42.8} \\
\hline & 1.2 & 1.55 & 1.375 & & & & \\
\hline & 5.41 & 4.36 & 4.885 & & & & \\
\hline & 0.95 & 1.13 & 1.04 & & & & \\
\hline & 0.6 & 1.06 & 0.83 & & & & \\
\hline & 6.19 & 4.77 & 5.48 & & & & \\
\hline \multirow{6}{*}{ Kidney } & 2.27 & 1.07 & 1.67 & \multirow{6}{*}{1.536} & \multirow{6}{*}{$2.6 \%$} & \multirow{6}{*}{0.05} & \multirow{6}{*}{4.9} \\
\hline & 0.77 & 0.5 & 0.635 & & & & \\
\hline & 2.34 & 1.38 & 1.86 & & & & \\
\hline & 0.48 & 0.251 & 0.3655 & & & & \\
\hline & 0.51 & 0.317 & 0.4135 & & & & \\
\hline & 4.42 & 4.12 & 4.27 & & & & \\
\hline \multirow{6}{*}{ Muscle } & 0.39 & 0.307 & 0.3485 & \multirow{6}{*}{0.514} & \multirow{6}{*}{$11 \%$} & \multirow{6}{*}{0.3} & \multirow{6}{*}{2.2} \\
\hline & 0.28 & 0.124 & 0.202 & & & & \\
\hline & 0.45 & 0.576 & 0.513 & & & & \\
\hline & 0.39 & 0.108 & 0.249 & & & & \\
\hline & 0.37 & 0.118 & 0.244 & & & & \\
\hline & 1.61 & 1.44 & 1.525 & & & & \\
\hline \multirow{7}{*}{$\begin{array}{c}\text { Fat } \\
\text { SC/PR }\end{array}$} & $3.55 / 2.36$ & $3.26 / 3.14$ & $2.96 / 3.20$ & \multirow{6}{*}{$\begin{array}{c}4.17 \\
\text { (all PR and } \\
\text { SC values) }\end{array}$} & \multirow{6}{*}{$44 \%$} & \multirow{6}{*}{0.05} & \multirow{6}{*}{1.1} \\
\hline & $0.15 / 0.78$ & $0.958 / 0.984$ & $0.47 / 0.97$ & & & & \\
\hline & $0.13 / 4.87$ & 7.8/3.75 & $2.50 / 5.78$ & & & & \\
\hline & $2.11 / 0.95$ & $1.8 / 0.815$ & $1.53 / 1.31$ & & & & \\
\hline & $0.72 / 0.81$ & $1.03 / 0.804$ & $0.77 / 0.92$ & & & & \\
\hline & $21.8 / 14.2$ & $11.9 / 11.5$ & $18.0 / 11.7$ & & & & \\
\hline & & & & & TOTAL CON & UUMPTION $(\mu \mathrm{g})=$ & 51.0 \\
\hline
\end{tabular}

NOTES: (1) Group Mean (Table 3.3) divided by Mean TRR (Table 3.2); (2) Consumption Factor (Table 3.3) $\times$ Upper 95\% Confidence interval (Table 3.2); (3) Analyses by VHR (Veterinary Health Research, Pty, Ltd); (4) Analyses by PAH (Pfizer Animal Health); $\mathrm{Cl}=$ Confidence interval; $\mathrm{PR}$ = perirenal; $\mathrm{SC}=$ subcutaneous

Table 3.4. Total Radioactive Residue data - Day 6

\begin{tabular}{|c|c|c|c|c|c|c|}
\hline Tissue & $\begin{array}{l}\text { TRR Data at } 6 \\
\text { days (Study 171) }\end{array}$ & $\begin{array}{l}\text { Adjust for } \\
3 / 2 \times \text { dose }\end{array}$ & $\begin{array}{c}\text { Mean TRR } \\
(\mu \mathrm{g} / \mathrm{kg})\end{array}$ & $\begin{array}{l}\text { Std Dev } \\
\text { Std Error }\end{array}$ & $\begin{array}{l}\text { T Value } \\
\text { (97.5\%; } \\
0.05 / 2.2)\end{array}$ & $\begin{array}{c}95 \% \text { Upper CI } \\
\text { Mean + T*SE } \\
(\mu \mathrm{g} / \mathrm{kg})\end{array}$ \\
\hline & 185.1 & 277.65 & & & & \\
\hline \multirow[t]{3}{*}{ Liver } & 140.6 & 210.9 & 207.3 & 72.22 & 4.3027 & 386.7 \\
\hline & 88.9 & 133.35 & & 41.69 & & \\
\hline & 32.5 & 48.75 & & & & \\
\hline \multirow[t]{3}{*}{ Kidney } & 25.3 & 37.95 & 38.05 & 10.65 & 4.3027 & 64.5 \\
\hline & 18.3 & 27.45 & & 6.15 & & \\
\hline & 2.8 & 4.2 & & & & \\
\hline \multirow[t]{3}{*}{ Muscle } & 2.4 & 3.6 & 3.25 & 1.17 & 4.3027 & 6.1 \\
\hline & 1.3 & 1.95 & & 0.67 & & \\
\hline & 1.9 & 2.85 & & & & \\
\hline \multirow[t]{2}{*}{ Fat } & 1.9 & 2.85 & 2.3 & 0.95 & 4.3027 & 4.7 \\
\hline & 0.8 & 1.2 & & 0.55 & & \\
\hline
\end{tabular}

NOTES: $\mathrm{Cl}=$ Confidence interval; $\mathrm{T}=$ total residue; $\mathrm{T}^{\star} \mathrm{SE}=\mathrm{T}$-value $\times$ standard error of the mean.

SOURCE: Data provided by the sponsor. 
Table 3.5. Derquantel Marker Residue data - Day 6

\begin{tabular}{|c|c|c|c|c|c|c|c|}
\hline \multicolumn{5}{|c|}{ Marker Residues (Chambers, 2009) ( $\mu \mathrm{g} / \mathrm{kg})$} & \multirow{2}{*}{$\begin{array}{c}\text { Marker to } \\
\text { Total } \\
\text { Ratio }\end{array}$} & \multicolumn{2}{|c|}{ Exposure at 6 Days } \\
\hline Tissue & $\mathbf{V H R}^{(3)}$ & $\mathbf{P A H}^{(4)}$ & Mean & $\begin{array}{l}\text { Group } \\
\text { Mean }\end{array}$ & & $\begin{array}{c}\text { Consumption } \\
\text { (kg) }\end{array}$ & $\begin{array}{c}\text { Total }^{(2)} \\
\text { Intake }(\mu \mathrm{g})\end{array}$ \\
\hline \multirow{6}{*}{ Liver } & 0.56 & 1.06 & 0.81 & \multirow{6}{*}{0.692} & \multirow{6}{*}{$0.33 \%$} & \multirow{6}{*}{0.1} & \multirow{6}{*}{38.7} \\
\hline & 0.42 & 1.34 & 0.88 & & & & \\
\hline & 0.53 & 0.962 & 0.746 & & & & \\
\hline & 0.39 & 0.356 & 0.373 & & & & \\
\hline & 0.42 & 0.537 & 0.4785 & & & & \\
\hline & 0.56 & 1.17 & 0.865 & & & & \\
\hline \multirow{6}{*}{ Kidney } & 0.15 & 0.123 & 0.1365 & \multirow{6}{*}{0.083} & \multirow{6}{*}{$0.22 \%$} & \multirow{6}{*}{0.05} & \multirow{6}{*}{3.2} \\
\hline & 0.08 & 0.0606 & 0.0703 & & & & \\
\hline & 0.09 & 0.0776 & 0.0838 & & & & \\
\hline & 0.05 & 0.0477 & 0.04885 & & & & \\
\hline & 0.09 & 0.04 & 0.065 & & & & \\
\hline & 0.1 & 0.0834 & 0.0917 & & & & \\
\hline \multirow{6}{*}{ Muscle } & 0.04 & 0.0436 & 0.0418 & \multirow{6}{*}{0.033} & \multirow{6}{*}{$1.0 \%$} & \multirow{6}{*}{0.3} & \multirow{6}{*}{1.8} \\
\hline & 0.04 & 0.022 & 0.031 & & & & \\
\hline & 0.04 & 0.0257 & 0.03285 & & & & \\
\hline & 0.04 & 0.022 & 0.031 & & & & \\
\hline & 0.04 & 0.022 & 0.031 & & & & \\
\hline & 0.04 & 0.0236 & 0.0318 & & & & \\
\hline \multirow{7}{*}{$\begin{array}{c}\text { Fat } \\
\text { SC/PR }\end{array}$} & $1.93 / 0.35$ & $1.22 / 0.398$ & $1.14 / 0.81$ & \multirow{6}{*}{$\begin{array}{c}0.398 \\
\text { (all PR and } \\
\text { SC values) }\end{array}$} & \multirow{6}{*}{$17 \%$} & \multirow{6}{*}{0.05} & \multirow{6}{*}{0.2} \\
\hline & $0.52 / 0.17$ & $0.302 / 0.233$ & $0.35 / 0.27$ & & & & \\
\hline & $0.48 / 0.46$ & $0.288 / 0.596$ & $0.47 / 0.44$ & & & & \\
\hline & $0.48 / 0.17$ & $0.149 / 0.226$ & $0.33 / 0.19$ & & & & \\
\hline & $0.35 / 0.17$ & $0.106 / 0.236$ & $0.26 / 0.17$ & & & & \\
\hline & $0.32 / 0.13$ & $0.128 / 0.151$ & $0.23 / 0.14$ & & & & \\
\hline & & & & & TOTAL CO & SUMPTION $(\mu \mathrm{g})=$ & 44.0 \\
\hline
\end{tabular}

NoteS: (1) Group Mean (Table 3.5) divided by Mean TRR (Table 3.4); (2) Consumption Factor (Table 3.5) $\times$ Upper 95\% Confidence interval (Table 3.4); (3) Analyses by VHR (Veterinary Health Research, Pty, Ltd); (4) Analyses by PAH (Pfizer Animal Health). $\mathrm{SC}=$ subcutaneous; $\mathrm{PR}=$ perirenal.

\section{Appraisal}

As part of the current assessment, the concerns raised by the Member State, the alternative approach proposed by the sponsor, and the original assessment by the 75th Meeting of the JECFA (FAO, 2012) were all considered.

The Committee reviewed the comments provided by the Member State. A re-assessment of the residue depletion data indicated that residues at Day 6 are consistent with a total exposure below the TMDI. Thus, the Day 6 time-point can be used for the recommendation of MRLs, rather than the Day 8 time-point used for the original assessment. Data through Day 6 were used to determine the MR:TR ratios.

Regarding the alternative approach, the Committee concluded that determining the MR:TR ratio from a radiolabel study was the customary and preferred practice. This customary approach is compatible with MR:TR ratios through Day 6. 


\section{Maximum Residue Limits}

In recommending MRLs for derquantel, the Committee considered the following factors:

- An ADI of 0-0.3 $\mu \mathrm{g} / \mathrm{kg}$ bw was established previously by the Committee and confirmed at this meeting, based on an acute toxicological end-point. The upper bound of this ADI is equivalent to $18 \mu \mathrm{g}$ /day for a $60 \mathrm{~kg}$ person.

- Derquantel is extensively metabolized; derquantel represents $6 \%$ of total residues in muscle, $3 \%$ in liver, $7 \%$ in kidney and $15 \%$ in fat. Derquantel, although constituting a small percentage of total residues, is suitable as the marker residue in tissues. No data are provided for residues in sheep milk.

- Liver contains the highest concentration of total radiolabelled residues at all sampling times. Fat contains the highest concentrations of derquantel residues in the unlabelled residue depletion study at early sampling points. At times beyond the Day 4 sampling time, derquantel residues are highest in liver. Derquantel residue concentrations are variable. The highest concentration of the proposed marker residue, derquantel, at the time-point relevant to recommending MRLs is found in liver, followed by fat, then kidney and then muscle. Liver and fat can serve as the target tissues.

- A validated analytical procedure for the determination of derquantel in edible sheep tissues (liver, kidney, muscle and fat) is available and may be used for monitoring purposes.

- The MRLs recommended for sheep tissues are based on the upper limit of the onesided $95 \%$ confidence interval over the 95th percentile (the "upper tolerance limit 95/95" or UTL 95/95) for the Day 6 post-treatment data from the unlabelled residue depletion study.

Based on these new assessments, the Committee proposed the following revised MRLs in sheep tissues: $0.3 \mu \mathrm{g} / \mathrm{kg}$ in muscle, $0.4 \mu \mathrm{g} / \mathrm{kg}$ in kidney, $0.8 \mu \mathrm{g} / \mathrm{kg}$ in liver and $7.0 \mu \mathrm{g} / \mathrm{kg}$ in fat. There were insufficient data to calculate an EDI, and the TMDI approach was used.

Using the model diet and the MT:TR approach, these MRLs result in an estimated dietary exposure of $6.8 \mu \mathrm{g} /$ person, which represents approximately $38 \%$ of the upper bound of the ADI.

Table 3.6. Calculation of the Theoretical Maximum Daily Intake (TMDI)

\begin{tabular}{lcccc}
\hline \multicolumn{1}{c}{ Tissue } & MRL $(\boldsymbol{\mu g} / \mathbf{k g})$ & Standard Food Basket $(\mathbf{k g})$ & MR:TR ratio & TMDI $(\boldsymbol{\mu g})$ \\
\hline Liver & 0.8 & 0.1 & 0.03 & 2.7 \\
Kidney & 0.4 & 0.05 & 0.07 & 0.3 \\
Muscle & 0.3 & 0.3 & 0.06 & 1.5 \\
Fat & 7 & 0.05 & 0.15 & 2.3 \\
\hline & & & TMDI & 6.8 \\
& & & As of ADI & $38 \%$ \\
\hline
\end{tabular}

NOTES: MR:TR ratio is the ratio of marker residue to total residues. 


\section{References}

Byrd, J. 2008. Pfizer Reference Number: 1545N-60-07-186. Southwest Bio-Labs Study Number: 00700963. Xenobiotic Laboratories Reference Number: 07035. $\left[{ }^{14} \mathrm{C}\right] \mathrm{PF}-00520904$ sheep tissue residues for marker ratio confirmation.

Byrd, J. \& Liu, D. 2006. Pfizer Reference Number: 1545R-60-05-169. Southwest Bio-Labs Study Number: 205-0832. Xenobiotics Laboratories Reference Number: XBL05795. Pilot total residue depletion study in sheep: Generation and TRR determination of ovine excreta and tissue samples containing $\left[{ }^{14} \mathrm{C}\right]$ PF-520904 residues.

Byrd, J. \& Liu, D. 2008. Pfizer Reference Number: 1545N-60-05-171. Southwest Bio-Labs Study Number: 005-00873. Xenobiotics Laboratories Reference Number: XBL0501330. Pivotal total residue depletion study in sheep: Generation and TRR determination of ovine excreta and tissue samples containing $\left[{ }^{14} \mathrm{C}\right]$ PF-520904 residues.

Chambers, M. 2009. Pfizer Reference Number: 1541N-14-07-184. Veterinary Health Research Pty Ltd Study Number: PFPO1934. Pivotal Study for the Determination of the PF 520904-00 (2-DOPH) and Abamectin Tissue Residue Profile in Sheep Following Oral Administration of the Final Formulation at $3 \mathrm{mg} 2-\mathrm{DOPH} / \mathrm{kg}$ and $0.3 \mathrm{mg}$ Abamectin $/ \mathrm{kg}$ bodyweight.

Concerns from a Member State. 2012. Submitted by the Delegation of Australia, includes one attachment with TMDI scenarios.

FAO. 2012. Derquantel. in: Residue evaluation of certain veterinary drugs in foods and animals. Report of the 75th Meeting of the Joint FAO/WHO Expert Committee on Food Additives, Rome, Italy, 8-17 November 2011. FAO JECFA Monographs, no. 12. Available at http://www.fao.org/fileadmin/user_upload/agns/pdf/JECFA_Monograph_12.pdf Accessed 2014-05-17.

FAO/WHO. 2013. Report of the Twenty-first Session of the Codex Committee on Residues of Veterinary Drugs in Foods, Minneapolis, United States of America, 26-30 August 2013. CAC doc. REP14/RVDF. Available at: http:/ /www.codexalimentarius.org/download/ report/802/REP14_RVe.pdf Accessed 2014-05-29.

Zoetis. 2013. Derquantel Residue Monograph: New Proposal for Maximum Residue Limits in Sheep Tissues Following Reassessment of the Acceptable Daily Intake Using Benchmark Dose Analysis. 



\title{
4. Emamectin Benzoate
}

\author{
First draft prepared by \\ Pascal Sanders, Fougères, France \\ and \\ Gerry Swan, Pretoria, South Africa
}

\section{Identity}

International Non-proprietary Name (INN): emamectin benzoate

Synonyms: AKOS015950774, AB1004837, (4"R)-4"-Deoxy-4"-(methylamino)-avermectin B1 benzoate(salt), emamectin benzoate

IUPAC Names: A mixture containing 90\% of (10E,14E,16E,22Z)-

(1R,4S,5'S,6S, 6'R,8R,12S,13S,20R,21R,24S)-6'-[(S)-sec-butyl]-21,24-

dihydroxy-5',11,13,22-tetramethyl-2-oxo-3,7,19-

trioxatetracyclo[15.6.1.1, $\left.1^{4,8} \cdot 0^{20,24}\right]$ pentacosa-10,14,16,22-tetraene-6-spiro-2'-

(5',6'-dihydro-2'H-pyran)-12-yl 2,6dideoxy-3-O-methyl-4-O-(2,4,6-trideoxy-

3-O-methyl-4-methylamino-alpha-L-lyxo-hexopyranosyl)-alpha-L-arabinohexopyranoside benzoate

and $10 \%$ of (10E,14E,16E,22Z)-(1R,4S,5'S,6S, $\left.6^{\prime} \mathrm{R}, 8 \mathrm{R}, 12 \mathrm{~S}, 13 \mathrm{~S}, 20 \mathrm{R}, 21 \mathrm{R}, 24 \mathrm{~S}\right)-$

21,24-dihydroxy-6'-isopropyl-5',11,13,22-tetramethyl-2-oxo-3,7,19-

trioxatetracyclo[15.6.1.1, $\left.1^{4,8} \cdot 0^{20,24}\right]$ pentacosa-10,14,16,22-tetraene-6-spiro-2'-

(5',6'-dihydro-2'H-pyran)-12-yl 2,6-dideoxy-3-O-methyl-4-O-(2,4,6-trideoxy-

3-O-methyl-4-methylamino-alpha-L-lyxo-hexopyranosyl)-alpha-L-arabinohexopyranoside benzoate.

Chemical Abstract Service Number: 155569-91-8, formerly 137512-74-4

Structural formula of main components:

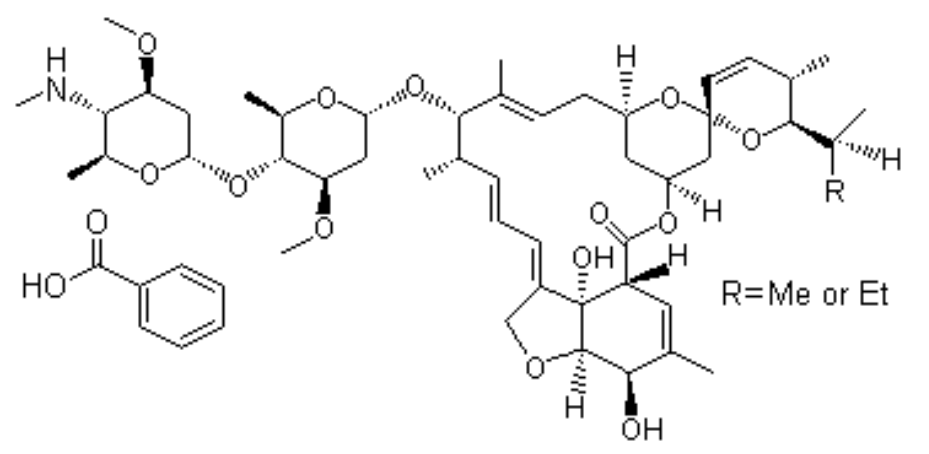

SOURCE: http://www.chemblink.com/products/155569-91-8.htm

Molecular formula: $\mathrm{B}_{1 \mathrm{a}}$ component $\mathrm{C}_{49} \mathrm{H}_{75} \mathrm{NO}_{13} \mathrm{C}_{7} \mathrm{H}_{6} \mathrm{O}_{2}$

$\mathrm{B}_{1 \mathrm{~b}}$ component $\mathrm{C}_{48} \mathrm{H}_{73} \mathrm{NO}_{13} \mathrm{C}_{7} \mathrm{H}_{6} \mathrm{O}_{2}$

Molecular weight: $B_{1 a}$ component: $1008.26 \mathrm{~g} / \mathrm{mol}$

$B_{1 b}$ component: $994.24 \mathrm{~g} / \mathrm{mol}$ 


\title{
Other information on identity and properties
}

\author{
Pure active ingredient: A mixture of two avermectin homologues: \\ $\geq 90 \%$ of $4^{\prime}$-epimethyamino- $4^{\prime}$-deoxyavermectin B1a benzoate \\ (MAB1a), and \\ $\leq 10 \%$ of $4^{\prime}$-epimethyamino- $4^{\prime}$-deoxyavermectin B1b benzoate \\ (MAB1b)
}

Appearance:

The benzoate salt of emamectin, EB, is a white to cream coloured powder.

Melting point:

$141-146^{\circ} \mathrm{C}$

Solubility:

Water: $24 \mathrm{mg} / \mathrm{L}\left(\mathrm{pH} 7,25^{\circ} \mathrm{C}\right)$

$\log \mathrm{Ko} / \mathrm{w}$ :

5

\section{Residues in food and their evaluation}

\section{Conditions of use}

Emamectin benzoate is used for the treatment of sea lice in salmon. Major regions of marine salmonid aquaculture activity worldwide include Japan, the east and west coasts of Canada, the northeastern coast of the United States of America, Ireland, Scotland, Norway, Chile, New Zealand and Tasmania (Johnson et al., 2004). Sea lice have not been reported as aquacultural pests in New Zealand or Tasmania. In areas where sea lice infections are common, secondary infections (e.g. with other diseases such as infectious pancreatic necrosis, bacterial kidney disease, and salmonid rickettsial septicaemia) and reduced growth are issues of concern. Secondary infections associated with sea lice infestations have been identified as a serious issue on the east coast of Canada, but not yet on the west coast (Johnson et al., 2004).

Emamectin benzoate received its first registration in Japan in 1998, under the trade name Affirm $^{\circledR}$. Its use was for the control of lepidopteran pests on leafy vegetables, brassicas and for trunk injection in pine trees to control the pine sawfly (Pesticide Management Advisory Committee, California Department of Pesticide Regulation, www.cdpr.ca.gov). However, emamectin benzoate is not widely used for sea lice control in Japan. Instead, problems associated with sea lice are avoided through rearing of coho salmon, which are less vulnerable to sea lice infestations than Atlantic salmon, coupled with restriction of grow-out periods to about one year.

The emamectin benzoate-based insecticide Proclaim ${ }^{\circledR}$ was granted emergency exemption in Hawaii for control of diamondback moth on horticultural crops and used in 1996 and 1997. Full registration for use was subsequently approved in 1999 (http://www.syngentacropprotection.com). In the United States of America, emamectin benzoate is used in terrestrial agriculture to control pests on head lettuce, celery, cauliflower, broccoli, cabbage and other crops. For example, about $260 \mathrm{~kg}$ of emamectin benzoate was applied to edible crops in California in 2002 (http://www.pesticideinfo.org; accessed October 2004). Emamectin benzoate has also been widely used in some countries as an anti-fungal agent, sold under the trade name Proclaim ${ }^{\circledR}$. Overall, emamectin benzoate first came into use in the United States of America and several other countries as a pesticide against terrestrial pests, and its use was shortly thereafter extended to use in finfish aquaculture.

Emamectin benzoate is also formulated as Slice ${ }^{\circledR}$, which is a trade name for a product developed by Schering-Plough Animal Health (SPAH) now Merck Animal Health. Internationally, Slice ${ }^{\circledR}$ has been developed as an alternative to the use of other sea lice control products, including ivermectin, dichlorvos, azamethiphos, hydrogen peroxide, cyper- 
methrin, teflubenzuron and diflubenzuron. Slice ${ }^{\circledR}$ was approved for use in the United Kingdom in 2000. Emamectin benzoate was provided with an "Animal Test Exemption" in 1999 in the UK by the Veterinary Medicine Directorate (VMD) in order to allow field trials to be conducted (Rae, 2000). Prior to this, the European Medicines Evaluation Committee set maximum residue levels (MRLs) for emamectin benzoate in foods intended for human consumption.

The present evaluation was performed on the basis of available published peer-reviewed literature, and monographs prepared by national agencies. Despite the request of the Committee, the sponsor of a marketed authorized emamectin benzoate formulation for sea lice control did not provide the dossier used by national authorities for risk assessment.

\section{Dosage}

Emamectin benzoate is administered in Canada as the active ingredient in Slice ${ }^{\circledR}$, manufactured by the Schering-Plough Animal Health Corporation. The product is supplied as a pre-mix containing $0.2 \%$ emamectin benzoate in a $99.8 \%$ inert carrier, which comprises $0.01 \%$ butylated hydroxyanisole, $2.5 \%$ propylene glycol, $47.40 \%$ maltodextrin, and corn starch (to 100\%) (Scottish Environment Protection Agency, 1999). The pre-mix is coated onto non-medicated fish feed pellets to achieve an intended dose of $50 \mu \mathrm{g}$ emamectin benzoate per $\mathrm{kg}$ of fish biomass per day for seven days. The suggested feeding rate is $0.5 \%$ of fish biomass per day. If the feeding rate differs from $0.5 \%$ biomass per day, then the concentrations of Slice ${ }^{\circledR}$ in feed must be adjusted accordingly.

The product may be used up to 3 times/year, with a maximum of 5 treatments in any 2year growth cycle. A withdrawal period of 25 days is required in Canada for emamectin benzoate under its current emergency registration.

\section{Pharmacokinetics and metabolism}

\section{Pharmacokinetics in laboratory animals}

The following information was obtained from a report issued by the European Medicines Agency (EMEA, 1999). A series of experiments was carried out to determine the fate of the B1a component of emamectin after administration of its benzoate salt to Sprague-Dawley rats. In the first experiment, rats were given a single oral dose of $20 \mathrm{mg} / \mathrm{kg}$ bw dual-labelled $\left[{ }^{14} \mathrm{C}\right] /\left[{ }^{3} \mathrm{H}\right]$ emamectin $\mathrm{B} 1 \mathrm{a}$ and killed 7 days later; the residues in tissues were very similar when based upon $\left[{ }^{14} \mathrm{C}\right]$ and $\left[{ }^{3}\right] \mathrm{H}$ radioactivity, indicating stability of the $\left[{ }^{3} \mathrm{H}\right]$ label. Following administration of a single oral dose of $0.5 \mathrm{mg} / \mathrm{kg}$ bw $\left[{ }^{14} \mathrm{C}\right]$ emamectin $\mathrm{B} 1 \mathrm{a}$, mean peak plasma concentrations of approximately 17 and $21 \mu \mathrm{g}$ equivalents $/ \mathrm{kg}$ bw were attained 12 hours and 4 hours after administration, in males and females, respectively. The absolute oral bioavailability of emamectin benzoate was estimated to be approximately $55 \%$ in males and $74 \%$ in females, and the half-life of plasma elimination was approximately 34 hours in males and 51 hours in females. When the same dose was administered intravenously, the half-life of plasma elimination was 29 hours in males and 41 hours in females. The substance was widely distributed within tissues. Seven days after oral administration of $20 \mathrm{mg} / \mathrm{kg}$ bw $\left[{ }^{14} \mathrm{C}\right] /\left[{ }^{3} \mathrm{H}\right]$ emamectin $\mathrm{B} 1 \mathrm{a}$, residues in tissues ranged from 8 to $2033 \mu$ g-equivalents $/ \mathrm{kg}$ in the following order: most being present in the lung, followed by the gastro-intestinal tract, kidney, liver, fat, bone, muscle, spinal cord and blood, with least residues in the brain. Residues were much lower in rats given $0.5 \mathrm{mg} / \mathrm{kg}$ bw. In both sexes, regardless of route of administration, more than $94 \%$ of the administrated dose was eliminated in faeces and less than $1 \%$ in the urine. 


\section{Pharmacokinetics in food animals}

\section{Salmon}

In a pharmacokinetic study of emamectin benzoate in Atlantic salmon, four dose rates $(100,200,400,800 \mu \mathrm{g} / \mathrm{kg} \mathrm{bw})$ were administered to smolt fish (average weight $49.7 \mathrm{~g})$ by intra-peritoneal injection (Table 4.1) (Glover et al., 2010). The mean concentrations of residues in muscle and skin were determined by LC/MS 14 days after administration. For all dosages, residue concentrations in skin were considerably higher than for muscle, and a clear relationship between dose and resultant concentration was observed.

Following a mean intra-peritoneal administration of $438 \mu \mathrm{g} / \mathrm{kg}$ (range 293-744) emamectin benzoate in smolts, concentrations of emamectin were observed at intervals of 1, 3, 6 and 9 weeks (Table 4.2). Elimination half-lives in muscle and skin were calculated as 11.1 and 10.6 days, respectively.

Concentrations of emamectin in plasma from salmon that received standard, oral treatments with emamectin benzoate were studied in two fish farms in mid-Norway, with post-smolts put to sea in cages in the autumn of 2005 (Berg and Horsberg, 2009). Samples were collected in the autumn of 2005 and repeated sampling was performed from the same sites in the summer of 2006.
Table 4.1. Mean concentration of emamectin residues in muscle and skin of Atlantic salmon 14 days following intra-peritoneal injection (individual dose)

\begin{tabular}{ccc}
\hline $\begin{array}{c}\text { Dosage } \\
(\boldsymbol{\mu g} / \mathbf{k g ~ b w})\end{array}$ & $\begin{array}{c}\text { Muscle } \\
(\boldsymbol{\mu} \mathbf{g} / \mathbf{k g}) \pm S D\end{array}$ & $\begin{array}{c}\text { Skin } \\
(\boldsymbol{\mu g} / \mathbf{k g}) \pm S D\end{array}$ \\
\hline 100 & $26.7 \pm 7.3$ & $100 \pm 17.2$ \\
200 & $76.6 \pm 16.7$ & $159.9 \pm 50.7$ \\
400 & $166.7 \pm 43.5$ & $439.8 \pm 101.1$ \\
800 & $265.2 \pm 58.4$ & $815.6 \pm 47.8$ \\
\hline
\end{tabular}

SOURCE: Reprinted with permission from Glover, K.A., Samuelsen, O.B., Skilbrei, O.T., Boxaspen, K. \& Lunestad, B.T. 2010. Table 1 in Pharmacokinetics of emamectin benzoate administered to Atlantic salmon, Salmo salar L. by intra-peritoneal injection. Journal of Fish Diseases, 33(2): 183186. Copyright - 2010 - John Wiley and Sons Ltd.

Table 4.2. Mean concentrations of emamectin residues in muscle and skin of Atlantic salmon over a 9-week period following a single mean intra-peritoneal injection of $438 \mu \mathrm{g} / \mathrm{kg}$ (range: 293-744) of emamectin benzoate

\begin{tabular}{ccc}
\hline $\begin{array}{c}\text { Time } \\
\text { (days) }\end{array}$ & $\begin{array}{c}\text { Muscle } \\
(\boldsymbol{\mu} \mathbf{g} / \mathbf{k g}) \pm S D\end{array}$ & $\begin{array}{c}\text { Skin } \\
(\boldsymbol{\mu} \mathbf{g} / \mathbf{k g}) \pm S D\end{array}$ \\
\hline 7 & $449 \pm 142$ & $499 \pm 245$ \\
21 & $158 \pm 93$ & $185 \pm 88$ \\
42 & $28 \pm 7$ & $43 \pm 13$ \\
63 & $10 \pm 5$ & $16 \pm 9$ \\
\hline
\end{tabular}

SouRCE: Glover, K.A., Samuelsen, O.B., Skilbrei, O.T., Boxaspen, K. \& Lunestad, B.T. 2010. Table 2 in

Pharmacokinetics of emamectin benzoate administered to Atlantic salmon, Salmo salar L. by intra-peritoneal injection. Journal of Fish Diseases, 33(2): 183-186. Copyright - 2010 John Wiley and Sons Ltd.

The tentative concentration of emamectin benzoate in the medicated feed was $10 \mathrm{mg} / \mathrm{kg}$, resulting in a daily dosage of $50 \mu \mathrm{g} / \mathrm{kg}$ bodyweight at a feeding rate of $5 \mathrm{~g}$ medicated feed $/ \mathrm{kg}$ bodyweight for seven days. Blood samples were collected the day after treatment ended. Blood samples collected from 25 randomly sampled fish at each site in autumn of 2005 and then again in the summer of 2006 were analysed for emamectin by a HPLC method. The overall median concentration of emamectin B1a in plasma for the results from all sampling dates was $116 \mathrm{ng} / \mathrm{ml}$, with concentrations ranging from $6 \mathrm{ng} / \mathrm{ml}$ in autumn, 2005, to $440 \mathrm{ng} / \mathrm{ml}$ in summer, 2006.

When tested statistically using Friedman's ANOVA, there were significant differences in the emamectin plasma concentrations among fish from three cages at one of the farms, both in the autumn of 2005 and in summer 2006. At the second farm, no significant differences among three cages could be demonstrated in 2005 or in 2006. When pooling the results from all three cages, no significant difference could be demonstrated between the samples collected in autumn 2005 and summer 2006 at the one farm, whereas at the second farm, a highly significant difference was demonstrated between seasons. When looking at the pooled results from each site, no significant difference was detected between the two sites in 2005, whereas in 2006 there was a highly significant difference. 


\section{Cod}

Emamectin benzoate was studied in cod, Gadus morhua, held in seawater at $9^{\circ} \mathrm{C}$ and weighing 100-200 g (Samuelsen, 2010). Concentrations of emamectin B1a were determined in plasma collected from treated fish after intravenous (i.v.) injection $(50 \mu \mathrm{g} / \mathrm{kg} \mathrm{bw})$ and in plasma, muscle and skin following single oral (through stomach intubation, $50 \mu \mathrm{g} / \mathrm{kg} \mathrm{bw}$ ) administration. Following i.v. injection, the plasma drug concentration-time profile showed two distinct phases. The plasma distribution half-life $\left(\mathrm{t}_{1 / 2} \alpha\right)$ was estimated to be $2.5 \mathrm{~h}$, the elimination half-life $\left(\mathrm{t}_{1} / \beta\right)$ as $216 \mathrm{~h}$, the total body clearance $\left(\mathrm{Cl}_{\mathrm{T}}\right)$ as $0.0059 \mathrm{~L} / \mathrm{kg} / \mathrm{h}$ and mean residence time (MRT) as $385 \mathrm{~h}$. The volume of distribution at steady state, $\mathrm{VD}_{\mathrm{ss}}$, was calculated to be $1.839 \mathrm{~L} / \mathrm{kg}$. Following per os administration, the peak plasma concentration $\left(C_{\max }\right)$ was $15 \mathrm{ng} / \mathrm{ml}$, the time to peak plasma concentration $\left(T_{\max }\right)$ was $89 \mathrm{~h}$ and $\mathrm{t}_{1 / 2} \beta$ was $180 \mathrm{~h}$. The highest concentration in muscle $(21 \mu \mathrm{g} / \mathrm{kg})$ was measured after 7 days, and $\mathrm{t}_{1 / 2} \beta$ was calculated to be $247 \mathrm{~h}$. For skin, a peak concentration of $28 \mu \mathrm{g} / \mathrm{kg}$ at 3 days was observed and a $t_{1} / \beta$ of $235 \mathrm{~h}$ was determined. The bio-availability following per os administration was calculated to be $38 \%$.

\section{Metabolism in laboratory animals}

\section{Rats}

In rats, approximately $80 \%$ of the radiolabelled material in faeces and in tissues was unchanged emamectin B1a (EMEA, 1999). An N-demethylated product of emamectin B1a, 4"-deoxy-4"epiaminoavermectin B1a, was the only metabolite found in faeces, liver, kidney, muscle and fat. The quantity of this metabolite in faeces increased with time post-dosing. In faeces, this metabolite represented approximately 1 to $2 \%$ of the radioactivity on Day 1 after dosing, but 18 to $19 \%$ on Day 7 after dosing. The percentage of this metabolite found in faeces was independent of the dose administered, the route of administration or the sex of the animal.

\section{Metabolism in food producing animals}

\section{Salmon}

One hundred and twenty-two unsexed Atlantic salmon, averaging $1.3 \mathrm{~kg}$ bw, were used in a metabolism study (Kim-Kang et al., 2004). The fish were maintained at $5^{\circ} \mathrm{C}$ in two identical $1800 \mathrm{~L}$ tanks (A and B) of re-circulating seawater connected to a single reservoir. After an acclimatization period of 14 days, 100 fish were given $\left[{ }^{3} \mathrm{H}\right]$ emamectin benzoate formulated in feed to provide a nominal dose of $50 \mu \mathrm{g} / \mathrm{kg}$ of live weight/day for 7 consecutive days, based on a feeding rate of $0.4 \%$ bodyweight per day and the total biomass in each tank. The entire daily medicated feed ration was offered to all fish in each tank over a 30-minute period and any uneaten feed then removed. The remaining 22 fish served as unmedicated controls, 4 being removed before dosing and 18 being placed in the tanks with the dosed fish after dosing was completed.

The treated feed was prepared by mixing a feed pre-mix containing the $\left[{ }^{3} \mathrm{H}\right]$ emamectin benzoate, sieved Atlantic salmon pellet feed, and fish oil. The feed pre-mix used for the treated feed preparation was of similar composition to commercial Slice ${ }^{\circledR}$. The actual daily dose of the drug received was approximately $33 \mu \mathrm{g} / \mathrm{kg}$ per fish. Analysis of the treated feed before and after dosing confirmed that the $\left[{ }^{3} \mathrm{H}\right]$ emamectin $\mathrm{B} 1 \mathrm{a}$ had a radiopurity of $98 \%$. Groups of 10 dosed fish were euthanized at 3, 12, 24 and $72 \mathrm{~h}$ and at 7, 15, 30, 45, 60 and 90 days post-dose. Faeces were collected daily from the tanks, beginning just prior to dosing to 90 days post-final dose. Control fish $(\mathrm{n}=4)$ were removed $96 \mathrm{~h}$ prior to initial dosing. After weighing, mucus was collected from both flanks. Samples $(n=5)$ of liver, kidney, gut contents, muscle, skin and intact skin-with-muscle were pooled by matrix and post-dose interval for metabolite profiling at 2 h, Day 7, Day 15, Day 45 and Day 90. Samples were analysed using a HPLC system combined with a UV detector and liquid cell radioactivity 
monitoring, or via fraction collection followed by liquid scintillation counting (LSC).

Muscle, skin and intact skin-with-muscle tissues containing incurred residues from the 3-, 12-, 24- and 72-h, and 7-, 15- and 30-day withdrawal times were analysed by HPLC with fluorescence detection (HPLC/FL). Methanolic extractions of pooled tissues (liver, kidney, muscle, skin and intact skin-with-muscle), as well as pooled gut contents and faeces samples, were prepared for selected intervals. The extractability of $\left[{ }^{3} \mathrm{H}\right]$ residues in each matrix at all time-points was excellent: $>99 \%$ (liver), $>98 \%$ (kidney, intact skin-with-muscle), $>97 \%$ (muscle, gut contents), $>94 \%$ (skin and faeces). Recovery of radioactivity for the method was excellent, ranging from $98.31 \%$ for faeces to $>100 \%$ (104-115\%) for other matrices.

The metabolic profiles of emamectin residues in tissues, gut contents and faeces were established by HPLC using emamectin B1a and four metabolite standards: desmethylemamectin B1a; 8,9-Zemamectin B1a; N-desmethyl-N-formylemamectin B1a; and $\mathrm{N}$-formylemamectin B1a. The final extracts of pooled samples from each time-point $(12 \mathrm{~h}$ through Day 90) were analysed by HPLC. The HPLC conditions used were sufficient to afford good baseline separation of the components identified in Figure 4.1. The proportion of emamectin B1a in all tissues generally decreased from 98 to $100 \%$ of TRR at $12 \mathrm{~h}$ post-final dose to $81-89 \%$ by Day 90 . Lesser amounts of $\left[{ }^{3} \mathrm{H}\right]$ component 7 , which co-chromatographed with desmethylemamectin B1a, were observed in nearly all tissue extracts, increasing from 0 to $1 \%$ TRR at $12 \mathrm{~h}$ post-final dose to $11-17 \%$ TRR by Day 90 . Another component $\left(\left[{ }^{3} \mathrm{H}\right]\right.$ component 11, N-formylemamectin B1a) was inconsistently observed at low levels $(<2 \%$ TRR) in several extracts. No other significant residues were observed in tissues. HPLC analysis of 12-h and 90-day gut contents indicated that emamectin B1a and its desmethyl metabolite were the primary residues, although several minor residues were also present. HPLC analysis of faeces collected during dosing showed emamectin B1a as essentially the only component, whereas analysis of pooled faeces collected from 0 to 7 days post-final dose indicated the presence of several minor components of $2-10 \%$ TRR each in addition to emamectin B1a at $57 \%$ TRR.

Figure 4.1. Structures of emamectin and metabolites

(Reprinted with permission from Kim-Kang, H., Bova, A., Crouch, L.S., Wislocki, P.G., Robinson, R.A. \& Wu, J. 2004. Figure 2 in: Tissue distribution, metabolism, and residue depletion study in Atlantic salmon following oral administration of

$\left[{ }^{3} \mathrm{H}\right]$ emamectin benzoate. Journal of Agricultural and Food Chemistry, 52(7): 2108-2118. Copyright - 2004 - American Chemical Society.

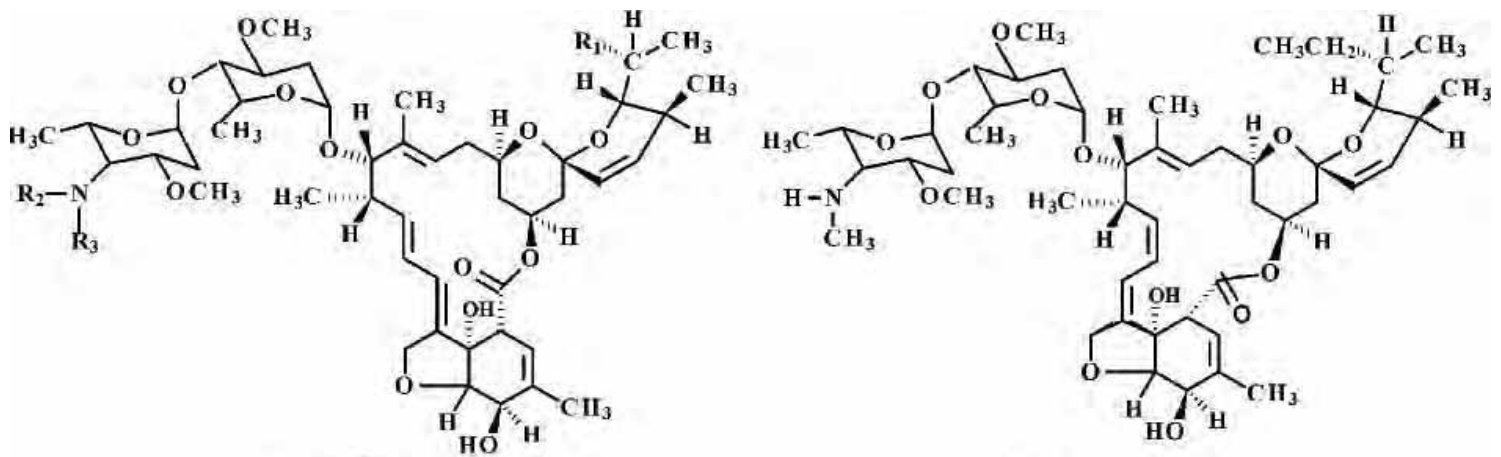

Emamectin B1

8,9-Z-emamectin BIa

\begin{tabular}{|c|c|c|c|}
\hline Compound ID & $\mathbf{R}_{\mathbf{1}}$ & $\mathbf{R}_{\mathbf{2}}$ & $\mathbf{R}_{\mathbf{3}}$ \\
\hline 8,9-Z-emamectin B1a & $\mathrm{CH}_{2} \mathrm{CH}_{3}$ & $\mathrm{H}$ & $\mathrm{CH}_{3}$ \\
\hline N-formyl emamectin B1 & $\mathrm{CH}_{2} \mathrm{CH}_{3}$ for $\mathrm{B} 1 \mathrm{a}, \mathrm{CH}_{3}$ for $\mathrm{B} 1 \mathrm{~b}$ & $\mathrm{CH}=\mathrm{O}$ & $\mathrm{CH}_{3}$ \\
\hline N-desmethyl, N-formyl-emamectin B1 & $\mathrm{CH}_{2} \mathrm{CH}_{3}$ for B1a, $\mathrm{CH}_{3}$ for B1b & $\mathrm{CH}=\mathrm{O}$ & $\mathrm{H}$ \\
\hline N-desmethyl-emamectin B1 & $\mathrm{CH}_{2} \mathrm{CH}_{3}$ for $\mathrm{B} 1 \mathrm{a}, \mathrm{CH}_{3}$ for $\mathrm{B} 1 \mathrm{~b}$ & $\mathrm{H}$ & $\mathrm{H}$ \\
\hline
\end{tabular}




\section{Tissue residue depletion studies}

\section{Radiolabelled residue depletion studies}

\section{Salmon}

Information on the relationship between total radiolabelled residues and marker residue was also obtained from the metabolism study in which Atlantic salmon $(1.3 \mathrm{~kg} \mathrm{bw})$ maintained in tanks of seawater at $5 \pm 1{ }^{\circ} \mathrm{C}$ were dosed with $\left[{ }^{3} \mathrm{H}\right]$ emamectin $\mathrm{B} 1$ benzoate in feed at a nominal rate of $50 \mu \mathrm{g}$ of emamectin benzoate/ $\mathrm{kg} /$ day for 7 consecutive days (Kim-Kang et al., 2004). Tissues, blood and bile were collected from 10 fish each at 3 and $12 \mathrm{~h}$ and at 1, 3, 7, 15, 30, 45, 60 and 90 days post-final dose. Samples of blood, liver, kidney, skin and muscle were collected for total radioactivity residue (TRR) determination by combustion/LSC using biological sample oxidizers analysis. Emamectin B1a concentrations in muscle and skin were quantified using a validated HPLC/FL method based on extraction and derivatization of emamectin B1a. The LOQ for both tissues was $40 \mu \mathrm{g} / \mathrm{kg}$ and the LODs were $2.6 \mu \mathrm{g} / \mathrm{kg}$ and $3.3 \mu \mathrm{g} / \mathrm{kg}$ for muscle and for skin, respectively.

The highest TRR concentration in tissues was found in kidney $(306 \pm 73 \mu \mathrm{g} / \mathrm{kg}$ on day 15 , declining to $144 \pm 44 \mu \mathrm{g} / \mathrm{kg}$ by Day 90 ). TRR concentrations in muscle varied from $53 \pm 19$ to $65 \pm 19 \mu \mathrm{g} / \mathrm{kg}$ in the first $72 \mathrm{~h}$ post-dose, declining to $19 \pm 5 \mu \mathrm{g} / \mathrm{kg}$ by Day 90 , whereas TRR levels in skin ranged from $69 \pm 27$ to $93 \pm 34 \mu \mathrm{g} / \mathrm{kg}$ during the first $72 \mathrm{~h}$ post-dose, declining to $36 \pm 10 \mu \mathrm{g} / \mathrm{kg}$ by Day 90 . For muscle-with-skin, TRR levels varied from $55 \pm 19$ to 64 $\pm 20 \mu \mathrm{g} / \mathrm{kg}$ in the first $72 \mathrm{~h}$ post-dose, decreasing to $20 \pm 6 \mu \mathrm{g} / \mathrm{kg}$ by Day 90 . TRR levels in plasma were modest, ranging from $119 \pm 40 \mu \mathrm{g} / \mathrm{kg}$ at $72 \mathrm{~h}$, to $30 \pm 10 \mu \mathrm{g} / \mathrm{kg}$ by Day 90 , whereas those in mucus amounted to $10 \pm 7 \mu \mathrm{g} / \mathrm{kg}$ through the entire testing interval. Residues in bone were also low, ranging from $7 \pm 2 \mu \mathrm{g} / \mathrm{kg}$ at $72 \mathrm{~h}$ to $2 \pm 1 \mu \mathrm{gg} / \mathrm{kg}$ by Day 90 . The TRR levels in bile and gut contents ranged from $638 \pm 121 \mu \mathrm{g} / \mathrm{kg}$ (bile, $72 \mathrm{~h}$ ) to 149 $\pm 53 \mu \mathrm{g} / \mathrm{kg}$ and from $669 \pm 140 \mu \mathrm{g} / \mathrm{kg}$ (gut content, $3 \mathrm{~h}$ ) to $156 \pm 62 \mu \mathrm{g} / \mathrm{kg}$ by Day 90 .

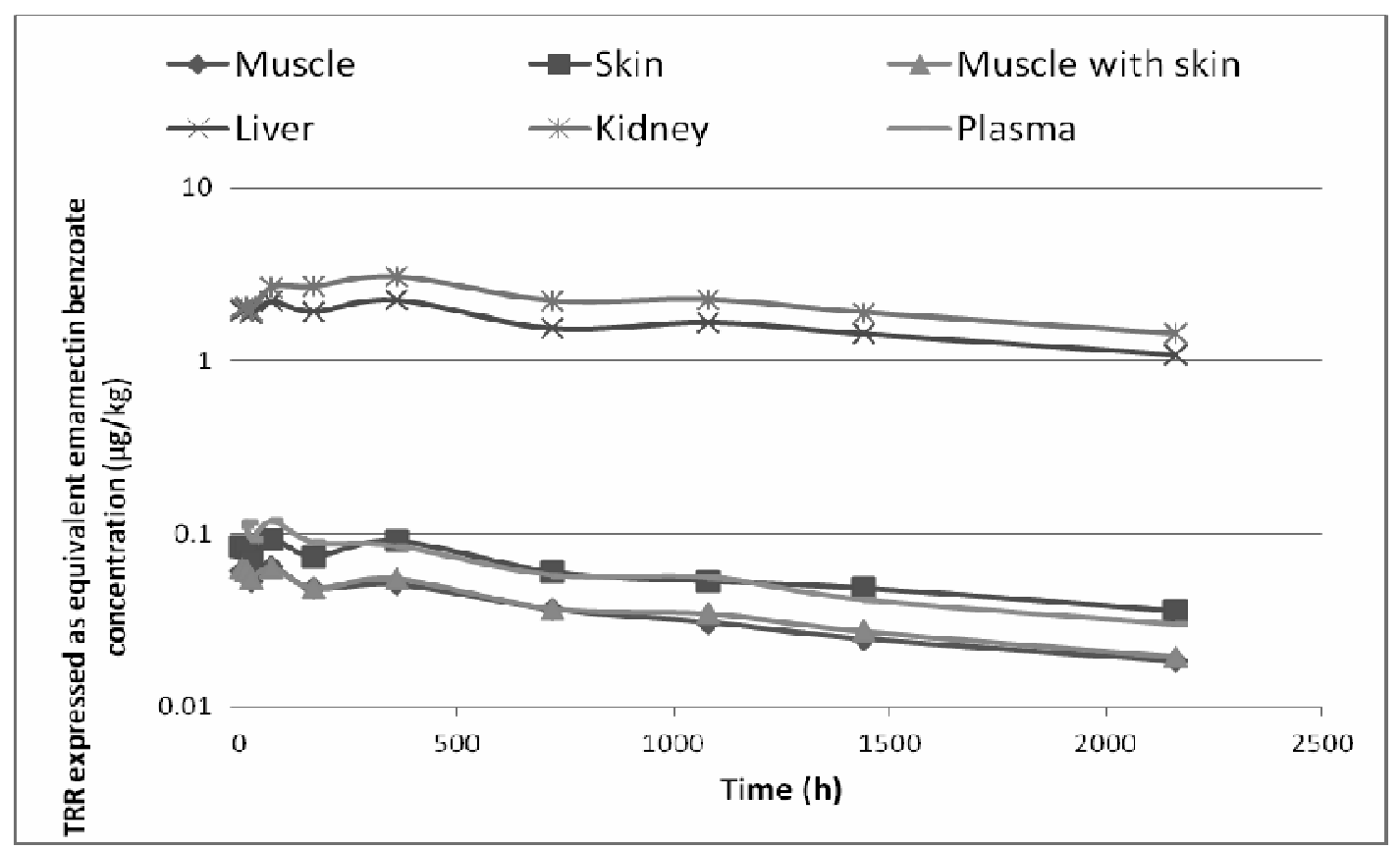

Figure 4.2. TRR depletion profiles in plasma muscle, skin, muscle-and-skin, liver and kidney of salmon dosed at a nominal rate of $50 \mu \mathrm{g}$ of $\left[{ }^{3} \mathrm{H}\right]$ emamectin $\mathrm{B} 1$ benzoate $/ \mathrm{kg} /$ day in feed for 7 consecutive days. 
The distribution of total residue was greatest in liver and kidney, with $28-34$ and $22-35 \%$ of the total residue found in these two organs, respectively. Muscle (13-20\%) and intact skinwith-muscle (15-22\%) also contained a sizable portion of the total emamectin residue. Bile and gut contents contained a small proportion of the total emamectin residue $(1-5 \%)$, whereas skin, bone, mucus and plasma each contained only $1 \%$ or less. The residue components identified in liver, kidney, muscle, and skin samples pooled by post-dose interval were emamectin B1a (81-100\% TRR) and desmethylemamectin B1a (0-17\% TRR) with $\mathrm{N}$-formylemamectin B1a seen in trace amounts $(<2 \%)$ in some muscle samples. The emamectin B1a concentration in individual samples of skin and muscle as determined using HPLC/FL was below $85 \mu \mathrm{g} / \mathrm{kg}$ in all samples analysed ( $3 \mathrm{~h}$ to 30 days post-dose).

Emamectin B1a in muscle ranged from 32 to $67 \mu \mathrm{g} / \mathrm{kg}$ at $3 \mathrm{~h}$, from 36 to $58 \mu \mathrm{g} / \mathrm{kg}$ at $12 \mathrm{~h}$, from 18 to $60 \mu \mathrm{g} / \mathrm{kg}$ at $24 \mathrm{~h}$, from 24 to $64 \mu \mathrm{g} / \mathrm{kg}$ at $72 \mathrm{~h}$, from 12 to $55 \mu \mathrm{g} / \mathrm{kg}$ at 7 days, from 19 to $48 \mu \mathrm{g} / \mathrm{kg}$ at 15 days, and from 13 to $39 \mu \mathrm{g} / \mathrm{kg}$ at 30 days. The mean ratio of the marker to total radioactive residue in muscle was rather constant, ranging from 0.66 to 0.73 . Emamectin B1a in skin ranged from 37 to $84 \mu \mathrm{g} / \mathrm{kg}$ at $3 \mathrm{~h}$, from 28 to $68 \mu \mathrm{g} / \mathrm{kg}$ at $12 \mathrm{~h}$, from 24 to $74 \mu \mathrm{g} / \mathrm{kg}$ at $24 \mathrm{~h}$, from 23 to $84 \mu \mathrm{g} / \mathrm{kg}$ at $72 \mathrm{~h}$, from 15 to $48 \mu \mathrm{g} / \mathrm{kg}$ at 7 days, from 31 to $61 \mu \mathrm{g} / \mathrm{kg}$ at 15 days, and from 16 to $59 \mu \mathrm{g} / \mathrm{kg}$ at 30 days. The mean ratio of the marker to total residue in skin was also rather constant, ranging from 0.56 to 0.66 (Kim-Kang et al., $\left.2004^{1}\right)$.

The ratio of emamectin B1a, as determined by HPLC/FL in the determinative assay relative to the TRR is significantly less than 1 , despite the high extractability of $\left[{ }^{3} \mathrm{H}\right]$ residues and the high proportion of $\left[{ }^{3} \mathrm{H}\right]$ emamectin $\mathrm{B} 1 \mathrm{a}$ as determined by HPLC-radiometry. This difference is accounted for by the expression of TRR in the study as emamectin B1 benzoate equivalents, whereas emamectin B1 benzoate is only $80 \%$ emamectin B1a free base and recoveries of $83-91 \%$ were obtained in the quantitative assay. After correction, the ratio of the mean concentration of the marker residue emamectin B1a to that of the total residue was calculated as 0.9 for muscle and fillet (muscle+skin), and 0.8 for skin.

\section{Salmon}

The tissue distribution of $\left[{ }^{3} \mathrm{H}\right]$ emamectin benzoate after a single oral dose in Atlantic salmon (Sevatdal et al., 2005) was investigated by means of whole-body autoradiography and scintillation counting. The distribution study demonstrated a high quantity of radioactivity in mucous membranes (gastrointestinal tract, gills) throughout the observation period (56 days). Activity was also high in the epiphysis, hypophysis and olfactory rosette throughout the study. The highest activity was observed in the bile, indicating this to be an important route for excretion. The distribution study confirmed the results from the elimination study with respect to concentrations in blood, skin mucous and muscle.

\section{Residue depletion studies with unlabelled drug}

\section{Salmon}

A study was conducted to investigate the content of emamectin in blood, mucus and muscle following field administration of the recommended dose of emamectin $(50 \mu \mathrm{g} / \mathrm{kg} \mathrm{bw}$, daily for 7 days) to salmon with an average weight of $135 \mathrm{~g}$ at the start of the treatment (Sevatdal et al., 2005). Salinity varied between 3.2 and $3.4 \%$ during the trial period. The study was

1 The reviewers noted some apparent discrepancies in Table 7 in Kim-Kang et al., 2004. The concentrations reported for emamectin B1a residues in skin for the group of fish 41-50 (Day 15) and 51-60 (Day 30) appear to have been transposed from the preceding table (i.e. Table 6 in Kim-Kang et al., 2004). The values reported for fish $42,44,46,48$ and 50 prior to the group 41-50 in the table may represent the concentrations of emamectin B1a found in skin of these fish, as they differ from the values reported in the preceding table. The Ratio of marker:TRRs reported in Table 7 of Kim-Kang et al., 2004, for emamectin residues in skin at Days 15 and 30 are not consistent with the ratios reported in the text of the original paper. These discrepancies did not, however, affect the ratio MR:TRR determined by the Committee. 
performed in the field at ambient water temperatures, which varied between $15^{\circ} \mathrm{C}$ (June) and $19^{\circ} \mathrm{C}$ (August). Blood, muscle and mucus samples were collected before the treatment started (Day 0) and on Days 7, $14,21,28,35,42,49,56,63,70,77,84,91$ and 98 after start of treatment. After derivatization of the samples with 1methylimidazole and trifluoroacetic anhydride $\left(60^{\circ} \mathrm{C}, \quad 90 \mathrm{~min}\right)$, the concentrations of emamectin B1a in plasma, mucus and muscle were determined by high-performance liquid chromatography using a fluorescence detector. Maximum concentrations of 128, 105 and $68 \mu \mathrm{g} / \mathrm{kg}$ of emamectin B1a were reached in blood, mucus and muscle, respectively, on Day 7 (the last day of treatment). From Day 7, the concentration of emamectin B1a in the blood declined until the concentration was less than the limit of detection $(1 \mu \mathrm{g} / \mathrm{kg})$ on Day 77. The concentration was significantly higher in mucus compared with plasma $(P$ $<0.05$ ) except on Days 7 and 21. The concentration of emamectin B1a decreased gradually from the end of treatment (Day 7)

to Day 70, with biological half-lives of 9.2, 10.0 and 11.3 days in muscle, plasma and mucus, respectively (Table 4.3).

The depletion of emamectin B1a in the edible tissues of Atlantic salmon (Salmo salar) was studied at two inclusion rates of emamectin benzoate (Slice $\left.{ }^{\circledR}\right)$ in commercially prepared diets (Whyte et al., 2011). Fish were maintained in tanks supplied by flow-through, temperature-controlled natural seawater at $10.08 \pm 0.26^{\circ} \mathrm{C}$, and administered a medicated diet containing a nominal dose rate of emamectin benzoate at either $50 \mu \mathrm{g} / \mathrm{kg}$ bw per day (the recommended manufacturer's dose), or $100 \mu \mathrm{g} / \mathrm{kg}$ bw per day, for seven consecutive days. Individual variability in concentrations of emamectin B1a in muscle and skin tissues was high and considered related to the hierarchal effects of feeding. Emamectin B1a residues were determined in muscle fillet and skin samples at intervals from 1 to 45 days post-feeding in the single-only dose study, and 1 to 20 days post-feeding in the single-double dose comparison study. Mean concentrations of emamectin B1a ranged from 60.5 to $7.3 \mu \mathrm{g} / \mathrm{kg}$ in the muscle and 199.7 to $28.1 \mu \mathrm{g} / \mathrm{kg}$ in the skin for the single-only study, and in the singledouble comparison study the range was 57.5 to $25.8 \mathrm{ng} / \mathrm{g}$ in the muscle of the single dose and 96.8 to $45.6 \mu \mathrm{g} / \mathrm{kg}$ in the muscle of the double dose. The maximum residue limits allowed by Health Canada of $100 \mu \mathrm{g} / \mathrm{kg}$ and $1000 \mu \mathrm{g} / \mathrm{kg}$ were never detected in the muscle and skin, respectively, for the recommended dosage of $50 \mu \mathrm{g} / \mathrm{kg}$, whereas $28.6 \%$ of the fish receiving the double dose of $100 \mu \mathrm{g} / \mathrm{kg}$ were observed to have residue concentrations greater than $100 \mu \mathrm{g} / \mathrm{kg}$ for muscle, ranging from Day 1 through Day 20 post-medication (Table 4.4). 
Table 4.4. Concentration of emamectin B1a in muscle and skin of Atlantic salmon $(\mu \mathrm{g} / \mathrm{kg})$ after administration of different doses of emamectin benzoate.

\begin{tabular}{|c|c|c|c|c|}
\hline \multirow{3}{*}{$\begin{array}{l}\text { Sampling interval } \\
\text { post-medication }\end{array}$} & \multicolumn{4}{|c|}{ Dosage } \\
\hline & \multicolumn{4}{|c|}{ Emamectin B1a concentration $(\mu \mathrm{g} / \mathrm{kg})$} \\
\hline & Muscle & Skin & Muscle & Muscle \\
\hline Control & 0 & 0 & 0 & 0 \\
\hline 1 day & $60.5 \pm 28.5$ & $199.7 \pm 115.9$ & $57.5 \pm 21.3$ & $96.8 \pm 84.6$ \\
\hline Internal control & 0 & 0 & Not applicable & \\
\hline 3 days & $55.4 \pm 32.8$ & $153.3 \pm 65.8$ & $33.0 \pm 36.9$ & $89.8 \pm 49.6$ \\
\hline Internal control & 0 & $2.42 \pm 2.1$ & Not applicable & \\
\hline Off-feed & $35.0 \pm 13.0$ & $121.1 \pm 83.2$ & Not applicable & \\
\hline 5 days & $36.5 \pm 19.4$ & $219.6 \pm 121.2$ & $39.5 \pm 28.2$ & $79.8 \pm 52.0$ \\
\hline Internal control & 0 & $2.37 \pm 2.1$ & Not applicable & \\
\hline Off-feed & $31.5 \pm 20.4$ & $99.4 \pm 63.6$ & Not applicable & \\
\hline 10 days & $32.3 \pm 17.0$ & $143.8 \pm 90.1$ & $25.6 \pm 17.8$ & $58.5 \pm 44.8$ \\
\hline Internal control & 0 & $1.47 \pm 1.3$ & Not applicable & \\
\hline 15 days & $24.9 \pm 15.7$ & $104.1 \pm 55.0$ & $21.3 \pm 10.4$ & $37.0 \pm 35.1$ \\
\hline Internal control & 0 & 0 & Not applicable & \\
\hline 20 days & Not applicable & & $25.8 \pm 17.3$ & $45.6 \pm 33.5$ \\
\hline 30 days & $12.9 \pm 7.4$ & $69.6 \pm 30.9$ & Not applicable & \\
\hline Internal control & 0 & $2.01 \pm 1.7$ & Not applicable & \\
\hline 45 days & $7.3 \pm 3.0$ & $28.1 \pm 13.0$ & Not applicable & \\
\hline Internal control & 0 & $0.89 \pm 1.3$ & Not applicable & \\
\hline
\end{tabular}

SOURCE: Reprinted with permission from Whyte, S.K., Westcott, J.D., Byrne, P. \& Hammell, K.L. 2011. Table 3 in: Comparison of the depletion of emamectin benzoate $\left(\right.$ Slice ${ }^{\circledR}$ ) residues from skeletal muscle and skin of Atlantic salmon (Salmo salar) for multiple dietary dose regimens at $10^{\circ} \mathrm{C}$. Aquaculture, 315(3-4): 228-235. Copyright - 2011 - Elsevier B.V.

In another study, juvenile Atlantic salmon with an initial mean weight of $132 \mathrm{~g}$ were experimentally medicated by a standard seven-day emamectin benzoate treatment of $50 \mu \mathrm{g} / \mathrm{kg}$ bw (Olsvik et al., 2008). The concentrations of emamectin B1a in liver, muscle and skin were determined, by LC-MS $/ \mathrm{MS}$ ( $\mathrm{LOQ}=5 \mu \mathrm{g} / \mathrm{kg}$, LOD $=2.5 \mu \mathrm{g} / \mathrm{kg}$ ), in samples collected at Days 7, 14 and 35 after the start of treatment. At Day 7, the mean concentration of emamectin B1a in samples of liver was $33 \mu \mathrm{g} / \mathrm{kg}$, whereas the mean concentrations in muscle were around $1 \mu \mathrm{g} / \mathrm{kg}$. The skin did not contain emamectin B1a in concentrations above the level of detection at Day 7. At Day 14, the mean concentrations in liver, muscle and skin were 9002, 81 and $369 \mu \mathrm{g} / \mathrm{kg}$, respectively. The corresponding mean concentrations at Day 35 were 4902,34 and $258 \mu \mathrm{g} / \mathrm{kg}$, respectively.

\section{Trout}

The depletion of emamectin B1a in the edible tissues of rainbow trout (Oncorhynchus mykiss) was studied at two temperatures following treatment with emamectin benzoate in feed using a standard seven-day treatment of $50 \mu \mathrm{g} / \mathrm{kg}$ bw (Roy et al., 2006). Fish approaching market size (400-1500 g) were held in tanks supplied with temperature-controlled seawater at 6 $\pm 1^{\circ} \mathrm{C}$ (cold water) or $15 \pm 1^{\circ} \mathrm{C}$ (warm water). In each study, the medicated group was offered feed containing emamectin benzoate at a nominal dose rate of $50 \mu \mathrm{g} / \mathrm{kg}$ bw fish/day for 7 days and the control group was offered un-medicated feed. Actual dose rates, calculated from growth rate and feed consumption data, and measured emamectin benzoate concentrations in feed, were $88.6 \%$ nominal in the cold water study $(96.6 \%$ adjusted for feed assay recovery) and $96.8 \%$ nominal in the warm water study (105.1\% adjusted for feed assay recovery). 
Concentrations of emamectin B1a were determined in fillet samples (muscle and skin in natural proportion) collected at intervals from $6 \mathrm{~h}$ to 77 days post-treatment in the cold water study, and $6 \mathrm{~h}$ to 49 days post-treatment in the warm water study. In the cold water study, mean emamectin B1a residues ranged from $81.8 \pm 44.5 \mu \mathrm{g} / \mathrm{kg}$ at 1 day post-treatment (102.3 $\pm 55.7 \mu \mathrm{g} / \mathrm{kg}$ adjusted for recovery) to $13.7 \pm 10.5 \mu \mathrm{g} / \mathrm{kg}$ at 77 days post-treatment $(17.2$ $\pm 13.1 \mu \mathrm{g} / \mathrm{kg}$ ). In the warm water study, mean residue concentrations ranged from 64.5 $\pm 50.3 \mu \mathrm{g} / \mathrm{kg}$ at $6 \mathrm{~h}$ post-treatment $(80.7 \pm 62.9 \mu \mathrm{g} / \mathrm{kg}$ adjusted for recovery) to $1.6 \pm 1.6 \mu \mathrm{g} / \mathrm{kg}$ at 49 days post-treatment $(2.0 \pm 2.0 \mu \mathrm{g} / \mathrm{kg})$. In the cold water study, residues in skin and muscle were also determined separately (Tables 4.5-4.8). On average, emamectin B1a concentrations in skin were approximately 1.8 times higher than in muscle. Measured residue levels ranged widely and no detectable residues were found in at least a few individual fish at all time-points. This high variability was considered to be due to differences in medicated feed consumption within the experimental population. Depletion of emamectin was faster at $15^{\circ} \mathrm{C}$ than at $6^{\circ} \mathrm{C}$. In both studies the depletion curve showed a small secondary peak at around 90 degree-days. This observation is consistent with recirculation of the compound from a body store.

Table 4.5. Residues of emamectin B1a at each time-point following treatment, in fillet (muscle + skin in natural proportion) from trout which received nominally $50 \mu \mathrm{g} / \mathrm{kg}$ bw emamectin benzoate for 7 days and which were maintained at $6^{\circ} \mathrm{C}$ for the duration of the experiment.

\begin{tabular}{ccccccc}
\hline $\begin{array}{c}\text { Days post- } \\
\text { treatment }\end{array}$ & \multicolumn{2}{c}{ Measured concentration $(\boldsymbol{\mu g} / \mathbf{k g})$} & \multicolumn{3}{c}{ Recovery adjusted concentration $(\boldsymbol{\mu g} / \mathbf{k g})$} \\
& Min. & Max. & Mean \pm SD & Min. & Max. & Mean \pm SD \\
\hline 0.25 & $<1.6$ & 99.3 & $54.4 \pm 28.4$ & $<2.0$ & 124 & $68.0 \pm 35.5$ \\
1 & $<1.6$ & 142 & $81.8 \pm 44.5$ & $<2.0$ & 178 & $102.3 \pm 55.7$ \\
3 & $<1.6$ & 112 & $48.4 \pm 34.3$ & $<2.0$ & 140 & $60.5 \pm 42.9$ \\
7 & $<1.6$ & 125 & $56.8 \pm 42.8$ & $<2.0$ & 156 & $70.9 \pm 53.4$ \\
21 & $<1.6$ & 99.4 & $32.1 \pm 30.6$ & $<2.0$ & 124 & $40.2 \pm 38.2$ \\
35 & $<1.6$ & 96.3 & $34.1 \pm 35.2$ & $<2.0$ & 120 & $42.6 \pm 43.9$ \\
56 & $<1.6$ & 77.1 & $17.9 \pm 21.0$ & $<2.0$ & 96.3 & $22.3 \pm 26.3$ \\
77 & $<1.6$ & 36.2 & $13.7 \pm 10.5$ & $<2.0$ & 45.2 & $17.2 \pm 13.1$ \\
\hline
\end{tabular}

NOTES: Mean \pm SD calculated from 15 fish. Individual measured values reported as ND (not detectable assigned value of $L O D / 2$; individual measured values reported as $N Q$ (not quantifiable) assigned value of $L O Q / 2$. $L O D=1.6 \mu g / \mathrm{kg}$, $L O Q=$ 20.6 rg/kg. SOURCE: Reprinted with permission from Roy, W.J., Gillan, N., Crouch, L., Parker, R., Rodger, H. \& Endris, R. 2006. Table $3 \mathrm{in}$ : Depletion of emamectin residues following oral administration to rainbow trout, Oncorhynchus mykiss. Aquaculture, 259(1-4): 6-16. Copyright - 2006 - Elsevier B.V.

Table 4.6. Residues of emamectin $\mathrm{B} 1 \mathrm{a}$ at each time-point following treatment, in skin of trout that received nominally $50 \mu \mathrm{g} / \mathrm{kg}$ bw emamectin benzoate for 7 days and which were maintained at $6^{\circ} \mathrm{C}$

\begin{tabular}{ccccccc}
\hline $\begin{array}{c}\text { Days post- } \\
\text { treatment }\end{array}$ & \multicolumn{2}{c}{ Measured concentration $(\boldsymbol{\mu g} / \mathbf{k g})$} & \multicolumn{3}{c}{ Recovery adjusted concentration $(\boldsymbol{\mu g} / \mathbf{k g})$} \\
& Min. & Max. & Mean \pm SD & Min. & Max. & Mean \pm SD \\
\hline 0.25 & $<2.1$ & 167 & $86.8 \pm 53.9$ & $<2.5$ & 199 & $103.4 \pm 64.1$ \\
1 & $<2.1$ & 337 & $120.6 \pm 87.4$ & $<2.5$ & 402 & $143.6 \pm 104.3$ \\
3 & $<2.1$ & 165 & $75.0 \pm 53.9$ & $<2.5$ & 196 & $89.3 \pm 64.2$ \\
7 & $<2.1$ & 169 & $88.1 \pm 58.7$ & $<2.5$ & 201 & $105.1 \pm 70.0$ \\
21 & $<2.1$ & 198 & $54.4 \pm 55.6$ & $<2.5$ & 235 & $64.8 \pm 66.1$ \\
35 & $<2.1$ & 175 & $51.8 \pm 54.5$ & $<2.5$ & 208 & $61.6 \pm 64.8$ \\
56 & $<2.1$ & 113 & $25.0 \pm 30.6$ & $<2.5$ & 135 & $29.9 \pm 36.5$ \\
77 & $<2.1$ & 50.1 & $20.3 \pm 13.2$ & $<2.5$ & 59.6 & $24.2 \pm 15.8$ \\
\hline
\end{tabular}

NOTES: Mean \pm SD calculated from 15 fish. Individual measured values reported as ND (not detectable) assigned value of $\mathrm{LOD} / 2$; individual measured values reported as NQ (not quantifiable) assigned value of $4.68 \mu \mathrm{g} / \mathrm{kg}$. $\mathrm{LOD}=2.1 \mu \mathrm{g} / \mathrm{kg}$, $\mathrm{LOQ}=$ 20.7 mg/kg. SOURCE: Reprinted with permission from Roy, W.J., Gillan, N., Crouch, L., Parker, R., Rodger, H. \& Endris, R. 2006. Table 5 in: Depletion of emamectin residues following oral administration to rainbow trout, Oncorhynchus mykiss. Aquaculture, 259(1-4): 6-16. Copyright - 2006 - Elsevier B.V. 
Table 4.7. Residues of emamectin B1a at each time-point following treatment, in muscle of trout that received nominally $50 \mu \mathrm{g} / \mathrm{kg}$ bw emamectin benzoate for 7 days and which were maintained at $6^{\circ} \mathrm{C}$

\begin{tabular}{ccccccc}
\hline $\begin{array}{c}\text { Days post- } \\
\text { treatment }\end{array}$ & \multicolumn{2}{c}{ Measured concentration $(\boldsymbol{\mu g} / \mathbf{k g})$} & \multicolumn{2}{c}{ Recovery adjusted concentration $(\boldsymbol{\mu g} / \mathbf{k g})$} \\
& Min & Max & Mean \pm SD & Min & Max & Mean \pm SD \\
\hline 0.25 & $<1.6$ & 103 & $52.8 \pm 28.5$ & $<1.9$ & 121 & $62.1 \pm 33.5$ \\
1 & $<1.6$ & 123 & $63.9 \pm 35.2$ & $<1.9$ & 145 & $75.2 \pm 41.5$ \\
3 & $<1.6$ & 118 & $48.0 \pm 36.5$ & $<1.9$ & 139 & $56.5 \pm 43.0$ \\
7 & $<1.6$ & 120 & $53.3 \pm 42.0$ & $<1.9$ & 141 & $62.8 \pm 49.4$ \\
21 & $<1.6$ & 86.1 & $23.4 \pm 26.9$ & $<1.9$ & 101 & $27.5 \pm 31.6$ \\
35 & $<1.6$ & 86.2 & $25.4 \pm 27.4$ & $<1.9$ & 101 & $29.9 \pm 32.2$ \\
56 & $<1.6$ & 51.5 & $13.4 \pm 13.6$ & $<1.9$ & 60.6 & $15.9 \pm 15.9$ \\
77 & $<1.6$ & 34.1 & $13.7 \pm 10.2$ & $<1.9$ & 40.1 & $16.2 \pm 12.0$ \\
\hline
\end{tabular}

NOTES: Mean \pm SD calculated from 15 fish. Individual measured values reported as ND (not detectable) assigned value of $\mathrm{LOD} / 2$; individual measured values reported as NQ (not quantifiable) assigned value of $4.7 \mu \mathrm{g} / \mathrm{kg}$. $\mathrm{LOD}=1.6 \mu \mathrm{g} / \mathrm{kg}$, $\mathrm{LOQ}=$ 20.6 gg/kg. SouRCE: Reprinted with permission from Roy, W.J., Gillan, N., Crouch, L., Parker, R., Rodger, H. \& Endris, R. 2006. Table 4 in: Depletion of emamectin residues following oral administration to rainbow trout, Oncorhynchus mykiss. Aquaculture, 259(1-4): 6-16. Copyright - 2006 - Elsevier B.V.

Table 4.8. Residues of emamectin B1a at each time-point following treatment, in fillet (muscle + skin in natural proportion) from trout which received nominally $50 \mu \mathrm{g} / \mathrm{kg}$ bw emamectin benzoate for 7 days and which were maintained at $15^{\circ} \mathrm{C}$ at each time-point following treatment.

\begin{tabular}{ccccccc}
\hline $\begin{array}{c}\text { Days post- } \\
\text { treatment }\end{array}$ & \multicolumn{2}{c}{ Measured concentration $(\boldsymbol{\mu g} / \mathbf{k g})$} & \multicolumn{2}{c}{ Recovery adjusted concentration $(\boldsymbol{\mu g} / \mathbf{k g})$} \\
& Min. & Max. & Mean \pm SD & Min. & Max. & Mean \pm SD \\
\hline 0.25 & $<1.6$ & 130 & $64.5 \pm 50.3$ & $<2.0$ & 162 & $80.5 \pm 62.8$ \\
1 & $<1.6$ & 106 & $45.1 \pm 31.8$ & $<2.0$ & 132 & $56.4 \pm 39.7$ \\
3 & $<1.6$ & 150 & $43.6 \pm 57.3$ & $<2.0$ & 188 & $54.6 \pm 71.8$ \\
7 & $<1.6$ & 81.3 & $17.9 \pm 31.1$ & $<2.0$ & 102 & $22.4 \pm 39.0$ \\
14 & $<1.6$ & 47.1 & $24.7 \pm 20.8$ & $<2.0$ & 158.9 & $30.8 \pm 26.0$ \\
21 & $<1.6$ & 24.1 & $8.7 \pm 9.4$ & $<2.0$ & 30.1 & $10.9 \pm 11.7$ \\
35 & $<1.6$ & $<9.35$ & $3.1 \pm 2.0$ & $<2.0$ & $<11.7$ & $3.9 \pm 2.5$ \\
49 & $<1.6$ & $<9.35$ & $2.0 \pm 1.9$ & $<2.0$ & $<11.7$ & $2.5 \pm 2.3$ \\
\hline
\end{tabular}

NOTES: Mean $\pm S D$ calculated from 15 fish. Individual measured values reported as ND (not detectable) assigned value of $\mathrm{LOD} / 2$; individual measured values reported as NQ (not quantifiable) assigned value of $L O Q / 2$. $L O D=1.6 \mu \mathrm{g} / \mathrm{kg}$, $L O Q=$ 20.6 mg/kg. SOURCE: Reprinted with permission from Roy, W.J., Gillan, N., Crouch, L., Parker, R., Rodger, H. \& Endris, R. 2006. Table 8 in: Depletion of emamectin residues following oral administration to rainbow trout, Oncorhynchus mykiss. Aquaculture, 259(1-4): 6-16. Copyright - 2006 - Elsevier B.V.

\section{Methods of analysis for residues in tissues}

An analytical method was developed and validated to determine residue concentration of emamectin B1a in muscle, skin, and intact muscle+skin in natural proportion from Atlantic salmon (Kim-Kang et al., 2004). The method is based on cleanup of an ethyl acetate extract of tissue on a propylsulfonic acid solid phase extraction cartridge, followed by derivatization with trifloroacectic anhydride in the presence of N-methylimidazole. The amount of derivatized emamectin B1a present is determined using reversed phase HPLC/FL. Calibration curves were obtained with fortified tissue over a range of $50-800 \mu \mathrm{g} / \mathrm{kg}$. The LODs were 2.6, 8.3 and $3.8 \mu \mathrm{g} / \mathrm{kg}$ as emamectin B1a for muscle, skin and intact muscle+skin, respectively. The LOQs were all at $50 \mathrm{ng} / \mathrm{g}$ for muscle, skin and intact muscle+skin. Recoveries were $94.4 \pm 6.89 \%$ for muscle, $88.4 \pm 5.35 \%$ for skin, $88.0 \pm 3.73 \%$ for intact muscle+skin. 
Another HPLC/FL method for determining residues of emamectin and ivermectin in fish tissues has been developed in which residues are extracted with acetonitrile and cleaned up on a C18 solid-phase extraction column (Van De Riet et al., 2001). Extracts are derivatized with 1-methylimidazole and trifluoroacetic anhydride, and the components are determined on a C18 reversed phase column with fluorescence detection (excitation: $365 \mathrm{~nm}$; emission: $470 \mathrm{~nm}$ ). The mobile phase is $94 \%$ acetonitrile-water run isocratically. Calibration curves were linear between 1 and $32 \mathrm{ng}$ injected for both emamectin and ivermectin. The limit of detection for both analytes was $0.5 \mu \mathrm{g} / \mathrm{kg}$, with a limit of quantitation of $1.5 \mu \mathrm{g} / \mathrm{kg}$. Recoveries of emamectin and ivermectin added to salmon muscle averaged $96 \pm 9 \%$ and 86 $\pm 6 \%$, respectively, at levels between 5 and $80 \mu \mathrm{g} / \mathrm{kg}$.
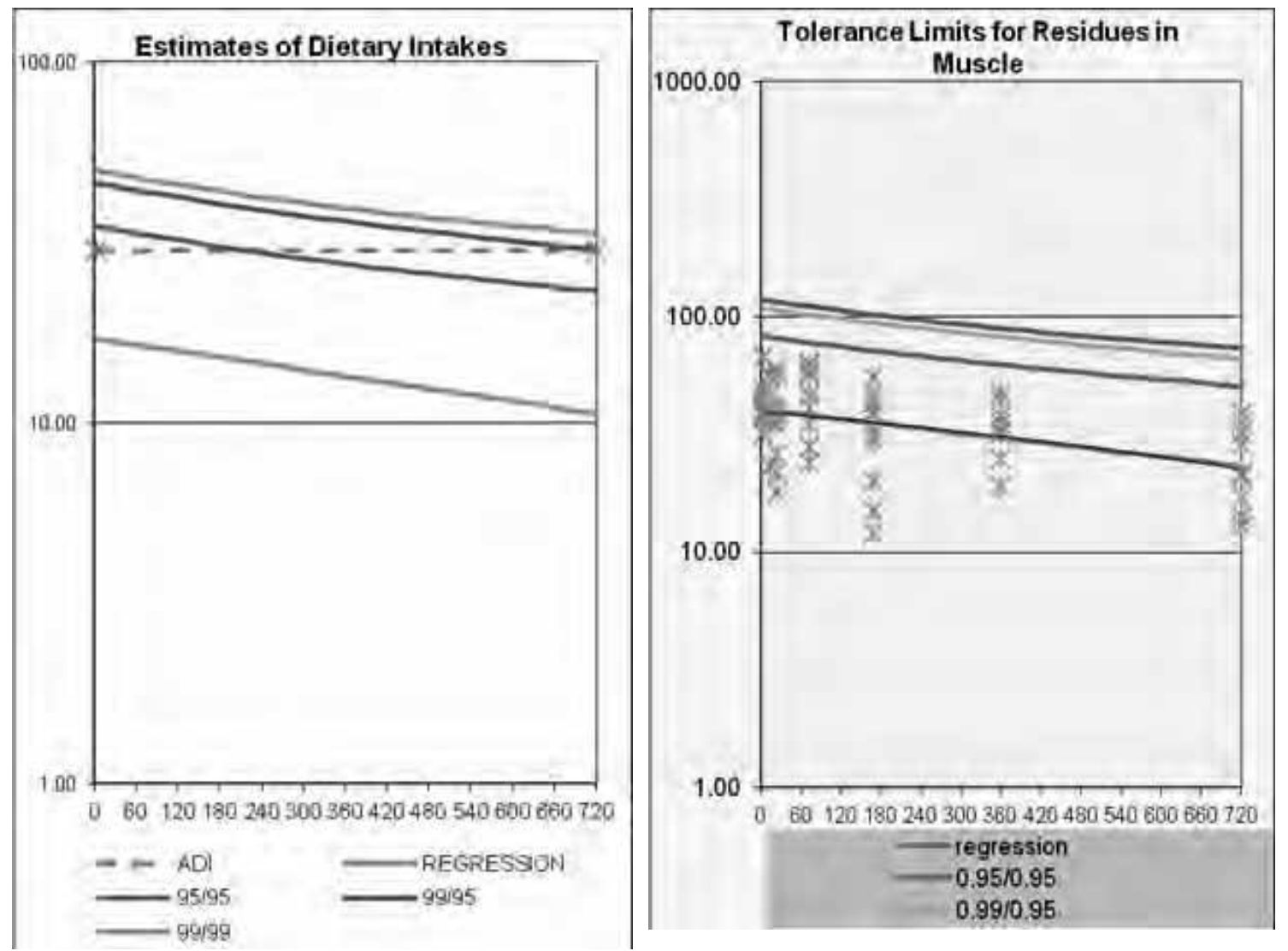

Figure 4.3. Estimated dietary intakes (expressed as emamectin benzoate equivalents) and tolerance limits in salmon muscle expressed as emamectin B1a

\section{Appraisal}

Emamectin has not been previously reviewed by the Committee. Emamectin benzoate is a semi-synthetic avermectin that is registered for aquaculture use in the treatment of salmon and trout at a maximum recommended dose of $50 \mu \mathrm{g} / \mathrm{kg}$ fish/day for 7 days, administered through medicated feed, for control of infestation by sea lice.

A radiolabelled study in salmon demonstrated that emamectin B1a is the marker residue and that it remains predominantly unmetabolized (Kim-Kang et al., 2004). Over the time interval between the last administration and 70 days post-administration, the ratio between the marker residue and the total radioactive residue (expressed as emamectin benzoate equivalents) was stable in muscle and skin, at $65 \pm 7 \%$ for both tissues. After correction, the ratio of the mean concentration of the marker residue emamectin B1a to that of the total residue was calculated as 0.9 for muscle and fillet (muscle+skin), and 0.8 for skin. Residues 
decline slowly in fish and terminal half-lives are dependent on environmental conditions.

The recommended MRLs of $100 \mu \mathrm{g} / \mathrm{kg}$ of emamectin in muscle and fillet (muscle+skin) are based on the upper limit of the one-sided 99\% confidence interval over the 99th percentile ("99/99 tolerance limit") for the 10-day post-treatment of the radiolabelled depletion curve. This highest value 99/99 instead of 95/95 was chosen by the committee to cover the uncertainty associated to the high terminal half-life and the variation of kinetics in fish in relation to life conditions.

Residue data were obtained using a validated analytical method to quantify emamectin $\mathrm{B} 1 \mathrm{a}$ in tissue. Residue data from two independent studies were also provided for trout administered unlabelled emamectin benzoate at the approved dose rate. Median concentrations in muscle and fillet reported in trout were in the same range as those observed in salmon (Roy et al., 2006). Trout and salmon belong to the sub-family of Salmonidae.

\section{Maximum Residue Limits}

In recommending MRLs for emamectin B1a in salmon and trout, the Committee considered the following factors:

- Emamectin benzoate is authorized for use in salmon and trout. For salmon, the maximum recommended dose is $50 \mu \mathrm{g} / \mathrm{kg}$ fish per day for 7 days, administered through medicated feed.

- An ADI for emamectin benzoate of $0-0.5 \mu \mathrm{g} / \mathrm{kg}$ bw was established by the Committee, corresponding to an upper bound of acceptable intake of $30 \mu \mathrm{g} /$ day for a $60 \mathrm{~kg}$ person.

- Emamectin B1a is predominantly unmetabolized.

- Emamectin B1a is the marker residue in tissues.

- The ratio of the concentration of marker residue to the concentration of total residue is 0.9 in muscle and fillet of salmon.

- Residue data were provided using a validated analytical method to quantify emamectin B1a in tissue.

- Residue data in trout were available.

- A validated analytical method for the determination of emamectin B1a in edible tissue of salmon and trout is available and may be used for monitoring purposes.

MRLs were calculated on the basis of the upper limit of the one-sided $99 \%$ confidence interval over the 99th percentile (UTL 99/99) of total residue concentrations in salmon derived from the pivotal study used for this assessment. The time-point at which the MRLs were set was based on the approach described at the 66th Meeting of the Committee.

The Committee recommended MRLs for emamectin B1a in salmon of $100 \mu \mathrm{g} / \mathrm{kg}$ in muscle and fillet, and extended these MRLs to trout.

The EDI is $11 \mu \mathrm{g} /$ person per day, which represents $37 \%$ of the upper bound of the ADI.

Table 4.9. The estimated dietary intake of emamectin residues in salmon or trout tissues

\begin{tabular}{ccccc}
\hline Tissue & $\begin{array}{c}\text { Median residue } \\
(\boldsymbol{\mu g} / \mathbf{k g})\end{array}$ & $\begin{array}{c}\text { Standard Food Basket } \\
(\mathbf{k g})\end{array}$ & $\begin{array}{c}\text { MR:TR } \\
\text { ratio }\end{array}$ & $\begin{array}{c}\text { Estimated Daily Intake } \\
(\boldsymbol{\mu g})\end{array}$ \\
\hline Muscle & 33 & 0.3 & 0.9 & 11 \\
\hline & & EDI & 11 \\
\hline
\end{tabular}

NOTES: MR:TR ratio is the ratio of marker residue to total residues 


\section{References}

Berg, A.G.T. \& Horsberg, T.E. 2009. Plasma concentrations of emamectin benzoate after Slice ${ }^{\mathrm{TM}}$ treatments of Atlantic salmon (Salmo salar): Differences between fish, cages, sites and seasons. Aquaculture, 288(1-2): 22-26.

EMEA [European Agency for the Evaluation of Medicinal Products]. 1999. Committee for Veterinary Medicinal Products. Emamectin. Summary Report (1). Doc. EMEA/MRL/546/99-FINAL. Available at http://www.ema.europa.eu/docs/en_GB/document_library/ Maximum_Residue_Limits_-_Report/2009/11/WC500014125.pdf Accessed 2014-05-07.

Glover, K.A., Samuelsen, O.B., Skilbrei, O.T., Boxaspen, K. \& Lunestad, B.T. 2010. Pharmacokinetics of emamectin benzoate administered to Atlantic salmon, Salmo salar L. by intra-peritoneal injection. Journal of Fish Diseases, 33(2): 183-186.

Johnson, S.C., Treasurer, J.W., Bravo, S., Nagasawa, K. \& Kabata, Z. 2004. A review of the impact of parasitic copepods on marine aquaculture. Zoological Studies, 43(2): 229-243.

Kim-Kang, H., Bova, A., Crouch, L.S., Wislocki, P.G., Robinson, R.A. \& Wu, J. 2004. Tissue distribution, metabolism, and residue depletion study in Atlantic salmon following oral administration of [ $\left.{ }^{3} \mathrm{H}\right]$ emamectin benzoate. Journal of Agricultural and Food Chemistry, 52(7): 2108-2118.

Olsvik, P.A., Lie, K.K., Mykkeltvedt, E., Samuelsen, O.B., Petersen, K. Stavrum, A.K. \& Lunestad, B.T. 2008; Online. Pharmacokinetics and transcriptional effects of the anti-salmon lice drug emamectin benzoate in Atlantic salmon (Salmo salar L.). BMC Pharmacology, 8: Article 16.

Rae, G.H. 2000. A national treatment strategy for control of sea lice on Scottish salmon farms. Caligus, 6: $2-3$.

Roy, W.J., Gillan, N., Crouch, L., Parker, R., Rodger, H. \& Endris, R. 2006. Depletion of emamectin residues following oral administration to rainbow trout, Oncorhynchus mykiss. Aquaculture, 259(14): $6-16$.

Samuelsen, O.B. 2010. A single-dose pharmacokinetic study of emamectin benzoate in cod, Gadus morhua L., held in sea water at $9^{\circ} \mathrm{C}$. Journal of Fish Diseases, 33(2): 137-142.

Scottish Environment Protection Agency. 1999. Emamectin benzoate, an environmental risk assessment. Fish Farm Advisory Group.

Sevatdal, S., Magnusson, Å., Ingebrigtsen, K., Haldorsen, R. \& Horsberg, T.E. 2005. Distribution of emamectin benzoate in Atlantic salmon (Salmo salar L.). Journal of Veterinary Pharmacology and Therapeutics, 28(2): 101-107.

Van De Riet, J.M., Brothers, N.N., Pearce, J.N. \& Burns, B.G. 2001. Simultaneous determination of emamectin and ivermectin residues in Atlantic salmon muscle by liquid chromatography with fluorescence detection. Journal of AOAC International, 84(5): 1358-1362.

Whyte, S.K., Westcott, J.D. Byrne, P. \& Hammell, K.L. 2011. Comparison of the depletion of emamectin benzoate (SLICE ${ }^{\circledR}$ ) residues from skeletal muscle and skin of Atlantic salmon (Salmo salar) for multiple dietary dose regimens at $10^{\circ} \mathrm{C}$. Aquaculture, 315(3-4): 228-235. 



\section{Gentian violet}

First draft prepared by

Holly Erdely, Rockville, MD, USA

and

Pascal Sanders, Fougéres, France

\section{Identity}

International Non-proprietary Name (INN): gentian violet

Synonyms: See Table 5.1 .

IUPAC Names: (4-[4,4-bis(dimethylamino)benzhydrylidene]cyclohexa-2,5-dien-1-yl-idenedimethylammonium chloride);

Tris(4-(dimethylamino)phenyl)methylium chloride

Chemical Abstract Service Number: 548-62-9 (gentian violet)

Structural formula of main components: See Table 5.1.

The structural identity, some major physical-chemical properties and characteristics of the trimethylphenyl dye, gentian violet, its de-methylated derivatives, and its metabolite leucogentian violet are summarized in Table 5.1. All information provided in Table 5.1 is for the parent compound unless otherwise noted.

Table 5.1. Physical-chemical properties of gentian violet and its metabolite leucogentian violet

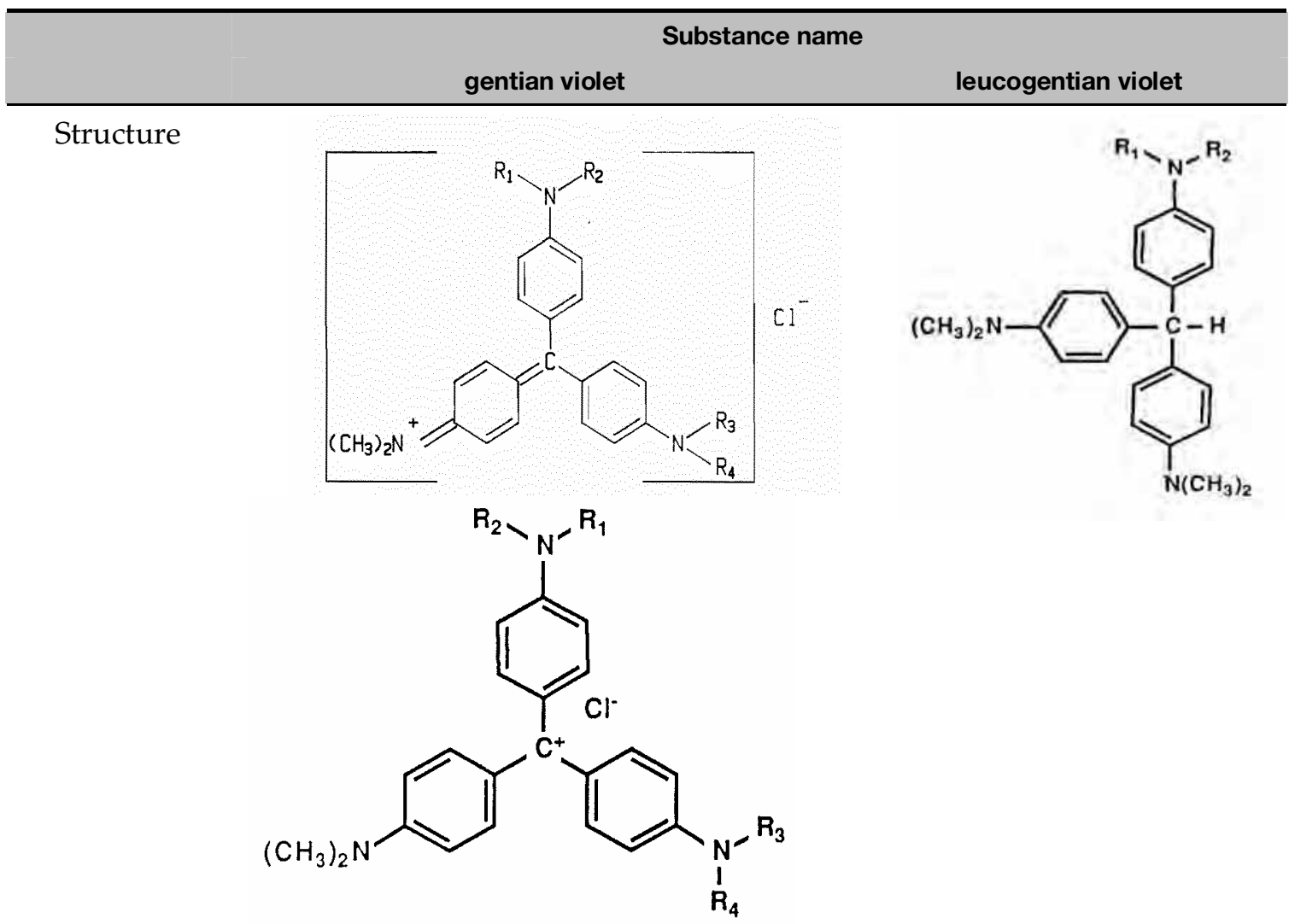




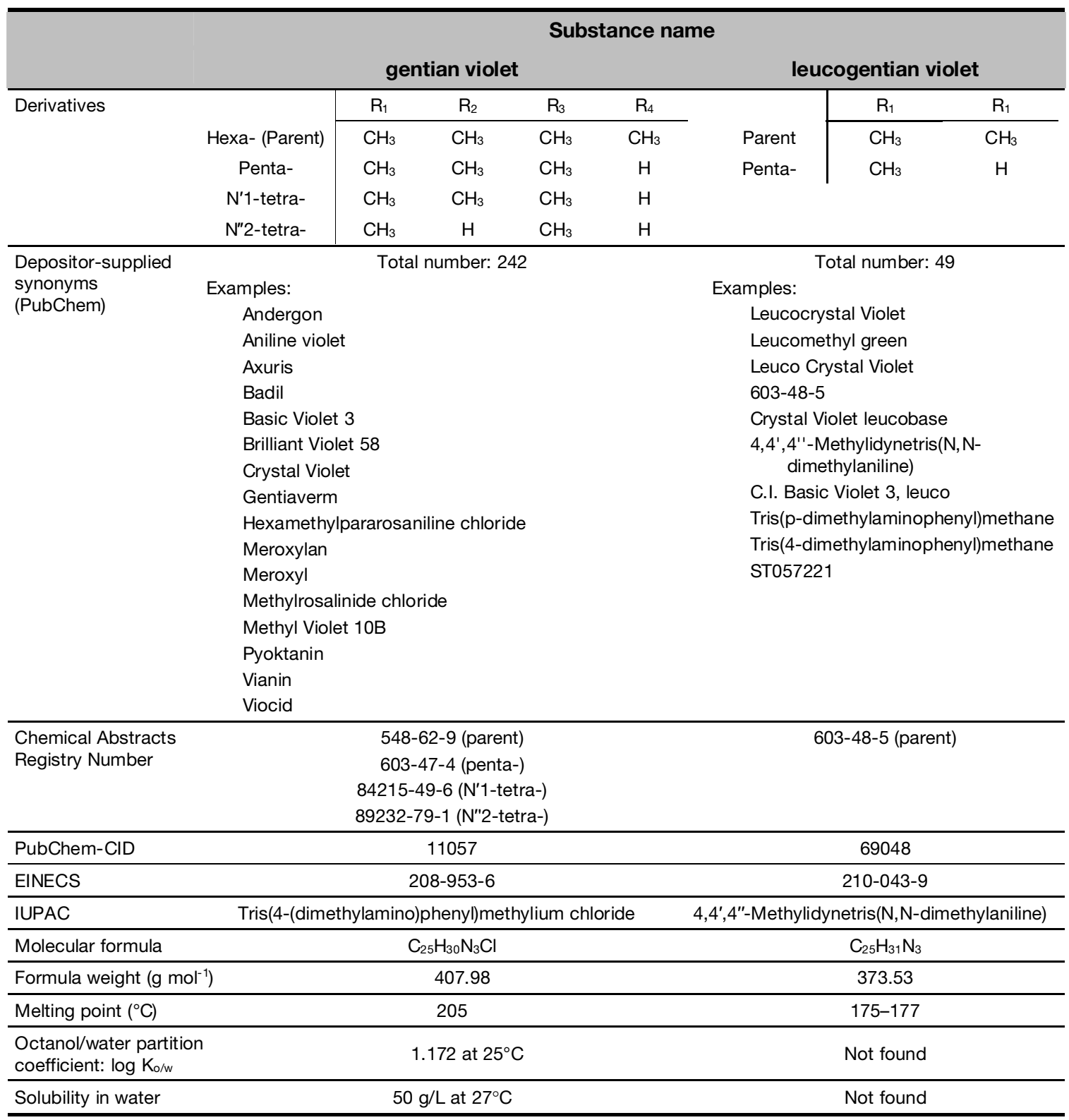

NOTE: Structural formulas from McDonald, 1989.

\section{Other information on identity and properties}

\section{Adsorption}

Adsorption characteristics of synthetic dyes such as gentian violet were studied in order to find approaches to remove them from wastewaters. Due to low biodegradability of dyes, traditional processes are often not very effective in removing these dyes from wastewater. Adsorption on activated carbon has been found to be an effective process for dye removal; however, the use of commercially available products is very costly. Therefore, other, lower cost, alternatives have been examined, including (but not limited to) chemically treated sawdust (Garg, 2003), preparation of activated carbon using various products such as spent tea leaves (Bajpai and Jain, 2010, 2012), peanut shells (Zhang and Ou, 2013), waste apricot (Başar, 2006; Önal, 2006), and rice husk (Mohanty et al., 2006). 


\section{Photodegradation}

Triphenylmethane dyes are known to be quite light sensitive. Exposure of gentian violet to ultraviolet light results in demethylation, and in the presence of oxygen, oxidation. Hydrogen peroxide is an inexpensive oxidant, and has been used in the presence of suitable photo catalysts to decolorize synthetic dyes such as gentian violet. It has been reported that in the presence of NADPH and light, gentian violet was photo-reduced to the same triarylmethyl free radical that is formed by enzymatic reduction (Harrelson and Mason, 1982).

\section{Binding to macromolecules}

Gentian violet binds to macromolecules. It is known to bind to DNA. Liu et al., (2013) investigated the binding of gentian violet to bovine haemoglobin. Binding of gentian violet to bovine haemoglobin changes spatial conformation of the bovine haemoglobin, leading to destabilization.

\section{Industrial uses}

Gentian violet and derivatives are used as a dye for various purposes, including as a dye for wood, leather, silk, nylon, paper and ribbon tapes, and also as a biological stain. It is also used in human medicine for use topically, and to inactivate Trypanosoma cruzi (the causative agent of Chagas disease) in blood collected for transfusion (Docampo and Moreno, 1990).

\section{Sources of data}

A collation and review of available data on gentian violet was provided by a national authority (Canada, 2013). For this document, published literature databases (Medline, CABI, Agricola and Toxnet) were searched for gentian violet using the terms: gentian violet, crystal violet, gentian [or crystal] violet toxicity, and gentian [or crystal] violet residues. Retrieved articles were assessed for relevance. References cited within the relevant articles were further assessed and reviewed where appropriate.

A supplementary search was conducting using the phrase "gentian [or crystal] violet" with the following primary search terms: adsorption, analytical method, aquaculture, biodegradation, depletion, detection, metabolism, photodegradation, and tissues.

\section{Residues in food and their evaluation}

\section{Conditions of use}

Gentian violet has been used as an antifungal and antiparasitic agent for treatment of fish, and also as a topical antiseptic, antibacterial and antifungal compound for treatment of skin and eye infections in livestock. It could also be used for treatment of Ichthyophthirius multifiliis, which causes 'white spot disease' in freshwater fish. Gentian violet is not currently authorised for use in aquaculture in most developed countries. However, because of its antibacterial and antifungal properties, and its similarities with malachite green, there is a potential for it to be used in aquaculture to mitigate bacterial or fungal infections in some countries (e.g. Khoshkho and Matin, 2013). Fish products imported to a number of countries, including Canada, EU member states and the United States of America have occasionally tested positive for gentian violet or its metabolite, leucogentian violet.

Gentian violet was previously used in poultry feeds to inhibit the growth of mould and fungus; however, several countries have withdrawn approval or registration of this use (FDA, 1991a; CFIA, 1992). It is currently prohibited from use in food producing animals in the United States of America (FDA, 1991b; Davis et al., 2009). There are currently no approved veterinary drug products containing gentian violet available in the United States of America. 
Australia conducted a special review of gentian violet in 1994 and subsequently: cancelled the clearance certificates for crystal (gentian) violet with effect from 1 November 1994; cancelled the MRLs for crystal (gentian) violet, with effect from 1 November 1994; and cancelled all registrations and relevant approvals of veterinary products containing crystal (gentian) violet, effective 1 November 1994 (APVMA, 1994). Heberer (2009) reported that "according to EU law, zero tolerance applies to all residues of malachite green (MG) and gentian violet in food for human consumption, as both compounds are not registered for use as veterinary drugs with food producing animals".

In Canada, gentian violet is approved as a topical preparation for use in food producing animals (Health Canada, 2013). Current indications include topical therapy for ringworm, treatment of pink eye and topical treatment of skin wounds. However, the use of gentian violet in animal feeds to prevent mould growth is prohibited in Canada (CFIA, 1992). Gentian violet (1\% solution) is approved for use in human medicine for topical use (Health Canada, 2013).

At the time of preparation of this monograph, some EU member states have established an action limit of $0.5 \mu \mathrm{g} / \mathrm{kg}$ for residues of gentian violet in internationally traded food consignments (DEFRA, 2007). Canada has set an action level of $\geq 0.5 \mu \mathrm{g} / \mathrm{kg}$ for leucogentian violet and/or gentian violet (in presence of leucogentian violet) for compliance purposes.

\section{Pharmacokinetics and metabolism}

\section{Metabolism in micro-organisms}

Biological decolourization of gentian violet has been widely reported. Some examples are presented below. A detailed review is beyond the scope of this monograph.

\section{Intestinal bacteria}

McDonald and Cerniglia (1984) studied the metabolism of gentian violet from human, rat, and chicken intestinal microflora, human faecal samples, and 12 pure anaerobic bacteria cultures representative of those found in the human gastro-intestinal tract. Incubations were carried out under anaerobic and aerobic conditions. All pure cultures and mixed intestinal microflora reduced gentian violet to leucogentian violet. Gentian violet and leucogentian violet were identified in the incubation mixtures using high performance liquid chromatography (HPLC) and mass spectrometry with electron ionization. Escherichia coli and Salmonella typhimurium possessed little ability to reduce gentian violet under either anaerobic or aerobic conditions. Gentian violet at a concentration of $2.67 \mu \mathrm{g} / \mathrm{ml}$ of incubation medium was not toxic and did not inhibit bacterial growth when compared with control incubations.

\section{Fungi}

Some ligninolytic (nitrogen-limited) fungi have been found capable of decolorizing synthetic dyes. Ligninolytic cultures of the white rot fungus Phanerochaete chrysosporium were shown to metabolize gentian violet to $\mathrm{N}$-demethylated metabolites catalyzed by lignin peroxidase. Non-ligninolytic (nitrogen-sufficient) cultures also degrade gentian violet, suggesting that there is an additional mechanism by which degradation occurs (Bumpus and Brock, 1988). Ganesh et al. (2011) reported decolourization of gentian violet by Aspergillus sp. CB-TKL-1. Addition of glucose or arabinose $(2 \%)$ and sodium nitrate or soyapeptone $(0.2 \%)$ enhanced the decolourization ability of the culture. Analysis also showed that the decolourization occurs in a stepwise pattern, and N-demethylation appears to be the dominating mechanism in decolourization.

\section{Microsomes}

The in vitro metabolism of gentian violet in microsomes isolated from livers of hamsters, guinea pigs, chickens, four strains of mice and three strains of rats has been investigated (McDonald et al., 1984a; McDonald, 1989). All three demethylated metabolites of gentian 
violet (Table 5.1) were produced, with mice microsomes producing less demethylated products than the other species. Microsomes from guinea pigs produced less of the N'1 tetrametabolite and more of the N"2 tetra- metabolite than the other species examined. Sex differences in de-methylation were not apparent among the species. Leucogentian violet was not mentioned by the authors, and therefore its potential fate in these studies is unknown.

Gentian violet was metabolized by rat liver microsomes under a nitrogen atmosphere while supplemented with NADPH to give a single-line electron spin resonance (ESR) spectrum, and considered to be the tri-(p-dimethylaminophenyl) methyl radical. Removal of the NADPH-generating system, gentian violet or using heat denatured microsomes resulted in no ESR spectrum. This one-electron reduction to produce a carbon centred free radical was inhibited approximately $50 \%$ by metyrapone, and also by an atmosphere of carbon monoxide, suggesting the involvement of cytochrome P-450 (Harrelson and Mason, 1982).

\section{Metabolism in laboratory animals}

\section{Rats}

One Fischer 344 female rat was given $0.84 \mathrm{mg}$ [phenyl-U_- ${ }^{14} \mathrm{C}$ ]-gentian violet $(5.68 \mu \mathrm{Ci})(94.8 \%$ gentian violet and $5.2 \%$ pentamethylpararosaniline) twice daily for three days, and faeces were collected between 48 and 72 hours after the first dose to examine gentian violet metabolism. Samples were extracted with diethyl ether, with metabolite identification using HPLC. Leucogentian violet accounted for $67 \%$ of the radioactivity in the ether extract, and a minimum of $11 \%$ of the total radioactivity present in the 48 to $72 \mathrm{~h}$ faeces collection (McDonald and Cerniglia, 1984; McDonald, 1989).

The depletion kinetics and metabolism of gentian violet in single- and multiple-dosing regimens have also been studied (McDonald et al., 1984b; McDonald, 1989). Six F344 rats (3 male, 3 female) were housed individually in metabolism cages and given a single dose by gavage of $\left[{ }^{14} \mathrm{C}\right.$ ]gentian violet ( $94.8 \%$ gentian violet and $5.2 \%$ pentamethylpararosaniline). The males and females received $4.8 \mathrm{mg}(3.1 \mu \mathrm{Ci})$ and $5.2 \mathrm{mg}(9.26 \mu \mathrm{Ci})$ gentian violet $/ \mathrm{kg}$, respectively, and were killed 2, 4, 14 or 24 hours later. Urine, faeces, liver, kidney, muscle, testes or ovaries, and a fat sample were collected and radioactivity measured (Tables 5.2 and 5.3). Half-lives of 14.5 and $14.4 \mathrm{~h}$ were calculated following a single dose for the liver and kidney, respectively, for males, and 17.0 and 18.3 hours, respectively, for females.

Table 5.2. Concentrations following a single oral dose of [phenyl-U- $\left.{ }^{14} \mathrm{C}\right]$-gentian violet in rats

\begin{tabular}{cccccc}
\hline $\begin{array}{c}\text { Time after } \\
\text { dose (h) }\end{array}$ & Liver & Kidney & Muscle & Testis/ovary & Fat \\
\hline & & & Males & \\
2 & $2.52 \pm 0.75$ & $0.48 \pm 0.11$ & $0.05 \pm 0.01$ & $0.03 \pm 0.01$ & $0.12 \pm 0.05$ \\
4 & $3.51 \pm 0.79$ & $0.47 \pm 0.04$ & $0.05 \pm 0.01$ & $0.02 \pm 0.02$ & $0.12 \pm 0.03$ \\
14 & $1.71 \pm 0.15$ & $0.22 \pm 0.01$ & $0.05 \pm 0.02$ & $0.04 \pm 0.01$ & $0.50 \pm 0.1$ \\
24 & $0.99 \pm 0.14$ & $0.13 \pm 0.01$ & $0.02 \pm 0.01$ & $0.02 \pm 0.01$ & $0.66 \pm 0.07$ \\
36 & $0.76 \pm 0.12$ & $0.10 \pm 0.01$ & $0.03 \pm 0.02$ & $0.02 \pm 0.01$ & $0.72 \pm 0.14$ \\
\hline & & & Females & \\
4 & $1.37 \pm 0.28$ & $0.48 \pm 0.11$ & $0.05 \pm 0.01$ & $0.03 \pm 0.01$ & $0.13 \pm 0.01$ \\
14 & $2.84 \pm 0.41$ & $0.52 \pm 0.11$ & $0.15 \pm 0.01$ & $0.02 \pm 0.02$ & $0.42 \pm 0.09$ \\
24 & $1.22 \pm 0.19$ & $0.23 \pm 0.05$ & $0.13 \pm 0.05$ & $0.04 \pm 0.01$ & $2.07 \pm 0.36$ \\
36 & $1.11 \pm 0.23$ & $0.21 \pm 0.06$ & $0.16 \pm 0.10$ & $0.02 \pm 0.01$ & $3.30 \pm 0.45$ \\
\hline
\end{tabular}

NOTES: Values are means \pm 1 SD for 3 rats. 
Table 5.3. Excretion following a single oral dose of [phenyl-U- $\left.{ }^{14} \mathrm{C}\right]$-gentian violet in rats

\begin{tabular}{ccc}
\hline \multirow{2}{*}{ Time after dose $(\mathbf{h})$} & Urine & Excretion $(\boldsymbol{\mu C i})$ \\
& \multicolumn{2}{c}{ Males } \\
2 & 0.045 & 0.001 \\
4 & 0.064 & 0.009 \\
14 & 0.25 & 3.76 \\
24 & 0.33 & 11.10 \\
36 & $0.29(2.2 \%)$ & $9.55(72.9 \%)$ \\
\hline & Females & \\
4 & 0.025 & 0.001 \\
14 & 0.017 & 0.011 \\
24 & 0.11 & 4.39 \\
36 & 0.33 & 5.14 \\
\hline
\end{tabular}

NOTES: Numbers in (parentheses) indicate $\%$ of dose.

For a multiple-dosing experiment, 8 male and 8 female $\mathrm{F} 344$ rats were housed individually in metabolism cages and administered 14 doses at $12 \mathrm{~h}$ intervals with $\left[{ }^{14} \mathrm{C}\right.$ ]gentian violet using a mixture of $94.8 \%$ gentian violet and $5.2 \%$ pentamethylpararosaniline (McDonald et al., 1984b). The total dose for males and females was 3.5 $(140 \mu \mathrm{Ci})$ and $5.69 \quad(79.72 \mu \mathrm{Ci}) \mathrm{mg} / \mathrm{kg}$, respectively. The rats were killed $2 \mathrm{~h}$ after receiving the final dose. Urine, faeces, liver, kidney, muscle, testes or ovaries and a fat sample were collected and radioactivity measured (Table 5.4).

Two female bile duct-cannulated rats were orally dosed with $300 \mu \mathrm{g}(3.27 \mu \mathrm{Ci})$ or $840 \mu \mathrm{g} \quad(9.16 \mu \mathrm{Ci}) \quad$ [phenyl-U- ${ }^{14} \mathrm{C}$ ]-gentian violet (94.8\% gentian violet and 5.2\% pentamethylpararosaniline) and bile collected for 24 and $28 \mathrm{~h}$, respectively (McDonald et al., 1984b; McDonald, 1989). The percentages of the oral dose collected from the 2 rats were $6.4 \%$ and $5.7 \%$ after 24 and $28 \mathrm{~h}$, respectively. The authors concluded that orally administrated gentian violet cation (which could be combined with a hydroxyl ion in the small intestine) with a molecular weight of 372 was absorbed to a greater extent than had been reported for other triphenylmethane dyes. It was speculated that leucogentian violet, which is produced under anaerobic conditions by intestinal bacteria, may be absorbed and accumulate in the fat (McDonald et al., 1984b; McDonald, 1989).

\section{Mice}

Twenty-four (12 male, 12 female) $\mathrm{B} \mathrm{C} 3 \mathrm{~F}_{1}$ mice were housed 3 per metabolism cage and administered [phenyl-U- ${ }^{14} \mathrm{C}$ ]-gentian violet $(94.8 \%$ gentian violet and $5.2 \%$ pentamethylpararosaniline) by oral gavage every 12 hours for 7 days (McDonald et al., 1984b; McDonald, 1989). The total dose for males and females was $5.6(19.55 \mu \mathrm{Ci})$ and $7.1(19.55 \mu \mathrm{Ci}) \mathrm{mg}$ gentian violet $/ \mathrm{kg}$, respectively. The mice were killed $2 \mathrm{~h}$ after receiving the final dose. Urine, faeces, 
liver, kidney, muscle, testes or ovaries and a fat sample were collected during the study and radioactivity measured (Table 5.5). The data show that gentian violet residues accumulated in the adipose tissue, although a major portion (64-73\%) excreted in faeces.

Similar to rats, gentian violet residues in mice accumulated in the adipose tissue, with more accumulation in females than in males. The percentages of gentian violet radioactivity administrated and excreted in the faeces of rats and mice were very similar, while a larger percentage of gentian violet was excreted in the urine of mice than that of rats.

\section{Metabolism in food producing animals}

\section{Chickens}

Eighteen (9 male, 9 female) Hubbard $\times$ Hubbard adult broiler breeders were fed a single dose of $\left[{ }^{14} \mathrm{C}\right]$ gentian violet $(31.78 \mu \mathrm{Ci})$ of $6.82 \mathrm{mg} /$ bird (Olentine, Gross and Burrows, 1980). Prior to dosing, the birds

Table 5.5. Disposition and excretion of multiple oral doses of [phenyl-U-14C]-gentian violet to mice

\begin{tabular}{lcc}
\hline \multirow{1}{*}{ Sample } & \multicolumn{2}{c}{$\begin{array}{c}\text { Gentian violet residues (mg } \\
\text { equivalents/kg) }\end{array}$} \\
\cline { 2 - 3 } & Male & Female \\
\hline Liver & $17.8 \pm 2.6^{\star \star}$ & $10.7 \pm 3.4^{\star \star}$ \\
Kidney & $1.6 \pm 0.1^{\star \star}$ & $2.7 \pm 0.8^{\star \star}$ \\
Muscle & $0.6 \pm 0.4^{\star \star}$ & $1.3 \pm 0.7^{\star \star}$ \\
Gonad & $0.49 \pm 0.08$ & $3.66 \pm 1.08^{(1)}$ \\
Fat & $14.3 \pm 3.0^{\star \star}$ & $24.1 \pm 7.0^{\star \star}$ \\
Urine & $1.16(5.9 \%)$ & $1.58(8.1 \%)$ \\
Faeces & $12.89(65.9 \%)$ & $13.17(67.4 \%)$ \\
\hline
\end{tabular}

NOTES: (1) Mean of 8 mice. Values are means \pm 1 SD for 12 male and female mice. Asterisks indicate a significant sex difference $\left({ }^{*}=\mathrm{P}<0.02 ;{ }^{* *}=\mathrm{P}<0.01\right.$ by student $\mathrm{T}$ test). Numbers in (parentheses) indicate\% of total dose. had received a diet containing $1 \mathrm{~kg}$ unlabelled gentian violet/1000 kg feed for 30 days. One female and one male were randomly selected and killed after 8, 24, 48, 120, 168, 240, 336, 432 and $504 \mathrm{~h}$ following the administration of the radiolabelled dose of gentian violet. Blood samples were taken after 1, 4 and $8 \mathrm{~h}$ and at time of slaughter. Liver, muscle, kidney, skin, fat and eggs were collected and analysed for radioactivity. Analysis of the blood $\left[{ }^{14} \mathrm{C}\right]$ activity data indicated half-lives of 1.43 and $1.68 \mathrm{~h}$ for males and females, respectively. Results of the analysis of the tissue samples collected for radioactive residues are presented in Table 5.6. All the eggs collected over the first $144 \mathrm{~h}$ had low but detectable levels of radioactivity, with one collected after $456 \mathrm{~h}$ having detectable levels of radioactivity.

Table 5.6. Calibrated residue concentration of $\left[{ }^{14} \mathrm{C}\right]$ gentian violet in tissues of broiler breeder chickens

\begin{tabular}{|c|c|c|c|c|c|c|c|c|c|c|}
\hline \multirow[t]{2}{*}{ Tissue } & \multirow[t]{2}{*}{ Sex } & \multicolumn{9}{|c|}{$\begin{array}{c}\text { Concentration of }{ }^{14} \mathrm{C} \text {-gentian violet ( } \mu \text { g equivalents } / \mathrm{kg} \text { ) at time-points (h) after } \\
\text { administration }{ }^{(1)(2)}\end{array}$} \\
\hline & & 8 & 24 & 48 & 120 & 168 & 240 & 336 & 432 & 504 \\
\hline \multirow[t]{2}{*}{ Muscle } & M & ND & ND & ND & ND & ND & ND & ND & ND & ND \\
\hline & $\mathrm{F}$ & 45 (164) & ND & ND & ND & ND & ND & ND & ND & ND \\
\hline \multirow[t]{2}{*}{ Skin } & M & $19(44)$ & ND & ND & ND & ND & ND & ND & ND & ND \\
\hline & $\mathrm{F}$ & 38 (52) & $26(37)$ & ND & ND & ND & ND & ND & ND & ND \\
\hline \multirow[t]{2}{*}{ Fat } & $M$ & $16(18)$ & ND & ND & ND & ND & ND & ND & ND & ND \\
\hline & $\mathrm{F}$ & $126(143)$ & ND & ND & ND & ND & ND & ND & ND & ND \\
\hline \multirow[t]{2}{*}{ Liver } & M & 81 (302) & 71 (258) & ND & ND & ND & ND & ND & ND & ND \\
\hline & $\mathrm{F}$ & $313(876)$ & 30 (106) & 37 (92) & $18(55)$ & ND & ND & ND & ND & ND \\
\hline \multirow[t]{2}{*}{ Kidney } & M & 234 (977) & 96 (282) & 57 (235) & 48 (199) & $16(58)$ & $17(58)$ & $17(63)$ & ND & ND \\
\hline & $\mathrm{F}$ & 319 (1188) & $101(374)$ & $94(221)$ & 36 (109) & 30 (121) & 58 (196) & $16(65)$ & $17(72)$ & ND \\
\hline
\end{tabular}

NOTES: (1) Values in (parentheses) represent dry weight concentration. (2) ND = not detectable.

In a GLP compliant study, five groups of Cornish-White Rock broiler chickens (5 male and 5 females per group) were given [phenyl-U_- ${ }^{14} \mathrm{C}$ ]-gentian violet $(94.3 \%$ pure, specific activity of $37.3 \mathrm{mCi} / \mathrm{mmol}$ ) by capsule 3 times daily for 7 days (McDonald, 1985). The dosing level was equal to $15 \mathrm{mg}$ gentian violet per $\mathrm{kg}$ feed, or 1.72 and $1.45 \mathrm{mg}$ gentian violet $/ \mathrm{kg}$ bw 
for males and females, respectively. The chickens were allowed access to regular feed and water ad libitum. Chickens were killed 6, 24, 48, 120 or $240 \mathrm{~h}$ after the last treatment, and samples of liver, kidney, gizzard, breast, thigh, heart and skin taken for total ${ }^{14} \mathrm{C}$ residue determination. Samples of excreta were collected from each chicken in the 240-h depletion group beginning $16 \mathrm{~h}$ after receiving the first capsule and then at $24 \mathrm{~h}$ intervals for total ${ }^{14} \mathrm{C}$ determination. Total residues (Tables 5.7 and 5.8), determined by combustion analysis and liquid scintillation counting, were calculated on the basis of the hexamethylpararosaniline cation (molecular weight 373) rather than on the molecular weight of the chloride (408). Highest residue concentrations were detected in the liver of males at the $6 \mathrm{~h}$ collection time. In females, liver and kidney contained almost equally high residue concentrations at $6 \mathrm{~h}$ withdrawal, but at subsequent withdrawal periods the highest concentrations were reported in liver. The depletion of total residues was bi-phasic in each tissue, with graphical half-lives in the range of 59 to $215 \mathrm{~h}$ for the second phase (Table 5.9). The depletion half-lives were consistent between the sexes, with the longest half-life of the second phase occurring in the liver. The authors concluded that the tissue residues had not reached equilibrium at cessation of dosing.

Table 5.7. Total residue concentrations $(\mu \mathrm{g} / \mathrm{kg}$; mean $\pm \mathrm{SD})$ of [phenyl-U- $\left.{ }^{14} \mathrm{C}\right]$-gentian violet equivalents for male chicken tissues

\begin{tabular}{cccccc}
\hline Tissue & \multicolumn{5}{c}{ Withdrawal period } \\
& $\mathbf{6} \mathbf{h}$ & $\mathbf{2 4} \mathbf{~ h}$ & $\mathbf{4 8} \mathbf{~ h}$ & $\mathbf{1 2 0} \mathbf{~}$ & $\mathbf{2 4 0} \mathbf{~}$ \\
\hline Liver & $169.1 \pm 112.6$ & $44.6 \pm 8.0$ & $38.0 \pm 15.4$ & $34.7 \pm 20.0$ & $20.9 \pm 12.2$ \\
Kidney & $78.7 \pm 18.4$ & $30.4 \pm 4.9$ & $18.6 \pm 5.7$ & $9.8 \pm 2.3$ & $3.8 \pm 0.6$ \\
Gizzard & $33.6 \pm 22.2$ & $7.8 \pm 3.6$ & $4.4 \pm 1.6$ & $2.6 \pm 1.1$ & $0.89 \pm 0.48$ \\
Breast & $11.4 \pm 5.9$ & $4.4 \pm 1.0$ & $3.2 \pm 1.5$ & $1.2 \pm 0.4$ & $0.48 \pm 0.61$ \\
Thigh & $18.7 \pm 10.8$ & $6.5 \pm 1.9$ & $4.1 \pm 2.2$ & $1.7 \pm 1.3$ & $0.73 \pm 0.24$ \\
Heart & $27.7 \pm 13.2$ & $5.0 \pm 0.9$ & $2.7 \pm 1.3$ & $2.1 \pm 0.6$ & $1.1 \pm 0.6$ \\
Skin & $45.3 \pm 12.8$ & $19.3 \pm 4.9$ & $12.6 \pm 2.5$ & $10.6 \pm 2.7$ & $6.1 \pm 2.6$ \\
\hline
\end{tabular}

Table 5.8. Total residue concentrations $(\mu \mathrm{g} / \mathrm{kg}$; mean $\pm \mathrm{SD})$ of [phenyl-U- $\left.-{ }^{14} \mathrm{C}\right]-$ gentian violet equivalents for female chicken tissues

\begin{tabular}{cccccc}
\hline Tissue & $\mathbf{5}$ & \multicolumn{3}{c}{ Withdrawal Period } \\
& $\mathbf{6} \mathbf{h}$ & $\mathbf{2 4} \mathbf{~ h}$ & $\mathbf{4 8} \mathbf{~ h}$ & $\mathbf{1 2 0} \mathbf{~}$ & $\mathbf{2 4 0} \mathbf{~}$ \\
\hline Liver & $73.9 \pm 20.9$ & $60.4 \pm 31.8$ & $31.4 \pm 9.9$ & $19.0 \pm 7.7$ & $12.8 \pm 10.1$ \\
Kidney & $73.3 \pm 15.1$ & $33.6 \pm 13.2$ & $15.3 \pm 2.2$ & $11.7 \pm 9.7$ & $2.9 \pm 1.3$ \\
Gizzard & $21.0 \pm 10.8$ & $10.1 \pm 4.9$ & $4.4 \pm 2.3$ & $1.6 \pm 0.9$ & $0.45 \pm 0.25$ \\
Breast & $5.9 \pm 3.2$ & $4.3 \pm 1.3$ & $2.4 \pm 1,3$ & $0.61 \pm 0.49$ & $0.27 \pm 0.26$ \\
Thigh & $7.6 \pm 2.3$ & $5.8 \pm 2.9$ & $2.6 \pm 1.3$ & $2.2 \pm 1.7$ & $0.41 \pm 0.32$ \\
Heart & $17.5 \pm 4.1$ & $7.1 \pm 3.1$ & $2.7 \pm 0.8$ & $2.7 \pm 2.6$ & $0.87 \pm 0.30$ \\
Skin & $18.2 \pm 8.8$ & $18.9 \pm 6.2$ & $12.7 \pm 4.0$ & $9.4 \pm 3.9$ & $3.4 \pm 1.3$ \\
\hline
\end{tabular}

For the determination of metabolites, tissues and excreta were extracted with acidic methanol, partitioned, and cleaned up and subjected to chromatography on a Bondapak $\mathrm{C}_{18}$ reversed phase column prior to liquid scintillation counting. The chromatographic conditions for tissue extracts were such that parent gentian violet, its demethylated derivatives, and leucogentian violet (see Table 5.1) eluted at 25.2 (parent gentian violet), 21.6, 17.9, 16.7 and 23.5 (leucogentian violet) minutes, respectively. The metabolite profile identified at the $6 \mathrm{~h}$ collection time-point is presented in Table 5.10. These metabolites were not present in samples taken past the $6 \mathrm{~h}$ withdrawal period; however some other unidentified metabolites were present at subsequent time-points. 
Table 5.9. Graphical half-lives (hours) for biphasic depletion of total residues of [phenyl-U- $\left.{ }^{14} \mathrm{C}\right]-$ gentian violet from chicken tissue

\begin{tabular}{|c|c|c|c|}
\hline & \multirow{2}{*}{$\begin{array}{c}\text { Phase } 1 \\
t_{1 / 2}(1)\end{array}$} & \multicolumn{2}{|c|}{ Phase 2} \\
\hline & & $t_{1 / 2}(2)$ & Correlation \\
\hline \multicolumn{4}{|c|}{ Males } \\
\hline Liver & 2.7 & 215 & -0.971 \\
\hline Kidney & 6.7 & 84.2 & -0.999 \\
\hline Gizzard & 5.0 & 82.7 & -0.999 \\
\hline Breast & 5.3 & 71.3 & -0.993 \\
\hline Thigh & 6.4 & 79.1 & -0.984 \\
\hline Heart & 4.9 & 146 & -0.994 \\
\hline Skin & 6.9 & 179 & -0.989 \\
\hline \multicolumn{4}{|c|}{ Females } \\
\hline Liver & 38.2 & 153 & -0.978 \\
\hline Kidney & 8.9 & 77.3 & -0.973 \\
\hline Gizzard & 11.1 & 59.0 & -0.996 \\
\hline Breast & 26.1 & 63.5 & -0.958 \\
\hline Thigh & 27.0 & 68.8 & -0.958 \\
\hline Heart & 9.1 & 110 & -0.928 \\
\hline Skin & $-{ }^{(3)}$ & 98.6 & -0.987 \\
\hline
\end{tabular}

NOTES: (1) Calculated using the difference between the 6- and 24-hour data points, and corresponding points on the phase 2 curves. (2) Calculated by least squares using the 48-, 120- and 240-hour data points. (3) Data did not allow calculation of halflife.

Table 5.10. Concentrations of metabolites and gentian violet $(\mu \mathrm{g} / \mathrm{kg})$ of $\left[\right.$ phenyl-U- $\left.{ }^{14} \mathrm{C}\right]$-gentian violet measured in chicken tissue (6-hour depletion)

\begin{tabular}{|c|c|c|c|c|c|c|}
\hline \multirow{2}{*}{ Tissue } & \multicolumn{2}{|c|}{ N'1-tetra- + N"2-tetra- } & \multicolumn{2}{|c|}{ Penta- } & \multicolumn{2}{|c|}{ Parent drug (gentian violet) } \\
\hline & male & female & male & female & male & female \\
\hline Liver & 5.7 & 0.64 & 2.4 & 0.26 & 2.3 & 0.26 \\
\hline Kidney & 2.8 & 2.9 & 2.4 & 2.6 & 2.1 & 2.8 \\
\hline Gizzard & 8.0 & $0.35^{(1)}$ & 6.6 & 0.66 & 20.3 & 1.8 \\
\hline Breast & 0.09 & 0.11 & 0.08 & 0.25 & 0.22 & 0.54 \\
\hline Thigh & 0.28 & 0.09 & 0.06 & 0.15 & 0.11 & 0.31 \\
\hline Heart & 0.83 & 0.61 & 1.2 & 0.82 & 1.1 & 1.3 \\
\hline Skin & n.a. & 0.15 & n.a. & 0.21 & n.a. & 0.29 \\
\hline
\end{tabular}

NOTES: (1) A portion of this sample was lost to spillage. n.a. = Values not available.

Insoluble residue in tissue, as determined by combustion analysis, represents a substantial portion of the total residue in most tissues at all depletion times (Table 5.11). The chromatographic conditions for excreta were such that parent gentian violet and each demethylated metabolite (see Table 5.1) eluted at 13.0 (parent gentian violet), 9.7, 7.1, 7.1 and 19.3 (leucogentian violet) minutes, respectively. The metabolic profile identified in excreta from the $240 \mathrm{~h}$ depletion group is presented in Table 5.12. De-methylated products were identified, but gentian violet was the predominant excretion product. Inconclusive evidence was obtained for the presence of leucogentian violet in tissues and excreta (McDonald, 1985). 
Table 5.11. Insoluble residue $(\mu \mathrm{g} / \mathrm{kg})$ of [phenyl $\left.1-\mathrm{U}-{ }^{14} \mathrm{C}\right]$-gentian violet cation equivalents for pooled, solvent-extracted chicken tissue

\begin{tabular}{|c|c|c|c|c|c|}
\hline & \multicolumn{5}{|c|}{ Withdrawal period } \\
\hline & $6 \mathrm{~h}$ & $24 \mathrm{~h}$ & $48 h$ & $120 \mathrm{~h}$ & $240 h$ \\
\hline \multicolumn{6}{|c|}{ Females } \\
\hline Liver & 27.4 & 33.0 & 18.8 & 34.8 & 9.06 \\
\hline Kidney & 24.5 & 12.6 & 6.42 & 2.75 & 0.08 \\
\hline Gizzard & 8.42 & 6.51 & 1.33 & 0.74 & 0.20 \\
\hline Breast & 2.38 & 3.09 & 0.59 & 0.22 & 0.04 \\
\hline Thigh & 1.19 & 1.27 & 0.97 & 0.74 & 0.21 \\
\hline Heart & 6.22 & 0.53 & 1.61 & 1.06 & 0.24 \\
\hline Skin & 0.15 & 6.92 & 3.68 & 2.29 & 0.78 \\
\hline \multicolumn{6}{|c|}{ Males } \\
\hline Liver & 105.1 & 22.6 & 20.8 & 17.1 & 1.06 \\
\hline Kidney & 51.8 & 12.7 & 0.82 & 0.49 & 2.49 \\
\hline Gizzard & 23.2 & 2.41 & 1.18 & 1.79 & 0.17 \\
\hline Breast & 2.05 & 1.10 & 0.76 & 0.31 & 0.01 \\
\hline Thigh & 8.85 & 2.07 & 0.62 & 0.56 & 0.51 \\
\hline Heart & 5.95 & 1.52 & 1.15 & 0.98 & 0.68 \\
\hline Skin & 16.8 & 4.37 & 5.71 & 5.61 & 3.32 \\
\hline
\end{tabular}

Table 5.12. Quantitation by $\left[{ }^{14} \mathrm{C}\right]$ of metabolites in excreta of chicken from the 240 -h depletion group

\begin{tabular}{|c|c|c|c|c|c|c|c|c|}
\hline & \multicolumn{8}{|c|}{ Collection Day } \\
\hline & \multicolumn{2}{|c|}{ Day 3} & \multicolumn{2}{|c|}{ Day 5} & \multicolumn{2}{|c|}{ Day 7} & \multicolumn{2}{|c|}{ Day 9} \\
\hline & Total & $(\%)^{(2)}$ & Total & $(\%)^{(2)}$ & Total & $(\%)^{(2)}$ & Total & $(\%)^{(2)}$ \\
\hline \multicolumn{9}{|c|}{ Female \#57 } \\
\hline N'1-tetra- , N"2-tetra- & 14.4 & (7.9) & 14.4 & $(8.1)$ & 14.2 & $(8.0)$ & 58 & (12.2) \\
\hline Penta- & 29.6 & (16.2) & 30.8 & (17.1) & 30.1 & (16.8) & 63 & (13.3) \\
\hline Parent & 112.4 & $(61.8)$ & 109.8 & $(62.3)$ & 110.0 & $(62.0)$ & 165 & (34.7) \\
\hline Leucogentian Violet & 2.7 & (1.5) & 0.0 & $(0)$ & 0.0 & (0) & 0 & (0) \\
\hline \multicolumn{9}{|c|}{ Male \#34 } \\
\hline N'1-tetra-, N"2-tetra- & 23.6 & (9.7) & 20.6 & (9.3) & 20.5 & (9.5) & 169 & (13.9) \\
\hline Penta- & 46.4 & $(19.0)$ & 40.6 & (18.3) & 42.3 & $(19.0)$ & 127 & (10.5) \\
\hline Parent & 134.2 & $(55.0)$ & 124.6 & $(56.2)$ & 127.9 & $(57.0)$ & 143 & (11.8) \\
\hline Leucogentian Violet & 2.6 & $(1.1)$ & 0.0 & (0) & 0.0 & (0) & 0 & (0) \\
\hline
\end{tabular}

NOTES: (1) Total = amount excreted in faeces for the day in ng. (2) Portion of total radioactivity in chromatogram.

As part of method development for determination of gentian violet, its demethylated metabolites and leucogentian violet, gentian violet residues were measured in livers and muscle from chickens treated with a standard broiler diet containing $30 \mathrm{mg} / \mathrm{kg}$ gentian violet for 3 weeks (Roybal et al., 1990). Feed containing gentian violet was withdrawn $3 \mathrm{~h}$ prior to slaughter. Mean results from 10 analyses of residue-incurred chicken liver were $31 \mu \mathrm{g} / \mathrm{kg}$ gentian violet (coefficient of variation (CV) $9.7 \%$ ), $34 \mu \mathrm{g} / \mathrm{kg}$ pentamethyl metabolite (CV 8.8\%), and $40 \mu \mathrm{g} / \mathrm{kg}$ tetramethyl metabolite(s) (CV 5.0\%), for an average value of $105 \mu \mathrm{g} / \mathrm{kg}$ total residues (CV 5.7\%); no leucogentian violet was found. Subsequent work on method development for detection of gentian violet residues in chicken tissues indicated that the method used could influence the recovery of gentian violet residues, in particular leucogentian violet (Munns et al., 1990). However, when the method is optimized, leucogentian violet represented the major residues in chicken fat when gentian violet is fed to chicken in feed. 


\section{Tissue residue depletion studies}

\section{Radiolabelled residue depletion studies}

There were no radiolabel residue depletion studies for evaluation in fish treated with gentian violet.

\section{Residue depletion studies with unlabelled drug}

Limited tissue residue depletion data are available for gentian violet. Where depletion and pharmacokinetics and metabolism were investigated in the same study, they are reported under the Pharmacokinetics and Metabolism section. No absorption or depletion data for topical administration in terrestrial species were available. Since gentian violet use in aquaculture for food is not authorized in many countries, reliable data to inform the exposure regime are not readily obtainable; however, anecdotal reports suggest that gentian violet is applied using similar exposure protocols to malachite green (100 mg malachite green $/ \mathrm{kg} / \mathrm{min}$ ).

\section{Atlantic salmon}

Chan et al. (2012) exposed 90 Atlantic salmon (approx. $100 \mathrm{~g},<12$ month old) to $1 \mu \mathrm{g}$ gentian violet / $\mathrm{L}$ as a bath in a tank with continual flushing. The calculated exposure was $100 \mu \mathrm{g}$ gentian violet/L-minute. Flush rates in the tank were adjusted to achieve a gentian violet exposure of $100 \mu \mathrm{g} / \mathrm{L}$-minute for $5 \mathrm{~h}$, then returned to normal flush rate, at which the gentian violet concentration in the tank was $<0.1 \mathrm{mg} / \mathrm{kg}$. The concentration of gentian violet in the tank was negligible $(<0.01 \mu \mathrm{g} / \mathrm{kg}) 24 \mathrm{~h}$ after addition of the gentian violet. Thirty-five fish were held in a separate tank as controls. Fish were sampled at 1, 7, 14, 28,63 and 91 days post-dosing, with tissues stored at $-20^{\circ} \mathrm{C}$ until analysis. Samples were analysed either for total residues (by oxidizing leucogentian violet back to gentian violet) or for the parent and the leucogentian violet separately, using LC-MS/MS. Data obtained by both methods were comparable; however, total gentian violet was measured with better precision. Gentian violet was rapidly metabolized to leucogentian violet within $24 \mathrm{~h}$ postdosing. The mean leucogentian violet and gentian violet concentrations on Day 1 post-dosing were $134 \pm 36 \mu \mathrm{g} / \mathrm{kg}$ and $2.4 \pm 0.0 \mu \mathrm{g} / \mathrm{kg}$, respectively (ratio of leucogentian violet:gentian violet $=56: 1)$. Gentian violet was not detected (LOD $2 \mu \mathrm{g} / \mathrm{kg}$ ) by 14 days post-dosing. Leucogentian violet was detected at all times post-treatment, with $8 \mu \mathrm{g} / \mathrm{kg}$ detected on Day 91 post-treatment.

\section{Channel catfish}

One study exposed channel catfish (Ictalurus punctatus) to gentian violet under simulated aquaculture farming conditions (Thompson et al., 1999). The uptake of gentian violet was determined by placing fish in water containing $100 \mu \mathrm{g}$ gentian violet/L of water for $1 \mathrm{~h}$. The fish were then transferred to gentian violet-free water for 79 days to study the depletion of gentian violet residues. Fillets of 5 fish per sampling time were analysed for gentian violet and leucogentian violet. Gentian violet was rapidly (approximately $2 \mathrm{~h}$ ) converted to leucogentian violet. Mean leucogentian

Table 5.13. Concentrations of gentian violet and leucogentian violet in muscle of catfish exposed to $100 \mathrm{ng} / \mathrm{ml}$ gentian violet in water for 1 hour

\begin{tabular}{ccc}
\hline $\begin{array}{c}\text { Withdrawal } \\
\text { period }\end{array}$ & $\begin{array}{c}\text { gentian violet } \\
(\boldsymbol{\mu} \mathbf{g} / \mathbf{k g})\end{array}$ & $\begin{array}{c}\text { leucogentian } \\
\text { violet }(\boldsymbol{\mu} \mathbf{g} / \mathbf{k g})\end{array}$ \\
\hline Pre-treatment & $<$ LOD & $0.0 \pm 0.1$ \\
1 hour & $0.5 \pm 0.1$ & $11.7 \pm 1.8$ \\
2 hour & $0.8 \pm 0.3$ & $16.8 \pm 2.2$ \\
4 hour & $<$ LOD & $15.9 \pm 4.3$ \\
7 hour & $<$ LOD & $15.5 \pm 3.6$ \\
1 day & $<$ LOD & $15.1 \pm 3.1$ \\
2 days & LOD & $13.5 \pm 3.3$ \\
5 days & $0.3 \pm 0.2$ & $9.4 \pm 3.3$ \\
8 days & $<$ LOD & $9.7 \pm 2.8$ \\
15 days & $<$ LOD & $5.7 \pm 2.2$ \\
22 days & LOD & $3.3 \pm 0.5$ \\
33 days & $<$ LOD & $2.8 \pm 0.9$ \\
51 days & LOD & $1.5 \pm 0.6$ \\
79 days & $<$ LOD & $3.1 \pm 0.5$ \\
\hline
\end{tabular}

NOTES: Method limit of detection (LOD): $0.2 \mu \mathrm{g} / \mathrm{kg}$ for gentian violet. Values are mean and SD of single determinations of five fish at each sampling point. 
violet residues were approximately 17 and $3 \mu \mathrm{g} / \mathrm{kg}$ after $2 \mathrm{~h}$ and 79 days, respectively (Table 5.13).

The concentrations of gentian violet in muscle from catfish that were exposed in an aquarium to concentrations of 10 or $100 \mu g$ gentian violet/ $\mathrm{L}$ for $1 \mathrm{~h}$ and then placed in clean water for $24 \mathrm{~h}$, were 0.4 and $0.8 \mu \mathrm{g} / \mathrm{kg}$, respectively (Doerge et al., 1996). The corresponding concentrations of leucogentian violet were 44 and $118 \mu \mathrm{g} / \mathrm{kg}$, respectively. Online LC$\mathrm{APCI} / \mathrm{MS}$ was used for confirmation of gentian violet and leucogentian violet residues.

\section{Eels}

Wild eels caught in river waters downstream of municipal sewage treatment plant effluents discharge in Germany were tested for gentian violet residues (Schuetze, Herberer and Juergensen, 2008). Using solid-phase extraction with LC-MS/MS, 35 of the 45 samples tested were positive for leucogentian violet. The range for the gentian violet and leucogentian violet combined residues was 0.06 to $6.7 \mu \mathrm{g} / \mathrm{kg}$ fresh weight of tissue. The maximum concentration of gentian violet detected was $0.35 \mu \mathrm{g} / \mathrm{kg}$. The predominant residue was leucogentian violet, with only trace levels of gentian violet detected (residue ratios varied from 10:1 to 20:1).

\section{Methods of analysis for residues in tissues}

\section{General}

Analytical methods for detecting gentian violet and leucogentian violet, either alone or together with other triphenylmethane dyes, have been published by a number of authors (Table 5.14). Most of these methods focus on detection and quantitation of gentian violet/leucogentian violet residues in seafood products.

Two strategies are currently followed for gentian violet and leucogentian violet determination in tissue. The first is based on the measurement of each molecule separately, and the second is based on measurement of the molecules together after conversion of gentian violet and leucogentian violet by chemical oxidation. Gentian violet and leucogentian violet are generally extracted from tissue with an acetonitrile buffer mixture and then purified on solid-phase extraction (SPE) cartridges. HPLC coupled to a UV or fluorescence detector has been reported, but methods based on these technologies have never achieved the performances of MS-based methods. Post-column oxidation (e.g. with lead dioxide) of leucogentian violet to gentian violet is often reported when UV is used as a detector. Due to the rapid metabolism of gentian violet into leucogentian violet, and the persistence of leucogentian violet residues in fish tissue, a method utilizing detection of leucogentian violet may be preferred for monitoring of residues in fish.

\section{Chickens}

Roybal et al., (1990) examined residues of gentian violet, its demethylated metabolites (pentamethyl and tetramethyl), and leucogentian violet in chicken tissue. The analytes were extracted from tissue with acetonitrile/buffer and partitioned into methylene chloride. Polar lipids were removed on an alumina column followed by partitioning into methylene chloride from a citrate buffer. The compounds of interest were isolated on a disposable carboxylic acid cation exchange column and then eluted with $0.02 \% \mathrm{HCl}$ in methanol. Gentian violet, its demethylated metabolites and leucogentian violet were determined by HPLC using isocratic elution from a cyano column with a buffered mobile phase and amperometric electrochemical detection. Average recoveries of gentian violet and leucogentian violet from commercially purchased chicken liver fortified with $20 \mu \mathrm{g} / \mathrm{kg}$ of each compound were $92 \%$ (CV 7.6\%) and 86\% (CV 8.1\%), respectively. Mean recoveries of gentian violet, leucogentian violet, the pentamethyl metabolite and one of the tetramethyl metabolites from control chicken liver fortified with $20 \mu \mathrm{g} / \mathrm{kg}$ of each compound were $80 \%$ (CV 8.8\%), 76\% (CV 3.9\%), $83 \%(\mathrm{CV} 7.2 \%$ ) and $76 \%$ (CV 10.5\%), respectively. Data are also presented to show 
applicability of the method to muscle tissue.

Munns et al., (1990) analysed leucogentian violet residues in chicken fat obtained from birds that were treated with $30 \mathrm{mg} / \mathrm{kg}$ of gentian violet in feed. The fat tissue was extracted with methylene chloride, and leucogentian violet on separation from the fat with $1 \mathrm{~N} \mathrm{HCl}$ was protonated and re-extracted into methylene chloride, and after evaporation dissolved in $\mathrm{ACN}$-water before being subjected to $\mathrm{LC}$ with an electrochemical detector. Average recovery for leucogentian violet was $84 \%$ with a $\mathrm{CV}$ of $13 \%$ for $5 \mu \mathrm{g} / \mathrm{kg}$ fat. Gentian violet and its oxidized metabolites were not detected in the fat tissue. Recovery of leucogentian violet was influenced by several factors within the analytical procedure, such as temperature and volume in the last evaporation step, and needed to be carefully controlled.

\section{Aquaculture}

A number of published articles describe analytical methods for residues of gentian violet in aquaculture products (Andersen et al., 2009; Chen and Miao, 2010; Doerge et al., 1996; Dowling et al., 2007; Li and Kijak, 2011; Rushing, Webb and Thompson, 1995; Rushing and Hansen, 1997; Rushing and Thompson, 1997; Thompson et al., 1999; Wu et al., 2007; Xie et al., 2013; Xu et al., 2012).

Catfish fillets were blended and then homogenized with aqueous hydroxylamine, p-TSA and $0.1 \mathrm{M}$ ammonium acetate, followed by extraction with acetonitrile. The acetonitrile was partitioned with water, methylene chloride and diethylene glycol mixture. The bottom layer was concentrated and chromatographed on an alumina cartridge. The leucogentian violet and gentian violet residues were eluted from the cartridges and subjected to liquid chromatography with a UV-visible detector set at $588 \mathrm{~nm}$. The method is capable of analyzing residues of gentian violet and leucogentian violet to $1 \mu \mathrm{g} / \mathrm{kg}$ level (Rushing, Webb and Thompson, 1995). The method was later modified by so that gentian violet, leucogentian violet, malachite green and leucomalachite green could be simultaneously determined (Rushing and Thompson, 1997). An analytical method for the confirmation of residues of gentian violet and leucogentian violet in catfish was also developed using a post-column oxidation colorimetric electrochemical cell, a UV-VIS diode array detector and a fluorescence detector (Rushing and Hansen, 1997). In a method to analyse gentian violet, leucogentian violet, malachite green and leucomalachite green in salmon tissue, tissue was extracted with pH 3 Mcllvaine buffer with clean up on a Bakerbond strong cation exchange solid phase extraction cartridge, and analysed by LC-MS/MS (Dowling et al., 2007).

A number of multi-residue methods have been reported for residues of the trimethylphenyl dyes in aquaculture products. A multi-residue method for determination of gentian violet, leucogentian violet, malachite green and leucomalachite green in a number of fish makes use of Mcllvaine buffer and acetonitrile for extraction, followed by partitioning with dichloromethane and clean-up on basic alumina and OASIS MCX SPE column (Wu et al., 2007). Detection and quantification use LC-ESI-MS/MS with the selected reaction monitoring mode. The LODs and LOQs were in the 0.02 and $0.13 \mu \mathrm{g} / \mathrm{kg}$ range, respectively, with recoveries ranging from 80 to $115 \%$ for $0.25-10 \mu \mathrm{g} / \mathrm{kg}$ tissue. In another method for the determination and confirmation of residues of gentian violet, leucogentian violet, malachite green, leucomalachite green, brilliant green and leucobrilliant green in fish tissue at $\leq 1 \mu \mathrm{g} / \mathrm{kg}$, residues were extracted with ammonium acetate buffer and acetonitrile, followed by clean up using dichloromethane portioning and solid-phase extraction, with analyses by liquid chromatography with visible detection (Andersen et al., 2009). 


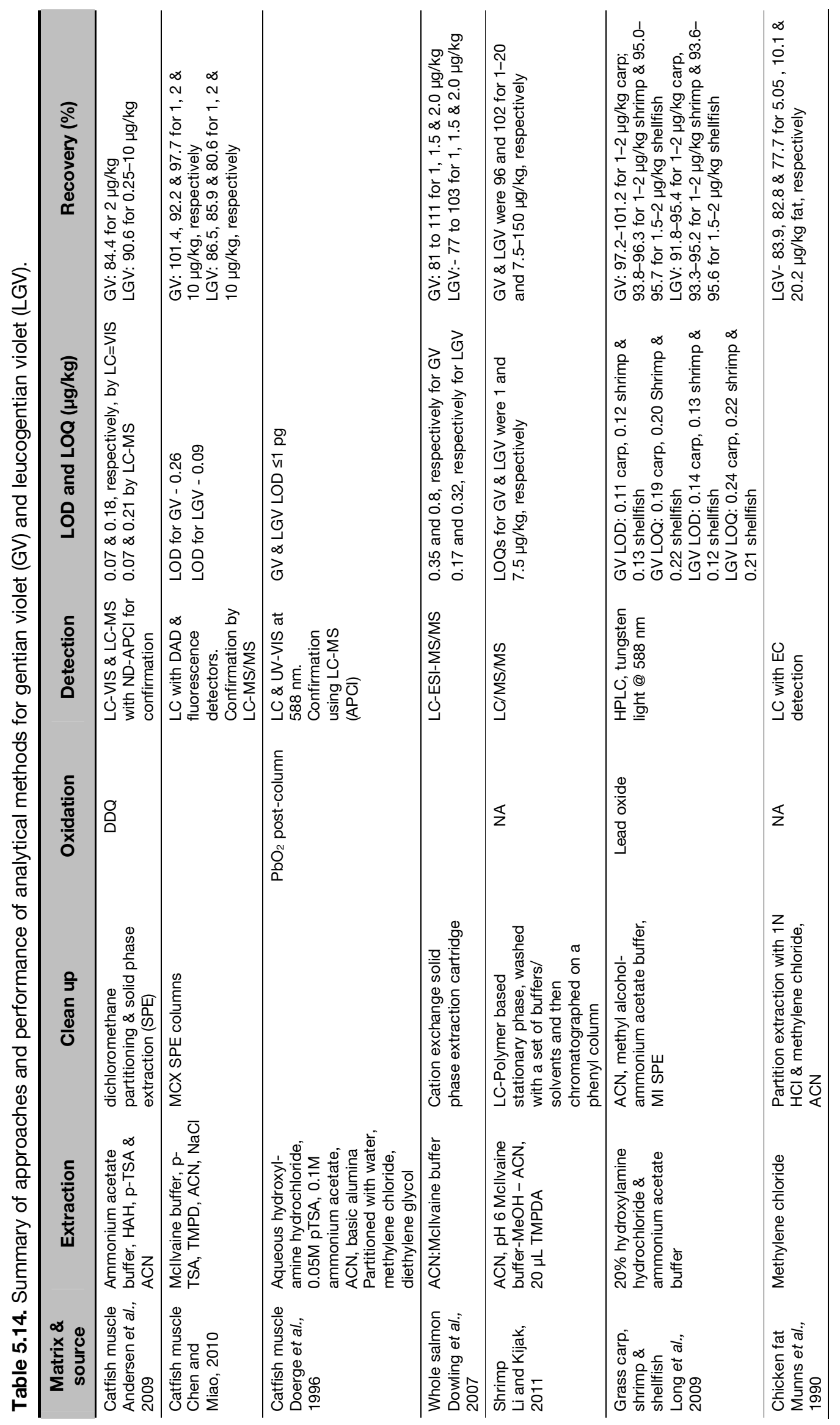




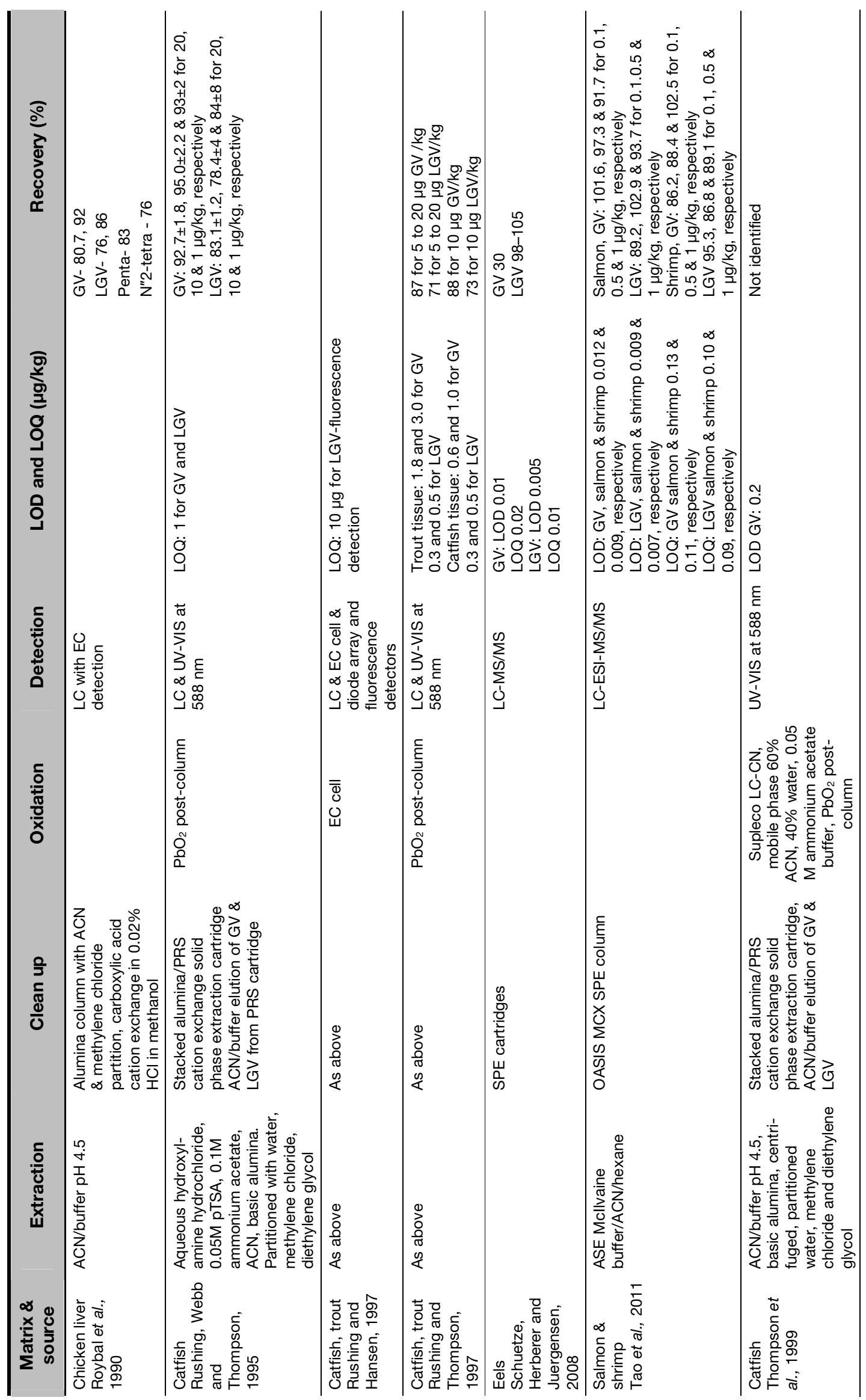




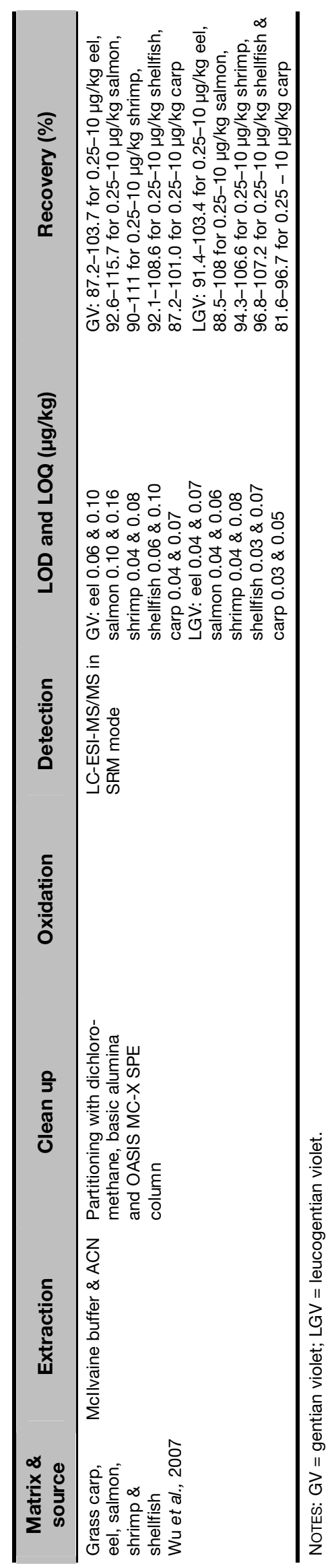


A multi-residue method making use of molecularly imprinted polymers (MIPs) for the selective detection and binding of analytes was developed using HPLC coupled with a diode array detector, for the analysis of gentian violet and leucogentian violet in carp, shrimp and shellfish (Long et al., 2009). The LOQs were in the $0.2 \mu \mathrm{g} / \mathrm{kg}$ range, with a recovery of greater than $95 \%$. A method was developed to determine 21 veterinary drugs in shrimp using an online SPE automated sample cleanup prior to LC-MS/MS analysis (Li and Kijak, 2011). The recoveries for gentian violet and leucogentian violet were 96 and 102\% over the linear ranges of 1-20 and 7.5-150 $\mathrm{\mu g} / \mathrm{kg}$ shrimp, respectively.

\section{Additional methods}

A method has been reported for residues in catfish muscle which does not require the oxidation of the leucogentian violet to gentian violet and can detect residues at $\leq 1 \mathrm{ng} / \mathrm{g}$ (Chen and Miao, 2010). Residues were extracted with pH 3 Mcllvaine buffer and acetonitrile, with clean up by a polymeric strong cation-exchange column, followed by HPLC with a diode array and fluorescence detectors and confirmed by MS/MS. An automated method for the determination of gentian violet, leucogentian violet, malachite green and leucomalachite green in shrimp and salmon by LC-MS/MS uses accelerated solvent extraction and auto solid-phase clean-up (Tao et al., 2011). The recoveries of gentian violet, leucogentian violet, malachite green and leucomalachite green at spiked levels of 0.1 to $1.0 \mu \mathrm{gg} / \mathrm{kg}$ averaged from 82.1 to $102.9 \%$, with the relative standard deviation less than $14.6 \%$.

\section{Estimation of daily intake}

There are limited data on detection of residues of gentian violet in terrestrial food-producing animals, especially when the animals are treated with topical drug products. In limited research studies, poultry fed gentian violet have been shown to contain residues (both gentian violet and leucogentian violet) in their tissues, with highest residues observed for leucogentian violet in fat. However, residue monitoring data for residues of gentian violet and leucogentian violet were not available from consistent or on-going monitoring programmes for terrestrial food-producing animals. Useful information on frequency of occurrence and concentrations of residues can primarily be obtained from monitoring activities, or from well conducted studies under field conditions. Given the limited data available from well conducted studies in food animals, many conclusions cannot be made from those data. The limited information available via monitoring activities permits only a very limited assessment due to the largely random nature of the sampling procedures, as well as the limited species involved.

Residues of gentian violet and leucogentian violet have been reported in fish products, both in wild fish and those from aquaculture. Gentian violet and leucogentian violet residues were detected in 35 of 45 tissues of wild eels caught in waters where effluents from municipal sewage treatment plants discharged. The range for the gentian violet and leucogentian violet combined residues was 0.06 to $6.7 \mu \mathrm{g} / \mathrm{kg}$ fresh weight of tissue. The maximum concentration of gentian violet detected was $0.35 \mu \mathrm{g} / \mathrm{kg}$. The predominant residue was leucogentian violet, with only trace amounts of gentian violet detected (residue ratios varied from 10:1 to 20:1) (Schuetze, Herberer and Juergensen, 2008). Twenty samples of salmon or shrimp from the market in China were analysed for gentian violet and leucogentian violet using a method with a LOQ of $0.1 \mu \mathrm{g} / \mathrm{kg}$ fresh tissue (Tao et al., 2011). Three samples (15\%) were positive; one sample contained $1.2 \mu \mathrm{g}$ gentian violet $/ \mathrm{kg}$ and $2.5 \mu \mathrm{g}$ leucogentian violet $/ \mathrm{kg}$ fresh tissue, and two other samples contained only leucogentian violet at 0.43 and $0.7 \mu \mathrm{g} / \mathrm{kg}$.

Residue monitoring results for gentian violet and leucogentian violet conducted on domestic and imported aquaculture products in Canada by the Canadian Food Inspection Agency (Canada, 2013) and in the United States of America by the US FDA (FDA, 2008, 2014) 
are summarized in Table 5.15. While the proportions of seafood samples testing positive ranged from 0 to $4.4 \%$ over the years, mean residues of gentian violet and leucogentian violet detected in these samples were low $(<3 \mathrm{ppb})$. However, residues as high as $26.9 \mu \mathrm{g} / \mathrm{kg}$ have been reported by the US FDA (2014) in imported fish products.

Table 5.15. Detection of gentian violet and leucogentian violet in aquaculture products monitored by Canada and the United States of America

\begin{tabular}{|c|c|c|c|c|c|c|}
\hline \multirow{2}{*}{$\begin{array}{c}\text { Monitoring } \\
\text { country }\end{array}$} & \multirow[t]{2}{*}{ Year } & \multirow{2}{*}{$\begin{array}{c}\text { Samples } \\
\text { tested (No.) }\end{array}$} & \multirow{2}{*}{$\begin{array}{c}\text { No. of samples } \\
\text { positive (\%) }\end{array}$} & \multicolumn{2}{|c|}{$\begin{array}{c}\text { Residue level }(\mu \mathrm{g} / \mathrm{kg})^{(1)} \text { in } \\
\text { positive samples }\end{array}$} & \multirow{2}{*}{$\begin{array}{c}\text { Positive sample } \\
\text { types }\end{array}$} \\
\hline & & & & Mean \pm SD & Range & \\
\hline \multirow[t]{5}{*}{ Canada } & $2008 / 09$ & 135 & $6(4.4 \%)$ & $2.48 \pm 2.32$ & $0.64-5.60$ & Tilapia, salmon, shrimp \\
\hline & $2009 / 10$ & 484 & $0(0 \%)$ & - & - & - \\
\hline & $2010 / 11$ & 542 & $11(2.0 \%)$ & $1.92 \pm 1.69$ & $0.50-4.30$ & $\begin{array}{l}\text { Tilapia, perch, shrimp, } \\
\text { milkfish, catfish }\end{array}$ \\
\hline & $2011 / 12$ & 396 & $2(0.5 \%)$ & $2.23 \pm 2.02$ & $0.80-3.65$ & Bass, prawn \\
\hline & $2012 / 13$ & 269 & $3(1.1 \%)$ & $3.06 \pm 2.07$ & $0.98-5.12$ & Perch, dried fish maw \\
\hline \multirow[t]{4}{*}{$\mathrm{USA}^{(2)}$} & 2004 & 622 & $0(0 \%)$ & - & - & - \\
\hline & 2005 & 536 & $0(0 \%)$ & - & - & - \\
\hline & 2006 & 588 & $0(0 \%)$ & - & - & - \\
\hline & 2007 & 686 & 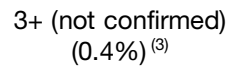 & $?$ & $2.5-26.9$ & Eel, catfish, shrimp \\
\hline
\end{tabular}

NOTES: (1) Residues for Canada are sum of gentian violet and leucogentian violet. Note that in Canada the presence of leucogentian violet is considered to be an indication of intentional use of the drug in aquaculture. (2) Sources: FDA, 2008, 2014. (3) Based on the description in FDA (2014), the values are probably an underestimate of \% samples positive.

\section{Maximum Residue Limits}

MRLs could not be recommended by the Committee, as it was not considered appropriate to establish an ADI. The Committee also noted that there was limited information on residues.

\section{References}

Andersen, W.C., Turnipseed, S.B., Karbiwnyk, C.M., Lee, R.H., Clark, S.B., Rowe, W.D., Madson, M.R. \& Miller, E.M. 2009. Multiresidue method for the triphenylmethane dyes in fish: malachite green, crystal (gentian) violet, and brilliant green. Analytica Chimica Acta, 637: 279-289.

APVMA [Australian Pesticide and Veterinary Medicines Authority]. 1994. Crystal (Gentian) Violet review history and regulatory outcomes. Available at:

http://www.apvma.gov.au/products/review/completed/crystal_violet_history.php Accessed 2014-05-09.

Bajpai, S.K. \& Jain, A. 2010. Sorptive removal of crystal violet from aqueous solution using spent tea leaves: part I optimization of sorption conditions and kinetic studies. Acta Chimica Slovenica, 57(3): 751-757.

Bajpai, S.K. \& Jain, A. 2012. Equilibrium and thermodynamic studies for adsorption of crystal Violet onto spent tea leaves (STL). Water, 4: 52-71.

Başar, C.A. 2006. Applicability of the various adsorption models of three dyes adsorption onto activated carbon prepared from waste apricot. Journal of Hazardous Materials, 135: 232-241.

Bumpus, J.A. \& Brock, B.J. 1988. Biodegradation of crystal violet by the white rot fungus Phanerochaete chrysosporium. Applied \& Environmental Microbiology, 54: 1143-1150. 
Canada. 2013. Review of Gentian Violet: Collation and review of available data on gentian violet (GV) for the risk assessment of safety of gentian violet residues by the 78th Meeting of JECFA; prepared by the Veterinary Drugs Directorate, Health Canada (Submitted by Canada to the JECFA Secretariat).

CFIA [Canadian Food Inspection Agency]. 1992. Regulatory guidance RG-8: Contaminants in Feed. Section 3: Gentian violet for use in livestock feeds. Date modified: 2012-10-01. Available at: http: / / www.inspection.gc.ca/animals/feeds/regulatory-guidance/rg8/eng/1347383943203/1347384015909?chap=3 Accessed 2014-05-09.

Chan, D., Tarbin, J.A., Stubbings, G., Kay, J. \& Sharman, M. 2012. Analysis of incurred crystal violet in Atlantic salmon (Salmo salar L.): comparison between the analysis of crystal violet as an individual parent and leucocrystal violet and as total crystal violet after oxidation with 2,3dichloro-5-6-dicyanobenzoquinone. Food Additives and Contaminants: Part A, 29: 66-72.

Chen, G. \& Miao, S. 2010. HPLC Determination and MS confirmation of malachite green, gentian violet, and their leuco metabolite residues in channel catfish muscle. Journal of Agricultural $\mathcal{E}$ Food Chemistry, 58: 7109-7114.

Davis, J.L., Smith, G.W., Baynes, R.E., Tell, L.A., Webb, A.I. \& Riviere, J.E. 2009. Update on drugs prohibited from extralabel use in food Animals. Journal of the American Veterinary Medical Association, 235: 528-534.

DEFRA [Department for Environment, Food and Rural Affairs]. 2007. Annual Report on Surveillance for Veterinary Residues in Food in the UK 2007. The Veterinary Residues Committee, Addlestone, UK.

Docampo, R. \& Moreno, S.N.J. 1990. The metabolism and mode of action of gentian violet. Drug Metabolism Reviews, 22: 161-178.

Doerge, D.R., Churchwell, M.I., Rushing, L.G. \& Bajic, S. 1996. Confirmation of gentian violet and its metabolite leucogentian violet in catfish muscle using liquid chromatography combined with atmospheric pressure ionization mass spectrometry. Rapid Communications in Mass Spectrometry, 10: 1479-1484.

Dowling, G., Mulder, P.P.J., Duffy, C., Regan, L. \& Smyth, M.R. 2007. Confirmatory analysis of malachite green, leucomalachite green, crystal violet and leucocrystal violet in salmon by liquid chromatography-tandem mass spectrometry. Analytica Chimica Acta, 586: 411-419.

Health Canada. 2013. Health Canada Drug Product Database. Available at: http:/ /webprod5.hcsc.gc.ca/dpd-bdpp/index-eng.jsp Accessed 2014-05-09.

FDA [United States Food and Drugs Administration]. 1991a. Code of Federal Regulations, Title 21, part 500.29-Gentian violet for animal drug use.

FDA. 1991b. Code of Federal Regulations, Title 21, part 500.30-Gentian violet for use in animal feed.

FDA. 2008. Enhanced aquaculture and seafood inspection - report to Congress, November 20, 2008. Available at:

http: / / www.fda.gov/Food/GuidanceRegulation/GuidanceDocumentsRegulatoryInformation/Se afood/ucm150954.htm Accessed 2014-05-22.

FDA. 2014. Import Alert 16-131. Published 07 April 2014. Available at: http: / / www.accessdata.fda.gov/cms_ia/importalert_33.html

Ganesh, K.C., Mongolla, P., Basha, A., Joseph, J., Sarma, V.U.M. \& Kamal, A. 2011. Decolourization and biotransformation of triphenylmethane dye, methyl violet, by Aspergillus sp. isolated from Ladakh, India. Journal of Microbiology E Biotechnology, 21(3): 267-273.

Garg, V.K., Gupta, R., Bala, Y.A. \& Kumar, R. 2003. Dye removal from aqueous solution by adsorption on treated saw dust. Bioresource Technology, 89: 121-124.

Harrelson, W.G. Jr., \& Mason, R.P. 1982. Microsomal reduction of gentian violet evidence for cytochrome P-450 catalyzed free radical formation. Molecular Pharmacology, 22: 239-242.

Heberer, T. 2009. Zero tolerance of chemical pollutants in food and animal feed: European policies and public health. Journal of Epidemiology E Community Health, 63: 865-866.

Khoshkho, Zh. \& Matin, R.H. 2013. Efficacy of medication therapy to control of Saprolegniasis on rainbow trout (Oncorhynchus mykiss) eggs. Global Veterinaria, 10(1): 80-83.

Li, H. \& Kijak, P.J. 2011. Development of a quantitative multiclass/multiresidue method for 21 veterinary drugs in shrimp. Journal of AOAC International, 94(2): 394-406. 
Liu, Y., Lin, J., Chen, M. \& Song, L. 2013. Investigation on the interaction of the toxicant, gentian violet, with bovine hemoglobin. Food Chemistry \& Toxicology, 58: 264-72.

Long, C., Mai, Z., Yang, Y., Zhu, B., Xu, X., Lu, L. \& Zou, X. 2009. Determination of multi-residue for malachite green, gentian violet and their metabolites in aquatic products by high-performance liquid chromatography coupled with molecularly imprinted solid-phase extraction. Journal of Chromatography A, 1216: 2275-2281.

McDonald, J.J. 1985. Metabolism of gentian violet in chickens. Final Report, Research Triangle Park.

McDonald, J.J. 1989. Metabolism of gentian violet in Fischer 344 rats and B6C3F1 mice. NCTR Technical Report for Experiments 302, 303. Jefferson, Arkansas.

McDonald, J.J. \& Cerniglia, C.E. 1984. Biotransformation of gentian violet to leucogentian violet by human, rat, and chicken intestinal microflora. The American Society for Pharmacology and Experimental Therapeutics, 12: 330-336.

McDonald, J.J., Breeden, C.R., North, B.M. \& Roth, R.W. 1984a. Species and strain comparison of the metabolism of gentian violet by liver microsomes. Journal of Agricultural and Food Chemistry, 32: 596-600.

McDonald, J.J., North, C.R., Breeden, C.R., Lai, C.C. \& Roth, R.W. 1984b. Synthesis and disposition of ${ }^{14} \mathrm{C}$-labelled gentian violet in $\mathrm{F} 344$ rats and B6C3F1 mice. Food Chemistry \& Toxicology, 22: 331336.

Mohanty, K., Naidu, J.T., Meikap, B.C. \& Biswas, M.N. 2006. Removal of crystal violet from wastewater by activated carbons prepared from rice husk. Industrial \& Engineering Chemistry Research, 45(14): 5165-5171.

Munns, R.K., Roybal, J.E., Hurlbut, J.A. \& Shimoda, W. 1990. Rapid method for determination of leucogentiam violet in chicken fat by liquid chromatography with electrochemical detection. Journal of the Association of Official Analytical Chemists, 73: 705-708.

Olentine, C.G., Gross, D.L. \& Burrows, P.M. $1980 .{ }^{14} \mathrm{C}$-Gentian violet residues in tissues of broiler breeders. Poultry Science, 59: 500-505.

Önal, Y. 2006. Kinetics of adsorption of dyes from aqueous solution using activated carbon prepared from waste apricot. Journal of Hazardous Materials, 137: 1719-1728.

Roybal, J.E., Munns, R.K., Hurlbut, J.A. \& Shimoda, W. 1990. Determination of gentian violet, its demethylated metabolites, and leucogentian violet in chicken tissue by liquid chromatography with electrochemical detection. Journal of the Association of Official Analytical Chemists, 73: 940-946.

Rushing, L.G., Webb, S.F. \& Thompson, H.C. Jr. 1995. Determination of leucogentian violet and gentian violet in catfish tissue by high-performance liquid chromatography with visible detection. Journal of Chromatography B: Biomedical Science Applications, 674: 125-131.

Rushing, L.G. \& Hansen, E.B. Jr. 1997. Confirmation of malachite green, gentian violet and their leuco analogs in catfish and trout tissue by high-performance liquid chromatography utilizing electrochemistry with ultraviolet-visible diode array detection and fluorescence detection. Journal of Chromatography B: Biomedical Science Applications, 700: 223-231.

Rushing, L.G. \& Thompson, H.C. Jr. 1997. Simultaneous determination of malachite green, gentian violet and their leuco metabolites in catfish or trout tissue by high performance liquid chromatography with visible detection. Journal of Chromatography B: Biomedical Science Applications, 688: 325-330.

Schuetze, A., Herberer, H. \& Juergensen, S. 2008. Occurrence of residues of the veterinary drug crystal (gentian) violet in wild eels caught downstream from municipal plants. Environmental Chemistry, 5: 194-199.

Tao, Y., Chen, D., Chao, X., Yu, H., Yuanhu, P., Liu, Z., Huang, L., Wang, Y. \& Yuan, Z. 2011. Simultaneous determination of malachite green, gentian violet and their leuco-metabolites in shrimp and salmon by liquid chromatography-tandem mass spectrometry with accelerated solvent extraction and auto solid-phase clean-up. Food Control, 22: 1246-1252.

Thompson, H.C. Jr., Rushing, L.G., Gehring, T. \& Lochmann, R. 1999. Persistence of gentian violet and leucogentian violet in channel catfish (Ictalurus punctatus) muscle after water-borne exposure. Journal of Chromatography B: Biomedical Science Applications, 723(1-2): 287-291. 
Wu, X., Zhang, G., Wu, Y., Hou, X. \& Yuan, Z. 2007. Simultaneous determination of malachite green, gentian violet and their leuco-metabolites in aquatic products by high-performance liquid chromatography-linear ion trap mass spectrometry. Journal of Chromatography A, 1172: 121-126.

Xie, J., Peng, T., Chen, D.D., Zhang, Q.J., Wang, G.M., Wang, X., Guo, Q., Jiang, F., Chen, D. \& Deng, J. 2013. Determination of malachite green crystal violet and their leuco-metabolites in fish by HPLC-VIS detection after immunoaffinity column clean-up. Journal of Chromatography B: Biomedical Science Applications, 913-914: 123-128.

Xu, Y.J., Tian, X.H., Zhang, X.Z., Gong, X.H., Liu, H.H., Zhang, H.J., Huang, H. \& Zhang, L.M. 2012. Simultaneous determination of malachite green, crystal violet, methylene blue and the metabolite residues in aquatic products by ultra-performance liquid chromatography with electrospray ionization tandem mass spectrometry. Journal of Chromatographic Science, 50: 591-597.

Zhang, J.X. \& Ou, L.L. 2013. Kinetic, isotherm and thermodynamic studies of the adsorption of crystal violet by activated carbon from peanut shells. Water Science and Technology, 67(4): 737-744. 



\section{Ivermectin}

First draft prepared by

Bruno Le Bizec, Nantes, France

Addendum to the monographs prepared by the 36th, 40th, 54th and 58th Meetings of the Committee and published in FAO Food and Nutrition Papers 41/3, 41/5, 41/13 and 41/14.

\section{Background}

Ivermectin is widely used as a broad-spectrum antiparasitic drug against nematode and arthropod parasites in food-producing animals. In human medicine, it is used mainly for the treatment of onchocerciasis. Ivermectin was previously considered by the Committee at its 36th, 40th, 44th and 54th Meetings. At its 40th Meeting, the Committee established an ADI of $0-1 \mu \mathrm{g} / \mathrm{kg}$ bw and recommended MRLs of $100 \mu \mathrm{g} / \mathrm{kg}$ for bovine liver and $40 \mu \mathrm{g} / \mathrm{kg}$ for bovine fat, determined as ivermectin B1a. The 21st Session of the CCRVDF requested that the 78th Meeting of the JECFA advise on whether it was possible to establish an MRL for bovine muscle (FAO/WHO, 2013).

\section{Current evaluation}

At the present meeting, the Committee reviewed residue depletion data contained in the monographs for ivermectin prepared by the 36th and 40th Meetings of the Committee, which contained the residue data used to recommend MRLs for bovine liver and fat by the 40th Meeting of the Committee. A depletion study using $\left[{ }^{14} \mathrm{C}\right]$ ivermectin reviewed by the 36th Meeting of JECFA showed that total ivermectin residues in muscle tissues of cattle were $1 \mu \mathrm{g} / \mathrm{kg}$ at 28 days following administration of a dose of $0.3 \mathrm{mg} / \mathrm{kg}$ bw by subcutaneous administration (FAO, 1991). The monograph also reported a study using unlabelled ivermectin in which cattle (approx. $260 \mathrm{~kg} \mathrm{bw}$ ) were administered ivermectin at $0.3 \mathrm{mg} / \mathrm{kg}$ bw by subcutaneous (s.c.) injection. In this study, no residues of ivermectin were detected at 28 days following treatment. The monograph reported that analytical methodology used for determination of the marker residue, ivermectin B1a, was based on high performance liquid chromatography with fluorescence detection (HPLC/FL), with a linear range of 5-60 $\mathrm{gg} / \mathrm{kg}$.

Subsequently, it was found that ivermectin residues were more persistent in heavy cattle (bw $450 \mathrm{~kg}$ ) and an additional residue depletion study was reviewed by the 40th Meeting of the Committee (FAO, 1993). In this study, using cattle weighing 297 to $401 \mathrm{~kg}$ at time of drug administration, each animal received an s.c. injection of $0.3 \mathrm{mg} / \mathrm{kg}$ bw. Tissue samples were analysed using an improved HPLC/FL method with a limit of detection (LOD) of $1 \mu \mathrm{g} / \mathrm{kg}$. At 28 days following treatment, there were detectable residues in muscle tissue, estimated at $1 \mu \mathrm{g} / \mathrm{kg}$ (the LOD). Typically, the limit of quantitation (LOQ) is approximately 3 times higher than the LOD, that is, the residues detected in the study were detectable, but below the LOQ and therefore not truly quantifiable. Based on the data considered by the 36th and 40th Meetings of the Committee, MRLs were recommended by the 40th Meeting of the Committee for bovine liver and fat, the two tissues in which greatest residues were detected. No MRLs were recommended for bovine muscle and kidney, although there were depletion data for both tissues, and concentrations of ivermectin in kidney and muscle were included in the calculation of the TMDI. The current Committee therefore concluded that it might be possible for JECFA to recommend an MRL for bovine muscle based on the existing summarized residue depletion data contained in the monographs, using the LOQ of current analytical methodology as a basis for an MRL for bovine muscle. 
The LOQ of HPLC/FL methods, such as the method used in the depletion study considered by the 40th meeting of the Committee, remains similar today. However, many residue control laboratories now use a multi-residue method for ivermectin and related compounds, based on high performance liquid chromatography combined with tandem mass spectrometry (LC-MS/MS). An analytical method for monitoring residues of ivermectin B1a in bovine muscle based on this technology was received and reviewed by the Committee.

\section{Methods of analysis}

\section{Preliminary considerations}

Muscle is frequently selected for residue surveillance of food of animal origin because it is a primary commodity in trade (Cooper et al., 2012). The majority of assays are based on the extraction of ivermectin using acetonitrile with clean-up on C8, C18 or HLB sorbents (Danaher et al., 2006, 2012). The use of LC gradient is recommended in analytical methods to reduce matrix carry-over peaks, particularly for fatty tissue. Similarly, single-residue methods have been applied for measuring ivermectin in the edible tissues of treated sheep (Nunez et al., 2007). Immunoaffinity chromatography (IAC)-based clean-up procedures have been developed for the isolation of ivermectin from bovine tissues prior to HPLCfluorimetry (He et al., 2005) and LC-MS/MS (Hou et al., 2006). Samples were simply extracted with acetonitrile and purified by C8 SPE prior to LC-MS/MS analysis. Another method was reported where samples were extracted using an acetone aqueous ammonia mixture and partitioned into iso-octane (Inoue et al., 2009). Extracts were concentrated, resuspended in n-hexane and partitioned into acetonitrile prior to LC-MS/MS analysis. Ivermectin residues are highly stable under a range of conditions (Danaher et al., 2012; Cooper et al., 2011). However, residues in minced meat submitted to cooking and frying diminished 45 and 50\%, respectively (Slanina et al., 1989; Rose, Shearer and Farrington, 1996).

\section{Method principle}

The TEAGASC laboratory (Dublin, Republic of Ireland) provided a validated method based on liquid chromatography coupled to tandem mass spectrometry (LC-MS/MS) for consideration by the Committee (Danaher, 2013). The method has been implemented in an ISO-17025 accredited laboratory. The sample is prepared for analysis using a modified QuEChERS method (Quick Easy Cheap Effective Rugged Safe). The sample is extracted by shaking in acetonitrile, $\mathrm{MgSO} 4$ and $\mathrm{NaCl}$ before being cleaned up by dispersive SPE, using $\mathrm{C} 18$ and $\mathrm{MgSO} 4$, concentrated, filtered and transferred to a HPLC vial. Ivermectin residues are determined by ultra-performance liquid chromatography on a reverse phase C18 column ( 1.8 micron particle size, flow rate of $0.6 \mathrm{ml} / \mathrm{min}$, column temperature set at $60^{\circ} \mathrm{C}$ ) and coupled via an electrospray interface operating in the positive mode to a triple quadrupole mass spectrometer (QqQ). The signal acquisition is programmed in the selected reaction monitoring mode (SRM). Two transitions are monitored for ivermectin B1a, i.e. 890.4>305.2 (cone voltage $15 \mathrm{~V}$, collision energy $25 \mathrm{eV}$ ) and $890.4>567.0$ (cone voltage $15 \mathrm{~V}$, collision energy $13 \mathrm{eV}$ ). An internal standard (selamectine, structural analogue) is used.

\section{Method performance}

The method has been validated for selectivity/specificity, linearity of calibration curve, working range, detection limit, decision limit $(C C \alpha)$, detection capability $(C C \beta)$, recovery, within-laboratory repeatability and within-laboratory reproducibility. The calibration curve was derived by fortifying negative muscle samples across a 1 to $50 \mu \mathrm{g} / \mathrm{kg}$ concentration range for ivermectin B1a. Value for the goodness of fit (R2) was 0.987 . The working ranges are derived from the range of the calibration curve, i.e. 1 to $50 \mu \mathrm{g} / \mathrm{kg}$. For each assay, 18 blank tissue samples were fortified at three different levels: 2,3 and $4 \mu \mathrm{g} / \mathrm{kg}$ ( $\mathrm{n}=6$ replicates 
each concentration). These concentrations represent 1, 1.5 and 2 times the second-lowest calibration level, i.e. $2 \mu \mathrm{g} / \mathrm{kg}$, considered as the minimum concentration of analyte that the method can determine with acceptable accuracy and precision. To establish the selectivity/specificity of the method, twenty muscle samples (non-fortified) were analysed. No interfering peaks were observed at the retention time of ivermectin in any of these samples. The LOD (defined by the laboratory as the limit above which it can be concluded with an error of probability of $1 \%$ that a sample contains the analyte) was $0.8 \mu \mathrm{g} / \mathrm{kg}$. The limit of decision $(C C \alpha)$ and the detection capability $(C C \beta)$ were calculated on the basis of the spectrometric signals observed at the second-lowest calibration level, i.e. $2 \mu \mathrm{g} / \mathrm{kg}$. CC $\alpha$ and CC $\beta$ were 2.8 and $3.9 \mu \mathrm{g} / \mathrm{kg}$, respectively. The recovery (expressed as a percentage) was calculated by analysing 18 blank muscle samples fortified at three different concentrations, 2, 3 and $4 \mu \mathrm{g} / \mathrm{kg}$ ( $\mathrm{n}=6$, each concentration) operated on three different days in one experiment and by three different operators in a second experiment. At $2 \mu \mathrm{g} / \mathrm{kg}$, the overall recoveries calculated for three days and three different operators were $99.2 \%$ and $105.2 \%$, respectively. The overall recovery was judged to meet the requirements of the CAC/GL 71-2009 guideline (FAO/WHO, 2012). For estimation of the precision in term of within-laboratory variation (repeatability), the same samples were used and the variation in recovery was presented as a relative standard deviation (RSD) by dividing the standard deviation by the mean concentration. At $2 \mu \mathrm{g} / \mathrm{kg}, 3 \mu \mathrm{g} / \mathrm{kg}$ and $4 \mu \mathrm{g} / \mathrm{kg}$, the precision was $6.5 \%, 12.0 \%$ and $6.4 \%$, respectively. The precision in terms of within-laboratory reproducibility was calculated at three fortification levels from the results of three different analysts. The results obtained were presented as RSD (\%). At $2 \mu \mathrm{g} / \mathrm{kg}, 3 \mu \mathrm{g} / \mathrm{kg}$ and $4 \mu \mathrm{g} / \mathrm{kg}$, the precision was $25.3 \%$, $22.5 \%$ and $18.3 \%$, respectively. Precision expressed in terms of within-laboratory repeatability and intermediary reproducibility was judged adequate to meet the requirements of guideline CAC/GL 71-2009.

The Committee assessed the validation data against the requirements as published in the Codex guidelines for analytical methods for residue control (CAC/GL71-2009). In particular, the Committee reviewed information on the LOD $(0.8 \mu \mathrm{g} / \mathrm{kg})$ and LOQ $(2 \mu \mathrm{g} / \mathrm{kg})$ of the submitted LC-MS/MS method for the determination of ivermectin B1a in muscle. The Committee concluded that the analytical method can be recommended for regulatory monitoring of ivermectin B1a residues in muscle samples.

\section{Maximum Residue Limits}

In recommending MRLs for ivermectin in cattle muscle, the Committee considered the following factors:

- A new compliant fully validated LC-MS/MS method complete with adequate performance factors and method validation was provided that was considered suitable for routine monitoring of ivermectin B1a as marker residue.

- The analytical method has been validated for use in bovine muscle, with an LOQ of $2 \mu \mathrm{gg} / \mathrm{kg}$.

- The radiolabel study considered by the 36th Meeting of the Committee demonstrated that the total residue of ivermectin in muscle at 28 days was $1 \mu \mathrm{g} / \mathrm{kg}$.

- The depletion study considered by the 40th Meeting of the Committee based on which MRLs were recommended for bovine fat and liver demonstrated that residues of the marker residue in bovine muscle at 28 days, the time-point at which MRLs were recommended for bovine fat and liver, were approximately $1 \mu \mathrm{g} / \mathrm{kg}$, using an analytical method with an LOD of $1 \mu \mathrm{g} / \mathrm{kg}$.

The Committee recommended an MRL of $4 \mu \mathrm{g} / \mathrm{kg}$ for cattle muscle determined as ivermectin B1a, based on $2 \times$ LOQ of the analytical method. The dietary intake calculation prepared by the 40th Meeting of the Committee included an estimate of the potential intake 
from muscle, based on the concentrations of total residue reported from the radiolabel study.

\section{References}

Cooper, K.M., Whelan, M., Danaher, M. \& Kennedy, D.G. 2011. Stability during cooking of anthelmintic veterinary drug residues in beef. Food Additives and Contaminants Part A - Chemistry Analysis Control Exposure \& Risk Assessment, 28(2): 155-165.

Cooper, K.M., Whelan, M., Kennedy, D.G., Trigueros, G., Cannavan, A., Boon, P.E., Wapperom, D. \& Danaher, M. 2012. Anthelmintic drug residues in beef: UPLC-MS/MS method validation, European retail beef survey, and associated exposure and risk assessments. Food Additives and Contaminants Part A - Chemistry Analysis Control Exposure \& Risk Assessment, 29(5): 746-760.

Danaher, M., Howells, L.C., Crooks, S.R.H., Cerkvenik-Flajs, V. \& O'Keefe, M. 2006. Review of methodology for the determination of macrocyclic lactone residues in biological matrices. Journal Of Chromatography B - Analytical Technologies in the Biomedical and Life Sciences, 844(2): 175-203.

Danaher, M., Radeck, W., Kolar, L., Keegan, J. \& Cerkvenik-Flajs, V. 2012. Recent developments in the analysis of avermectin and milbemycin residues in food safety and the environment. Current Pharmaceutical Biotechnology, 13(6): 936-951.

Danaher, M. 2013. Private communication to JECFA reporting validation of performance of LCMS/MS method for ivermectin Bq1a residues in bovine muscle used by TEAGASC, Dublin, Ireland.

FAO. 1991. Ivermectin. pp. 45-64, in: Residues of some veterinary drugs in animals and foods. FAO Food and Nutrition Paper, No. 41/3. Available at: http://www.fao.org/food/food-safetyquality/scientific-advice/jecfa/jecfa-vetdrugs/en/ Accessed 2014-05-10.

FAO. 1993. Ivermectin. pp. 37-39, in: Residues of some veterinary drugs in animals and foods. Monographs prepared by the Fortieth Meeting of the Joint FAO/WHO Expert Committee on Food Additives Geneva, 9-18 June 1992. FAO Food and Nutrition Paper, No. 41/5. Available at http://www.fao.org/docrep/014/T0721E/T0721E.pdf Accessed 2014-05-18.

FAO/WHO. 2012. [Codex Alimentarius Commission] Guidelines for the design and implementation of national regulatory food safety. No. 12 - Assurance programmes associated with the use of veterinary drugs in food producing animals. Doc. 13 CAC/GL 71-2009, rev. 2012. Available at: http://www.codexalimentarius.org/ download/standards/11252/CXG_071e.pdf Accessed 201405-29.

FAO/WHO. 2013. Report of the Twenty-first Session of the Codex Committee on Residues of Veterinary Drugs in Foods, Minneapolis, United States of America, 26-30 August 2013. CAC doc. REP14/RVDF. Available at: http://www.codexalimentarius.org/download/ report/802/REP14_RVe.pdf Accessed 2014-05-29.

He, J.H., Hou, X.L., Jiang, H.Y. \& Shen, J Z. 2005. Multiresidue analysis of avermectins in bovine liver by immunoaffinity column cleanup procedure and liquid chromatography with fluorescence detector. Journal of AOAC International, 88(4): 1099-1103.

Hou, X.L., Jiang, H.Y., Ding, S.Y., Zhang, S.X., Li, X.W. \& Shen, J.Z. 2006. Multiresidue analysis of avermectins in cattle liver by liquid chromatography/tandem mass spectrometry. Journal of AOAC International, 89(4): 1110-1115.

Inoue, K., Yoshimi, Y., Hino, T. \& Oka, H. 2009. Simultaneous determination of avermectins in bovine tissues by LC-MS/MS. Journal of Separation Science, 32(21): 3596-3602.

Nunez, M.J., Palma, C., Araneda, M., Cabezas, I. \& Perez, R. 2007. Validation of an analytical method and determination of ivermectin residues in sheep tissues. Revista Cientifica-Facultad de Ciencias Veterinarias, 17(6): 557-565.

Rose, M.D., Shearer, G. \& Farrington, W.H.H. 1996. The thermal stability and effect of cooking on veterinary drug residues in food. pp. 829-834, in: N. Haagsma and A. Ruiter (Eds.). Proceedings of Euroresidue III Conference on Residues of Veterinary Drugs in Food. Veldhoven, The Netherlands, 6-8 May 1996. Utrecht University, Faculty of Veterinary Medicine, Veldhoven, The Netherlands.

Slanina, P., Kuivinen, J., Ohlsen, C. \& Ekstrom, L.C. 1989. Ivermectin residues in the edible tissues of swine and cattle. Effect of cooking and toxicological evaluation. Food Additives and Contaminants Part A - Chemistry Analysis Control Exposure \& Risk Assessment, 6(4): 475-481. 


\title{
7. Lasalocid sodium
}

\author{
First draft prepared by \\ Zonghui Yuan, Wuhan, Hubei, China \\ and \\ Lynn G. Friedlander, Rockville, MD, USA
}

\section{Identity}

International Non-proprietary Name (INN): lasalocid sodium

Synonyms: Lasalocid sodium A; Lasalocid sodium; Lasalocid sodium salt;

Ro 2-2985 (lasalocid A); Ro 2-2985/001; Avatec; Avatec 150G;

Avatec 15\% cc; Avatec 20\% cc; X-537A (lasalocid A)

IUPAC Names: Sodium6-[(3R,4S,5S,7R)-7-[(2S,3S,5S)-5-ethyl-5[(2R,3R,6S)-5-ethyl-5-hydroxy6-methyltetrahydro-2H-pyran-2-yl)]tetrahydro-3-methyl-2-furyl)]-4hydroxy-3,5-dimethyl-6-oxononyl)]-2,3-cresotate

Chemical abstract Service No: 25999-20-6

Structural formula:

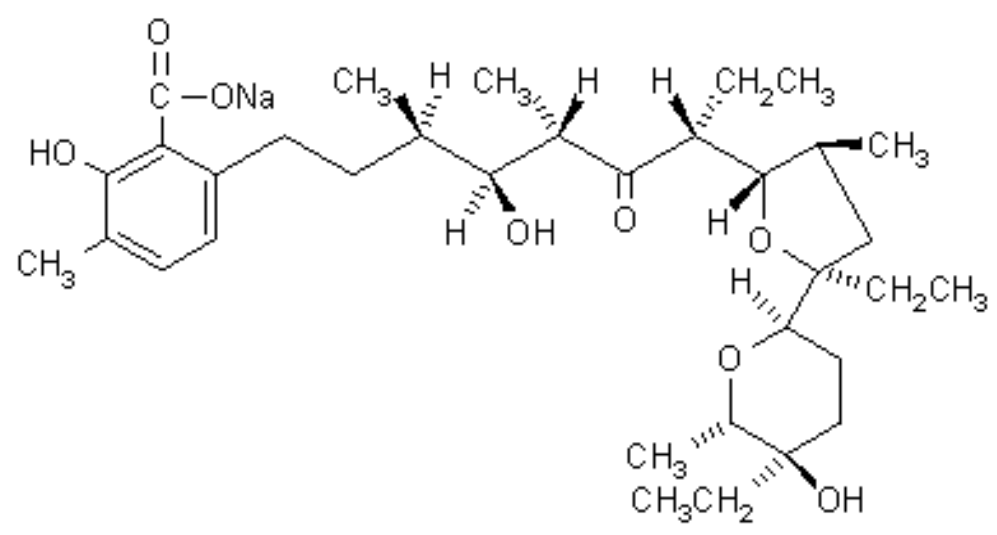

Molecular formula: $\mathrm{C}_{34} \mathrm{H}_{53} \mathrm{O}_{8} \mathrm{Na}$

Molecular weight of the salt: 612.78

\section{Other information on identity and properties \\ Degree of impurity}

Lasalocid homologues: Lasalocid B, Lasalocid C, Lasalocid D, Lasalocid E.

Lasalocid homologues B, C, D and E make up no more than a total of $10 \%$ of the total weight of the active substance.

Other impurities: Heavy metals, sulphated ash, $\mathrm{C}_{18}$ fatty acid methyl ester, oleic acid Melting point: $\quad 180^{\circ} \mathrm{C}$

Solubility: $\quad 0.5 \mathrm{~g} / \mathrm{L}$ water; $2.0 \mathrm{~g} / \mathrm{L}$ ethanol $95 \% ; 500 \mathrm{~g} / \mathrm{L}$ chloroform; $93 \mathrm{~g} / \mathrm{L}$ acetone 


\section{Residues in food and their evaluation}

\section{Conditions of use}

Lasalocid, a divalent polyether ionophore antibiotic, is produced by Streptomyces lasaliensis, and recommended as a medicinal feed additive for continuous use to control coccidiosis in poultry species. It is a broad spectrum anticoccidial agent approved to protect against Eimeria species in broilers and replacement pullets, turkeys, pheasants and quails. The mechanism of action of lasalocid and other ionophores has been extensively investigated and reported. Like other carboxylic polyether ionophores, lasalocid disturbs ionic homeostasis, leading to osmotic lysis of coccidia.

Lasalocid is not approved for use in laying birds as it partitions into fat (egg yolks) at high concentrations. For completeness, a section on contamination of eggs is included in this evaluation.

\section{Dosage}

Lasalocid is approved for continuous use in broilers, replacement pullets, turkeys, guinea fowl, pheasants, partridges, quail, rabbits, cattle and sheep at concentrations of 75 to $125 \mathrm{mg} / \mathrm{kg}$ of lasalocid sodium in feed as a pre-mix containing $20 \%$ lasalocid sodium.

\section{Pharmacokinetics and metabolism}

\section{Pharmacokinetics in laboratory animals}

\section{Mice}

In a GLP-compliant study, $\left[{ }^{14} \mathrm{C}\right]$ lasalocid sodium in 30\% ethanol was administered to 13 male and 13 female CD-1 mice via oral gavage at $1 \mathrm{mg} / \mathrm{kg} /$ day for 7 days (Hawkins, Elsom and de Salis, 1987a). Five animals of each sex constituted the control group and were untreated. Urine, faeces and cage wash were collected daily. Four hours after the final dose, animals were sacrificed and their livers harvested and pooled. The radioactivity was detected with liquid scintillation following combustion. Within $24 \mathrm{~h}$ after the first dose, approximately $97 \%$ of the dose was recovered in excreta and cage wash. By $4 \mathrm{~h}$ after the last dose, approximately $77 \%$ of the dose was recovered in the faeces, $1 \%$ in the urine and $2.6 \%$ in cage wash. Radioactivity in pooled liver samples was approximately $2.1 \mu \mathrm{g}$ equivalents/g fresh tissue.

In another GLP-compliant study, a single dose of $1 \mathrm{mg} / \mathrm{kg}\left[{ }^{14} \mathrm{C}\right]$ lasalocid sodium was administered to 35 male Charles River CD-1 mice via oral gavage (Laurencot et al., 1979a). Five mice were sacrificed at 15 and 30 minutes, and 1, 3, 6, 24 and $48 \mathrm{~h}$ after dosing. The following samples were collected and assayed for radioactivity by liquid scintillation following combustion: whole blood, brain, carcass, faeces, fat, heart, kidney, large intestine, large intestine contents, liver, small intestine, small intestine contents, spleen, stomach, stomach contents, thymus and urine. Urine and faeces were collected from each animal according to their withdrawal time-point and assayed. Excreta from $48 \mathrm{~h}$ withdrawal animals were collected as two $24 \mathrm{~h}$ samples. The highest levels of radioactivity within the contents of the gastrointestinal tract were found after 15 minutes, 3 and $6 \mathrm{~h}$ for the stomach, small intestine and large intestine, respectively. Peak concentrations in gastrointestinal tissues were: stomach $5.4 \mu \mathrm{g} / \mathrm{g}, 6.3 \%$ of treatment radioactivity, 15 minutes post-dose; small intestine $2.6 \mathrm{\mu g} / \mathrm{g}, 14.4 \%$ of treatment radioactivity, $3 \mathrm{~h}$ post-dose; and large intestine $1.6 \mu \mathrm{g} / \mathrm{g}, 3.3 \%$ of treatment radioactivity, $6 \mathrm{~h}$ post-dose. Radioactivity in whole blood peaked at $0.62 \mu \mathrm{g} / \mathrm{ml}, 1.4 \%$ of treatment radioactivity, 15 minutes after dosing. The whole blood elimination half-life was $3 \mathrm{~h}$ and by $24 \mathrm{~h}$ no radioactivity was detectable in blood. Radioactivity was seen in all remaining tissues, with highest concentrations identified in liver at $3.49 \mu \mathrm{g} / \mathrm{g}, 17.6 \%$ of treatment radioactivity, $1 \mathrm{~h}$ post-dose, and heart at $0.41 \mu \mathrm{g} / \mathrm{g}, 0.26 \%$ of treatment radioactivity, $1 \mathrm{~h}$ post-dose. Radioactivity was only detectable in the liver 
$(0.06 \mu \mathrm{g} / \mathrm{g})$ by $48 \mathrm{~h}$ post-dose. Approximately $95 \%$ of the treatment radioactivity was recovered in faeces collected within $24 \mathrm{~h}$ of dosing; a further $2 \%$ was recovered in $24-48 \mathrm{~h}$ faeces. Less than $1 \%$ of treatment radioactivity was recovered in $0-24 \mathrm{~h}$ urine. No radioactivity was detectable in $24-48 \mathrm{~h}$ urine.

In a similar study conducted in compliance with GLP, $\left[{ }^{14} \mathrm{C}\right]$ lasalocid sodium was administered to 40 male Charles River CD-1 mice via oral gavage at $1 \mathrm{mg} / \mathrm{kg} /$ day for 7 days (Laurencot et al., 1980). Five mice were sacrificed at $0.25,0.5,1,3,6,24$ and $48 \mathrm{~h}$ after treatment. The following samples were collected and assayed for radioactivity by liquid scintillation following combustion: whole blood, brain, carcass, faeces, fat, heart, kidney, large intestine, large intestine contents, liver, small intestine, small intestine contents, spleen, stomach, stomach contents, thymus and urine. Urine and faeces samples were collected from each animal according to their withdrawal time and assayed. Urine and faeces samples were collected from the mice sacrificed at $48 \mathrm{~h}$ as two separate samples for the periods $0-24 \mathrm{~h}$ and $24-48 \mathrm{~h}$ withdrawal, respectively. Radioactivity in whole blood peaked at $0.69 \mu \mathrm{g} / \mathrm{ml}, 0.23 \%$ of treatment radioactivity at the 30-minute withdrawal. The whole blood elimination half-life was $3 \mathrm{~h}$. By $24 \mathrm{~h}$ withdrawal, no radioactivity was detectable in blood. Excluding the gastrointestinal tissues, highest tissue concentrations were found in liver at $2.64 \mu \mathrm{g} / \mathrm{g}$, or $1.95 \%$ of treatment radioactivity, at $3 \mathrm{~h}$ withdrawal; heart at $0.37 \mu \mathrm{g} / \mathrm{g}$, or $0.04 \%$ of treatment radioactivity, at 30-minute withdrawal; lung at $0.33 \mu \mathrm{g} / \mathrm{g}$, or $0.03 \%$ of treatment radioactivity, at $1 \mathrm{~h}$ withdrawal; thymus at $0.21 \mu \mathrm{g} / \mathrm{g}$, or $0.004 \%$ of treatment radioactivity, at $1 \mathrm{~h}$ withdrawal; kidneys at $0.19 \mu \mathrm{g} / \mathrm{g}$, or $0.05 \%$ of treatment, at $0.5-3 \mathrm{~h}$ withdrawal, and spleen at $0.12 \mu \mathrm{g} / \mathrm{g}$, or $0.004 \%$ of treatment radioactivity, at $1 \mathrm{~h}$ withdrawal. By $48 \mathrm{~h}$ withdrawal, excluding the gastrointestinal tissues and contents, radioactivity was only detectable in liver at $0.09 \mu \mathrm{g} / \mathrm{g}$ and in kidneys at $0.001 \mu \mathrm{g} / \mathrm{g}$. Approximately $13-14 \%$ of the total treatment radioactivity, i.e. $91-98 \%$ of the daily treatment radioactivity, was recovered in faeces collected within $24 \mathrm{~h}$ of dosing. Approximately $94 \%$ of the total treatment radioactivity was recovered in faeces within $24 \mathrm{~h}$ following the final dose and a further $2 \%$ was recovered in the $24-48 \mathrm{~h}$ faeces. Less than $1 \%$ of treatment radioactivity was recovered in the urine.

A single dose of $1 \mathrm{mg} / \mathrm{kg}\left[{ }^{14} \mathrm{C}\right]$ lasalocid sodium in aqueous ethanol was administered to 5 male and 5 female CD-1 mice via oral gavage in compliance with GLP (Westheimer and Hutchinson, 1978a). Excreta were collected during the $24 \mathrm{~h}$ pre-dose period and at 4, 8, 12, 24, 48 and $72 \mathrm{~h}$ post-dose. Within $24 \mathrm{~h}$ post-dose, approximately $95 \%$ and $92 \%$ of radioactivity had been recovered in faeces for males and females, respectively. Approximately $2 \%$ and $3 \%$, respectively, were additionally recovered in 24-72 $\mathrm{h}$ faeces. For males, the sampling period with the highest faecal excretion, approximately $58 \%$ of treatment radioactivity, was $8-12 \mathrm{~h}$. For females, the greatest recovery, approximately $49 \%$ of treatment radioactivity, was in the $4-8 \mathrm{~h}$ faeces samples. Less than $1 \%$ of the radioactivity administered was recovered in urine for each sex.

\section{Rats}

In a GLP-compliant study using rats, $\left[{ }^{14} \mathrm{C}\right]$ lasalocid sodium in aqueous ethanol was administered to 5 male and 5 female CD Sprague-Dawley rats via oral gavage at $1 \mathrm{mg} / \mathrm{kg} /$ day for 7 days (Hawkins, Elsom and de Salis, 1987b). Three animals per sex constituted the control group and were untreated. Urine and faeces were collected daily. Four hours after the final dose, animals were sacrificed and their livers harvested and pooled. Within $24 \mathrm{~h}$ after the first dose, approximately $67 \%$ of the dose was recovered in excreta. Radioactivity in pooled liver samples was approximately $3.6 \mu$ g equivalents/g fresh tissue.

In another GLP-compliant study, a single dose of $1 \mathrm{mg} / \mathrm{kg}\left[{ }^{14} \mathrm{C}\right]$ lasalocid sodium was administered to 35 male Charles River CD rats via oral gavage (Laurencot et al., 1979b). Five rats were sacrificed at $0.25,0.5,1,3,6,24$ and $48 \mathrm{~h}$ after dosing. The following samples were 
collected and assayed for radioactivity by liquid scintillation following combustion: whole blood, brain, carcass, faeces, fat, heart, kidney, large intestine, large intestine contents, liver, small intestine, small intestine contents, spleen, stomach, stomach contents, thymus and urine. Urine and faeces samples were collected from each animal according to their withdrawal and assayed. Excreta from $48 \mathrm{~h}$ withdrawal animals were collected as two $24 \mathrm{~h}$ samples. The highest levels of radioactivity within gastrointestinal tissues were: stomach at $5.86 \mu \mathrm{g} / \mathrm{g}, 2.8 \%$ of treatment radioactivity, 30 minutes post-dose; small intestine at $2.57 \mu \mathrm{g} / \mathrm{g}$, $6.6 \%$ of treatment radioactivity, $3 \mathrm{~h}$ post-dose; and large intestine at $1.03 \mu \mathrm{g} / \mathrm{g}, 1.0 \%$ of treatment radioactivity, $6 \mathrm{~h}$ post-dose. Radioactivity in whole blood peaked at $0.05 \mu \mathrm{g} / \mathrm{ml}$, $0.12 \%$ of treatment radioactivity, $3 \mathrm{~h}$ after dosing. The whole blood elimination half-life was $4.8 \mathrm{~h}$. By $48 \mathrm{~h}$, no radioactivity was detectable in blood. Radioactivity was seen in all remaining tissues, with highest concentrations identified in liver at $2.85 \mu \mathrm{g} / \mathrm{g}, 10.0 \%$ of treatment radioactivity, $6 \mathrm{~h}$ post-dose, and thymus at $0.15 \mu \mathrm{g} / \mathrm{g}, 0.003 \%$ of treatment radioactivity, $1 \mathrm{~h}$ post-dose. Forty-eight hours post-dose, radioactivity was only detectable in liver at $0.09 \mu \mathrm{g} / \mathrm{g}, 0.38 \%$ of treatment radioactivity, and heart at $0.001 \mu \mathrm{g} / \mathrm{g}, 0.0003 \%$ of treatment radioactivity. Approximately $86 \%$ of the treatment radioactivity was recovered in faeces collected within $24 \mathrm{~h}$ of dosing. A further approximately $9 \%$ was recovered in the $24-$ $48 \mathrm{~h}$ faeces. Less than $1 \%$ of treatment radioactivity was recovered in the urine.

In a non-GLP study, a single dose of $1 \mathrm{mg} / \mathrm{kg}\left[{ }^{14} \mathrm{C}\right]$ lasalocid sodium in aqueous ethanol was administered to 5 male and 5 female $C D$ rats via oral gavage (Westheimer and Hutchinson, 1978b). Excreta were collected during the 24-h pre-dose period and at 4, 8, 12, 24, 48 and $72 \mathrm{~h}$ post-dose. Within $24 \mathrm{~h}$ post-dose, approximately $81 \%$ and $59 \%$ of radioactivity had been recovered in faeces for males and females, respectively. Approximately $11 \%$ and $28 \%$, respectively, were additionally recovered in $24-72 \mathrm{~h}$ faeces. For both sexes, the sampling period with the highest faecal excretion was 12-24 h. Less than $1 \%$ of the radioactivity administered was recovered in urine for each sex.

In another non-GLP experiment, a single dose of $1 \mathrm{mg} / \mathrm{kg}\left[{ }^{14} \mathrm{C}\right]$ lasalocid sodium was administered to 5 male CD rats, in which the stomach and upper part of the common bile duct had been previously cannulated, and a gastric catheter had been inserted for the continuous infusion of sodium taurocholate (Laurencot et al., 1978). Bile was collected predose and 0-2, 2-4, 4-6, 6-8, 8-12, 12-24 and 24-48 h post-dose. Excreta were also collected pre-dose and at $0-4,4-8,8-12,12-24$ and $24-48 \mathrm{~h}$ post-dose. At $48 \mathrm{~h}$, animals were sacrificed and the following tissues were collected: carcass, gastrointestinal tract tissue, gastrointestinal tract contents, and liver. Within $48 \mathrm{~h}$ post-dose, approximately $60.9 \%$ of the treatment radioactivity was absorbed and approximately $96 \%$ of this (approximately $58.7 \%$ of the treatment radioactivity) was subsequently recovered in bile. Approximately $1 \%$ of the treatment radioactivity was absorbed and subsequently recovered in urine within $48 \mathrm{~h}$. Almost all of the absorbed radioactivity was recovered in the bile, whence it would be eliminated back into the intestinal tract and subsequently end up in the faeces. Approximately 1\% was retained in the tissues and eliminated in the urine.

\section{Pharmacokinetics in food-producing animals}

\section{Chickens}

A mass balance study in compliance with GLP was conducted with $\left[{ }^{14} \mathrm{C}\right]$ lasalocid sodium in chickens to determine the pattern of elimination (Hawkins et al., 1987). Following a 7-day pre-treatment phase, two groups of three male and three female 7-week-old Cobb broiler chickens received $\left[{ }^{14} \mathrm{C}\right]$ lasalocid sodium at either 0 or $127 \mathrm{mg} / \mathrm{kg}$ in the diet for 7 days. Excreta were analysed by liquid scintillation counting following combustion. Within 8 days withdrawal of the test diet, $77.5 \%$ of the treatment radioactivity was recovered in combined excreta. 
In an earlier non-GLP compliant mass balance study, twelve 33-day old female Cornish Cross chickens received unlabelled lasalocid sodium at $75 \mathrm{mg} / \mathrm{kg}$ in the feed (equivalent to $5 \mathrm{mg} /$ chicken/day) for 16 days, after which time the birds were treated with $\left[{ }^{14} \mathrm{C}\right]$ lasalocid sodium via oral capsules at $5 \mathrm{mg} /$ day for 3 days (Laurencot $e t$ al., 1973). Blood samples were taken at administration of the first capsule, at 2 and $24 \mathrm{~h}$ after the first and second administrations, and at 2, 6, 24, 48, 72, 96 and $120 \mathrm{~h}$ after the third administration. Two hours after the third capsule administration, one pair of birds was sacrificed and excreta were collected. Remaining pairs of birds were sacrificed at 24-h intervals. Radioactivity was measured by liquid scintillation following combustion. It was found that systemic absorption and elimination was rapid. Peak blood concentrations of radiolabelled material $(5.62 \mu \mathrm{g} / \mathrm{ml})$ were observed at $2 \mathrm{~h}$ after dosing and a blood elimination half-life of ca. $3 \mathrm{~h}$ was calculated. Forty-eight hours after dosing, concentrations of radiolabelled material in blood had decreased to $0.04 \mu \mathrm{g} / \mathrm{ml}$. Within $24 \mathrm{~h}$ of dosing, approximately $94.3 \%$ of the treatment radioactivity had been recovered in the combined excreta. Overall total radioactivity recovery was $98.1 \%$.

In a GLP-compliant study, five groups of 3 male and 3 female 25-day old broiler chickens received $\left[{ }^{14} \mathrm{C}\right]$ lasalocid sodium, via twice-daily capsule administration, at doses equivalent to dietary supplementation at $125 \mathrm{mg} / \mathrm{kg}$ of feed for 7 days (MacLellan et al., 2003). The $\left[{ }^{14} \mathrm{C}\right]$ lasalocid sodium contained lasalocid A, the major homologue, as well as the homologues B to E. Excreta and cage wash samples were collected daily from one group throughout the treatment period and for the 7-day withdrawal period. Plasma samples also were collected from this group at various intervals as 15 minutes, 30 minutes, 1, 2, 4, 8, 24, 72, 120, 168, 216, 264, 312 and $336 \mathrm{~h}$ post-first dose. After 7 days withdrawal, birds were sacrificed and liver, kidney, skin-with-fat, and breast/thigh muscle were harvested. Tissues were assayed for total radioactive residues (TRR) and were also subjected to marker residue (lasalocid A) analysis. The nature of the radioactivity within excreta was also investigated using HPLC. Three groups of birds underwent interim sacrifices after 1, 3 and 5 days withdrawal, and their edible tissues subjected to TRR analysis. The final group of birds was sacrificed at 0 days withdrawal, edible tissues subjected to TRR analysis and the source of the radioactivity present investigated by HPLC.

Following the first dose, the concentration of radioactivity in plasma increased, reaching a mean of $1.30 \mu \mathrm{g}$ equiv $/ \mathrm{ml}$ at $2 \mathrm{~h}$ post-dose, before declining to $0.35 \mu \mathrm{g}$ equiv $/ \mathrm{ml}$ at $8 \mathrm{~h}$ postdose, immediately prior to administration of the second dose. Between $24 \mathrm{~h}$ and 7 days after the first dose, the mean concentration of radioactivity in plasma increased steadily from $0.43 \mu \mathrm{g}$ equiv $/ \mathrm{ml}$ to $0.56 \mu \mathrm{g}$ equiv $/ \mathrm{ml}$, declining thereafter to $0.003 \mu \mathrm{g}$ equiv $/ \mathrm{ml}$ at 336 hours, i.e. 14 days after the first dose, or 7 days withdrawal following the final dose. The excretion of total radioactivity was rapid, with $>99 \%$ of the excreted radioactivity being recovered by $168 \mathrm{~h}$ post-first dose, approximately $16 \mathrm{~h}$ after the last administration. At this time, a mean of $89.7 \%$ of the total radioactivity had been recovered from excreta and cage wash. By $336 \mathrm{~h}$ post-first dose, $90.6 \%$ of the administered dose had been recovered in the excreta, cage wash and feather wash.

Excreta had a larger number of unidentified components and homologues. Up to five unidentified components were detected in excreta, as well as up to three homologues. The major component in excreta from birds of both sexes at both the $24 \mathrm{~h}$ and $168 \mathrm{~h}$ sampling times was lasalocid A, constituting $9.6-10.6 \%$ of the administered radioactivity, approximately $75-83 \%$ TRR. Up to 3 components, believed to be homologues of lasalocid, chromatographed after lasalocid A, representing from $0.10-0.53 \%$ of the administered dose, approximately $0.8-4.1 \% \mathrm{TRR}$, as well as up to 5 more polar unidentified components, representing from $0.04-0.56 \%$ of the administered dose, approximately $0.3-4.4 \%$ TRR, were also detected. Lasalocid A was the major residue identified in all tissues; up to seven unidentified components also were detected in tissues, although two of these were likely to 
have been homologues of lasalocid. Metabolic profiles were generally similar for each tissue and also between sexes.

In a non-GLP compliant study, thirty (15 male and 15 female) 3-day old Cornish Cross (White Mountain $\times$ Vantress) chickens received feed containing $125 \mathrm{mg} / \mathrm{kg}$ unlabelled lasalocid sodium for 34 days, after which 12 birds of each sex received feed containing $132 \mathrm{mg} / \mathrm{kg}\left[{ }^{14} \mathrm{C}\right] \mathrm{lasalocid}$ for 21 days and the remaining birds continued on unlabelled medicated feed as a positive control (Laurencot, Crowley and Gonzales, 1977). After 21 days, all birds were maintained on non-medicated feed for a 0 - to 5-day withdrawal period. At 0 days withdrawal, radioactivity concentrations in blood were approximately $4.4 \mu \mathrm{g} / \mathrm{ml}$. After 3 and 5 days withdrawal, blood contained concentrations above $0.1 \mu \mathrm{g} / \mathrm{ml}$ and $0.07 \mu \mathrm{g} / \mathrm{ml}$, respectively.

\section{Turkeys}

The distribution and elimination of $\left[{ }^{14} \mathrm{C}\right]$ lasalocid sodium was studied in compliance with GLP in growing turkeys after dietary administration at a concentration of $127 \mathrm{mg} / \mathrm{kg}$ for 14 days, followed by a drug withdrawal period of up to 5 days (Hawkins et al., 1986). Sixteen 10-week-old turkeys (8 males, 8 females) were individually housed during the treatment and withdrawal periods. The average weight of the female turkeys during treatment was $7.1 \mathrm{~kg}$ and the average daily lasalocid dose was $6.1 \mathrm{mg} / \mathrm{kg}$ bw. The average weight of the male birds was $8.9 \mathrm{~kg}$ and the average daily lasalocid dose was $4.7 \mathrm{mg} / \mathrm{kg}$ bw. Excretion of radioactivity in the first $24 \mathrm{~h}$ following administration of $\left[{ }^{14} \mathrm{C}\right]$ lasalocid sodium was fairly rapid, with means of $57.5 \%$ and $56.7 \%$ eliminated for male and female birds, respectively. After 14 days of administration, $83.5 \%$ of the dose was excreted by a male turkey and $80.2 \%$ by a female turkey sacrificed at $120 \mathrm{~h}$ after the last $\left[{ }^{14} \mathrm{C}\right]$ lasalocid administration. Elimination of radioactivity in excreta was mainly completed within $48 \mathrm{~h}$ after drug withdrawal. The concentration of radioactivity derived from $\left[{ }^{14} \mathrm{C}\right]$ lasalocid and its metabolites found in whole blood reached a plateau between Days 3 to 13 of treatment, at $0.51 \pm 0.09 \mathrm{mg} / \mathrm{L}$ in male birds and $1.04 \pm 0.46 \mathrm{mg} / \mathrm{L}$ in female birds. The higher concentration of radioactivity in the female turkeys may reflect the higher daily $\left[{ }^{14} \mathrm{C}\right]$ lasalocid intake on a bodyweight basis. Mean concentrations of radioactivity declined rapidly during withdrawal, from $0.50 \mathrm{mg} / \mathrm{L}$ at $8 \mathrm{~h}$ down to $0.04 \mathrm{mg} / \mathrm{L}$ at $120 \mathrm{~h}$ in the female turkeys.

\section{Comparative pharmacokinetics and metabolism}

In a non-GLP compliant experiment to compare the metabolic profiles in the faeces and livers resulting from oral administration of $\left[{ }^{14} \mathrm{C}\right]$ lasalocid sodium to target food animal species (chicken, turkey and swine) and to species used to assess compound toxicity (rat, mouse and $\operatorname{dog}$ ), the faeces and livers from these species were extracted in methanol, fractionated in hexane or chloroform, and analysed by thin layer and high performance liquid chromatography along with liquid scintillation counting (Laurencot, Weiss and Elsom, 1987). The samples generated in separate studies were lyophilized prior to being analysed in the study. It was found that the metabolic profiles of all six species showed qualitative similarities. Pig, dog and rat had the greatest similarity in faecal metabolites, while the chicken and turkey were similar to each other (see Table 7.1). For the livers, the chicken and turkey showed the greatest similarity. The major component found in the livers and faeces of all six species was intact lasalocid. Due to the similar metabolism and metabolites formed, this study demonstrates that the animals used in the toxicology studies were exposed to the same metabolites as humans who consume lasalocid and metabolites in edible tissues. 
Table 7.1. Radioactivity in liver and faecal fractions collected from various species, as indicated

\begin{tabular}{|c|c|c|c|c|c|c|c|c|c|c|c|c|}
\hline \multirow{3}{*}{ Fraction } & \multicolumn{12}{|c|}{$\%$ of total radioactivity } \\
\hline & \multicolumn{2}{|c|}{ pig } & \multicolumn{2}{|c|}{ turkey } & \multicolumn{2}{|c|}{ chicken } & \multicolumn{2}{|c|}{ dog } & \multicolumn{2}{|c|}{ rat } & \multicolumn{2}{|c|}{ mouse } \\
\hline & liver & faeces & liver & faeces & liver & faeces & liver & faeces & liver & faeces & liver & faeces \\
\hline 1 & 71.7 & 30.6 & 52.5 & 22.4 & 49.7 & 32.2 & 32.2 & 20.7 & 15.4 & 17.9 & 24.2 & 27.8 \\
\hline II & 28.3 & 69.4 & 47.5 & 77.6 & 50.3 & 67.8 & 67.8 & 79.3 & 84.6 & 82.1 & 75.8 & 72.2 \\
\hline III & 9.5 & 38.3 & 5.6 & 28.4 & 26.3 & 17.6 & 21.0 & 42.3 & 35.3 & 68.6 & 28.7 & 30.2 \\
\hline IV & 18.8 & 31.1 & 41.9 & 49.2 & 24.0 & 50.2 & 46.8 & 37.0 & 49.3 & 13.5 & 47.1 & 42.0 \\
\hline V & 2.6 & 3.8 & $<5.9$ & 2.1 & 2.3 & 16.7 & 2.9 & 13.4 & 1.7 & 1.1 & $<2.2$ & 3.9 \\
\hline $\mathrm{VI}$ & 17.5 & 19.1 & 36.3 & 43.5 & 28.0 & 44.7 & 47.6 & 21.1 & 32.9 & 10.2 & 37.8 & 36.3 \\
\hline VII & 2.8 & 1.4 & 5.2 & 0.7 & 4.5 & 1.8 & 24.0 & 0.5 & 9.1 & 0.5 & 8.2 & 2.1 \\
\hline VIII & 4.9 & 6.0 & 14.1 & 22.5 & 10.7 & 29.2 & 11.8 & 15.2 & 16.3 & 5.9 & 27.8 & 17.5 \\
\hline IX & 1.5 & 1.9 & 1.7 & 5.0 & 3.6 & 1.0 & 3.3 & 1.6 & 1.0 & 0.4 & $<1.4$ & 1.3 \\
\hline lasalocid A & 6.2 & 33.2 & 3.8 & 10.0 & 11.4 & 12.0 & 18.1 & 32.2 & 31.9 & 43.7 & 28.1 & 22.1 \\
\hline
\end{tabular}

\section{Tissue residue depletion studies}

\section{Radiolabelled residue depletion studies}

\section{Chicken}

In a GLP-compliant study, three groups of 3 male and 3 female 25-day-old broiler chickens received $\left[{ }^{14} \mathrm{C}\right]$ lasalocid sodium, via twice-daily capsule administration, at doses equivalent to dietary supplementation at $125 \mathrm{mg} / \mathrm{kg}$ for 7 days (MacLellan et al., 2003). The $\left[{ }^{14} \mathrm{C}\right]$ lasalocid sodium contained lasalocid A, the major homologue, as well as homologues B to E. Two groups of birds were slaughtered at each of 1, 3, 5 and 7 days withdrawal following starting after 7 days of continuous treatment, and edible tissues such as liver, kidney, skin-with-fat, and muscle (composite of breast and thigh) were collected and analysed for total radioactive residues (TRR) using liquid scintillation and for the marker residue (lasalocid A) using a validated high performance liquid chromatography method with fluorescence detection (HPLC/FL). The final group of birds was dosed as detailed above, but at a higher test compound specific activity. These birds were sacrificed at $0 \mathrm{~h}$ withdrawal. Samples of edible tissues were collected and processed for TRR and radio-chromatographic analysis. The nature of the radioactivity present in composite samples of edible tissues was investigated using HPLC.

The concentrations of total radioactivity and the mean concentrations of lasalocid A are listed in Table 7.2. No residues in excess of $20 \mu \mathrm{g} / \mathrm{kg}$ were found in liver, kidney or skinwith-fat samples after 7 days withdrawal. No residues greater than $20 \mu \mathrm{g} / \mathrm{kg}$ were found in muscle samples at any time except at 0 day withdrawal.

Lasalocid sodium A was the major residue in all tissue extracts from both sexes. Up to seven unidentified components were detected in tissues, although two of these are likely to be homologues of lasalocid. The metabolite profiles were generally similar for all tissues and between sexes. Table 7.2 shows the calculated marker to total residue ratios in the edible tissues. The major component in liver was lasalocid A, representing 175-294 $\mu \mathrm{g} / \mathrm{kg}$, or 21.4$23.4 \%$ of TRR. Seven other components were detected, representing $10-163 \mu \mathrm{g} / \mathrm{kg}$, or $1.2-$ $16.0 \%$ of TRR. In male livers, one of these was a homologue of lasalocid, and in female livers two were lasalocid homologues. In kidney samples from male birds, six components were identified. The major component was lasalocid A, representing $125 \mu \mathrm{g} / \mathrm{kg}$, or $31.1 \%$ of TRR. The remaining components represented $7-48 \mu \mathrm{g} / \mathrm{kg}$, or $1.8-12.0 \%$ of TRR. One of these was a homologue of lasalocid. In female kidney samples, only two components were detected. The major component was lasalocid A, representing $0.119 \mathrm{mg} / \mathrm{kg}(50.3 \% \mathrm{TRR})$; the other 
unidentified component represented $27 \mu \mathrm{g} / \mathrm{kg}$ (11.5\% TRR). Three components were detected in muscle samples. The major component was lasalocid A, representing 31$51 \mu \mathrm{g} / \mathrm{kg}$ (53.7-55.7\% TRR). The other unidentified components represented $617 \mu \mathrm{g} / \mathrm{kg}(8.8-$ $18.4 \%$ TRR). Six components were detected in samples of skin-with-fat. The major component was lasalocid A, representing $342 \mu \mathrm{g} / \mathrm{kg}(53.1 \%$ TRR) in males and $73 \mu \mathrm{g} / \mathrm{kg}$ (50.2\% TRR) in females. The other components represented $356 \mu \mathrm{g} / \mathrm{kg}(0.8-8.7 \%$ TRR). In both sexes, one of these was a homologue of lasalocid.

Table 7.2. Concentrations $(\mu \mathrm{g} / \mathrm{kg})$ of total radioactive residues (TRR) and lasalocid sodium A residues (Marker Residue - MR) in tissues of chickens dosed with $\left[{ }^{14} \mathrm{C}\right]$ lasalocid sodium at $125 \mathrm{mg} / \mathrm{kg}$ for 7 days

\begin{tabular}{|c|c|c|c|c|c|c|c|c|c|c|c|c|}
\hline \multirow{2}{*}{$\begin{array}{l}\text { With- } \\
\text { drawal } \\
\text { time (h) }\end{array}$} & \multicolumn{3}{|c|}{ Kidney } & \multicolumn{3}{|c|}{ Liver } & \multicolumn{3}{|c|}{ Muscle } & \multicolumn{3}{|c|}{ Skin-with-fate } \\
\hline & TRR & MR & $\begin{array}{c}\text { MR:TR } \\
\text { ratio (\%) }\end{array}$ & TRR & MR & $\begin{array}{l}\text { MR:TR } \\
\text { ratio (\%) }\end{array}$ & TRR & MR & $\begin{array}{c}\text { MR:TR } \\
\text { ratio (\%) }\end{array}$ & TRR & MR & $\begin{array}{c}\text { MR:TR } \\
\text { ratio (\%) }\end{array}$ \\
\hline $0^{(1)}$ & 395 & 122 & 40.6 & 1223 & 234 & 22.4 & 80 & 41 & 55.2 & 432 & 208 & 51.8 \\
\hline 24 & 172 & $<24.5$ & 14.2 & 838 & 73.9 & 8.6 & 20 & $<$ LOD & NA & 112 & $<32.7$ & 28.3 \\
\hline 72 & 97 & $<21.6$ & 27.0 & 558 & 49.7 & 9.5 & 15 & $<\mathrm{LOD}$ & NA & 70 & $<22.9$ & 33.9 \\
\hline 120 & 68 & $<29.4$ & 85.8 & 325 & $<37.4$ & 13.2 & 12 & $<\mathrm{LOD}$ & NA & 55 & $<23.0$ & 38.8 \\
\hline 168 & 20 & $<\mathrm{LOD}$ & - & 135 & $<L O D$ & - & 2 & $<\mathrm{LOD}$ & - & 20 & $<\mathrm{LOD}$ & - \\
\hline
\end{tabular}

NOTES: (1) 0-hour in this context is defined as 16 hours after administration of the final capsule dose. As twice-daily capsule administration was used to simulate continuous administration in the feed, this time interval $(16 \mathrm{~h}$ after administration of $1 / 2$ of the total daily dose) was judged to be equivalent to sacrifice at a 0 -day withdrawal (following continuous feeding).

(2) $\mathrm{LOQ}=5 \mu \mathrm{g} / \mathrm{kg}$. NA = not applicable. MR:TR is MR:TRR ratio.

Using a LC-MS method, lasalocid A was confirmed to be the marker residue in the liver, kidney and skin-with-fat of male and female birds. Additionally, it was shown that none of the homologues of lasalocid eluted with lasalocid A.

In a study conducted in compliance with GLP, two groups of 3 male and 3 female 7 -weekold Cobb broiler chickens received $\left[{ }^{14} \mathrm{C}\right]$ lasalocid sodium at either 0 or $127 \mathrm{mg} / \mathrm{kg}$ in the diet for 7 days, before being maintained for an $8 \mathrm{~h}$ withdrawal period, after which birds were slaughtered and their livers removed (Hawkins et al., 1987). Radioactivity in liver samples was analysed by liquid scintillation counting following combustion and HPLC. It was found that at $8 \mathrm{~h}$ withdrawal, concentrations of radioactivity in the individual liver samples ranged from 950-2600 $\mu \mathrm{g}$ equivalents $\left[{ }^{14} \mathrm{C}\right]$ lasalocid sodium $/ \mathrm{kg}$ fresh tissue with the pooled sample assaying at $2010 \mu \mathrm{g} / \mathrm{kg}$. The concentration of lasalocid sodium equivalents in the pooled liver sample was $94 \mu \mathrm{g} / \mathrm{kg}$ fresh tissue. Using the pooled values, the calculated marker to total ratio was $4.7 \%$ at $8 \mathrm{~h}$ withdrawal, consistent with the ratio determined at $24 \mathrm{~h}$ for liver in the study discussed above (MacLellan et al., 2003).

In a non-GLP compliant study, 30 (15 male + 15 female) 3-day-old Cornish Cross (White Mountain $\times$ Vantress) chickens received feed containing $125 \mathrm{mg} / \mathrm{kg}$ unlabelled lasalocid for 34 days, after which 12 birds of each sex received feed containing $132 \mathrm{mg} / \mathrm{kg}\left[{ }^{14} \mathrm{C}\right]$ lasalocid for 21 days and the remaining birds continued on unlabelled medicated feed (Laurencot, Crowley and Gonzales, 1977). After 21 days, all birds were returned to non-medicated feed for a 0- to 5-day withdrawal period. Two birds were slaughtered on 0 day withdrawal, 3 birds on Days 1 and 2, 4 birds on Day 3, and 5 birds on Day 4 and Day 5 withdrawal. Tissues were harvested from each bird. At 0 withdrawal, the highest tissue concentrations were found in the liver at $11930 \mu \mathrm{g} / \mathrm{kg}$ and kidney at $2500 \mu \mathrm{g} / \mathrm{kg}$. Radioactivity concentrations rapidly decreased in tissues. After 3 days withdrawal, liver, kidney and skin-with-fat contained concentrations above $100 \mu \mathrm{g} / \mathrm{kg}$. After 5 days withdrawal, concentrations in liver and kidney were 1150 and $130 \mu \mathrm{g} / \mathrm{kg}$, respectively (see Table 7.3). 
Table 7.3. Concentrations of residues of $\left[{ }^{14} \mathrm{C}\right]$ lasalocid equivalents $(\mu \mathrm{g} / \mathrm{kg})$ in tissues from chickens fed $125 \mathrm{mg} / \mathrm{kg}\left[{ }^{14} \mathrm{C}\right]$ lasalocid sodium for 21 days, followed by a drug withdrawal period

\begin{tabular}{|c|c|c|c|c|c|c|}
\hline \multirow{2}{*}{$\begin{array}{c}\text { Withdrawal } \\
\text { day }\end{array}$} & \multicolumn{6}{|c|}{ Concentration of $\left[{ }^{14} \mathrm{C}\right]$ lasalocid equivalents $(\mu \mathrm{g} / \mathrm{kg})$} \\
\hline & fat & kidney & liver & breast muscle & leg + wing muscle & skin-with-fat \\
\hline 0 & 860 & 2480 & 11930 & 610 & 720 & 1590 \\
\hline 1 & 140 & 360 & 2630 & 60 & 80 & 220 \\
\hline 2 & 60 & 230 & 1720 & 30 & 40 & 130 \\
\hline 3 & 60 & 170 & 1590 & 30 & 30 & 110 \\
\hline 4 & 50 & 190 & 1370 & 30 & 30 & 90 \\
\hline 5 & 40 & 130 & 1150 & 20 & 20 & 70 \\
\hline
\end{tabular}

In another non-GLP compliant study, twelve 33-day-old female Cornish Cross chickens received unlabelled lasalocid sodium at $75 \mathrm{mg} / \mathrm{kg}$ in the feed (equivalent to $5 \mathrm{mg} /$ day) for 16 days, after which birds were administered $\left[{ }^{14} \mathrm{C}\right]$ lasalocid sodium via oral capsules at $5 \mathrm{mg} /$ day for 3 days (Laurencot et al., 1973). Two hours after the third capsule administration, one pair of birds was slaughtered and both edible and non-edible tissues were harvested. Remaining pairs of birds were sacrificed at $24 \mathrm{~h}$ intervals. The nature of the radioactivity in the liver samples also was investigated. Radioactivity was detected by liquid scintillation counting in each edible tissue, with highest concentrations found at $2 \mathrm{~h}$ in all tissues. At $2 \mathrm{~h}$ withdrawal, concentrations of radioactivity in liver were $10.28 \mu \mathrm{g} / \mathrm{g}$. At $48 \mathrm{~h}$ post-dose, concentrations of radioactivity were below $0.1 \mu \mathrm{g} / \mathrm{g}$ in all edible tissues, except liver at $0.40 \mu \mathrm{g} / \mathrm{g}$. By $120 \mathrm{~h}$ post-dose, concentrations in liver had decreased to $0.19 \mu \mathrm{g} / \mathrm{g}$, of which $0.15 \mu \mathrm{g} / \mathrm{g}$ was found in the ethanol-insoluble liver fraction. The results suggest incorporation of radioactivity into natural liver constituents.

\section{Turkeys}

A GLP-compliant residue depletion study was conducted in growing turkeys after dietary administration at $127 \mathrm{mg} / \mathrm{kg}$ of $\left[{ }^{14} \mathrm{C}\right]$ lasalocid sodium in feed for 14 days, followed by a drug withdrawal period of up to 5 days (Hawkins et al., 1986). Sixteen 10-week-old turkeys (8 males, 8 females) were individually housed during the treatment and withdrawal periods. The average weight of the female turkeys during treatment was $7.1 \mathrm{~kg}$ and the average lasalocid dose was $6.1 \mathrm{mg} / \mathrm{kg}$ bw/day. The average weight of the male birds was $8.9 \mathrm{~kg}$ and the average lasalocid dose was $4.7 \mathrm{mg} / \mathrm{kg}$ bw/day. The concentration of intact lasalocid, as measured by HPLC, and total radioactivity were determined in the edible tissues at slaughter during the 5-day withdrawal period (six birds at $8 \mathrm{~h}$ and two birds each at 24, 48, 72,96 and $120 \mathrm{~h}$ withdrawal). The bile and liver contained the most radioactivity at all timepoints (see Table 7.4). At $8 \mathrm{~h}$, the concentrations of radioactivity were $2590-4180 \mu \mathrm{g} / \mathrm{kg}$ in liver, $360-510 \mu \mathrm{g} / \mathrm{kg}$ in kidney, $20-50 \mu \mathrm{g} / \mathrm{kg}$ in muscle and $150-460 \mu \mathrm{g} / \mathrm{kg}$ in skin-with-fat. After $120 \mathrm{~h}$ withdrawal, concentrations were $850-890 \mu \mathrm{g} / \mathrm{kg}$ in liver, $70-90 \mu \mathrm{g} / \mathrm{kg}$ in kidney, $<20 \mu \mathrm{g} / \mathrm{kg}$ in muscle, and 70-110 $\mu \mathrm{g} / \mathrm{kg}$ in skin-with-fat.

Concentrations of intact lasalocid in muscle, abdominal fat and liver were $<25 \mu \mathrm{g} / \mathrm{kg}$ (LOD) at all sacrifice times. In kidneys, only one bird sacrificed at $8 \mathrm{~h}$ had a detectable level $(27 \mu \mathrm{g} / \mathrm{kg})$. In skin-with-fat, two birds had detectable lasalocid levels. One turkey sacrificed at $8 \mathrm{~h}$ withdrawal had a concentration of $170 \mu \mathrm{g} / \mathrm{kg}$ and another turkey sacrificed at $96 \mathrm{~h}$ had a concentration of $110 \mu \mathrm{g} / \mathrm{kg}$. 
Table 7.4. Concentrations $(\mu \mathrm{g} / \mathrm{kg})$ of total radioactivity in tissues of turkeys dosed with $\left[{ }^{14} \mathrm{C}\right] l$ lasalocid sodium at $127 \mathrm{mg} / \mathrm{kg}$ for 14 days

\begin{tabular}{lcccccc}
\hline & \multicolumn{7}{c}{ Withdrawal time (hours) } \\
& $\mathbf{8}$ & $\mathbf{2 4}$ & $\mathbf{4 8}$ & $\mathbf{7 2}$ & $\mathbf{9 6}$ & $\mathbf{1 2 0}$ \\
\hline Number of birds & 6 & 2 & 2 & 2 & 2 & 2 \\
Abdominal fat $(\mu \mathrm{g} / \mathrm{kg})$ & 160 & 80 & 100 & 120 & 130 & 120 \\
Kidneys $(\mu \mathrm{g} / \mathrm{kg})$ & 430 & 200 & 170 & 120 & 120 & 80 \\
Liver $(\mu \mathrm{g} / \mathrm{kg})$ & 3380 & 1430 & 1490 & 1040 & 1100 & 870 \\
Muscle $(\mu \mathrm{g} / \mathrm{kg})$ & 30 & $<\mathrm{LOD}$ & $<\mathrm{LOD}$ & $<\mathrm{LOD}$ & $<\mathrm{LOD}$ & $<$ LOD \\
Skin-with-fat $(\mu \mathrm{g} / \mathrm{kg})$ & 300 & 160 & 110 & 100 & 140 & 90 \\
\hline NOTES: $\mathrm{LOD}=25 \mu \mathrm{gg} / \mathrm{kg}$ & & & & & &
\end{tabular}

\section{Residue depletion studies with unlabelled drug}

\section{Chickens}

A study in compliance with GLP was conducted to determine the residues of lasalocid A in tissues of broiler chickens administered lasalocid sodium at a dosage of $130 \mathrm{mg} / \mathrm{kg}$ in feed for 6 weeks (Croubels, 2010a). Forty-eight healthy Ross broiler chickens (24 male, 24 female) were allotted to the study. Birds were slaughtered after 0, 1, 2 and 3 days drug withdrawal. Each withdrawal group contained 12 chickens (6 male, 6 female) and samples of liver, kidney, muscle (breast) and skin-with-fat were collected at sacrifice. Lasalocid A concentrations in tissues were determined using a validated LC-MS/MS method with electrospray ionization. The method had a limit of quantification (LOQ) of $5.0 \mu \mathrm{g} / \mathrm{kg}$ in all tissues. The concentrations of lasalocid A in edible tissues are summarized in Table 7.5.

Table 7.5. Mean concentrations $(\mu \mathrm{g} / \mathrm{kg})$ of lasalocid A residues in edible tissues of chickens given feed containing lasalocid sodium at $130 \mathrm{mg} / \mathrm{kg}$ for 42 days

\begin{tabular}{ccccc}
\hline Withdrawal period & \multicolumn{3}{c}{ Mean concentration of lasalocid A $(\boldsymbol{\mu g} / \mathbf{k g})$} \\
& muscle & kidney & liver & skin-with-fat \\
\hline 0 days & $447 \pm 144$ & $1050 \pm 339$ & $1840 \pm 385$ & $1040 \pm 282$ \\
1 day & $65 \pm 103$ & $128 \pm 194$ & $244 \pm 329$ & $106 \pm 165$ \\
2 days & $23 \pm 23$ & $61 \pm 70$ & $138 \pm 131$ & $37 \pm 54$ \\
3 days & $8.4 \pm 2.7$ & $26 \pm 11$ & $72 \pm 56$ & $10 \pm 3.8$ \\
\hline
\end{tabular}

An earlier study was conducted in compliance with GLP to provide residue depletion data of lasalocid sodium in muscle, liver, kidney and skin-with-fat from chickens fed a test diet containing $15 \%$ lasalocid sodium at ca. $125 \mathrm{mg} / \mathrm{kg}$ of feed for 42 consecutive days, followed by a drug withdrawal period (McLellan and King, 2006). Thirty broiler chickens (15 male and 15 female) were allotted to five groups. They were fed a starter diet containing ca. $138 \mathrm{mg} / \mathrm{kg}$ lasalocid sodium for 21 days until the first sacrifice. Groups of 6 birds were slaughtered at each of 0 (on-feed), 24, 72, 120 and $168 \mathrm{~h}$ following withdrawal from the test diet. A non-medicated finisher diet was fed during the withdrawal period. The concentrations of lasalocid A were determined using a validated HPLC procedure with fluorimetric detection. Recoveries using this method were $81.0 \%, 87.0 \%$ and $88.4 \%$ of actual concentration in liver, kidney and muscle, respectively. Recovery for skin-with-fat was $68.5 \%$, slightly below the $70 \%$ criteria, but was deemed acceptable due to the tight coefficient of variation $(9.4 \%)$. Data for skin-with-fat were reported without correction for recovery values. The limit of quantification (LOQ) for the method in all tissues was $20 \mu \mathrm{g} / \mathrm{kg}$. It was shown that concentrations of lasalocid A in liver were less than $100 \mu \mathrm{g} / \mathrm{kg}$ in all individual 
birds at $24 \mathrm{~h}$ withdrawal. Residues of lasalocid A in kidney, muscle and skin-with-fat were less than 50, 20 and $100 \mu \mathrm{g} / \mathrm{kg}$, respectively, in all individual birds by $24 \mathrm{~h}$ withdrawal (see Table 7.6).

Table 7.6. Mean concentration $(\mu \mathrm{g} / \mathrm{kg})$ of lasalocid $A$ in tissues of chickens given feed containing lasalocid sodium at ca. $130 \mathrm{mg} / \mathrm{kg}$ for 42 days

\begin{tabular}{|c|c|c|c|c|}
\hline \multirow{2}{*}{$\begin{array}{l}\text { Withdrawal time } \\
\text { (hours) }\end{array}$} & \multicolumn{4}{|c|}{ Mean concentration of lasalocid A ( $\mu \mathrm{g} / \mathrm{kg})$} \\
\hline & Liver & Kidney & Muscle & Skin-with-fat \\
\hline 0 & 1301 & 734 & 201 & 446 \\
\hline 24 & 57 & $<25$ & $<\mathrm{LOQ}$ & $<22$ \\
\hline 72 & 76 & $<28$ & $<\mathrm{LOQ}$ & $<21$ \\
\hline 120 & $<25$ & $<\mathrm{LOQ}$ & $<\mathrm{LOQ}$ & $<\mathrm{LOQ}$ \\
\hline 168 & $<31$ & $<\mathrm{LOQ}$ & $<\mathrm{LOQ}$ & $<\mathrm{LOQ}$ \\
\hline
\end{tabular}

NOTES: $L O Q=20 \mu \mathrm{g} / \mathrm{kg}$ (all tissues)

An early non-GLP compliant residue trial was conducted to quantify lasalocid elimination from the skin-with-fat and internal fat of chickens fed lasalocid sodium (MacDonald, Kaykaty and Popick, 1977). Chickens were fed from Day 18 to 59 with feed containing $125 \mathrm{mg} / \mathrm{kg}$ of lasalocid sodium, and then subjected to a 5-day withdrawal interval. Ten birds each were slaughtered after $0,1,2,3,4$ or 5 days withdrawal, at which time skin-with-subcutaneous fat and internal fat were excised, collected, and frozen immediately, pending analysis. Tissues were assayed for lasalocid using a bio-autographic method that could detect residues present at $10 \mu \mathrm{g} / \mathrm{kg}$. It was found that mean lasalocid concentrations at 0 withdrawal in internal fat and skin-with-fat were 120 and $150 \mu \mathrm{g} / \mathrm{kg}$, respectively. At 1 day withdrawal, concentrations decreased to 90 and $80 \mu \mathrm{g} / \mathrm{kg}$, respectively, and at 2 days withdrawal, to 0 and $9 \mu \mathrm{g} / \mathrm{kg}$, respectively. Thereafter, no lasalocid was detectable in either fat type.

In a non-GLP compliant experiment, one pen of 64 broilers were fed lasalocid sodium at a concentration of $125 \mathrm{mg} / \mathrm{kg}$ for 42 days, followed by a drug withdrawal period (Mathis, 2011). Three male and three female birds were slaughtered after 3, 24, 48, 72, 120, 168 and 240 hours withdrawal. Skin with adhering fat and breast muscle samples were collected from each bird and submitted for analysis of lasalocid A residues using validated LC-MS/MS methods (LOQ $=1 \mu \mathrm{g} / \mathrm{kg}$ ). Lasalocid A residues depleted rapidly with an alpha depletion phase between 3 and 24 hours withdrawal in both skin-with-fat and muscle. Subsequently, residue depletion in the beta depletion phase was much slower and measurable lasalocid A concentrations were still detectable at 240 hours withdrawal in both tissues. Lasalocid A concentrations in all skin-with-fat samples were below $300 \mu \mathrm{g} / \mathrm{kg}$ by 24 hours after drug withdrawal. Residues of lasalocid A were below $60 \mu \mathrm{g} / \mathrm{kg}$ in all muscle samples by 24 hours withdrawal.

\section{Turkeys}

A study was performed in accordance with GLP to provide residue depletion data for lasalocid A in muscle, kidney, liver and skin-with-fat of growing turkeys provided feed containing $130 \mathrm{mg} / \mathrm{kg}$ lasalocid sodium for 112 days, followed by a withdrawal period (Dibb-Fuller, 2008). Groups of six birds (3 male and 3 female) were slaughtered at 0, 72, 120, 168 and $240 \mathrm{~h}$ following drug withdrawal. Tissues were analysed for lasalocid A using a validated LC-MS/MS method with LOQ of ca. $50 \mu \mathrm{g} / \mathrm{kg}$ for liver and skin-with-fat, ca. $25 \mu \mathrm{g} / \mathrm{kg}$ for kidney and ca. $10 \mu \mathrm{g} / \mathrm{kg}$ for muscle. Lasalocid A residues in liver, kidney, muscle and skin-with-fat were below the LOQ in each tissue after a 3-day withdrawal period. 


\section{Quail}

A residue depletion study in quail (non-GLP compliant) was conducted in which lasalocid sodium was administered to farmed quail at a dietary concentration of $90 \mathrm{mg} / \mathrm{kg}$ for 27 days (Angold and Klünter, 2000). After this time, the test diet was replaced with a non-medicated diet and birds were maintained for a 9-day withdrawal period. On days 27, 30, 33 and 36, one male and one female were randomly selected from six sections of the quail farm. One breast muscle with skin was taken from each bird. Samples from the 2 birds from each section were combined so that, for each of the 4 tissue sampling times there were 6 composite muscle samples and 6 composite skin samples. Samples were frozen prior to transport for analysis. Tissue samples were analysed for lasalocid A by HPLC with a LOQ of $20 \mu \mathrm{g} / \mathrm{kg}$. At 0 withdrawal, the concentration of lasalocid A in muscle samples was $39.5 \mu \mathrm{g} / \mathrm{kg}$. By Day 30 (3 days withdrawal), only 1 muscle composite had a residue at $25 \mu \mathrm{g} / \mathrm{kg}$ or greater than the LOQ. The concentration of lasalocid A in skin was $298 \mu \mathrm{g} / \mathrm{kg}$ at Day 27 (i.e. 0 withdrawal), but rapidly decreased to $30.8 \mu \mathrm{g} / \mathrm{kg}$ by Day 33 (6 days of withdrawal).

\section{Methods of analysis for residues in tissues}

Methods based on high performance liquid chromatography with tandem mass spectrometry (LC-MS/MS) and high performance liquid chromatography with fluorimetric detection (HPLC/FL) were developed and validated in compliance with GLP.

\section{High performance liquid chromatography with tandem mass spectrometry}

\section{Determination of lasalocid in chicken tissues}

A LC-MS/MS method was developed and validated in accordance with GLP for the quantitative determination of lasalocid in the muscle, liver, kidney, skin-with-fat and abdominal fat of chicken (Croubels, 2010b; Powell, 2011a, b, 2012). Tissues were extracted with methanol:water $(90: 10, \mathrm{v} / \mathrm{v})$ followed by hexane formic acid partition. The hexane layer was evaporated and re-constituted in acetonitrile. Final extracts were analysed for lasalocid A by LC-MS/MS. Method performance parameters are provided in Table 7.7.

Table 7.7. Summary of the performance of the LC-MS/MS method for the determination of lasalocid A residues in chicken tissues

\begin{tabular}{|c|c|c|c|c|c|}
\hline \multicolumn{2}{|c|}{ Assay parameter } & \multirow{2}{*}{$\frac{\text { Liver }}{>0.9960}$} & \multirow{2}{*}{$\begin{array}{l}\text { Kidney } \\
>0.9967\end{array}$} & \multirow{2}{*}{$\begin{array}{c}\text { Muscle } \\
>0.9948\end{array}$} & \multirow{2}{*}{$\frac{\text { Skin-with-fat }}{>0.9930}$} \\
\hline Linearity $r^{2}$ & & & & & \\
\hline LOD $(\mu \mathrm{g} / \mathrm{kg})$ & & 0.56 & 0.70 & 0.60 & 0.67 \\
\hline LOQ $(\mu \mathrm{g} / \mathrm{kg})$ & & 5.0 & 5.0 & 5.0 & 5.0 \\
\hline \multirow{3}{*}{$\begin{array}{l}\text { Interday accuracy } \\
\pm \text { precision }(\%)\end{array}$} & concentration 1 & $97.2 \pm 9.1$ & $104.8 \pm 18.2$ & $99.0 \pm 11.3$ & $102.6 \pm 4.7$ \\
\hline & concentration 2 & $97.8 \pm 2.7$ & $99.8 \pm 7.6$ & $95.0 \pm 6.0$ & $107.4 \pm 9.8$ \\
\hline & concentration 3 & $97.7 \pm 3.0$ & $103.1 \pm 7.3$ & $87.0 \pm 20.3$ & $93.2 \pm 7.4$ \\
\hline
\end{tabular}

NOTES: Concentrations 1, 2 and 3 are, respectively, 10, 20 and $40 \mu \mathrm{g} / \mathrm{kg}$ for muscle; 25, 50 and $100 \mu \mathrm{g} / \mathrm{kg}$ for kidney; and 50, 100 and $200 \mu \mathrm{g} / \mathrm{kg}$ for liver and for skin-with-fat.

Selectivity/specificity: The specificity of the method for lasalocid A was demonstrated with respect to lasalocid homologues $(\mathrm{B}, \mathrm{C}, \mathrm{D}$ and $\mathrm{E})$ and possible interference from other endogenous compounds with the same retention time as lasalocid $\mathrm{A}$ and the internal standard, sodium nigericin.

Storage stability: Lasalocid A was stable in methanol at ca. $-15^{\circ} \mathrm{C}$ for at least 225 days. Lasalocid A was stable in acetonitrile and a working solution for at least 115 days, and stable in tissue extracts during analysis, in tissue extracts stored at $+2-+8^{\circ} \mathrm{C}$ for 3 days, and in chicken tissues (liver, kidney, skin-with-fat) during storage at $<-70^{\circ} \mathrm{C}$ for at least 6 months, and 8 months (kidney). 


\section{Determination of lasalocid A in turkey tissues}

A LC-MS/MS method was developed in compliance with GLP to determine the marker residue, lasalocid A, in edible tissues of turkeys (Ferguson, 2008). Tissues were extracted into methanol:water (90:10, v/v) followed by hexane partition. Final extracts were analysed by LC-MS/MS in the multiple reaction monitoring mode. Lasalocid was quantified as lasalocid A, relative to a non-extracted matrix calibration line. Method performance parameters are summarized in Table 7.8.

Table 7.8. Summary of the performance of the LC-MS/MS method for the determination of lasalocid A residues in turkey tissues

\begin{tabular}{|c|c|c|c|c|c|}
\hline \multicolumn{2}{|c|}{ Assay parameter } & Liver & Kidney & Muscle & Skin-with-fat \\
\hline \multicolumn{2}{|l|}{ Linearity $\mathrm{r} 2$} & $>0.9988$ & $>0.9986$ & $>0.9992$ & $>0.9987$ \\
\hline \multicolumn{2}{|l|}{ LOD $(\mu \mathrm{g} / \mathrm{kg})$} & 4.68 & 0.45 & 0.81 & 6.14 \\
\hline \multicolumn{2}{|l|}{ LOQ $(\mu \mathrm{g} / \mathrm{kg})$} & 50 & 25 & 10 & 50 \\
\hline \multirow{3}{*}{$\begin{array}{l}\text { Interday accuracy } \\
\pm \text { precision (\%) }\end{array}$} & concentration 1 & $94.4 \pm 6.8$ & $87.9 \pm 9.4$ & $94.6 \pm 7.5$ & $90.6 \pm 5.9$ \\
\hline & concentration 2 & $88.0 \pm 8.8$ & $86.5 \pm 8.4$ & $87.3 \pm 7.5$ & $93.4 \pm 9.0$ \\
\hline & concentration 3 & $89.9 \pm 9.8$ & $87.0 \pm 11.4$ & $87.1 \pm 7.6$ & $97.2 \pm 8.0$ \\
\hline
\end{tabular}

NOTES: Concentrations 1, 2 and 3 are, respectively, 10, 20 and $40 \mu \mathrm{g} / \mathrm{kg}$ for muscle; 25, 50 and $100 \mu \mathrm{g} / \mathrm{kg}$ for kidney; and 50, 100 and $200 \mu \mathrm{g} / \mathrm{kg}$ for liver and for skin-with-fat.

Selectivity/specificity: Control tissue samples were shown to have no significant interfering substances eluting at or near the retention time of lasalocid A in each tissue, showing that the assay was specific for the test item examined. Small peaks were observed from the injection of ca. $1.5 \mathrm{ng} / \mathrm{ml}$ solutions of antibiotics (enrofloxacin, tetracycline, amoxicillin and lincomycin-spectinomycin) and the anticoccidial maduramicin. Injection of solution standards result in a worst-case level of possible interference, as samples did not undergo the extraction process. The calculated concentrations for all injected standards were ca. $1.5 \%$ of the actual concentration injected (ca. $1.5 \mathrm{ng} / \mathrm{ml}$ ). All responses were less than the lowest lasalocid calibration standard (ca. $0.025 \mathrm{ng} / \mathrm{ml}$ ) and below all tissue LOQs for this study. The liver, kidney, muscle and skin-with-fat tissues used for this study were shown to have no interferences $>30 \%$ LOQ at the retention time of lasalocid.

Storage stability: Liver, kidney, muscle and skin-with-fat samples were stable following storage at room temperature for ca. $4 \mathrm{~h}$, for 3 freeze/thaw cycles and during storage under autosampler conditions, ca. $4^{\circ} \mathrm{C}$ for ca. $72 \mathrm{~h}$. The standard solutions were stable for 60 days at ca. $100 \mu \mathrm{g} / \mathrm{ml}$ and 34 days at ca. 0.5 to $5.0 \mu \mathrm{g} / \mathrm{ml}$. Solvent and matrix calibration lines at ca. 0.025 to $1.5 \mathrm{ng} / \mathrm{ml}$ were stable for ca. $72 \mathrm{~h}$. However, preparation of fresh working standards on each day analyses are conducted is recommended, where possible. All solutions were stored at ca. $4^{\circ} \mathrm{C}$ in the dark when not in use. The results from the extended storage stability indicate that lasalocid is stable for at least 4 months (liver and skin-with-fat) and 2 months (kidney and muscle). All samples were analysed following frozen storage (ca. $-20^{\circ} \mathrm{C}$ ).

\section{High performance liquid chromatography coupled with fluorescence detection}

\section{Determination of lasalocid A in chicken tissues}

An HPLC method using fluorescence detection, written in ISO 78/2 format, was developed in compliance with GLP to determine the marker residue (lasalocid A) in edible tissues of chickens (Sanderson et al., 2003). This method involved extraction into methanol:water (13:2, $\mathrm{v}: \mathrm{v})$ followed by basification and liquid-liquid partition using hexane:toluene $(1: 1, \mathrm{v}: \mathrm{v})$. The resulting extract was then evaporated and re-dissolved in acetonitrile:ammonium acetate buffer $(55: 45, \mathrm{v} / \mathrm{v})$. The final extracts were analysed by HPLC using a mobile phase consisting of acetonitrile (A):ammonium acetate buffer $125 \mathrm{mM}, \mathrm{pH} 4.75$ (B) with gradient 
elution. All reagents used during the analysis were of analytical grade. Samples were stored at ca. $-20^{\circ} \mathrm{C}$ pending analysis. Method performance parameters are summarized in Table 7.9.

Table 7.9. Summary of the performance of the HPLC method for lasalocid in chicken tissues

\begin{tabular}{lccccc}
\hline \multicolumn{1}{c}{ Assay parameter } & Liver & Kidney & Muscle & Skin-with-fat \\
\hline LOD $(\mu \mathrm{g} / \mathrm{kg})$ & & 1.60 & 2.03 & 0.44 & 0.55 \\
$\mathrm{LOQ}(\mu \mathrm{g} / \mathrm{kg})$ & 20 & 20 & 20 & 20 \\
\hline & $20 \mu \mathrm{g} / \mathrm{kg}$ & $82.9 \pm 2.5$ & $88.4 \pm 2.4$ & $72.6 \pm 3.0$ & $78.1 \pm 7.7$ \\
Interday accuracy & $40 \mu \mathrm{g} / \mathrm{kg}$ & $71.4 \pm 21.9$ & $86.0 \pm 8.7$ & $75.0 \pm 5.0$ & $89.4 \pm 2.7$ \\
\pm precision $(\%)$ & $100 \mu \mathrm{g} / \mathrm{kg}$ & $82.5 \pm 11.9$ & $87.7 \pm 5.2$ & $79.8 \pm 5.6$ & $92.4 \pm 6.4$ \\
& $400 \mu \mathrm{g} / \mathrm{kg}$ & $85.7 \pm 8.0$ & $87.3 \pm 5.8$ & $83.1 \pm 6.1$ & $92.8 \pm 2.4$ \\
\hline
\end{tabular}

Specificity: Control tissue samples were shown to have no significant interfering substances eluting at or near the retention time of lasalocid A in each tissue, showing that the assay was specific for the test item examined. Interference of other ionophores with the retention time of marker residue, lasalocid sodium, was not investigated. It is considered unlikely that poultry species will receive concomitant ionophore therapy whilst receiving lasalocid sodium. It is expected that inadvertent co-administration of ionophores, while possible, would result in overt target animal toxicity. The presence of broiler chicken muscle, liver or kidney was found to have no effect on the response for lasalocid A and only a slight positive effect at a low concentration of lasalocid A in skin-with-fat.

Storage stability: Lasalocid A was stable in solvent (acetonitrile:water, 75:25 v:v) stored at ca. $4^{\circ} \mathrm{C}$ for ca. 12 weeks. It was stable in tissue samples during 1,2 and 3 freeze/thaw cycles, in tissue samples stored at ambient temperature for ca. 3 hours and in tissue extracts stored at ca. $8^{\circ} \mathrm{C}$ for ca. 24 hours.

This method also was validated in compliance with GLP for assay of liver and skin-withfat from pheasant at concentrations in the range ca. 5 to $500 \mu \mathrm{g} / \mathrm{kg}$ for all tissues (Macpherson and Davidson, 2004). All matrix samples were quantified against a non-matrix calibration line in the range equivalent to ca. 20 to $500 \mu \mathrm{g} / \mathrm{kg}$ (ca. 130 to $3300 \mathrm{ng}$ on-column). Samples were prepared at ca. 100, 50, 20 and $100 \mu \mathrm{g} / \mathrm{kg}$ for liver, kidney, muscle and skinwith-fat, respectively. The mean recoveries were all between 75.2 and $88.9 \%$ (target $70-110 \%$ ) with coefficients of variation of $2.6 \%$ to $14.4 \%$ (target of $15 \%$ for concentration of $100 \mu \mathrm{g} / \mathrm{kg}$ and $20 \%$ for concentration $>10 \mu \mathrm{g} / \mathrm{kg}$ but $<100 \mu \mathrm{g} / \mathrm{kg}$ ). The mean results from the extended storage stability study indicate that lasalocid $\mathrm{A}$ is stable in all edible tissues for a period of eight months when stored at ca. $-20^{\circ} \mathrm{C}$ (McLellan, King and Coyle, 2007).

\section{Contamination of eggs with lasalocid}

\section{Lasalocid carry-over in eggs}

Lasalocid A residues were determined in eggs from 161 egg producers in Northern Ireland using a liquid chromatography-electrospray ionization mass spectrometry method with LOD and LOQ of 0.3 and $1.0 \mu \mathrm{g} / \mathrm{kg}$, respectively (Kennedy et al., 1996). Carryover of lasalocid from manufacture of medicated broiler and turkey feeds to unmedicated layer feed in local feed mills was identified as the possible source of the residues in eggs. Of the egg samples tested from the 161 egg producers, ca. $66 \%$ of the eggs contained measurable lasalocid residues $(>0.3 \mu \mathrm{g} / \mathrm{kg})$, with $58.4 \%$ above the LOQ. Only $3.7 \%$ of the eggs surveyed had a lasalocid concentration above $40 \mu \mathrm{g} / \mathrm{kg}$, while $96.7 \%$ were negative for lasalocid using $40 \mu \mathrm{g} / \mathrm{kg}$ as a cut-off concentration.

The study also was designed to examine this possibility of contamination of feed via carryover by feeding meal containing various low levels $(0.1-5.0 \mathrm{mg}$ lasalocid $/ \mathrm{kg}$ feed) to 
laying hens for 16 days, followed by a withdrawal period of 10 days. Lasalocid carry-over into subsequent batches of feed was also examined by manufacturing an initial batch of feed containing $125 \mathrm{mg}$ lasalocid $/ \mathrm{kg}$, followed by blank batches of feed. Carry-over using feed mill manufactured pre-mixes was also examined. It was found that eggs contained measurable lasalocid residues starting the first day after feeding with contaminated feed. The concentrations reached a plateau after ca. one week. The lasalocid concentrations in eggs had a very strong correlation with the lasalocid concentration in the feed. Birds fed with feed containing the highest contamination level $(5 \mathrm{mg} / \mathrm{kg})$ produced eggs that contained concentrations of lasalocid greater than $200 \mu \mathrm{g} / \mathrm{kg}$ during the treatment period. By 10 days withdrawal, this concentration had rapidly depleted down to LOQ. Investigations of the carry-over during feed manufacture showed that a low level of lasalocid (ca. $1 \mathrm{mg} / \mathrm{kg}$ feed) persisted for the next nine batches of feed manufactured, starting with the third batch. This level of contamination would produce lasalocid residues of ca. $50 \mu \mathrm{g} / \mathrm{kg}$ in eggs. Carry-over during the manufacture of a lasalocid pre-mix persisted for only the next 5 batches of premix manufactured and was less than $1 \mathrm{mg} / \mathrm{kg}$ in all compounded feeds.

\section{Radiolabelled residue depletion studies}

A GLP-compliant residue depletion study was conducted to investigate the magnitude and nature of residues in eggs following three-daily oral administration of $\left[{ }^{14} \mathrm{C}\right]$ lasalocid sodium in gelatine capsules to 24 laying hens for 12 consecutive days (King and Coyle, 2005). The total quantity of lasalocid sodium administered (radiolabelled plus cold) simulated a daily dosage of $125 \mathrm{mg} / \mathrm{kg}$, the highest authorized feeding level. Eggs were collected from all birds on the day prior to the first dose administration, daily during the dosing period and for 14 days following the final dose administration. In addition, eggs from birds 13 to 24 were collected on Days 17 and 21 following the final dose administration. TRRs were determined in the egg yolk and albumin from birds 1 to 12 and in the whole egg from birds 13 to 24 by combustion and liquid scintillation counting.

Six randomly selected whole egg samples from 13 day post-first morning dose (2 days post-last morning dose), 10 samples from 19 days post-first morning dose (8 days post-last morning dose) and 8 samples from 20 days post-first morning dose ( 9 days last-morning dose) were analysed by HPLC for metabolic profiling. Ten randomly selected whole egg samples from 11 days post-first morning dose (0 days post-last morning dose), 19 days (8 days post-last morning dose), 21 days post-first morning dose (10 days post-last morning dose) and the 8 samples collected from 20 days post-first morning dose ( 9 days post-last morning dose) were analysed for the marker residue, lasalocid A, using a LC-MS/MS method. One whole egg sample from bird 17 collected at 20 days post-first morning dose (9 days post-last morning dose) was subjected to LC-MS/MS analysis to identify the metabolites present at $>10 \%$ of the extracted radioactivity. Test portions from six randomly selected whole egg samples from 13 days post-first morning dose (2 days post-last morning dose) were initially analysed by HPLC within a week of collection. Additional material from these samples was stored at $-20^{\circ} \mathrm{C}$ and re-analysed after acceptance of the final data (105 days following initial analysis) to document the incurred storage stability of lasalocid sodium in whole egg samples. All whole egg samples were analysed for marker residue analysis within one month of collection.

Total radioactivity in albumin: Throughout the dosing period, mean concentrations of TRR ranged from $0.036 \mu \mathrm{g}$ equiv/g (range: $0.002-0.167 \mu \mathrm{g}$ equiv/g) at 1 day post-first morning dose administration to $0.283 \mu \mathrm{g}$ equiv/g (range: $0.142-0.407 \mu \mathrm{g}$ equiv/g) at 11 days post-first morning dose administration. Throughout the 12-day dosing period, the highest mean concentration of TRR in albumin was $0.291 \mu \mathrm{g}$ equiv/g (range: $0.087-0.644 \mu \mathrm{g}$ equiv/g) at 9 days post-first morning dose administration. At 17 days post-first morning dose administration (6 days post-last morning dose administration), the mean concentration of TRR was $0.002 \mu \mathrm{g}$ equiv/g (range: $0.001-0.005 \mu \mathrm{g}$ equiv/g). By 20 days post-first morning 
dose administration (9 days post-last dose administration), the mean concentration of TRR was $0.001 \mu \mathrm{g}$ equiv/g (range: $0.001-0.003 \mu \mathrm{g}$ equiv/g) and continued to decrease slowly to $0.001 \mu \mathrm{g}$ equiv/g (range: $0.001-0.002 \mu \mathrm{g}$ equiv/g) by 25 days post-first morning dose (14 days post-last morning dose administration).

Total radioactivity in egg yolk: Throughout the dosing period, the lowest mean concentration of TRR (0.024 $\mathrm{gg}$ equiv/g; range: $<0.001-3.7 \mu \mathrm{g}$ equiv/g) was observed at 1 day post-first morning dose administration. The highest mean concentration of TRR (32.6 $\mu \mathrm{g}$ equiv/g; range: $24.5-40.8 \mu \mathrm{g}$ equiv/g) throughout the dosing period was observed at 11 days post-first morning dose administration. At 12 days post-last morning dose administration, the mean TRR concentration in egg yolk was $33.5 \mu \mathrm{g}$ equiv/g (range: $21.2-$ $38.9 \mu \mathrm{g}$ equiv/g). The mean concentration was on a plateau starting 7 days post-first dose administration and continuing on the plateau until 14 days post-first dose administration ( 3 days post-last morning dose administration). Mean concentrations then steadily decreased throughout the subsequent drug withdrawal time period. By 9 days post-last morning dose administration (20 days post-first morning dose administration), the mean concentration of TRR had decreased to $1.2 \mu \mathrm{g}$ equiv/g (range: 0.57-2.43 $\mathrm{gg}$ equiv/g). By 25 days post-first morning dose administration (14 days post-last morning dose administration), the mean TRR concentration had decreased to $0.14 \mu \mathrm{g}$ equiv/g (range: $0.06-0.44 \mu \mathrm{g}$ equiv/g).

Total radioactivity in whole eggs: Throughout the dosing period, the lowest mean concentrations of TRR $(0.037 \mu \mathrm{g}$ equiv/g; range: $0.001-0.23 \mu \mathrm{g}$ equiv/g) was observed at 1 day post-first morning dose administration. The highest mean concentration of TRR (12.5 $\mu \mathrm{g}$ equiv/g; range: $9.9-15 \mu \mathrm{g}$ equiv/g) throughout the dosing period was observed at 11 days post-first dose administration. At 12 days post-first morning dose administration (1 day post-last morning dose administration), the mean TRR concentration in whole egg was $11.2 \mu \mathrm{g}$ equiv/g (range: 9.0-14.3 $\mu \mathrm{g}$ equiv/g). The mean concentrations reached a steady-state starting 7 days post-first morning dose administration. The plateau concentrations continued until 14 days post-first morning dose administration (3 days postlast morning dose administration) when mean concentrations steadily decreased throughout subsequent withdrawal times. By 20 days post-first morning dose administration (9 days post-last morning dose administration), mean concentrations of TRR had declined to $0.38 \mu \mathrm{g}$ equiv/g (range: $0.14-0.83 \mu \mathrm{g}$ equiv/g). By 32 days post-first morning dose administration (21 days post-last morning dose administration), mean concentrations of TRR had decreased to $0.008 \mu \mathrm{g}$ equiv/g (range: $0.004-0.022 \mu \mathrm{g}$ equiv/g). Egg yolk accounted for the majority of the radioactive residues, which is not surprising given the lipophilicity of lasalocid (and common to other ionophores).

Marker residue in eggs: Results of the analysis of the egg samples showed a decline in the amount of lasalocid detected as the time from last dose increased. The average concentration of lasalocid detected at 11 days post-first dose ( 0 days post-last morning dose) was $6206 \mu \mathrm{g} / \mathrm{kg}$. This declined to $460 \mu \mathrm{g} / \mathrm{kg}$ at 19 days post-first morning dose (8 days post-last morning dose), $128 \mu \mathrm{g} / \mathrm{kg}$ at 20 days post-first morning dose (9 days post-last morning dose) and $61 \mu \mathrm{g} / \mathrm{kg}$ at 21 days post-first morning dose (10 days post-last morning dose). Lasalocid A was identified as the major residue in each egg matrix (albumin, yolk and whole egg) by LC-MS/MS analysis. While $\left[{ }^{14} \mathrm{C}\right]$ lasalocid A was found to make up the greatest portion of the residue, a number of hydroxylated and oxidized metabolites also were present. Lasalocid A was detected at each egg collection time-point and was therefore selected as the marker residue.

Ratio of marker residue to TRR: The mean ratio of marker residue to TRR in whole egg was $49.8 \pm 6.9 \%$ (range: $40.3-60 \%$ ), $48.3 \pm 5.8 \%$ (range: $40.6-58.1 \%$ ), $35.7 \pm 23.9 \%$ (range: $10.8-90.5 \%$ ) and $26.2 \pm 7.4 \%$ (range: $14.7-35.9 \%$ ) at $0,8,9$ and 10 days post-last dose, respectively. 


\section{Residue depletion studies with unlabelled drug}

In a non-GLP compliant study, laying hens received simulated cross-contaminated feed at a ratio of $2.5 \%, 5 \%$ and $10 \%$ of the highest dose level of lasalocid $(125 \mathrm{mg} / \mathrm{kg}$ feed) and monensin $(125 \mathrm{mg} / \mathrm{kg}$ feed) authorized for broilers (Vandenberge et al., 2012). For the lasalocid experiment, the laying hens were randomly divided into three groups of 18 laying hens, housed in laying pens of 3 birds each. Experimental feed at the 3 cross-contamination levels was administered during the 14-day treatment period, followed by a depletion period of 17 days during which the birds received blank feed. Eggs were collected daily. Ten whole eggs were pooled, with the remainder being separated into whites and yolks. Analysis of the samples was conducted on a regular basis with lasalocid A being analysed using a LCMS/MS method. For all egg matrices, the method LOQ for lasalocid A was $2 \mu \mathrm{g} / \mathrm{kg}$. Concentrations of lasalocid residues in egg for the $2.5 \%$ and $5 \%(1.12$ and $6.25 \mathrm{mg}$ lasalocid $/ \mathrm{kg}$ feed, respectively) groups reached a plateau concentration at Day 7 and at Day 9 for the $10 \%$ group $12.5 \mathrm{mg}$ lasalocid $/ \mathrm{kg}$ feed, although the $5 \%$ and $10 \%$ groups did not reach a distinct plateau. Residue concentrations at the plateau were ca. 300, 600 and $1200 \mu \mathrm{g} / \mathrm{kg}$ for the $2.5 \%, 5 \%$ and $10 \%$ groups, respectively. The residue concentrations in whole egg were below LOQ $(2 \mu \mathrm{g} / \mathrm{kg})$ by depletion Day 13 for the $2.5 \%$ group and at depletion Day 17 for the 5\% and 10\% groups. Residue concentrations in the egg matrices (whole egg, egg white and egg yolk) demonstrated that the highest lasalocid A residues were found in egg yolk, followed by whole egg. Very low concentrations of lasalocid A were found in egg white. This pattern is similar to the results found previously and confirmed that lasalocid is transferred to a high degree to eggs, as all three groups contained lasalocid residues exceeding $150 \mu \mathrm{g} / \mathrm{kg}$ during the treatment and early depletion phases. After depletion for 7 days, whole eggs from all three cross-contamination groups contained residue concentrations of $150 \mu \mathrm{g} / \mathrm{kg}$.

\section{Determination of lasalocid in chicken eggs}

A method for the determination of lasalocid in chicken eggs was validated in compliance with GLP (Cairns and Davidson, 2005). Samples of control whole chicken egg were fortified with lasalocid as appropriate. The samples were then extracted using organic solvents, followed by dilution. The final extracts were analysed by LC-MS/MS. The assay LOQ for lasalocid in whole chicken eggs was determined to be $10 \mu \mathrm{g} / \mathrm{kg}$ and the assay LOD was determined to be $0.09 \mu \mathrm{g} / \mathrm{kg}$. The method is applicable to residues of lasalocid A in eggs, with good linearity in the range of 10 to $750 \mu \mathrm{g} / \mathrm{kg}$. All reagents used during the analysis were of analytical grade from commercial sources. The inter-day accuracy was $78-84 \%$ with precision of $3-5.6 \%$. No interferences were found at the retention time for lasalocid. Matrix effects were examined on several occasions and did not exceed $\pm 15 \%$.

Specificity: In a GLP-compliant study, to demonstrate the specificity of the above method for the analysis of lasalocid A in chicken eggs and to evaluate the stability of lasalocid A in chicken eggs when stored at ca. $-20^{\circ} \mathrm{C}$ for ca. 1 month, samples of control chicken egg were fortified with lasalocid over a concentration range of ca. 0.05 to $2.0 \mathrm{ng} / \mathrm{ml}$ (Ferguson, 2007). The samples were then extracted using organic solvents, followed by centrifugation and then dilution. Final extracts were analysed by the LC-MS/MS method. The specificity of the assay was examined by extraction and analysis of aliquots of whole egg with and without lasalocid. In addition, the method was assessed to determine if other commonly used anticoccidials would interfere. Individual aliquots of control whole egg were fortified with maduramicin, salinomycin, robenidine, semduramicin, monensin, narasin and nicarbazin, and analysed using the method. The effects of storing samples frozen at ca. $-20^{\circ} \mathrm{C}$ were investigated by preparing quality control samples with lasalocid at ca. $300 \mu \mathrm{g} / \mathrm{kg}$. The storage stability was determined after ca. 1 month of frozen storage. Samples were thawed and assayed together with freshly prepared fortified samples. 
No interference from commonly used anticoccidials was observed at the retention time of lasalocid. Lasalocid was stable in chicken whole eggs for a period of ca. one month when stored at ca. $-20^{\circ} \mathrm{C}$. Post-storage analysis of samples fortified with ca. $300 \mu \mathrm{g} / \mathrm{kg}$ was $-12 \%$ of the mean fresh recovery samples analysed on the same day.

Stability: Lasalocid was stable in whole eggs when subjected to three freeze/thaw cycles. Post-freeze/thaw assay of samples fortified at 300 and $600 \mu \mathrm{g} / \mathrm{kg}$ were $19.6 \%$ and $7.6 \%$ less than the baseline concentration for lasalocid, respectively. Lasalocid was not stable in whole eggs at 300 and $600 \mu \mathrm{g} / \mathrm{kg}$ when stored at $4^{\circ} \mathrm{C}$ for $17 \mathrm{~h}$ prior to assay. Post- $72 \mathrm{~h}$ autosampler stability analysis of samples fortified at 300 and $600 \mu \mathrm{g} / \mathrm{kg}$ were $27.9 \%$ and $36.3 \%$ greater than the baseline concentration for lasalocid, respectively. Lasalocid sodium was found to be stable in solvent solutions for at least 24 day.

\section{Appraisal}

Following oral administration to poultry species, lasalocid sodium is rapidly absorbed and detected in the peripheral circulation. Peak concentrations in blood are observed within two hours, with a half-life of three hours. Distribution is widespread and rapid with lasalocid detected in all edible tissues. Metabolism in each tissue is significant, with 5-7 unidentified polar metabolites produced. Excretion of the parent moiety and metabolites is rapid and primarily via the faeces, with ca. $94 \%$ of an administered radioactive dose reported as recovered in combined excreta $24 \mathrm{~h}$ after the final dose.

Residue depletion studies conducted in poultry identify lasalocid A as marker residue in all edible tissues. Ratios of marker to total residues in each edible tissue have been determined in chickens at 0-day withdrawal as 0.22 in liver, 0.41 in kidney, 0.55 in muscle and 0.52 in skin-with-fat. Skin-with-fat and liver are identified as principal target tissues with comparatively minimal amounts of incurred residues being observed in muscle and kidney following repeated oral administration. Residue depletion studies in turkeys confirm lasalocid A as the marker residue in each of the proposed target tissues. On this basis, the same MRLs may be proposed for all poultry species.

LC-MS/MS methods have been developed and validated by several laboratories for the marker residue studies in chickens and turkeys. These state-of-the-art methods have a LOQ in the range of 1 to $5 \mu \mathrm{g} / \mathrm{kg}$ in all tissues and are considered acceptable for routine residue surveillance programs. A validated high performance liquid chromatographic analytical method using fluorescence detection, with a LOQ of $20 \mu \mathrm{g} / \mathrm{kg}$ in all edible tissues, is also available for use during routine residue surveillance programmes in poultry.

An estimated dietary intake (EDI) of $80 \mu \mathrm{g} /$ person per day was calculated, based on median residues from a 1-day withdrawal, and is equivalent to $26.7 \%$ of the upper bound of the ADI (see Table 7.10). 
Table 7.10. The estimated dietary intake of lasalocid sodium residues in chicken tissues

\begin{tabular}{|c|c|c|c|c|c|c|}
\hline \multirow[b]{2}{*}{ Tissue } & \multicolumn{2}{|c|}{ Median residue concentration $(\mu \mathrm{g} / \mathrm{kg})$} & \multirow{2}{*}{$\begin{array}{c}\text { MR:TR } \\
\text { ratio }\end{array}$} & \multirow{2}{*}{$\begin{array}{l}\text { Food } \\
\text { basket } \\
(\mathbf{k g})\end{array}$} & \multicolumn{2}{|c|}{ Estimated daily intake $(\mu \mathrm{g})$} \\
\hline & Withdrawal Day 0 & Withdrawal Day 1 & & & $\begin{array}{c}\text { Withdrawal } \\
\text { Day } 0\end{array}$ & $\begin{array}{l}\text { Withdrawal } \\
\text { Day } 1\end{array}$ \\
\hline Liver & 1705.0 & 123.9 & 0.22 & 0.100 & 775.0 & 56.3 \\
\hline Kidney & 867.3 & 50.0 & 0.41 & 0.050 & 105.8 & 6.1 \\
\hline Muscle & 401.2 & 25.0 & 0.55 & 0.300 & 218.8 & 13.6 \\
\hline \multirow[t]{3}{*}{ Skin-with-fat } & 1017.1 & 41.7 & 0.52 & 0.050 & 97.8 & 4.0 \\
\hline & & & & Total intake $=$ & 1197.4 & 80.0 \\
\hline & & & & $\%$ of $\mathrm{ADI}=$ & $399.1 \%$ & $26.7 \%$ \\
\hline
\end{tabular}

NOTES: MR:TR ratio is the ratio of marker residue to total residues.

The estimated dietary intake of lasalocid residues from chicken tissue is illustrated in Figure 7.1.

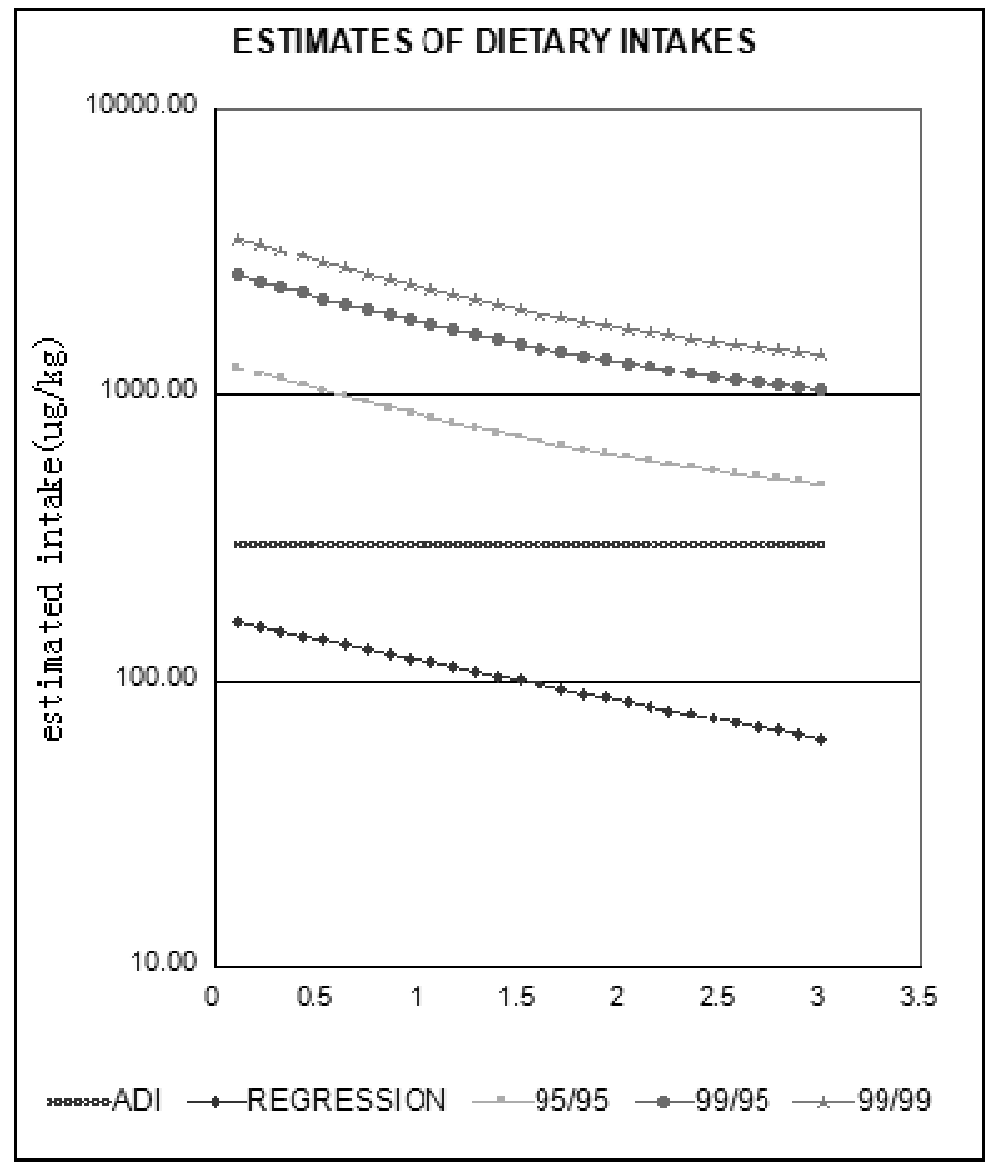

Figure 7.1. The estimated dietary intakes of lasalocid sodium residues from chicken tissues 
The tolerance limits for lasalocid residues in edible tissues of chicken are demonstrated in Figure 7.2.
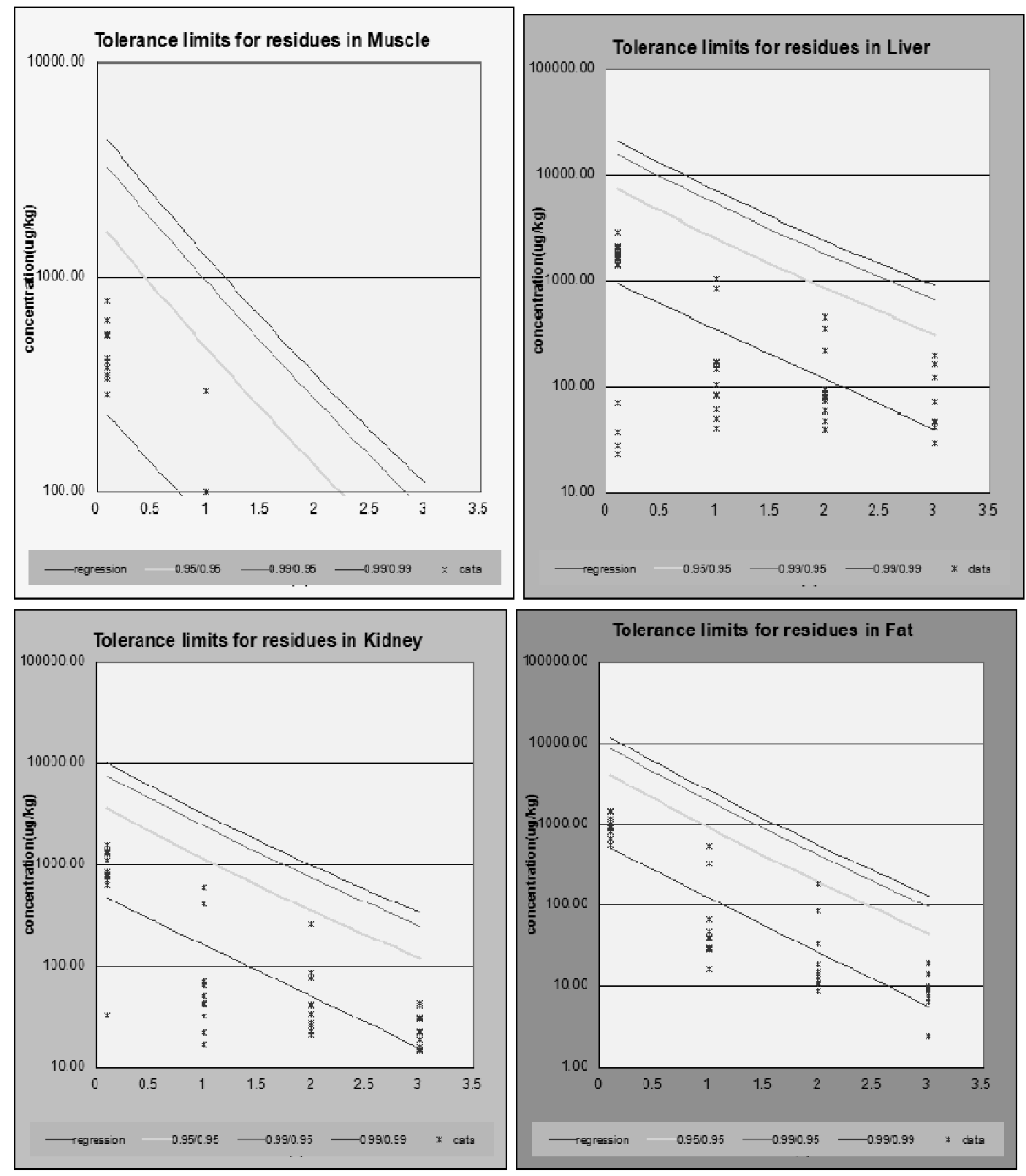

Figure 7.2. Tolerance limit considerations for lasalocid sodium residues in chicken tissues 


\section{Maximum Residues Limits}

In recommending MRLs for lasalocid in poultry food commodities, the Committee considered following factors:

- An ADI of 0-5 $\mu \mathrm{g} / \mathrm{kg}$ of bodyweight was established by the Committee. The upper bound of the ADI is equivalent to $300 \mu \mathrm{g}$ lasalocid sodium for a $60 \mathrm{~kg}$ person.

- Where information on approved veterinary uses was provided, withdrawal times were in the range 0 to 7 days.

- Lasalocid sodium is extensively metabolized in poultry, although the metabolites were not identified.

- Lasalocid A is a suitable marker residue in all edible tissues of poultry.

- Lasalocid A represents, conservatively, $22 \%$ of lasalocid sodium in liver, $41 \%$ in kidney, $55 \%$ in muscle, and $52 \%$ in skin-with-fat in chicken.

- The extension of MRLs to turkey and quail and the extrapolation of MRLs to pheasant are appropriate as depletion data were available, the marker residue was demonstrated and information was available on authorized uses.

- Validated LC-MS/MS and HPLC methods were provided and considered suitable for routine monitoring of lasalocid A as marker residue in poultry tissues.

The Committee recommended MRLs for lasalocid sodium determined as lasalocid A in chicken, turkey, quail and pheasant tissues.

The MRLs recommended for chicken, turkey, quail and pheasant tissues are based on the upper limit of the one-sided 95\% confidence interval over the 95th percentile (UTL 95/95) for the 1 day post-treatment data from the unlabelled residue depletion study in chicken.

The recommended MRLs for chicken, turkey, quail and pheasant are $1200 \mu \mathrm{g} / \mathrm{kg}$ in liver, $600 \mu \mathrm{g} / \mathrm{kg}$ in kidney, $400 \mu \mathrm{g} / \mathrm{kg}$ in muscle and $600 \mu \mathrm{g} / \mathrm{kg}$ in skin-with-fat. An EDI of $80 \mu \mathrm{g} /$ person per day was calculated, based on median residues for a 1-day withdrawal in chicken, and are equivalent to $27 \%$ of the upper bound of the ADI.

No information was available for the use of lasalocid in ducks, including approved uses. According to the sponsor, the compound is not registered for use in laying hens. It is therefore not appropriate to recommend MRLs for eggs.

\section{References}

Angold, M. \& Klünter, A.-M. 2000. The effect of feeding lasalocid sodium (AVATEC 15\% CC) on edible tissues residues in farmed quail. Roche Research Report B-171,689. Unpublished report submitted to FAO by Zoetis.

Cairns, S.D. \& Davidson, J. 2005. Development and validation of an analytical method for the determination of lasalocid in chicken eggs. Inveresk Study No. 208050, Inveresk Report 25029. Inveresk, Tranent, Edinburgh EH33 2NE, UK. Unpublished report submitted to FAO by Zoetis.

Croubels, S. 2010a. Tissue residue study of lasalocid in chickens after administration of Avatec 150G in the feed. UGhent Reference No. LAS-ALP.04, Sponsor Reference RB012-09LAxxxx. Unpublished report submitted to FAO by Zoetis.

Croubels, S. 2010b. Development and validation of an analytical method for determination of lasalocid in chicken tissues. UGhent Reference No. LAS-ALP.03, Sponsor Reference No. RB01209LAxxxx. Unpublished report submitted to FAO by Zoetis. 
Dibb-Fuller, M. 2008. A study to investigate the residue depletion of lasalocid sodium following oral administration in the diet of growing turkeys for 112 consecutive days. Inveresk Project No. 285575, Report No. 29087, Sponsor Reference No. RT005-07LAxxxx Part II. Unpublished report submitted to FAO by Zoetis.

Ferguson, L. 2008. Development and validation of an analytical method for the determination of lasalocid in turkey liver, kidney, muscle and skin-with-fat. Inveresk Project No. 210604, Inveresk Report No. 29085, Sponsor Reference No. RT003-06LAxxxx. Unpublished report submitted to FAO by Zoetis.

Ferguson, L. 2007. Evaluation of the specificity of Charles River Laboratories Method No. 8050 and the stability of lasalocid sodium in frozen chicken eggs. Charles River Laboratories Study No. 211058, Charles River Laboratories Report No. 27214, Charles River Laboratories, Tranent, Edinburgh EH33 2NE. Unpublished report submitted to FAO by Zoetis.

Hawkins, D.R., Elsom, L.F., Jackson, R., Thompson, J.K. \& Girkin. R. 1986. The uptake, distribution and elimination of lasalocid- ${ }^{14} \mathrm{C}$ in the turkey. HRC Report No. HLR 158/861020. Unpublished report submitted to FAO by Zoetis.

Hawkins D., Elsom L.F. \& de Salis C. 1987a. The metabolism of lasalocid $-{ }^{14} \mathrm{C}$ in mice. Study HRC/HLR 159/879, Huntingdon Research Centre Ltd. Unpublished report submitted to FAO by Zoetis.

Hawkins D., Elsom L. F. and de Salis C. 1987b. The metabolism of lasalocid- ${ }^{14} C$ in rat. Study HRC/HLR 164/8710, Huntingdon Research Centre Ltd. Unpublished report submitted to FAO by Zoetis.

Hawkins, D.R., Elsom, L.F., de Salis, C., Roberts, N.L. \& Fairley, C. 1987. The metabolism of lasalocid ${ }^{14} \mathrm{C}$ in chickens. HRC Report No. HLR 161/861765. Unpublished report submitted to FAO by Zoetis.

Kennedy, D.G., Blanchflower, W.J., Hughes, P.J. \& McCaughey, W.J. 1996. The incidence and cause of lasalocid residues in eggs in Northern Ireland. Food Additives and Contaminants, 13(7): 787-794.

King, N. \& Coyle, D. 2005. The magnitude and nature of the residues in eggs from laying hens following the repeated oral administration of $\left[{ }^{14} \mathrm{C}\right]$ lasalocid sodium. Inveresk Study No. 805663, Inveresk Report No. 25086, Inveresk, Tranent, Edinburgh EH33 2NE, UK. Unpublished report submitted to FAO by Zoetis.

Laurencot, H., Reese, J., Santodonato J. and Rose, N. 1973. The uptake and elimination of $\left[{ }^{14} \mathrm{C}\right]$ lasalocid in the chicken. Unpublished report submitted to FAO by Zoetis.

Laurencot, H., Crowley, C. and Gonzales, L. 1977. The uptake and elimination of $\left[{ }^{14} \mathrm{C}\right]$ lasalocid in chickens which were fed $\left[{ }^{14} \mathrm{C}\right]$ lasalocid at $0.0125 \%$ in the feed for 21 days. Unpublished report submitted to $\mathrm{FAO}$ by Zoetis.

Laurencot, H.J., Crowley, C., Gonzales, L., Campbell, J. 1978. Biliary excretion of radioactivity after oral administration of $\left[{ }^{14} \mathrm{C}\right]$ lasalocid to male rats at a dose of $1 \mathrm{mg} / \mathrm{kg}$.. Unpublished Roche Report submitted to FAO by Zoetis.

Laurencot. H., Crowley C., Gonzales L. and Campbell J. 1979a. The whole blood concentration and tissue distribution of radioactivity after a single oral administration of $\left[{ }^{14} \mathrm{C}\right]$ lasalocid to adult male mice at a dose of $1 \mathrm{mg} / \mathrm{kg}$. Unpublished Roche Report submitted to FAO by Zoetis.

Laurencot. H., Crowley C., Gonzales L. and Campbell J. 1979b. The whole blood concentration and tissue distribution of radioactivity after a single oral administration of $\left[{ }^{14} \mathrm{C}\right]$ lasalocid to adult male rats at a dose of $1 \mathrm{mg} / \mathrm{kg}$. Unpublished Roche Report submitted to FAO by Zoetis.

Laurencot. H., Crowley C., Gonzales L. and Campbell J. 1980. The whole blood concentration and tissue distribution of radioactivity after a repeated oral administration of $\left[{ }^{14} \mathrm{C}\right]$ lasalocid to adult male mice at a dose of $1 \mathrm{mg} / \mathrm{kg}$ for one week. Unpublished Roche Report submitted to FAO by Zoetis.

Laurencot, H., Weiss G. and Elsom, L.F. 1987. The metabolism of $\left[{ }^{14} \mathrm{C}\right]$ lasalocid in the turkey, swine, mouse, rat, dog and chicken. Research Report No. N-124400. Unpublished report submitted to FAO by Zoetis.

MacDonald, A., Kaykaty, M. \& Popick, A. 1977. Elimination of lasalocid from the skin/fat and internal fat of chickens fed lasalocid at $125 \mathrm{ppm}$ in the ration. Unpublished report submitted to FAO by Zoetis. 
McLellan, G. \& King, N. 2006. Residue depletion of lasalocid A in broiler chickens following administration of Avatec $150 \mathrm{G} \mathrm{(15 \%} \mathrm{lasalocid} \mathrm{sodium)} \mathrm{in} \mathrm{the} \mathrm{diet} \mathrm{for} 42$ consecutive days. Inveresk Project No. 805197, Report No. 24791. Unpublished report submitted to FAO by Zoetis.

MacLellan, G.J., McLean, C.L., Phillips, M. \& Gedik, L. 2003. Metabolism and residue depletion of $\left[{ }^{14} \mathrm{C}\right]$ lasalocid. Inveresk Project No. 203031, Inveresk Report No. 22659. Unpublished report submitted to FAO by Zoetis.

McLellan, G. J., King, N. and Coyle, D. 2007. Residue Depletion of Avatec 150G (15\% Lasalocid Sodium) in Pheasants. Inveresk Project 205620. Unpublished report submitted to FAO by Zoetis.

Macpherson, D. \& Davidson, J. 2004. Validation of an analytical method for the determination of lasalocid in pheasant tissues by HPLC with fluorimetric detection. Inveresk Project No. 205678, Report No. 23571. Unpublished report submitted to FAO by Zoetis.

Mathis, G.F. 2011. Residue depletion in muscle and skin/fat obtained from broiler chickens treated with Avatec (lasalocid) medicated feed at $113 \mathrm{~g} /$ ton for 42 days followed by treatment with nonmedicated feed for up to 10 days. Study Number: 1511R-60-11-325. Unpublished report submitted to FAO by Zoetis.

Powell, K.D. 2011a. Validation of an LC/MS/MS method for the quantification of lasalocid in chicken skin tissue. Tandem Labs Project ALP10-001, Method ENTALP001, Sponsor Reference No. 1517N60-11-322. Unpublished report submitted to FAO by Zoetis.

Powell, K.D. 2011b. Validation of an LC/MS/MS method for the quantification of lasalocid in chicken muscle tissue. Tandem Labs Project ALP10-001, Method ENTALP002, Pfizer Reference Number: 1517N-60-11-321. Unpublished report submitted to FAO by Zoetis.

Powell, K.D. 2012. LC/MS/MS analysis of lasalocid in chicken muscle and skin/fat. Study Number: 1511R-60-11-325. Unpublished report submitted to FAO by Zoetis.

Sanderson, R.D., Pattison, C., Vance, C.J., Marshall, D.E. and McGuire, G.M. 2003. Establishment and validation of an analytical method for the determination of lasalocid A in broiler chicken tissues. Inveresk Project 302312, Inveresk Report 22690, Inveresk Method No. 0231 version 1. Unpublished report submitted to FAO by Zoetis.

Vandenberge, V., Delezie, E., Huyghebaert, G., Delahaut, P., Pierret, G., De Backer, P., Groubels, S. \& Daeseleire, E. 2012. Transfer of the coccidiostats monensin and lasalocid from feed at crosscontamination levels to whole egg, egg white and egg yolk. Food Additives $\mathcal{E}$ Contaminants: Part A, 29(12): 1881-1892.

Westheimer, J. \& Hutchinson, H. 1978a. Fecal and urinary excretion of radioactivity after oral administration of $\left[{ }^{14} \mathrm{C}\right]$ lasalocid sodium to female and male mice at a dose of $1 \mathrm{mg} / \mathrm{kg}$. Unpublished Roche Report submitted to FAO by Zoetis.

Westheimer, J. \& Hutchinson, H. 1978b. Fecal and urinary excretion of radioactivity after oral administration of $\left[{ }^{14} \mathrm{C}\right]$ lasalocid sodium to female and male rats at a dose of $1 \mathrm{mg} / \mathrm{kg}$. Unpublished Roche Report submitted to FAO by Zoetis. 



\title{
8. Monepantel
}

\author{
First draft prepared by \\ Lynn G. Friedlander, Rockville, MD, USA \\ and \\ Joe Boison, Saskatoon, Saskatchewan, Canada
}

Addendum to the monograph prepared by the 75th Meeting of the Committee and published in FAO Food \& Nutrition Papers/FAO JECFA Monographs

\section{Identity}

IUPAC Name: N-[(1S)-1-Cyano-2-(5-cyano-2-trifluoromethyl-phenoxy)-1-methyl-ethyl]-4trifluoromethylsulfanyl-benzamide

Synonyms: $\quad$ N-[2-(5-cyano-2-trifluormethyl-phenyloxy)-1-(S)-1-cyano-1-methyl-ethyl]-4trifluoromethylthio-benzoic amide, Zolvix

Chemical Abstracts Service Number: 887148-69-8<smiles>C[C@](C#N)(COc1cc(C#N)ccc1C(F)(F)F)NC(=O)c1ccc(SC(F)(F)F)cc1</smiles><smiles>C[C@](C#N)(COc1cc(C#N)ccc1C(F)(F)F)NC(=O)c1ccc(SC(F)(F)F)cc1</smiles>

Molecular formula: $\quad \mathrm{C}_{20} \mathrm{H}_{13} \mathrm{~F}_{6} \mathrm{~N}_{3} \mathrm{O}_{2} \mathrm{~S}$

Molecular weight: $\quad 473.4$

\section{Background}

Monepantel (CAS No. 887148-69-8) is a member of the amino-acetonitrile derivative anthelmintics. Monepantel causes a paralysis of gastrointestinal nematodes by binding to a unique receptor. It is administered as an oral drench to control gastrointestinal nematodes (roundworms) in sheep.

Monepantel was previously reviewed by the Committee at its Seventy-fifth Meeting (FAO, 2011), which established an ADI of 0-20 $\mu \mathrm{g} / \mathrm{kg} \mathrm{bw}$, corresponding to an upper bound of acceptable intake of $1200 \mu \mathrm{g} /$ day for a $60 \mathrm{~kg}$ person. The Committee recommended MRLs, determined as monepantel sulfone, in sheep tissue of $300 \mu \mathrm{g} / \mathrm{kg}$ in muscle, $700 \mu \mathrm{g} / \mathrm{kg}$ in kidney, $3000 \mu \mathrm{g} / \mathrm{kg}$ in liver and $5500 \mu \mathrm{g} / \mathrm{kg}$ in fat. Because sufficient data were available to calculate median residue values, the EDI approach was used. Using the model diet and marker to total residue ratio of 1 for muscle and 0.66 for fat, liver and kidney, and after applying a correction factor of 0.94 to account for the mass difference between monepantel sulfone (the marker residue) and monepantel, the EDI calculated is $201 \mu \mathrm{g} /$ person per day, which represents $17 \%$ of the upper bound of the ADI.

At the Twentieth Session of the Codex Committee on Residue of Veterinary Drugs in Food (CCRVDF), concerns were raised that the recommended MRLs were significantly lower than those already established in some countries and could create trade problems (FAO/WHO, 2012). It was also noted that the recommended MRLs were not consistent with 
the withdrawal times in some countries. The CCRVDF discussed higher MRLs, recognizing that it was within the purview of the Codex Committee, as risk managers, to modify the MRLs recommended by JECFA. Some Delegations did not consider advancing higher MRLs appropriate without an evaluation of their safety by JECFA, in recognition of JECFA's role as risk assessor for Codex. The CCRVDF agreed to request that JECFA evaluate the safety of the proposed higher MRLs in light of the information provided by the Committee. Specifically, JECFA was asked to consider if higher MRLs (Muscle, $700 \mu \mathrm{g} / \mathrm{kg}$; Liver, $5000 \mu \mathrm{g} / \mathrm{kg}$; Kidney, $2000 \mu \mathrm{g} / \mathrm{kg}$; Fat, $7000 \mu \mathrm{g} / \mathrm{kg}$ ) are compatible with the ADI and consistent with the JECFA process for the derivation of MRLs.

\section{Current evaluation}

No new data or studies were provided for the current evaluation. A summary of global approvals, the MRLs assigned by regulatory authorities, and associated withdrawal periods is provided in Table 8.1 (Novartis, 2013).

Table 8.1. Currently approved MRLs and withdrawal periods for Monepantel, all based on Monepantel sulfone as Marker Residue

\begin{tabular}{lcc}
\hline \multicolumn{1}{c}{ Country or region } & MRLs $(\boldsymbol{\mu g} / \mathbf{k g})$ & Withholding period (days) \\
\hline European Union & & 7 \\
Argentina & & 7 \\
Chile & Fat 7000 & 7 \\
Uruguay & Kiver 5000 & 7 \\
Brazil & Muscy 2000 700 & 7 \\
Republic of South Africa & & 10 \\
New Zealand & & 7 \\
Australia & & 14 \\
Switzerland & As above plus "Other edible tissues 7000" & 7 \\
\hline Japan (Import tolerance only) & N/A (Import tolerance only) \\
\hline
\end{tabular}

The MRLs and withdrawal period in New Zealand were confirmed by that country (New Zealand, 2013).

The information provided in response to the re-evaluation request noted that the MRLs proposed by the 75th Meeting of JECFA are lower than those established in the countries where monepantel is approved. Additionally, based on the residue studies provided in the original dossier, the proposed MRLs would be violated if animals were slaughtered at the established withholding periods in all of the countries listed in Table 8.1, except for Australia and the Republic of South Africa.

The MRLs listed in Table 8.1 would lead to a theoretical consumption of $84 \%$ of the ADI (Novartis, 2013). The EDI was described as being "...considerably lower." Neither the EDI nor the ADI referenced in this comment were provided.

\section{Appraisal}

The summary of global approvals clearly indicates the conditions of use for monepantel in several countries or regions of the world. It also includes the applicable MRLs and withdrawal times. Absent from the information is the assigned ADI that underpins these MRL assignments in Table 8.1.

EDI calculations based on the evaluation of the 75th JECFA and the EDI that would be consistent with the shortest identified withdrawal times in Table 8.1 are summarized in Tables 8.2 and 8.3 . 
Table 8.2. EDI based on median residues at Day $13^{(1)}$

\begin{tabular}{lccccc}
\hline \multicolumn{1}{c}{ Tissue } & Median & Consumption & MR:TR & $\begin{array}{l}\text { Monepantel parent: } \\
\text { Monepantel sulfone }\end{array}$ & Total \\
\hline Muscle & 76 & 0.3 & 1 & 0.94 & 21 \\
Liver & 595 & 0.1 & 0.66 & 0.94 & 85 \\
Kidney & 169 & 0.05 & 0.66 & 0.94 & 12 \\
Fat & 1156 & 0.05 & 0.66 & 0.94 & 82 \\
\hline TOTAL & & & & 201 \\
\hline
\end{tabular}

NOTES: (1) Day 13 is the withdrawal day used by the 75th JECFA in its EDI calculation.

Table 8.3. EDI based on median residues at Day $7^{(1)}$

\begin{tabular}{lccccc}
\hline \multicolumn{1}{c}{ Tissue } & Median & Consumption & MR:TR & $\begin{array}{c}\text { Monepantel parent: } \\
\text { Monepantel sulfone }\end{array}$ & Total \\
\hline Muscle & 152 & 0.3 & 1 & 0.94 & 43 \\
Liver & 1295 & 0.1 & 0.66 & 0.94 & 184 \\
Kidney & 406 & 0.05 & 0.66 & 0.94 & 29 \\
Fat & 2620 & 0.05 & 0.66 & 0.94 & 187 \\
\hline TOTAL & & & & & $\mathbf{4 4 3}$ \\
\hline
\end{tabular}

NOTES: Day 7 is the shortest withdrawal period identified for monepantel approvals in Table 8.1.

The upper bound of the ADI assigned by JECFA is $1200 \mu \mathrm{g} /$ day for a $60 \mathrm{~kg}$ person. The EDI, based on median residues at Day 13, is approximately $17 \%$ of the JECFA assigned ADI. The EDI based on median residues at Day 7, the shortest assigned withdrawal time cited in Table 8.1, is approximately $37 \%$ of the JECFA assigned ADI.

\section{Maximum Residue Limits}

In recommending MRLs for monepantel in sheep, the Committee considered the following factors:

- An ADI of monepantel of 0-20 $\mu \mathrm{g} / \mathrm{kg}$ bw was previously established by the Committee, corresponding to an upper bound of the acceptable intake of $1200 \mu \mathrm{g} /$ day for a $60 \mathrm{~kg}$ person.

- Monepantel is extensively metabolized.

- The metabolite monepantel sulfone is the marker residue in tissues.

- Fat contains the highest concentration of monepantel sulfone at all sampling times, followed by liver, then kidney and muscle. Liver and fat can serve as the target tissues.

- The ratios of the concentration of marker residue to total residues (MR:TR) are 1.0 in muscle and 0.66 in fat, liver and kidney.

- A validated analytical method for the determination of monepantel sulfone in edible sheep tissues (liver, kidney, muscle and fat) is available and may be used for monitoring purposes.

- MRLs were calculated on the basis of the upper limit of the one-sided $95 \%$ confidence interval over the 95th percentile of residue concentrations (UTL 95/95).

Consistent with the shortest withdrawal time assigned in Member States with an approved use of monepantel, the Committee recommended MRLs determined as monepantel sulfone, expressed as monepantel, in sheep tissue of $500 \mu \mathrm{g} / \mathrm{kg}$ in muscle, $1700 \mu \mathrm{g} / \mathrm{kg}$ in kidney, $7000 \mu \mathrm{g} / \mathrm{kg}$ in liver and $13000 \mu \mathrm{g} / \mathrm{kg}$ in fat. Using the model diet and marker residue to total residue ratio of 1.00 for muscle and 0.66 for fat, liver and kidney, and 
applying a correction factor of 0.94 to account for the mass difference between monepantel sulfone (the marker residue) and monepantel, the EDI is $443 \mu \mathrm{g} /$ person per day, which represents $37 \%$ of the upper bound of the ADI.

Table 8.4. Calculation of the estimated daily intake (EDI)

\begin{tabular}{|c|c|c|c|c|c|}
\hline Tissue & $\begin{array}{l}\text { Median } \\
\text { residue }\end{array}$ & $\begin{array}{l}\text { Standard Food } \\
\text { Basket (kg) }\end{array}$ & MR:TR ratio & $\begin{array}{l}\text { Monepantel parent: } \\
\text { Monepantel sulfone }\end{array}$ & $\begin{array}{l}\text { Estimated Daily } \\
\text { Intake }(\mu \mathrm{g})\end{array}$ \\
\hline Muscle & 152 & 0.3 & 1 & 0.94 & 43 \\
\hline Liver & 1295 & 0.1 & 0.66 & 0.94 & 184 \\
\hline Kidney & 406 & 0.05 & 0.66 & 0.94 & 29 \\
\hline \multirow[t]{3}{*}{ Fat } & 2620 & 0.05 & 0.66 & 0.94 & 187 \\
\hline & & & & EDI & 443 \\
\hline & & & & As $\%$ of $A D I$ & $37 \%$ \\
\hline
\end{tabular}

NOTES: MR:TR ratio is the ratio of marker residue to total residues (MR:TR).

\section{References}

FAO. 2011. Monepantel. In: Online Edition: "Residues of some veterinary drugs in foods and animals" Residue Monograph 12-2012. Available at http://www.fao.org/food/food-safetyquality/scientific-advice/jecfa/jecfa-vetdrugs/en/ Accessed 2014-05-10.

FAO/WHO. 2012. Report of the Twentieth Session of the Codex Committee on Residues of Veterinary Drugs in Foods. REP12/RVDF. San Juan, Puerto Rico, 7-11 May 2012. Available at:

http://www.codexalimentarius.org/download/report/778/rv20_01e.pdf Accessed 2014-05-10.

New Zealand. 2013. New Zealand Comments to JECFA and Zolvix label (e-mail to JECFA Secretariat).

Novartis. 2013. Monepantel CODEX MRLs: re-evaluation at the Seventy-eighth Meeting of the Joint FAO/WHO Committee on Food Additives (JECFA): Data in support of higher MRLs. See:

http://www.fao.org/food/food-safety-quality/scientific-advice/jecfa/jecfa-vetdrugs/en/ 


\title{
9. Recombinant bovine somatotrophins
}

\author{
First draft prepared by \\ Shiva C. Ghimire, Ottawa, Ontario, Canada \\ Gerry Swan, Onderstepoort, Republic of South Africa \\ Fernando Ramos, Coimbra, Portugal \\ Penelope Rice, Rockville, MD, USA \\ and \\ Leonard Ritter, Guelph, Ontario, Canada
}

Addendum to the monographs prepared by the 40th and 50th Meetings of the Committee and published in FAO Food \& Nutrition Paper 41/5 and FAO Food \& Nutrition Paper 41/11, respectively ${ }^{5}$.

\section{Explanation}

Somatotrophins are proteins secreted by the anterior pituitary gland that stimulate growth, cell regeneration and reproduction in humans and animals. Most anabolic and growthpromoting effects of somatotrophins are mediated through insulin-like growth factor-I (IGFI). Bovine somatotrophins (bSTs) produced by recombinant deoxyribonucleic acid (DNA) techniques (rbSTs) are used in lactating dairy cows to increase milk production. Four bST analogues (somagrebove, sometribove, somavubove and somidobove) were previously evaluated by the Joint FAO/WHO Expert Committee on Food Additives (JECFA) at its 40th Meeting (JECFA, 1993 [TRS 832]) and further evaluated at its 50th Meeting (JECFA, 1999 [TRS 888]). Although the chemical properties of the recombinant products vary slightly from those of pituitary bST (for chemical structures, see FAO, 1993), the Committee considered the recombinant products to be biologically and toxicologically similar, as they all act by binding with high affinity to the bST receptor.

The Committee at its 40th Meeting established an acceptable daily intake (ADI) and maximum residue limits (MRLs) "not specified" for these four rbSTs. The term "not specified" was used because of the lack of bio-activity following oral intake of rbSTs and IGF-I, and the low concentrations and non-toxic nature of the residues of these compounds. The ADI and MRLs "not specified" were re-affirmed by the Committee at its 50th Meeting.

Draft Codex standards for rbSTs have been held at the final step (before adoption) for more than a decade. When considering the adoption of these standards, the Codex Alimentarius Commission at its Thirty-fifth Session (FAO/WHO, 2012) requested a reevaluation of the four analogues of natural bST (somagrebove, sometribove, somavubove and somidobove) by JECFA, noting that the scientific assessment of bST dated back to the 1990s. In particular, the Commission requested that JECFA (i) update the toxicological evaluation, (ii) update the exposure assessment based on any new occurrence data in food, (iii) evaluate potential adverse health effects, and (iv) consider the need to revise or maintain the ADI and MRLs for rbSTs. The Commission further requested that JECFA consider new data and information related to other factors pertaining to human health, including (i) the possible increased use of antimicrobials to treat mastitis in cows, (ii) the possibility of increased levels of IGF-I in the milk of cows treated with rbSTs, (iii) the potential effects of rbSTs on the expression of certain viruses in cattle, and (iv) the possibility that exposure of human neonates and young children to milk from rbST-treated cows increases health risks (e.g. the development of insulin-dependent diabetes mellitus). JECFA was also asked to

${ }^{5}$ The text of this monograph also appears in Toxicological evaluation of certain veterinary drug residues in food. WHO Food Additives Series, No. 69 (2014). 
consider aspects of antimicrobial resistance associated with the use of rbSTs in relation to human health.

rbSTs are registered in 21 countries in the world (Bolivia (Plurinational State of), Brazil, Chile, Colombia, Costa Rica, Ecuador, El Salvador, Guatemala, Honduras, Jamaica, Lebanon, Mexico, Pakistan, Panama, Peru, Republic of Korea, South Africa, Uruguay, Venezuela, the USA and Puerto Rico) for use in dairy cows and in Pakistan for use in buffaloes. Sometribove, marketed as Lactotropin, Posilac, Somatech or Lactotropina, is authorized for use at a dosage of $500 \mathrm{mg}$ subcutaneously every 14 days in all cases. A dose of $375 \mathrm{mg}$ is also authorized for use in Mexico. Treatment commences approximately 50-90 days postpartum until the end of lactation. Somavubove, marketed as Boostin or Hilac, is also registered for use in the Republic of Korea, and is exported to Mexico, Brazil, Colombia, Pakistan and South Africa. A zero withdrawal period exists in all cases. bST is administered to cattle either subcutaneously or intramuscularly.

In response to JECFA's call for data, data were submitted to the Committee by a sponsor and two Member countries. Additionally, the Committee undertook a systematic review to address the following questions:

- What are the hormone levels in the milk and/or meat of cattle, goats or sheep treated with rbSTs compared with untreated animals?

- Are the incidences of clinically relevant mastitis different among cattle, sheep and goats treated with rbSTs compared with untreated animals? Are there differences in antimicrobial residue levels in the milk and meat products from treated compared with untreated animals?

- Are retroviral/lentiviral levels and serotype distributions different among cattle, sheep and goats treated with rbSTs compared with untreated animals?

- Are prion levels in meat and milk and prion infectivity different between cows treated with rbSTs compared with untreated animals?

- Is consumption of milk or meat from rbST-treated cattle, sheep or goats associated with increased rates of morbidity and mortality in infants or in the general population compared with the equivalent age groups consuming meat or milk from untreated animals?

Details of the search strategy and databases used are available on the WHO website as supplementary information to the meeting report, at http:/ / www.who.int/foodsafety/chem/jecfa/publications/reports/en/index.html.

In addition, PubMed and Web of Knowledge databases were searched for toxicity studies of rbSTs in laboratory animals; bio-availability and bio-activity of oral IGF-I; and analytical methods.

\section{Biological data}

\section{Biochemical aspects}

The Committee at its 40th and 50th Meetings concluded that human and bovine somatotrophins are structurally different and have species-specific receptor binding activity. Furthermore, the total concentration of bSTs detected in tissues and milk of rbST-treated cattle is similar to that from untreated cattle, and rbSTs are denatured by high temperatures (e.g. by cooking and pasteurization) and biodegradation processes in the gut.

\section{Laboratory animals}

No new studies on biochemical aspects of rbSTs were submitted with the recent call for data, and none was available in the literature. Since the assessment of rbSTs by the 50th Meeting, a Health Canada expert panel has suggested, based on the detection of anti-rbST antibodies in 
rats, that some rbSTs administered orally could potentially be absorbed (Health Canada, 1999). The study that reported this finding was a 90-day study in rats (Richard, Odaglia and Deslex, 1989). This study also included a satellite investigation on anti-rbST antibodies in sera of rats administered an rbST by gavage. The 40th Meeting had reviewed the toxicity data from this study; however, the results of the satellite study on the anti-rbST antibodies were not discussed in the toxicological monograph from the 40th Meeting and are summarized below.

\section{Rats}

Sometribove was administered daily by gavage at a dose of $0,0.1,0.5,5$ or $50 \mathrm{mg} / \mathrm{kg}$ bodyweight (bw) per day or subcutaneously at $1 \mathrm{mg} / \mathrm{kg}$ bw per day (positive control) to Charles River CD VAF rats (30 rats of each sex per group) for 13 consecutive weeks. Of these 30 rats of each sex per group, 15 rats were considered part of a satellite study to investigate the development of anti-rbST antibodies. Ten rats of each sex per group from the satellite study were euthanized at week 14, and five rats of each sex per group were maintained without dosing for an additional 14 weeks of recovery. Blood samples were collected from all rats pre-treatment and at week 14 (i.e. at the end of the treatment period), at week 7 from 10 rats of each sex per group that were euthanized at week 14 and at week 28 from the remaining 5 rats of each sex per group.

Sera were analysed by radioimmunoprecipitation, and the radioactivity in the pellet was corrected for non-specific binding. The titre in the test sera was expressed as the percentage of the corrected counts per minute in the precipitate over the total counts per minute tested. Greater than $11 \%$ sometribove binding capacity, which was equivalent to the upper 75 th percentile plus 1.5 times the inter-quartile range for negative control sera, was used as a cutoff to classify a sample as antibody positive.

All rats were seronegative at the start of the study. Animals in the negative control and $0.5 \mathrm{mg} / \mathrm{kg}$ bw per day groups remained seronegative for sometribove antibodies throughout the experiment. In contrast, $20 \%$ of the animals were seropositive on both week $7(4 / 20)$ and week $14(6 / 30)$ in the $5 \mathrm{mg} / \mathrm{kg}$ bw per day group. In the $50 \mathrm{mg} / \mathrm{kg}$ bw per day group, $15 \%$ $(3 / 20)$ and $30 \%(9 / 30)$ of the animals were seropositive at weeks 7 and 14, respectively. One animal only (3\%) was seropositive on week 14 in the lowest-dose group $(0.1 \mathrm{mg} / \mathrm{kg}$ bw per day). All but one positive control animal administered sometribove subcutaneously were seropositive (Richard, Odaglia and Deslex, 1989). Antibody levels in orally dosed animals were generally lower than those observed in the positive controls. Oral doses of rbST did not increase bodyweight or feed consumption, although a concomitant marked increase in bodyweight and feed consumption was recorded in the positive control group from week 2 of the experiment.

The study did not measure rbST in sera and cannot confirm whether intact rbST was absorbed into the systemic circulation. Also, there was no effect on bodyweight or feed intake, suggesting that a sufficient quantity of bio-active sometribove was not absorbed into the systemic circulation. Consequently, it is not possible to confirm whether the anti-rbST antibody response was a result of absorption of intact rbST or only an immunologically active peptide fragment (epitope or antigenic determinant) of rbST into the systemic circulation or due to mucosal immunity in the gut. It is known that exposure to ingested foreign proteins could stimulate a mucosal immune response in the gut, and activated antibody-producing cells could enter and produce antibodies in the systemic circulation (McCluskie and Davis, 1999; Valdes-Ramos et al., 2010; Shin et al., 2013). The findings of this study therefore do not confirm the systemic bio-availability of orally administered rbSTs.

Considering the similar levels of total bST detected in milk or tissues of animals treated with rbSTs (see section below on Bovine somatotrophin in tissues and milk), the expected level of human exposure to rbSTs would be much lower than the dose used in anti-rbST antibodypositive rats. Furthermore, because of the structural dissimilarities between human and 
bovine somatotrophins, species-specific receptor binding, destruction of rbSTs by high temperatures (e.g. cooking or pasteurization) and biochemical degradation by gastrointestinal enzymes, small quantities of rbSTs in milk or tissues of treated animals, if present, are not expected to have biological activity when administered orally.

\section{Cattle}

In a recent study (Le Breton et al., 2009), the elimination kinetics of an rbST in serum was characterized in a cow in which the concentrations after treatment with a single subcutaneous injection of $500 \mathrm{mg}$ sometribove (Lactotropin, Monsanto, Elanco Animal Health) were measured using liquid chromatography coupled to tandem mass spectrometry in positive electrospray ionization mode. This allowed for the unambiguous identification and quantification of rbST in serum. Detection of the rbST was possible from 4.5 hours to 4 days after administration, and concentrations up to $10 \mathrm{ng} / \mathrm{ml}$ were reported.

No other new biological or pharmacokinetic studies were available.

\section{Toxicological studies}

The Committee at its 40th Meeting evaluated the toxicity of different rbSTs (JECFA, 1993 [TRS 832]). Acute oral toxicity studies in rats with rbST doses up to $5 \mathrm{~g} / \mathrm{kg}$ bw, two 2-week oral feeding studies in rats with doses of rbSTs up to $10 \mathrm{mg} / \mathrm{kg}$ bw per day and two 4-week oral feeding studies in rats with doses up to $50 \mathrm{mg} / \mathrm{kg}$ bw per day caused no effects up to the highest dose tested. Similarly, no treatment-related effects were observed at the highest dose tested in two 90-day oral feeding studies in rats with rbSTs at doses up to $100 \mathrm{mg} / \mathrm{kg}$ bw per day and a 90-day oral feeding study in dogs at doses up to $10 \mathrm{mg} / \mathrm{kg}$ bw per day.

No new toxicity studies on rbSTs were available since the previous evaluation of rbSTs by the Committee at the 50th Meeting (JECFA, 1999 [TRS 888]).

\section{Long-term studies on toxicity and carcinogenicity of recombinant mouse and rat somatotrophins}

A search of the published literature identified long-term (2-year) carcinogenicity studies in mice and rats for related, but distinct, compounds (i.e. mouse and rat growth hormones) (Farris et al., 2007). These studies did not use the oral/gavage route for administration of the test articles and did not test rbSTs. The Committee therefore considered these data not directly relevant to the risk assessment of rbSTs, but relevant to understanding the carcinogenic potential of other related somatotrophins in respective mammalian species. The study findings are therefore summarized briefly in this monograph.

\section{Mice}

In a 2-year study compliant with good laboratory practice (GLP), groups of CD-1 mice 39 days of age and weighing 18.5-27.5 $\mathrm{g}$ (females) and 20.2-32.8 $\mathrm{g}$ (males) at the beginning of the study were allocated into five groups (50 mice of each sex per group). Mice received daily subcutaneous injections of vehicle (two groups) or recombinant mouse somatotrophin $(\mathrm{rmST})$ at $0.1,0.2$ or $0.5 \mathrm{mg} / \mathrm{kg}$ bw. Animals were observed daily for mortality and weekly for clinical signs. Bodyweight measurements and ophthalmic examinations were conducted routinely. Dead mice and those euthanized at the end of the study were necropsied, and 58 tissues per mouse were examined for gross and histopathological lesions.

Daily subcutaneous injection of rmST over 2 years elicited no treatment-related mortality or physical or ocular signs in mice. No effects on bodyweight were seen in trend analysis in either sex. The final mean bodyweights were $36.8,37.5,37.1$ and $38.2 \mathrm{~g}$ in females and 46.1, $48.3,49.3$ and $47.6 \mathrm{~g}$ in males in the control, $0.1,0.2$ and $0.5 \mathrm{mg} / \mathrm{kg}$ bw per day treatment groups, respectively. Examination of the pituitary gland at necropsy did not reveal treatment-related gross changes or changes in pituitary weight. When compared with concurrent or historical controls, there was no significant treatment-related increase in the 
incidence of tumours in any tissue examined in both males and females (Farris et al., 2007).

Rats

In a GLP-compliant 2-year study (Farris et al., 2007), groups of Sprague-Dawley rats 37 days of age and weighing 102-149 $\mathrm{g}$ (females) and 129-195 $\mathrm{g}$ (males) at the start of the study were allocated into five groups (50 rats of each sex per group). Rats received daily subcutaneous injections of vehicle (two groups) or recombinant rat somatotrophin (rrST) at 0.2, 0.4 or $0.8 \mathrm{mg} / \mathrm{kg} \mathrm{bw}$. Animals were observed daily for mortality and weekly for clinical signs. Bodyweight measurements and ophthalmic examinations were conducted routinely. Dead rats and those euthanized at the end of the study were necropsied, and 57 tissues per rat were subjected to gross and histopathological examination.

Daily subcutaneous injection of rrST over 2 years elicited a treatment-related decrease in mortality in female rats, but there was no effect on mortality of male rats. Compared with $62-64 \%$ survival of the control groups, $82 \%$ of female rats treated with $\mathrm{rrST}$ at $0.4 \mathrm{mg} / \mathrm{kg}$ bw per day and $80 \%$ of female rats treated with $\mathrm{rrST}$ at $0.8 \mathrm{mg} / \mathrm{kg}$ bw per day survived to study termination. The increased survival was attributed in part to reduction in deaths due to pituitary tumours in females. No treatment-related physical or ocular signs were observed. Female rats treated with rrST had a higher average bodyweight $(P<0.001)$ at all doses. At the end of the study, mean bodyweights of female rats were 324, 343, 363 and $381 \mathrm{~g}$ in the control, $0.2,0.4$ and $0.8 \mathrm{mg} / \mathrm{kg}$ bw per day treatment groups, respectively. In male rats, the bodyweights in the 0.4 and $0.8 \mathrm{mg} / \mathrm{kg}$ bw per day groups were significantly higher than those in the control and $0.2 \mathrm{mg} / \mathrm{kg}$ bw per day dose groups. Bodyweights at the end of the study in male rats were $627,630,647$ and $650 \mathrm{~g}$ at $0,0.2,0.4$ and $0.8 \mathrm{mg} / \mathrm{kg}$ bw per day, respectively. Overall, when compared with concurrent or historical controls, no significant difference in tumour incidence was detected in the different treatment groups. However, after adjustment for multiplicity of statistical tests, the incidence of pituitary adenoma in female rats showed a decreasing trend when the treatment dose was increased.

\section{Bovine somatotrophin in tissues and milk}

Bovine somatotrophin is not readily transferred from blood or plasma to milk. At the 40th Meeting of the Committee (JECFA, 1993 [TRS 832]), it was concluded that studies of rbST residues in milk demonstrate that the proposed use of rbSTs, even at exaggerated doses, will not lead to any detectable concentrations of total bST in milk above those normally present in milk from untreated cows (0.9-1.6 $\mu \mathrm{g} / \mathrm{L})$. Similarly, cows treated with rbSTs have, at most, a 2 -fold increase in residues in tissues, to total bST concentrations of $3.1-4.2 \mu \mathrm{g} / \mathrm{kg}$ in muscle and $16-25 \mu \mathrm{g} / \mathrm{kg}$ in liver, compared with $2.2-3.7 \mu \mathrm{g} / \mathrm{kg}$ in muscle and $9-13 \mu \mathrm{g} / \mathrm{kg}$ in liver of untreated cows.

The 50th Committee meeting evaluated a published study (Choi et al., 1997) in which rbST was administered in two different dosage forms by subcutaneous injection to beef cattle every 2 weeks for 20-24 weeks. Treated cattle were slaughtered 2 weeks after the final dose. Tissue concentrations of total bST ranging from $1.45 \pm 0.86$ to $4.94 \pm 1.47 \mu \mathrm{g} / \mathrm{kg}$ in muscle, 4.82 \pm 1.95 to $9.33 \pm 5.23 \mu \mathrm{g} / \mathrm{kg}$ in fat, $3.56 \pm 1.73$ to $5.36 \pm 1.21 \mu \mathrm{g} / \mathrm{kg}$ in liver, and $3.58 \pm 1.14$ to 4.49 $\pm 1.83 \mu \mathrm{g} / \mathrm{kg}$ in kidney were reported. Total bST concentrations were measured using a radioimmunoassay procedure. There were no significant differences between treated animals and controls in the concentrations of total bST in muscle, fat, liver or kidney (FAO, 1999; JECFA, 1999 [TRS 888]).

A limited number of studies that provide new data on bST residues in tissues (Kweon et al., 2000) and in milk of lactating cows and buffaloes were published since the 50th Committee meeting (Mishra et al., 2005; Mishra, Mahapatra and Shukla, 2006; Vicini et al., 2008). Also, the results of several studies published before the previous meeting were not discussed in the reports of the previous meetings (Torkelson and Miller, 1987; Groenewegen et al., 1990). 
Torkelson and Miller (1987) injected eight cows intramuscularly and another eight subcutaneously at 14-day intervals with $500 \mathrm{mg}$ rbST in a sustained release formulation. Ten untreated animals served as controls. Milk and blood samples were collected 2 days prior to injection, on the day of injection and on Days 1, 2, 3, 4, 6, 8, 10, 12 and 14 after injection during the fourth treatment cycle. The concentration of total bST in milk was determined by radioimmunoassay. No further information on validation of the assay was provided. The results demonstrated no correlations between total bST concentrations in blood and milk, regardless of the route of administration. Total bST concentrations in most milk samples were below the limit of detection $(<0.3 \mathrm{ng} / \mathrm{ml})$.

Groenewegen et al. (1990) determined the concentrations of total bST in milk of untreated cows $(n=3)$ at $82.3 \pm 17$ days postpartum and cows $(n=3)$ treated at $78 \pm 6$ days postpartum. Cows in the treated groups received $10.6 \mathrm{mg}$ rbST (American Cyanamid) daily starting at 28 days postpartum. This formed part of the study in which the bio-activity of milk from cows treated with rbST was examined in hypophysectomized rats. The concentration of total bST in milk was measured by radioimmunoassay, with a level of detection of $0.5 \mathrm{ng} / \mathrm{ml}$ and an average recovery of $96 \%$, and was reported as 3.3 and $4.2 \mathrm{ng} / \mathrm{ml}$ in milk of control and treated cows, respectively.

Mishra et al. (2005) reported somatotrophin concentrations in milk of lactating buffaloes $(\mathrm{n}=20)$ treated with rbST (Boostin-250, LG Chemicals India) subcutaneously at $250 \mathrm{mg}$ on three occasions at 14-day intervals, compared with saline-treated controls $(n=10)$. Total somatotrophin concentrations were measured in six fortnightly milk samples starting from 15 days pre-treatment to 60 days post-injection using a double antibody sandwich enzymelinked immunosorbent assay (ELISA) that utilized (r)bST-specific antibodies. The assay was validated for sensitivity, specificity, precision and recovery. Parallelism was demonstrated between the standard curve using rbST (NHPP, California) and serially diluted serum, milk and pituitary-derived growth hormone. The sensitivity of the assay was $0.1 \mathrm{ng} / \mathrm{ml}$. The specificity of the assay was determined by western blot using non-specific proteins such as bovine serum albumin, gelatine and bovine prolactin with rbST. Presence of a single band only on the rbST column indicated that the antibody used in the assay was specific to bST only. The intra-assay and inter-assay variations for serum and milk were $3.36-8.81 \%$ and $6.01-14.31 \%$, respectively. Recovery of exogenous bST from serum and milk ranged from $90 \%$ to $102 \%$ and from $96 \%$ to $108 \%$, respectively. Mean total somatotrophin concentrations pre-treatment and post-treatment in both rbST-treated and control animals at each fortnightly collection are summarized in Table 9.1. No significant difference in the total somatotrophin concentrations was observed between rbST-treated and control animals. These concentrations are similar to those reported for cattle at the 40th Committee meeting.

Table 9.1. Fortnightly changes in total somatotrophin concentrations in milk in lactating buffaloes treated with rbST $(n=20)$ compared with saline-treated buffaloes $(n=10)$

\begin{tabular}{|c|c|c|c|c|c|c|c|c|}
\hline \multirow{2}{*}{$\begin{array}{l}\text { Treatment } \\
\text { group }\end{array}$} & \multicolumn{6}{|c|}{ Somatotrophin concentrations (ng/ml) } & \multirow{2}{*}{$\begin{array}{l}\text { Overall } \\
\text { mean }\end{array}$} & \multirow{2}{*}{ Significance } \\
\hline & Pre-treatment & 1 & 2 & 3 & 4 & 5 & & \\
\hline Saline & $1.27 \pm 0.07$ & $1.10 \pm 0.11$ & $1.06 \pm 0.10$ & $1.10 \pm 0.10$ & $1.18 \pm 0.06$ & $1.13 \pm 0.05$ & $1.14 \pm 0.04$ & NS \\
\hline rbST & $1.39 \pm 0.03$ & $1.16 \pm 0.08$ & $1.17 \pm 0.07$ & $1.22 \pm 0.07$ & $1.19 \pm 0.04$ & $1.25 \pm 0.06$ & $1.23 \pm 0.03$ & \\
\hline
\end{tabular}

NOTES: NS = not significant; rbST = recombinant bovine somatotrophin.

SOURCE: Adapted from Mishra et al., 2005.

Mishra, Mahapatra and Shukla (2006) performed a study similar in design to the one previously reported in buffaloes (Mishra et al., 2005), in lactating crossbred (Bos taurus $\times$ Bos indicus) cows $(\mathrm{n}=20)$ treated with rbST (Boostin-250, LG Chemicals India) subcutaneously at $250 \mathrm{mg}$ on three occasions at 14-day intervals, compared with saline-treated control cows (n 
$=10)$. No significant difference $(P>0.05)$ was found in the mean total bST concentrations in milk from rbST-treated cows $(1.16 \pm 0.08 \mathrm{ng} / \mathrm{ml})$ compared with control cows $(1.10$ $\pm 0.34 \mathrm{ng} / \mathrm{ml}$ ) measured in fortnightly milk samples by indirect sandwich ELISA. No validation information on the assay used was provided in the publication.

In a cross-sectional study, total bST concentrations were determined in retail milk samples $(\mathrm{n}=344)$ collected from retail outlets in 48 contiguous states within the United States of America where rbST is approved for use (Vicini et al., 2008). Samples were obtained in blocks over a period of three weeks from purchased milk labelled as conventional (milk that did not contain any claims about supplementation with rbST or organic practices), rbST-free (milk that has a processor claim that cows were not supplemented with rbST) or organic (milk from farms that were certified as meeting United States Department of Agriculture (USDA) organic standards). A block consisted of a shipping container collected on one day by one sampler and in one city to minimize the effects of shipping conditions. At least two blocks of samples were collected from each state. More samples were collected from states with larger populations or larger quantities of milk production. The freshest (based on expiry date) pasteurized whole milk in plastic or paper containers of any retail brand was preferred. Ultra-high-temperature pasteurized milk was avoided. bST concentrations in milk were measured by electrochemiluminescent immunoassays (ECLIA) using a Sector Imager 6000. Assays were performed at Monsanto. No information on the validation of the assay was provided. The milk samples were also examined for quality (antimicrobials and bacterial counts), nutritional value (fat, protein and solid-not-fat) and additional hormonal composition. There were no significant differences $(P>0.05)$ in concentration of total bST in milk, regardless of label type. Approximately $82 \%$ of milk samples had total bST levels below the limit of quantification $(0.033 \mathrm{ng} / \mathrm{ml})$, and $72 \%$ were less than the limit of detection $(0.010 \mathrm{ng} / \mathrm{ml})$ for the assay.

Another study was reported by Kweon et al. (2000), in which 32 Holstein bulls and steers were randomly assigned to one of four groups: (i) bull group, (ii) untreated steer group, (iii) steers treated with rbST when they were about $80 \mathrm{~kg}$ live weight $\left(\mathrm{rbST}_{1}\right)$, or (iv) steers treated with rbST when they were about $300 \mathrm{~kg}$ live weight $\left(\mathrm{rbST}_{2}\right)$. Treated steers were given rbST every 14 days at $0.03 \mathrm{mg} / \mathrm{kg}$ bw per day intramuscularly, alternately in the rump and shoulder. Concentrations of total bST were measured using an immunoradiometric assay. No details on the validation procedure of the analytical method were provided. The concentrations of total bST in tissue with or without rbST treatment are summarized in Table 9.2. There were no significant differences between rbST-treated and untreated steers. The tissue concentrations of total bST reported in this study in both control and rbST-treated animals are slightly higher than those reported at the 40th and 50th Committee Meetings.

Table 9.2. Concentrations of total bST in tissues of rbST-treated and untreated steers

\begin{tabular}{|c|c|c|c|c|}
\hline \multirow{2}{*}{ Tissues } & \multirow{2}{*}{$\begin{array}{c}\text { Total bST in tissues of } \\
\text { untreated steers }(\mathrm{ng} / \mathrm{ml})\end{array}$} & \multicolumn{3}{|c|}{ Total bST in tissues of treated steers $(\mathrm{ng} / \mathrm{ml})$} \\
\hline & & $\operatorname{rbST}_{1}$ & $\mathrm{rbST}_{2}$ & SEM \\
\hline Injection site & 5.80 & 7.23 & 8.83 & 0.89 \\
\hline Muscle & 6.18 & 6.85 & 7.63 & 0.91 \\
\hline Kidney & 15.93 & 17.75 & 23.05 & 1.77 \\
\hline Liver & 19.83 & 18.05 & 20.10 & 1.15 \\
\hline
\end{tabular}

NOTES: bST = bovine somatotrophin; $\mathrm{rbST}_{1}=$ steers treated with recombinant bovine somatotrophin when they were about $80 \mathrm{~kg}$ live weight; $\mathrm{rbST}_{2}=$ steers treated with recombinant bovine somatotrophin when they were about $300 \mathrm{~kg}$ live weight; $\mathrm{SEM}=$ standard error of the mean.

SouRcE: Reproduced from: Kweon, U.G., Kim, H.S., Yun, S.K., Nam, K.T., Kim, J.B., Ahn, J.B. \& Kim, J.S. 2000. Effects of rbST administration on the changes in the concentration of blood and carcass hormones in Holstein bulls and steers. Journal of Animal Science \& Technology (Korea), 42(4): 451-458. with permission of the Korean Society of Animal Science and Technology. 


\section{Insulin-like growth factor-I in tissues and milk}

\section{IGF-I concentrations in milk}

The 40th Committee Meeting cited an average concentration of IGF-I in milk of $3.7 \mathrm{ng} / \mathrm{ml}$ for untreated cows (JECFA, 1993 [TRS 832]). An average concentration of $5.9 \mathrm{ng} / \mathrm{ml}$ was reported in cows treated with rbST; although this average concentration was significantly higher than that in milk from untreated cows, most of the concentrations were less than $10 \mathrm{ng} / \mathrm{ml}$ and within the normal physiological range observed in the milk of lactating cows. IGF-II concentrations in cows' milk were not affected by rbST treatment.

At the 50th Committee Meeting, it was noted that the IGF-I content in normal bovine milk was highly variable, depending on the state of lactation, nutritional status and age (JECFA, 1999 [TRS 888]). Over an entire lactation, IGF-I concentrations in milk ranged between 1 and $30 \mathrm{ng} / \mathrm{ml}$, with the highest concentrations in colostrum and a constant decline thereafter. Multiparous animals were reported to have higher concentrations of IGF-I in milk compared with primiparous cows. Bulk milk from cows not given rbST had IGF-I concentrations of 1$9 \mathrm{ng} / \mathrm{ml}$. In milk from rbST-treated cows, the concentrations of IGF-I ranged from 1 to $13 \mathrm{ng} / \mathrm{ml}$ in most studies.

Since the 50th Committee Meeting, there have been limited additional data published on IGF-I residues in milk from untreated lactating cows (Daxenberger, Sauerwein and Breier, 1998; Liebe and Schams, 1998; Taylor et al., 2004) and from lactating cows treated with rbSTs (Daxenberger, Sauerwein and Breier, 1998; Pauletti et al., 2005; Collier et al., 2008). Additionally, concentrations of IGF-I in retail milk in the United States of America based on the label, e.g. rbST-free, organic or conventional, were reported (Vicini et al., 2008). Changes in IGF-I concentrations in milk from lactating buffaloes and goats following treatment have also been reported (Faulkner, 1999; Prasad and Singh, 2010; Castigliego et al., 2011). A summary of all new studies is provided in Tables 9.3a and 9.3b.

Daxenberger, Sauerwein and Breier (1998) determined naturally occurring IGF-I concentrations in 5777 random milk samples from dairy cows (not treated with rbST) collected over a 1-year period covering all regions of Bavaria. In samples from lactation weeks 7 through 33, the effect of somatic cell count, protein content and parity was quantified and corrected to obtain a normal distribution of the corrected logarithmic IGF-I concentrations. IGF-I concentrations in the milk were measured using a validated nonextraction radioimmunoassay following de-fattening. The method involved competitive displacement of IGF-I from IGF binding proteins by IGF-II and has an intra-assay variation of $5.1 \%$ and an inter-assay variation of $13.4 \%$. IGF-I concentrations in milk from untreated animals ranged from 1 to $83 \mathrm{ng} / \mathrm{ml}$. The distribution of the IGF-I was skewed to the right, with a median concentration of $4.4 \mathrm{ng} / \mathrm{ml}$ and 90th and 95th percentiles of 9.5 and $12.5 \mathrm{ng} / \mathrm{ml}$, respectively. There was no detectable effect of region, season, the quantity of milk produced or the milk's fat content on IGF-I concentrations. Stage of lactation strongly influenced the concentration of IGF-I in milk (Figure 9.1). 
Table 9.3a. Summary of the normal variation of IGF-I concentration in cow's milk and the effect of rbST treatment on IGF-I concentrations in milk. (a) Naturally occurring IGF-I

\begin{tabular}{|c|c|c|c|}
\hline Study & No. of samples & IGF-I concentrations & Assay method \\
\hline $\begin{array}{l}\text { Daxenberger, } \\
\text { Sauerwein } \\
\text { and Breier, } \\
1998\end{array}$ & 5777 & $\begin{array}{l}\text { Range } 1-83 \mathrm{ng} / \mathrm{ml} \text {; median } 4.4 \mathrm{ng} / \mathrm{ml} \text {; 90th } \\
\text { percentile } 9.5 \mathrm{ng} / \mathrm{ml} \text {; 95th percentile } 12.5 \mathrm{ng} / \mathrm{ml}\end{array}$ & $\begin{array}{l}\text { Non-extraction radioimmuno- } \\
\text { assay following de-fattening }\end{array}$ \\
\hline $\begin{array}{l}\text { Liebe and } \\
\text { Schams, } 1998\end{array}$ & $\begin{array}{l}12 \text { in barned study } \\
12 \text { with clinical mastitis } \\
22 \text { with subclinical } \\
\text { mastitis }\end{array}$ & $\begin{array}{l}\text { Healthy quarters: } 8.3 \pm 1.7,8.5 \pm 2.1,14.1 \pm 1.7 \text { and } \\
15.1 \pm 1.8 \mathrm{ng} / \mathrm{ml} \text { in loose housing, and } 10.7 \pm 2.1 \\
\text { and } 6.6 \pm 1.5 \mathrm{ng} / \mathrm{ml} \text { in tied portion of barned study } \\
\text { Clinical mastitis: } 35.5 \pm 23.5 \text { vs } 21.2 \pm 6.8 \mathrm{ng} / \mathrm{ml} \text { in } \\
\text { healthy quarters } \\
\text { Subclinical mastitis: } 36.9 \pm 31.3 \text { vs } 17.7 \\
\pm 11.3 \mathrm{ng} / \mathrm{ml} \text { in healthy quarters }\end{array}$ & $\begin{array}{l}\text { Extraction radioimmunoassay } \\
\text { in skimmed milk }\end{array}$ \\
\hline $\begin{array}{l}\text { Taylor et al., } \\
2004\end{array}$ & 50 multiparous & $\begin{array}{l}>16 \mathrm{ng} / \mathrm{ml} 1 \text { st week of calving; } 6-9 \mathrm{ng} / \mathrm{ml} 2-20 \\
\text { weeks postpartum }\end{array}$ & $\begin{array}{l}\text { Ethanol-acetone-acetic acid } \\
\text { radioimmunoassay in whole } \\
\text { milk }\end{array}$ \\
\hline
\end{tabular}

Table 9.3b. Summary of the normal variation of IGF-I concentration in cow's milk and the effect of rbST treatment on IGF-I concentrations in milk. (b) rbST treatment studies

\begin{tabular}{|c|c|c|c|c|c|}
\hline \multirow{2}{*}{ Study } & \multirow{2}{*}{ Treatment } & \multirow{2}{*}{$\begin{array}{l}\text { No. of } \\
\text { animals }\end{array}$} & \multicolumn{2}{|c|}{ IGF-I concentrations } & \multirow{2}{*}{ Assay method } \\
\hline & & & No rbST & rbST & \\
\hline \multicolumn{6}{|c|}{ Cows } \\
\hline $\begin{array}{l}\text { Daxenberger } \\
\text { Sauerwein and } \\
\text { Breier, } 1998\end{array}$ & $\begin{array}{l}1 \times 500 \mathrm{mg} \text { sometribove } \\
\text { (Posilac, Monsanto) }\end{array}$ & $\begin{array}{l}34 \text { (33 for } \\
\text { data } \\
\text { analysis) }\end{array}$ & $\sim 4 \mathrm{ng} / \mathrm{ml}$ & $\begin{array}{l}\text { Increase of } 2.3 \mathrm{ng} / \mathrm{ml} \text { for } \\
\text { lactation } 1 ; 1.6 \mathrm{ng} / \mathrm{ml} \text { for } \\
\text { lactation } 2-6 ; \text { and } \\
1.9 \mathrm{ng} / \mathrm{ml}(48 \%) \text { for all } \\
\text { lactations }\end{array}$ & $\begin{array}{l}\text { Non-extraction } \\
\text { radioimmunoassay } \\
\text { following de- } \\
\text { fattening }\end{array}$ \\
\hline \multirow[t]{2}{*}{$\begin{array}{l}\text { Collier et al., } \\
2008\end{array}$} & $\begin{array}{l}25 \mathrm{mg} / \text { day sometribove } \\
\text { (winter) }\end{array}$ & 6 per group & $3.7 \mathrm{ng} / \mathrm{ml}$ & $4.8 \mathrm{ng} / \mathrm{ml}$ & \multirow[t]{2}{*}{ Radioimmunoassay } \\
\hline & $\begin{array}{l}25 \mathrm{mg} / \text { day sometribove } \\
\text { (summer) }\end{array}$ & 6 per group & $3.4 \mathrm{ng} / \mathrm{ml}$ & $3.8 \mathrm{ng} / \mathrm{ml}$ & \\
\hline $\begin{array}{l}\text { Pauletti et al., } \\
2005\end{array}$ & $\begin{array}{l}3 \times 500 \mathrm{mg} \text { (Boostin) at } \\
14 \text {-day intervals from } \\
\text { Day } 35 \text { prepartum until } \\
\text { parturition }\end{array}$ & $\begin{array}{l}21 \text { per } \\
\text { group }\end{array}$ & $\begin{array}{l}\text { Day } 1 \text { postpartum } \\
\text { (colostrum): } 674 \\
\pm 270 \mathrm{ng} / \mathrm{ml} \\
\text { Day } 7 \mathrm{no} \\
\text { significant } \\
\text { differences from } \\
\text { treated animals }\end{array}$ & $\begin{array}{l}\text { Day } 1 \text { post-partum } \\
\text { (colostrum): } 875 \\
\pm 335 \mathrm{ng} / \mathrm{ml} \\
\text { Day } 7 \mathrm{postpartum:} \\
12.9 \mathrm{ng} / \mathrm{ml}\end{array}$ & $\begin{array}{l}\text { Immune radiometric } \\
\text { assay }\end{array}$ \\
\hline \multicolumn{6}{|c|}{ Buffaloes } \\
\hline $\begin{array}{l}\text { Castigliego et } \\
\text { al., } 2011\end{array}$ & $\begin{array}{l}5 \times 500 \mathrm{mg} \text { (Boostin) } \\
\text { s.c. at } 14 \text {-day intervals }\end{array}$ & 8 per group & $1.5-3.0 \mathrm{ng} / \mathrm{ml}$ & $4.5-7.0 \mathrm{ng} / \mathrm{ml}$ & Sandwich ELISA \\
\hline $\begin{array}{l}\text { Prasad and } \\
\text { Singh, } 2010\end{array}$ & $\begin{array}{l}5 \mathrm{mg} \text { rbST (Boostin) i.v. } \\
\text { daily for } 5 \text { days }\end{array}$ & 10 & $\begin{array}{l}29.7 \pm 4.5 \text { to } 38.1 \\
\pm 3.4 \mathrm{ng} / \mathrm{ml}\end{array}$ & $\begin{array}{l}42.0 \pm 5.2 \mathrm{ng} / \mathrm{ml} \text { (highest } \\
\text { concentration measured } \\
\text { on Day } 1 \text { after treatment) }\end{array}$ & $\begin{array}{l}\text { Double-antibody } \\
\text { radioimmunoassay }\end{array}$ \\
\hline \multicolumn{6}{|c|}{ Goats } \\
\hline Faulkner, 1999 & $\begin{array}{l}2 \times 3 \mathrm{mg} \text { s.c. of ovine } \\
\text { somatotrophin }\end{array}$ & 5 & $\sim 5 \mathrm{ng} / \mathrm{ml}$ & Maximum of $\sim 15 \mathrm{ng} / \mathrm{ml}$ & $\begin{array}{l}\text { Double-antibody } \\
\text { radioimmunoassay }\end{array}$ \\
\hline \multicolumn{6}{|c|}{ Retail milk survey } \\
\hline $\begin{array}{l}\text { Vicini et al., } \\
2008\end{array}$ & $\begin{array}{l}\text { Conventional; rbST-free } \\
\text { labelled milk }\end{array}$ & and organic & $\begin{array}{l}\text { "rbST free" } 3.0 \\
\pm 0.1 \mathrm{ng} / \mathrm{ml} \\
\text { "organic" } 2.7 \\
\pm 0.1 \mathrm{ng} / \mathrm{ml}\end{array}$ & $\begin{array}{l}\text { "Conventional" } 3.1 \\
\pm 0.1 \mathrm{ng} / \mathrm{ml}\end{array}$ & ECLIA \\
\hline
\end{tabular}

NOTES: ECLIA = electrochemiluminescent immunoassay; ELISA = enzyme-linked immunosorbent assay; IGF-I = insulin-like growth factor-l; i.v. = intravenously; rbST = recombinant bovine somatotrophin; s.c. $=$ subcutaneously. 
IGF-I concentrations in milk varied 2- to 3-fold across lactation, with the average concentration being the highest in the first 1.5 weeks of lactation at approximately $11.5 \mathrm{ng} / \mathrm{ml}$, then falling rapidly before levelling out between weeks 7 and 33 at approximately $5 \mathrm{ng} / \mathrm{ml}$, before rising steadily again to reach a concentration of approximately $8 \mathrm{ng} / \mathrm{ml}$ in late lactation. Somatic cell count in milk and milk protein percentage had small but positive correlations with IGF-I concentrations in milk. The number of lactations (first, second or third to sixth) and breed also had some influence on IGF-I concentration in milk. High variability in IGF-I concentrations was observed in cows after six lactations. Samples of HolsteinFriesian cows showed slightly higher IGF-I concentrations compared with other breeds. The Daxenberger, Sauerwein and Breier (1998) study also included an animal phase in which 34 Brown Swiss cows were given a single treatment of rbST (Posilac, Monsanto) according to the label instructions (500 mg). Milk samples were taken twice daily from these animals for 2 weeks during the pre-treatment period and for 4 weeks in the posttreatment period. Statistical analysis was performed on the changes in IGF-I concentration in milk derived from 33 animals from days 7 to 13 after treatment (period B) compared with the 7
Figure 9.1. Mean IGF-I concentrations $( \pm$ SEM) in milk from cows not treated with rbST during the entire lactation.

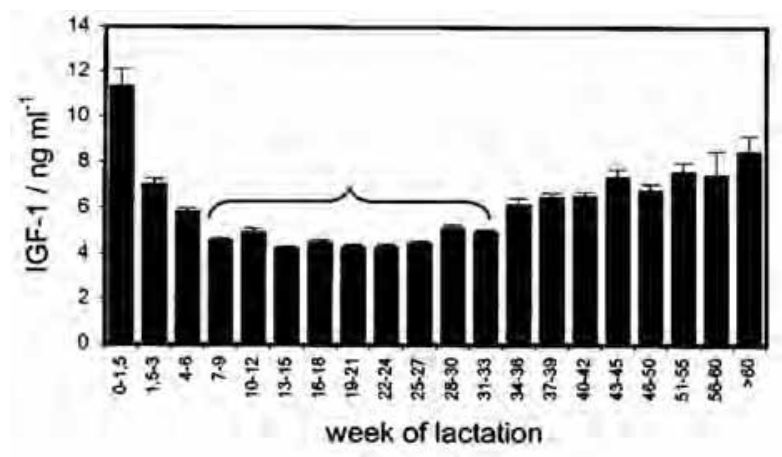

NOTES: IGF-I = insulin-like growth factor-I, given as IGF-1 in figure; SEM = standard error of the mean; rbST = recombinant bovine somatotrophin

SOURCE: Reproduced from Daxenberger, A., Sauerwein, H. \& Breier, B.H. 1998. Increased milk levels of insulin-like growth factor 1 (IGF-1) for the identification of bovine somatotrophin (bST) treated cows. Analyst,

123: 2429-2435, with permission of the Royal Society of Chemistry.
Figure 9.2. Mean IGF-I* concentrations in milk after rbST ${ }^{\star *}$ treatment. Statistical analysis was based on (A) the control period and $(B)$ the main effect period

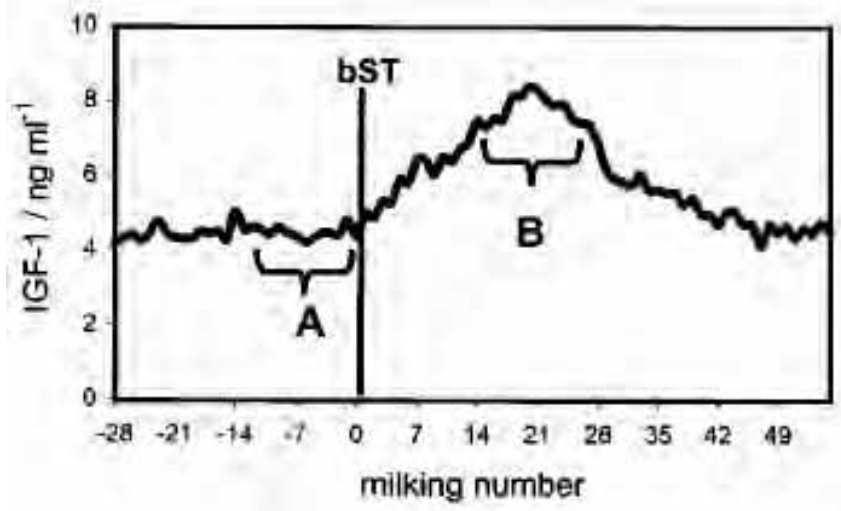

NOTES: IGF-I = insulin-like growth factor-I, given as IGF-1 in figure; rbST = recombinant bovine somatotrophin, given as bST in figure.

SOURCE: Reproduced from Daxenberger, A., Sauerwein, H. \& Breier, B.H. 1998. Increased milk levels of insulin-like growth factor 1 (IGF-1) for the identification of bovine somatotrophin (bST) treated cows. Analyst, 123: 2429-2435, with permission of the Royal Society of Chemistry. close to $4 \mathrm{ng} / \mathrm{ml}$, which increased significantly after treatment, with the maximum concentration (approximately $8 \mathrm{ng} / \mathrm{ml}$ ) detected 10 days after treatment. The mean increase in IGF-I compared with that of the contemporary control was $2.3 \mathrm{ng} / \mathrm{ml}$ for lactation 1 , $1.6 \mathrm{ng} / \mathrm{ml}$ for lactations $2-6$ and $1.9 \mathrm{ng} / \mathrm{ml}(48 \%)$ for all lactations combined.

Liebe and Schams (1998) studied the interrelationship between concentrations of IGF-I, basic fibroblast growth factor and somatic cell count in normal milk and the presence of these growth factors in the milk from cows with clinical and subclinical mastitis. Twelve 
Brown Swiss cows in their fourth lactation and in their 1st to 10th months of lactation were used. The study was performed in two periods, with four and eight cows in periods 1 and 2, respectively. Cows with chronically elevated somatic cell count in at least one quarter due to a history of mastitis or trauma were selected from their loose housing and moved to a separate stanchion barn for a period of 5 days and then transferred back to the original loose environment. The periods of 5 days before and after relocation were referred to as control. Four milk samples from each quarter were taken daily at the morning milking. In addition, quarter milk samples $(\mathrm{n}=48)$ from 12 cows affected by clinical mastitis and quarter milk samples $(\mathrm{n}=88)$ from 22 cows (German Fleckvieh) affected by subclinical mastitis obtained from four small Bavarian farms were investigated. IGF-I concentrations were measured in skimmed milk samples by using an extraction radioimmunoassay technique with $3.8 \%$ intraassay and $16 \%$ inter-assay coefficients of variation. The concentrations of IGF-I in milk in the relocation portion of the study in the controls were $15.1 \pm 1.8$ and $14.1 \pm 1.7 \mathrm{ng} / \mathrm{ml}$ before and after being barned in the first period of the study, and $8.3 \pm 1.7$ and $8.5 \pm 2.1 \mathrm{ng} / \mathrm{ml}$ in the second period; concentrations of IGF-I were $10.7 \pm 2.1$ and $6.6 \pm 1.5 \mathrm{ng} / \mathrm{ml}$ during the time barned during the first and second study periods, respectively. The concentrations of IGF-I in milk from quarters with clinical $(35.5 \pm 23.5 \mathrm{ng} / \mathrm{ml})$ and subclinical $(36.9 \pm 31.3 \mathrm{ng} / \mathrm{ml})$ mastitis were almost twice the concentrations detected in corresponding healthy quarters $(21.2 \pm 6.8 \mathrm{ng} / \mathrm{ml}$ and $17.7 \pm 11.3 \mathrm{ng} / \mathrm{ml}$, respectively).

Taylor et al., (2004) reported the concentrations of IGF-I in blood from Holstein-Friesian cows not treated with rbST and the influence of stage of lactation from 142 primiparous and 177 multiparous (mean lactation number of 3, range 2-8) cows. Blood samples were collected from 1 week before to at least 12 weeks after calving in the multiparous cows and before calving and 3,5 and 8 weeks after calving in the primiparous cows. The concentrations of IGF-I in milk were measured in 50 of the multiparous cows. Whole milk samples were collected weekly after calving until week 12 and at week 20, and frozen until assayed for IGF-I. The concentrations of IGF-I in plasma and milk were determined by radioimmunoassay after ethanol-acetone-acetic acid extraction of IGF-I binding proteins. The inter-assay and intra-assay coefficients of variation were $11.2 \%$ and $6.7 \%$, respectively. Concentrations of IGF-I in plasma were significantly $(P<0.001)$ higher in the primiparous cows (about 130 and $100 \mathrm{ng} / \mathrm{ml}$ ) than in the multiparous cows $(85$ and $60 \mathrm{ng} / \mathrm{ml}$ ) before and after calving, respectively. IGF-I concentrations in milk in the 1st week after calving were above $16 \mathrm{ng} / \mathrm{ml}$, decreased rapidly in subsequent weeks and thereafter fluctuated between 6 and $9 \mathrm{ng} / \mathrm{ml}$ until 20 weeks post-calving (Figure 9.3). There was no direct correlation between concentrations of IGF-I in blood plasma and milk.

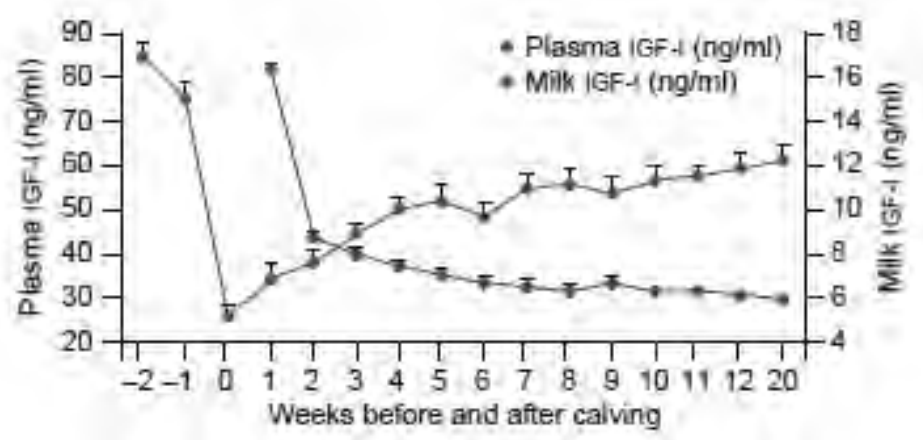

Figure 9.3. Insulin-like growth factor-I (IGF-I) concentrations in plasma and milk from 50 multiparous Holstein-Friesian cows (SOURCE: Reproduced from Taylor et al., 2004. Relationships between the plasma concentrations of insulin-like growth factor-I in dairy cows and their fertility and milk yield. Veterinary Record, 155: 583-588, with permission from BMJ Publishing Group Ltd.) 
Collier et al., (2008) investigated the effect of rbST on IGF-I concentrations in milk from lactating cows separately in summer and winter. Summer and winter each consisted of six treatment periods: (1) season farm management of all cows for the first 30 days; (2) 7 days' adjustment to conditions in the climate chambers; (3) exposure of one half of the animals to thermoneutral conditions and exposure of the other half to appropriate cold or hot conditions for 10 days; (4) cold or hot adjustment for 4 days; (5) reversed temperature exposure from period 3 for 10 days; and (6) 5 days post-treatment in a switchover design. Winter conditions were $5^{\circ} \mathrm{C}$ and climate chambers for cold set at -5 to $+5^{\circ} \mathrm{C}$ and for thermoneutral conditions at $15-22^{\circ} \mathrm{C}$. Summer conditions were $18-35^{\circ} \mathrm{C}$ and climate chambers set at $24-35^{\circ} \mathrm{C}$ for hot conditions and at $15-22^{\circ} \mathrm{C}$ for thermoneutral conditions. Cows were given daily injections of rbST (sometribove, USAN; $25 \mathrm{mg} /$ day; six cows each study) or saline (control; six cows each study). During on-farm periods, blood and milk (morning and afternoon) samples were collected once weekly. During climate chamber periods, blood samples were collected every 2 days, and milk samples (morning and afternoon) were collected daily. Plasma and milk concentrations of IGF-I and IGF-II were determined by radioimmunoassay. IGF-I and IGF-II concentrations in plasma were increased in cows treated with rbST. Milk yields in experimental cows were higher in winter $(31.3 \mathrm{~kg}$ /day) than in summer $(27.0 \mathrm{~kg} /$ day $)$, but the response to rbST in milk production was numerically greater in summer than in winter $(7.5 \mathrm{~kg} /$ day versus $5.0 \mathrm{~kg} /$ day $)$. A pronounced seasonal pattern in basal and rbST-stimulated IGF-I concentrations, but not IGFII concentrations, was detected in plasma. Higher basal and rbST-stimulated IGF-I concentrations in plasma occurred in summer despite large decreases in feed intake and energy balance. IGF-I and IGF-II concentrations in milk were not affected by rbST treatment or season (Table 9.4). Although IGF-I and IGF-II concentrations in milk were unaffected by rbST treatment, total IGF output increased due to increased milk yield. It was concluded that the observed seasonal patterns in IGF-I concentrations in plasma (winter: $3.7 \mathrm{ng} / \mathrm{ml}$ versus $4.8 \mathrm{ng} / \mathrm{ml}$; and summer: $3.4 \mathrm{ng} / \mathrm{ml}$ versus $3.8 \mathrm{ng} / \mathrm{ml}$, in control and treated groups, respectively) may be indicative of seasonal differences in the coupling of the somatotrophinIGF axis. The studies failed to detect an uncoupling of the somatotrophin-IGF-I axis in summer, despite an induced negative energy balance during thermal stress.

Table 9.4. The effect of treatment and season on milk yield, IGF-I and IGF-II concentrations in milk and total milk IGF-I and IGF-II output

\begin{tabular}{|c|c|c|c|c|c|}
\hline & \multirow{2}{*}{$\begin{array}{l}\text { Milk yield } \\
\text { (kg/day) }\end{array}$} & \multicolumn{2}{|c|}{ Milk IGF-I } & \multicolumn{2}{|c|}{ Milk IGF-II } \\
\hline & & $\begin{array}{c}\text { Concentration } \\
(\mathrm{ng} / \mathrm{ml})\end{array}$ & $\begin{array}{l}\text { Output } \\
\text { ( } \mu \mathrm{g} / \text { day) }\end{array}$ & $\begin{array}{l}\text { Concentration } \\
\text { (ng/ml) }\end{array}$ & $\begin{array}{l}\text { Output } \\
\text { (mg/day) }\end{array}$ \\
\hline \multicolumn{6}{|c|}{ Treatment } \\
\hline Control & 26.0 & 3.91 & 101.6 & 45.7 & 1.2 \\
\hline rbST & $32.3^{\star \star}$ & 4.26 & $137.6^{\star \star}$ & 51.2 & $1.7^{\star}$ \\
\hline \multicolumn{6}{|c|}{ Season } \\
\hline Winter & $31.3^{\star \star \star}$ & 4.67 & $146.2^{\star \star \star}$ & 48.2 & 1.5 \\
\hline Summer & 27.0 & $3.51^{* *}$ & 94.8 & 48.7 & 1.3 \\
\hline
\end{tabular}

NOTES: IGF-I = insulin-like growth factor-I: IGF-II = insulin-like growth factor-II; rbST = recombinant bovine somatotrophin;

${ }^{\star}=$ rbST different from control, $P<0.05 ;{ }^{* \star}=$ rbST different from control, $P<0.01$; ${ }^{\star \star \star}=$ winter different from summer, $P<0.01$

SouRCE: Reprinted from Collier, R.J., Miller, M.A., McLaughlin, C.L., Johnson, H.D. and Baile, C.A. 2008. Effects of recombinant bovine somatotrophin (rbST) and season on plasma and milk insulin-like growth factors I (IGF-I) and II (IGF-II) in lactating dairy cows. Domestic Animal Endocrinology, 35(1): 16-23, with permission from Elsevier. 
Pauletti et al., (2005) studied the changes in IGF-I concentrations in colostrum in 42 pregnant multiparous Holstein cows randomly assigned to equally sized groups treated with either $500 \mathrm{mg}$ of rbST (Boostin, Cooper) or vitamin E, used as control. The treatments were initiated 35 days prepartum and repeated each 14 days until parturition. Colostrum and mammary secretions were collected daily for 7 days postpartum. IGF-I concentrations in serum, colostrum and milk were measured using an immunoradiometric assay. The mean IGF-I concentration in colostrum of rbST-treated cows was significantly $(P<0.05)$ higher than that of the control cows $(874.5 \pm 335.0 \mathrm{ng} / \mathrm{ml}$ versus $674.2 \pm 269.5 \mathrm{ng} / \mathrm{ml})$ on day 1 after calving. No significant differences $(P>0.05)$ in IGF-I concentrations in milk were subsequently observed between the two treatment groups; by day 7 postpartum, IGF-I concentrations in milk had decreased to $12.9 \mathrm{ng} / \mathrm{ml}$. At days 6 and 8, concentrations of IGF-I in milk in the control group were higher than those in rbST-treated cows, but not significantly.

In the cross-sectional study on retail milk samples (Vicini et al., 2008), described above, the mean concentrations of IGF-I in conventionally labelled milk and milk labelled as rbST-free and organic were $3.1 \pm 0.1,3.0 \pm 0.1$ and $2.7 \pm 0.1 \mathrm{ng} / \mathrm{ml}$, respectively. The mean IGF-I concentration was not different $(P>0.05)$ between conventional and rbST-free labelled milk, but was significantly lower $(P<0.05)$ in organic labelled milk. IGF-I concentrations in milk were measured by ECLIA using a Sector Imager 6000. Assays were performed at Monsanto. No information on the validation of the assay was provided.

Castigliego et al., (2011) determined hormone variations in serum and milk as potential indicators of treatment with an rbST in buffaloes. Eight lactating Italian buffaloes (Bubalus bubalis) were treated 5 times with a slow-release formulation of an rbST (Boostin ${ }^{\circledR}$, LG Life Sciences) at $500 \mathrm{mg}$ subcutaneously every 2 weeks over a period of 10 weeks. An additional eight buffaloes were administered physiological saline and used as controls. Blood samples were collected on the day before treatment and on Days 2, 5, 9 and 14 following each treatment. Milk samples were collected at the end of the mechanized morning milking on the day prior to the second and fifth treatment cycles and on Days 2, 9 and 14 following these two treatments. Concentrations of total somatotrophin in serum and concentrations of IGF-I in milk were measured using a sandwich ELISA validated for each compound and matrix. Total somatotrophin concentrations in serum increased on Day 2 after rbST treatment. The average total somatotrophin concentrations were approximately 20 times higher in treated relative to control buffaloes, and were significantly different $(P<0.001)$ in all five treatment cycles. IGF-I concentrations in serum increased rapidly after rbST treatment and persisted at least until Day 9, with significant differences $(P<0.001)$ in treated and
Figure 9.4. IGF-I variation in buffalo milk after rbST treatment. Comparisons between treated buffaloes $(n=8)$ and the controls $(n=8)$ are reported for Days 2, 9 and 14 of the cycles of injection 2 and 5. Data are reported as means \pm SEM; ${ }^{*} P<0.05 ;{ }^{* \star} P<0.01 ;{ }^{\star \star \star} P<0.001$.

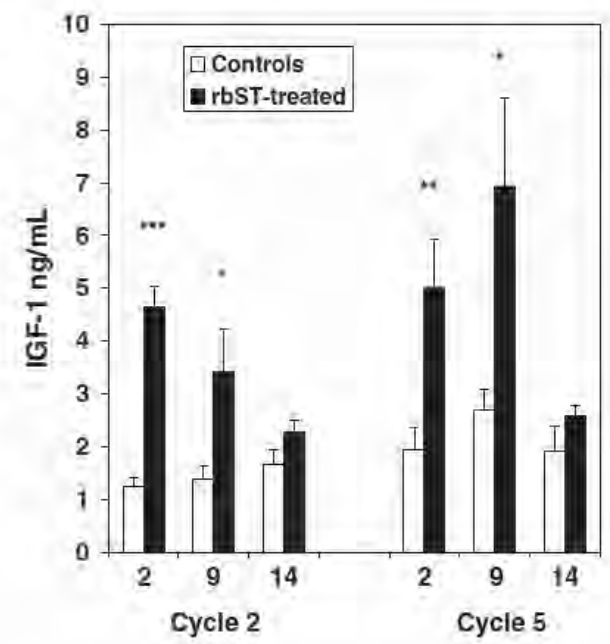

NOTES: IGF-I = insulin-like growth factor-I (given as IGF-1 in figure); rbST = recombinant bovine somatotrophin; SEM = standard error of the mean.

SOURCE: Reproduced from Castigliego, L., Li, X.N., Armani, A., Grifoni, G., Boselli, C., Rosati, R., Gianfaldoni, D. and Guidi, A. 2011. Hormone variations in serum and milk of buffaloes (Bubalus bubalis) as potential indicators of treatment with recombinant bovine somatotrophin. Journal of Dairy Research, 78: 412-420, with permission of Cambridge University Press. 
control animals. The IGF-I concentrations in milk were significantly $(P<0.05$ to $<0.001$ ) higher in treated animals compared with the control animals at each day after treatment on each treatment cycle (Figure 9.4). The IGF-I concentration in milk increased after treatment but returned to a concentration similar to that of controls by 14 days post-treatment. The highest IGF-I concentrations reported in milk from treated buffaloes were $4.5-7 \mathrm{ng} / \mathrm{ml}$, compared with $1.5-3 \mathrm{ng} / \mathrm{ml}$ in untreated controls.

Prasad and Singh (2010) determined the influence of short-term treatment of rbST on plasma growth hormone, IGF-I, prolactin and milk production of Murrah buffaloes in early lactation. Ten Murrah buffaloes in early production were each infused with $5 \mathrm{mg}$ of an intravenous solution of rbST (rbST, Monsanto; NHPP-NIDDK, lot M010-001) per day for 5 consecutive days (Days 21-25 postpartum). A mean IGF-I concentration in milk of 34.8 $\pm 3.5 \mathrm{ng} / \mathrm{ml}(29.7 \pm 4.5$ to $38.1 \pm 3.4 \mathrm{ng} / \mathrm{ml})$ was observed pre-treatment. IGF-I concentrations were low at the start of the treatment on Days 1, 2 and 3 but increased on Day 4 onwards, reaching a maximum of $42.0 \pm 5.2 \mathrm{ng} / \mathrm{ml}$ on Day 1 after the last treatment and declining thereafter. No significant changes $(P>0.05)$ in IGF-I concentration in milk were observed in pooled data of all three phases (before, during and after treatment) of the study.

Faulkner (1999) studied the changes in concentrations of glucose and IGF-I in plasma and milk in response to ovine somatotrophin in five British Saanen goats in their third to fifth lactations. Lactating goats were treated with $3 \mathrm{mg}$ ovine somatotrophin subcutaneously on the 3rd and 4th days of the study. The concentrations of IGF-I were determined in milk after de-fattening using a double-antibody radioimmunoassay. Prior to determination of total IGF-I in fat-free milk, samples were extracted for 48 hours at $\mathrm{pH} 3.7$ in glycylglycine to remove or inactivate binding proteins. The concentration of total IGF-I in milk increased significantly $(P<0.04)$ immediately after ovine somatotrophin treatment $(30$-minute sample) from pre-treatment concentrations of about $5 \mathrm{ng} / \mathrm{ml}$, reaching a peak of about $15 \mathrm{ng} / \mathrm{ml}$, and preceded that in plasma by approximately 48 hours. This would indicate that the increased concentrations of IGF-I in milk are due to increased local production within the environment of the mammary gland or as a result of an efficient extraction of IGF-I from the circulation.

Although the species most commonly used for milk production is cattle, references to administration in goat (Faulkner, 1999) and buffaloes (Prasad and Singh, 2010; Castigliego et al., 2011) showed that even using different dosages, the resulting effects and concentrations of rbST and IGF-I are constant, regardless of the species.

The Committee considered all new information on the normal variation in IGF-I concentrations in cow milk and the effect of rbST treatment on IGF-I concentrations in milk, as summarized in Table 9.3, and noted that the conclusions made at the 40th and 50th Meetings are not substantially changed. No new information provided by the sponsor or sourced from the literature was obtained from studies performed according to GLP. Analytical methods used for bST and IGF-I in the various biological matrices are all immunologically based and measure mostly total content. Nevertheless, the available data examined corroborate the Committee's previous conclusions that IGF-I concentrations in cow's milk are highly variable and are influenced by parity, stage of lactation, season, udder health and somatic cell counts of the milk. Treatment of cows with rbST increases the mean IGF-I concentration in milk, but such increases are within the normal physiological variations observed in lactating cows. The wide range of IGF-I concentrations and different conclusions about the increase after bST application might be due to different analytical methods used, including potential interference caused by IGF binding proteins.

\section{IGF-I concentrations in tissues}

The 40th Meeting reported that IGF-I concentrations in biopsied muscle and liver of rbSTtreated cows increased at most 2-fold when compared with those of untreated cattle (JECFA, 1993 [TRS 832]). The concentrations of IGF-I in muscle and liver ranged from 91 to $312 \mu \mathrm{g} / \mathrm{kg}$ and from 72 to $162 \mu \mathrm{g} / \mathrm{kg}$, respectively, in rbST-treated cattle, compared with $68-272 \mu \mathrm{g} / \mathrm{kg}$ 
and $70-77 \mu \mathrm{g} / \mathrm{kg}$, respectively, in untreated cattle. It was suggested that the elevated IGF-I concentrations in muscle could have been attributed to wound healing and not to rbST treatment. At the 50th Meeting, no significant differences were found between treated cows and untreated controls in the concentrations of IGF-I in muscle, fat, liver or kidney (JECFA, 1999 [TRS 888]). Concentrations of IGF-I measured by radioimmunoassay varied from 34.9 \pm 15.2 to $131.8 \pm 24.6 \mu \mathrm{g} / \mathrm{kg}$ in muscle, from $203.6 \pm 52.6$ to $339.1 \pm 229.2 \mu \mathrm{g} / \mathrm{kg}$ in fat, from $294.4 \pm 88.4$ to $389.6 \pm 132.3 \mu \mathrm{g} / \mathrm{kg}$ in liver, and from $821.1 \pm 124.0$ to $997.0 \pm 140.2 \mu \mathrm{g} / \mathrm{kg}$ in kidney. Previous assessments of the Committee summarized that the residues of rbST or IGF-I in various tissues of rbST-treated cows did not significantly differ from those of controls or that the slight increase in tissue residues is unlikely to be of concern for human health. A literature search did not identify new information on tissue IGF-I concentrations in rbST-treated animals.

\section{Methods of analysis}

The analytical methods used to determine bST and IGF-l in milk and tissues evaluated at the 40th and 50th Meetings of the Committee were exclusively immunoassay procedures and could not distinguish between natural bST and rbST.

Methods for assaying IGF-I were considered by the present Committee. Although incomplete removal of IGF binding proteins or variation of standard source and extraction methods might influence reported values, these factors were not perceived to materially alter the conclusions that were taken. While some studies reported higher concentrations of IGF-I in milk, the Committee considered these studies to reflect differences in extraction procedures.

Some of the new methods that have been developed for detection of $\mathrm{rbST} / \mathrm{bST}$ are summarized in Table 9.5. Most of the methods (e.g. immunoassays) do not differentiate between native bST and rbSTs. However, a few mass spectrometry methods allow the unambiguous identification of endogenous and recombinant forms (Pinel, André and Le Bizec, 2004; Bailly-Chouriberry et al., 2008). These methods were developed to identify noncompliant use of rbSTs in countries where they are not authorized.

The Committee noted that a recent review described the state of the art in the detection of rbSTs in food-producing animals (Dervilly-Pinel et al., 2014).

Table 9.5. Summary of recent bST analytical methods

\begin{tabular}{llll}
\hline \multicolumn{1}{c}{ Method } & Species and tissues & Sensitivity & \multicolumn{1}{c}{ Reference } \\
\hline ECLIA & Bovine milk & $<5 \mathrm{pg} / \mathrm{ml}$ & McGrath et al., 2008 \\
ELISA & Bovine milk & $0.05 \mathrm{ng} / \mathrm{ml}$ & Castigliego et al., 2007 \\
ELISA & Buffalo serum and milk & $0.1 \mathrm{ng} / \mathrm{ml}$ & $\begin{array}{l}\text { Mishra et al., 2005; } \\
\text { Mishra, Goswani and Shukla, 2007 }\end{array}$ \\
ELISA & Shrimp feed & $10 \mu \mathrm{g} / \mathrm{g}$ & Munro and Boon, 2010 \\
LC-MS/MS & Goat plasma & $10 \mathrm{ng} / \mathrm{ml}$ & Le Breton et al., 2008 \\
LC-MS/MS & Bovine serum & $10 \mathrm{ng} / \mathrm{ml}$ & Le Breton et al., 2009 \\
LC-MS/MS & Bovine milk & $C C \alpha \leq 1.24 \mathrm{ng} / \mathrm{ml} ; C C \beta \leq 1.92 \mathrm{ng} / \mathrm{ml}$ & Le Breton et al., 2010a \\
LC-MS/MS & Bovine blood & $C C \alpha \leq 2.5 \mathrm{ng} / \mathrm{ml} ; C C \beta \leq 6.8 \mathrm{ng} / \mathrm{ml}$ & Le Breton et al., 2010b \\
LC-MS/MS & Trout serum & $0.5 \mu \mathrm{gl} / \mathrm{ml}$ & Rochereau-Roulet et al., 2013 \\
\hline
\end{tabular}

NOTES: bST = bovine somatotrophin; $C C \alpha=$ decision limit; $C C \beta=$ detection capability; $E C L I A=$ electrochemiluminescent immunoassay; ELISA = enzyme-linked immunosorbent assay; LC-MS/MS = liquid chromatography-tandem mass spectrometry. 


\section{Bio-availability and bio-activity of IGF-I}

The 40th Committee Meeting concluded that many of the physiological effects of rbSTs are mediated by bovine IGF-I, which is structurally identical to human IGF-I and is likely to have similar effects in humans (JECFA, 1993 [TRS 832]). The Meeting further concluded that IGF-I had no bio-activity when administered orally to normal and hypophysectomized rats at doses up to $2 \mathrm{mg} / \mathrm{kg}$ bw per day.

The 50th Committee Meeting (JECFA, 1999 [TRS 888]) reported that IGF-I is found in abundance in a variety of body fluids (Table 9.6).

The 50th Meeting indicated that, for quantitative risk assessment, the slight increases in IGF-I concentrations in milk from rbST-treated cows have to be compared with the physiological variations in IGF-I during lactation as well as with the concentrations in human breast milk, in the secretions of the gastrointestinal tract and in serum. It estimated that the incremental human exposure to IGF-I through consumption of $1.5 \mathrm{~L} /$ day of rbST-treated cow milk represented $0.79 \%$ of the IGF-I secreted daily in the gastrointestinal tract and less than $0.09 \%$ of the daily production $\left(10^{7} \mathrm{ng} /\right.$ day $)$ of IGF-I in adults. Whereas the 40th Meeting considered IGF-I to be completely and rapidly degraded in the gastrointestinal tract, the 50th Meeting considered that some milk-borne IGF-I may escape digestion by gastrointestinal enzymes and be bio-available, leading to some absorption. Nonetheless, the 50th Meeting concluded that even if IGF-I in milk were absorbed, the additional amount would be negligible and unlikely to have an adverse impact in humans. Limited additional data available on the bio-availability or bio-activity of IGF-I since then, and summarized below, do not substantially change the previous conclusions of the Committee.
Table 9.6. IGF-I concentrations in milk and body fluids of humans

\begin{tabular}{|c|c|}
\hline Fluid & $\begin{array}{c}\text { IGF-I } \\
\text { concentration } \\
\text { (ng/ml) }\end{array}$ \\
\hline \multicolumn{2}{|c|}{ Cow's milk (bulk milk) } \\
\hline Untreated & $1-9$ \\
\hline Treated with rbSTs & $1-13$ \\
\hline \multicolumn{2}{|c|}{ Human milk } \\
\hline Milk & $5-10$ \\
\hline Colostrum & $8-28$ \\
\hline \multicolumn{2}{|c|}{ Human plasma } \\
\hline Children & $17-250$ \\
\hline Adolescents & $182-780$ \\
\hline Adults & $123-460$ \\
\hline \multicolumn{2}{|c|}{ Human gastrointestinal secretions } \\
\hline Saliva & 6.8 \\
\hline Gastric juice & 26 \\
\hline Pancreatic juice & 27 \\
\hline Bile & 6.8 \\
\hline Jejunal chyme & 180 \\
\hline $\begin{array}{l}\text { Daily adult human } \\
\text { production }\end{array}$ & $10^{7} \mathrm{ng} /$ day \\
\hline
\end{tabular}

NOTES: IGF-I = insulin-like growth factor-I; rbSTs $=$ recombinant bovine somatotrophins. SOURCE: Adapted from Table 8 in WHO, 1998.

Consistent with previous reports of the Committee, new in vitro digestion studies (Rao et al., 1998; Shen and Xu, 2000; Fellah et al., 2001; Anderle et al., 2002; Nabil et al., 2011) suggest that IGF-I is degraded by intestinal enzymes, but in vivo IGF-I degradation by gastrointestinal enzymes could be delayed by the components in milk/colostrum (Shen and $\mathrm{Xu}, 2000$ ). Also, analytical methods used could influence the outcome of such measurements. For example, degradation of IGF-I measured by trichloroacetic acid precipitation often overestimated the amount of intact IGF-I when compared with the data from receptor binding assays (Rao et al., 1998; Shen and Xu, 2000).

New data from in vivo studies in laboratory animals (Philipps et al., 2000, 2002) demonstrate that a fraction of orally administered IGF-I is absorbed from the intestines. Suckling rats 10-12 days of age were administered ${ }^{125}$ I-labelled recombinant human (rh) IGFI $\left(4 \times 10^{6}\right.$ counts per minute) by gavage in milk, and the radioactivity in portal and cardiac blood was examined at 5, 10, 20 and 30 minutes post-treatment (Philipps et al., 2000). Purified radioactive samples were tested by gel chromatography and receptor binding assays. Radioactivity was detected in both portal and cardiac blood (maximum levels detected at 2030 minutes post-treatment), but it was lower in the latter. The radioactivity present in the cardiac blood co-migrating at the position of native IGF-I was highest at 5 minutes posttreatment, but decreased significantly thereafter. However, a statistically non-significant 
numerical increase in radioactivity was observed in the portal blood from 5 to 30 minutes post-treatment. It was estimated that approximately $17-26 \%$ of the dose administered, as measured by radioactivity, reached the portal blood, but only a fraction of that reached the systemic circulation. Also, the radioactive peak found in hepatic blood from IGF-I-fed animals was receptor active, although its binding in the competitive assay was weaker when compared with native IGF-I binding. Owing to extremely low concentrations, the authors could not perform adequate competitive binding studies on purified radioactive material from cardiac blood. This study, while demonstrating that almost a quarter of IGF-I administered in milk is absorbed from the intestine, could not definitively determine what proportion of IGF-I absorbed into the portal circulation enters the systemic circulation. In a subsequent study, the intestinal transport of IGF-I in suckling rats was shown to be nonsaturable up to $1 \mu \mathrm{g} / \mathrm{ml}$ of IGF-I, a concentration 200-fold in excess of that in colostrum (Philipps et al., 2002).

Kim et al. (2006) demonstrated that weanling mice $(\mathrm{n}=35)$ administered a single oral dose $(1 \mu \mathrm{g} / \mathrm{g})$ of IGF-I in phosphate-buffered saline (PBS) had a transient higher concentration of serum IGF-I between 4 and 8 hours after treatment, with the highest concentration at 4 hours, when compared with PBS-treated controls $(n=35)$. Serum concentrations of IGF-I and IGF-II did not differ in weanling mice $(\mathrm{n}=20)$ administered five separate doses of IGF-I at $1 \mu \mathrm{g} / \mathrm{g}$ repeated every 3 days, compared with PBS-treated controls $(\mathrm{n}=20)$ at Days 7 and 13 post-treatment. Although the authors concluded that increased serum concentrations of IGF-I in treated rats are evidence of its oral bio-availability, the experimental design cannot rule out whether such an increase was modulated by the local action of IGF-I in intestinal mucosa or due to its systemic availability. The dose of IGF-I administered to the mice, which is more than 150 times the amount that a person would consume per day in milk from rbSTtreated cows ( $9 \mu \mathrm{g}$ per $1.5 \mathrm{~L}$ of milk, as concluded at the 50th Meeting), may further have contributed to the systemic absorption.

Also, there is some evidence in the literature that orally administered IGF-I might have some local activity in the gut (e.g. increase in the weight of small intestine, increased enzyme activities) of laboratory animals (Burrin, 1997; Houle et al., 2000; Alexander and Carey, 2001; Burrin et al., 2001; Kim et al., 2006).

Le Breton et al. (2010a) conducted a study on the effects of industrial processes on milk stability together with the detection of rbSTs. The study was conducted on commercial ultrahigh-temperature (UHT) milk as well as on raw milk, condensed milk and milk powder. The milk treatments analysed were defatting, heating, freezing, pasteurization and spray-drying. The results demonstrated that the processes that did not involve heating allowed a recovery of the hormone up to $90 \%$, whereas heating, pasteurization and spray-drying induced a significant loss. Regarding the concentration of IGF-I, it is known that higher temperatures, such as those associated with infant formula preparation, will denature it.

Studies in humans suggest that low nutrition level, including malnutrition, starvation, semi-starvation, fasting and caloric restrictions, lowers the IGF-I concentration in plasma (Livingstone, 2013). IGF-I concentrations in plasma are also affected by various physiological or pathological stages in humans (Livingstone, 2013). Several studies have indicated that IGF-I concentrations in human serum could be associated with nutritional status and milk intake. Milk consumption is particularly shown to be associated with an increase in concentrations of IGF-I in plasma in both the young and adults. In an intervention study, when men aged 55-85 years were instructed to drink three servings of non-fat or 1\% milk per day as part of their normal diet, IGF-I concentrations in serum increased significantly $(10 \%)$ in the intervention group by the end of the 12-week intervention period compared with concentrations in those who maintained their normal diet (Heaney et al., 1999). In another intervention study in Mongolia, after a month of drinking whole milk, 10- to 11-year-old school children had higher mean levels of IGF-I, ratios of IGF-I to IGF binding protein 3 
(IGFBP-3) and 75th percentiles of growth hormone levels in plasma. A similar, albeit smaller and non-significant, increase in IGF-I, IGF-I/IGFBP-3 and growth hormone levels in plasma was also observed after a week of drinking low-fat milk by girls aged 6-8 years in Boston, Massachusetts, United States of America (Rich-Edwards et al., 2007). A Danish intervention study demonstrated that IGF-I concentrations in serum and serum IGF-I/IGFBP-3 ratio in 8year-old boys $(n=12)$ increased from baseline after daily consumption of $1.5 \mathrm{~L}$ of milk for 7 days. However, in boys $(\mathrm{n}=12)$ supplemented with similar levels of protein from $250 \mathrm{~g}$ of low-fat meat, these changes were not observed, suggesting that consumption of milk, but not animal protein alone, is associated with the increase in IGF-I level in plasma (Hoppe et al., 2004). A case-control study in the United States of America also suggested that low-fat-milk intake, but neither red meat, poultry nor fish intake, was positively associated with IGF-I level in serum and IGF-I/IGFBP-3 ratio (Ma et al., 2001). A European prospective investigational study (Crowe et al., 2009) associated dairy protein and calcium intake with increased IGF-I concentrations in serum. A mean increase in IGF-I concentration in plasma of $13.8 \mathrm{ng} / \mathrm{ml}$ (95\% confidence interval 6.1-21.5) in intervention groups consuming cow milk when compared with the controls was reported in a meta-analysis of published literature (Qin, $\mathrm{He}$ and $\mathrm{Xu}, 2009$ ). Evidence therefore points to the fact that drinking milk is associated with an increase in IGF-I levels in plasma, which, however, could be modulated by the existing nutritional or health status of a person. The effect of nutrition or foods, especially milk, on IGF-I level in plasma is, however, short lived (i.e. with no long-term effect). In a British long-term study (Carnegie [Boyd Orr] Survey) involving 728 subjects followed up for 65 years, IGF-I level in adulthood was negatively correlated with childhood family diets (based on 7-day household food inventories) high in milk (Martin et al., 2007).

Although the studies reviewed above demonstrated that consumption of milk could increase the IGF-I concentrations in blood, whether such increases were due to absorption of IGF-I from milk into the systemic circulation or stimulation of endogenous IGF-I production was not investigated.

Studies on the absorption of orally consumed IGF-I in humans were also available. In one study, the effect of enteral IGF-I supplementation on feeding tolerance, growth and gut permeability in premature infants during the 1st month of life in a prospective, double-blind, randomized study was examined (Corpeleijn et al., 2008). The study was conducted according to European good clinical practice regulations. Neonates received either standard infant formula $(\mathrm{n}=32)$ or standard formula supplemented with IGF-I, extracted from bovine whey, at $100 \mu \mathrm{g} / \mathrm{L}(\mathrm{n}=28)$ during the first 28 days of life. Enteral IGF-I supplementation had no statistical effects $(P>0.05)$ on concentrations of IGF-I, IGFBP-1 and IGFBP-3 or growth hormone in serum compared with the control group throughout the study. No statistical difference in the primary end-points of days to full enteral feeding, days to regain birth weight or rate of weight gain as well as a range of clinical and anthropometric measures was observed. The results of a lactulose/mannitol excretion test as a secondary end-point, performed at 7-day intervals as a measure of intestinal permeability, indicated no statistically significant differences $(P>0.05)$ between the two groups on Day 1, 7, 21 or 28 . On Day 14, the ratio was significantly reduced $(P=0.022)$, indicating reduced gut permeability in the IGF-Itreated group. There were no differences in intestinal maturation expressed as lactase activity at the same time-points. This study, where the controls were supplemented with similar formula with lower levels of IGF-I, provided no evidence of oral absorption of IGF-I at a dose roughly 1-2 times the concentration found in human colostrum (Table 9.6) and at about 20 times that of milk from contemporary rbST-untreated cows.

The second study specifically examined the effect of bovine colostrum supplementation on IGF-I concentrations in serum in one portion of the study and the oral absorption of IGF-I in a second portion in adult athletes (Mero et al., 2002). In the first portion of the study, adult male and female athletes were randomly assigned in a double-blind design to either a 
colostrum-treated group $(n=19)$ or a placebo-treated control group $(n=11)$. The colostrumtreated group received an oral bovine colostrum supplement $(20 \mathrm{~g})$ that contained a total of $74 \mu \mathrm{g}$ IGF-I, and the control group received maltodextrin $(20 \mathrm{~g})$, daily during a 2-week training period. A significant increase $(17 \% ; P<0.01)$ in IGF-I concentrations in serum was observed in the colostrum-treated group compared with the placebo-treated group. The concentration of circulating IGF-I steadily increased $(0.38 \mathrm{nmol} / \mathrm{L}$ per day) over the 14-day treatment period, which was ascribed to either direct absorption of IGF-I from the colostrum supplementation or enhanced stimulation of human IGF-I synthesis. In the second portion of the study, the absorption of ${ }^{123}$ I-labelled rhIGF-I orally administered to six male (mean age 29.1 years) and six female (mean age 23.9 years) athletes was examined. The study involved the preparation of ${ }^{123} \mathrm{I}$-labelled IGF-I, validation of the biological activity of the radiolabelled IGF-I by receptor binding assay and blood sampling $(n=7)$ of subjects over the test day following oral administration of the ${ }^{123}$ I-labelled rhIGF-I. IGF-I concentrations in serum measured using a two-site immuno-enzymometric assay showed no significant differences during the first 180 minutes after ${ }^{123}$ I-labelled rhIGF-I treatment. At 7 hours after treatment, following a standard lunch, the concentrations were significantly increased $(17 \% ; P<0.01)$ compared with the pre-treatment concentration $(20 \mathrm{nmol} / \mathrm{L})$. Gel filtration of serum samples demonstrated radiolabel in low molecular weight substances, but no radioactivity at the elution positions of free IGF-I or the IGF-I binding proteins. The results provided no evidence for the absorption of orally consumed IGF-I in adult athletes; alternatively, the absorbed IGF-I was subject to an extensive first-pass effect.

Four separate randomized controlled studies investigated whether supplementing bovine colostrum with IGF-I $(2 \mathrm{mg} / \mathrm{kg})$ would increase the concentrations of IGF-I in plasma from human volunteers who were active athletes or participating in endurance training (Buckley et al., 2002; Coombes et al., 2002; Kuipers et al., 2002; Buckley, Brinkworth and Abbott, 2003). Volunteers were supplemented with $60 \mathrm{~g}$ of bovine colostrum or $60 \mathrm{~g}$ of concentrated whey protein for 4 or 8 weeks. In all four studies, IGF-I concentrations in plasma from the intervention group did not differ either pre-treatment or during or at the end of the supplementation when compared with whey protein-fed controls. Data reviewed in the earlier section Insulin-like growth factor-I in tissues and milk and those reviewed by the 50th Meeting of the Committee (WHO, 1998) suggest that the mean IGF-I concentrations in milk from rbST-treated and control cows are approximately $6 \mathrm{ng} / \mathrm{ml}$ and $4 \mathrm{ng} / \mathrm{ml}$, respectively. A person consuming $1.5 \mathrm{~L}$ of milk from rbST-treated cows would therefore be exposed to 9000 ng of IGF-I per day, and the incremental increased exposure coming from the rbST use would be only $3000 \mathrm{ng} /$ day. In contrast, in the trials reviewed above, study participants were supplemented with 120000 ng of IGF-I per day. However, the IGF-I concentrations in their plasma did not differ from those of whey protein-fed controls. These findings suggest that the circulating IGF-I concentrations in humans would increase by ingestion of milk (or its components), but would not be affected by the amount of IGF-I ingested in food.

\section{Milk nutritional composition}

The Committee at its 40th and 50th Meetings examined the effects of rbST on milk composition and concluded that nutritional components and further processing characteristics of milk are not altered by rbST treatment (JECFA, 1993 [TRS 832]; JECFA, 1999 [TRS 888]). Furthermore, the composition of milk from treated cows is well within the normal variation observed during the course of a lactation.

The composition of milk from cows treated with rbST in comparison with untreated controls that are available from recent publications is summarized in Table 9.7. In concurrence with the conclusions of the previous meetings, these data demonstrate that there is no impact of rbSTs on the nutritional qualities of milk. 
Table 9.7. Milk yield and protein, fat and lactose contents among rbST-treated and control animals

\begin{tabular}{|c|c|c|c|c|c|c|}
\hline Species & $\begin{array}{l}\text { Group } \\
\text { treatment }\end{array}$ & $\begin{array}{l}\text { Milk yield (kg/day } \\
\text { or L/day) }\end{array}$ & $\begin{array}{l}\text { Protein } \\
(\%)\end{array}$ & $\begin{array}{l}\text { Fat } \\
\text { (\%) }\end{array}$ & $\begin{array}{l}\text { Lactose } \\
\text { (\%) }\end{array}$ & Reference \\
\hline \multirow[t]{2}{*}{ Cattle } & Control & 23.5 & 3.65 & 4.29 & 9.00 & \multirow[t]{2}{*}{ Kim and Kim, 2012} \\
\hline & rbST & 27.7 & 3.30 & 3.84 & 8.89 & \\
\hline \multirow[t]{2}{*}{ Cattle } & Control & 20.7 & 3.16 & 3.50 & 4.51 & \multirow[t]{2}{*}{ Campos et al., 2011} \\
\hline & rbST & 22.6 & 3.16 & 3.52 & 4.39 & \\
\hline \multirow[t]{2}{*}{ Cattle } & Control & 15.6 & 3.27 & 3.67 & - & \multirow{2}{*}{$\begin{array}{l}\text { Macrina, Tozer and } \\
\text { Kensinger, } 2011\end{array}$} \\
\hline & rbST & 17.9 & 3.28 & 3.65 & - & \\
\hline \multirow[t]{2}{*}{ Cattle } & Control & 41.9 & 2.86 & 3.65 & - & \multirow[t]{2}{*}{ Rivera et al., 2010} \\
\hline & rbST & 45.4 & 2.81 & 3.30 & - & \\
\hline \multirow[t]{2}{*}{ Cattle } & Control & 36.1 & 2.90 & 3.82 & - & \multirow[t]{2}{*}{ Liboni et al., 2008} \\
\hline & $\mathrm{rbST}$ & 37.6 & 2.83 & 3.78 & - & \\
\hline \multirow[t]{2}{*}{ Cattle } & Control & 12.9 & 3.45 & 3.94 & 4.90 & \multirow[t]{2}{*}{ Chaiyabutr et al., 2007, 2008} \\
\hline & rbST & 14.6 & 3.51 & 4.24 & 4.62 & \\
\hline \multirow[t]{2}{*}{ Cattle } & Control & 33.5 & 3.08 & 3.53 & - & \multirow{2}{*}{$\begin{array}{l}\text { Al-Seaf, Keown and van } \\
\text { Vleck, 2007a, b }\end{array}$} \\
\hline & rbST & 36.8 & 3.06 & 3.55 & - & \\
\hline \multirow[t]{2}{*}{ Cows } & Control & $22.3^{(1)}$ & 3.0 & 3.6 & 4.8 & \multirow[t]{2}{*}{ Annen et al., 2007} \\
\hline & rbST & $22.4^{(1)}$ & 3.1 & 3.5 & 4.9 & \\
\hline \multirow[t]{2}{*}{ Cattle } & Control & 38.8 & 2.84 & 3.61 & - & \multirow{2}{*}{$\begin{array}{l}\text { Blevins, Shirley and } \\
\text { Stevenson, } 2006\end{array}$} \\
\hline & rbST & 39.6 & 2.78 & 3.54 & - & \\
\hline \multirow[t]{2}{*}{ Cattle } & Control & 32.5 & 3.11 & 3.57 & 4.75 & \multirow{2}{*}{$\begin{array}{l}\text { Rose, Weekes and } \\
\text { Rowlinson, } 2005\end{array}$} \\
\hline & rbST & 36.6 & 3.03 & 4.33 & 4.79 & \\
\hline \multirow[t]{2}{*}{ Cattle } & Control & 13.11 & 3.27 & 3.60 & 4.52 & \multirow{2}{*}{$\begin{array}{l}\text { Maksiri, Chanpongsang and } \\
\text { Chaiyabutr, } 2005\end{array}$} \\
\hline & rbST & 16.02 & 3.16 & 4.70 & 4.79 & \\
\hline Cattle & Control & 16.2 & 3.22 & 3.65 & - & Fike et al., 2002 \\
\hline & rbST & 17.7 & 3.23 & 3.80 & - & \\
\hline Cattle & Control & 25.9 & 3.13 & 3.55 & 5.00 & Capuco et al., 2001 \\
\hline & rbST & 29.3 & 2.84 & 3.80 & 4.98 & \\
\hline Cattle & Control & 40.2 & 2.92 & 3.12 & - & Moallem, Folman and Sklan, \\
\hline & rbST & 45.4 & 2.94 & 3.19 & - & 2000 \\
\hline Cattle & Control & 29.0 & 3.05 & 3.13 & 4.89 & Tarazon Herrera et al., 1999 \\
\hline & rbST & 32.6 & 3.05 & 3.31 & 4.95 & \\
\hline Cattle & Control & 30.5 & 3.3 & 4.2 & 4.8 & Miller et al., 1999 \\
\hline & $\mathrm{rbST}$ & 25.2 & 3.3. & 4.2 & 4.7 & \\
\hline Cattle & Control & 28.8 & 3.15 & 3.64 & - & Bauman et al., 1999 \\
\hline & rbST & 33.0 & 3.17 & 3.57 & - & \\
\hline Buffaloes & Control & 7.17 & 3.78 & 4.69 & 4.75 & Feckinghaus, 2009 \\
\hline & rbST & 8.59 & 3.78 & 4.85 & 4.90 & \\
\hline Buffaloes & Control & 5.67 & 4.75 & 6.96 & - & Jorge, Gomes and Halt, 2002 \\
\hline & rbST & 7.53 & 4.58 & 6.82 & - & \\
\hline Goats & Control & 0.960 & 3.14 & 4.64 & 3.58 & Qudus et al., 2013 \\
\hline & rbST & 1.473 & 3.28 & 4.76 & 3.92 & \\
\hline Goats & Control & 8.9 & 3.31 & 4.39 & 4.34 & Moraes e Amorim et al., 2006 \\
\hline & rbST & 9.0 & 3.30 & 4.44 & 4.47 & \\
\hline Sheep & Control & 1.23 & 4.89 & 6.14 & - & Andrade et al., 2008 \\
\hline & rbST & 2.51 & 4.88 & 5.92 & - & \\
\hline Sheep & Control & 0.683 & 4.6 & 3.6 & 4.8 & Sallam, Nasser and Yousef, \\
\hline & $\mathrm{rbST}$ & 0.868 & 4.8 & 3.8 & 4.8 & 2005 \\
\hline
\end{tabular}

NOTES: rbST = recombinant bovine somatotrophin; (1) Half udder milk yield. 


\section{Possible effects of rbSTs on the expression of certain viruses and prions in cattle}

The 50th Meeting of the Committee evaluated whether the immunomodulatory effect of bST would affect expression of retroviruses or prion proteins in treated animals and concluded that (i) available studies provided no evidence that rbSTs affect the expression of retroviruses in cattle, and (ii) the possibility of a link between rbST treatment and bovine spongiform encephalopathy (BSE) was highly speculative, and there was no evidence for a direct link between rbST treatment and BSE (JECFA, 1999 [TRS 888]).

The literature search as described above for publications from 1998 to August 2013 retrieved 126 unique articles that included the term "virus" OR "lentivirus" OR "retrovirus" OR "prion". None of these articles, however, investigated the effects of rbSTs on the expression of viruses or prions in cattle or other ruminants. No new information on the role of rbSTs in the expression of retroviruses or prion proteins in ruminants was available from the literature.

\section{Possible increased health risks to human neonates and young children}

\section{Diabetes}

The published literature does not associate milk or dairy consumption with type 2 diabetes (Aune et al., 2013; Gao et al., 2013). However, the literature is inconsistent on an association between milk or dairy consumption and risk for development of type 1 diabetes. Some, but not all, published studies have indicated that in children genetically predisposed to type 1 diabetes, cow milk feeding in early infancy, when an infant's gastrointestinal tract is not fully developed, could stimulate the production of antibodies that can cross-react with pancreatic islet $\beta$-cell surface antigens (Knip, Virtanen and Akerblom, 2010; Norris, 2010). These autoantibodies may be a risk factor for activation of autoreactive $\mathrm{T}$ cells and type 1 diabetes (Skyler, 2007). Stimulation of aberrant immune response in infancy, however, is not limited to milk components alone, as infants genetically predisposed to type 1 diabetes also have a generalized aberrant immune response to several other proteins, including those from cereals, fruits, berries, bacteria and viruses (Harrison and Honeyman, 1999; Vaarala, 2005, 2012; Simpson and Norris, 2008; Atkinson, 2012; Eringsmark Regnéll and Lernmark, 2013; Pugliese, 2013).

Studies reviewed by the 50th Meeting, as well as those published in the scientific literature since then (see Table 9.7), suggest that the composition of milk from rbST-treated cows does not differ from that of untreated controls. The only exception is a transient increase in the mean concentration of IGF-I in the milk from rbST-treated cows, which, however, falls within the normal physiological range observed in untreated animals (see earlier section on Insulin-like growth factor-I in tissues and milk).

Data primarily from knockout mice, but also from human studies, suggest that IGF-I is unlikely to have an adverse impact on the pathogenesis of diabetes in humans. When IGF-I was locally expressed in pancreatic islet $\beta$-cells, transgenic mice treated with streptozotocin had milder type 1 diabetes, and all transgenic mice survived, in contrast to control mice, which developed severe diabetes and died (George et al., 2002). Similarly, transgenic CD-1 mice expressing IGF-I in $\beta$-cells were also able to counteract the effect of autoimmune destruction of $\beta$-cells (Casellas et al., 2006). Results from other studies (Agudo et al., 2008; Robertson et al., 2008) also support that IGF-I produced locally in the islet of Langerhans promotes $\beta$-cell replication, reduces apoptosis and has antidiabetic effects by improving islet cell survival and/or providing insulin-like effects. Locally expressed IGF-I, however, did not cause the growth or mass increase of the islet itself. The parenteral administration of IGF-I or IGF-I/IGFBP-3 combinations reduced the severity of insulitis and reduced the onset of type 1 diabetes in non-obese diabetic transgenic mice (Chen et al., 2004).

In general, circulating levels of IGF-I are lower in patients with diabetes (Capoluongo et al., 2006), and case reports in humans have demonstrated that patients with severely insulin- 
resistant type 1 diabetes could become insulin sensitive for a prolonged period after weekly intravenous bolus infusion of IGF-I at $500 \mu \mathrm{g} / \mathrm{kg}$ bw (Usala et al., 1994). A clinical trial evaluated the efficacy of rhIGF-I in patients with type 1 diabetes in a randomized doubleblind study (Thrailkill et al., 1999). Treatment with rhIGF-I and insulin improved glycaemic control and significantly reduced the glycosylated haemoglobin level and daily insulin requirements. Other studies in humans have also demonstrated beneficial effects of IGF-I in the treatment of type 1 (Carroll et al., 2000) or type 2 diabetes (Moses et al., 1996; Murphy, 2006).

Available evidence suggests that IGF-I is unlikely to have an adverse impact on the pathogenesis of type 1 or type 2 diabetes in humans. As the milk composition did not materially differ between cows treated with rbSTs and untreated cows, the milk from rbSTtreated cows would not pose an additional risk for the development of diabetes.

\section{Cancer}

The Committee considered the potential cancer risk to humans associated with the consumption of milk from rbST-treated cows. rbSTs are not absorbed from the gastrointestinal tract, have species-specific receptor binding and are not bio-active in humans. Also, the orthologue (e.g. mouse and rat) somatotrophins did not cause cancer in mice and rats, respectively, when administered subcutaneously (see section above: Long-term studies on toxicity and carcinogenicity of recombinant mouse and rat somatotrophins). Therefore, the carcinogenicity risk of rbSTs themselves was considered negligible.

The normal physiological range of IGF-I in human plasma is very wide, ranging from 17 to $250 \mathrm{ng} / \mathrm{ml}$ in children, from 182 to $780 \mathrm{ng} / \mathrm{ml}$ in adolescents and from 123 to $460 \mathrm{ng} / \mathrm{ml}$ in adults (see Table 9.6). Several prospective and case-control epidemiological studies have shown that circulating IGF-I levels are higher, although within the normal physiological range, in some cancer patients (Clayton et al., 2011). Moreover, these findings were inconsistent between studies and between different types of cancer. No significant difference was noted in the concentrations of IGF-II or IGF binding proteins in blood between cancer patients and their controls (Clayton et al., 2011). Most of the observations on higher levels of circulating IGF-I in cancer patients were made in epidemiological studies in which the impact of reverse causation cannot be ruled out. Additionally, a recent review on possible carcinogenic hazard to consumers from IGF-I in the diet concluded that the available database is insufficient to link dietary IGF-I directly with breast cancer (Committee on Carcinogenicity, 2012).

Literature reviewed on the bio-availability of IGF-I (see the earlier section on Bioavailability and bio-activity of IGF-I) suggested that milk consumption could increase the concentrations of IGF-I in human serum. However, evidence was lacking that the increase was due to absorption of IGF-I in milk. The endogenous IGF-I production in humans will therefore be influenced by whether a person consumes milk at all, irrespective of whether the milk comes from rbST-treated or untreated cows. Further, when compared with the overall daily IGF-I production in human adults of $10 \mathrm{mg}$ (see Table 9.6), the putative contribution of milk-borne IGF-I is considered negligible. For example, a person consuming $1.5 \mathrm{~L}$ of milk from rbST-treated cows on average will be exposed to $9000 \mathrm{ng}$ of IGF-I per day, which is equal to $0.09 \%$ of the daily production of IGF-I in an adult.

\section{Increased use of antimicrobial agents to treat mastitis in cows treated with rbSTs}

The effect of rbST treatment on mastitis incidence and somatic cell count in milk from treated cows was not reviewed by the Committee at its 40th Meeting, as these effects were considered outside the Committee's terms of reference. At its 50th Meeting, the Committee reviewed published information and the results of a post-approval monitoring programme for sometribove $\left(\right.$ Posilac $^{\circledR}$ ) in the United States of America on the influence of rbSTs on mastitis and animal health. The Committee concluded that the effects of rbSTs on the 
incidence of mastitis and general health as well as the resulting days of treatment per animal with any medication are an issue of animal health and outside the terms of reference of the Committee. However, the Committee did consider the results of the post-approval monitoring programme on the percentage of milk discarded due to non-compliant (violative) drug residue as a consequence of antimicrobial use after the market availability of Posilac ${ }^{\circledast}$. It was concluded, based on the results of the programme, that the use of rbSTs will not result in a higher risk to human health due to the use of antimicrobial agents to treat mastitis and that the increased potential for drug residue in milk could be managed by practices currently in use by the dairy industry and by following label directions for use.

The present Committee updated the assessment performed at the 50th Meeting of the Committee. While acknowledging the issue of mastitis per se to be one of animal health and outside the terms of reference of the Committee, the Committee performed a systematic review of the literature concerning the effects of rbSTs on mastitis incidence and somatic cell counts, with particular reference to antimicrobial residues in milk. The literature search, as described above, for publications from 1998 to August 2013 retrieved 29 unique articles that included the term "somatic cell count(s)" OR "antibiotic" OR "mastitis". Some studies were located that evaluated the effects of rbSTs as a treatment for mastitis or that evaluated the effects of rbSTs on animal health parameters other than mastitis. These studies were excluded as irrelevant. An additional four relevant papers identified from review articles by De Vliegher et al. (2012) and Pezeshki et al. (2010) were also included in the review (Table 9.8).

Table 9.8. Studies investigating rbST use and mastitis or milk somatic cell counts in dairy animals.

\begin{tabular}{|c|c|c|c|c|c|}
\hline Study & Study design & Test animal & No. per group & Treatment & Results \\
\hline $\begin{array}{l}\text { Bauman et } \\
\text { al., } 1999\end{array}$ & $\begin{array}{l}\text { Epidemiologica } \\
\text { I }\end{array}$ & $\begin{array}{l}\text { Dairy herds of the } \\
\text { north-eastern USA } \\
\text { during years 1994- } \\
1998\end{array}$ & $\begin{array}{l}\text { Herd no. per } \\
\text { group: } 164-176\end{array}$ & $\begin{array}{l}\text { Herds that used Posilac } \\
\text { during specified time } \\
\text { period vs herds that did } \\
\text { not use Posilac }\end{array}$ & $\begin{array}{l}\text { Significant increase in } \\
\text { SCC in rbST-treated herds } \\
\text { vs control }(P<0.01)\end{array}$ \\
\hline $\begin{array}{l}\text { Boutinaud et } \\
\text { al., } 2003\end{array}$ & $\begin{array}{l}\text { Prospective } \\
\text { clinical }\end{array}$ & $\begin{array}{l}\text { Saanen goats } \\
\text { (INRA Experimental } \\
\text { Farm, Brouessy, } \\
\text { France) in week } 32 \\
\text { of lactation }\end{array}$ & 3 & $\begin{array}{l}5 \mathrm{mg} \text { rbST/day s.c. for } 23 \\
\text { days vs control. Each } \\
\text { goat milked } 3 \times / \text { day on } \\
\text { right udder half and } \\
1 \times / \text { day on left udder half }\end{array}$ & $\begin{array}{l}\text { Increased SCC with rbST } \\
\text { from treatment days } 5 \text { to } \\
17 \text {, after which no } \\
\text { difference }\end{array}$ \\
\hline $\begin{array}{l}\text { Brozos et al., } \\
1998\end{array}$ & $\begin{array}{l}\text { Prospective } \\
\text { clinical }\end{array}$ & $\begin{array}{l}\text { Polytocous Chios } \\
\text { ewes (Institute of } \\
\text { Reproduction and } \\
\text { Al, lonia, } \\
\text { Thessaloniki, } \\
\text { Greece) }\end{array}$ & 11 & $\begin{array}{l}160 \text { mg rbST sc every } 14 \\
\text { days during lactation } \\
\text { days } 5-182 \text { vs control } \\
\text { (no injection) }\end{array}$ & $\begin{array}{l}\text { Increase in mean SCC } \\
\text { after lactation day 105; no } \\
\text { significant differences in } \\
\text { percentages of } \\
\text { bacteriologically positive } \\
\text { milk samples, distribution } \\
\text { of bacterial isolates, or } \\
\text { prevalence of subclinical } \\
\text { mastitis }\end{array}$ \\
\hline $\begin{array}{l}\text { Campos et } \\
\text { al., } 2011\end{array}$ & $\begin{array}{l}\text { Prospective } \\
\text { clinical }\end{array}$ & Dairy cows & $12-14$ & $\begin{array}{l}500 \text { mg rbST every } 14 \\
\text { days, starting on } 63 \mathrm{rd} \\
\text { day of lactation; } 500 \mathrm{mg} \\
\text { rbST every } 12 \text { days, from } \\
\text { the } 63 \text { rd day of lactation, } \\
\text { treatment continued until } \\
280 \text { days in milk; control }\end{array}$ & $\begin{array}{l}\text { No effects on SCC or } \\
\text { mastitis incidence }\end{array}$ \\
\hline $\begin{array}{l}\text { Chadio et al., } \\
2000\end{array}$ & $\begin{array}{l}\text { Prospective } \\
\text { clinical, switch- } \\
\text { back design } \\
\text { with three 28- } \\
\text { day periods }\end{array}$ & $\begin{array}{l}\text { Multiparous } \\
\text { crossbred alpine } \\
\text { goats in lactation } \\
\text { week } 8\end{array}$ & 4 & $\begin{array}{l}160 \text { mg sustained } \\
\text { release rbST sc every } 14 \\
\text { days vs control }\end{array}$ & $\begin{array}{l}\text { No significant difference in } \\
\text { SCC }\end{array}$ \\
\hline $\begin{array}{l}\text { Chiofalo et } \\
\text { al., } 1999\end{array}$ & $\begin{array}{l}\text { Prospective } \\
\text { clinical }\end{array}$ & $\begin{array}{l}\text { Multiparous } \\
\text { Comisana lactating } \\
\text { ewes }\end{array}$ & 40 & $\begin{array}{l}120 \text { mg rbST sc every } 21 \\
\text { days (total two } \\
\text { treatments) vs control }\end{array}$ & No effect on SCC \\
\hline
\end{tabular}




\begin{tabular}{|c|c|c|c|c|c|}
\hline Study & Study design & Test animal & No. per group & Treatment & Results \\
\hline $\begin{array}{l}\text { Collier et al., } \\
2001\end{array}$ & $\begin{array}{l}\text { Prospective } \\
\text { clinical }\end{array}$ & $\begin{array}{l}\text { Commercial dairy } \\
\text { herds (Holstein or } \\
\text { Jersey cows) in the } \\
\text { north-eastern, } \\
\text { south-eastern, } \\
\text { upper Midwest and } \\
\text { western USA }\end{array}$ & $\begin{array}{l}\text { Primiparous: } \\
\text { 209-210; } \\
\text { multiparous: } \\
352-355\end{array}$ & $\begin{array}{l}500 \mathrm{mg} \text { sometribove } \\
\text { zinc-oil formulation sc/14 } \\
\text { days) or control (oil } \\
\text { excipient sc), lactation } \\
\text { week } 9 \text { or } 10 \text { to dry-off or } \\
\text { lactation day } 400\end{array}$ & $\begin{array}{l}\text { No effects on percentages } \\
\text { of cows with mastitis, } \\
\text { average mastitis } \\
\text { cases/100 cow-days, } \\
\text { mastitis case duration, } \\
\text { use of mastitis therapies, } \\
\text { mastitis ORs for } \\
\text { primiparous or } \\
\text { multiparous cows, and } \\
\text { numbers of cows culled } \\
\text { for mastitis }\end{array}$ \\
\hline $\begin{array}{l}\text { de Souza } \\
\text { Paula and da } \\
\text { Silva, } 2011\end{array}$ & $\begin{array}{l}\text { Prospective } \\
\text { clinical }\end{array}$ & $\begin{array}{l}\text { Dairy cows in Santa } \\
\text { Rosa, Brazil }\end{array}$ & 12 & $\begin{array}{l}\text { rbST, } 2 \text { applications, } 14 \\
\text { days apart vs saline } \\
\text { control }\end{array}$ & $\begin{array}{l}\text { Increased SCC values } \\
\text { with rbST treatment }\end{array}$ \\
\hline $\begin{array}{l}\text { Dohoo et al., } \\
2003\end{array}$ & $\begin{array}{l}\text { Meta-analysis } \\
\text { of prospective } \\
\text { clinical trial } \\
\text { data }\end{array}$ & Dairy cows & Unstated & Unstated & $\begin{array}{l}\text { Significant increase in } \\
\text { incidence rates and RRs } \\
\text { ( 25\%) for clinical mastitis } \\
\text { in rbST-treated cows; no } \\
\text { significant effect on } \\
\text { incidence rate or RR for } \\
\text { subclinical mastitis (as } \\
\text { increase in SCC) }\end{array}$ \\
\hline $\begin{array}{l}\text { Feckinghaus, } \\
2009\end{array}$ & $\begin{array}{l}\text { Prospective } \\
\text { clinical }\end{array}$ & $\begin{array}{l}\text { Lactating Murrah } \\
\text { water buffaloes }\end{array}$ & 14 & $\begin{array}{l}\text { Single application } \\
500 \mathrm{mg} \text { rbST vs no } \\
\text { injection }\end{array}$ & $\begin{array}{l}\text { No effect on SCC on 1st, } \\
\text { 3rd, 5th, 7th, 10th and } \\
\text { 14th days after application }\end{array}$ \\
\hline $\begin{array}{l}\text { Fitzgerald et } \\
\text { al., } 2007\end{array}$ & $\begin{array}{l}\text { Prospective } \\
\text { clinical }\end{array}$ & $\begin{array}{l}\text { Healthy primi- } \\
\text { parous Holstein } \\
\text { cows }(2 \mathrm{nd} \text { gest- } \\
\text { ation, } 1 \text { st dry } \\
\text { period; Univ. of } \\
\text { Arizona) with SCC } \\
\text { scores of }<300000\end{array}$ & 4 & $\begin{array}{l}\text { Control vs } 500 \mathrm{mg} \\
\mathrm{rbST} / 14 \text { days during the } \\
60 \text {-day dry period } \\
\text { through lactation day } 30 \text {, } \\
\text { with half-udder treat- } \\
\text { ments of either } 2 \times / \text { day } \\
\text { milking or } 4 \times / \text { day milking }\end{array}$ & $\begin{array}{l}\text { No significant differences } \\
\text { in SCC during the } 1 \text { st } 30 \\
\text { days postpartum }\end{array}$ \\
\hline $\begin{array}{l}\text { Gulay et al., } \\
2003\end{array}$ & $\begin{array}{l}\text { Prospective } \\
\text { clinical }\end{array}$ & $\begin{array}{l}\text { Multiparous } \\
\text { Holstein cows } \\
\text { (University of } \\
\text { Florida), } 4 \text { weeks } \\
\text { prior to calving }\end{array}$ & $95-98$ & $\begin{array}{l}\text { Control vs biweekly } \\
142.9 \text { mg rbST s.c. } 21 \pm 3 \\
\text { days prior to calving } \\
\text { through postpartum day } \\
42 \text {; all cows received } \\
\text { Posilac beginning } 100 \pm 4 \\
\text { days postpartum }\end{array}$ & $\begin{array}{l}\text { No significant differences } \\
\text { in SCC, incidences of } \\
\text { health problems (types } \\
\text { unspecified) or culling } \\
\text { rates }\end{array}$ \\
\hline $\begin{array}{l}\text { Gulay et al., } \\
2004\end{array}$ & $\begin{array}{l}\text { Prospective } \\
\text { clinical }\end{array}$ & $\begin{array}{l}\text { Multiparous } \\
\text { Holstein cows } \\
\text { (Univ. of Florida) } \\
\text { were assigned to } \\
\text { treatment groups in } \\
\text { a } 2 \times 3 \times 2 \text { factorial } \\
\text { arrangement } 8-9 \\
\text { weeks pre calving }\end{array}$ & 42 & $\begin{array}{l}\text { Control vs biweekly } \\
\text { injections } 0.4 \text { ml } \\
\text { ( } 142.9 \mathrm{mg} \text { ) Posilac per } \\
\text { cow from } 21 \pm 3 \text { days } \\
\text { prior to calving to } 42 \pm 2 \\
\text { days postpartum; all } \\
\text { cows treated with rbST } \\
\text { after } 56 \pm 2 \text { days } \\
\text { postpartum }\end{array}$ & $\begin{array}{l}\text { Decreased SCC in treated } \\
\text { cows through } 42 \pm 2 \text { days } \\
\text { postpartum }\end{array}$ \\
\hline $\begin{array}{l}\text { Gulay et al., } \\
2007\end{array}$ & $\begin{array}{l}\text { Prospective } \\
\text { clinical, also } \\
\text { data from a } \\
\text { retrospective } \\
\text { study analysed } \\
\text { separately }\end{array}$ & $\begin{array}{l}\text { Holstein cows in } \\
\text { the University of } \\
\text { Florida Dairy } \\
\text { Research herd }\end{array}$ & $\begin{array}{c}\text { 162-166 } \\
\text { (prospective) } \\
109 \\
\text { (retrospective } \\
\text { cohort) }\end{array}$ & $\begin{array}{l}142.9 \mathrm{mg} \mathrm{rbST} / \mathrm{cow} \text { s.c. } \\
2 \text {-week intervals, } 19-24 \\
\text { days before calving until } \\
39-45 \text { days postpartum } \\
\text { vs control }\end{array}$ & $\begin{array}{l}\text { Decreased incidences of } \\
\text { mastitis and total disease } \\
\text { in rbST-treated versus } \\
\text { controls }\end{array}$ \\
\hline $\begin{array}{l}\text { Judge et al., } \\
1999\end{array}$ & $\begin{array}{l}\text { Prospective } \\
\text { clinical }\end{array}$ & $\begin{array}{l}\text { Commercial dairy } \\
\text { herds in Michigan } \\
\text { Dairy Herd } \\
\text { Improvement } \\
\text { Association }\end{array}$ & $261-277$ & $\begin{array}{l}500 \mathrm{mg} \text { rbST every } 14 \\
\text { days between lactation } \\
\text { days } 63 \text { and } 301 \text { vs } \\
\text { control }\end{array}$ & $\begin{array}{l}\text { No effect of rbST on } \\
\text { incidence of mastitis }\end{array}$ \\
\hline $\begin{array}{l}\text { Kim, Chang } \\
\text { and Kim, } \\
2002\end{array}$ & $\begin{array}{l}\text { Prospective } \\
\text { clinical }\end{array}$ & Holstein dairy cows & 9 & $\begin{array}{l}\text { Group I: rbST alone; } \\
\text { Groups II, III and IV: rbST } \\
\text { treatment + retinyl } \\
\text { palmitate and } \\
\text { cholecalciferol; an } \\
\text { untreated control group }\end{array}$ & $\begin{array}{l}\text { No significant effect on } \\
\text { mastitis incidence, but } \\
\text { there was decreased SCC } \\
\text { in rbST + retinyl palmitate } \\
\text { and cholecalciferol- } \\
\text { treated groups }\end{array}$ \\
\hline
\end{tabular}




\begin{tabular}{|c|c|c|c|c|c|}
\hline Study & Study design & Test animal & No. per group & Treatment & Results \\
\hline $\begin{array}{l}\text { Kim and Kim, } \\
2012\end{array}$ & $\begin{array}{l}\text { Prospective } \\
\text { clinical }\end{array}$ & $\begin{array}{l}\text { Lactating Holstein } \\
\text { dairy cows in } \\
\text { Kyunggi Province, } \\
\text { Republic of Korea }\end{array}$ & 25 & $\begin{array}{l}\text { Boostin-250 and vehicle } \\
\text { (control), administered } \\
\text { weekly; Boostin-S and } \\
\text { Posilac every } 14 \text { days }\end{array}$ & $\begin{array}{l}\text { No effect on incidence of } \\
\text { clinical mastitis and SCC }\end{array}$ \\
\hline $\begin{array}{l}\text { Liboni et al., } \\
2008\end{array}$ & $\begin{array}{l}\text { Prospective } \\
\text { clinical }\end{array}$ & $\begin{array}{l}\text { Multiparous } \\
\text { Holstein cows } \\
\text { (University of } \\
\text { Florida) }\end{array}$ & $25-27$ & $\begin{array}{l}\text { Group I: no rbST; Group } \\
\text { II: postpartum rbST; } \\
\text { Group III: prepartum } \\
\text { rbST; Group IV: pre- } \\
\text { partum and postpartum } \\
\text { rbST; prepartum rbST } \\
\text { every } 2 \text { weeks beginning } \\
21 \text { days before calving; } \\
\text { postpartum rbST during } \\
\text { the first } 63 \text { days of } \\
\text { lactation every } 2 \text { weeks; } \\
\text { all cows received rbST } \\
\text { after } 63 \text { days in lactation }\end{array}$ & $\begin{array}{l}\text { No changes in SCC } \\
\text { between treatment groups }\end{array}$ \\
\hline $\begin{array}{l}\text { Lucci et al., } \\
1998\end{array}$ & $\begin{array}{l}\text { Prospective } \\
\text { clinical }\end{array}$ & $\begin{array}{l}\text { Crossbred Holstein } \\
\text { first-lactation } \\
\text { pregnant heifers }\end{array}$ & 9 & $\begin{array}{l}\text { rbST } 500 \text { mg dose, } \\
\text { Groups (A) control; (B) } \\
\text { bST each } 28 \text { days; (C) } \\
\text { bST each } 21 \text { days; (D) } \\
\text { bST each } 14 \text { days for } \\
112 \text { days }\end{array}$ & No effect on SCC \\
\hline $\begin{array}{l}\text { Masoero et } \\
\text { al., } 1998\end{array}$ & $\begin{array}{l}\text { Prospective } \\
\text { clinical }\end{array}$ & $\begin{array}{l}\text { Italian Friesian } \\
\text { lactating cows }\end{array}$ & $\begin{array}{l}25 \text { per trial } \times 2 \\
\text { trials: } 1 \text {. winter- } \\
\text { spring, } 2 \text {. } \\
\text { autumn-winter }\end{array}$ & $\begin{array}{l}\text { rbST ( } 500 \mathrm{mg} \text {, every } 2 \\
\text { weeks for } 10 \text { times) vs } \\
\text { control }\end{array}$ & No effect on SCC \\
\hline $\begin{array}{l}\text { Moraes e } \\
\text { Amorim et al., } \\
2006\end{array}$ & $\begin{array}{l}\text { Prospective } \\
\text { clinical }\end{array}$ & $\begin{array}{l}\text { Toggenburg goats } \\
\text { at farm in Agua } \\
\text { Limpa, Brazil }\end{array}$ & 12 & $\begin{array}{l}250 \text { mg rbST, every } 14 \\
\text { days (four injections) vs } \\
\text { saline (control) }\end{array}$ & $\begin{array}{l}\text { Decreased SCC in treated } \\
\text { goats }\end{array}$ \\
\hline $\begin{array}{l}\text { Mukherjee, } \\
2007\end{array}$ & $\begin{array}{l}\text { Prospective } \\
\text { clinical }\end{array}$ & Lactating buffaloes & 30 & $\begin{array}{l}\text { Boostin }(250 \mathrm{mg} / 2 \\
\text { weeks); no control group }\end{array}$ & $\begin{array}{l}\text { Increase in SCC on day } 4 \text {, } \\
18 \text { and } 32 \text {, bacterial } \\
\text { plate count }<0.40 \times 10^{3} \\
\text { cfu } / \mathrm{ml}\end{array}$ \\
\hline $\begin{array}{l}\text { Posada et al., } \\
2008\end{array}$ & $\begin{array}{l}\text { Prospective } \\
\text { clinical }\end{array}$ & $\begin{array}{l}\text { Holstein-Freisian } \\
\text { cows, } 1-4 \text { parity, } \\
60-180 \text { days in milk } \\
\text { (Antioquia, } \\
\text { Colombia) }\end{array}$ & 10 & $\begin{array}{l}\text { Group 1, rbST ( } 500 \mathrm{mg})+ \\
\text { vitamin E + lecithin, } \\
\text { group 2, rbST ( } 500 \mathrm{mg}) \text {, } \\
\text { and control group } \\
\text { without treatment; nine } \\
\text { injections every } 2 \text { weeks }\end{array}$ & $\begin{array}{l}\text { No significant effect on } \\
\text { mastitis incidence } \\
\text { (measured by California } \\
\text { Mastitis Test, and } \\
\text { analysed for proportion } \\
\text { affected by confidence } \\
\text { intervals) }\end{array}$ \\
\hline $\begin{array}{l}\text { Requena et } \\
\text { al., } 2010\end{array}$ & $\begin{array}{l}\text { Prospective } \\
\text { clinical }\end{array}$ & $\begin{array}{l}\text { Lactating } \\
\text { Manchega dairy } \\
\text { ewes (Polytechnic } \\
\text { University of } \\
\text { Valencia, Spain) }\end{array}$ & 18 & $\begin{array}{l}\text { Control vs } 40,80 \text { or } \\
120 \mathrm{mg} \text { of bST every } 14 \\
\text { days from } 2 \text { to } 20 \text { weeks } \\
\text { of lactation }\end{array}$ & No effect on SCC \\
\hline $\begin{array}{l}\text { Ruegg, } \\
\text { Fabellar and } \\
\text { Hintz, } 1998\end{array}$ & $\begin{array}{l}\text { Epidemio- } \\
\text { logical }\end{array}$ & $\begin{array}{l}32 \text { dairy herds in } \\
\text { Indiana, Michigan } \\
\text { and Ohio surveyed } \\
\text { August } 1994- \\
\text { August } 1995\end{array}$ & $\begin{array}{l}\text { Herd nos per } \\
\text { group: } 13-19\end{array}$ & $\begin{array}{l}\text { rbST used for } \geq 25 \% \\
\text { cow-days vs control }\end{array}$ & $\begin{array}{l}\text { No effects on culling } \\
\text { density, or rate or } \\
\text { incidences of SCC-related } \\
\text { or mastitis-related culling }\end{array}$ \\
\hline $\begin{array}{l}\text { Schneider et } \\
\text { al., } 2012\end{array}$ & $\begin{array}{l}\text { Prospective } \\
\text { clinical }\end{array}$ & $\begin{array}{l}\text { Holstein heifers, } \\
\text { southern Brazil, } 35 \\
\text { days prior to } \\
\text { expected calving }\end{array}$ & $15-16$ & $\begin{array}{l}500 \mathrm{mg} \mathrm{rbST/cow} \text { s.c. } \\
35,21 \text { and (if relevant) } 7 \\
\text { days before calving vs } \\
\text { control }\end{array}$ & $\begin{array}{l}\text { Significantly decreased } \\
\text { SCC with rbST }\end{array}$ \\
\hline $\begin{array}{l}\text { Vallimont et } \\
\text { al., } 2001\end{array}$ & $\begin{array}{l}\text { Prospective } \\
\text { clinical }\end{array}$ & $\begin{array}{l}\text { Multiparous } \\
\text { Holstein dairy cows }\end{array}$ & $13-15$ & $\begin{array}{l}500 \text { mg sustained } \\
\text { release Posilac, s.c. } 28 \\
\text { and } 14 \text { days prior to } \\
\text { calving vs control }\end{array}$ & $\begin{array}{l}\text { No effects on mastitis } \\
\text { incidence or SCC }\end{array}$ \\
\hline $\begin{array}{l}\text { VanBaale et } \\
\text { al., } 2005\end{array}$ & $\begin{array}{l}\text { Prospective } \\
\text { clinical }\end{array}$ & $\begin{array}{l}\text { Multiparous } \\
\text { Holstein cows at } \\
\text { Arizona commercial } \\
\text { dairy }\end{array}$ & 60 & $\begin{array}{l}\text { rbST, } 60-66 \text { to } 305 \text { days } \\
\text { in milk vs control (cows } \\
\text { in both groups were } \\
\text { milked } 6 \times / \text { day during the } \\
\text { first } 21 \text { days in lactation, } \\
\text { and } 3 \times / \text { day thereafter) }\end{array}$ & $\begin{array}{l}\text { Increased SCC in cows } \\
\text { treated with rbST }\end{array}$ \\
\hline
\end{tabular}




\begin{tabular}{|c|c|c|c|c|c|}
\hline Study & Study design & Test animal & No. per group & Treatment & Results \\
\hline \multicolumn{6}{|c|}{ Studies available in abstract form only } \\
\hline $\begin{array}{l}\text { Bayram et al., } \\
2006\end{array}$ & $\begin{array}{l}\text { Prospective } \\
\text { clinical }\end{array}$ & $\begin{array}{l}\text { Anatolian } \\
\text { buffaloes in mid- } \\
\text { and late lactation }\end{array}$ & 10 & $\begin{array}{l}500 \mathrm{mg} \text { rbST sc every } 14 \\
\text { days vs control }\end{array}$ & No effect on SCC \\
\hline $\begin{array}{l}\text { Hassan et al., } \\
2007\end{array}$ & $\begin{array}{l}\text { Prospective } \\
\text { clinical }\end{array}$ & $\begin{array}{l}\text { Buffaloes in } 2 \text { nd- } \\
\text { 3rd lactations, } 70- \\
80 \text { days } \\
\text { postpartum }\end{array}$ & 6 & $\begin{array}{l}\text { Control vs biweekly low } \\
(250 \mathrm{mg} / \mathrm{head}) \text { and high } \\
\text { ( } 500 \mathrm{mg} / \mathrm{head} \text { ) doses of } \\
\text { rbST for } 90 \text { days }\end{array}$ & $\begin{array}{l}\text { Significantly }(P<0.01) \\
\text { increased SCC }\end{array}$ \\
\hline
\end{tabular}

NOTES: cfu = colony-forming units; $\mathrm{OR}=$ odds ratio; rbST = recombinant bovine somatotrophin; $\mathrm{RR}=$ risk ratio; s.c. = subcutaneously; SCC $=$ somatic cell count.

The meta-analysis publication by Dohoo et al., (2003) was a re-analysis of data already published prior to approval of Posilac (1989-1994) and included 53 randomized clinical trials that Monsanto had provided to Health Canada (Health Canada, 1998). These represented the experimental data considered in previous evaluations by the 40th and 50th Meetings. This study reported a $25 \%$ increase in incidence of mastitis in rbST-treated herds versus nontreated herds. In contrast, a systematic review by the present Committee of clinical (Brozos et al., 1998; Judge et al., 1999; Collier et al., 2001; Vallimont et al., 2001; Gulay et al., 2003, 2007; VanBaale et al., 2005) and epidemiological studies (Ruegg, Fabellar and Hintz, 1998) published since then (see Table 9.8) found no effect of rbST on mastitis incidence, possibly due to insufficient power to detect differences in mastitis incidence and exclusive use of multiparous animals as test subjects. It was noted that many of the studies listed in Table 9.8 and reviewed by the Committee did not follow the label recommended use directions.

Regarding the incidence of subclinical mastitis, assessed as increased somatic cell count scores in milk, the vast majority of studies reported no effect of rbST treatment on somatic cell count values (Ruegg, Fabellar and Hintz, 1998; Chiofalo et al., 1999; Vallimont et al., 2001; Dohoo et al., 2003; Gulay et al., 2003, 2007; VanBaale et al., 2005; Schneider et al., 2012; USDA, 2012), although a few studies reported small, transient increases (Brozos et al., 1998; Bauman et al., 1999; Boutinaud et al., 2003).

The Committee at its 50th Meeting compared the non-compliant antimicrobial drug residues in bulk tank milk in the United States of America 2 years before approval of rbST (1992-1993) and 2 years after approval of rbST (1994-1995) as part of a post-approval monitoring programme. Results of the same programme were available for the years 19962012 (NMDRD, 2013) for the present Committee to review. The National Milk Drug Residue Database (NMDRD) is a voluntary industry-reporting programme, whereas mandatory reporting is required by state regulatory agencies under the National Conference on Interstate Milk Shipments (NCIMS). Data are reported on the extent of the national testing activities, the analytical methods used, the kind and extent of the animal drug residues identified and the amount of contaminated milk that was removed from the human food supply. The system includes all of the milk supply, of which approximately $95 \%$ is regulated through the NCIMS by state regulatory agencies. The trend in milk tankers positive for antimicrobial residues in the United States of America since 1995 is presented in Figure 9.5. As noted at the 50th Meeting, the United States of America switched to a more sensitive test for antimicrobial residues in 1995, corresponding to the highest level of residue noncompliance reported. The bulk milk tankers positive for antimicrobial residues increased slightly between 1995 and 1996. Since 1996, the percentage of bulk milk tankers positive for antimicrobial residues has steadily declined to $0.017 \%$ in 2012 , compared with $0.10 \%$ in 1995 (Figure 9.5). These results provide no evidence of increased human risk for exposure to antimicrobial drug residues associated with the use of rbSTs in the dairy industry in the United States of America over the last 19 years. 


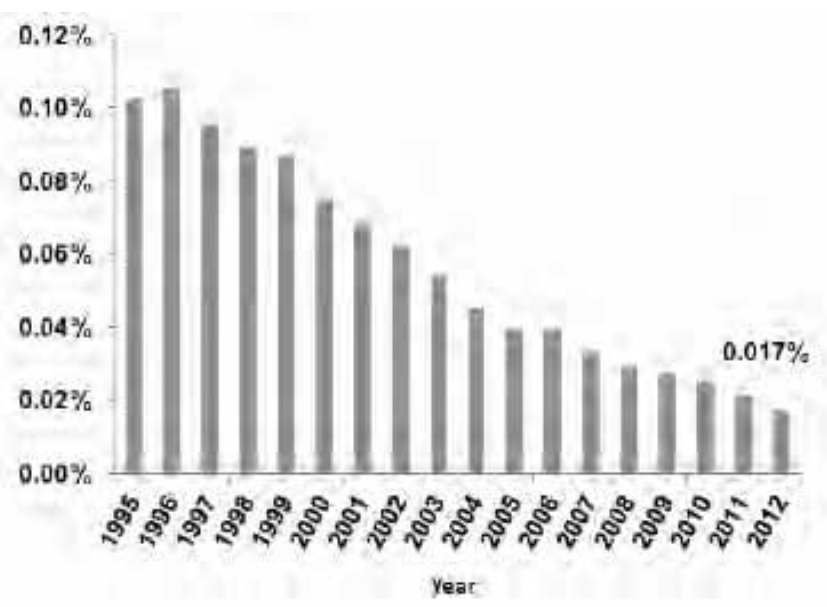

Figure 9.5. Percentage of bulk tankers positive for antimicrobial residues from 1995 to 2012 (Source: NMDRD, 2013)

Several factors could influence the observed decline in non-compliant drug residues, including adherence to good veterinary practice and improved animal husbandry practices. Moreover, the available data did not provide individual animal-level data to correlate with the use of rbSTs. Nonetheless, the available evidence suggests that in the United States of America, the approval of rbSTs was not associated with an increased incidence of noncompliant antimicrobial residues in bulk milk. However, no relevant monitoring data were available from other jurisdictions where rbSTs are authorized for use.

A survey of retail milk in the United States of America (Vicini et al., 2008), which tested 334 retail milk samples labelled as conventional, rbST-free or organic milk from stores in 48 contiguous states within the United States of America, detected no antimicrobial residues.

The use of antimicrobial agents is an important tool in the management of clinical mastitis. However, the Committee could not analyse the potential association between the use of rbSTs and the use of antimicrobial agents. This was due to the unavailability of data on the use of antimicrobial agents to treat mastitis on farms using rbSTs when compared with farms not using rbSTs. The results of the systematic literature review of the studies published since the last Committee meeting and the antimicrobial residue monitoring data from the United States of America, however, provided an indirect indication that when antimicrobial agents are used in accordance with the label directions, human exposure to antimicrobial residues is unlikely to increase due to potential increased use of antimicrobial agents to treat mastitis in rbST-treated cows.

An excerpt from the USDA's Animal and Plant Health Inspection Service's Centers for Epidemiology and Animal Health fact sheet on bulk tank milk somatic cell counts (BTSCC) was also provided (Bauman and Collier, 2013). BTSCC refers to the number of white blood cells (primarily macrophages and leukocytes), secretory cells and squamous cells per millilitre of raw milk. The average BTSCC in milk in the United States of America was stable between 1998 and 2003 and has declined steadily since 2003. BTSCC declined from 319000 cells $/ \mathrm{ml}$ in 2003 to 233000 cells $/ \mathrm{ml}$ in 2009 (27\% decline). An average BTSCC of 224000 cells $/ \mathrm{ml}$ in 2010 and 206000 cells $/ \mathrm{ml}$ in 2011 indicates that the pattern of decline continues. Operations with increased BTSCC are more likely to have milk that is non-compliant with antimicrobial residues (van Schaik, Lotem and Schukken, 2002). A continuous decrease in somatic cell count in milk in the United States of America is an additional indirect support for the lack of evidence linking the use of rbSTs with an increased risk for antimicrobial residues in milk. 
Studies from the USDA's National Animal Health Monitoring System (NAHMS) reported that $10.1 \%$ of cows in the United States of America in 1996, 22.3\% in 2002 and $17.1 \%$ in 2007 were treated with rbSTs (USDA, 2007). During those years, the percentages of cows with mastitis increased slightly, from $13.4 \%$ (1996) to $14.7 \%$ (2002) to $16.5 \%$ (2007). Although the slight increase in prevalence of mastitis from 1996 to 2002 could be linked with a more than doubling in the percentage of cows given rbSTs, mastitis prevalence continued a trend upwards in 2007, despite a 5\% decrease in the percentage of cows administered rbSTs. The increase in mastitis prevalence was more closely related to the increased annual milk yield per cow of $1-3 \%$ per year since 1991 (USDA, 2007).

Ruzante et al. (2010) analysed data collected during the NAHMS Dairy 2007 study (USDA, 2007) from dairy farms in the United States of America to study factors associated with the presence of Salmonella in environmental samples in dairies in the United States of America. Environmental samples to test for Salmonella were collected from a subset of 260 dairy operations used in the overall study. The association of the presence of Salmonella in environmental samples with the use of rbSTs was examined as one of the factors. A higher presence of Salmonella in the environment was observed with the use of rbSTs. The biological significance of this finding is unclear, and the study was not designed to capture any related factors, such as management practices.

In its systematic review of the literature, the Committee did not find specific studies that investigated the associations between the use of rbSTs and the development of antimicrobial resistance in mastitis pathogens. Controlled studies have not determined whether the use of rbSTs may increase this risk or, for that matter, help to decrease it. Although bovine mastitis is considered the single most important reason for antimicrobial use in lactating dairy cows (Erskine et al., 2004) and although antimicrobial resistance in mastitis pathogens is a cause for concern (Oliver, Murinda and Jayarao, 2011; Oliver and Murinda, 2012), in the absence of properly designed studies, whether the use of rbSTs in cows or farms increases antimicrobial resistance remains speculative. It is concluded that there is a lack of evidence that the use of rbSTs in dairy herds contributes to antimicrobial resistance in dairy herds.

Available new information therefore does not change the conclusion of the 50th Committee Meeting in regards to the risk to human health due to the use of antimicrobial agents to treat mastitis.

\section{Comments}

\section{Biochemical data}

The Committee at its 40th and 50th Meetings concluded that human and bovine somatotrophins are structurally different and have species-specific receptor binding activity. Furthermore, the total concentration of bST detected in tissues and milk of rbST-treated cattle is similar to that from untreated cattle, and bST is denatured by high temperatures (e.g. by cooking or pasteurization) and biodegradation processes in the gut. No new biochemical data on rbSTs were available since the previous evaluation of the compound by the Committee at its 50th Meeting. The Committee evaluated a part of a study submitted to previous JECFA meetings, but not specifically discussed in the respective monographs. This study investigated the level of anti-rbST antibodies in serum as a surrogate measure for oral absorption/bio-availability in rats administered an rbST by gavage for 90 days. The results indicated increased levels of circulating anti-rbST antibodies in $20 \%$ and $30 \%$ of rats treated with the rbST at 5 and $50 \mathrm{mg} / \mathrm{kg}$ bw per day, respectively, and in one animal (3\%) treated with the rbST at $0.1 \mathrm{mg} / \mathrm{kg}$ bw per day. The experimental design, however, did not allow an assessment as to whether the antibody response was a result of absorption of intact rbST or only an immunologically active peptide fragment (epitope or antigenic determinant) of the rbST into the systemic circulation or due to mucosal immunity in the gut. Also, there were no 
systemic effects on growth or feed intake in orally treated rats. These data, together with the data evaluated at previous meetings of the Committee, confirm the absence of the biological activity of rbSTs following oral intake.

\section{Toxicological data}

The Committee at its 40th Meeting evaluated the toxicity of different rbSTs. Acute oral toxicity studies in rats with rbST doses up to $5 \mathrm{~g} / \mathrm{kg}$ bw, two 2-week oral feeding studies in rats with rbST doses up to $10 \mathrm{mg} / \mathrm{kg}$ bw per day and two 4-week oral feeding studies in rats with rbST doses up to $50 \mathrm{mg} / \mathrm{kg}$ bw per day caused no effects up to the highest dose tested. Similarly, no treatment-related effects were observed in two 90-day oral feeding studies in rats at rbST doses up to $100 \mathrm{mg} / \mathrm{kg}$ bw per day and a 90-day oral feeding study in dogs at rbST doses up to $10 \mathrm{mg} / \mathrm{kg}$ bw per day, the highest doses tested. No new toxicity studies on rbSTs were available since the previous evaluation of rbSTs by the Committee at the 50th Meeting.

The present Committee evaluated long-term carcinogenicity studies in rats and mice using related, but distinct, compounds (i.e. rrST and rmST). Daily subcutaneous administration of rrST and rmST to groups of rats and mice, respectively, for 2 years did not show any carcinogenic effects. Although the Committee considered these data not directly relevant to the risk assessment of rbSTs, these observations do illustrate that other somatotrophins are not potential carcinogens.

\section{Concentrations of rbSTs and IGF-I in milk and tissues}

Previous meetings of the Committee have concluded that owing to the structural dissimilarity between bovine and human somatotrophins and species-specific receptor binding, rbSTs are not biologically active in humans. Also, similar concentrations of total bST are detected in milk and tissues of rbST-treated and untreated cows. Very few new publications investigating the concentrations of bST in milk and tissues following treatment with rbSTs were available in the literature since the 50th Meeting of the Committee. Available information supports the conclusions of the previous Committee that there is no significant change in the concentrations of total bST detected in milk and tissues of rbSTtreated cows when compared with untreated controls.

Available new information supports previous conclusions that the IGF-I concentration in milk varies widely in lactating cows and is influenced by parity, stage of lactation, nutritional status, season and somatic cell counts (an indication of udder health) of the milk. IGF-I concentrations measured in colostrum are substantially higher than concentrations in milk produced subsequently. Treatment of cows with rbSTs transiently increased the mean IGF-I concentration in milk by up to $50 \%$, but such increases were within the physiological variations observed in untreated cows.

A new cross-sectional study of retail milk in the United States of America suggests that the IGF-I concentrations in retail milk labelled as conventional, which includes milk from both rbST-treated and untreated cows $(3.1 \pm 0.1 \mathrm{ng} / \mathrm{ml})$, were not different from concentrations in milk labelled to be from rbST-free cows $(3.0 \pm 0.1 \mathrm{ng} / \mathrm{ml})$. However, the percentage of conventional milk that comes from cows treated with rbSTs is not known.

The 50th Meeting of the Committee considered that some milk-borne IGF-I may escape degradation by gastrointestinal tract enzymes and get absorbed from the gastrointestinal tract. In vitro digestion studies indicated that IGF-I is rapidly degraded by gastrointestinal tract enzymes. However, subsequent studies in experimental animals showed that the rate of degradation could be reduced by the components in milk and colostrum. In vivo studies in laboratory animals suggested that up to $25 \%$ of IGF-I fed with milk could be absorbed from the gastrointestinal tract, although only a fraction of it would reach the systemic circulation. Studies in infants showed that feeding a formula supplemented with a 20-fold higher 
concentration of IGF-I did not increase the IGF-I concentrations in serum compared with feeding a standard formula. Randomized trials in active adult athletes did not detect any difference in IGF-I concentrations in plasma from an intervention group fed up to $120000 \mathrm{ng}$ IGF-I per person per day from bovine colostrum for up to 8 weeks when compared with controls fed whey protein during pre-treatment, treatment or post-treatment periods.

The literature suggests that the concentration of IGF-I in serum in humans is influenced by a number of factors, including age, physiological stage and nutritional status. Consumption of milk per se was associated with increased blood IGF-I concentrations in humans. There is evidence that orally administered IGF-I has some local bio-activity in the gastrointestinal tract. However, given the large quantity of IGF-I secreted in the digestive tract of humans, the small additional quantity of IGF-I in milk from cows treated with rbSTs is unlikely to make a biologically relevant contribution to the effects of endogenous IGF-I. The endogenous IGF-I production in humans will be more influenced by the consumption of milk per se, irrespective of whether it is from rbST-treated or untreated cows.

The present Committee concluded that some milk-borne IGF-I may not be degraded by gastrointestinal enzymes. However, even if some of the IGF-I in milk were absorbed, the incremental human exposure would be negligible when compared with total daily human production of IGF-I of $10 \mathrm{mg} /$ day, as reported by the Committee at the 50th Meeting. This is consistent with the previous conclusion of the Committee.

\section{Expression of retroviruses and prion proteins}

The 50th Meeting of the Committee concluded that the available studies provided no evidence that rbSTs affect the expression of retroviruses in cattle. The Committee also concluded that the possibility of a link between rbST treatment and BSE was highly speculative, as there was no evidence for a direct link. No new information on the role of rbSTs in the expression of retroviruses or prion proteins in ruminants was available from the literature.

\section{Risk of type 1 diabetes in genetically susceptible infants}

There is evidence that in infants genetically susceptible to type 1 diabetes, exposure to cow milk early in infancy, when an infant's gastrointestinal tract is not fully developed, may stimulate the production of antibodies that can cross-react with pancreatic islet $\beta$-cell surface antigens. This may be a risk factor for the development of type 1 diabetes. Stimulation of aberrant immune response in infancy, however, is not limited to milk components alone, as infants genetically predisposed to type 1 diabetes also have a generalized aberrant immune response to several other proteins (e.g. cereals, fruits, bacteria, viruses).

Animal and human studies suggest that IGF-I is unlikely to have an adverse impact on the pathogenesis of diabetes in humans. The composition of milk from cows treated with rbSTs did not differ materially from that of untreated cows, and therefore consumption of milk from rbST-treated cows would not pose an additional risk for the development of diabetes.

\section{Risk of cancer}

The Committee also considered the potential cancer risk in humans associated with the consumption of milk from rbST-treated cows. The Committee concluded that any carcinogenic risk from rbSTs themselves was negligible, because they are not absorbed from the gastrointestinal tract, they are not bio-active in humans and the respective orthologues did not cause cancer in rats or mice when administered subcutaneously.

As stated above, the IGF-I exposure from consumption of milk from cows treated with rbSTs represented a small fraction of the physiological amounts produced in humans, and endogenous IGF-I production in humans will be influenced more by the consumption of milk per se than by whether the milk is from rbST-treated or untreated cows. Circulating IGF- 
I concentrations at the higher end of the normal physiological range were observed in some cancer patients, although these were inconsistent between studies and between different types of cancers. Moreover, these observations came from epidemiological studies in which the impact of reverse causation cannot be excluded.

\section{Risk to human health from use of antimicrobial agents}

The 50th Committee Meeting concluded that the use of rbSTs would not result in a higher risk to human health due to the use of antimicrobial agents to treat mastitis and that increased potential for drug residues in milk could be managed by practices currently in use within the dairy industry and by following the directions for use.

The potential risk to human health due to the potential for increased use of antimicrobial agents to treat mastitis or increased incidence of non-compliant residues in milk of cows treated with rbSTs was also considered by the present Committee. A meta-analysis published in 1998 observed that cows treated with rbSTs had a higher incidence (up to 25\%) of mastitis compared with untreated cows. A systematic review of the literature published since the 50th Meeting of the Committee did not find any significant difference in the incidence of mastitis between rbST-treated and untreated cows. However, the Committee did not have data to determine the use of antimicrobial agents to treat mastitis on farms using rbSTs.

The 50th Meeting of the Committee had assessed the data from a post-approval monitoring programme established in the United States of America to monitor the effects on animal health, including mastitis and non-compliant drug residues in milk. Additional monitoring data for 1996-2012 from the same programme were assessed for the long-term trend in antimicrobial residues in bulk milk. Since 1996, there has been a consistent decrease in the number of bulk milk samples positive for non-compliant antimicrobial residues, with only $0.017 \%$ of samples testing positive in 2012 , compared with $0.1 \%$ in 1996 . Several factors could influence the observed results, including adherence to good veterinary practice and improved animal husbandry practices. Moreover, the available data did not provide individual animal-level data to correlate with the use of rbSTs. Nonetheless, the Committee considered that the available evidence suggested that in the United States of America, the approval of rbSTs did not lead to an increased incidence of non-compliant antimicrobial residues in bulk milk. The Committee found no relevant monitoring data from other jurisdictions where rbSTs are authorized for use.

Although the Committee was aware of the concern regarding potential antimicrobial resistance, its systematic review of the literature did not find specific studies correlating the use of rbSTs with the development of antimicrobial resistance in mastitis pathogens.

Based on the data reviewed, the Committee concluded that there was no evidence to suggest that the use of rbSTs would result in a higher risk to human health due to the possible increased use of antimicrobial agents to treat mastitis or the increased potential for non-compliant antimicrobial residues in milk.

\section{Evaluation}

Based on the above assessment, the Committee's responses to the issues raised by the Codex Alimentarius Commission are as follows:

\section{(i) Update the toxicological evaluation}

No new toxicological studies were available. Owing to structural differences between bovine and human somatotrophins, species-specific receptor binding of somatotrophins and lack of bio-activity of rbSTs following oral intake, the Committee concluded that if any rbST residues are present in milk or tissues, they would pose a negligible risk to human health. 


\section{(ii) Update the exposure assessment based on any new occurrence data in food}

The Committee concluded that similar concentrations of total bST were present in milk and tissues of rbST-treated and untreated cows.

(iii) Consider new data and information related to the possibility of increased levels of IGF-I in the milk of cows treated with rbSTs

There is a transient increase in IGF-I concentrations in milk of rbST-treated cows, which fall within the normal physiological range. IGF-I is substantially, if not completely, degraded in the gut and is unlikely to be absorbed from the gut and be bio-available at biologically relevant exposures. Therefore, the contribution of exogenous IGF-I resulting from the ingestion of milk from rbST-treated cows is extremely low in comparison with endogenous production.

(iv) Evaluate potential adverse health effects, including the possibility that exposure of human neonates and young children to milk from rbST-treated cows increases health risks (e.g. the development of insulin-dependent diabetes mellitus)

Exogenous IGF-I from milk makes no significant contribution to circulating levels of IGF-I in humans, and there are no significant differences in the composition of milk from rbSTtreated cows when compared with the milk from untreated cows. The Committee concluded that there was no additional risk for the development of type 1 diabetes due to the consumption of milk from rbST-treated cows. The Committee also concluded that the literature did not support a link between exposure to IGF-I in milk from rbST-treated cows and an increased risk of cancer.

(v) Consider new data and information related to the potential effects of rbSTs on the expression of certain viruses in cattle

There was no new information on the link between rbST use and either potential stimulation of retrovirus expression or prion protein expression in cattle. The present Committee considers that the position expressed by the previous Committee remains valid.

(vi) Consider new data and information related to the possible increased use of antimicrobials to treat mastitis in cows and aspects of antimicrobial resistance associated with the use of rbSTs in relation to human health

The Committee concluded that there was no evidence to suggest that the use of rbSTs would result in a higher risk to human health due to the possible increased use of antimicrobial agents to treat mastitis or the increased potential for non-compliant antimicrobial residues in milk. The Committee found no specific studies linking the use of rbSTs with the development of antimicrobial resistance. The present Committee considers that the position expressed by the previous Committee remains valid.

(vii) Consider the need to revise or maintain the ADI and MRLs for rbSTs

The Committee reaffirmed its previous decision on ADIs and MRLs "not specified" for somagrebove, sometribove, somavubove and somidobove.

\section{References}

Agudo, J., Ayuso, E., Jimenez, V., Salavert, A., Casellas, A., Tafuro, S., Haurigot, V., Ruberte, J., Segovia, J.C., Bueren, J. \& Bosch, F. 2008. IGF-I mediates regeneration of endocrine pancreas by increasing beta cell replication through cell cycle protein modulation in mice. Diabetologia, 51 : 18621872.

Alexander, A.N. \& Carey, H.V. 2001. Involvement of PI 3-kinase in IGF-I stimulation of jejunal $\mathrm{Na}^{+}-$ $\mathrm{K}^{+}$-ATPase activity and nutrient absorption. American Journal of Physiology: Gastrointestinal and Liver Physiology, 280: G222-228. 
Al-Seaf, A., Keown, J.F. \& van Vleck, L.D. 2007a. Estimates of correlations among yield traits and somatic cell score with different models to adjust for bovine somatotrophin effects on Holstein dairy cows. Genetics and Molecular Research, 6: 67-78.

Al-Seaf, A., Keown, J.F. \& van Vleck, L.D. 2007b. Genetic parameters for yield traits of cows treated or not treated with bovine somatotrophin. Journal of Dairy Science, 90: 501-506.

Anderle, P., Langguth, P., Rubas, W. \& Merkle, H.P. 2002. In vitro assessment of intestinal IGF-I stability. Journal of Pharmaceutical Science, 91: 290-300.

Andrade, B.R., Salama, A.A.K., Caja, G., Castillo, V., Albanell, E. \& Such, X. 2008. Response to lactation induction differs by season of year and breed of dairy ewes. Journal of Dairy Science, 91: 2299-2306.

Annen, E.L., Fitzgerald, A.C., Gentry, P.C., McGuire, M.A., Capuco, A.V., Baumgard, L.H. \& Collier, R.J. 2007. Effect of continuous milking and bovine somatotrophin supplementation on mammary epithelial cell turnover. Journal of Dairy Science, 90: 165-183.

Atkinson, M.A. 2012. The pathogenesis and natural history of type 1 diabetes. Cold Spring Harbor Perspectives in Medicine, 2(11): pii: a007641.

Aune, D., Norat, T., Romundstad, P. \& Vatten, L.J. 2013. Dairy products and the risk of type 2 diabetes: a systematic review and dose-response meta-analysis of cohort studies. American Journal of Clinical Nutrition, 98: 1066-1083.

Bailly-Chouriberry, L., Pinel, G., Garcia, P., Popot, M.-A., Le Bizec, B. \& Bonnaire, Y. 2008. Identification of recombinant equine growth hormone in horse plasma by LC-MS/MS: a confirmatory analysis in doping control. Analytical Chemistry, 80: 8340-8347.

Bauman, D.E. \& Collier, R.J. 2013. Expert report on questions posed in the call for data for recombinant bovine somatotrophins for the 78th Committee Meeting of the WHO/FAO Joint Expert Committee on Food Additives. Bovine somatotrophins - other factors. Unpublished report provided to JECFA by Elanco Animal Health, Greenfield, IN, USA.

Bauman, D.E., Everett, R.W., Weiland, W.H. \& Collier, R.J. 1999. Production responses to bovine somatotrophin in northeast dairy herds. Journal of Dairy Science, 82: 2564-2573.

Bayram, I., Ucar, M., Kucukkebapci, M., Siriken, B. \& Yildirir, M. 2006. Effect of recombinant bovine somatotrophin on milk production and composition in buffaloes. Indian Veterinary Journal, 83: $1223-1224$.

Blevins, C.A., Shirley, J.E. \& Stevenson, J.S. 2006. Milking frequency, estradiol cypionate, and somatotrophin influence lactation and reproduction in dairy cows. Journal of Dairy Science, 89: 4176-4187.

Boutinaud, M., Rousseau, C., Keisler, D.H. \& Jammes, H. 2003. Growth hormone and milking frequency act differently on goat mammary gland in late lactation. Journal of Dairy Science, 86: 509520.

Brozos, C., Saratsis, P., Boscos, C., Kyriakis, S.C. \& Tsakalof, P. 1998. Effects of long-term recombinant bovine somatotrophin (bST) administration on milk yield, milk composition and mammary gland health of dairy ewes. Small Ruminant Research, 29: 113-120.

Buckley, J.D., Brinkworth, G.D. \& Abbott, M.J. 2003. Effect of bovine colostrum on anaerobic exercise performance and plasma insulin-like growth factor I. Journal of Sports Sciences, 21: 577-588.

Buckley, J.D., Abbott, M.J., Brinkworth, G.D. \& Whyte, P.B. 2002. Bovine colostrum supplementation during endurance running training improves recovery, but not performance. Journal of Science and Medicine in Sport, 5: 65-79.

Burrin, D.G. 1997. Is milk-borne insulin-like growth factor-I essential for neonatal development? Journal of Nutrition, 127(5 Suppl): 975S-979S.

Burrin, D.G., Stoll, B., Fan, M.Z., Dudley, M.A., Donovan, S.M. \& Reeds, P.J. 2001. Oral IGF-I alters the post-translational processing but not the activity of lactase-phlorizin hydrolase in formula-fed neonatal pigs. Journal of Nutrition, 131: 2235-2241.

Campos, B.G., Coelho, S.G., Quintão, A.M.L., Rabelo, E., Machado, T. \& Silper, B. 2011. [Use of bovine somatotrophin (bST) $500 \mathrm{mg}$ in crossbred Bos taurus $\times$ Bos indicus cows every 12 or 14 days.] A Hora Veterinária, 179: 8-13 (in Portuguese). 
Capoluongo, E., Pitocco, D., Santonocito, C., Concolino, P., Santini, S.A., Manto, A., Lulli, A., Ghirlanda, G., Zuppi, C. \& Ameglio, A. 2006. Association between serum free IGF-I and IGFBP-3 levels in type-I diabetes patients affected with associated autoimmune diseases or diabetic complications. European Cytokine Network, 17(3): 167-174.

Capuco, A.V., Wood, D.L., Elsasser, T.H., Kahl, S., Erdman, R.A., Van Tassell, C.P., Lefcourt, A. \& Piperova, L.S. 2001. Effect of somatotrophin on thyroid hormones and cytokines in lactating dairy cows during ad libitum and restricted feed intake. Journal of Dairy Science, 84: 2430-2439.

Carroll, P.V., Christ, E.R., Umpleby, A.M., Gowrie, I., Jackson, N., Bowes, S.B., Hovorka, R., Croos, P., Sönksen, P.H. \& Russell-Jones, D.L. 2000. IGF-I treatment in adults with type 1 diabetes: effects on glucose and protein metabolism in the fasting state and during a hyperinsulinemiceuglycemic amino acid clamp. Diabetes, 49: 789-796.

Casellas, A., Salavert, A., Agudo, J., Ayuso, E., Jimenez, V., Moya, M., Muñoz, S., Franckhauser, S. \& Bosch, F. 2006. Expression of IGF-I in pancreatic islets prevents lymphocytic infiltration and protects mice from type 1 diabetes. Diabetes, 55: 3246-3255.

Castigliego, L., Iannone, G., Grifoni, G., Rosati, R., Gianfaldoni, D. \& Guidi, A. 2007. Natural and recombinant bovine somatotrophin: immunodetection with a sandwich ELISA. Journal of Dairy Research, 74: 79-85.

Castigliego, L., Li, X.N., Armani, A., Grifoni, G., Boselli, C., Rosati, R., Gianfaldoni, D. \& Guidi, A. 2011. Hormone variations in serum and milk of buffaloes (Bubalus bubalis) as potential indicators of treatment with recombinant bovine somatotrophin. Journal of Dairy Research, 78: 412-420.

Chadio, S.E., Zervas, G., Kiriakou, K., Goulas, C. \& Menegatos, J. 2000. Effects of recombinant bovine somatotrophin administration to lactating goats. Small Ruminant Research, 35: 263-269.

Chaiyabutr, N., Thammacharoen, S., Komolvanich, S. \& Chanpongsang, S. 2007. Effects of longterm administration of recombinant bovine somatotrophin on the plasminogen-plasmin system and milk composition of crossbred Holstein cattle. Animal Science Journal, 78: 251-258.

Chaiyabutr, N., Thammacharoen, S., Komolvanich, S. \& Chanpongsang, S. 2008. Effects of longterm administration of recombinant bovine somatotrophin on the concentration of metabolites in milk in different stages of lactation in crossbred Holstein cattle. Animal Science Journal, 79: 41-50.

Chen, W., Salojin, K.V., Mi, Q.S., Grattan, M., Meagher, T.C., Zucker, P. \& Delovitch, T.L. 2004. Insulin-like growth factor (IGF)-I/IGF-binding protein-3 complex: therapeutic efficacy and mechanism of protection against type 1 diabetes. Endocrinology, 145: 627-628.

Chiofalo, V., Baldi, A., Savoini, G., Polidori, F., Dell'Orto, V. \& Politis, I. 1999. Response of dairy ewes in late lactation to recombinant bovine somatotrophin. Small Ruminant Research, 34: 119-125.

Choi, J., Choi, M.J., Kim, C., Ha, J., Hong, B., Ji, Y. \& Chang, B. 1997. Effect of recombinant bovine somatotrophin (rBST) administration on residual BST and insulin-like growth factor-1 levels in various tissues of cattle. Journal of the Food Hygiene Society of Japan, 38(4): 225-232.

Clayton, P.E., Banerjee, I., Murray, P.G. \& Renehan, A.G. 2011. Growth hormone, the insulin-like growth factor axis, insulin and cancer risk. Nature Reviews Endocrinology, 7: 11-24.

Collier, R.J., Byatt, J.C., Denham, S.C., Eppard, P.J., Fabellar, A.C., Hintz, R.L., McGrath, M.F., McLaughlin, C.L., Shearer, J.K., Veenhuizen, J.J. \& Vicin, J.L. 2001. Effects of sustained release bovine somatotrophin (sometribove) on animal health in commercial dairy herds. Journal of Dairy Science, 84: 1098-1108.

Collier, R.J., Miller, M.A., McLaughlin, C.L., Johnson, H.D. \& Baile, C.A. 2008. Effects of recombinant bovine somatotrophin (rbST) and season on plasma and milk insulin-like growth factors I (IGF-I) and II (IGF-II) in lactating dairy cows. Domestic Animal Endocrinology, 35: 16-23.

Committee on Carcinogenicity. 2012. Possible carcinogenic hazard to consumers from insulin-like growth factor-1 (IGF-1) in the diet (CC/2012/06). Committee on Carcinogenicity of Chemicals in Food, Consumer Products and the Environment (CC/MIN/2012/2; http:/ /www.iacoc.org.uk/ meetings/documents/COC2012-02AprilFinalminutes.pdf Accessed 10 November 2013).

Coombes, J.S., Conacher, M., Austen, S.K. \& Marshall, P.A. 2002. Dose effects of oral bovine colostrum on physical work capacity in cyclists. Medicine E Sci. in Sports and Exercise, 34: 1184-1188.

Corpeleijn, W.E., van Vliet, I., de Gast-Bakker, D.-A.H., van der Schoor, S.R.D., Alles, M.S., Hoijer, M.S., Tibboel, D. \& van Goudoever, J.B. 2008. Effect of enteral IGF-1 supplementation on feeding tolerance, growth, and gut permeability in enterally fed premature neonates. Journal of Pediatric Gastroenterology and Nutrition, 46: 184-190. 
Crowe, F.L., Key, T.J., Allen, N.E. and 41 others. 2009. The association between diet and serum concentrations of IGF-I, IGFBP-1, IGFBP-2, and IGFBP-3 in the European Prospective Investigation into Cancer and Nutrition. Cancer Epidemiology, Biomarkers and Prevention, 18: 1333-1340.

Daxenberger, A., Sauerwein, H. \& Breier, B.H. 1998. Increased milk levels of insulin-like growth factor 1 (IGF-1) for the identification of bovine somatotrophin (bST) treated cows. Analyst, 123: 2429-2435.

Dervilly-Pinel, G., Prévost, S., Monteau, F. \& Le Bizec, B. 2014. Analytical strategies to detect use of recombinant bovine somatotrophin in food-producing animals. Trends in Analytical Chemistry, 53: 1-10.

de Souza Paula, K. \& da Silva, D.A. 2011. [Somatotrophin: aspects related to its application in dairy cows.] Acta Biomedica Brasiliensia, 2: 8-15 (in Portuguese).

De Vliegher, S., Fox, L.K., Piepers, S., McDougall, S. \& Barkema, H.W. 2012. Mastitis in dairy heifers: nature of the disease, potential impact, prevention, and control [invited review]. Journal of Dairy Science, 95: 1025-1040.

Dohoo, I.R., DesCôteaux, L., Leslie, K., Fredeen, A., Shewfelt, W., Preston, A. \& Dowling, P. 2003. A meta-analysis review of the effects of recombinant bovine somatotrophin. 2. Effects on animal health, reproductive performance, and culling. Canadian Journal of Veterinary Research, 67: 252-264.

Eringsmark Regnéll, S. \& Lernmark, Å. 2013. The environment and the origins of islet autoimmunity and type 1 diabetes. Diabetic Medicine, 30: 155-60.

Erskine, R., Cullor, J., Schaellibaum, M., Yancey, B. \& Zecconi, A. 2004. Bovine mastitis pathogens and trends in resistance to antibacterial drugs. NMC Annual Meeting Proceedings, National Mastitis Council Research Committee Report, 400-414.

FAO. 1993. Bovine somatotrophins. pp. 113-142, in: Residues of some veterinary drugs in animals and foods. Monographs prepared by the Fortieth Meeting of the Joint FAO/WHO Expert Committee on Food Additives Geneva, 9-18 June 1992. FAO Food and Nutrition Paper, No. 41/5. Available at http://www.fao.org/docrep/014/T0721E/T0721E.pdf Accessed 2014-05-18.

FAO. 1999. Bovine somatotrophin. pp. 3-21, in: Residues of some veterinary drugs in animals and foods. FAO Food and Nutrition Paper, No. 41/11. The relevant monograph is available at http: / / www.fao.org/food/food-safety-quality/scientific-advice/jecfa/jecfa-vetdrugs/en/ Accessed 2014-06-01.

FAO/WHO. 2012. Report of the Thirty-fifth Session of the Codex Alimentarius Commission, Rome, Italy, 2-7 July 2012. Rome, Food and Agriculture Organization of the United Nations and World Health Organization, Joint FAO/WHO Food Standards Programme, Codex Alimentarius Commission (REP12/CAC). Available at http:/ / www.codexalimentarius.org/ download/report/772/REP12_CACe.pdf Accessed 15 January 2014.

Farris, G.M., Miller, G.K., Wollenberg, G.K., Molon-Noblot, S., Chan, C. \& Prahalada, S. 2007. Recombinant rat and mouse growth hormones: risk assessment of carcinogenic potential in 2-year bioassays in rats and mice. Toxicological Sciences, 97: 548-561.

Faulkner, A. 1999. Changes in plasma and milk concentrations of glucose and IGF-I in response to exogenous growth hormone in lactating goats. Journal of Dairy Research, 66: 207-214.

Feckinghaus, M.A. 2009. [Influence of recombinant bovine somatotrophin (rBST) in the lipid profile and milk composition of lactating Murrah water buffaloes.] Master's thesis. Faculdade de Medicina Veterinaria e Zootecnia, Universidade de São Paulo, Sao Paulo, SP, Brazil (in Portuguese with English abstract).

Fellah, A.M., Philipps, A.F., Gillespie, T.J., Galo, J.R. \& Dvorák, B. 2001. Degradation of insulin-like growth factors in small intestine of suckling rats. Regulatory Peptides, 98: 19-25.

Fike, J.H., Staples, C.R., Sollenberger, L.E., Moore, J.E. \& Head, H.H. 2002. Southeastern pasturebased dairy systems: housing, Posilac, and supplemental silage effects on cow performance. Journal of Dairy Science, 85: 866-878.

Fitzgerald, A.C., Annen-Dawson, E.L., Baumgard, L.H. \& Collier, R.J. 2007. Evaluation of continuous lactation and increased milking frequency on milk production and mammary cell turnover in primiparous Holstein cows. Journal of Dairy Science, 90: 5483-5489.

Gao, D., Ning, N., Wang, C., Wang, Y., Li, Q., Meng, Z., Lui, Y. \& Li, Q. 2013. Dairy products consumption and risk of type 2 diabetes: systematic review and dose-response meta-analysis. PLoS One, 8(9): e73965. 
George, M., Ayuso, E., Casellas, A., Costa, C., Devedjian, J.C. \& Bosch, F. 2002. Beta cell expression of IGF-I leads to recovery from type 1 diabetes. Journal of Clinical Investigation, 109: 1153-1163.

Groenewegen, P.P., McBride, B.W., Burton, J.H. \& Elsasser, T.H. 1990. Bioactivity of milk from bST treated cows. The Journal of Nutrition, 120: 514-520.

Gulay, M.S., Hayen, M.J., Teixeira, L.C., Wilcox, C.J. \& Head, H.H. 2003. Responses of Holstein cows to a low dose of somatotrophin (bST) prepartum and postpartum. Journal of Dairy Science, 86: 3195205.

Gulay, M.S., Hayen, M.J., Liboni, M., Belloso, T.T., Wilcox, C.J. \& Head, H.H. 2004. Low doses of bovine somatotrophin during the transition period and early lactation improves milk yield, efficiency of production, and other physiological responses of Holstein. Journal of Dairy Science, 87: 948-960.

Gulay, M.S., Liboni, M., Hayen, M.J. \& Head, H.H. 2007. Supplementing Holstein cows with low doses of bovine somatotrophin prepartum and postpartum reduces calving-related diseases. Journal of Dairy Science, 90: 5439-5445.

Harrison, L.C. \& Honeyman, M.C. 1999. Cow's milk and type 1 diabetes: the real debate is about mucosal immune function. Diabetes, 48: 1501-1507.

Hassan, G.A., El-Hanafy, A.A., Ali, B.A., Mohamed, M.M., El-Zarkouny, S.Z. \& Salem, M.H. 2007. Effect of recombinant bovine somatotrophin (rBST) on milk production, milk composition, and reproductive performance of lactating Egyptian buffaloes. Buffalo Journal, 23: 29-39.

Health Canada. 1998. Report of the Canadian Veterinary Medical Association Expert Panel on rbST. Health Canada, Ottawa. Available at http:/ / www.hc-sc.gc.ca/dhp-mps/vet/issues-enjeux/rbststbr/rep_cvma-rap_acdv_tc-tm-eng.php Accessed 2014-05-18.

Health Canada. 1999. Report of the Royal College of Physicians and Surgeons of Canada - Expert Panel on Human Safety of rbST. Health Canada, Ottawa. Available at http://www.hcsc.gc.ca/dhp-mps/vet/issues-enjeux/rbst-stbr/rep_rcpsc-rap_crmcc_final-a-eng.php Accessed 2014-05-18.

Heaney, R.P., McCarron, D.A., Dawson-Hughes, B., Oparil, S., Berga, S.L., Stern, J.S., Barr, S.I. \& Rosen, C.J. 1999. Dietary changes favorably affect bone remodeling in older adults. Journal of the American Dietetic Association, 99: 1228-1233.

Hoppe, C., Udam, T.R., Lauritzen, L., Molgaard, C., Juul, A. \& Michaelsen, K.F. 2004. Animal protein intake, serum insulin-like growth factor I and growth in healthy 2.5-y-old Danish children. American Journal of Clinical Nutrition, 80: 447-452.

Houle, V.M., Park, Y.K., Laswell, S.C., Freund, G.G., Dudley, M.A. \& Donovan, S.M. 2000. Investigation of three doses of oral insulin-like growth factor-I on jejunal lactase phlorizin hydrolase activity and gene expression and enterocyte proliferation and migration in piglets. Pediatric Research, 48: 497-503.

JECFA. 1993. Evaluation of certain veterinary drug residues in food (Fortieth Report of the Joint FAO/WHO Expert Committee on Food Additives). WHO Technical Report Series, No. 832.

JECFA. 1999. Evaluation of certain veterinary drug residues in food (Fiftieth Report of the Joint FAO/WHO Expert Committee on Food Additives). WHO Technical Report Series, No. 888.

Jorge, A.M., Gomes, M.I.F.V. \& Halt, R.C. 2002. Efeito da Utilização da Somatotrophina Bovina Recombinante (bST) sobre a Produção de Leite em Búfalas. Revista Brasileira de Zootecnia, 31: 12301234.

Judge, L.J., Bartlett, P.C., Lloyd, J.W. \& Erskine, R.J. 1999. Recombinant bovine somatotrophin: association with reproductive performance in dairy cows. Theriogenology, 52: 481-496.

Kim, Y. \& Kim, D. 2012. Effects of Boostin-250 supplementation on milk production and health of dairy cows. Journal of Veterinary Clinics, 29: 213-219.

Kim, N., Chang, B. \& Kim, D. 2002. Effects of retinyl palmitate and cholecalciferol combined with recombinant BST on milk production and health in dairy cows. Journal of Veterinary Clinics, 19: 4348.

Kim, W.A., Ryu, Y.H., Seo, D.S., Lee, C.Y. \& Ko, Y. 2006. Effects of oral administration of insulin-like growth factor-I on circulating concentration of insulin-like growth factor-I and growth of internal organs in weanling mice. Biology of the Neonate, 89: 199-204. 
Knip, M., Virtanen, S.M. \& Akerblom, H.K. 2010. Infant feeding and the risk of type 1 diabetes. American Journal of Clinical Nutrition, 91: 1506S-1513S.

Kuipers, H., van Breda, E., Verlaan, G. \& Smeets, R. 2002. Effects of oral bovine colostrum supplementation on serum insulin-like growth factor-I levels. Nutrition, 18: 566-567.

Kweon, U.G., Kim, H.S., Yun, S.K., Nam, K.T., Kim, J.B., Ahn, J.B. \& Kim, J.S. 2000. Effects of rbST administration on the changes in the concentration of blood and carcass hormones in Holstein bulls and steers. Journal of Animal Science \& Technology (Korea), 42: 451-458.

Le Breton, M., Rochereau-Roulet, S., Pinel, G., Bailly-Chouriberry, L., Rychen, G., Jurjanz, S., Goldman, T. \& le Bizec, B. 2008. Direct determination of recombinant bovine somatotrophin in plasma from a treated goat by liquid chromatography/high-resolution mass spectrometry. Rapid Communications in Mass Spectrometry, 22: 3130-3136.

Le Breton, M., Rochereau-Roulet, S., Pinel, G., Cesbron, N. \& Le Bizec, B. 2009. Elimination kinetic of recombinant somatotrophin in bovine. Analytica Chimica Acta, 637: 121-127.

Le Breton, M., Beck-Henzelin, A., Richoz-Payot, J., Rochereau-Roulet, S., Pinel, G., Delatour, T. \& Le Bizec, B. 2010a. Detection of recombinant bovine somatotrophin in milk and effect of industrial processes on its stability. Analytica Chimica Acta, 672: 45-49.

Le Breton, M., Rochereau-Roulet, S., Chéreau, S., Pinel, G., Delatour, T. \& Le Bizec, B. 2010b. Identification of cows treated with recombinant bovine somatotrophin Journal of Agricultural and Food Chemistry, 58: 729-733.

Liboni, M., Gulay, M.S., Hayen, M.J., Belloso, T.I. \& Head, H.H. 2008. Supplementation of Holstein cows with low doses of bovine somatotrophin (bST) prepartum and postpartum affects physiological adaptations and milk production. Asian-Australasian Journal of Animal Science, 21: 404-413.

Liebe, A. \& Schams, D. 1998. Growth factors in milk: interrelationships with somatic cell count. Journal of Dairy Research, 65: 93-100.

Livingstone, C. 2013. Insulin-like growth factor-I (IGF-I) and clinical nutrition. Clinical Science, 125: 265-280.

Lucci, C. de S., Rodrigues, P.H.M., Santos, E.J. Jr. \& Castro, A.L. 1998. [Use of bovine somatotrophin (BST) in high producing dairy cows.] Brazilian Journal of Veterinary Research and Animal Science São Paulo, 35: 46-50 (in Portuguese).

Ma, J., Giovannucci, M., Pollak, M., Chan, J.M., Gaziano, J.M., Willett, W. \& Stampfer, M.J. 2001. Milk intake, circulating levels of insulin-like growth factor I, and risk of colorectal cancer in men. Journal of the National Cancer Institute, 93: 1330-1336.

Macrina, A.L., Tozer, P.R. \& Kensinger, R.S. 2011. Induced lactation in pubertal heifers: efficacy, response to bovine somatotrophin, and profitability. Journal of Dairy Science, 94: 1355-1364.

Maksiri, W., Chanpongsang, S. \& Chaiyabutr, N. 2005. Relationship of early lactation and bovine somatotrophin to water metabolism and mammary circulation of crossbred Holstein cattle. AsianAustralasian Journal of Animal Science, 18: 1600-1608.

Martin, R.M., Holly, J.M.P., Middleton, N., Davey, Smith, G. \& Gunnell, D. 2007. Childhood diet and insulin-like growth factors in adulthood: 65-year follow-up of the Boyd Orr Cohort. European Journal of Clinical Nutrition, 61: 1281-1292.

Masoero, F., Moschini, M., Rossi, F. \& Piva, G. 1998. Effect of bovine somatotrophin on milk production, milk quality and the cheese-making properties of Grana Padano cheese. Livestock Science, 54: 107-114.

McCluskie, M.J. \& Davis, H.L. 1999. Mucosal immunization with DNA vaccines. Microbes and Infection, 1: 685-698.

McGrath, M.F., Bogosian, G., Fabellar, A.C., Staub, R.L., Vicini, J.L. \& Wigler, L.A. 2008. Measurement of bST and IGF-I in milk using electrochemiluminescent assay. Journal of Agricultural and Food Chemistry, 54: 7044-7048.

Mero, A., Kähkönen, J., Nykänen, T., Parviainen, T., Jokinen, I., Takala, T., Nikula, T., Rasi, S. \& Leppäluoto, J. 2002. IGF-I, IgA, and IgG responses to bovine colostrum supplementation during training. Journal of Applied Physiology, 93: 732-739.

Miller, A.R., Stanisiewski, E.P., Erdman, R.A., Douglass, L.W. \& Dahl, G.E. 1999. Effects of long daily photoperiod and bovine somatotrophin (Trobest) on milk yield in cows. Journal of Dairy Science, 82: 1716-1722. 
Mishra, A., Gade, S.N., Mahapatra, R.K. \& Shukla, D.C. 2005. Effect of recombinant bovine somatotrophin (Boostin-250) on serum endocrines and milk GH of lactating buffaloes. Buffalo Journal, 1: 9-16.

Mishra, A., Mahapatra, R.K. \& Shukla, D.C. 2006. Changes in blood metabolites, endocrines and milk yield of crossbred cows treated with recombinant bovine somatotrophin. Journal of Applied Animal Research, 30: 33-36.

Mishra, A., Goswani, T.K. \& Shukla, D.C. 2007. An enzyme-linked immunosorbent assay (ELISA) to measure growth hormone level in serum and milk of buffaloes (Bubalus bubalis). Indian Journal of Experimental Biology, 45: 594-598.

Moallem, U., Folman, Y. \& Sklan, D. 2000. Effects of somatotrophin and dietary calcium soaps of fatty acids in early lactation on milk production, dry matter intake, and energy balance of highyielding dairy cows. Journal of Dairy Science, 83: 2085-2094.

Moraes e Amorim, E.A., Torres, C.A.A., Bruschi, J.H., da Fonseca, J.F., Guimaraes, J.D., Cecon, P.R. \& Carvalho, G.R. 2006. [Milk yield and composition, blood metabolites and hormonal profile of lactating Toggenburg goats treated with recombinant bovine somatotrophin.] Revista Brasileira de Zootecnia, 35: 147-153.

Moses, A.C., Young, S.C., Morrow, L.A., O'Brien, M. \& Clemmons, D.R. 1996. Recombinant human insulin-like growth factor I increases insulin sensitivity and improves glycemic control in type II diabetes. Diabetes, 45: 91-100.

Mukherjee, R. 2007. Effect of bovine recombinant somatotrophin on occurrence of clinical mastitis in lactating buffaloes. Indian Journal of Veterinary Medicine, 27: 60-62.

Munro, J.L. \& Boon, V.A. 2010. Quantitative determination of recombinant bovine somatotrophin in commercial shrimp feed using a competitive enzyme-linked immunosorbent assay. Journal of Agricultural and Food Chemistry, 58: 1429-1433.

Murphy, L.J. 2006. Insulin-like growth factor-I: a treatment for type 2 diabetes revisited. Endocrinology, 147: 2616-2618.

Nabil, S.S., Gauthier, F., Drouin, R., Poubelle, P.E. \& Pouliot, Y. 2011. In vitro digestion of proteins and growth factors in a bovine whey protein extract as determined using a computer-controlled dynamic gastrointestinal system (TIM-1). Food Digestion, 2: 13-22.

NMDRD [National Milk Drug Residue Database]. 2013. National Milk Drug Residue Database, 1994 to 2012. United States Food and Drug Administration - through a third party contractor website (http://www.kandc-sbcc.com/nmdrd/index.html Accessed 8 September 2013).

Norris, J.M. 2010. Infant and childhood diet and type 1 diabetes risk: recent advances and prospects. Current Diabetes Reports, 10: 345-349.

Oliver, S.P. \& Murinda, S.E. 2012. Antimicrobial resistance of mastitis pathogens. Veterinary Clinics of North America: Food Animal Practice, 28: 165-185.

Oliver, S.P., Murinda, S.E. \& Jayarao, B.M. 2011. Impact of antibiotic use in adult dairy cows on antimicrobial resistance of veterinary and human pathogens: a comprehensive review. Foodborne Pathogens and Disease, 8: 337-55.

Pauletti, P., Bagaldo, A.R., Kindlein, L., de Paz, C.C.P., Lanna, D.P.D. \& Machado Neto, R. 2005. IGF-I e IgG Séricos e nas Secreções Lácteas em Vacas Tratadas com rbST no Período Pré-Parto. Revista Brasileira de Zootecnia, 34: 976-986.

Pezeshki, A., Capuco, A.V., De Spiegeleer, B., Peelman, L., Stevens, M., Collier, R.J. \& Burvenich, C. 2010. An integrated view on how the management of the dry period length of lactating cows could affect mammary biology and defence. Journal of Animal Physiology and Animal Nutrition (Berlin), 94: e7-e30.

Philipps, A.F., Dvora, K.B., Kiling, P.J., Grille, J.G. \& Koldovsky, O. 2000. Absorption of milkborne insulin-like growth factor-I into portal blood of suckling rats. Journal of Pediatric Gastroenterology and Nutrition, 31: 128-135.

Philipps, A.F., Kling, P.J., Grille, J.G. \& Dvorák, B. 2002. Intestinal transport of insulin-like growth factor-I (IGF-I) in the suckling rat. Journal of Pediatric Gastroenterology and Nutrition, 35: 539-544.

Pinel, G., André, F. \& Le Bizec, B. 2004. Discrimination of recombinant and pituitary-derived bovine and porcine growth hormones by peptide mass mapping. Journal of Agricultural and Food Chemistry, 52: 407-414. 
Posada, S.L., Echavarria, H., Montoya, G., Cardona, A.F. \& Echeverri, O.F. 2008. [Productive and microeconomic evaluation of commercial sources of bovine somatotrophin application in dairy cows.] Revista Colombiana de Ciencias Pecuarias, 21: 27-38.

Prasad, J. \& Singh, M. 2010. Milk production and hormonal changes in Murrah buffaloes administered recombinant bovine somatotrophin (rBST). Agriculture and Biology Journal of North America, 1: 325-1327.

Pugliese, A. 2013. The multiple origins of type 1 diabetes. Diabetic Medicine, 30(2): 135-146.

Qin, L.Q., He, K. \& Xu, J.Y. 2009. Milk consumption and circulating insulin-like growth factor-I level: a systematic literature review. Intl. Journal of Food Science and Nutrition, 60(Suppl. 7): 330-340.

Qudus, M.A., Ahmad, N., Javed, K., Abdullah, M., Jabbar, M.A., Omer, M.O., Iqbal, Z.M. \& Ahmad, I. 2013. Effect of recombinant bovine somatotrophin on milk production and composition of lactating Beetal goats. Journal of Animal and Plant Science, 23(Suppl. 1): 26-30.

Rao, R.K., Philipps, A.F., Williams, C.S., McCraken, D.M. \& Koldovsky, O. 1998. Luminal stability of insulin-like growth factors I and II in developing rat gastro-intestinal tract. Journal of Pediatric Gastroenterology and Nutrition, 26: 179-189.

Requena, R., Balasch, S., Peris, C., Rodriguez, M. \& Fernandez, N. 2010. Dose response of lactating dairy ewes during suckling and milking to bovine somatotrophin. Journal of Animal Science, 88: 3136-3144.

Richard, D., Odaglia, G. \& Deslex, P. 1989. Three-month (90-day) oral toxicity study of sometribove in the rat. Unpublished results of study SF 0361, Monsanto study SA-88-353. Monsanto Agricultural Company, St Louis, MO, USA. Submitted to WHO by Elanco Animal Health.

Rich-Edwards, J.W., Ganmaa, D., Pollak, M.N., Nakamoto, E.K., Kleinman, K., Tserendolgor, U., Willett, W.C. \& Frazier, A.L. 2007. Milk consumption and the prepubertal somatotropic axis. Nutrition Journal, 6: 28.

Rivera, F., Narciso, C., Oliveira, R., Cerri, R.L.A., Correa-Calderón, A., Chebel, R.C. \& Santos, J.E.P. 2010. Effect of bovine somatotrophin $(500 \mathrm{mg})$ administered at ten-day intervals on ovulatory responses, expression of estrus, and fertility in dairy cows. Journal of Dairy Science, 93: 1500-1510.

Robertson, K., Lu, Y., De Jesus, K., Li, B., Su, Q., Lund, P.K. \& Liu, J.-L. 2008. A general and islet cellenriched overexpression of IGF-I results in normal islet cell growth, hypoglycemia, and significant resistance to experimental diabetes. American Journal of Physiology - Endocrinology and Metabolism, 294: E928-E938.

Rochereau-Roulet, S., Gicquiau, A., Morvan, M.L., Blanc, G., Dervilly-Pinel, G. \& Le Bizec, B. 2013. Recombinant bovine growth hormone identification and the kinetic of elimination in rainbow trout treated by LC-MS/MS. Food Additives and Contaminants A, 30: 1020-1026.

Rose, M.T., Weekes, T.E.C. \& Rowlinson, P. 2005. Correlation of blood and milk components with the milk yield response to bovine somatotrophin in dairy cows. Domestic Animal Endocrinology, 28: 296-307.

Ruegg, P.L., Fabellar, A. \& Hintz, R.L. 1998. Effect of the use of bovine somatotrophin on culling practices in thirty-two dairy herds in Indiana, Michigan, and Ohio. Journal of Dairy Science, 81: 1262-1266.

Ruzante, J.M., Lombard, J.E., Wagner, B., Fossler, C.P., Karns, J.S., van Kessel, J.A.S. \& Gardner, I.A. 2010. Factors associated with Salmonella presence in environmental samples and bulk tank milk from US dairies. Zoonoses and Public Health, 57: e217-e225.

Sallam, S.M.A., Nasser, M.E.A. \& Yousef, M.I. 2005. Effect of recombinant bovine somatotrophin on sheep milk production, composition and some hemato-biochemical components. Small Ruminant Research, 56: 165-171.

Schneider, A., Schwegler, E., Montagner, P., Hax, L.T., Schmitt, E., Pfeifer, L.F., Del Pino, F.A.B., Bianchi, I., Paludo, G.R. \& Corrêa, M.N. 2012. Effect of prepartum somatotrophin injection in latepregnant Holstein heifers on metabolism, milk production and postpartum resumption of ovulation. Animal, 6: 935-940.

Shen, W.H. \& Xu, R.J. 2000. Stability of insulin-like growth factor-I in the gastrointestinal lumen in neonatal pigs. Journal of Pediatric Gastroenterology and Nutrition, 30: 299-304. 
Shin, M.K., Lee, W.J., Jung, M.H., Cha, S.B., Shin, S.W., Yoo, A., Kim., D.-H. \& Yoo, H.S. 2013. Oral immunization of mice with Saccharomyces cerevisiae expressing a neutralizing epitope of ApxIIA exotoxin from Actinobacillus pleuropneumoniae induces systemic and mucosal immune responses. Microbiology and Immunology, 57: 417-425.

Simpson, M.D. \& Norris, J.M. 2008. Mucosal immunity and type 1 diabetes: looking at the horizon beyond cow's milk. Pediatric Diabetes, 9: 431-433.

Skyler, J.S. 2007. Prediction and prevention of type 1 diabetes: progress, problems, and prospects. Clinical Pharmacology \& Therapeutics, 81: 768-771.

Tarazon Herrera, M., Huber, J.T., Santos, J., Mena, H., Nusso, L. \& Nussio, C. 1999. Effects of bovine somatotrophin and evaporative cooling plus shade on lactation performance of cows during summer heat stress. Journal of Dairy Science, 82: 2352-2357.

Taylor, V.J., Cheng, Z., Pushpakumara, P.G.A., Beever, D.E. \& Wathes, D.C. 2004. Relationships between the plasma concentrations of insulin-like growth factor-I in dairy cows and their fertility and milk yield. Veterinary Record, 155: 583-588.

Thrailkill, K.M., Quattrin, T., Baker, L., Kuntze, J.E., Compton, P.G. \& Martha, P.M. Jr. 1999. Cotherapy with recombinant human insulin-like growth factor I and insulin improves glycemic control in type 1 diabetes. RhIGF-I in IDDM Study Group. Diabetes Care, 22: 585-592.

Torkelson, A.R. \& Miller, M.A. 1987. Comparison of milk and blood serum concentrations of bovine somatotrophin following intramuscular and subcutaneous injections of CP115099. Unpublished report MSL 6479. Monsanto Agricultural Company, St Louis, MO, USA. Submitted to WHO by Elanco Animal Health.

Usala, A.L., Madigan, T., Burguera, B., Cefalu, W., Sinha, M.K., Powell, J.G. \& Usala, S.J. 1994. High dose intravenous, but not low dose subcutaneous, insulin-like growth factor-I therapy induces sustained insulin sensitivity in severely resistant type I diabetes mellitus. Journal of Clinical Endocrinology \& Metabolism, 79: 435-440.

USDA [United States Department of Agriculture]. 2007. NAHMS Dairy 2007. United States Department of Agriculture, National Animal Health Monitoring System Fort Collins. Available at http: / / www.aphis.usda.gov/animal_health/nahms/dairy/index.shtml Accessed 20 October 2013.

USDA. 2012. Determining U.S. milk quality using bulk-tank somatic cell counts, 2011. United States Department of Agriculture, APHIS, Centers for Epidemiology and Animal Health, Veterinary Services Fort Collins. Available at http:/ / www.aphis.usda.gov/animal_health/ nahms/dairy/downloads/dairy_monitoring/BTSCC_2011infosheet.pdf Accessed 23 October 2013.

Vaarala, O. 2005. Is type 1 diabetes a disease of the gut immune system triggered by cow's milk insulin? Advances in Experimental Medicine and Biology, 569: 151-156.

Vaarala, O. 2012. Gut microbiota and type 1 diabetes. The Review of Diabetic Studies, 9: 251-259.

Valdes-Ramos, R., Martinez-Carrillo, B.E., Aranda-González, I.I., Guadarrama, A.L., Pardo-Morales, R.V., Tlatempa, P. \& Jarillo-Luna, R.A. 2010. Diet, exercise and gut mucosal immunity. Proceedings of the Nutrition Society, 69: 644-650.

Vallimont, J.E., Varga, G.A., Arieli, A., Cassidy, T.W. \& Cummins, K.A. 2001. Effects of prepartum somatotrophin and monensin on metabolism and production of periparturient Holstein dairy cows. Journal of Dairy Science, 84: 2607-2621.

VanBaale, M.J., Ledwith, D.R., Thompson, J.M., Burgos, R., Collier, R.J. \& Baumgard, L.H. 2005. Effect of increased milking frequency in early lactation with or without recombinant bovine somatotrophin. Journal of Dairy Science, 88: 3905-3912.

van Schaik, G., Lotem, M. \& Schukken, Y.H. 2002. Trends in somatic cell counts, bacterial counts, and antibiotic residue violations in New York State during 1999-2000. Journal of Dairy Science, 85: 782-789.

Vicini, J., Etherton, T., Kris-Etherton, P., Ballam, J., Denham, S., Staub, R., Goldstein, D., Cady, R., McGrath, M. \& Lucy, M. 2008. Survey of retail milk composition as affected by label claims regarding farm management practices. Journal of the American Dietetic Association, 108: 1198-1203.

WHO. 1998. Toxicological evaluation of certain veterinary drug residues in food. WHO Food Additives Series, 41: 125-146. 


\title{
10. Zilpaterol hydrochloride
}

\author{
First Draft prepared by \\ Joe Boison, Saskatoon, Canada, \\ Fernando Ramos, Coimbra, Portugal, \\ Pascal Sanders, Fougères, France, \\ Al Chicoine, Saskatoon, Canada \\ and \\ Stefan Scheid, Berlin, Germany
}

\section{Identity}

International Non-proprietary name (INN): Zilpaterol hydrochloride Synonyms: RU 42173, zilpaterol HCl, Zilmax ${ }^{\circledR}$, Zilmax ${ }^{\circledR}$ Pre-mix.

IUPAC Names: ( \pm )-Trans-4,5,6,7-Tetrahydro-7-hydroxy-6-(isopropylamino)-imidazo[4,5,1jk]-[1]benzazepin -2(1H)- one, monohydrochloride Trans( \pm )-4,5,6,7-Tetrahydro-7-hydroxy-6-[(1-methyl-ethyl)amino]imidazo[4,5,1-jk]-[1]benzazepin-2(1H)-one, monohydrochloride

Chemical Abstract Service Number: Zilpaterol hydrochloride: 119520-06-8.

Structural Formula (zilpaterol free base):<smiles>CC(C)N[C@H]1CCn2c(=O)[nH]c3cccc(c32)[C@H]1O</smiles>

$(6 R, 7 R)$<smiles>CC(C)N[C@H]1CCn2c(=O)[nH]c3cccc(c32)[C@H]1O</smiles>

$(6 \mathrm{~S}, 7 \mathrm{~S})$

Molecular Formula: $\mathrm{C}_{14} \mathrm{H}_{19} \mathrm{~N}_{3} \mathrm{O}_{2} \bullet \mathrm{HCl}$ (zilpaterol hydrochloride)

Molecular Weight: $297.56 \mathrm{~g}$ for zilpaterol hydrochloride, and $261.113 \mathrm{~g}$ for zilpaterol free base.

\section{Other information on identity and properties}

Pure active ingredient: Zilpaterol has two chiral carbons and consequently four optical enantiomers. These enantiomers are: "(6R,7R)", "(6R,7S)", "(6S,7R)" and "(6S,7S)".

RU 42173 corresponds to racemic trans zilpaterol hydrochloride, a mixture of the (6R,7R) and (6S,7S) enantiomers.

Appearance: White to practically white powder

Melting point: $219.5-220.5^{\circ} \mathrm{C}$

Solubility: Zilpaterol hydrochloride is very soluble in water and in other aqueous media (about $50 \%$ of product dissolved) at different $\mathrm{pH}$ values (1-10). It is only slightly soluble in methanol (about $3 \%$ ) and practically insoluble in most organic solvents $(<0.1 \%)$ such as 
ethanol, acetone, ethyl-acetate, isopropyl ether, hexane, toluene, chloroform, dichloromethane or n-octanol.

\section{Residues in food and their evaluation}

\section{Conditions of use}

Zilmax ${ }^{\circledR}$, the commercial formulation of zilpaterol hydrochloride, is composed of $4.8 \% \mathrm{w} / \mathrm{w}$ zilpaterol hydrochloride as active ingredient, $8 \%$ polyoxyl 35 castor oil, $4.3 \%$ povidone 30 (40\% aqueous solution) and $82.9 \%$ corn cob grit. Zilmax ${ }^{\circledR}$ is used to increase rate of bodyweight gain, improve feed efficiency, and increase carcass leanness in cattle fed in confinement for a period of 20-40 consecutive days at the end of the feeding period before slaughter.

\section{Dosage}

Zilpaterol hydrochloride should be mixed into the feed at a level of $7.5 \mathrm{mg} / \mathrm{kg}$ on a $90 \%$ dry matter basis. This represents a dose of approximately $0.15 \mathrm{mg} / \mathrm{kg}$ bw or 60 to $90 \mathrm{mg}$ zilpaterol hydrochloride per animal per day.

\section{Registered uses}

Zilmax ${ }^{\circledR}$ has been registered for use in Columbia, Costa Rica, the Dominican Republic, Ecuador, Guatemala, Honduras, Mexico, Nicaragua, Panama, Peru and South Africa. Marketing authorization has been obtained for Zilmax® in Brazil, Canada, Kazakhstan and the United States of America. Import licences have recently been granted for the use of Zilmax ${ }^{\circledR}$ in Lebanon and Pakistan, while registration procedures are currently ongoing in Australia, Belarus, Indonesia and Taiwan. A procedure for registering "import MRLs" is currently active in Japan. The product was registered initially in South Korea as a feed additive, but this licence was withdrawn and the product was recently registered as a medicated pre-mix product. Zilpaterol hydrochloride is not permitted for use in lactating dairy cattle.

\section{Pharmacokinetics and metabolism}

\section{Test material used in radiolabel pharmacokinetic and metabolism studies}

Pharmacokinetic and metabolism studies were conducted with

$\left[{ }^{14} \mathrm{C}\right]$ zilpaterol hydrochloride (trans ( \pm )-6(1-methyletylamino)-7-hydroxy-4,5,6,7-tetrahydro$\left[2-{ }^{14} \mathrm{C}\right]$ azepino[1.2.3-cd]benzimidazole-2 $(1 \mathrm{H})$-one, hydrochloride) where the label is in the carbonyl position of the molecule (Figure 10.1). The position of this ${ }^{14} \mathrm{C}$ label has been shown to be in a stable, non-metabolized, part of the molecule (Veltz, 1999; Tremblay et al., 1988).

Specific activity: 6.06-6.27 MBq/mg.

Purity: > 99.0\% (by TLC and HPLC methods)

The good radio-purity, together with radiolabelling in a stable, non-metabolized position, allowed use of this product to assess pharmacokinetics and metabolism in laboratory animal species and in cattle.

Figure 10.1. The structure of $\left[{ }^{14} \mathrm{C}\right] z$ zilpaterol free base showing the position of the label<smiles>CC(C)N[C@H]1CCn2c(=O)[nH]c3cccc(c32)C1O</smiles> 


\section{Pharmacokinetics and metabolism in laboratory animals}

\section{Rats}

A study (non-GLP-compliant) was conducted with $\left[{ }^{14} \mathrm{C}\right]$ zilpaterol hydrochloride in 12 male fasted Sprague-Dawley rats (mean weight $202 \mathrm{~g}$ ) to assess absolute oral bio-availability, the feeding status/effect of repeated oral administrations and then the distribution into the body (Tremblay et al., 1990a). The rats were allocated to two groups of 6 animals each. The rats were fasted $21 \mathrm{~h}$ and administered $1 \mathrm{mg} / \mathrm{kg}$ bw zilpaterol hydrochloride by either an oral or intravenous route, and fasted $6 \mathrm{~h}$ after dosing; the oral bio-availability was determined to be $99.3 \%$ based on urinary excretion. Administration into the food at a dose of $0.055 \mathrm{mg} / \mathrm{kg} \mathrm{bw}$ produced lower systemic exposure (both area under the curve (AUC) and maximum concentration (plasma) $\left.\left(\mathrm{C}_{\max }\right)\right)$ than after oral gavage, with a slightly higher exposure in females than in males. $\mathrm{C}_{\max }$ was approximately proportional to the dose.

Another study (non-GLP compliant) was reported in which $\left[{ }^{14} \mathrm{C}\right]$ zilpaterol hydrochloride was administered in a single oral dose of $1 \mathrm{mg} / \mathrm{kg}$ by gastric intubation to 10 male and 10 female Sprague-Dawley rats, mean weight $203 \mathrm{~g}$ (Tremblay et al., 1989). The 10 rats were divided into two groups of 5 each. The first group was anaesthetized and killed $0.5 \mathrm{~h}$ after drug administration and the second group $24 \mathrm{~h}$ after drug administration. The total radioactivity in the different tissues and plasma collected was determined by liquid scintillation counting (LSC). The ratio of tissue radioactivity concentration to that of plasma $\left(R_{t / p}\right)$ was calculated for each tissue collected (Table 10.1). The $R_{t / p}$ results of the study conducted to determine the tissue distribution of zilpaterol as a function of time in the rat after a single oral dose administration showed that the radioactivity concentration of the drug depletes between $0.5 \mathrm{~h}$ and $24 \mathrm{~h}$ for all tissue matrices and organs of the males or females tested. Kidneys and liver involved in the metabolism and elimination of zilpaterol hydrochloride and its metabolite displayed the highest $R_{t / p}$. At $24 h$, the residual radioactivity was low and there was no retention in the organ samples, with no marked difference between male and female rats.

The $R_{t / p}$ 's measured for plasma, liver, kidneys, skeletal muscle and lung tissues are given in Table 10.2 for the male rats used in the above study and sacrificed at 0.5 and $24 \mathrm{~h}$ after the oral dose. These results show that the concentration of residues likely to be found in muscle are lower than would be found in kidney, liver and lung tissue.

Table 10.1. Tissue distribution of zilpaterol at 0.5 and $24 \mathrm{~h}$ following a single administration of

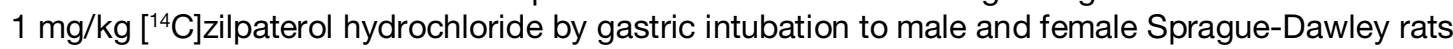
(Tremblay et al., 1989)

\begin{tabular}{lll}
\hline & \multicolumn{1}{c}{$\mathbf{R}_{\mathrm{t} / \mathrm{p}>>\mathbf{1}}$} & \multicolumn{1}{c}{$\mathbf{R}_{\mathrm{t} / \mathrm{p}}<<<1$} \\
\hline $0.5 \mathrm{~h}$ male rats & Vascular system (heart, spleen, bone marrow) & CNS (cortex, cerebellum, medulla) \\
& Respiratory system (diaphragm, lung) & Eyes \\
& Endocrine system (thyroid, adrenals, pituitary) & Fat (subcutaneous, perirenal) \\
& Digestive system (pancreas, duodenum, stomach) & Testis and thymus \\
& Liver - 5.96; kidney - 34.4 & \\
\hline $0.5 \mathrm{~h}$ female rats & Reproductive system (vagina, oviducts, uterus, \& ovaries) & Subcutaneous fat \\
& Skeletal muscle, adrenals, liver - 7.24; kidneys - 37.4 & \\
\hline $24 \mathrm{~h}$ male rats & Respiratory system (lung, diaphragm) & CNS (cortex, cerebellum, medulla) \\
& Vascular system (blood, erythrocytes) & Endocrine system (thyroid, pituitary) \\
& Relational system (skin, skeletal muscle) & Vascular system (heart, bone marrow) \\
& Adrenals - 7.0; stomach - 13.3; kidney - 16.6; urinary & Thymus, pancreas, eyes, perirenal fat \\
& bladder - 24.2; liver - 75 & \\
\hline $24 \mathrm{~h}$ female rats & Ovaries, liver - 71; kidneys - 11.4 & \\
\hline
\end{tabular}

NOTES: $R_{t / p}=$ ratio of tissue radioactivity concentration to that of plasma. 
A GLP compliant study was undertaken in which 70 male (mean bodyweight $272 \mathrm{~g}$ ) and 70 female (mean bodyweight $213 \mathrm{~g}$ ) Sprague-Dawley rats (about 8 weeks old) were allocated to two groups of 15 animals/sex/group, which received a dietary admixture, and two groups of 20 animals/sex/group dosed by gavage (Sauvez, 1995). Unlabelled zilpaterol doses used were 0.05 or $1.10 \mathrm{mg} / \mathrm{kg} /$ day (gavage and dietary admixture) for 13 days. All the animals were fasted for gavage purposes. Blood samples were collected Days 2-3 and Days 13-14, and harvested plasmas were analysed for unchanged zilpaterol using a validated radioimmunoassay method with a LOQ of $0.025 \mathrm{ng} / \mathrm{ml}$. After a 2-week repeated administration by oral route (dietary or gavage) at a dose of $0.05 \mathrm{mg} / \mathrm{kg}$ or $1.0 \mathrm{mg} / \mathrm{kg}$ bw in male and female rats, the mean plasma $\mathrm{AUC}_{(24 \mathrm{~h} \text { period) }} /$ dose were generally $2-4$ times higher in females than in males; the mean plasma $\mathrm{AUC}_{(24 \mathrm{~h} \text { period) }}$ and $\mathrm{C}_{\max }$ were $1.5-4$ and 10-13 times higher, respectively, by gavage than by dietary admixture (Table 10.3).

Table 10.3. Mean pharmacokinetic parameters for zilpaterol in Sprague-Dawley rat plasma after dosing by dietary admixture or gavage (Sauvez, 1995)

\begin{tabular}{|c|c|c|c|c|c|c|}
\hline $\begin{array}{c}\text { Route of } \\
\text { administration }\end{array}$ & Days & $\begin{array}{c}\text { Dose } \\
\text { (mg/kg/day) }\end{array}$ & Sex & $T_{\max }(\mathbf{h})$ & $\begin{array}{c}\mathrm{C}_{\max } \\
\text { (ng/ml) }\end{array}$ & $\begin{array}{c}\operatorname{AUC}_{(0-24 \mathrm{~h})} \text { or } \mathrm{AUC}_{(19-19 \mathrm{~h})} \\
\text { (ng.h/ml) }\end{array}$ \\
\hline \multirow[t]{8}{*}{ Dietary admixture } & $2-3$ & 0.055 & M & 23 & 0.24 & 3.64 \\
\hline & & & $\mathrm{F}$ & 23 & 1.90 & 29.5 \\
\hline & & 1.10 & $M$ & 3 & 3.65 & 56.1 \\
\hline & & & $\mathrm{F}$ & 23 & 8.71 & 159 \\
\hline & $13-14$ & 0.055 & M & 3 & 0.18 & 2.92 \\
\hline & & & $\mathrm{F}$ & 7 & 0.68 & 10.0 \\
\hline & & 1.10 & M & 7 & 3.78 & 47.2 \\
\hline & & & $\mathrm{F}$ & 7 & 9.46 & 157 \\
\hline \multirow[t]{8}{*}{ Gavage } & $2-3$ & 0.055 & $M$ & 0.75 & 2.50 & 5.44 \\
\hline & & & $\mathrm{F}$ & 0.25 & 5.99 & 13.4 \\
\hline & & 1.10 & M & 0.50 & 44.5 & 139 \\
\hline & & & $\mathrm{F}$ & 0.50 & 11.5 & 356 \\
\hline & $13-14$ & 0.055 & M & 0.75 & 2.35 & 6.35 \\
\hline & & & $\mathrm{F}$ & 0.25 & 8.29 & 18.4 \\
\hline & & 1.10 & M & 0.75 & 46.0 & 188 \\
\hline & & & $\mathrm{F}$ & 0.75 & 95.5 & 397 \\
\hline
\end{tabular}

NOTES: $T_{\max }=$ time at which $\mathrm{C}_{\max }$ occurs; $\mathrm{C}_{\max }=$ maximum concentration $($ plasma); $\mathrm{AUC}=$ area under the curve.
Table 10.2. Ratio $\left(R_{t / p}\right)$ of concentrations of $\left[{ }^{14} \mathrm{C}\right]$ zilpaterol in male Sprague-Dawley rats killed 0.5 and $24 \mathrm{~h}$ after a single oral dose (Tremblay et al., 1989)

\begin{tabular}{lcccc}
\hline \multirow{2}{*}{ Tissue } & \multicolumn{2}{c}{$\mathbf{0 . 5} \mathbf{h}$ withdrawal } & \multicolumn{2}{c}{$\mathbf{2 4} \mathbf{h}$ withdrawal } \\
& $\mathbf{n}$ & Mean $\mathbf{+ S . D}$. & $\mathbf{n}$ & Mean \pm S.D. \\
\hline Plasma & 5 & 1 & 5 & \\
Liver & 5 & $5.96 \pm 0.24$ & 5 & $75 \pm 14$ \\
Kidneys & 5 & $34.4 \pm 3.7$ & 5 & $16.6 \pm 3.7$ \\
$\begin{array}{l}\text { Skeletal } \\
\text { muscle }\end{array}$ & 5 & $1.24 \pm 0.08$ & 5 & $2.46 \pm 0.44$ \\
\begin{tabular}{l} 
Lung \\
\hline
\end{tabular} & 5 & $1.65 \pm 0.27$ & 5 & $1.43 \pm 0.19$ \\
\hline
\end{tabular}


In a non-GLP-compliant study of the in vitro binding of zilpaterol to rat serum proteins, 30 fasted male Sprague-Dawley rats with a mean bodyweight of $200 \mathrm{~g}$ were administered $\left[{ }^{14} \mathrm{C}\right]$ zilpaterol hydrochloride at a concentration of 0.005, 0.05, 0.5, 10 and $100 \mu \mathrm{g} / \mathrm{ml}$ (Tremblay, Biechler and Cousty, 1990b). Blood samples were collected from all the rats. After dialysis to equilibrium point, the percentage binding was calculated from the concentrations measured by counting radioactivity using a liquid scintillation counter. The results presented in Table 10.4 indicate that a mean percentage binding of zilpaterol to rat serum protein was $14 \%(13.7 \%)$ at $37^{\circ} \mathrm{C}$.

Two studies (non GLP-compliant) were conducted to determine the routes of excretion, characterize the residues in the excreta and compare the metabolites observed in cattle and rat excreta. The 3 male and 3 female Wistar rats (Tulliez, 2000a) and 3 male and 3 female Sprague-Dawley rats (Tulliez, 2000b) weighing 200-250 g were administered a single oral dose of $\left[{ }^{14} \mathrm{C}\right]$ zilpaterol hydrochloride synthetic diet by gavage at $0.2 \mathrm{mg} / \mathrm{kg}$ bw. In the first study, two Wistar rats (one male and one female) were sacrificed at $12 \mathrm{~h}$ and $48 \mathrm{~h}$ post-dose and the remaining two Wistar rats were sacrificed after 8 days. Urine and faeces were collected daily, and liver and remaining carcass tissue were collected at $12 \mathrm{~h}, 48 \mathrm{~h}$ and 8 days post-dose and analysed by LSC, combustion, HPLC and mass spectrometry. In the second study, the Sprague-Dawley rats were assigned to three groups of 2 ( 1 male and 1 female) and urine and faeces were collected for 8 days. Rats were killed 8 days post-dose and liver samples were collected.

The metabolic profile in the Wistar rat urine (Table 10.5) contains predominantly unchanged zilpaterol at $60 \%$ of the administered dose the first day, and at about $47 \%$ on Day 2. There were five other metabolites observed in the urine, of which the de-isopropylderivative is the most abundant at about $20 \%$. This metabolite is undetectable in the faeces, while hydroxy-zilpaterol is the most abundant metabolite in faeces at about $58 \%$, together with small percentages of acetylated de-isopropyl-zilpaterol and the glucuronate conjugate of hydroxy-zilpaterol (Table 10.5).

The metabolic profiles in the Sprague-Dawley rat urine and faeces were similar to those observed in the Wistar rat (Table 10.6).

Table 10.5. Distribution of metabolites in urine and faeces in Wistar rats treated with $\left[{ }^{14} \mathrm{C}\right] z i l$ paterol hydrochloride (Tulliez, 2000a)

\begin{tabular}{|c|c|c|c|c|c|}
\hline \multirow{2}{*}{$\begin{array}{c}\text { Metabolite } \\
\text { Number }\end{array}$} & \multirow{2}{*}{ Identification } & \multicolumn{2}{|c|}{ Faeces (\%) } & \multicolumn{2}{|c|}{ Urine (\%) } \\
\hline & & Day 1 & Day 2 & Day 1 & Day 2 \\
\hline A & Acetylated de-isopropyl-zilpaterol & 7.1 & 8.6 & 4.4 & 4.2 \\
\hline $\mathrm{B}$ & Unidentified & 3.1 & 1.3 & 2.2 & 0.7 \\
\hline $\mathrm{C}$ & Glucoronate conjugate of hydroxyl-zilpaterol & 3.3 & 5.3 & 9.3 & 22.3 \\
\hline $\mathrm{D}$ & Unidentified & ND & ND & 0.5 & ND \\
\hline$E_{1}$ & De-isopropyl-zilpaterol & Trace & Trace & 19.5 & 14.2 \\
\hline$E_{2}$ & Hydroxy-zilpaterol & 60.3 & 55.8 & - & - \\
\hline $\mathrm{F}$ & Zilpaterol & 15.8 & 3.9 & 60.3 & 46.7 \\
\hline
\end{tabular}

NOTES: ND = not detectable.
Table 10.4. In vitro determination of percentage
binding of zilpaterol to Sprague-Dawley rat serum proteins (Tremblay, Biechler and Cousty, 1990b)

\begin{tabular}{cc}
\hline $\begin{array}{c}\text { Concentration of } \\
{\left[{ }^{14} \mathbf{C}\right] \text { zilpaterol }} \\
\text { hydrochloride }(\boldsymbol{\mu} \mathbf{g} / \mathrm{ml})\end{array}$ & $\begin{array}{c}\% \text { Mean binding } \pm \text { S.D. } \\
\text { to Sprague-Dawley rat } \\
\text { serum protein }\end{array}$ \\
\hline 0.005 & $15.8 \pm 1.1$ \\
0.05 & $10.9 \pm 1.7$ \\
0.5 & $12.0 \pm 1.0$ \\
10 & $14.3 \pm 0.7$ \\
100 & $15.4 \pm 0.3$ \\
Overall mean \% binding & $13.7 \pm 2.1$ \\
\hline
\end{tabular}


Table 10.6. Percentage distribution of metabolites in urine and faeces after a single dose of $\left[{ }^{14} \mathrm{C}\right]$ zilpaterol administered to Sprague-Dawley rats (Tulliez, 2000b)

\begin{tabular}{|c|c|c|c|c|c|c|}
\hline \multirow{2}{*}{$\begin{array}{c}\text { Metabolite } \\
\text { Number }\end{array}$} & \multirow[b]{2}{*}{ Identification } & \multirow{2}{*}{$\begin{array}{c}\text { Faeces (\%) } \\
\text { Days 1-3 } \\
\text { M+F }\end{array}$} & \multicolumn{2}{|c|}{ Urine (\%) Day 1} & \multicolumn{2}{|c|}{ Urine (\%) Day 2} \\
\hline & & & $\mathbf{M}$ & $\mathbf{F}$ & $\mathbf{M}$ & $\mathbf{F}$ \\
\hline$A$ & $\begin{array}{l}\text { Acetylated de- } \\
\text { isopropyl-zilpaterol }\end{array}$ & 3.7 & 11.1 & 3.1 & 14.3 & 3.7 \\
\hline $\mathrm{B}$ & Unidentified & 2.7 & 3.7 & 0.6 & 9.1 & 0.4 \\
\hline C & $\begin{array}{l}\text { Glucoronate conjugate } \\
\text { of hydroxy-zilpaterol }\end{array}$ & 1.5 & 0.5 & 7.1 & 5.3 & 6.0 \\
\hline $\mathrm{D}$ & Unidentified & ND & 0.4 & 0.1 & 0.4 & ND \\
\hline$E_{1}$ & De-isopropyl-zilpaterol & 4.1 & 15.2 & 8.4 & 10.9 & 7.3 \\
\hline $\mathrm{E}_{2}$ & Hydroxy-zilpaterol & 68.8 & 5.9 & 3.3 & 16.6 & 6.4 \\
\hline $\mathrm{F}$ & Zilpaterol & 7.1 & 50.0 & 73.2 & 24.9 & 70.9 \\
\hline
\end{tabular}

NOTES: ND = not detectable.

The data collected to monitor the cumulative excretion of radioactivity indicated that more than $60 \%$ of the dose at $48 \mathrm{~h}$ and about $92 \%$ of the dose 8 days after dosing could be accounted for (data not shown). While no sex-related differences were observed for the excretion of total radioactivity, there was nevertheless an apparent more rapid urinary excretion for male rats compared with female rats (30\% versus 20\%). Radioactivity concentrations in the liver and carcass amounted to less than $1 \%$ of the administered dose. The results of the comparative metabolic profile study for zilpaterol in the two rat species is shown in Table 10.7.

When $\left[{ }^{14} \mathrm{C}\right]$ zilpaterol hydrochloride is administered to rats by oral gavage, the compound is excreted almost equally in the urine $(49-51 \%)$ and faeces $(42-44 \%)$. Less than $0.1 \%$ of the radioactive concentration was retained in the liver 8 days post-dose. The structure of the major metabolite in faeces was confirmed by GC-MS to be the hydroxy-zilpaterol. It is concluded that the metabolic profile for zilpaterol in the urine of the Sprague Dawley rat is quantitatively and qualitatively similar to that obtained for the Wistar rats.

Table 10.7. Metabolic balance in Wistar and Sprague Dawley rats administered $\left[{ }^{14} \mathrm{C}\right] z i l p a t e r o l$ hydrochloride (Tulliez, 2000a, b)

\begin{tabular}{|c|c|c|c|c|c|c|}
\hline Rat \# & Sex & Urine & Faeces & Liver & Carcass & Total \\
\hline \multicolumn{7}{|c|}{ Metabolic Balance in Wistar rats (\% administered dose) } \\
\hline 1 & M & 54.3 & 39.9 & 0.07 & 0.46 & 94.7 \\
\hline 2 & M & 47.8 & 44.0 & 0.04 & 0.63 & 92.5 \\
\hline 3 & M & 51.1 & 40.0 & 0.06 & 0.63 & 91.8 \\
\hline 4 & $\mathrm{~F}$ & 51.1 & 44.8 & 0.06 & 0.45 & 96.4 \\
\hline 5 & $F$ & 49.0 & 44.3 & 0.09 & 0.90 & 94.3 \\
\hline 6 & $\mathrm{~F}$ & 40.0 & 40.8 & 0.05 & 1.00 & 81.9 \\
\hline \multicolumn{2}{|c|}{ Mean \pm SD } & $48.9 \pm 4.9$ & $42.3 \pm 2.3$ & $0.06 \pm 0.02$ & $0.68 \pm 0.23$ & $91.9 \pm 5.2$ \\
\hline \multicolumn{7}{|c|}{ Metabolic Balance in Sprague-Dawley rats (\% administered dose) } \\
\hline 7 & M & 63.3 & 34.6 & 0.05 & & 98.0 \\
\hline 8 & M & 52.4 & 46.7 & 0.06 & & 99.0 \\
\hline 9 & M & 51.1 & 41.3 & 0.06 & & 93.0 \\
\hline 10 & $\mathrm{~F}$ & 42.4 & 47.4 & 0.04 & & 89.9 \\
\hline 11 & $\mathrm{~F}$ & 45.4 & 48.0 & 0.05 & & 93.4 \\
\hline 12 & $\mathrm{~F}$ & 50.3 & 44.0 & 0.06 & & 94.3 \\
\hline \multicolumn{2}{|c|}{ Mean \pm SD } & $50.8 \pm 7.2$ & $43.7 \pm 5.1$ & $0.05 \pm 0.01$ & & $94.6 \pm 3.4$ \\
\hline
\end{tabular}


In a non-GLP-compliant study, 10 adult Wistar rats ( 5 males and 5 females) each received a single $0.2 \mathrm{mg} / \mathrm{kg}$ of $\left[{ }^{14} \mathrm{C}\right]$ zilpaterol hydrochloride by oesophageal catheter (Zalko, 1993). Two rats (1 male and 1 female) were killed at 12 and $48 \mathrm{~h}$. The other six were killed after 8 days. The radioactivity present in the liver, kidneys, perirenal fat, muscle and the rest of the carcass was measured after grinding the tissue. Urine and faeces from two animals in the last group were collected each day and their radioactivity contents were measured (Table 10.8).

On average, nearly $91 \%$ of the administered radioactivity was eliminated in the urine ( $49 \%$ ) or faeces $(42 \%)$ during the 8 days, with $63 \%$ of the radioactivity excreted during the first $24 \mathrm{~h}$. At kill time on the 8th day, only $0.72 \pm 0.19 \%$ of the administered radioactivity was detectable in the carcass. The liver at this same time-point contained $0.06 \pm 0.02 \%$ of the administered radioactivity. In liver, the concentrations of zilpaterol $\mathrm{HCl}$ equivalents decreased quickly from $36 \mu \mathrm{g} / \mathrm{kg}$ after $12 \mathrm{~h}$ to $2 \mu \mathrm{g} / \mathrm{kg}$ on the 8th day. The same trend was seen in

Table 10.8. Radioactivity in rat tissues, expressed in $\mu \mathrm{g} / \mathrm{kg}$, after a single oral administration of $\left[{ }^{4} \mathrm{C}\right]$ zilpaterol hydrochloride at a dose of $0.2 \mathrm{mg} / \mathrm{kg}$ (Zalko, 1993)

\begin{tabular}{cccccc}
\hline $\begin{array}{c}\text { Post- } \\
\text { dose }\end{array}$ & $\begin{array}{c}\text { Rat \# } \\
\text { \& sex }\end{array}$ & Liver & Kidney & Muscle & Fat \\
\hline $12 \mathrm{~h}$ & $1 \mathrm{M}$ & 33 & 7 & $\mathrm{ND}$ & $\mathrm{ND}$ \\
& $2 \mathrm{~F}$ & 38 & 5 & 2 & 1 \\
$48 \mathrm{~h}$ & $3 \mathrm{M}$ & 12 & 3 & ND & ND \\
& $4 \mathrm{~F}$ & 20 & 4 & ND & 2 \\
8 days & $5 \mathrm{M}$ & 2 & $\mathrm{ND}$ & $\mathrm{ND}$ & $\mathrm{ND}$ \\
& $6 \mathrm{~F}$ & 3 & $\mathrm{ND}$ & $\mathrm{ND}$ & $\mathrm{ND}$ \\
\hline
\end{tabular}

NOTES: ND $=$ not detectable

the kidney, with much lower concentrations $(7 \mu \mathrm{g} / \mathrm{kg}$ to ND). There was no significant radioactivity determined in the fat or muscle (Table 10.8).

The main metabolites were deisopropyl-zilpaterol, hydroxy-zilpaterol and unchanged zilpaterol, accounting for 2, 9 and $81 \%$ respectively of the total radioactivity detected in urine. In faeces, these were 7, 40 and $44 \%$ respectively, totalling about $91 \%$ of the total areas under the radioactive HPLC peak. This high percentage supports the view that conjugation metabolic pathways are absent (or occur to only a very slight extent), which is in contrast to the behaviour of other $\beta$-agonists, which have always shown that glucorono-conjugation or sulfo-conjugation are the dominant mechanisms. This difference, the study authors presume, may be due to the chemical structure, which is not strictly of the phenyl-ethanolamine type. The hydroxy-metabolite of zilpaterol is the dominant extractable metabolite in the liver.

\section{Dogs}

An open dose randomized cross-over study using 4 fasted male beagle dogs (mean weight of $10 \mathrm{~kg}$ ) in a non-GLP-compliant study was undertaken to measure the absolute bio-availability of $\left[{ }^{14} \mathrm{C}\right]$ zilpaterol hydrochloride in the dog after a single dose administration of $1 \mathrm{mg} / \mathrm{kg} \quad \mathrm{bw}$ intravenously or orally (Tremblay et al., 1990c; Tremblay, Biechler and Cousty, 1990d). The dogs were fasted for $24 \mathrm{~h}$ before and $8 \mathrm{~h}$ after drug administration. Urine samples were collected over a $48 \mathrm{~h}$ period and analysed for zilpaterol by LSC. The

Table 10.9. Mean binding constants for zilpaterol to beagle dog serum proteins (Tremblay, Biechler and Cousty, 1990b)

\begin{tabular}{cc}
\hline $\begin{array}{c}\text { Concentration of } \\
{\left[{ }^{14} \mathrm{C}\right] \text { zilpaterol }} \\
\text { hydrochloride }(\boldsymbol{\mu g} / \mathbf{m l})\end{array}$ & $\begin{array}{c}\% \text { Mean binding } \pm \text { S.D. to } \\
\text { beagle dog serum } \\
\text { protein }\end{array}$ \\
\hline 0.005 & $22.7 \pm 4.5$ \\
0.05 & $13.2 \pm 0.9$ \\
0.5 & $14.2 \pm 2.0$ \\
10 & $13.0 \pm 1.1$ \\
100 & $12.2 \pm 0.7$ \\
Overall Mean\% Binding & $\mathbf{1 5 . 1} \pm \mathbf{4 . 3}$ \\
\hline
\end{tabular}
overall mean binding to dog serum proteins at $37^{\circ} \mathrm{C}$ was calculated to be $15 \%$ (Table 10.9). After intravenous administration, the radioactivity concentration was $22.8 \pm 2.1 \%$ of the dose, and $23.9 \pm 2.4 \%$ after oral administration. The absolute bio-availability of zilpaterol in the beagle dog was calculated as $100 \%$. This represents a renal clearance of $23 \%$ of total clearance. 


\section{Humans}

A study (non-GLP-compliant) was conducted with 9 healthy male fasted volunteers aged between 28 and 55 years weighing between 56 and $76 \mathrm{~kg}$, using a single-blind protocol versus a placebo to measure the clinical tolerance of humans to zilpaterol (Sutton and Budhram, 1987; Tremblay and Mouren , 1988). Zilpaterol was administered as a solution at single doses of $0.25,0.50,1.0$ and $2.0 \mathrm{mg}$ to the healthy volunteers and blood was collected from each volunteer at 15 minutes following drug administration, then 1, 2, 3, 4, 5, 6, 8 and $24 \mathrm{~h}$ after dosing and zilpaterol concentrations in plasma were analysed by radioimmunoassay $(\mathrm{LOQ}=0.1 \mathrm{ng} / \mathrm{ml})$. Time $\left(\mathrm{T}_{\max }\right)$ to reach the maximal concentration $\left(\mathrm{C}_{\max }\right)$ was observed 1 hour after dosing whatever the dose, and there was a linear relationship between both the $\mathrm{C}_{\max }$ or $\mathrm{AUC}$, and the dose. The plasma concentrations were proportional to the dose administered and the $t_{1 / 2}$ was independent of the administered dose. In this study, it was observed that the $1.0 \mathrm{mg}$ dose was badly tolerated by volunteers and as result, none of the volunteers was given a dose greater than $2.0 \mathrm{mg}$.

\section{Pharmacokinetics and metabolism in food producing animals}

\section{Pigs}

In a GLP-compliant study (Sauvez, 1993), two healthy 8-month-old pigs (1 male and 1 female), each weighing about $20 \mathrm{~kg}$, were administered a single oral dose at $1 \mathrm{mg} / \mathrm{kg} \mathrm{bw}$ of $\left[{ }^{14} \mathrm{C}\right]$ zilpaterol hydrochloride by gavage to assess the absorption of the drug into swine. Seven millilitres of blood were taken from each animal 1, 2, 4, 7, 24 and $48 \mathrm{~h}$ after dosing, into heparinized tubes. The data in Table 10.10 show that the highest radioactivity concentration $\mathrm{C}_{\max }$ of $414 \pm 212 \mu \mathrm{g}$-eq $/ \mathrm{kg}$ was achieved at $\mathrm{T}_{\max }$ of $1 \mathrm{~h}$ for both male and female pigs following the single dose administration. There was still low but detectable radioactivity concentration of $5 \pm 2 \mu \mathrm{g}$-eq $/ \mathrm{kg}$ of zilpaterol $48 \mathrm{~h}$ after the single dose administration. The $\mathrm{AUC}_{(0-48 \mathrm{~h})}$ was $3720 \pm 244 \mu \mathrm{g}$-eq.h $/ \mathrm{kg}$.

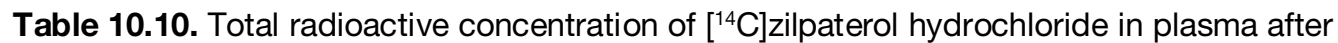
administration of a single dose by gavage to pigs (Sauvez, 1993)

\begin{tabular}{|c|c|c|c|}
\hline Sampling time (h) & Swine & $\begin{array}{c}\text { Radioactivity concentration } \\
\text { (ng-eq/g) }\end{array}$ & $\begin{array}{c}\text { Mean radioactivity concentration } \\
\text { (ng-eq/g) }\end{array}$ \\
\hline 1 & $\begin{array}{c}M \\
F\end{array}$ & $\begin{array}{l}500 \\
328\end{array}$ & $414 \pm 122$ \\
\hline 2 & $\begin{array}{c}M \\
F\end{array}$ & $\begin{array}{l}364 \\
274\end{array}$ & $319 \pm 64$ \\
\hline 4 & $\begin{array}{c}M \\
F\end{array}$ & $\begin{array}{l}278 \\
229\end{array}$ & $253 \pm 35$ \\
\hline 7 & $\begin{array}{l}M \\
F\end{array}$ & $\begin{array}{l}145 \\
195\end{array}$ & $170 \pm 35$ \\
\hline 24 & $\begin{array}{l}M \\
F\end{array}$ & $\begin{array}{l}15 \\
27\end{array}$ & $21 \pm 9$ \\
\hline 48 & $\begin{array}{l}\mathrm{M} \\
\mathrm{F}\end{array}$ & $\begin{array}{l}4 \\
6 \\
\end{array}$ & $5 \pm 2$ \\
\hline$T_{\max }$ & \multicolumn{3}{|c|}{$1 \mathrm{~h}$} \\
\hline Mean Concentration at $1 \mathrm{~h}(\mathrm{nc}$ & & \multicolumn{2}{|c|}{$414 \pm 122$} \\
\hline \multicolumn{2}{|c|}{ Mean concentration $24 \mathrm{~h}$ after dosage $(\mathrm{ng}-\mathrm{eq} / \mathrm{g}$ ) } & \multicolumn{2}{|c|}{$5 \pm 2$} \\
\hline$A \cup C_{(0-48 h)}($ ng-eq.h/g) & $\begin{array}{l}M \\
F\end{array}$ & $\begin{array}{l}3547 \\
3893\end{array}$ & $3720 \pm 244$ \\
\hline
\end{tabular}


In a GLP-compliant study (Chevolleau, 2004), two 8-month-old Camborough $15 \times$ DRX strain pigs (1 castrated male, $122 \mathrm{~kg}$, and 1 female, $118 \mathrm{~kg}$ ) were administered $0.3 \mathrm{mg} / \mathrm{kg}$ bw $\left[{ }^{14} \mathrm{C}\right]$ zilpaterol hydrochloride in a single oral dose poured onto a $300 \mathrm{~g}$ pellet, and killed $24 \mathrm{~h}$ after administration. Urine and faeces were collected during the $24 \mathrm{~h}$ period following the labelled drug administration. At slaughter, liver, kidneys and samples of muscle (longissimus dorsi), perirenal (PR) and subcutaneous (SC) adipose tissue, were excised, trimmed of any extraneous tissue, weighed and homogenized for analysis. Four samples were analysed for each matrix by LSC, combustion, HPLC and radio-HPLC. The results of these analyses are shown in Table 10.11.

After oral administration to swine, more than $85 \%$ of the administered dose is eliminated in urine and about $3 \%$ in faeces of female pigs (Table 10.12). In liver, about $80 \%$ of the administered radioactivity was extractable, although approximately $90 \%$ is extractable from other tissues (Table 10.12).

In urine and faeces, unchanged zilpaterol accounts for about $90 \%$ of the total residue, the remainder being deisopropyl-zilpaterol and hydroxyzilpaterol (Table 10.13). In all tissues, zilpaterol represents about $92 \%$ of the extractable radioactivity, followed by deisopropylzilpaterol (about $5 \%$ ) and hydroxy-zilpaterol (3\%).

Table 10.13. Metabolic profiles (as percentage of extractable radioactivity for Camborough swine

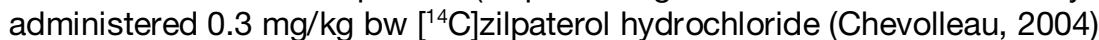

\begin{tabular}{lcccccc} 
& \% Zilpaterol extractable & $\begin{array}{c}\text { \% Deisopropyl-zilpaterol } \\
\text { extractable }\end{array}$ & \multicolumn{2}{c}{$\begin{array}{c}\text { Hydroxy-zilpaterol } \\
\text { extractable }\end{array}$} \\
& Male & Female & Male & Female & Male & Female \\
\hline Urine & 89 & 91 & 5 & 4 & 2 & 1 \\
Faeces & 92 & 94 & 4 & 4 & 7 & 2 \\
Liver & 89 & 90 & 6 & 7 & - & 4 \\
Kidneys & 94 & 93 & 6 & 8 & - & - \\
Muscle & 94 & 93 & 6 & $4 \pm 2$ & $4 \pm 2$ & $2 \pm 2$ \\
\hline Range & $92 \pm 3$ & $92 \pm 2$ & $5 \pm 1$ & &
\end{tabular}

Table 10.11. Zilpaterol residues in excreta and tissues of Camborough strain swine administered $0.3 \mathrm{mg} / \mathrm{kg}$

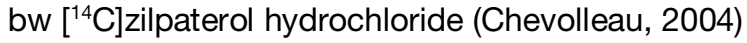

\begin{tabular}{lccc}
\hline & \multicolumn{2}{c}{$\begin{array}{c}\text { Concentration of zilpaterol excreted in } \\
\text { excreta and tissues }(\boldsymbol{\mu g} / \mathbf{k g})\end{array}$} \\
& Male & Female & Average \\
\hline Urine & 12062 & 13655 & 12859 \\
Faeces & 1399 & 5320 & 3360 \\
Liver & 58 & 42 & 50 \\
Kidney & 73 & 29 & 51 \\
Muscle & 20 & 13 & 17 \\
Fat (perirenal) & 2 & 1 & 1 \\
Fat (subcutaneous) & 2 & 1 & 1.5 \\
\hline
\end{tabular}

Table 10.12. Measurement of extractable radioactivity from Camborough strain swine administered $0.3 \mathrm{mg} / \mathrm{kg}$

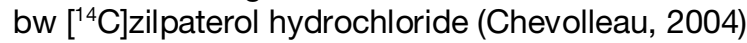

\begin{tabular}{lccc|c}
\hline & \multicolumn{2}{c}{ Male } & \multicolumn{2}{c}{ Female } \\
& $\begin{array}{c}\text { \% dose } \\
\text { adminis- } \\
\text { tered }\end{array}$ & $\begin{array}{c}\text { Extract- } \\
\text { able radio- } \\
\text { activity (\%) }\end{array}$ & $\begin{array}{c}\text { Extract- } \\
\text { able radio- } \\
\text { activity (\%) }\end{array}$ & $\begin{array}{c}\text { \% dose } \\
\text { adminis- } \\
\text { tered }\end{array}$ \\
\hline Urine & 88.5 & & & 85.8 \\
Faeces & 2.5 & 97.1 & 99.6 & 3.3 \\
Liver & 0.2 & 80.2 & 84.9 & 0.2 \\
Kidney & 0.1 & 91.0 & 95.6 & 0.00 \\
Muscle & - & 84.9 & 92.0 & - \\
\hline
\end{tabular}




\section{Cattle}

A GLP-compliant study was conducted with four Salers steers and four Charolais $x$ Salers heifers averaging $295 \mathrm{~kg}$ bw and allotted to four groups of two animals, each group comprising one steer and one heifer (Tulliez, 1992). The first group was kept on feed supplemented with unlabelled zilpaterol and was used as control. Animals in the three other groups were given a single dose of $0.2 \mathrm{mg} / \mathrm{kg}$ bw of $\left[{ }^{14} \mathrm{C}\right]$ zilpaterol hydrochloride by gavage of the pellet and were killed at $12 \mathrm{~h}, 48 \mathrm{~h}$ and 8 days, respectively. Plasma was collected from each animal during the first $10 \mathrm{~h}$ and then at the 14th, 21st and 24th hours, and then every day until they were killed. Urine and faeces were collected daily from the individual animals for the 8-day surviving animals. At kill point, liver, kidneys and samples of muscle (longissimus dorsi), perirenal and visceral fat and of the four stomachs were excised and frozen until analysis.

There was a rapid increase in radioactivity in plasma, which reached a maximal value $12 \mathrm{~h}$ and $10 \mathrm{~h}$ following drug administration in the male and female, respectively. The corresponding highest concentrations in plasma were $16.8 \mathrm{ng} / \mathrm{ml}$ and $22.4 \mathrm{ng} / \mathrm{ml}$ zilpaterol equivalents. Depletion of radioactivity in plasma occurred on a biphasic basis. The $\mathrm{T}_{1 / 2}$ for the first phase was observed at 11.9 and $13.2 \mathrm{~h}$ for the male and female, respectively. The second phase corresponded to a very slow decrease of radioactivity but could not be accurately described because the signal was not significantly different from the background. Over $90 \%$ of the dose $(97 \%$ in steers and $93 \%$ in heifers) was excreted over the 8 days (Table 10.14). In males, $88 \%$ of the excreted material was in the urine and $8.7 \%$ was in the faeces, while in females $84 \%$ was in the urine and $8.6 \%$ was in the faeces.

At $12 \mathrm{~h}$ post-dose, the radioactive concentrations were observed in the following order: liver=kidney >reticulum >omasum $>$ abomasum $>$ rumen $>$ muscle $>$ fat. Radioactivity was not detectable in any tissues except liver at $192 \mathrm{~h}$ post-dose (Table 10.15).
Table 10.14. Excretion of $\left[{ }^{14} \mathrm{C}\right]$ zilpaterol in steers (Salers) and heifers (Charolais $\times$ Salers) during the eight days following a single administration of $\left[{ }^{14} \mathrm{C}\right]$ zilpaterol by gavage (Tulliez, 1992)

\begin{tabular}{|c|c|c|}
\hline & \multicolumn{2}{|c|}{$\begin{array}{l}\text { Radioactivity excreted as } \\
\% \text { of administered dose }\end{array}$} \\
\hline & Steer & Heifer \\
\hline Urine & 88.2 & 84.3 \\
\hline Faeces & 8.7 & 8.6 \\
\hline Total & 96.9 & 92.9 \\
\hline
\end{tabular}

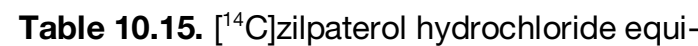
valents $(\mu \mathrm{g} / \mathrm{kg}$ of fresh sample) in tissues and stomachs of steers and heifers at different withdrawal periods following a single administration of $\left[{ }^{14} \mathrm{C}\right]$ zilpaterol hydrochloride by gavage (Tulliez, 1992)

\begin{tabular}{|c|c|c|c|c|}
\hline & \multicolumn{4}{|c|}{$\begin{array}{l}{\left[{ }^{14} \mathrm{C}\right] \text { zilpaterol hydrochloride equivalents }} \\
(\mu \mathrm{g} / \mathrm{kg}) \text { post-dosing }\end{array}$} \\
\hline & & $12 \mathrm{~h}$ & $48 h$ & $192 \mathrm{~h}$ \\
\hline Liver & $\begin{array}{c}\mathrm{M} / \mathrm{F} \\
\text { Average }\end{array}$ & $\begin{array}{c}112 / 116 \\
(114)\end{array}$ & $\begin{array}{c}42 / 39 \\
(41)\end{array}$ & $\begin{array}{c}15 / 11 \\
(13)\end{array}$ \\
\hline Kidney & $\begin{array}{c}\mathrm{M} / \mathrm{F} \\
\text { Average }\end{array}$ & $\begin{array}{c}110 / 118 \\
(114)\end{array}$ & $\begin{array}{c}25 / 23 \\
(24)\end{array}$ & $\begin{array}{c}\text { NS/NS* } \\
\text { NS }\end{array}$ \\
\hline Perirenal fat & $\begin{array}{c}\mathrm{M} / \mathrm{F} \\
\text { Average }\end{array}$ & $\begin{array}{l}2 / 2 \\
(2)\end{array}$ & $\begin{array}{c}1 / N S \\
N S\end{array}$ & $\begin{array}{c}\text { NS/NS } \\
\text { NS }\end{array}$ \\
\hline Visceral fat & $\begin{array}{c}\mathrm{M} / \mathrm{F} \\
\text { Average }\end{array}$ & $\begin{array}{l}7 / 3 \\
(5)\end{array}$ & $\begin{array}{l}4 / 2 \\
(3)\end{array}$ & $\begin{array}{c}\text { NS/NS } \\
\text { NS }\end{array}$ \\
\hline Muscle & $\begin{array}{c}\mathrm{M} / \mathrm{F} \\
\text { Average }\end{array}$ & $\begin{array}{c}17 / 15 \\
(16)\end{array}$ & $\begin{array}{l}4 / 3 \\
(4)\end{array}$ & $\begin{array}{c}\text { NS/NS } \\
\text { NS }\end{array}$ \\
\hline Rumen & $\begin{array}{c}\mathrm{M} / \mathrm{F} \\
\text { Average }\end{array}$ & $\begin{array}{c}61 / 43 \\
(52)\end{array}$ & $\begin{array}{c}20 / 20 \\
(20)\end{array}$ & $\begin{array}{c}\text { NS/NS } \\
\text { NS }\end{array}$ \\
\hline Reticulum & $\begin{array}{c}\mathrm{M} / \mathrm{F} \\
\text { Average }\end{array}$ & $\begin{array}{c}83 / 147 \\
(115)\end{array}$ & $\begin{array}{c}14 / 16 \\
(15)\end{array}$ & $\begin{array}{c}\text { NS/NS } \\
\text { NS }\end{array}$ \\
\hline Omasum & $\begin{array}{c}\mathrm{M} / \mathrm{F} \\
\text { Average }\end{array}$ & $\begin{array}{c}82 / 79 \\
(81)\end{array}$ & $\begin{array}{c}60 / 34 \\
(47)\end{array}$ & $\begin{array}{c}\text { NS/NS } \\
\text { NS }\end{array}$ \\
\hline Abomasum & $\begin{array}{c}\mathrm{M} / \mathrm{F} \\
\text { Average }\end{array}$ & $\begin{array}{c}50 / 63 \\
(57)\end{array}$ & $\begin{array}{c}12 / 14 \\
(14)\end{array}$ & $\begin{array}{c}\text { NS/NS } \\
\text { NS }\end{array}$ \\
\hline
\end{tabular}

NOTES: NS = not significant. The result in brackets represents the average of the readings from the 2 animals.

Analysis of the urine showed that unchanged zilpaterol represented more than $60 \%$ of the radioactivity, with the remainder distributed among four metabolites. In tissues, unchanged zilpaterol was the main residue, and one major metabolite, which represents about $20 \%$ of the extractable residue in tissues and about $13 \%$ of the radioactive residue in urine, was identified by GC-mass spectral analysis as deisopropyl zilpaterol (Table 10.16). 
Table 10.16. Metabolites identified in the urine and tissues of cattle following a single administration of $\left[{ }^{14} \mathrm{C}\right]$ zilpaterol by gavage (Tulliez, 1992)

\begin{tabular}{cllcccc}
\hline $\begin{array}{c}\text { Metabolite peak } \\
\text { identification (1) }\end{array}$ & \multicolumn{1}{c}{ Name } & Urine & $\begin{array}{c}\text { Liver } \\
\text { Kidney }\end{array}$ & $\begin{array}{c}\text { Muscle } \\
\text { Percentage distribution (\%) }\end{array}$ \\
\hline F & Zilpaterol & 65.7 & 62.3 & 69.5 & 71.9 \\
$\mathrm{E}_{1}$ & Deisopropyl-zilpaterol & 13.2 & 20.6 & 17.9 & 21.2 \\
$\mathrm{E}_{2}$ & Hydroxy-zilpaterol & ND & ND & ND & ND \\
A & Acetylated deisopropyl-zilpaterol & 7.0 & ND & ND & ND \\
B & Unidentified & 11.3 & ND & ND & ND \\
C & Hydroxy-Zilpaterol-Glucuronide & Trace ${ }^{(3)}$ & ND & ND & ND \\
D & Unidentified & 3.5 & 3.3 & 5.7 & ND \\
\hline
\end{tabular}

NOTES: (1) Metabolite peak identifications are based on those assigned in the rat studies (Tulliez, 2000a, b). (2) ND = not detected. (3) Trace: metabolite detected as trace in urine from steers, but not detected in urine from heifers.

In a GLP-compliant pilot steady state study, four groups of two animals each (one Charolais steer and one Charolais heifer, 200-220 kg bw) were used in 4 consecutive trials (multi-dose administration) (Tulliez, 2000c). The animals were administered daily an oral dose of $\left[{ }^{14} \mathrm{C}\right]$ zilpaterol at $0.15 \mathrm{mg} / \mathrm{kg}$ bw for $10,12,15$ and 21 days, and killed 20-24 $\mathrm{h}$ after the last dose administration. Another group of 2 non-medicated animals served as controls. Radio analysis of the extractable radioactivity from liver, muscle, kidneys showed that, other than parent drug, the only other major metabolite was deisopropyl zilpaterol (10-15\%). Blood samples were collected daily before the daily dosing, and at kill time, liver, kidneys and muscle (longissimus dorsi) and fat (perirenal) were collected. Total radioactivity in the tissues was determined by LSC, and zilpaterol-related metabolites were isolated, purified by HPLC and identified by mass spectrometry (ESI-MS, GC-MS, and thermospray mass spectrometry - TSP-MS). Radioactivity levels reached a steady state concentration of $20 \mu \mathrm{g} / \mathrm{kg}$ in plasma after 4-6 days of dosing.

No significant radioactivity could be detected in fat samples. Total residue concentrations in the liver, kidney and muscle of

Table 10.17. Total residues determined in liver, kidney and muscle of cattle killed 20-24 h after the last dose of $\left[{ }^{14} \mathrm{C}\right] z i l p a t e r o l ~(T u l l i e z, 2000 \mathrm{c})$.

\begin{tabular}{|c|c|c|c|}
\hline \multirow{2}{*}{$\begin{array}{l}\text { Days of } \\
\text { treatment }\end{array}$} & \multicolumn{3}{|c|}{$\begin{array}{l}\text { Residue concentrations in tissues } \\
\text { ( } \mathrm{\mu g} / \mathrm{kg} \text { of }\left[{ }^{14} \mathrm{C}\right] \text { zilpaterol hydrochloride equivalents) }\end{array}$} \\
\hline & Liver (M / F) & Kidney (M / F) & Muscle (M / F) \\
\hline 10 & 249 / 292 & $129 / 154$ & $23 / 18$ \\
\hline 12 & $361 / 417$ & $183 / 240$ & 28 / 32 \\
\hline 15 & 329 / 456 & 228 / 251 & $34 / 31$ \\
\hline 21 & $383 / 344$ & $234 / 166$ & $21 / 22$ \\
\hline
\end{tabular}

NOTES: $M=$ males; $F=$ females. male and female cattle after 10,12, 15 and 21 days of dosing, respectively, are shown in Table 10.17. The concentrations of the different components in the extractable radioactivity in liver, muscle and kidney are presented in Table 10.18.

Table 10.18. Distribution of extractable $\left[{ }^{14} \mathrm{C}\right]$ zilpaterol-related metabolites in tissues of cattle killed 20-24 $\mathrm{h}$ after the last dose of $\left[{ }^{14} \mathrm{C}\right] z i l p a t e r o l ~(T u l l i e z, 2000 \mathrm{c})$

\begin{tabular}{|c|c|c|c|c|c|c|}
\hline \multirow{3}{*}{$\begin{array}{c}\text { Treatment } \\
\text { days }\end{array}$} & \multicolumn{6}{|c|}{$\begin{array}{l}\text { Concentrations of zilpaterol and deisopropyl-zilpaterol } \\
\text { in }\left[{ }^{14} \mathrm{C}\right] \text { zilpaterol hydrochloride equivalents }(\mu \mathrm{g} / \mathrm{kg})\end{array}$} \\
\hline & \multicolumn{2}{|c|}{ Liver } & \multicolumn{2}{|c|}{ Kidney } & \multicolumn{2}{|c|}{ Muscle } \\
\hline & Zilpaterol & $\begin{array}{l}\text { Deisopropyl- } \\
\text { zilpaterol }\end{array}$ & Zilpaterol & $\begin{array}{l}\text { Deisopropyl- } \\
\text { zilpaterol }\end{array}$ & Zilpaterol & $\begin{array}{l}\text { Deisopropyl- } \\
\text { zilpaterol }\end{array}$ \\
\hline 10 & 68 & 16 & 62 & 13 & 73 & 13 \\
\hline 12 & 76 & 8 & 87 & 5 & 85 & 10 \\
\hline 15 & 67 & 12 & 79 & 6 & 86 & 15 \\
\hline 21 & 69 & 13 & 72 & 7 & 94 & 13 \\
\hline
\end{tabular}




\section{Comparative metabolism}

Zilpaterol is readily absorbed and the parent compound and metabolites are readily eliminated, primarily in the urine (80\% in cattle, $85 \%$ in swine and $50 \%$ in rats), with the remainder in the faeces. Unchanged parent compound is the main compound excreted in the urine of the three species and is the main residue found in cattle tissues (liver, kidney and muscle). In cattle, swine and rats, the main non-parent metabolite excreted in urine is deisopropyl-zilpaterol. This metabolite and unchanged zilpaterol are the only metabolites (at $>10 \%$ of the radioactivity) found in edible tissues from cattle. Furthermore, rats of both strains (Wistar and Sprague-Dawley) produce all the metabolites that are found in cattle edible tissues, in relatively similar proportions, and these represent approximately $90 \%$ of the entire extracted radioactivity.

In conclusion, the results of the studies demonstrate that the metabolic profiles of zilpaterol in Sprague-Dawley and Wistar rats, swine and cattle (Table 10.19) are qualitatively similar.

Table 10.19. Comparison of the percentage distribution of metabolites in urine of cattle and rats after

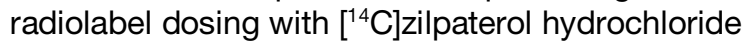

\begin{tabular}{cllccccc}
\hline $\begin{array}{c}\text { Metab } \\
\text { olite }\end{array}$ & \multicolumn{1}{c}{ Identification } & Wistar rat & $\begin{array}{c}\text { Males } \\
\text { Sprague- } \\
\text { Dawley rat }\end{array}$ & Steer & Wistar rat & $\begin{array}{c}\text { Sprague- } \\
\text { Dawley rat }\end{array}$ & Heifer \\
\hline A & Acetylated deisopropyl-zilpaterol & 5.2 & 11.1 & 5.8 & 3.5 & 3.1 & 3.3 \\
B & Unidentified & 3.5 & 3.7 & 13.5 & 1.0 & 0.6 & 6.8 \\
C & Glucoronate conjugate of & 10.0 & 0.5 & TR & 8.5 & 7.1 & ND \\
& hydroxy-zilpaterol & & & & & & \\
D & Unidentified & 0.4 & 0.4 & 3.6 & 15.3 & 0.1 & 3.1 \\
E1 $_{1}$ & De-isopropyl-zilpaterol & 23.7 & 15.2 & 14.7 & 15.3 & 8.4 & 7.9 \\
E2 $_{2}$ & Hydroxy-zilpaterol & & 5.9 & TR & & 3.3 & ND \\
F & Zilpaterol & 51.5 & 50.0 & 62.3 & 69.1 & 73.2 & 78.7 \\
\hline
\end{tabular}

NOTES: TR $=$ Trace; ND $=$ Not determined.

On the basis of the experimental observations, the metabolic pathway shown in Figure 10.2 has been proposed. 
Figure 10.2. Proposed metabolic scheme for zilpaterol hydrochloride

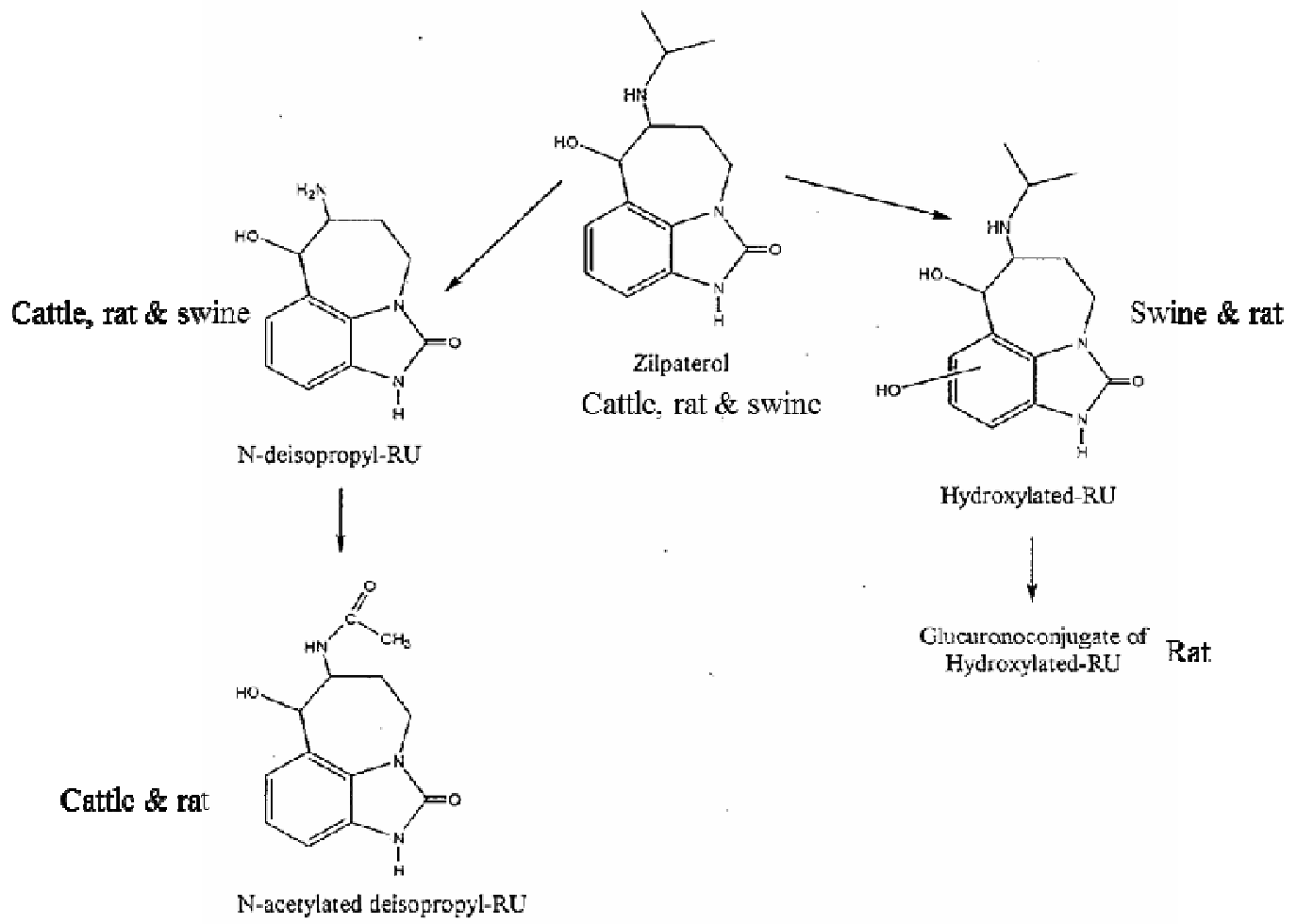

\section{Tissue residue depletion studies}

\section{Radiolabelled residue depletion studies}

\section{Cattle}

A GLP-compliant study was conducted in which 17 healthy Hereford cattle (9 steers, 6 heifers) weighing between 200 and $230 \mathrm{~kg}$ were allocated into six groups (Tulliez, 1999). Group I (1 male and 1 female) was a non-medicated group designed to provide control samples. Each of the remaining Groups (II-VI) comprised 3 animals ( 2 males and 1 female, or the opposite). During the experimental period, each animal received the radiolabelled $\left[{ }^{14} \mathrm{C}\right]$ zilpaterol and unlabelled zilpaterol at $0.15 \mathrm{mg} / \mathrm{kg}$ bw/day for 12 days. The Group II animals were killed $12 \mathrm{~h}$ after the last dose on the 12th day, Group IV $24 \mathrm{~h}$, Group V $48 \mathrm{~h}$ and Group VI $96 \mathrm{~h}$ after the last dose. Group III animals were fed for 15 days and killed $12 \mathrm{~h}$ after the last dose. Liver samples were collected as follows: LL - left lobe; RL - right lobe; CL caudate lobe; SL - square lobe. Adipose tissue was either PR - perirenal; or SC - subcutaneous. A validated liquid chromatographic/fluorescence method was used for the analysis of zilpaterol and zilpaterol metabolites in edible tissues and fat of cattle. The tissue samples were analysed for total radioactivity (Table 10.20) and percentage of extractable radioactivity (Table 10.21), as well as for unchanged zilpaterol and deisopropyl-zilpaterol metabolite by HPLC with radiometric detection. Extractable parent zilpaterol in tissues was measured using HPLC with fluorescence detection (Table 10.22). 
A mass balance for unchanged zilpaterol and its metabolites in tissues was calculated from the recovery of the radioactivity after different extraction steps. Labelled zilpaterol and labelled metabolites were extracted from liver, kidney and muscle using an ammonia-acetonitrile-methanol mixture and then purified by solid phase extraction. Liver was again the tissue containing the highest total residue concentrations, expressed as zilpaterol $\mathrm{HCl}-$ equivalents, with concentrations of $291 \pm 56$, $205 \pm 14,157 \pm 23$, and $113 \pm 17 \mu \mathrm{g} / \mathrm{kg}$ at 12 , 24,48 and $96 \mathrm{~h}$, respectively, after the last dose for the animals administered 12 daily doses of the drug (Table 10.20). The next highest total residue concentrations were observed in kidney, with concentrations of $184 \pm 31,100 \pm 5,37 \pm 25$ and $9 \pm 4 \mu \mathrm{g} / \mathrm{kg}$ at $12,24,48$ and $96 \mathrm{~h}$, respectively, after administration of the final dose. The total residue concentration in muscle was already very low $12 \mathrm{~h}$ after the last dose, at $22 \mathrm{\mu g} / \mathrm{kg}$, and depleted quickly to nondetectable concentrations $96 \mathrm{~h}$ after the last dose.

Residues in tissues were similar in animals administered zilpaterol when slaughtered at zero withdrawal time ( $12 \mathrm{~h}$ after the last dose) whether the drug was administered for 12 or 15 days. The residue levels reached a steady state by 12 days after dosing. Analysis of the total $\left[{ }^{14} \mathrm{C}\right]$ zilpaterol-related residues showed that percentage of extractability decreased from about $50 \%$ in liver at $12 \mathrm{~h}$ to $24 \%$ at $96 \mathrm{~h}$ (Figure 10.3). In kidney, percentage of extractability also decreased with time (Figure 10.4). Essentially all of the residues in muscle were extractable at the 12 and $24 \mathrm{~h}$ withdrawal periods (Table 10.21).

The radioactivity extracted from tissues was analysed using radio-HPLC. Radioactivity extracted from liver and kidney is mainly associated with unchanged zilpaterol and deisopropyl-zilpaterol. Very minor metabolites are also present. No difference is observed between sexes, and the distribution between zilpaterol and deisopropyl zilpaterol does not vary significantly with the withdrawal time. In muscle, the same pattern is generally observed, although in some samples, deisopropyl-zilpaterol is not detectable. The results are shown in Table 10.22.

Parent zilpaterol together with smaller amounts of deisopropyl-zilpaterol were the predominant compounds found in the extractable residues from tissues. Parent zilpaterol was approximately 4-8 times more abundant than the deisopropyl-zilpaterol. 
Table 10.22. Measurement of $\left[{ }^{14} \mathrm{C}\right]$ zilpaterol and $\left[{ }^{14} \mathrm{C}\right]$ deisopropyl-zilpaterol residues in cattle tissues, mean $\pm \mathrm{SD}$ expressed as zilpaterol $\mathrm{HCl}$ equivalents in $\mu \mathrm{g} / \mathrm{kg}$ (Tulliez, 1999)

\begin{tabular}{|c|c|c|c|c|c|c|}
\hline \multirow{3}{*}{$\begin{array}{c}\text { Withdrawal } \\
\text { time }\end{array}$} & \multicolumn{6}{|c|}{ Residues of $\left[{ }^{14} \mathrm{C}\right]$ zilpaterol and $\left[{ }^{14} \mathrm{C}\right]$ deisopropyl-zilpaterol $(\mu \mathrm{g} / \mathrm{kg})$} \\
\hline & \multicolumn{2}{|c|}{ Liver } & \multicolumn{2}{|c|}{ Kidney } & \multicolumn{2}{|c|}{ Muscle } \\
\hline & zilpaterol & $\begin{array}{c}\text { deisopropyl- } \\
\text { zilpaterol }\end{array}$ & zilpaterol & $\begin{array}{l}\text { deisopropyl- } \\
\text { zilpaterol }\end{array}$ & zilpaterol & $\begin{array}{c}\text { deisopropyl- } \\
\text { zilpaterol }\end{array}$ \\
\hline $12^{(1)}$ & $104.7 \pm 33.3$ & $11.2 \pm 1.7$ & $127.1 \pm 22.3$ & $14.9 \pm 1.9$ & $13.3 \pm 1.8$ & $1.6 \pm 0.1$ \\
\hline $12^{(2)}$ & $84.4 \pm 19.8$ & $15.7 \pm 2.3$ & $92.6 \pm 28.5$ & $16.3 \pm 3.4$ & $12.7 \pm 3.8$ & $3.7 \pm 0.4$ \\
\hline $24^{(1)}$ & $48.4 \pm 5.3$ & $6.5 \pm 1.4$ & $57.9 \pm 5.0$ & $7.8 \pm 1.7$ & $4.8 \pm 2.0$ & $N D^{(3)}$ \\
\hline $48^{(1)}$ & $22.9 \pm 13.3$ & $2.5 \pm 0.3$ & $18.9 \pm 22.8$ & $1.4 \pm 0.8$ & ND & ND \\
\hline $96^{(1)}$ & $7.5 \pm 3.4$ & $1.1(0.2)^{(4)}$ & $0.3(0.3)^{(4)}$ & 0.14 & ND & ND \\
\hline
\end{tabular}

NOTES: (1) Group was fed medicated feed for 12 days. (2) Group was fed medicated feed for 15 days. (3) ND = Not detectable. (4) Only one value available for the 96-h samples, so no mean and SD were calculated.

Parent zilpaterol was also measured by a validated HPLC/FL method. At $12 \mathrm{~h}$, it represented $28 \pm 7 \%$ of the total radioactivity residue (TRR) and $57 \pm 11 \%$ of extracted radioactive residue (ERR) in liver. The MR:TRR and MR:ERR ratios decreased with time to reach, respectively, $1.2 \pm 0.1$ and $5.2 \pm 0.1 \%$ at $96 \mathrm{~h}$. For kidney, a similar trend was observed (Table 10.23). Zilpaterol residues in liver show a biphasic curve of depletion for total radioactive residue related to a slow decrease of non-extractable radioactive residue. It should also be noted that there was a difference in the sensitivities of the radiometric versus the fluorescence detection method used for the quantification of zilpaterol hydrochloride.

Table 10.23. Distribution of zilpaterol-related residues in kidney, muscle and liver over the four-day (96 h) tissue withdrawal period (Tulliez, 1999)

\begin{tabular}{|c|c|c|c|c|c|c|c|c|}
\hline $\begin{array}{c}\text { Withdrawal } \\
\text { time }\end{array}$ & $\begin{array}{c}\text { TRR } \\
\mathrm{Eq} \mu \mathrm{g} / \mathrm{kg}\end{array}$ & $\begin{array}{c}\text { ERR } \\
\text { Eq } \mu g / k g\end{array}$ & 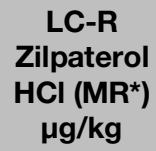 & $\begin{array}{c}\text { LC-F } \\
\text { Zilpaterol } \\
\text { HCI (MR) } \\
\mu \mathbf{\mu g} / \mathbf{k g}\end{array}$ & $\begin{array}{c}\text { MR*:TRR } \\
\%\end{array}$ & $\begin{array}{c}\text { MR:TRR } \\
\%\end{array}$ & $\begin{array}{c}\text { MR*:ERR } \\
\%\end{array}$ & $\begin{array}{c}\text { MR:ERR } \\
\%\end{array}$ \\
\hline \multicolumn{9}{|c|}{ Liver } \\
\hline $12 \mathrm{~h}$ & $291 \pm 56$ & $143 \pm 29$ & $95 \pm 27$ & $81 \pm 22$ & $66 \pm 13$ & $28 \pm 7$ & $76 \pm 12$ & $57 \pm 11$ \\
\hline $24 \mathrm{~h}$ & $205 \pm 14$ & $82 \pm 4$ & $48 \pm 5$ & $40 \pm 1$ & $59 \pm 4$ & $20 \pm 1$ & $59 \pm 4$ & $49 \pm 1$ \\
\hline $48 \mathrm{~h}$ & $157 \pm 23$ & $52 \pm 19$ & $23 \pm 13$ & $15 \pm 12$ & $42 \pm 9$ & $9 \pm 6$ & $42 \pm 9$ & $25 \pm 12$ \\
\hline $96 \mathrm{~h}$ & $113 \pm 17$ & $27 \pm 3$ & $7.5 \pm 3.4$ & $1.4 \pm 0.2$ & $27 \pm 11$ & $1.2 \pm 0.1$ & $27 \pm 11$ & $5.2 \pm 0.1$ \\
\hline \multicolumn{9}{|c|}{ Kidney } \\
\hline $12 \mathrm{~h}$ & $184 \pm 31$ & $68 \pm 21$ & $110 \pm 30$ & $106 \pm 25$ & $60 \pm 12$ & $58 \pm 8$ & $100 \pm 48$ & $96 \pm 44$ \\
\hline $24 \mathrm{~h}$ & $100 \pm 5$ & $85 \pm 3$ & $58 \pm 5$ & $58 \pm 5$ & $58 \pm 4$ & $57 \pm 3$ & $68 \pm 4$ & $67 \pm 4$ \\
\hline $48 \mathrm{~h}$ & $37 \pm 25$ & $62 \pm 31$ & $19 \pm 23$ & $21 \pm 23$ & $40 \pm 25$ & $46 \pm 23$ & $70 \pm 34$ & $83 \pm 37$ \\
\hline $96 \mathrm{~h}$ & $9 \pm 4$ & $38 \pm 4$ & $0.3 \pm 0.3$ & & $3.2 \pm 1.5$ & & $8.2 \pm 3.1$ & \\
\hline \multicolumn{9}{|c|}{ Muscle } \\
\hline $12 \mathrm{~h}$ & $22 \pm 2.4$ & $22 \pm 3.8$ & $13 \pm 3$ & $15 \pm 2$ & $60 \pm 10$ & $69 \pm 5$ & $59 \pm 8$ & $68 \pm 8$ \\
\hline $24 \mathrm{~h}$ & $12 \pm 2.6$ & $12 \pm 2.0$ & $5 \pm 2$ & $8 \pm 2$ & $39 \pm 8$ & $63 \pm 4$ & $39 \pm 10$ & $64 \pm 8$ \\
\hline $48 \mathrm{~h}$ & 6 & 2 & 2 & 5 & 38 & 75 & 39 & 76 \\
\hline $96 \mathrm{~h}$ & ND & ND & ND & ND & - & - & - & - \\
\hline
\end{tabular}

NOTES: TRR $=$ Total radioactive residue (as Zilpaterol $\mathrm{HCL}$ equivalents). ERR = Extracted radioactive residue (as Zilpaterol $\mathrm{HCL}$ equivalents). $\mathrm{MR}^{\star}=$ Parent zilpaterol (Marker residue) determined by radio-HPLC. MR $=$ Parent zilpaterol (Marker residue) measured by HPLC-fluorescence. ND = not detected. 


\section{Bio-availability of zilpaterol bound residue}

A GLP-compliant study was conducted to determine the bio-availability of non-extractable residues from cattle liver (Girkin, 1999). The bio-availability of non-extractable residues remaining in the liver from cattle administered labelled zilpaterol was determined using Sprague-Dawley rats (16 male, 16 female) ranging in age from 6 to 10 weeks and weighing 200-239 g. Liver was obtained from cattle killed at 12, 24, 48 and $96 \mathrm{~h}$ after 12 repeated daily doses and following $12 \mathrm{~h}$ withdrawal after the last of 15 repeated daily doses. Pooled liver samples from each dosagexwithdrawal time were extracted, lyophilized, finely powdered and pelleted. Groups of 4 rats (2 males and 2 females) were surgically altered. After a 24hour recovery, the rats were fed lyophilized pelleted control liver. In addition, 2 groups of surgically altered rats fed with either rat diet or control rat liver were administered an intragastric dose of labelled zilpaterol in aqueous solution at a nominal dose of $1 \mathrm{mg} / \mathrm{kg}$. Following extraction of cattle liver from the animals killed at 12, 24, 48, and $96 \mathrm{~h}$ after the last of 12 repeated daily doses of labelled zilpaterol, the proportions of unextracted radioactivity were $36.8,53.6,65.2$ and $70.7 \%$, respectively.

After extraction of cattle liver from animals killed $12 \mathrm{~h}$ after the last of the 15 repeated daily doses of labelled zilpaterol, the proportion of unextracted radioactivity was $48.3 \%$. Following administration of labelled zilpaterol by gastric cannulae to bile-duct cannulated rats, zilpaterol was well absorbed (mean $>88 \%$ of the administered dose) by rats fed with rat diet or control pelleted liver. The results show that the non-extractable residues from livers of cattle at all sacrifice points were only poorly absorbed by the rats, with a mean maximum of $3.3 \%$ of the dose being absorbed and therefore bio-available (Table 10.24).

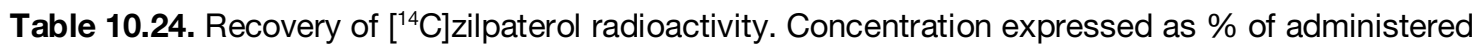
dose following intragastric administration to Sprague-Dawley rats (Girkin, 1999)

\begin{tabular}{|c|c|c|c|c|c|}
\hline & \multicolumn{5}{|c|}{$\%$ Radioactivity ( $n=4)$} \\
\hline & Group III & Group IV & Group V & Group VI & Group VII \\
\hline Days of administration (days) & 12 & 15 & 12 & 12 & 12 \\
\hline Withdrawal period (hours) & 12 & 12 & 24 & 48 & 96 \\
\hline \multicolumn{6}{|c|}{ Absorbed } \\
\hline Urine & 2.4 & 2.2 & 2.0 & 0.8 & 1.1 \\
\hline Bile & 0.0 & 0.2 & 0.0 & 0.0 & 0.1 \\
\hline Carcass \& Tissues & 3.3 & 2.5 & 2.0 & 0.8 & 1.2 \\
\hline \multicolumn{6}{|c|}{ Non-absorbed } \\
\hline Faeces & 88.0 & 97.2 & 101.9 & 96.1 & 99.3 \\
\hline GIT contents & 2.4 & 0.5 & 0.1 & 0.0 & 0.1 \\
\hline Cage washes & 0.0 & 0.2 & 0.0 & 0.0 & 0.0 \\
\hline Total non-absorbed & 90.4 & 97.8 & 101.9 & 96.1 & 99.4 \\
\hline Total Recovery & 93.3 & 100.3 & 104.0 & 96.8 & 100.6 \\
\hline
\end{tabular}


Figure 10.3. Depletion of zilpaterol residues in cattle liver.

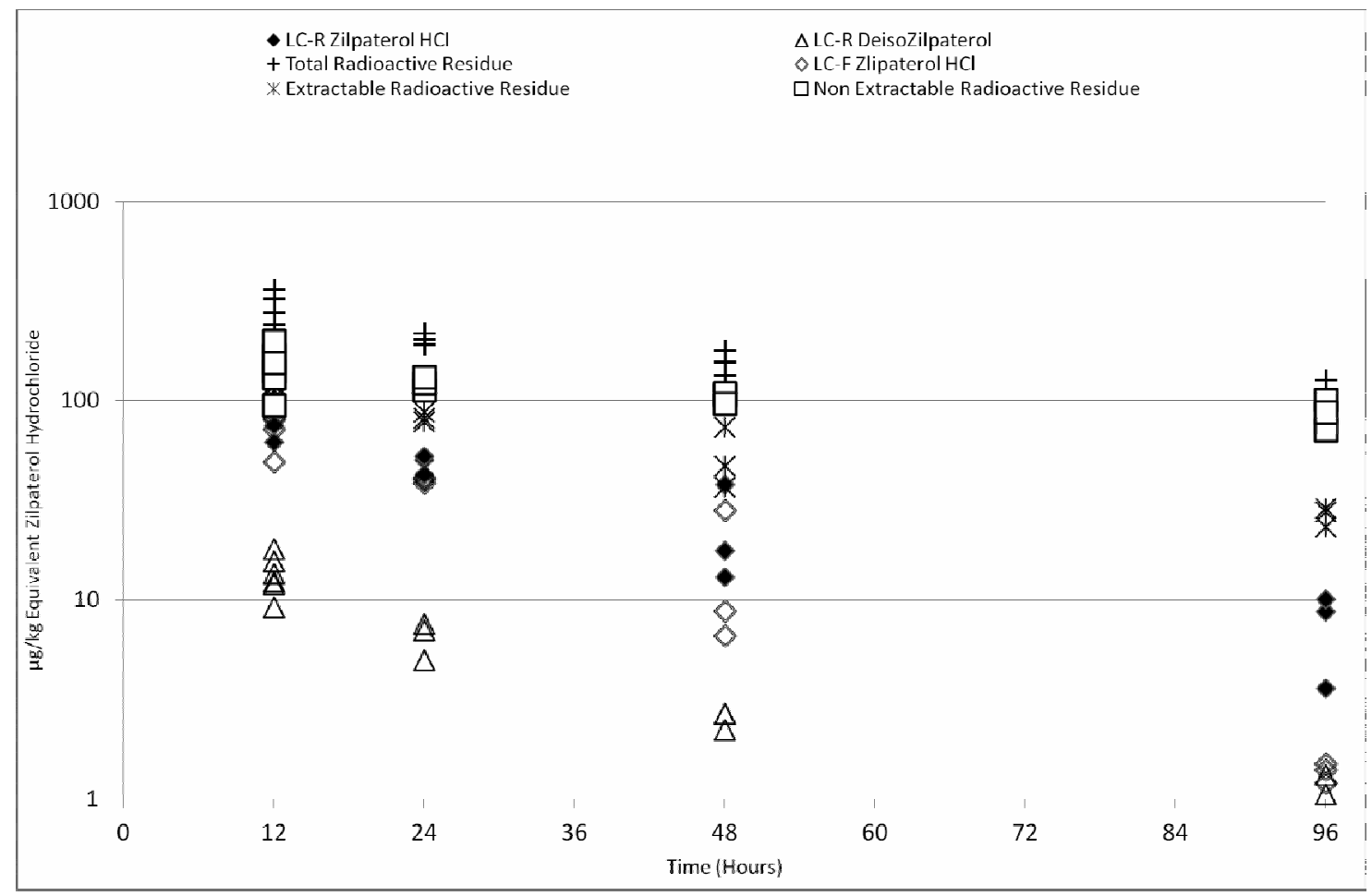

Figure 10.4. Depletion of zilpaterol residues in cattle kidney

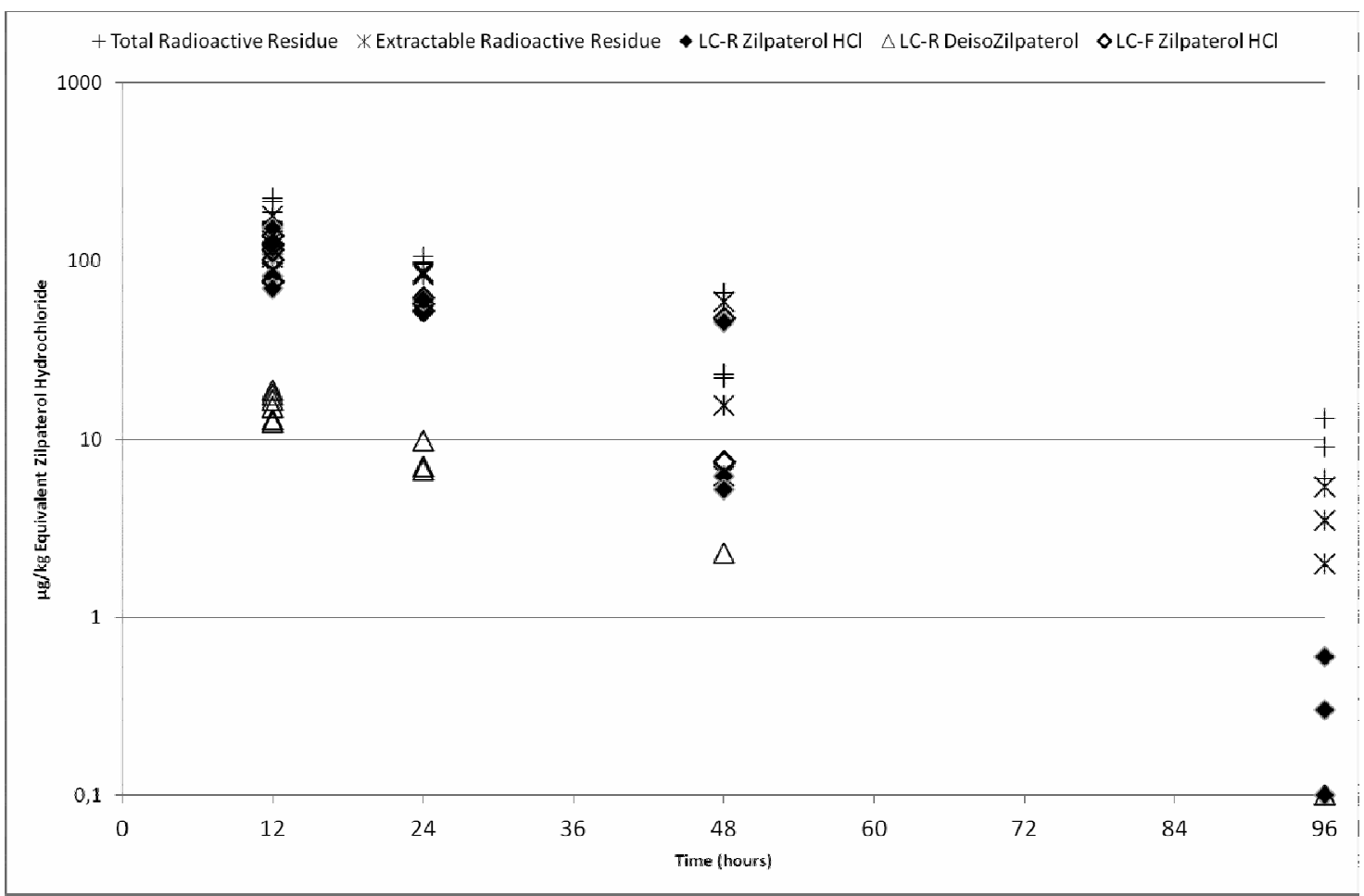




\section{Residue depletion studies with unlabelled drug}

\section{Cattle}

In the first of three pivotal GLP-compliant tissue residue depletion studies conducted to measure the concentration of zilpaterol in the liver, muscle and kidney tissues of cattle (Hughes, McDonald and Bomkamp, 1999), 18 crossbred beef cattle (9 steers weighing 455 to $595 \mathrm{~kg}$ and 9 heifers weighing $480 \mathrm{~kg}$ to $573 \mathrm{~kg}$ at the initiation of treatment) were randomly assigned to four groups ( 2 of each sex per group). The cattle were treated for 12 consecutive days with the commercial pre-mix medicated feed at the recommended dosage of $0.15 \mathrm{mg} / \mathrm{kg}$ bw per day or $7.5 \mathrm{mg} / \mathrm{kg}$ in feed. After receiving the final dose via medicated feed, one group of animals was killed at each of 12, 24, 48 or $96 \mathrm{~h}$ post-dose. Two animals were non-medicated control animals. These animals were considered representative of standard feedlot cattle.

Samples of liver, muscle and kidney from the four-day withdrawal study were assayed by the validated HPLC/FL method (Table 10.25). Recoveries of marker residue were $\quad 91.8 \pm 3.72 \%, \quad 86.1 \pm 13.9 \%$ and $98.4 \pm 4.57 \%$, respectively, for the liver, muscle and kidney. The LOQs for the method were $3 \mu \mathrm{g} / \mathrm{kg}, 1 \mu \mathrm{g} / \mathrm{kg}$ and $1 \mu \mathrm{g} / \mathrm{kg}$, respectively, for liver, muscle and kidney, while LODs were $1 \mu \mathrm{g} / \mathrm{kg}$, $0.1 \mu \mathrm{g} / \mathrm{kg}$ and $0.5 \mu \mathrm{g} / \mathrm{kg}$, respectively, for the liver, muscle and kidney. The mean concentrations of zilpaterol in liver depleted from $28.3 \mu \mathrm{g} / \mathrm{kg} 12 \mathrm{~h}$ after the last 12th-day dose to $11.4 \mu \mathrm{g} / \mathrm{kg} 24 \mathrm{~h}$ after the last dose and to $4.5 \mu \mathrm{g} / \mathrm{kg} 48 \mathrm{~h}$ after the last dose. At 12,24 and $48 \mathrm{~h}$ after the last dose, the concentrations of residues in kidney were 51,13 and $6 \mu \mathrm{g} / \mathrm{kg}$, respectively. It was noted that in this particular study the residue concentrations in kidney were slightly higher than the residue concentrations in liver.

In the remaining two pivotal GLP-compliant studies, a total of 25 steers and 25 heifers, including 48 treated and 2 controls, forming 9 groups, were used in each of the studies (Crouch, 2011a, b). The group assignments, treatment and withdrawal periods are shown in Table 10.26 .

Table 10.26. Experimental design used in the two 10-days withdrawal period pivotal studies for zilpaterol hydrochloride (Zilmax) residue depletion study in cattle (Crouch, 2011a, b)

\begin{tabular}{cccccc}
\hline Group & $\begin{array}{c}\text { Withdrawal time } \\
\text { (days) }\end{array}$ & $\begin{array}{c}\text { Zilmax dose } \\
\text { (mg/head/day) }\end{array}$ & $\begin{array}{c}\text { Dosing period } \\
\text { (consecutive days) }\end{array}$ & Steers & Heifers \\
\hline I & 0.5 & 90 & 20 & 3 & 3 \\
II & 1 & 90 & 20 & 3 & 3 \\
III & 2 & 90 & 20 & 3 & 3 \\
IV & 3 & 90 & 20 & 3 & 3 \\
V & 4 & 90 & 20 & 3 & 3 \\
VI & 6 & 90 & 20 & 3 & 3 \\
VII & 8 & 90 & 20 & 3 & 3 \\
VIII & 10 & 90 & NA & 3 & 3 \\
Control & NA & NA & & 1 & 1 \\
\hline
\end{tabular}

Table 10.25. Mean zilpaterol concentrations in cattle liver, muscle and kidney tissues in the fourday (96-h) withdrawal period pivotal study (Hughes, McDonald and Bomkamp, 1999)

\begin{tabular}{|c|c|c|c|}
\hline \multirow{2}{*}{$\begin{array}{c}\text { Withdrawal } \\
\text { Period }\end{array}$} & \multicolumn{3}{|c|}{$\begin{array}{l}\text { Mean zilpaterol hydrochloride } \\
\text { equivalents }(\mu \mathrm{g} / \mathrm{kg})(n=4)\end{array}$} \\
\hline & Liver & Muscle & Kidney \\
\hline Group II (12 h) & $28.3 \pm 9.1$ & $5.0 \pm 1.9$ & $50.8 \pm 33.1$ \\
\hline $\begin{array}{l}\text { Group III } \\
(24 \text { h) }\end{array}$ & $11.4 \pm 2.8$ & $2.1 \pm 0.5$ & $1.3 \pm 1.54$ \\
\hline $\begin{array}{l}\text { Group IV } \\
(48 \mathrm{~h})\end{array}$ & $4.5 \pm 4.0$ & $<\mathrm{LOQ}^{(1)}$ & $5.7 \pm 5.2$ \\
\hline Group V (96 ) & $<\operatorname{LOD}^{(2)}$ & $<\operatorname{LOD}^{(3)}$ & $<\operatorname{LOD}^{(4)}$ \\
\hline LOD ( $\mu \mathrm{g} / \mathrm{kg})$ & 1 & 0.1 & 0.5 \\
\hline LOQ $(\mu \mathrm{g} / \mathrm{kg})$ & 3 & 1 & 1 \\
\hline
\end{tabular}

NOTES: (1) LOQ $=1 \mu \mathrm{g} / \mathrm{kg}$; (2) LOD $=1 \mu \mathrm{g} / \mathrm{kg}$;

(3) $\mathrm{LOD}=0.1 \mu \mathrm{g} / \mathrm{kg}$; (4) LOD $=0.5 \mu \mathrm{g} / \mathrm{kg}$.

NOTES: NA $=$ not applicable 
For the purpose of these two studies, cattle were administered Zilmax® either via component feeding (Crouch, 2011a) or via a pelleted type $C$ top dress supplement (Crouch, $2011 \mathrm{~b}$ ) at the recommended dosage regimen of $90 \mathrm{mg}$ zilpaterol hydrochloride per head, and for 20 consecutive days. The males were castrated and no female was pregnant. The bodyweights ranged from $433 \mathrm{~kg}$ to $574 \mathrm{~kg}$ for heifers, and from $480 \mathrm{~kg}$ to $584 \mathrm{~kg}$ for steers. Samples (muscle and liver) were assayed by the validated HPLC/FL method. The LOD for the method was $0.90 \mu \mathrm{g} / \mathrm{kg}$ with an LOQ of $2.0 \mu \mathrm{g} / \mathrm{kg}$ for liver, while the LOD and LOQ were $0.53 \mu \mathrm{g} / \mathrm{kg}$ and $2.0 \mu \mathrm{g} / \mathrm{kg}$, respectively, for muscle tissue. The concentrations of residues in liver were significantly lower than the residue levels observed in the earlier pivotal study (Hughes, McDonald and Bomkamp, 1999). Residues in muscle tissue were too low to permit a depletion curve plot (Table 10.27).

Table 10.27. Mean zilpaterol free base residue concentrations in liver and muscle at withdrawal times of $12,24,48,72,96,144,192$ and $240 \mathrm{~h}$ in cattle

\begin{tabular}{|c|c|c|c|c|}
\hline \multirow[t]{2}{*}{$\begin{array}{l}\text { Slaughter } \\
\text { time }\end{array}$} & \multicolumn{2}{|c|}{ Top dress supplement (Crouch, 2011b) } & \multicolumn{2}{|c|}{$\begin{array}{c}\text { Component feeding (Crouch, } \\
\text { http://www.fao.org/fileadmin/user_upload/ag } \\
\text { ns/pdf/jecfa/Dietary_Exposure_AssessmentM } \\
\text { ethodologies_for_Residues_of_Veterinary_Dr } \\
\text { ugs.pdfa) }\end{array}$} \\
\hline & Liver $(\mu \mathrm{g} / \mathrm{kg})$ & Muscle $(\mu \mathrm{g} / \mathrm{kg})$ & Liver $(\mu \mathrm{g} / \mathrm{kg})$ & Muscle $(\mu \mathrm{g} / \mathrm{kg})$ \\
\hline $12 \mathrm{~h}$ & $12.9 \pm 5.3$ & $3.0 \pm 0.7^{(1)}$ & $13.9 \pm 7.3$ & $3.8 \pm 0.5^{(2)}$ \\
\hline $24 \mathrm{~h}$ & All values but one $(3.6)<L^{\prime O Q}{ }^{(4)}$ & All values $<\mathrm{LOQ}$ & $5.7 \pm 2.4$ & All values $<\mathrm{LOQ}$ \\
\hline $48 \mathrm{~h}$ & All values $<$ LOQ & All values $<\mathrm{LOQ}$ & $3.8 \pm 1.0^{(3)}$ & Al values $<$ LOQ \\
\hline $72 \mathrm{~h}$ & All values but one $(2.9)<\mathrm{LOQ}$ & All values $<$ LOD & $2.3 \pm 0.4^{(3)}$ & All values $<$ LOD \\
\hline $96 \mathrm{~h}$ & All values $<\mathrm{LOD}^{(5)}$ & All values $<$ LOD & All values $<\mathrm{LOQ}$ & All values $<$ LOD \\
\hline $144 \mathrm{~h}$ & All values $<$ LOD & All values $<$ LOD & All values but one $(2.01)<\mathrm{LOQ}$ & All values $<$ LOD \\
\hline $192 \mathrm{~h}$ & All values $<\mathrm{LOQ}$ & All values $<$ LOD & All values $<\mathrm{LOQ}$ & All values $<$ LOD \\
\hline $240 \mathrm{~h}$ & All values $<$ LOD & All values $<$ LOD & All values $<$ LOD & All values $<$ LOD \\
\hline
\end{tabular}

NOTES: (1) 4 out of 6 values $>$ LOQ. (2) 2 out of 6 values $>$ LOQ. (3) 3 out of 6 values $>L O Q$. (4) LOQ $=2 \mu g / k g$.

(5) $\mathrm{LOD}=0.527 \mu \mathrm{g} / \mathrm{kg}$.

\section{Methods of analysis for residues in tissues}

Residues of unlabelled zilpaterol in the three pivotal residue depletion studies (Hughes, McDonald and Bomkamp, 1999; Crouch, 2011a, b) were measured using a validated HPLC method with fluorescence detection, HPLC/FL (Nandihalli, Hughes and Bomkamp, 1999). The HPLC/FL method involves the extraction of unchanged zilpaterol from liver, kidney and muscle homogenate with a basic mixture of acetonitrile and methanol. The extract is filtered and the filtrate partitioned with iso-octane to remove non-polar co-extractives. Following removal of the organic fraction, ammonium acetate is added to the concentrated aqueous extract and the mixture is centrifuged. The aqueous supernatant is cleaned up on a conditioned SPE cartridge from which the retained zilpaterol is eluted with ammonium acetate. The eluate is further cleaned up on a C8 RP Select B cartridge. Zilpaterol is eluted from the cartridge with a mixed solution of ammonium acetate/methanol/water. After evaporating to dryness, the residue is taken up into an ammonium acetate solution containing sodium azide. The chemically stable fluorescent zilpaterol derivative is separated from other co-extractives and non-fluorescent compounds by HPLC using a Puropher RP-18 column and detected with fluorescence detection at $640 \mathrm{~nm}$ (excitation at $285 \mathrm{~nm}$ ).

In two of these pivotal studies, significant matrix interference effects were observed from the analysis of liver tissue, necessitating modification to the validated method in order to minimize the matrix effect (Crouch, 2011a, b). The LOQ was set at $2 \mu \mathrm{g} / \mathrm{kg}$ for both muscle 
and liver, although the LODs were $0.53 \mu \mathrm{g} / \mathrm{kg}$ and $0.90 \mu \mathrm{g} / \mathrm{kg}$ in muscle and liver, respectively. The average recoveries from fortified Quality Control samples were $71.4 \%$ and $71.8 \%$ at levels of $6 \mu \mathrm{g} / \mathrm{kg}$ and $24 \mu \mathrm{g} / \mathrm{kg}$, respectively, in incurred liver, and $76.2 \%$ and $72.9 \%$ at $5 \mu \mathrm{g} / \mathrm{kg}$ and $20 \mu \mathrm{g} / \mathrm{kg}$, respectively, in incurred muscle (Crouch, 2011b). They were $69.2 \%$ and $68.5 \%$ at levels of $6 \mu \mathrm{g} / \mathrm{kg}$ and $24 \mu \mathrm{g} / \mathrm{kg}$, respectively, in liver, and $78.5 \%$ and $72.7 \%$ at $5 \mu \mathrm{g} / \mathrm{kg}$ and $20 \mu \mathrm{g} / \mathrm{kg}$, respectively, in muscle (Crouch, 2011a).

All the concentrations were reported as zilpaterol hydrochloride equivalents by the sponsor. In view of the fact that it is zilpaterol free base and not zilpaterol hydrochloride that is being analysed with these methods, the operational parameters of the method have been re-calculated to reflect this, as shown in Table 10.28.

Table 10.28. Validation parameters of the routine HPLC/FL method for the quantification of zilpaterol in cattle tissues

\begin{tabular}{lccc}
\hline \multicolumn{1}{c}{ Validation criterion } & Liver & Kidney & Muscle \\
\hline Precision (\%) RSD & 8.76 & 6.95 & 6.96 \\
Accuracy (\% Recovery) (mean \pm SD) & $93.5 \pm 8.2$ & $92.1 \pm 6.4$ & $84.3 \pm 5.9$ \\
LOQ $(\mu \mathrm{g} / \mathrm{kg})$ - Zilpaterol hydrochloride & 3.0 & 1 & 1 \\
$\quad$ - Zilpaterol free base & 2.6 & 0.9 & 0.9 \\
LOD $(\mu \mathrm{g} / \mathrm{kg})$ - Zilpaterol hydrochloride & 1.0 & 0.5 & 0.1 \\
$\quad$ Zilpaterol free base & 0.9 & 0.4 & 0.09 \\
Linearity 0.5 to $200 \mu \mathrm{g} / \mathrm{kg}$ as Zilpaterol HCl tissue equivalents & $\mathrm{R}^{2}>0.98$ & $\mathrm{R}^{2}>0.98$ & $\mathrm{R}^{2}>0.98$ \\
Selectivity ${ }^{(1)}$ & No interference & No interference & No interference \\
Residue Stability 3 Freeze/thaw cycles ${ }^{(2)}$ & $88.4 \pm 1.2$ to & $79.9 \pm 5.5$ to & $84.8 \pm 10.2$ to \\
Low, High (\% Recovery) & $95.5 \pm 4.6$ & $96.2 \pm 14.7$ & $99.2 \pm 2.1$ \\
Stability of extract 24 hour or 1 month ${ }^{(3)}$ & $72.7 \pm 0.4$ to & $85.5 \pm 7.1$ to & $81.2 \pm 3.9$ to \\
(\% Recovery) & $84.3 \pm 10.1$ & $110.8 \pm 4.3$ & $85.9 \pm 3.7$ \\
\hline
\end{tabular}

NOTES: (1) No interference with other feed additive products or therapeutic $\beta$-agonist compounds. (2) Low = samples fortified with $3 \mu \mathrm{g} / \mathrm{kg}$, and high = samples fortified with $12 \mu \mathrm{g} / \mathrm{kg}$. (3) Range of values for samples stored for 24 hours in HPLC autosampler or stored in the freezer for one month. Samples fortified at 3 and $12 \mu \mathrm{g} / \mathrm{kg}$. For the purpose of this table, the molecular weights of $247.113 \mathrm{~g}$ for zilpaterol free base and $283.56 \mathrm{~g}$ for zilpaterol hydrochloride were retained.

\section{LC-MS/MS Method}

In another GLP-compliant study, an LC-MS/MS method developed by the Sponsor was validated for the determination and confirmation of zilpaterol residues in bovine liver and muscle tissue (Wrzesinski, 2012). Briefly, after homogenization with dry ice, about $1 \mathrm{~g}$ of tissue is fortified with the internal standard, and 0.5, 1.0 and 2.0 times the concentrations of 10 and $12 \mu \mathrm{g} / \mathrm{kg}$ in muscle and liver, respectively, and extracted with $5 \mathrm{ml}$ methanol. Following centrifugation, $500 \mu \mathrm{l}$ of supernatant are applied to an Oasis ${ }^{\circledR}$ MCX 96-well plate $(10 \mathrm{mM})$ in metanol. After sequential washing, plates are eluted with $2 \times 200 \mu \mathrm{l} 0.1 \%$ ammonium acetate in methanol and evaporated to dryness. Reconstitution is performed with $150 \mu \mathrm{l}$ 90:10 ammonium acetate $10 \mathrm{mM}$ containing $0.1 \%$ formic acid:methanol. The final extract is analysed by LC-MS/MS. The extraction recovery was reported as $78 \%$ and $82 \%$ for bovine liver and muscle tissues, respectively. The LOD and LOQ are similar to those achieved with the HPLC/FL method. A summary of the performance characteristics of the LC-MS/MS method developed by the Sponsor is provided in Table 10.29.

Unlike other $\beta$-agonists such as clenbuterol and ractopamine, there are very few analytical methods published for zilpaterol. The first methods published used gas chromatographymass spectrometry (GC-MS) to measure residues of zilpaterol in feeds (Bocca et al., 2003a) and tissues (Bocca et al., 2003b). Sensitive liquid chromatography-mass spectrometric (LCMS) methods were later reported for zilpaterol in urine, faeces and tissues (Stachel, Radeck and Gowik, 2003; Blanca et al., 2005; Van Hoof et al., 2005). In one of these published validated methods (Stachel, Radeck and Gowik, 2003), zilpaterol residues in urine, retina and 
plasma and muscle tissue are extracted after hydrolysis with protease, and zilpaterol residues in liver and kidney tissues are extracted after hydrolysis with glucoronidase/arylsulfatase mix, cleaned up using solid-phase extraction and analysed by LC-MS/MS. The method was used to quantify incurred zilpaterol residues in muscle, kidney, retina and liver samples collected from 2 cattle administered zilpaterol $\mathrm{HCl}$ at $0.15 \mathrm{mg} / \mathrm{kg}$ bw once daily for 14 days, and killed 1 and 10 days post-dosing (i.e. 1 animal on each sampling date). The concentrations of zilpaterol measured in muscle, kidney and liver samples collected were $0.01 \mu \mathrm{g} / \mathrm{kg}, 0.03 \mu \mathrm{g} / \mathrm{kg}$ and $0.03 \mu \mathrm{g} / \mathrm{kg}$ at 10 days, respectively. This LC-MS/MS method demonstrated detection limits 10-100 times better than those of the HPLC/FL and the LC-MS/MS methods used in the pivotal residue depletion studies provided to the Committee (Hughes, McDonald and Bomkamp, 1999; Crouch, 2011a, b).

More recently, rapid analytical methods have been developed using polyclonal and monoclonal antibody-based immunoassay and immune-biosensor analyses that are applicable for the analysis of residues of zilpaterol in swine, cattle and sheep (Shelver and Smith, 2011).

Table 10.29. Validation parameters of the LC-MS/MS method for zilpaterol free base quantification in cattle liver and muscle tissue (Wrzesinski, 2012)

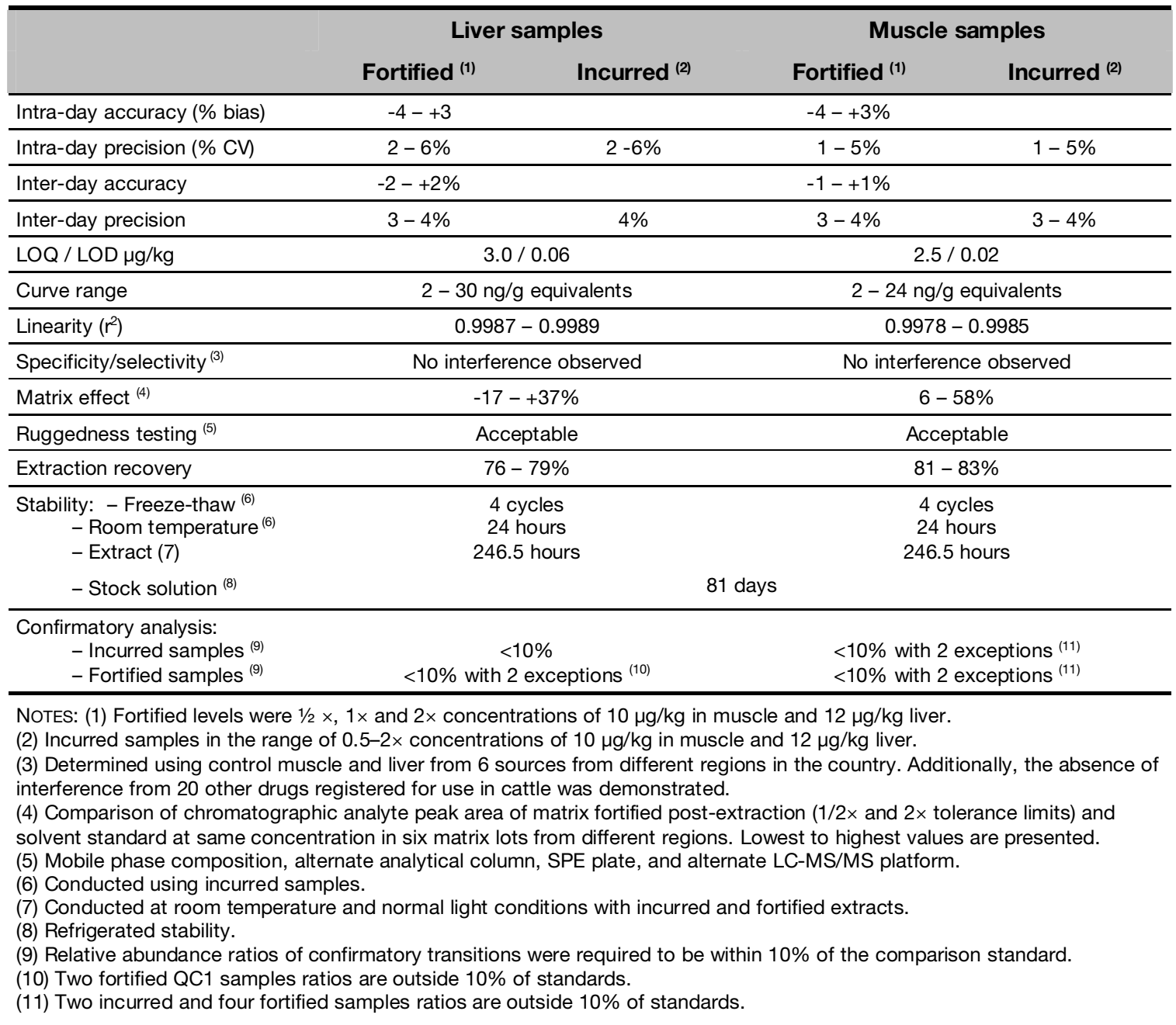




\section{Stability of residues in frozen tissues}

The stability of incurred zilpaterol residues was evaluated in liver, kidney and muscle during storage at temperature of $\leq 10^{\circ} \mathrm{C}$ for up to 12 months (Hughes and Halverson, 2000). Tissues from control animals fortified with 6 or $12 \mu \mathrm{g} / \mathrm{kg}$ zilpaterol hydrochloride were selected for storage and re-analysis at $0,1,3,6$ and 12 months of storage. Tissues from three treated animals that had two different levels of incurred zilpaterol residues at the first analysis were also selected and stored for periodic re-analysis. The zilpaterol $\mathrm{HCl}$ content of the tissues was measured by the HPLC/FL method, and the recovery was at least $73 \%$ (Nandihalli, Hughes and Bomkamp, 1999; method also described in Hughes, McDonald and Bomkamp (1999). The results show that the stability of residues of zilpaterol in liver, kidney and muscle tissues was not adversely influenced by storage for up to 12 months at or below $-10^{\circ} \mathrm{C}$. Table 10.30 shows the results of tissues from treated-animals with two different levels of incurred residues.

Table 10.30. Storage stability of zilpaterol in frozen tissue samples from treated cattle that were stored at or below $-10^{\circ} \mathrm{C}$ for up to 12 months (Hughes and Halverson, 2000)

\begin{tabular}{lcccccc}
\hline $\begin{array}{l}\text { Tissue } \\
\text { Matrix }\end{array}$ & Animal No. & \multicolumn{5}{c}{ Zilpaterol HCl equivalents found $(\boldsymbol{\mu g} / \mathbf{k g})$} \\
& & 0 Month & 1 Month & 3 Months & 6 Months & 12 Months \\
\hline Liver & 2911 & 6.9 & 7.2 & 8.0 & 6.8 & 6.5 \\
& 2910 & 27.1 & 26.4 & 26.1 & 26.5 & 30.6 \\
\hline Muscle & 2910 & 4.2 & 4.1 & 4.2 & 3.5 & 4.4 \\
& 2913 & 8.0 & 7.6 & 8.2 & 7.5 & 8.6 \\
\hline Kidney & 2911 & 8.3 & 8.0 & 7.3 & 7.4 & 7.3 \\
& 2910 & 49.2 & 47.3 & 45.8 & 47.8 & 52.9 \\
\hline
\end{tabular}

The methods available for the analysis of zilpaterol in biological matrices are summarized in Table 10.31.

Table 10.31. Summary of analytical methods for zilpaterol residues

\begin{tabular}{|c|c|c|c|c|}
\hline Method & $\begin{array}{l}\text { Species and } \\
\text { tissues }\end{array}$ & LOD / LOQ ( $\mu \mathrm{g} / \mathrm{kg})$ & Reported validation & Reference \\
\hline \multirow[t]{2}{*}{ LC-MS/MS } & $\begin{array}{l}\text { cattle urine and } \\
\text { pig liver }\end{array}$ & $\begin{array}{l}\text { CCa (urine) }=0.11^{(1)} \\
\text { CCa (liver) }=0.13\end{array}$ & $\begin{array}{l}\text { Validated according to } \\
\text { the Commission }\end{array}$ & Blanca et al., 2005 \\
\hline & & $\begin{array}{l}\operatorname{cc} \beta \text { (urine) }=0.26+{ }^{(2)} \\
\operatorname{Cc} \beta \text { (liver) }=0.52\end{array}$ & Decision 2002/657/EC & \\
\hline GC-MS/MS & retinal extracts (cattle) & $\begin{array}{l}C C \alpha=65.7 \\
C C \beta=73.9\end{array}$ & $\begin{array}{l}\text { Validated according to } \\
\text { SANCO/1805/2000 }\end{array}$ & Bocca, et al., 2003b \\
\hline GC-MS & $\begin{array}{l}\text { commercial feeds for } \\
\text { cattle }\end{array}$ & $\begin{array}{l}\mathrm{LOD}=7.5 \\
\mathrm{LOQ}=25.0\end{array}$ & Internal validation & Bocca et al., 2003a \\
\hline \multirow[t]{2}{*}{ HPLC/FL } & cattle liver and muscle & $\begin{array}{l}\text { LOD (liver) }=0.53 \\
\text { LOQ (liver) }=2\end{array}$ & Internal validation & Crouch, 2011a, b \\
\hline & & $\begin{array}{l}\text { LOD (muscle) }=0.90 \\
\text { LOQ (muscle) }=2\end{array}$ & & \\
\hline \multirow[t]{2}{*}{ HPLC/FL } & $\begin{array}{l}\text { cattle liver, muscle, } \\
\text { kidney }\end{array}$ & $\begin{array}{l}\text { LOD }(\text { liver })=1.0 \\
\text { LOD (muscle) }=0.1 \\
\text { LOD }(\text { kidney) }=0.5\end{array}$ & Validated method & $\begin{array}{l}\text { Hughes, McDonald and } \\
\text { Bomkamp, } 1999\end{array}$ \\
\hline & & $\begin{array}{l}\text { LOQ } \text { (liver) }=3.0 \\
\mathrm{LOQ} \text { (muscle) }=1.0 \\
\mathrm{LOQ}(\text { kidney })=1.0\end{array}$ & & \\
\hline
\end{tabular}




\begin{tabular}{|c|c|c|c|c|}
\hline Method & $\begin{array}{l}\text { Species and } \\
\text { tissues }\end{array}$ & LOD / LOQ ( $\mu \mathrm{g} / \mathrm{kg})$ & Reported validation & Reference \\
\hline \multirow[t]{2}{*}{ HPLC/FL } & $\begin{array}{l}\text { cattle liver, kidney and } \\
\text { muscle }\end{array}$ & $\begin{array}{l}\text { LOD (liver) }=1 \\
\text { LOD (kidney) }=0.5 \\
\text { LOD }(\text { muscle) }=0.1\end{array}$ & Internal validation & $\begin{array}{l}\text { Nandihalli, Hughes and } \\
\text { Bomkamp, } 1999\end{array}$ \\
\hline & & $\begin{array}{l}\text { LOQ (liver) }=3 \\
\text { LOQ }(\text { kidney) }=1 \\
\text { LOQ }(\text { muscle) }=1\end{array}$ & & \\
\hline ELISA & horse urine & LOD/LOQ $\leq 0.8$ & External validation ${ }^{(3)}$ & Shelver and Smith, 2011 \\
\hline LC-MS/MS & $\begin{array}{l}\text { pig liver, kidney, } \\
\text { muscle } \\
\text { cattle liver, kidney, } \\
\text { muscle }\end{array}$ & $\begin{array}{l}\text { LOD/LOQ (liver) } \leq 0.15 \\
\text { LOD/LOQ (kidney) } \leq 0.28 \\
\text { LOD/LOQ (muscle) } \leq 0.020 \\
\text { LOD/LOQ (liver) } \leq 003 \\
\text { LOD/LOQ (kidney) } \leq 0.03 \\
\text { LOD/LOQ (muscle) } \leq 0.01\end{array}$ & Internal validation & $\begin{array}{l}\text { Stachel, Radeck and } \\
\text { Gowik, } 2003\end{array}$ \\
\hline \multirow[t]{2}{*}{ HPLC/FL } & $\begin{array}{l}\text { cattle liver, kidney, } \\
\text { muscle }\end{array}$ & $\begin{array}{l}\text { LOD }(\text { liver })=1 \\
\operatorname{LOD}(\text { kidney) }=1 \\
\operatorname{LOD}(\text { muscle })=0.1\end{array}$ & Internal validation & Tulliez, 1999 \\
\hline & & $\begin{array}{l}\text { LOQ (liver) }=3 \\
\text { LOQ (kidney) }=5 \\
\text { LOQ }(\text { muscle) }=1\end{array}$ & & \\
\hline $\begin{array}{l}\text { LC-MS } \\
\text { LC-MS/MS }\end{array}$ & calf urine, faeces & $\begin{array}{l}C C \beta \leq 1 \text { (urine) } \\
\operatorname{CC} \beta \leq 1 \text { (faeces) }\end{array}$ & Internal validation & Van Hoof et al., 2005 \\
\hline \multirow[t]{2}{*}{ LC-MS/MS } & cattle liver, muscle & $\begin{array}{l}\text { LOD (liver) }=0.06 \\
\operatorname{LOD} \text { (muscle) }=0.02\end{array}$ & Internal validation & Wrzesinski, 2012 \\
\hline & & $\begin{array}{l}\text { LOQ (liver) }=3.0 \\
\text { LOQ (muscle) }=2.5\end{array}$ & & \\
\hline
\end{tabular}

NOTES: (1) $C C \alpha=$ Decision limit. (2) $C C \beta=$ Detection capability; (3) External validation was conducted using chemical standards.

\section{Appraisal}

Zilpaterol hydrochloride, ( \pm )-trans-4,5,6,7-tetrahydro-7-hydroxy-6-(isopropylamino)imidazo [4,5,1-jk]-[1]benzazepin-2(1H)-one hydrochloride, is a $\beta 2$-adrenergic repartition agent used in cattle for increased rate of bodyweight gain, improved feed efficiency, and increased carcass leanness in cattle fed in confinement for slaughter for a period of 20-40 consecutive days before withdrawal from the feed. Zilpaterol hydrochloride has not been previously reviewed by the Committee.

Zilpaterol hydrochloride should be mixed into the feed at a level of $7.5 \mathrm{mg} / \mathrm{kg}$ on a $90 \%$ dry matter basis. This level in the feed is designed to treat the animals with approximately $0.15 \mathrm{mg}$ zilpaterol hydrochloride/ $\mathrm{kg}$ bw or $60-90 \mathrm{mg}$ zilpaterol hydrochloride per animal per day. The product Zilmax ${ }^{\circledR}$ is not permitted for use in lactating dairy cattle. Where information on authorized uses was provided, withdrawal periods ranged from 2 to 4 days.

Studies conducted in rats, swine and cattle demonstrated that the metabolism was qualitatively and quantitatively comparable in these three species following oral administration of zilpaterol hydrochloride, with two major metabolites, deisopropylzilpaterol and hydroxy-zilpaterol, together with the parent zilpaterol free base being observed. The drug is readily absorbed and the parent compound and metabolites are readily eliminated, primarily in the urine $(80 \%$ in cattle, $85 \%$ in swine and $50 \%$ in rats) with the remainder in the faeces. Unchanged parent compound is the main compound excreted in the urine of these three species. Zilpaterol residue concentrations were approximately 4 to 8 times higher than those of the only significant metabolite, deisopropyl-zilpaterol, in tissues and urine. In rat faeces, the major metabolite is the hydroxyl-zilpaterol. A metabolism study conducted in cattle with $\left[{ }^{14} \mathrm{C}\right]$ zilpaterol shows that radioactive residues are detectable in liver 8 days following a single oral dose of $0.2 \mathrm{mg} / \mathrm{kg} \mathrm{bw}$.

Radiolabelled residue depletion studies conducted in cattle after treatment at the 
recommended dose of $0.15 \mathrm{mg} / \mathrm{kg}$ bw/day demonstrated that a steady state is achieved in 12 days of treatment. However, the data available from these studies was from a limited number of animals and only provided a depletion curve of total residue for a period limited to $96 \mathrm{~h}$ post-dose. No residues were detected in fat after 12 hours and no residues were detected in muscle after 24 hours. Residues were detected in liver and kidney at $96 \mathrm{~h}$ postdose. Extractable residues account for $24-58 \%$ of total residues in liver, whereas residues in muscle are approximately $100 \%$ extractable. Extractable residues in kidney vary between 28 and $90 \%$ between animals. The extractable fraction of the total residue in liver and kidney decreased with time, so that the ratios between zilpaterol and extractable residue in liver and kidney decrease with time, as do the ratios between zilpaterol and total residue in liver and kidney.

A bio-availability study conducted with cannulated rats using liver containing incurred residues of $\left[{ }^{14} \mathrm{C}\right]$ zilpaterol, obtained from treated animals, demonstrated that less than $3 \%$ of the bound residues in liver were absorbed and considered to be biologically available. The bio-availability of non-extractable residues in kidney and muscle was not determined.

The residue data provided are insufficient to identify a marker residue correlated with the total residue depletion curve observed in liver and kidney after a period of 4 days. The LOQs of the analytical methods used in the depletion studies submitted by the Sponsor were insufficient to provide the data required to calculate an estimated daily intake and the percentile concentrations associated with the depletion curves used for the recommendation of MRLs. MRLs based on the method LOQ of $2 \mu \mathrm{g} / \mathrm{kg}$, if used to recommend MRLs for muscle and fat, would result in an EDI or TMDI that exceeds the upper bound of the ADI. The validated methods provided by the Sponsor were considered to have an inadequate LOQ for effective residue control of zilpaterol.

\section{Maximum Residue Limits}

In recommending MRLs for zilpaterol, the Committee considered the following factors:

- An ADI of 0-0.04 $\mu \mathrm{g} / \mathrm{kg}$ bw for zilpaterol was established by the Committee, corresponding to an upper bound of acceptable intake of $2.4 \mu \mathrm{g} /$ day for a $60 \mathrm{~kg}$ person.

- Zilpaterol $\mathrm{HCl}$ is registered to be mixed into feed at a level of $7.5 \mathrm{mg} / \mathrm{kg}$ on a $90 \%$ dry matter basis. This level is designed to treat animals with approximately $0.15 \mathrm{mg} / \mathrm{kg}$ bw or 60-90 mg zilpaterol $\mathrm{HCl}$ per animal per day.

- Where information on authorized uses was provided, withdrawal periods ranged from 2 to 4 days.

- Zilpaterol $\mathrm{HCl}$ is not permitted for use in lactating dairy cattle.

- Zilpaterol has two major metabolites: deisopropyl zilpaterol (tissues and urine) and hydroxy-zilpaterol (faeces).

- The Committee agreed that parent zilpaterol was an appropriate marker residue in muscle. Only limited data were available for tissues other than muscle, and the Committee was unable to determine a suitable marker residue in other edible tissues. Liver and kidney contained the highest concentration of zilpaterol at all sampling times, followed by muscle. The data provided are not sufficient to determine the total residue half-life in the liver after 96 hours. There are no measurable residues in adipose fat.

- The ratios of the concentration of zilpaterol to the concentration of the total residues for liver and for kidney over the 96-hour withdrawal period after the last drug administration could not be determined with any confidence due to the very limited data available and lack of sensitivity of the methods used.

- The ratio of zilpaterol to total radioactive residues in muscle is approximately $50 \%$. 
- The analytical methods used in the depletion studies do not allow the characterization of the pharmacokinetics at times when, even at the LOQ, the concentrations are not compatible with dietary exposures below the ADI, particularly in liver.

A marker residue could not be established in any edible tissue other than muscle, and the Committee concluded that an appropriate marker residue for other tissues should be identified. In the absence of an appropriate marker residue for liver and kidney, a marker residue to total residue ratio could not be established for these tissues.

The Committee used the highest concentrations of total residues to estimate dietary exposure, because no median residue levels could be determined and no marker residue in liver and kidney was defined. These highest concentrations of extractable radioactivity, expressed as zilpaterol equivalent, were 1.0, 28.6 and $5.4 \mu \mathrm{g} / \mathrm{kg}$ at 96 hours for muscle, liver and kidney, respectively. These calculations indicated that the dietary exposure was higher than the ADI for the withdrawal times for which data were provided. It was also noted that the ADI is based on an acute end-point and is applicable to both acute and chronic exposure.

The Committee concluded that it was not possible to recommend MRLs for zilpaterol. The following data are needed to establish MRLs:

- results from studies investigating marker residue in liver and kidney;

- results from studies determining marker residue to total residue ratio in liver and kidney; and

- results from depletion studies to enable the derivation of MRLs compatible with the ADI.

All such studies should use sufficiently sensitive, validated analytical methods capable of measuring zilpaterol and its major metabolites in edible tissues of cattle.

\section{References}

Blanca, J., Muñoz, P., Morgado, M., Méndez, N., Aranda, A., Reuvers, T. \& Hooghuis, H. 2005. Determination of clenbuterol, ractopamine and zilpaterol in liver and urine by liquid chromatography tandem mass spectrometry. Analytica Chimica Acta, 529(1-2): 199-205.

Bocca, B., Di Mattia, M., Cartonia, C., Fioria, M., Felli, M., Neri, B. \& Brambilla, G. 2003a. Extraction, clean-up and gas chromatography-mass spectrometry characterization of zilpaterol as feed additive in fattening cattle. Journal of Chromatography B, 783(1): 141-149.

Bocca, B., Fiori, M., Cartoni, C. \& Brambilla, G. 2003b. Simultaneous determination of Zilpaterol and other beta agonists in calf eye by gas chromatography/tandem mass spectrometry. Journal of AOAC International, 86(1): 8-14.

Chevolleau, S. 2004. A first approach for metabolism of 14C-RU 42173 (zilpaterol hydrochloride) in swine. Unpublished report of study No. XLB/04/ZILPAPIG from INRA-Laboratoire des Xénobiotiques, 180 chemin de tournefeuille, 31931 Toulouse, France. Document No. V-0238-0176 submitted to FAO by MSD Animal Health.

Crouch, L. 2011a. Tissue residue depletion of zilpaterol in cattle administered zilpaterol hydrochloride (Zilmax) orally via component feeding. Unpublished report of study No. N09-087-01, Midwest Veterinary Services, Inc (MVS), Oakland NE, USA. Document No. Report V-0238-0271 submitted to FAO by MSD Animal Health.

Crouch, L. 2011b. Tissue residue depletion of zilpaterol in cattle administered zilpaterol hydrochloride (Zilmax) orally via a pelleted Type C top dress supplement. Unpublished report of study No. N09086-01, Midwest Veterinary Services, Inc (MVS), Oakland NE, USA. Document No. Report V-02380270 submitted to FAO by MSD Animal Health. 
Girkin, R. 1999. ${ }^{14} \mathrm{C}$-Zilpaterol: Bioavailability in the rat of liver non-extractable residues from cattle. Unpublished report of study No HST 456/993307 from Huntingdon Research Centre Ltd., Cambridgeshire, PE18 6ES, England. Document No. V-0238-0152, submitted to FAO by MSD Animal Health.

Hughes, D.L. \& Halverson, R.J. 2000. Storage stability of the marker residues, zilpaterol hydrochloride, in bovine liver, muscle and kidneys tissues. Unpublished report of HRV study No. V99.116, Covance Study No. 6187-174 from Covance Laboratories Inc. Madison, WI 53707, USA. Document No. V-0238-0150, submitted to FAO by MSD Animal Health.

Hughes, D.L., McDonald, F.B.W. \& Bomkamp, D. D. 1999. Tissue residue depletion study in cattle administered zilpaterol hydrochloride orally via medicated feed for 12 days. Unpublished report of study No. 6187-173. Covance Laboratories Inc., Waunakee and Madison, WI 53597 and WI 53704, USA. Document No. V-0238-0006.

Nandihalli, U.B., Hughes, D.L. \& Bomkamp, D.D. 1999. Validation of a determinative assay for zilpaterol residue in cattle liver, kidney and muscle. Unpublished report of HRV study No. HRV V98.116, Covance study No 6178-172 from Covance Laboratories Inc., Madison, WI 53704, USA. Document No. V-0238-0149, submitted to FAO by MSD Animal Health.

Sauvez, F. 1993. Pilot pharmacokinetic study (absorption assessment) after single administration by oral route (gavage) in Yucatan microswine. Unpublished report of study No. 10577 PAN from Centre International de Toxicologie (C.I.T.), Miserey, 27005 Evreux, France. Document No. V-02380123, submitted to FAO by MSD Animal Health.

Sauvez, F. 1995. Comparative study of pharmacokinetics in plasma after repeated oral administration for 2 weeks (dietary admixture or gavage) in rats (orientating study). Unpublished report of study No. 11557 PSR from Centre International de Toxicologie (C.I.T.), Miserey, 27005 Evreux, France. Document No. V-0238-0213 submitted to FAO by MSD Animal Health.

Shelver, W.L. and Smith, D.J. 2011. Immunochemical-based zilpaterol measurement and validation in urine and tissues. Food and Agricultural Immunology, 22(3): 247-258.

Stachel, C.S., Radeck, W. \& Gowik, P. 2003. Zilpaterol - a new focus of concern in residue analysis. Analytica Chimica Acta, 493: 63-67.

Sutton, J.A. and Budhram, R. 1987. An ascending dose tolerance study of RU 42173 including an exploration of pharmacodynamics dose-response characteristics. Unpublished report of study No. SWIN/287/173 (GB/87/173/02) from Clinical pharmacology unit, Roussel Laboratories Ltd, Covingham, Swindon, SN3 5BZ, UK, submitted to WHO by MSD Animal Health.

Tremblay, D. \& Mouren, M. 1988. RU 42173 plasma concentrations obtained during a study of clinical pharmacology at single increasing doses (GB/87/173/02). Unpublished report of study No. 88/886/CN from Direction of Health Development, Roussel UCLAF, 93235 Romainville, France, submitted to WHO by MSD Animal Health.

Tremblay, D., Biechler, J.C. \& Cousty, C. 1990b. RU 42173 - in vitro binding to rat serum proteins. Unpublished report of study No. 90/1782//CN from Direction of preclinical development, Roussel UCLAF, 93235 Romainville, France. Document No. V-0238-0282 submitted to FAO by MSD Animal Health.

Tremblay, D., Biechler, J.C. \& Cousty, C. 1990d. RU 42173 - in vitro binding to dog serum proteins. Unpublished report of study No. 90/2123/CN from Direction of preclinical development, Roussel UCLAF, 93235 Romainville, France. Document No. V-0238-0285 submitted to FAO by MSD Animal Health.

Tremblay, D., Coussediere, D., Biechler, J.C. \& Audegond, L. 1988. 14C-RU 42173 Biological stability of the Carbon 14-labelled molecule. Unpublished report of study No. 88/788/CN from Direction of Health Development, Roussel UCLAF, 93235 Romainville, France. Document No. V-0238-0103 submitted to FAO by MSD Animal Health.

Tremblay, D., Chatelet, P., Cousty, C., Biechler, J.C. \& Audegond, L. 1989. RU 42173 Tissue distribution of ${ }^{14} \mathrm{C}-\mathrm{RU} 42173$ in the male and female rat after oral administration. Unpublished report of study No. 89/1147/CN from Direction of Health Development, Roussel UCLAF, 93235 Romainville, France. Document No. V-0238-0211 submitted to FAO by MSD Animal Health. 
Tremblay, D., Cousty, C., Biechler, J.C. \& Audegond, L. 1990a. RU 42173 - urinary excretion of the unchanged substance following intravenous or oral administration of a single oral dose of $1 \mathrm{mg} . \mathrm{kg}$ ${ }^{1}$ in rats. Unpublished report of study No. 90/1783/CN from Health development division of Roussel UCLAF, 93235 Romainville, France. Document No. V-0238-0283, submitted to FAO by MSD Animal Health.

Tremblay, D., Cousty, C., Biechler, J.C. \& Audegond, L. 1990c. RU 42173 - urinary excretion of the unchanged substance following intravenous or oral administration of a single oral dose of $1 \mathrm{mg} . \mathrm{kg}$ ${ }^{1}$ in dog. Unpublished report of study No. 90/1950/CN from Health development division of Roussel UCLAF, 93235 Romainville, France. Document No. V-0238-0284, submitted to FAO by MSD Animal Health.

Tulliez, J. 1992. Metabolism and residue study of ${ }^{14} \mathrm{C}$-RU 42173 in the cattle (steer and heifer) after single oral administration. Unpublished report of study No. 90/01/XL from INRA-Laboratoire des Xénobiotiques, 180 chemin de tournefeuille, 31931 Toulouse, France. Document No. V-0238-0104, submitted to FAO by MSD Animal Health.

Tulliez, J. 1999. ${ }^{14}$ C-RU 42173 (zilpaterol hydrochloride) pivotal residue depletion study in steers and heifers. Unpublished report of study No. XL/97/RU42173/01 from INRA-Laboratoire des Xénobiotiques, 180 chemin de tournefeuille, 31931 Toulouse, France. Document No. V-0238-0158, submitted to FAO by MSD Animal Health.

Tulliez, J. 2000a. Metabolic fate of ${ }^{14} \mathrm{C}$-RU 42173 (zilpaterol hydrochloride) in the Wistar rat. Unpublished report of study No. 92/01/XL from INRA-Laboratoire des Xénobiotiques, 180 chemin de tournefeuille, 31931 Toulouse, France. Document No. V-0238-0107 submitted to FAO by MSD Animal Health.

Tulliez, J. 2000b. Metabolic fate of ${ }^{14} \mathrm{C}$-RU 42173 (zilpaterol hydrochloride) in the Sprague Dawley rat. Unpublished report of study No. 96/01/XL from INRA-Laboratoire des Xénobiotiques, 180 chemin de tournefeuille, 31931 Toulouse, France. Document No. V-0238-0112, submitted to FAO by MSD Animal Health.

Tulliez, J. 2000c. Metabolism and residue study of ${ }^{14} \mathrm{C}-\mathrm{RU} 42173$ in the cattle (steer and heifer) after single oral administration. Unpublished additional report of study No. 90/01/XL from INRALaboratoire des Xénobiotiques, 180 chemin de tournefeuille, 31931 Toulouse, France. Document No. V-0238-0105, submitted to FAO by MSD Animal Health.

Tulliez, J. 2000d. Pilot steady state study of ${ }^{14} \mathrm{C}-\mathrm{RU} 42173$ steer and heifer. Unpublished report of study No. 94/03/XL from INRA-Laboratoire des Xénobiotiques, 180 chemin de tournefeuille, 31931 Toulouse, France. Document No. V-0238-0109, submitted to FAO by MSD Animal Health.

Van Hoof, N., Schilt, R., Van der Vlis, E., Boshuis, P., Van Baak, M., Draaijer, A., De Wasch, K., Van de Wiele, M., Van Hende, J., Courtheyn, D. \& De Brabander, H. 2005. Detection of zilpaterol $\left(\right.$ Zilmax $\left.^{\circledR}\right)$ in calf urine and faeces with liquid chromatography-tandem mass spectrometry. Analytica Chimica Acta, 529: 189-197.

Wrzesinski, C. 2012. Validation of LC-MS/MS determinative and confirmatory procedures for zilpaterol in bovine liver and muscle. Unpublished report of study No. S10159-00-ZIL-ANA-RM from Global preclinical development, BA-US, Intervet Inc., Summit, NJ 07901, USA. Document No. V-0238-0281 \& V-0238-0281-rawdata, submitted to FAO by MSD Animal Health.

Veltz, J.N. 1999. Synthesis of $\left[{ }^{14} \mathrm{C}\right]$-zilpaterol $\mathrm{HCl}$, radio-synthesis and quality control report. Unpublished report of study No. V-0238-0009 from Laboratoire de marquage isotopique (LMI) Hoechst Marion Roussel, 93235 Romainville, France. Doc. No. V-0238-0009, submitted to WHO by MSD Animal Health.

Zalko, D. 1993. Metabolism of zilpaterol (RU 42173) in vivo in the rat and by hepatic microsome fractions. Biochemical and toxicological implications. Unpublished mémoire of National D.E.A. of toxicology conducted at INRA-Laboratoire des Xénobiotiques, 180 chemin de tournefeuille, 31931 Toulouse, France. Document No. V-0238-0216, submitted to FAO by MSD Animal Health. 



\section{Annex 1 - Summary of JECFA evaluations of veterinary drug residues from the 32nd Meeting to the present}

The following table summarizes the veterinary drug evaluations conducted by JECFA at the 32nd (1987), 34th (1989), 36th (1990), 38th (1991), 40th (1992), 42nd (1994), 43rd (1994), 45th (1995), 48th (1997), 50th (1998), 52nd (1999), 54th (2000), 58th (2002), 60th (2003), 62nd (2004), 66th (2006), 70th (2008) and 75th (2011) Meetings. These meetings were devoted exclusively to the evaluation of veterinary drug residues in food. This table must be considered in context with the full reports of these meetings, published in the WHO Technical Report Series.

Some notes regarding the table:

- The "ADI Status" column refers to the ADI and indicates whether an ADI was established, if a full ADI was given, or if the ADI is temporary (T).

- Where an MRL is temporary, it is indicated by " $\mathrm{T}$ ".

- Where a compound has been evaluated more than once, the data given are for the most recent evaluation, including the 78th Meeting of the Committee. 


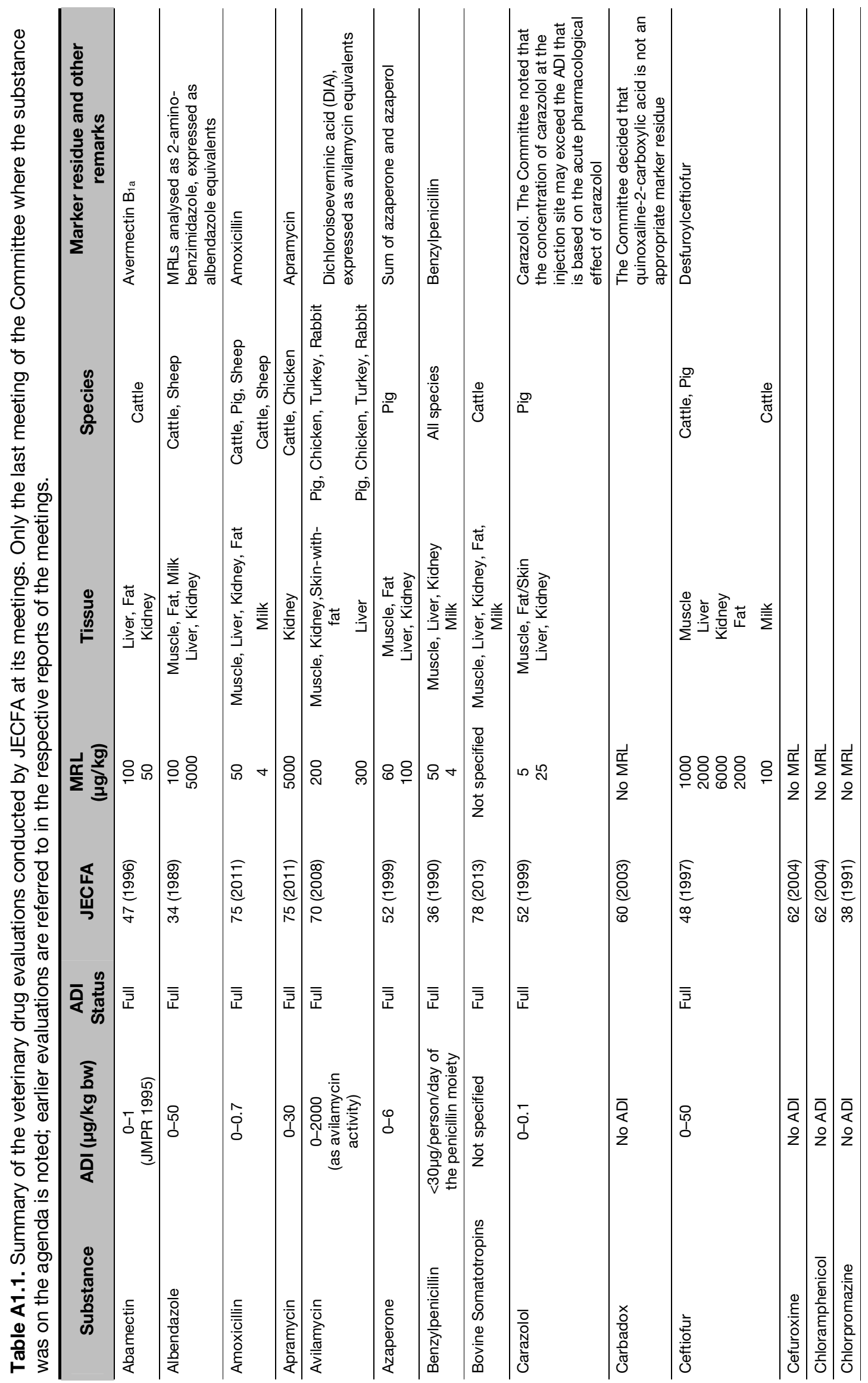




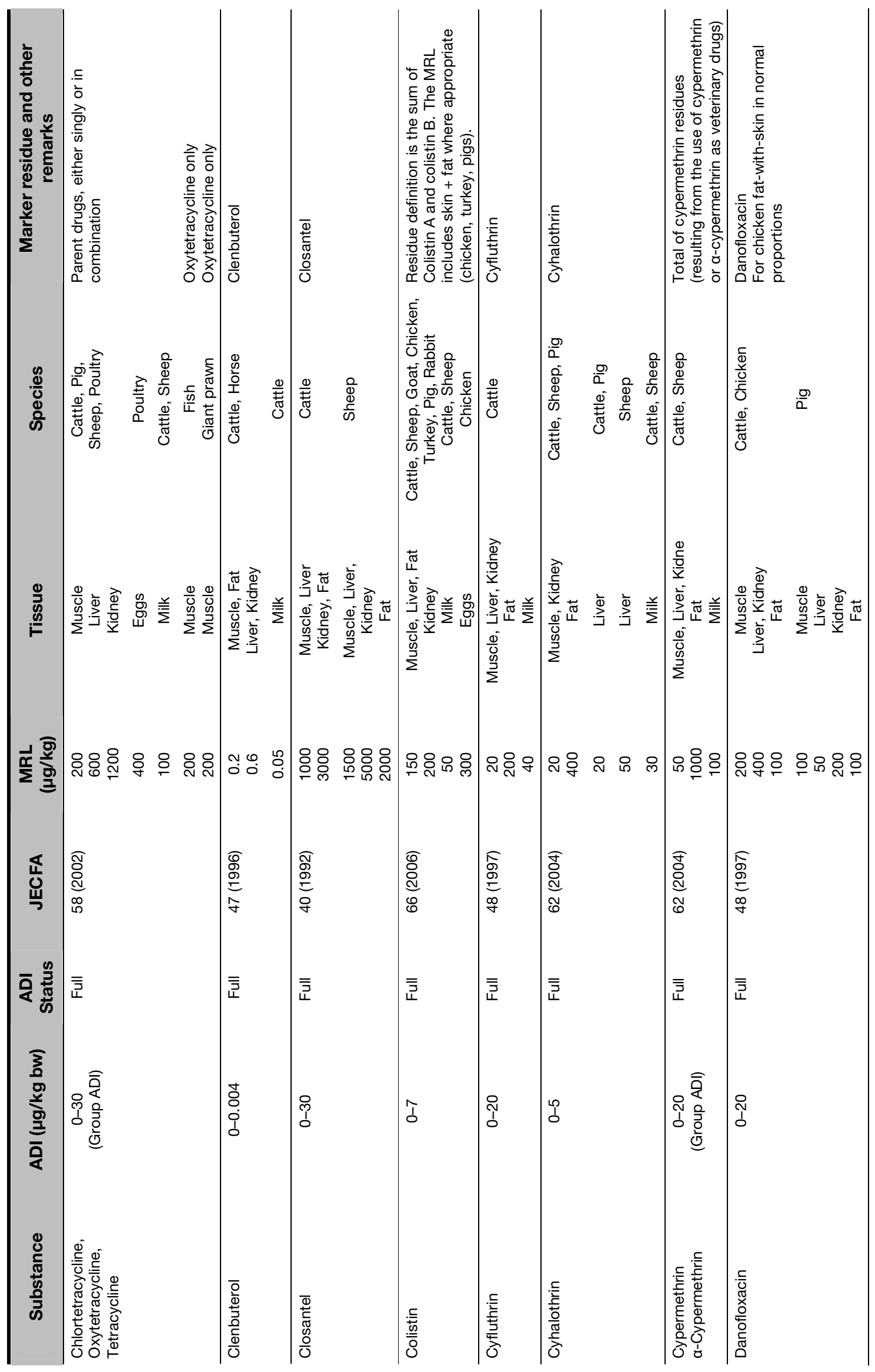




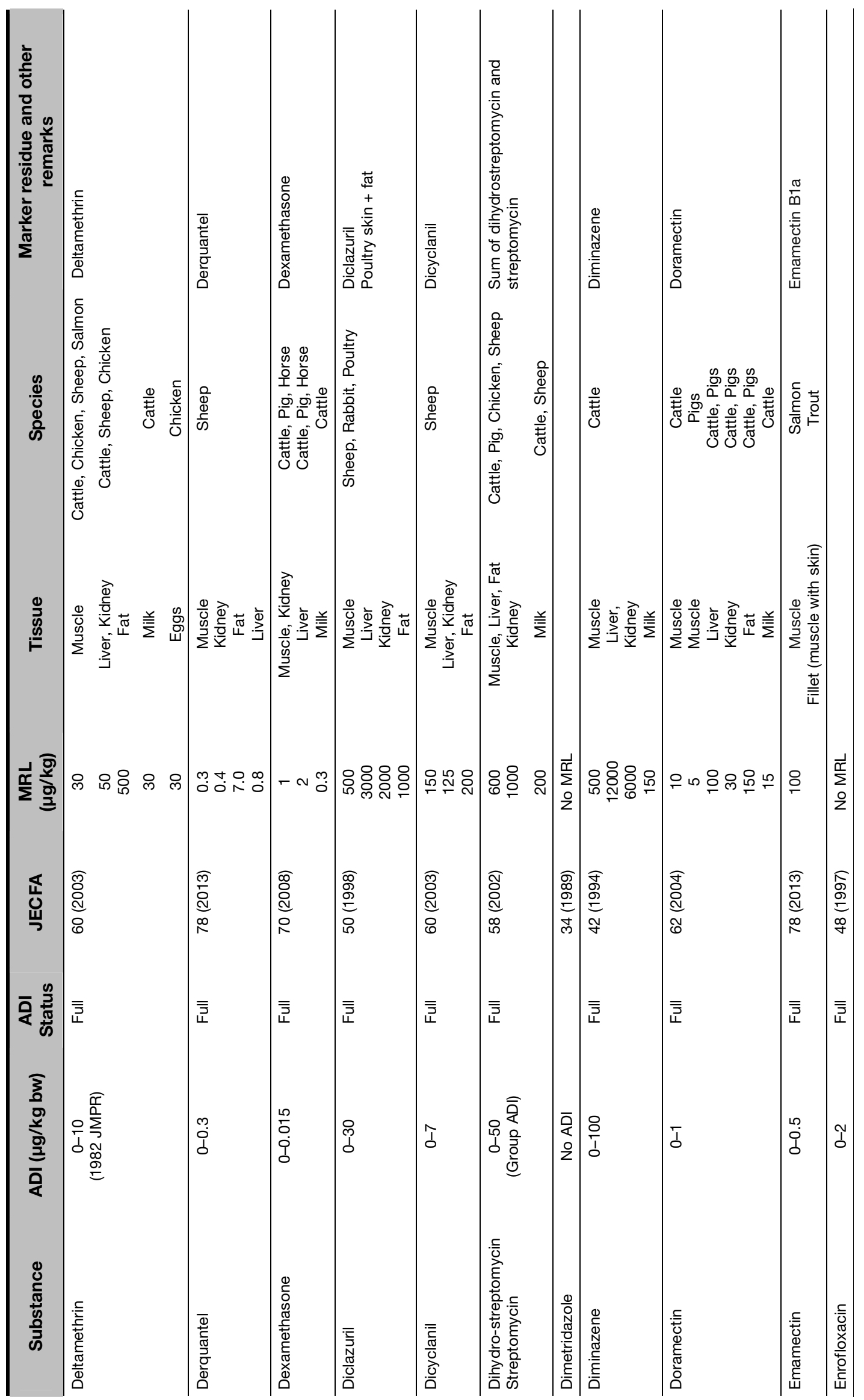




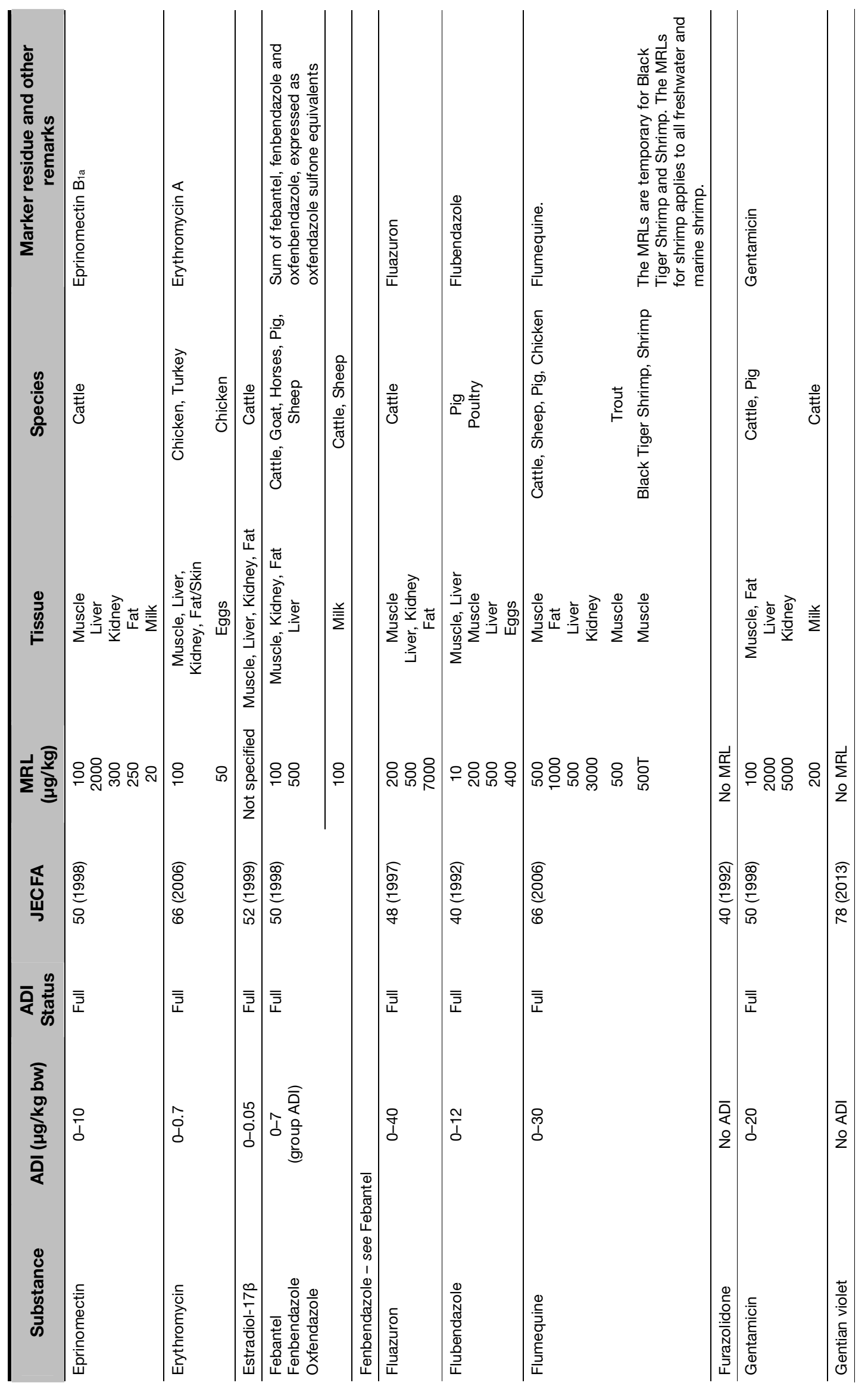




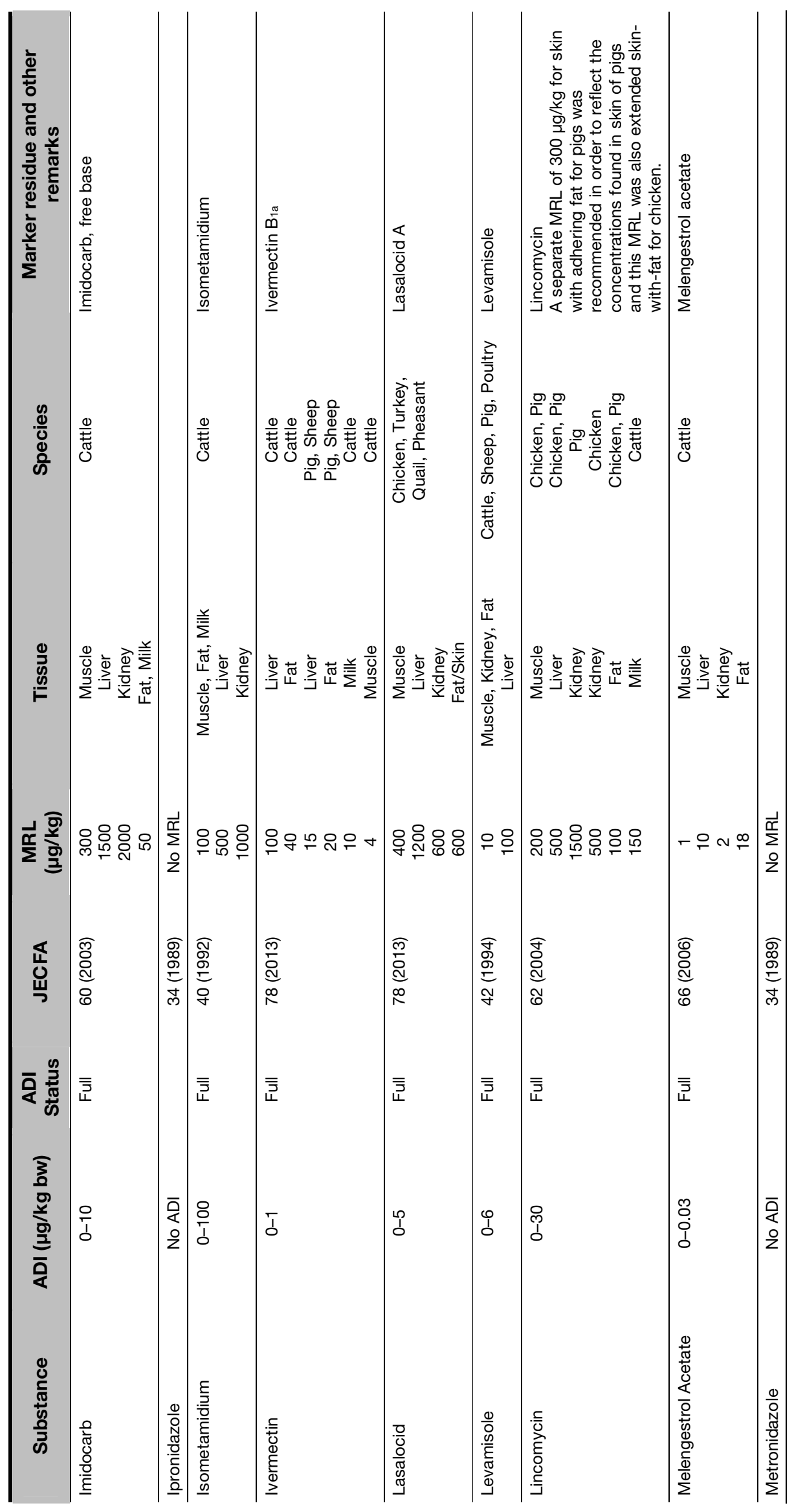




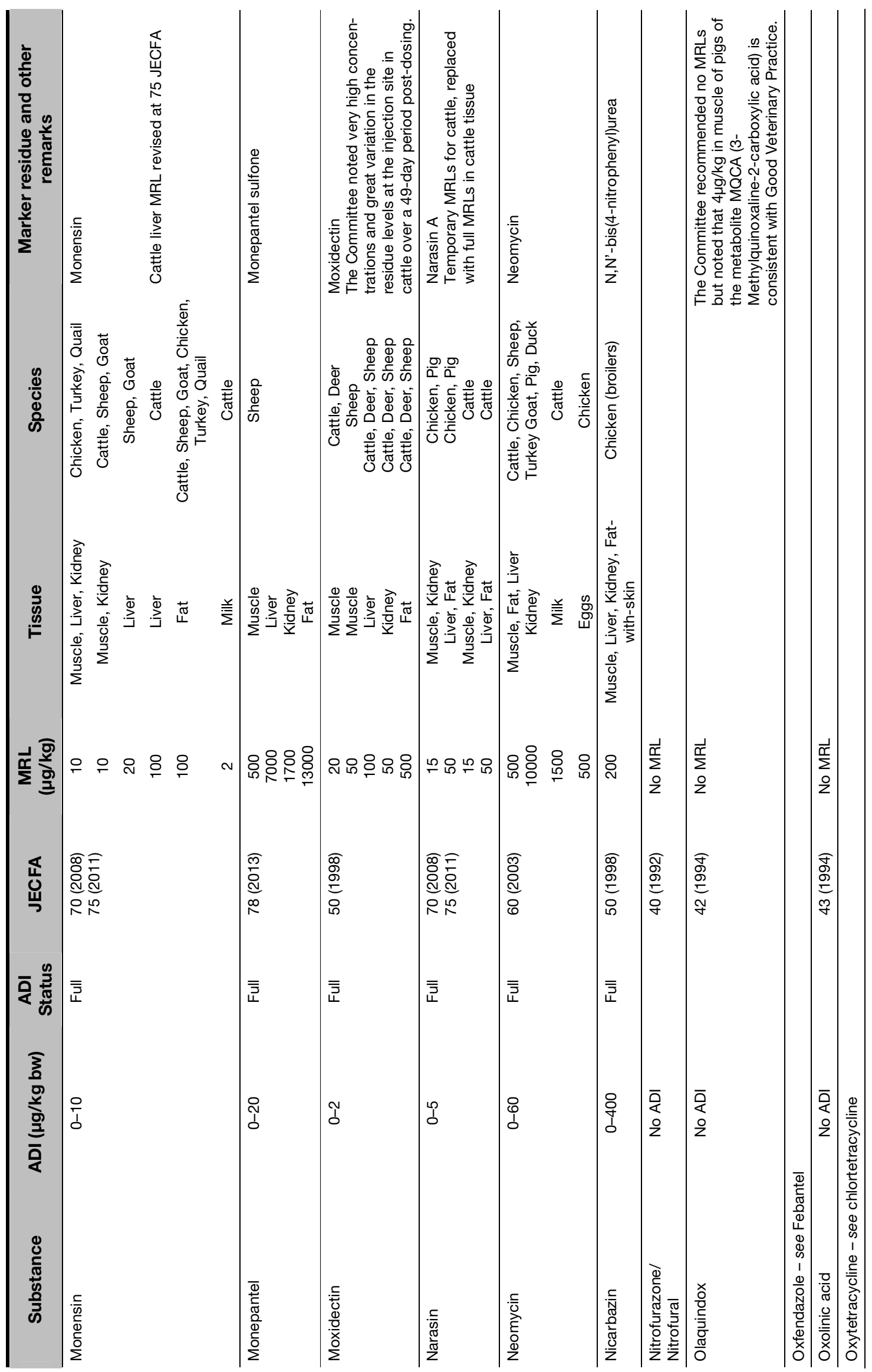




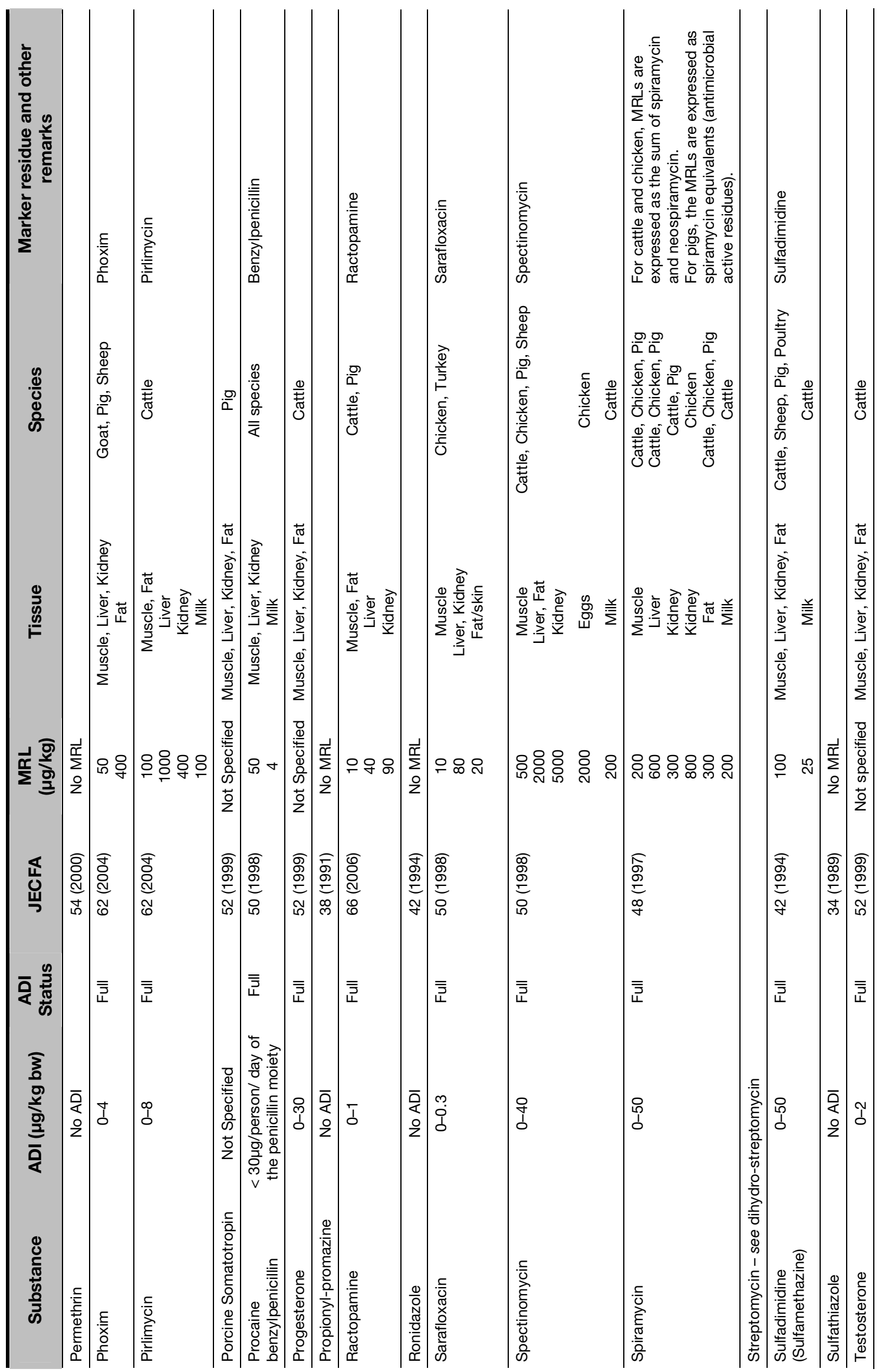




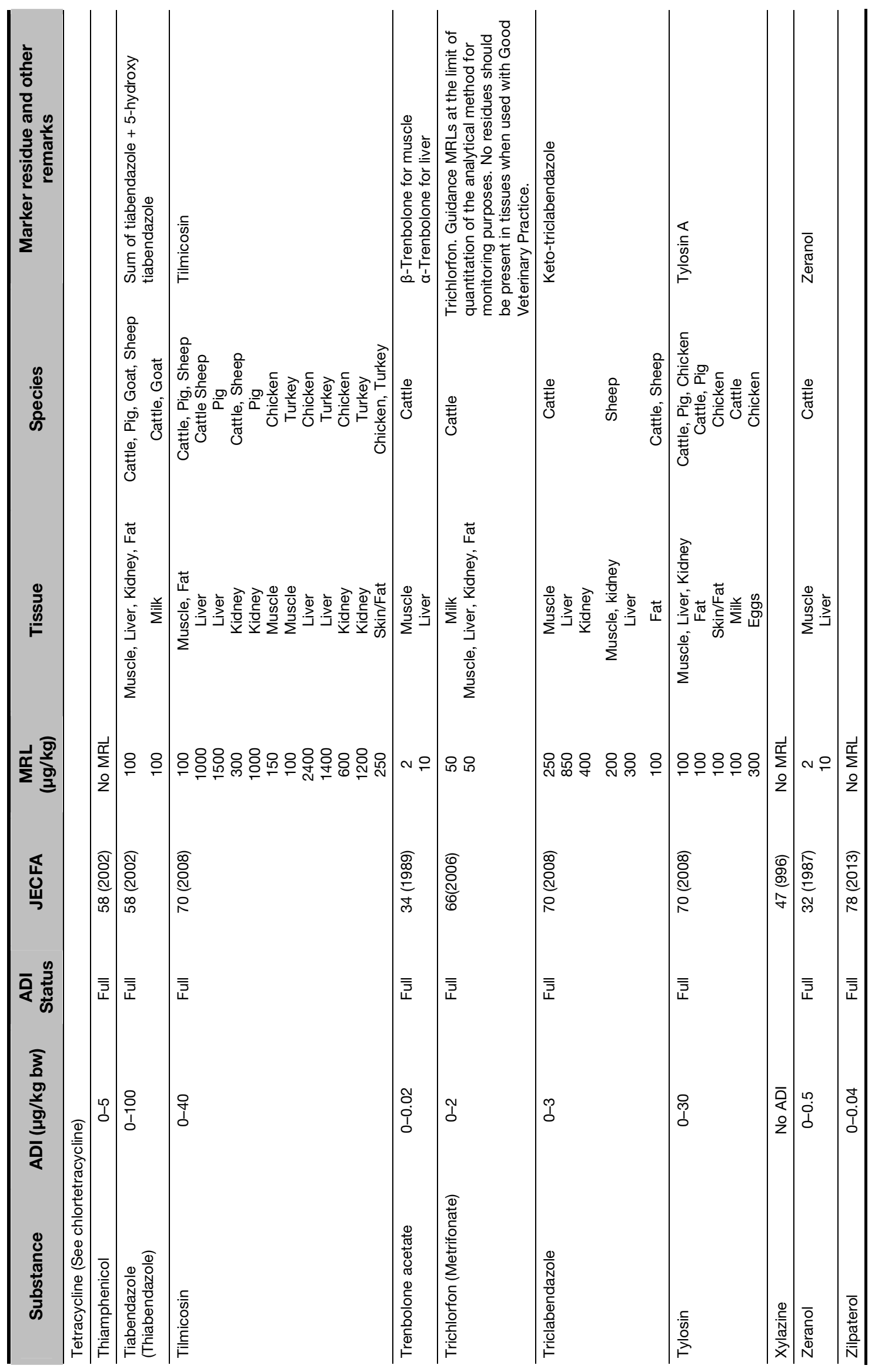





\section{Annex 2-Summary of Recommendations from the 78th JECFA on Compounds on the Agenda and Further Information Required}

\section{Derquantel (anthelminthic agent)}

Acceptable daily intake: The Committee maintained the ADI of $0-0.3 \mu \mathrm{g} / \mathrm{kg}$ bw established at its Seventy-fifth Meeting (JECFA, 2012 [TRS 969]).

Residue definition: Derquantel

Recommended maximum residue limits (MRLs) for Derquantel

\begin{tabular}{ccccc}
\hline Species & Fat $(\boldsymbol{\mu g} / \mathbf{k g})$ & Kidney $(\boldsymbol{\mu g} / \mathbf{k g})$ & Liver $(\boldsymbol{\mu g} / \mathbf{k g})$ & Muscle $(\boldsymbol{\mu g} / \mathbf{k g})$ \\
\hline Sheep & 7.0 & 0.4 & 0.8 & 0.3 \\
\hline
\end{tabular}

Emamectin benzoate (antiparasitic agent)

Acceptable daily intake: The Committee confirmed the ADI of $0-0.0005 \mathrm{mg} / \mathrm{kg}$ bw established by the Joint FAO/WHO Meeting on Pesticide Residues in 2011 (FAO/WHO, 2011).

Residue definition: Emamectin B1a

Recommended maximum residue limits (MRLs) ${ }^{(1)}$ for

\begin{tabular}{ccc}
\hline Species & Muscle $(\boldsymbol{\mu g} / \mathbf{k g})$ & Fillet $^{(2)}(\boldsymbol{\mu g} / \mathbf{k g})$ \\
\hline Salmon & 100 & 100 \\
Trout & 100 & 100 \\
\hline
\end{tabular}

NOTES: (1) MRLs for salmon were extended to trout. (2) Fillet is muscle with adhering skin.

\section{Gentian violet (antibacterial, antifungal and anthelminthic agent)}

Acceptable daily intake: The Committee concluded that it is inappropriate to set an ADI for gentian violet because it is genotoxic and carcinogenic.

Residues: MRLs could not be recommended by the Committee, as it was not considered appropriate to establish an ADI. The Committee also noted that there was limited information on residues.

\section{Ivermectin (antiparasitic agent)}

Acceptable daily intake: $0-1 \mu \mathrm{g} / \mathrm{kg}$ bw (established at the Fortieth Meeting of the Committee, JECFA, 1993 [TRS 832]).

Residue definition: Ivermectin B1a

Recommended maximum residue limits (MRLs) ${ }^{(1)}$ for Ivermectin B1a

\begin{tabular}{cc}
\hline Species & Muscle $(\boldsymbol{\mu g} / \mathbf{k g})$ \\
\hline Cattle & 4 \\
\hline
\end{tabular}

NOTES: (1) MRL based on $2 \times L O Q$ of analytical method. 


\section{Lasolocid sodium (antibiotic)}

Acceptable daily intake: The Committee established an ADI of $0-5 \mu \mathrm{g} / \mathrm{kg} \mathrm{bw}$.

Residue definition: Lasalocid A

Recommended maximum residue limits (MRLs) ${ }^{(1)}$ for Lasalocid $A$

\begin{tabular}{ccccc}
\hline Species & Skin + fat $(\boldsymbol{\mu g} / \mathbf{k g})$ & Kidney $(\boldsymbol{\mu g} / \mathbf{k g})$ & Liver $(\boldsymbol{\mu g} / \mathbf{k g})$ & Muscle $(\boldsymbol{\mu g} / \mathbf{k g})$ \\
\hline Chicken & 600 & 1200 & 600 & 400 \\
Turkey & 600 & 1200 & 600 & 400 \\
Quail & 600 & 1200 & 600 & 400 \\
Pheasant & 600 & 1200 & 600 & 400 \\
\hline
\end{tabular}

NOTES: (1) The MRLs in chicken were extended to turkeys and quail, and extrapolated to pheasants, No information was available for ducks, including approved uses. According to the sponsor, the compound is not registered for use in laying hens. Therefore it is not appropriate to recommend MRLs for eggs.

\section{Monepantel (anthelminthic)}

Acceptable daily intake: $0-20 \mu \mathrm{g} / \mathrm{kg}$ bw (established by the Seventy-fifth Meeting of the Committee, JECFA, 2012 [TRS 932]).

Residue definition: Monepantel sulfone, expressed as monepantel

Recommended maximum residue limits (MRLs) for Monepantel sulfone, expressed as monepantel

\begin{tabular}{ccccc}
\hline Species & Fat $(\boldsymbol{\mu g} / \mathbf{k g})$ & Kidney $(\boldsymbol{\mu g} / \mathbf{k g})$ & Liver $(\boldsymbol{\mu g} / \mathbf{k g})$ & Muscle $(\boldsymbol{\mu g} / \mathbf{k g})$ \\
\hline Sheep & 13000 & 1700 & 7000 & 500 \\
\hline
\end{tabular}

\section{Recombinant bovine somatotrophins (growth hormone)}

Acceptable daily intake: The Committee re-affirmed the decision on ADIs as "not specified" for somagrebove, sometribove, somavubove and somidobove (established at the Fortieth Meeting of the Committee, JECFA, 1993 [TRS 832]).

Residues: The Committee re-affirmed its previous decision on MRLs as "not specified" for somagrebove, sometribove, somavubove and somidobove (established at the Fortieth Meeting of the Committee, JECFA, 1993 [TRS 832]).

\section{Zilpaterol hydrochloride ( $\beta 2$-adrenoceptor agonist)}

Acceptable daily intake: The Committee established an ADI of $0-0.04 \mu \mathrm{g} / \mathrm{kg} \mathrm{bw}$. The Committee noted that the ADI is based on an acute effect.

Residue definition: Zilpaterol (in muscle). The Committee was unable to determine a suitable marker residue in other edible tissues.

Maximum residue limits: The Committee concluded that it was not possible to recommend MRLs for zilpaterol and that the following information is needed to establish MRLs:

- studies to investigate marker residue in liver and kidney;

- studies to determine marker residue to total residue ratio in liver and kidney; and

- results from depletion studies to enable the derivation of an MRL compatible with the ADI using sufficiently sensitive validated analytical methods capable of measuring zilpaterol and its major metabolites in edible tissues of cattle. 


\section{References}

FAO/WHO. 2011. Pesticide residues in food 2011. Joint FAO/WHO Meeting on Pesticide Residues. Report of the Joint Meeting of the FAO Panel of Experts on Pesticide Residues in Food and the Environment and the WHO Core Assessment Group on Pesticide Residues, Geneva, Switzerland, 20-29 September 2011. FAO Plant Production and Protection Paper, No. 211. Available at http://www.fao.org/fileadmin/templates/agphome/documents/Pests_Pesticides/JMPR/Report 11/JMPR_2011_Report.pdf Accessed 2014-06-05.

JECFA. 2012. Evaluation of certain veterinary drug residues in food (Seventy-fifth report of the Joint FAO/WHO Expert Committee on Food Additives). WHO Technical Report Series, No. 969. Available at: http:/ / whqlibdoc.who.int/ publications /2012/9789241209694_eng.pdf?ua=1 Accessed 2014-0515.

JECFA. 1993. Evaluation of certain veterinary drug residues in food (Fortieth report of the Joint FAO/WHO Expert Committee on Food Additives). WHO Technical Report Series, No. 832. Available at http://whqlibdoc.who.int/trs/WHO_TRS_832.pdf?ua=1 Accessed 2014-05-15. 



\title{
Annex 3 - Pilot of new approaches to estimate dietary exposure to veterinary drug residues
}

\author{
First draft prepared by \\ Rainer Reuss, Barton, ACT, Australia
}

\section{Introduction}

At its 70th Meeting, the Committee identified a need for further work to refine chronic and acute exposure assessments for veterinary drug residues in foods for integration into the decision-tree approach (JECFA, 2009 [TRS 954]). The 18th and 19th Sessions of the Codex Committee on Residues of Veterinary Drugs in Foods (CCRVDF), in response to the statement by JECFA, requested FAO and WHO to convene an expert consultation on exposure assessment methodologies for residues of veterinary drugs in foods (FAO/WHO, 2009a, 2011a) to:

- review the current model diet (so-called market basket approach) applied by JECFA;

- consider possible simplification of the current model diet;

- investigate the possible development of several model diets to reflect regional differences in consumption patterns; and

- develop approaches for acute and sub-chronic dietary exposure assessment.

FAO and WHO issued a Call for Data on consumption of foods of animal origin in 2010 (FAO/WHO, 2010) and received food consumption data from 47 countries and a submission from an interested party. Subsequently, an expert meeting on dietary exposure assessment of veterinary drug residues in foods took place at FAO in Rome from 7 to 11 November 2011, which included participation by the attendees at the 75th Meeting of JECFA. Opinions were also sought from an open stakeholder meeting in Rome on 7 November 2011.

The report prepared by the experts on exposure assessment proposed new approaches for acute and chronic dietary exposure assessment for veterinary drug residues, taking the key findings, concerns and recommendations of the stakeholders into consideration (FAO/WHO, 2011b). Discussions and exchanges between participants at both the meeting on dietary exposure assessment methodologies and the 75th JECFA provided some examples to compare the exposure models used by JECFA with the proposed new models for dietary exposure. These were further discussed, with the outcome that the final report of the expert consultation should be further considered at a future meeting of JECFA, with input from the CCRVDF (JECFA, 2012 [TRS 969]).

The Report of the 75th JECFA noted that acute dietary exposure estimates should cover a time-period of food consumption over a single meal (i.e. a single eating occasion) or 1 day and are intended to be used for comparison with acute reference dose (ARfD) values in a risk assessment process. The Committee emphasized that, depending on the health end-points for acute risk, acute exposure should be estimated for both the general population and children. The report of the Joint FAO/WHO Expert Meeting on Dietary Exposure Assessment Methodologies for Residues of Veterinary Drugs noted that JECFA had not, as of the date of the report, developed principles for acute dietary exposure assessments (FAO/WHO, 2011b). The 75th JECFA report also noted that chronic dietary exposure estimates cover food consumption over the long term. Such estimates can be compared with a health-based guidance value based on chronic toxicity, such as an Acceptable Daily Intake (ADI), in a risk assessment process.

The 70th Meeting of the Committee confirmed that the median residue level from 
depletion studies with a correction for marker residue to total residue (the Estimated Dietary Intake, or EDI) would continue to be used in chronic exposure assessments for long-term dietary exposure estimates, when supported by the available data (JECFA, 2009 [TRS 954]). Only when median residue data are not available may the chronic exposure estimate be based on a calculation using the MRL with a correction for marker residue to total residue to calculate a Theoretical Maximum Daily Intake, or TMDI. It should also be noted that when data on bio-availability are available, a correction for bio-availability might also be used in the dietary exposure calculation (JECFA, 1989 [TRS 788]).

The report of the Joint FAO/WHO Expert Meeting on Dietary Exposure Assessment Methodologies for Residues of Veterinary Drugs (FAO/WHO, 2011b) proposed models to estimate both acute and chronic exposure to residues of veterinary drugs in food: the Global Estimate of Acute Dietary Exposure (GEADE) and the Global Estimate of Chronic Dietary Exposure (GECDE). The 75th JECFA noted that the proposed models use more detailed consumption data than the EDI. It also noted that comments on the draft report of the expert meeting would be sought from participants of the 75th Meeting of the Committee soon after the meeting and that, following consideration of these comments, a revised draft report would be prepared for public comments. The final report was discussed at the 20th Session of the CCRVDF. The expert report and comments from the CCRVDF would then be discussed at a future meeting of the Committee, at which time additional worked examples would be prepared using the GECDE and GEADE to provide more experience with their application.

\section{Purpose}

Following the outcomes and recommendations of the expert report, the 78th JECFA included a pilot study on use of the GEACDE and GEADE. The purpose of the study was to explore the new calculations for dietary exposure assessment, compare them with estimates calculated using the model diet approach, identify the practical impact of using the new methods and make recommendations for dietary exposure assessment at future meetings. Dietary exposures were estimated for four veterinary drug residues, using the model diet approach as well as the new methods for chronic and acute dietary exposure estimation.

The study is intended to pilot and explore the new calculations for dietary exposure assessment rather than forming part of the risk assessment per se. For example, acute exposures are calculated, even though ARfD have not been set for the chemicals included in the pilot study.

\section{Background}

\section{Theoretical maximum daily intake (TMDI)}

The initial approach to estimating dietary exposure, the TMDI, was adopted at the 34th Meeting of the Committee (JECFA, 1989 [TRS 788]). Using this approach, the quantity of residues of toxic concern is currently calculated for a food basket that includes $300 \mathrm{~g}$ of muscle, $100 \mathrm{~g}$ of liver, $50 \mathrm{~g}$ of kidney, $50 \mathrm{~g}$ of fat, $1.5 \mathrm{~kg}$ of milk, $100 \mathrm{~g}$ of eggs and $50 \mathrm{~g}$ of honey. The concentration of residues is calculated using the MRL, expressed as the marker residue, with inclusion of a factor (when required) to convert the marker residue concentration to total residues. An example of this calculation is provided below for colistin (Table A3.1). 
Table A3.1. Example of calculation of Theoretical Maximum Daily Intake (TMDI) for Colistin

\begin{tabular}{lcccc}
\hline Food Item & MRL $(\boldsymbol{\mu g} / \mathbf{k g})$ & Standard Food Basket $(\mathbf{k g})$ & MR:TR $^{(1)}$ & Exposure $(\boldsymbol{\mu g} / \mathbf{p e r s o n} / \mathbf{d a y})$ \\
\hline Muscle & 150 & 0.3 & 0.8 & 56 \\
Liver & 150 & 0.1 & 0.8 & 19 \\
Kidney & 200 & 0.05 & 0.8 & 13 \\
Fat & 150 & 0.05 & 0.8 & 9 \\
Milk & 50 & 1.5 & 0.8 & 94 \\
Eggs & 300 & 0.1 & 0.8 & 38 \\
\hline \multicolumn{5}{r}{} \\
\end{tabular}

NOTES: (1) MR:TR is ratio of marker residue (parent drug) (MR) to total residues (TR).

The 66th Meeting of the Committee concluded that the TMDI was no longer the most suitable estimate of chronic exposure, because the MRL was a single concentration representing the estimated upper limit of a high percentile of the distribution of marker residue present in a given tissue of the treated animals (JECFA, 2006 [TRS 939]). Therefore, the Committee decided to use the median of the residue distribution to substitute for the MRL in the exposure estimate. The new estimate of exposure is the EDI. Further considerations are in the report of the 70th Meeting of the Committee in reply to comments submitted by the Committee for Medicinal Products for Veterinary Use (CVMP), European Medicines Agency (JECFA, 2009 [TRS 954]).

\section{Estimated Daily Intake (EDI)}

The use of an extreme value of the distribution (the MRL) is not realistic in a scenario describing chronic exposure. Instead, all concentrations of the distribution of residues should be considered. The median concentration is selected as representing the best point estimate of a central tendency over a prolonged period. Hence the EDI, calculated using the same factors as the TMDI, but using the median residue concentration instead of the MRL. An example of the EDI calculation for colistin is provided in Table A3.2.

As noted by the 66th JECFA, the EDI should not be applied when there is concern for acute toxicity or acute exposure (JECFA, 2006 [TRS 939]). The use of the EDI is currently applicable only to the evaluation of chronic toxicity of, and chronic exposure to, residues as reflected by the ADI.

Table A3.2. Example of calculation of Estimated Daily Intake (EDI) for Colistin

\begin{tabular}{lcccc}
\hline Food Item & $\begin{array}{c}\text { Median Residue } \\
(\boldsymbol{\mu g} / \mathbf{k g})\end{array}$ & $\begin{array}{c}\text { Standard Food } \\
\text { Basket (kg) }\end{array}$ & MR:TR ${ }^{* 1)}$ & $\begin{array}{c}\text { Estimated Daily } \\
\text { Intake }(\boldsymbol{\mu g})\end{array}$ \\
\hline Muscle (turkey) & 38 & 0.3 & 0.8 & 14.3 \\
Liver (pig) & 38 & 0.1 & 0.8 & 4.8 \\
Kidney (rabbits) & 145 & 0.05 & 0.8 & 9.1 \\
Fat (rabbit) & 82 & 0.05 & 0.8 & 5.1 \\
Milk (cattle) & 11 & 1.5 & 0.8 & 20.6 \\
Eggs (chicken) & 24 & 0.1 & 0.8 & 3.0 \\
\hline & & & ADI (upper bound) & 56.9 \\
\hline
\end{tabular}

NOTES: (1) MR:TR is ratio of marker residue (parent drug) (MR) to total residues (TR). 


\section{Concerns raised about the use of the model diet}

The 19th Session of the CCRVDF (FAO/WHO, 2011a) identified a number of concerns about the EDI calculations, including:

- consumers are unlikely to ingest large quantities of different animal products at the same time;

- the model diet was only suitable for evaluation of residues exhibiting chronic toxicity;

- the model diet did not reflect regional differences in diet; and

- data are lacking on consumption of certain tissues, such as lung.

These issues were considered in the development of the proposed new approaches in the Expert Report, but certain data deficiencies remain, such as data on consumption of certain tissues and data on regional diets (FAO/WHO, 2011b).

\section{New approaches for estimating drug residues: GEADE and GECDE}

The Joint FAO/WHO Expert Meeting on Dietary Exposure Assessment Methodologies for Residues of Veterinary Drugs developed two new approaches for the calculation of potential dietary exposure to residues of veterinary drugs in foods (FAO/WHO, 2012b). The same general equation applies for both acute and chronic dietary exposure estimates, represented as:

$$
\text { Dietary exposure }=\sum \frac{\text { Concentration of chemical in food } \times \text { Food consumption }(\mathrm{g})}{\text { Bodyweight }(\mathrm{kg})}
$$

The equation is applied to any food containing the residue.

\section{GEADE: estimating acute exposure}

The current approach to estimating exposure does not explicitly estimate acute exposure. However, the proposed new acute dietary exposure model, the Global Estimated Acute Dietary Exposure (GEADE), is an explicit estimate of acute exposure. The GEADE considers high-level exposure from each relevant food of animal origin individually. The concurrent occurrence of the selected high residue concentration in each food to which a consumer might be exposed (e.g. an MRL or high residue concentration derived from depletion studies, such as the upper one-sided $95 \%$ confidence limit over the 95th percentile residue concentration) is combined with a high daily consumption (97.5th percentile) of that food (meat, offal, milk, others). The 97.5th percentile food consumption amount (consumers only) was selected as being a more statistically robust value than the maximum food consumption amount because it represents an actual distribution of values. The GEADE is calculated as follows:

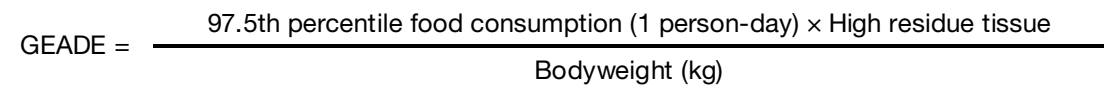

Unlike the EDI, estimates are derived for the children as well as for the general population, following the principle that dietary exposure assessments should cover the whole population and should include children. When calculating the GEADE, instead of the amounts of food consumed set out in the model diet, more detailed estimates of consumption are used to calculate exposure.

For an acute dietary exposure assessment, an Acute Reference Dose (ARfD) ${ }^{6}$ must first be established. The GEADE is used to calculate the percentage exposure of the ARfD it

\footnotetext{
${ }^{6}$ The ARfD has been defined as an "estimate of the amount of a substance in food or drinking water, expressed on a bodyweight basis, that can be ingested over a short period of time, usually during one meal or one day, without appreciable health risk to the consumer on the basis of all the known facts at the time of the evaluation" (FAO, 1967)
} 
represents for each population. JECFA has made limited use of an approach to acute exposure based on an ARfD. The Committee has considered this approach primarily when:

- there is a concern that residues of an injectable drug may remain in excess of the MRL at the injection site after the residues in normal muscle tissue are below the MRL; and

- the residue concentrations at the injection site could pose a serious risk to consumers (JECFA, 2000 [TRS 893]).

For example, in the case of the $\beta$-adrenoreceptor blocking agent carazolol, which is used as a sedative for transport of pigs, the Committee noted that at $2 \mathrm{~h}$ following treatment, residues at the injection site could result in an exposure of $18 \mu \mathrm{g}$ of parent carazolol, which is three times the ARfD. The Committee therefore advised that, unless appropriate measures could be taken to ensure that residues at the injection site do not result in residues exceeding the ARfD, use of carazolol prior to transport for slaughter is not consistent with the safe use of this drug (JECFA, 2000 [TRS 893]).

\section{GECDE: estimating chronic exposure}

In assessment of chronic exposure, consumption reflects the ongoing average (mean) and habitual high consumption of a food. In contrast, consumption derived for acute exposure reflects consumption at a single eating occasion. In addition to the general population, exposure is also estimated for children and infants using this method.

The Global Estimated Chronic Dietary Exposure (GECDE) uses median residues combined with two different types of consumption data to estimate chronic dietary exposure. Firstly, the highest exposure at the 97.5th percentile of consumption is selected from all the foods relevant to exposure. This value is derived from chronic consumers of the food; that is, the percentile consumption is calculated from consumers of the food only and is different from the 97.5th percentile of consumption used in acute exposure, which reflects a single eating occasion (acute). Secondly, the mean dietary exposures from all the other relevant foods are then added to estimate total exposure. The mean dietary exposure is derived from the total population; in other words, non-consumers of the food are included in the mean calculation. In addition to the general population and children, dietary exposure of infants can also be estimated.

The GECDE assumes that, in the longer term, an individual would be a high-level consumer of only one category of food and that their consumption of other foods containing the residue would remain at the population average (total population). Therefore, the 97.5th percentile food consumption amount for consumers only should be used, to be derived from surveys with individual records of two or more days' duration by first calculating the average food consumption amount per day per person, preferably expressed on a per kilogram bodyweight basis for each individual. The choice of a high percentile, such as the 97.5th, is justified by its application for a single commodity (instead of two, as applied for other food chemicals). The 97.5th percentile is used because it was more commonly reported in the data submitted. It is essential to document information on the number of consumers on which the percentile is based to demonstrate that the data are truly representative of the population of interest.

In summary, the GECDE is the highest exposure calculated using the 97.5th percentile consumption figure for a single food selected from all the foods, plus the mean dietary exposure from all the other relevant foods, and is calculated as:

GECDE $=$ Highest exposure from one animal product + Total mean exposure from all other products

In most cases, the food with the highest estimate of exposure using the 97.5th percentile consumption value drives the resulting dietary exposure estimate. In the rare case where two foods have similar 97.5th percentile exposure values, the calculation is undertaken for each one to determine the higher GECDE. 


\section{Food consumption data}

In order to assess whether the food consumption amounts used in the current model diet were overly conservative for the purpose of undertaking a chronic dietary exposure assessment or were suitable for the purpose of undertaking an acute dietary exposure assessment, it was necessary to obtain up-to-date food consumption data from Codex Alimentarius Member countries. A request for food consumption data for standard and nonstandard animal tissues and food of animal origin was issued by FAO and WHO on 26 October 2010 (FAO/WHO, 2010). Forty-seven countries submitted data in response to this request. For some countries, more than one data set was submitted. A variety of methods were used to collect these data, and the details are summarized in Annex 3 of the report of the Joint FAO/WHO Expert Meeting on Dietary Exposure Assessment Methodologies for Residues of Veterinary Drugs (FAO/WHO, 2012b). At the meeting the experts used the best available data from the call for data to develop food consumption data for use in acute and chronic dietary exposure assessments. The current pilot exercise uses the most up-to-date available consumption data compiled from the call for data for chronic dietary exposure estimates in the general population, for children (Table A3.3), for infants (Table A3.4) and for acute dietary exposure estimates for the general population and children (Table A3.5).

It should be noted that consumption amounts for infants are not reported for some categories (e.g. mammalian fat, poultry fat and skin) and therefore are not included in estimates. Other categories are not reported separately as consumed according to the surveys used to derive consumption amounts. In such cases, the broader categories are used, with the highest residue concentration used as the input. For example, "mammalian kidney" consumption is not reported for infants; therefore the residue found in kidney would be assigned to "All mammalian offal", which is the best available match for kidney consumption in this population.

\section{Food consumption data for acute exposure estimates}

For acute exposure, the highest 97.5th percentile value for each food was selected from the data submitted for the Expert Meeting or from the GEMS/Food large portion size database. Some of the submitted data were higher than values in the current GEMS/Food database (WHO, 2013), such as new data from China and Australia (FAO/WHO, 2011b). When considering food consumption data for acute exposure estimates, one person-day data from surveys with individual records were considered by preference, as recommended in EHC 240 (FAO/WHO, 2009b). For example, for a survey of 2 days' duration, days 1 and 2 were treated as separate records for each individual.

\section{Food consumption data for chronic exposure estimates}

When considering food consumption data for chronic dietary exposure assessments, the duration of the survey from which the food consumption data are derived should be taken into account. For chronic exposure estimates, it is preferable to use surveys of more than 1 day's duration to represent "usual" consumption patterns so that the average food consumption is calculated per day for each individual in the survey over the number of days of the survey, before the high percentile is derived from the distribution of food consumption values.

The range of distribution therefore tends to decrease towards the central measure the longer the duration of the survey. A 97.5th percentile consumption from a 2-day survey will tend to be lower than that derived from 1-day data and provides a better representation of high chronic consumption; that from a 7-day survey would tend to be lower again.

For exposure estimates based on broad food categories (e.g. muscle or milk) that are likely to be consumed daily by the majority of the population, survey duration is not such a critical issue. In a given population, the amounts of these foods consumed tend not to vary 
significantly from day to day, so the difference between food consumption estimates from 1 and 2 or more days of data is minimal.

Survey duration is much more important when considering foods that are consumed infrequently and in high amounts in some countries, but only rarely in some others, such as liver and kidney, and it is significant to note that these commodities are more likely to contain higher concentrations of veterinary drug residues. For foods such as liver and kidney, the longer the duration of the survey in countries that consume them infrequently, the more consumers are identified, so that the proportion of the population consuming ( $\%$ consumers) appears to increase. Conversely, the average amount that a consumer eats ( $\mathrm{g} /$ day) appears to decline as the survey duration is extended. In this case, the proportion of the population consuming may be very small; this makes reliable estimates of long-term consumption of such commodities extremely difficult.

From the information submitted, the most comprehensive data sets for high food consumption values were for one person-day 97.5th percentile food consumption values (e.g. GEMS/Food large portion size database). However, some information was available on 97.5th percentile food consumption from surveys of two or more days' duration, where the amount of food consumed by each individual in the survey was averaged over the number of days of the survey before the 97.5th percentile for the population group of interest was derived. This latter type of data is more appropriate for use in chronic dietary exposure assessment. 


\begin{tabular}{|c|c|c|c|c|c|c|c|c|}
\hline \multirow{4}{*}{ 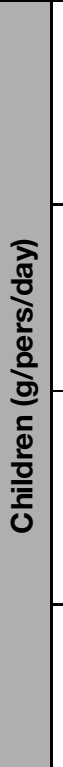 } & 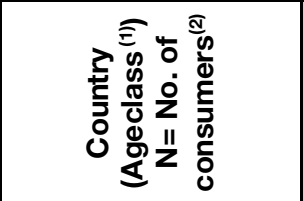 & 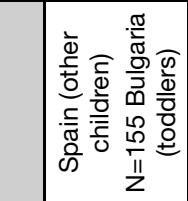 & 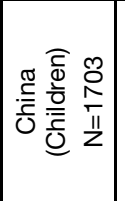 & 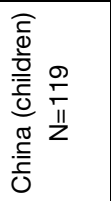 & 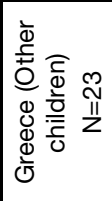 & 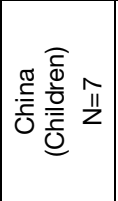 & 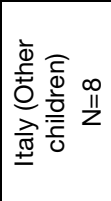 & 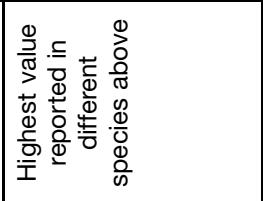 \\
\hline & 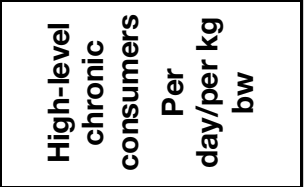 & 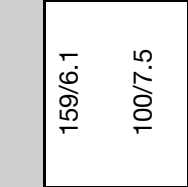 & 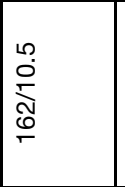 & 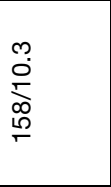 & 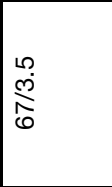 & 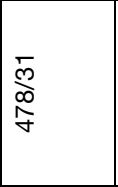 & $\begin{array}{l}\stackrel{L}{\infty} \\
\infty \\
\stackrel{\infty}{\sigma} \\
\stackrel{+}{+}\end{array}$ & $\begin{array}{l}\bar{m} \\
\infty \\
\stackrel{f}{f}\end{array}$ \\
\hline & 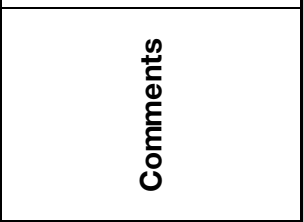 & 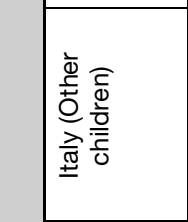 & 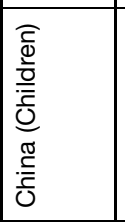 & 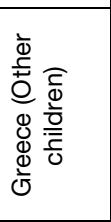 & 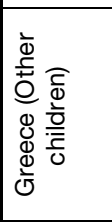 & 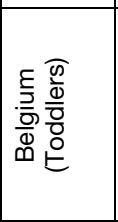 & 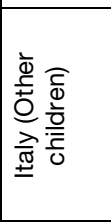 & 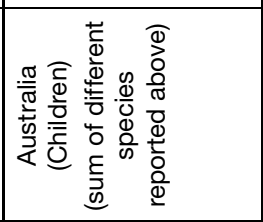 \\
\hline & 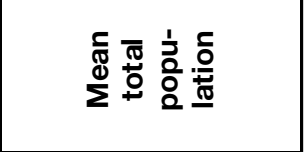 & $\hat{m}$ & ह & $\stackrel{m}{\longrightarrow}$ & - & $\sim$ & $\sim$ & $\widetilde{ఠ}$ \\
\hline \multirow{6}{*}{ 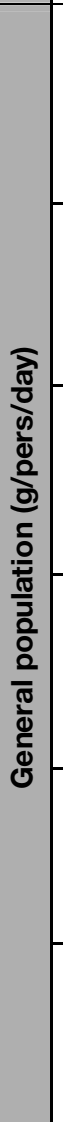 } & 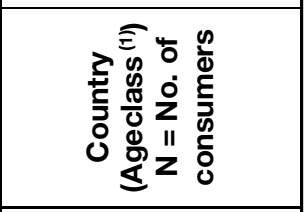 & 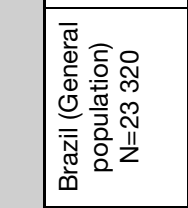 & 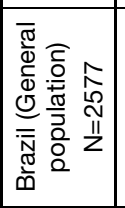 & 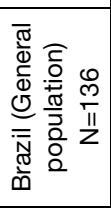 & 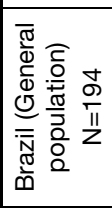 & 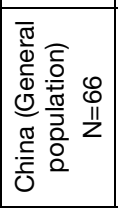 & 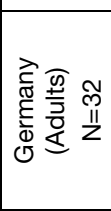 & 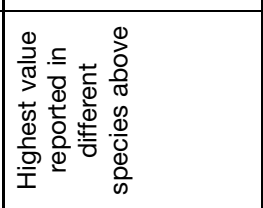 \\
\hline & 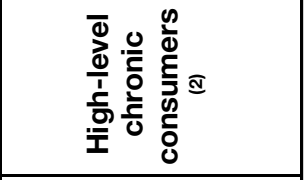 & 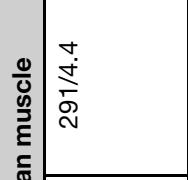 & 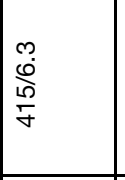 & 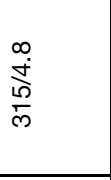 & $\frac{\infty}{\dot{+}}$ & 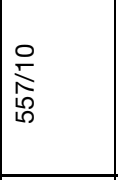 & $\begin{array}{l}0 \\
\stackrel{p}{ } \\
\delta \\
0 \\
\infty\end{array}$ & 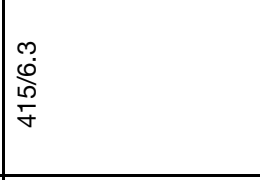 \\
\hline & 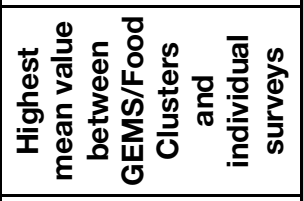 & 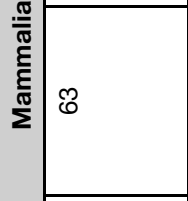 & $\stackrel{\nabla}{\rightleftharpoons}$ & $\bar{N}$ & م & m & $\nabla$ & $\stackrel{\nabla}{\rightleftharpoons}$ \\
\hline & 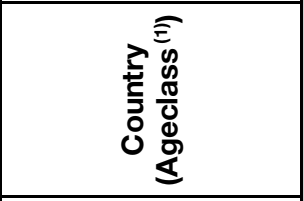 & 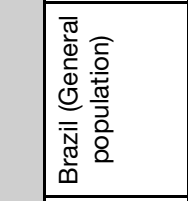 & 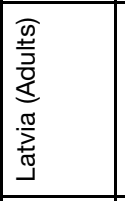 & 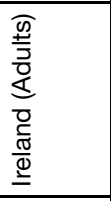 & 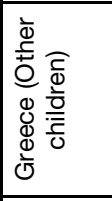 & 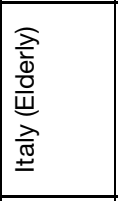 & 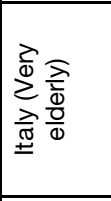 & 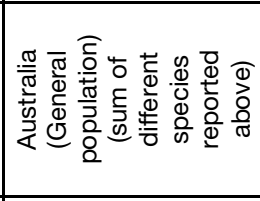 \\
\hline & 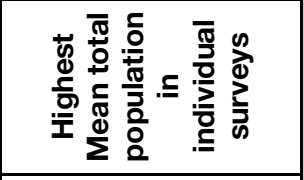 & $\varnothing$ & 必 & $\stackrel{m}{\square}$ & - & $r$ & $\nabla$ & $\stackrel{\circ}{\circ}$ \\
\hline & 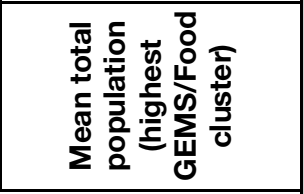 & $\begin{array}{l}\hat{0} \\
0 \\
0 \\
\hat{f}\end{array}$ & 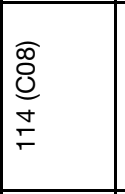 & $\begin{array}{l}\frac{\pi}{\tilde{U}} \\
\frac{N}{N}\end{array}$ & $\frac{\pi}{0}$ & $\begin{array}{l}\text { तु } \\
\text { d } \\
\text { m }\end{array}$ & 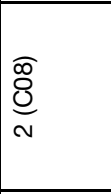 & 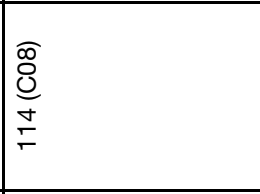 \\
\hline & 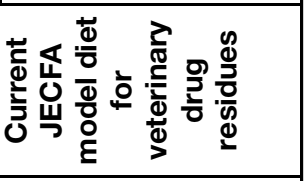 & & & & & & & ৪্ল \\
\hline & 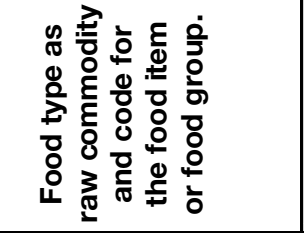 & 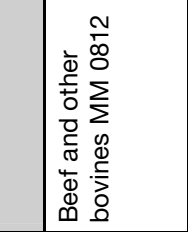 & 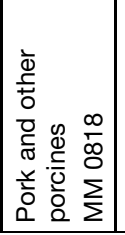 & 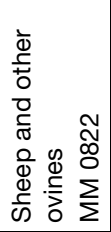 & 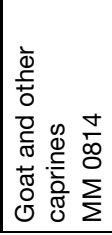 & 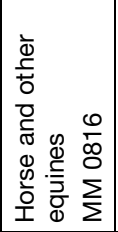 & 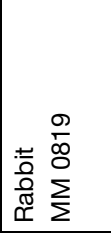 & 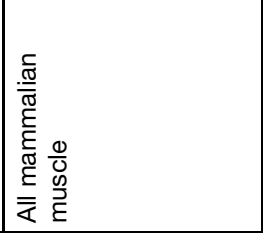 \\
\hline
\end{tabular}




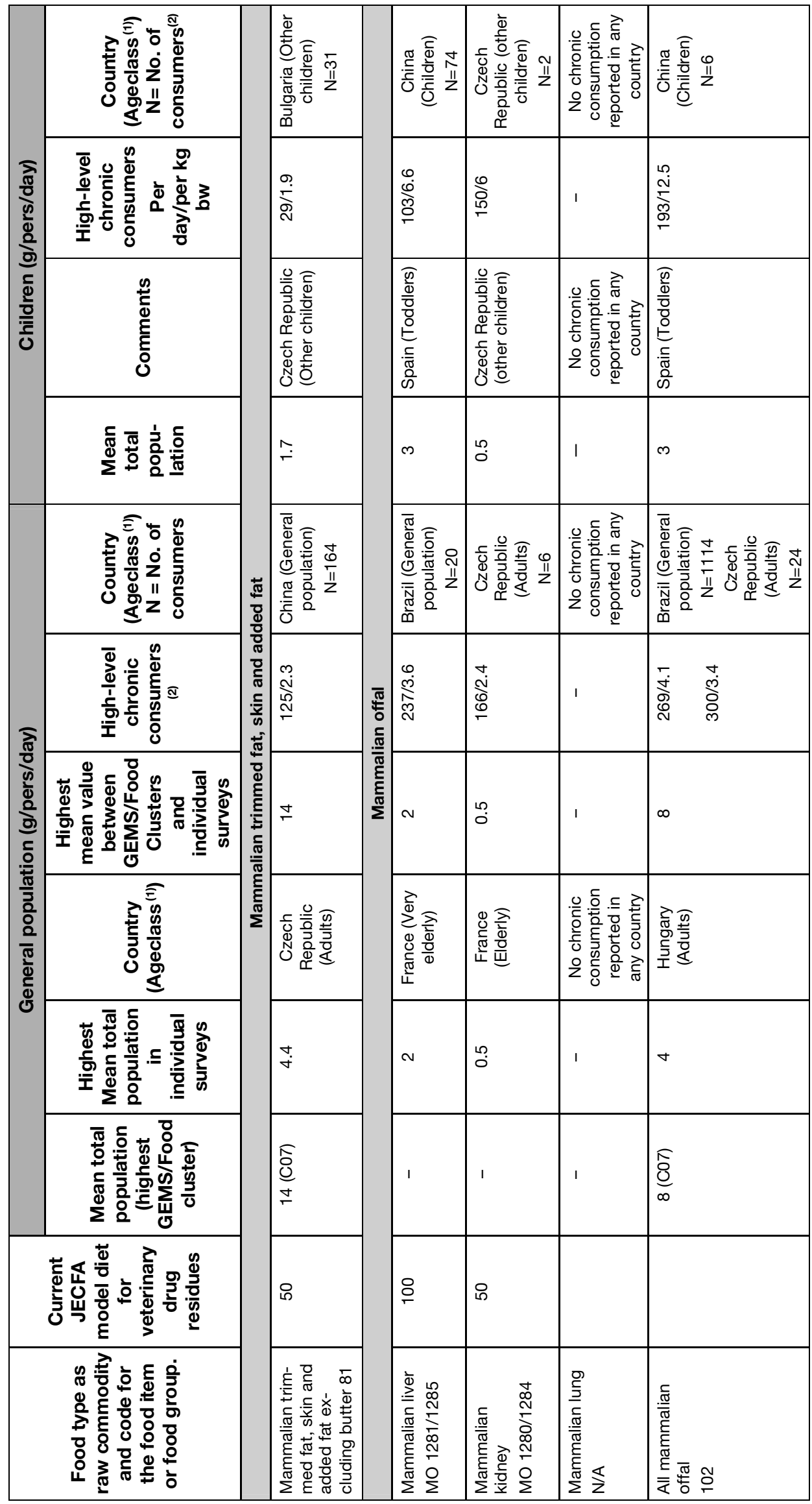




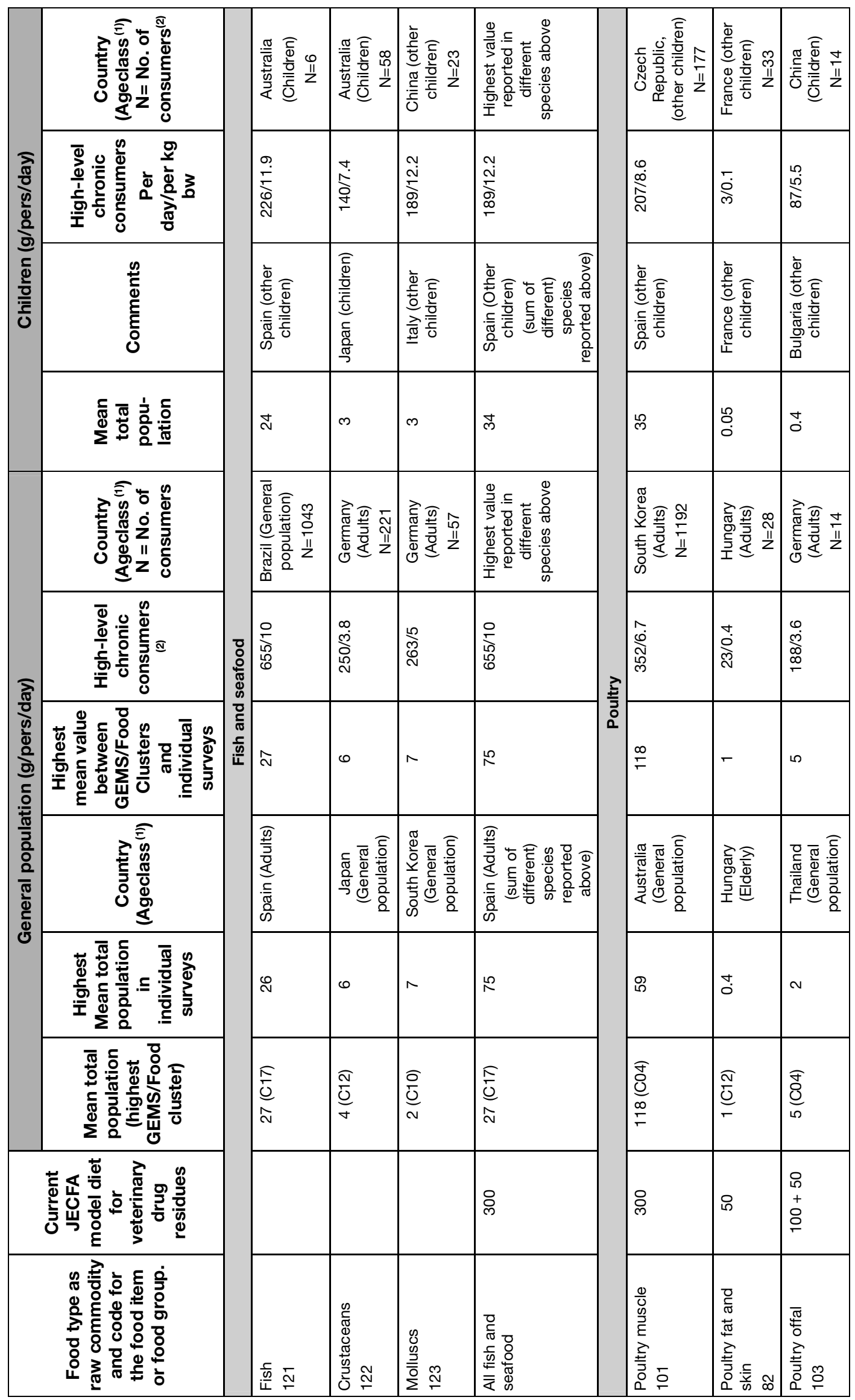




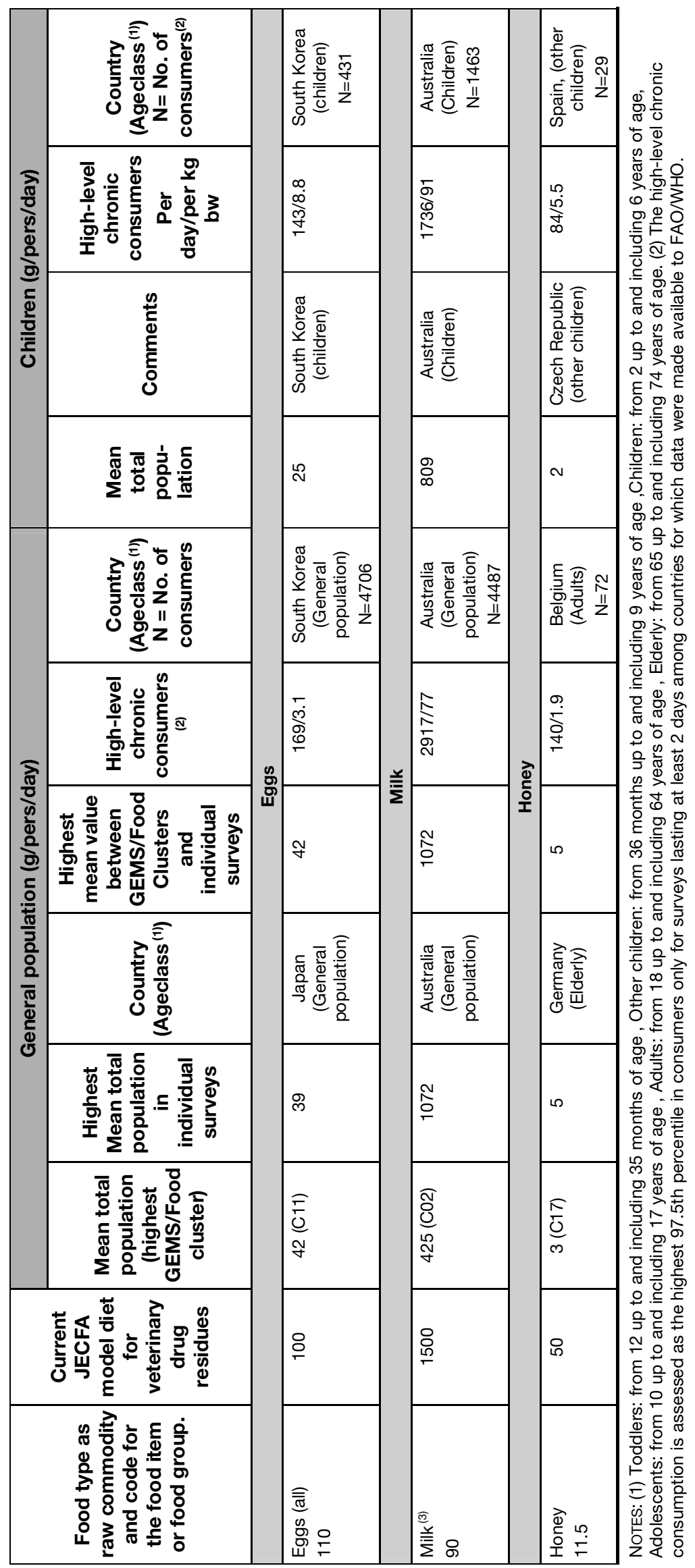




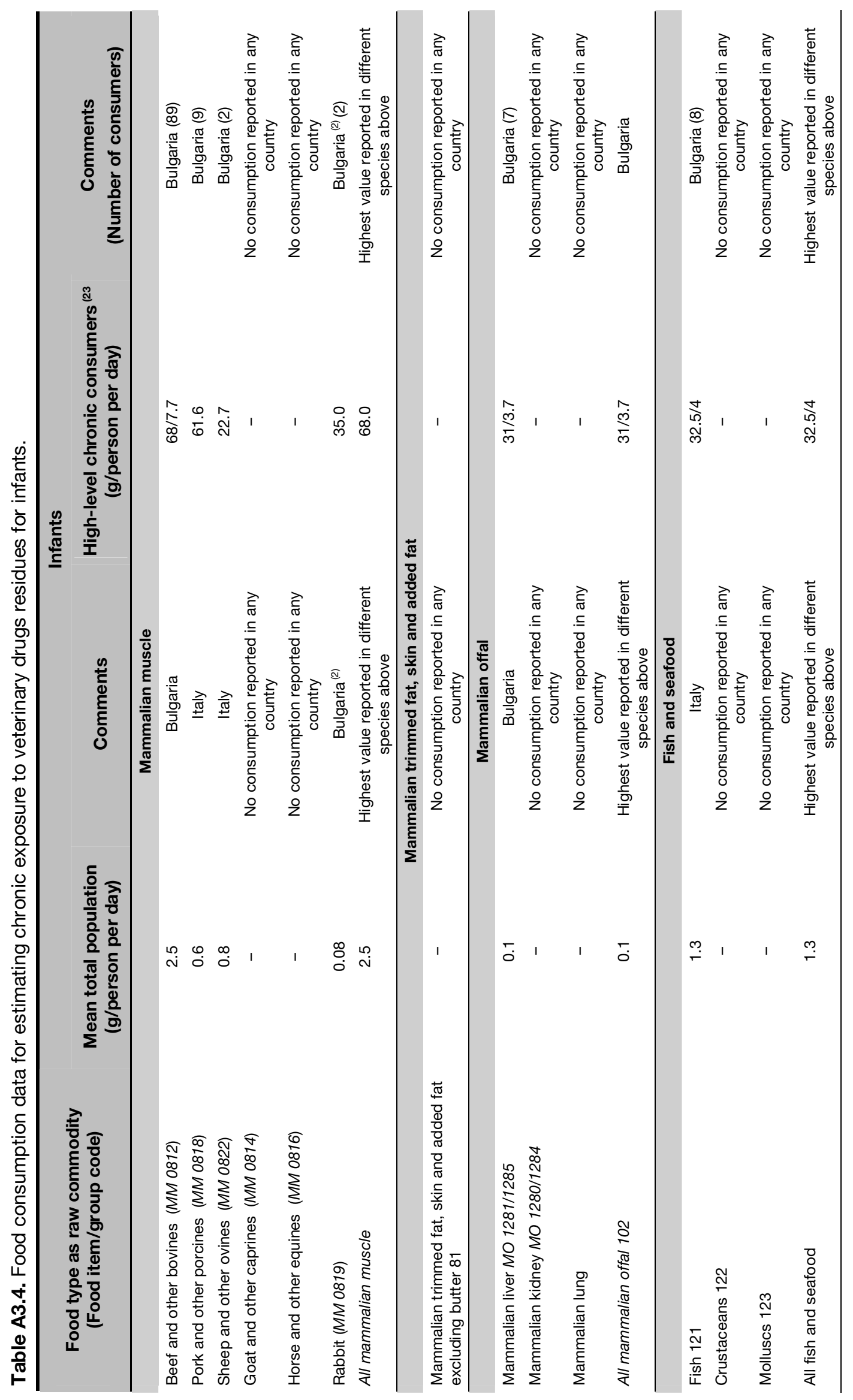




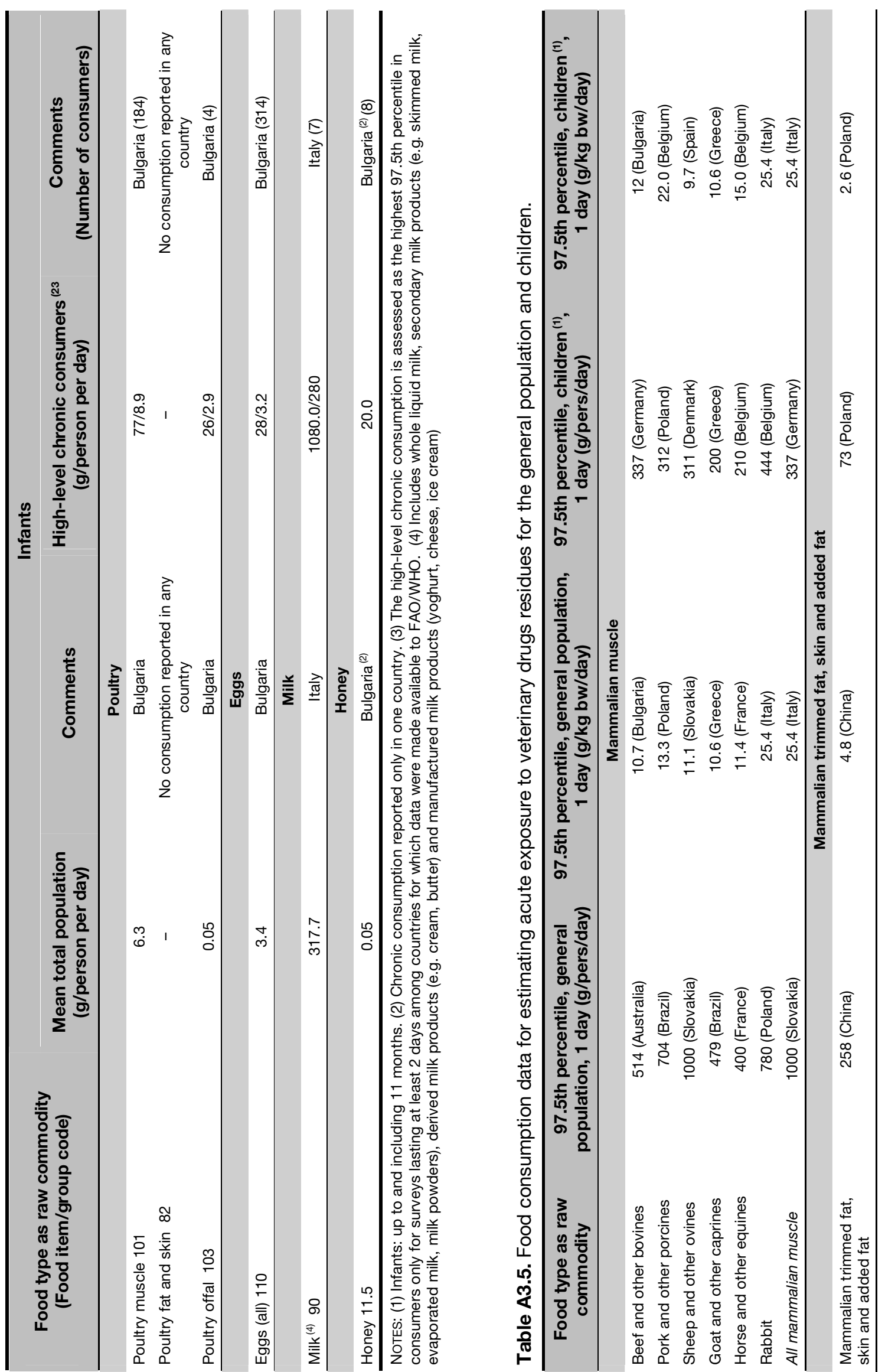




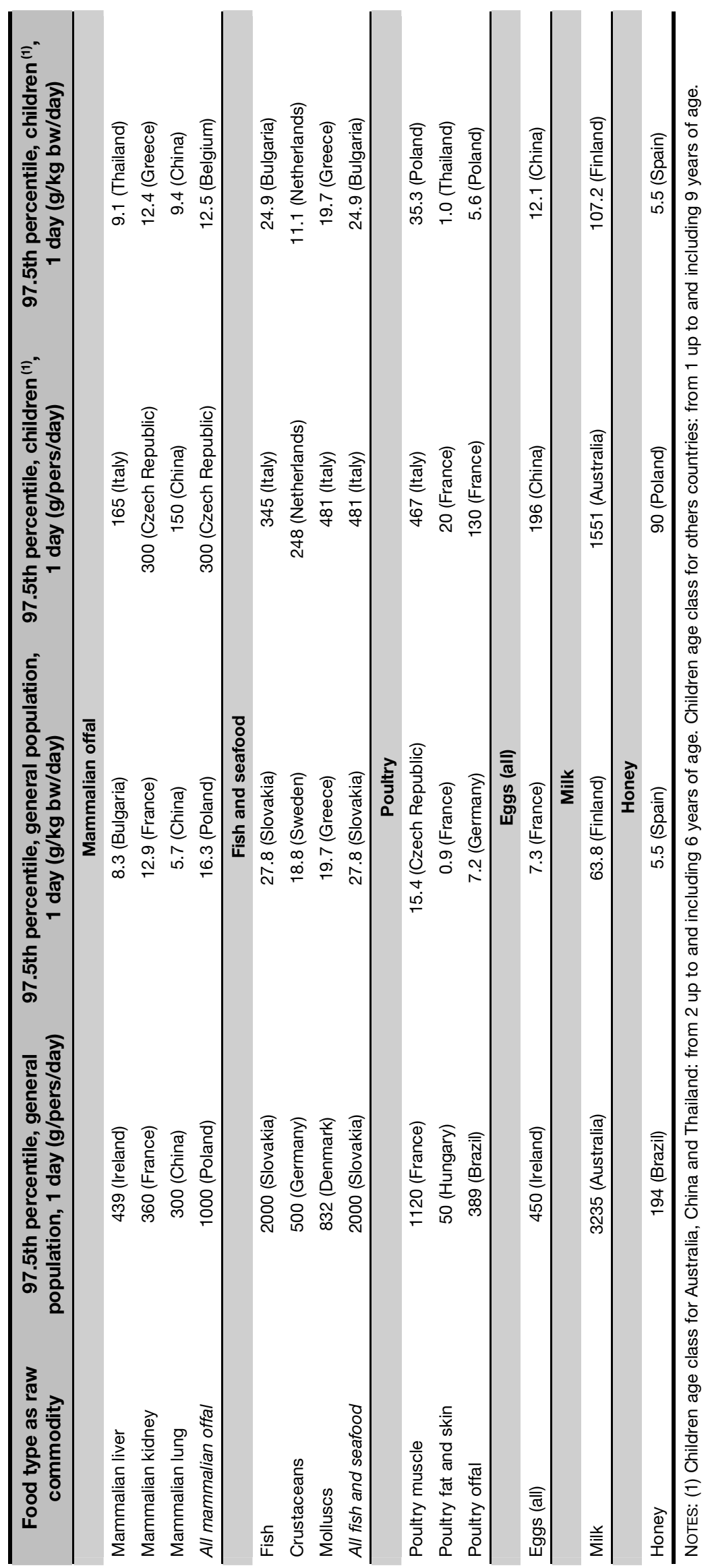




\section{Approach}

\section{Overall approach}

Currently, for estimating chronic dietary exposures to veterinary drug residues in foods, JECFA uses the median of the residue depletion, when available, to derive the EDI. These calculations have been carried out as part of the standard work of the 78th JECFA as well as for this pilot study to compare with the GECDE. Where a median residue cannot be derived, the MRL may be substituted for the median residue to calculate the TMDI, as was the case with derquantel at the 78th JECFA meeting. Both the EDI and TMDI assume that the food consumption applies to a standard human with a bodyweight of $60 \mathrm{~kg}$. This weight represents the average bodyweight of the whole population including adults, children, male and female. The model diet is also intended to also cover the consumption of all processed foods with these foods as ingredients. All muscle tissues are equivalent, so meat and fish consumed are considered as equivalent in the calculations.

As was discussed above, the GECDE and GEADE take a different approach. The GECDE and GEADE given below differ from the EDI by having estimated specific dietary exposure for additional population groups (children aged 12 months and older, and infants younger than 12 months) and by using more realistic global consumption amounts as inputs into the calculations. Consumption data used are based on surveys (see tables above) and have been expressed per person for the whole population estimates to be compared with the current approach, or per $\mathrm{kg}$ bodyweight, based on values reported in food consumption surveys. Instead of the set amounts of food in the model diet, more detailed food consumption data have been used where available. For example, muscle tissue has been differentiated by species, and finfish have been considered separately from molluscs and crustaceans.

As discussed above, the EDI is not suitable for estimating acute dietary exposure, which should be based on the highest probable exposure from a single commodity on a single day. In contrast, the GEADE is an explicit estimate that can be used to calculate acute dietary exposures. Estimates have been derived specifically for children as well as for the general population, following the principle that dietary exposure assessments should cover the whole population, including children. Only in the case of emamectin was a health-based guidance value (HBGV) available and the GEADE was expressed as a proportion of the ARfD.

\section{Principles}

The following guiding principles apply to all exposure assessments:

- Objectives must be clear before food consumption and concentration data are selected.

- Different approaches should provide equivalent consumer protection.

- The most appropriate data and method should be used.

- International assessments should provide estimates that are equal to or lower than national estimates.

- Assessments need to cover the general population as well as vulnerable groups.

\section{Age groups}

The GECDE and GEADE have been used to estimate exposure for population groups other than the whole population. Ideally, dietary exposure assessments should cover the whole population and should also include relevant population sub-groups, such as young children, 'at risk' or target groups. Regardless of the method of dietary exposure assessment used, if dietary exposure of young children to the food chemical in question is estimated it will generally be reported separately from that of the whole population. 
On a bodyweight basis, children have higher energy needs than adults because they are growing and developing and therefore they eat more food in relation to their size than adults. Children may have unusual eating patterns, ranging from picky and irregular eating, overeating, to disinhibited or binge eating (Lewinsohn et al., 2005; Marcus and Kalarchian, 2003), that may be particularly relevant when assessing exposure to some hazards. Very young children may eat a more limited range of foods than older children and adults, and therefore can be vulnerable to a hazard found in a particular food they consume (Buck-Louis et al., 2006). Children are unlikely to have higher dietary exposure per kilogram bodyweight than adults except when exposure occurs through a food or beverage not usually consumed by children (e.g. alcoholic beverages).

\section{Model diets compared with individual records of consumption}

The GECDE and GEADE shown below used a more detailed set of consumption data than the EDI. The use of appropriate food consumption data in dietary exposure assessments is obviously extremely important. Many methods can be used to collect food consumption data, with the type of food chemical and the purpose of the assessment determining the most appropriate source of data.

Where no consumption data for individuals are available, a model diet such as is used in the EDI (also referred to as 'simulated' or 'theoretical' diets) may be constructed to represent a 'typical' diet for a given population group. The advantages of the model diet approach are that it:

- is cost effective;

- can take different population sub-groups into account;

- can take different chemical levels into account; and

- is useful when limited data are available.

The disadvantages of the model diet approach are that:

- it is subject to error when many foods are involved;

- the outcome is very dependent on assumptions made; and

- it does not account for individual variation in consumption.

The best data for conducting dietary exposure estimates are food consumption data collected from individuals, as is used in the new approach. Dietary exposure assessments using food consumption data for individuals may be necessary if the results of exposure assessments, using screening methods or model diets, are not conclusive or indicate that potential dietary exposure to a food chemical is likely to approach or exceed a HBGV.

Alternatively, they may be used in the first instance if the data are available and an accurate estimate of dietary exposure is likely to be required. The usual dietary modelling approach involves the use of individual dietary records derived from national nutrition surveys. These individual consumption records may be used in a deterministic assessment, as typically occurs for agricultural and veterinary chemicals, or they can be used as inputs in semi or fully probabilistic techniques.

The advantages of using individual food consumption data are:

- dietary exposure for a wide range of food chemicals can be estimated if the consumption data are representative and comprehensive;

- a range of consumption amounts for each food or food group can be taken into account;

- dietary exposures for different population sub-groups can be estimated;

- dietary exposure of consumers at low and high points of the distribution can be assessed to represent low or high consumers; and 
- scenarios of food chemical concentrations can be modelled to predict exposure under different risk management options.

The disadvantages of using individual food consumption data include:

- data collection is resource intensive;

- their use is more time consuming than use of data from screening techniques and requires more technical expertise; and

- some critical groups may not be adequately represented (e.g. very young children).

\section{Duration of exposure - acute or chronic assessments?}

GEADE or GECDE were used in dietary exposure assessments in the context of whether or not a hazard presents a short-term or long-term risk. A short-term risk is assessed using acute dietary exposure assessment techniques, while chronic dietary exposure assessment techniques are used to assess long-term risks. Each of these assessments presents challenges in the appropriate use of food chemical and food consumption data. Although there are different general approaches that are followed for acute compared with chronic assessments, the exact nature of the hazard being assessed determines the final dietary exposure assessment approach on a case-by-case basis.

\section{Acute dietary exposure assessments}

An estimate of acute dietary exposure is required for each food or commodity for which an MRL is proposed for those agricultural and veterinary chemicals where an ARfD has been established. Acute dietary exposure assessments are conducted for food chemicals that have toxic effects from short-term exposure (from one meal or over one day). In estimating acute dietary exposure, the aim is to generate a 'worst case' assessment that takes into account the potential occurrence of someone who eats a large amount of a food happening to also select food that has a high concentration of the chemical in question. Therefore, in a deterministic acute exposure assessment, a high consumption amount (typically the 97.5th percentile) is multiplied by a high chemical concentration amount, where a distribution of chemical concentrations is known. In some circumstances, a factor is also included to account for variability in the chemical concentration data set arising from lack of homogeneity in foods or due to small data sets being use. Although acute dietary exposure assessments generally focus on exposure from a single food, exposure from a range of dietary sources can be taken into account if this is relevant.

\section{Chronic dietary exposure assessments}

Chronic dietary exposure assessments are conducted for food chemicals that have toxicological effects from exposure over a long period. Because exposure over a long time is being assessed, it is not usually appropriate to select extremes of food chemical concentration data. Mean or median concentration data are most often used as, over a lifetime, people are most likely to consume an average concentration of a chemical in a food rather than continually be exposed to high levels of a chemical (FAO/WHO, 2009b). There may be assessments involving a subset of a population who have unusual eating patterns and who may select foods with persistent high chemical levels. For example, recreational fishers or indigenous peoples who regularly eat fish caught in a single area may have long-term high exposures to chemicals present in waters in that area.

For chronic dietary exposure assessment, it would be beneficial for long-term food consumption data to be used. Considerable care must be taken to use data that represent long-term food consumption patterns. 


\section{Estimating exposure to residues from foods derived from multiple species}

When estimating exposure, it is necessary to consider the contribution of all foods to the total exposure that may be experienced by a population. For example, if a residue is contained in muscle meat of more than one species, then both types of foods are potential contributors to exposure. This is the case with the EDI as well as the GEADE and GECDE.

The EDI calculation considers this by assigning worst-case median residues to the various foods in the model diet. For each food commodity, the highest species-specific median residue value is used in the calculation. For example, the calculation of an EDI for the antimicrobial colistin (Table A3.2) uses the median residue for turkey muscle to assign to muscle meat, pig liver to assign to liver, rabbit kidney to assign to kidney, and so on. It is important, when reporting the EDI, to identify the relevant species for each of the edible commodities used in the calculation.

The proposed new approaches follow a similar approach to the EDI calculations. For the chemicals piloted, exposure from multiple species did not emerge as an issue. Using colistin again to illustrate the approach, for mammalian offal the worst-case median residues found in pig liver would be assigned to mammalian liver and the worst-case median residue in rabbit kidney would be mapped to mammalian kidney. However, in some cases, such as mammalian muscle meat, the exposure estimates may include residues from more than one species, say from cattle as well as poultry. It should be noted that for the GECDE there is only a single major contributor to exposure: the food that is the highest contributor to exposure using the chronic 97.5th percentile of consumption. This makes it unlikely that including additional foods in the exposure assessment would substantially increase chronic exposure estimates.

\section{Pilot Study results}

In the following Tables, exposure on a per-person basis is given, rounded to one decimal place. Exposures on a per-kg bodyweight basis were rounded to two decimal places. Exposures expressed as \%ADI or \%ARfD were rounded to whole numbers.

\section{Derquantel}

\section{Summary of TMDI}

There were insufficient data to establish median residues for derquantel. A TMDI was therefore calculated using the MRLs set for liver, kidney, muscle and fat from sheep. Based on the established model diet, the TMDI was estimated to be $6.7 \mu \mathrm{g}$ per person per day. This was equivalent to $38 \%$ of the

Table A3.6. TMDI for derquantel based on MRLs in sheep tissues: $0.3 \mu \mathrm{g} / \mathrm{kg}$ in muscle, $0.4 \mu \mathrm{g} / \mathrm{kg}$ in kidney, $0.8 \mu \mathrm{g} / \mathrm{kg}$ in liver and $7.0 \mu \mathrm{g} / \mathrm{kg}$ in fat.

\begin{tabular}{llc}
\hline & \multicolumn{2}{c}{ Exposure (TMDI) } \\
\hline TMDI, general population & $\mu \mathrm{g} /$ person/day & 6.7 \\
ADI, general population & $\% \mathrm{ADI} /$ person/day & 38 \\
\hline
\end{tabular}
upper bound of the ADI of $0-0.3 \mu \mathrm{g} / \mathrm{kg}$ bw per day.

\section{Assumptions for dietary exposure assessment}

The following assumptions were used in dietary exposure estimates:

- Residues are only found in sheep and other ovines.

- Residues are found only in muscle, liver and kidney and fat.

- For infants, all offal consumed is assumed to be worst case.

\section{Inputs}

The inputs for the dietary exposure assessment are given in Tables A3.7 and A3.8. The consumption figures used for estimating exposure to derquantel are given in Tables A3.9 and A3.10). 
Table A3.7. Reference values for derquantel exposure assessment

\begin{tabular}{lcc}
\hline LOAEL & 0.1 & $\mathrm{mg} / \mathrm{kg} \mathrm{bw} / \mathrm{d}$ \\
Safety factor & 300 & \\
ADI & $0-0.3$ & $\mu \mathrm{g} / \mathrm{kg} \mathrm{bw} / \mathrm{d}$ \\
\hline
\end{tabular}

Table A3.8. Foods included in the exposure assessment and the associated MRL and marker residue to total residue ratio

\begin{tabular}{ccc}
\hline Food & MRL $(\mathbf{u g} / \mathbf{k g})$ & MR:TR \\
\hline Muscle & 0.3 & 0.06 \\
Liver & 0.8 & 0.03 \\
Kidney & 0.4 & 0.07 \\
Fat & 7.0 & 0.15 \\
\hline
\end{tabular}

NOTES: MR:TR is the ratio of marker residue to total residues.

Table A3.9. Consumption of food used in chronic exposure assessment for derquantel

\begin{tabular}{|c|c|c|c|c|c|c|c|c|}
\hline \multirow{3}{*}{ Category } & \multirow{3}{*}{ Type } & \multicolumn{7}{|c|}{ Consumption (g) } \\
\hline & & \multirow{2}{*}{$\begin{array}{l}\text { Model } \\
\text { diet }\end{array}$} & \multicolumn{2}{|c|}{ Whole population } & \multicolumn{2}{|c|}{ children } & \multicolumn{2}{|c|}{ infants } \\
\hline & & & Mean & High & Mean & High & Mean & High \\
\hline Mammalian muscle & Sheep and other ovines & 300 & 21 & 315 & 13 & 158 & 1 & 23 \\
\hline $\begin{array}{l}\text { Mammalian trimmed } \\
\text { fat, skin and added fat }\end{array}$ & $\begin{array}{l}\text { Mammalian trimmed fat, } \\
\text { skin and added fat }\end{array}$ & 50 & 14 & 125 & 1.7 & 29 & 14 & 125 \\
\hline \multirow[t]{3}{*}{ Mammalian offal } & Mammalian liver & 100 & 2 & 237 & 3 & 103 & & \\
\hline & Mammalian kidney & 50 & 0.5 & 166 & 0.5 & 150 & & \\
\hline & All mammalian offal & & & & & & 0.1 & 31 \\
\hline
\end{tabular}

Table A3.10. Consumption of food used in acute exposure assessment for derquantel

\begin{tabular}{llcccccc}
\hline \multicolumn{1}{c}{ Category } & \multicolumn{1}{c}{ Type } & \multicolumn{3}{c}{ Chole population } \\
& & & Model diet & $\begin{array}{c}\text { C7.5th/ } \\
\text { person }\end{array}$ & $\begin{array}{c}\text { 97.5th/ } \\
\text { kg bw }\end{array}$ & $\begin{array}{c}\text { 97.5th/ } \\
\text { person }\end{array}$ & $\begin{array}{c}\text { 97.5th/ } \\
\text { kg bw }\end{array}$ \\
\hline Mammalian muscle & Sheep and other ovines & 300 & 1000 & 11.1 & 311 & 9.7 \\
\hline $\begin{array}{l}\text { Mammalian trimmed fat, } \\
\text { skin and added fat }\end{array}$ & Mammalian trimmed fat, & 50 & 258 & 4.8 & 73 & 2.6 \\
\hline Mammalian offal & skin and added fat & Mammalian liver & 100 & 439 & 8.3 & 165 & 9.1 \\
& Mammalian kidney & 50 & 360 & 12.9 & 300 & 12.4 \\
\hline
\end{tabular}

\section{GECDE}

The GECDE was calculated from the consumption of sheep and other ovine muscle, mammalian liver, mammalian kidney and mammalian trimmed fat. Using the established MRLs as input, the GECDE for the general population was $7.1 \mu \mathrm{g} /$ person per day $(0.12 \mu \mathrm{g} / \mathrm{kg}$ bw per day), very similar to the TMDI. The estimated exposure of children was $0.19 \mu \mathrm{g} / \mathrm{kg}$ bw per day; it was estimated that infants were exposed at $0.17 \mu \mathrm{g} / \mathrm{kg}$ bw per day (Table A3.11)

None of the GECDE exceeded the upper bound of the ADI (general population 39\%, children $64 \%$ and infants $55 \%$ ). For all population groups, mammalian offal was the major contributor to estimated dietary exposure from derquantel residue (Table A3.12). 
Table A3.11. GECDE for the general population, children and infants based on the corrected MRL and an $\mathrm{ADI}$ of $0.3 \mu \mathrm{g} / \mathrm{kg}$ bw/day for derquantel

\begin{tabular}{|c|c|c|c|c|}
\hline \multirow{2}{*}{ Population } & \multirow{2}{*}{$\begin{array}{l}\text { Bodyweight } \\
\text { (kg bw) }\end{array}$} & \multicolumn{2}{|c|}{ GECDE } & \multirow{2}{*}{$\begin{array}{l}\text { ADI } \\
\text { (\%) }\end{array}$} \\
\hline & & $\mu \mathrm{g} /$ person/day & $\mu \mathrm{g} / \mathrm{kg}$ bw/day & \\
\hline General population & 60 & 7.1 & 0.12 & 39 \\
\hline Children & 15 & 2.9 & 0.19 & 64 \\
\hline Infants & 5 & 0.8 & 0.17 & 55 \\
\hline
\end{tabular}

Table A3.12. Exposure by food for the general population, children and infants (up to 11 months). The major contributors to exposure (based on high usual consumers at the 97.5th percentile) are shown shaded.

\begin{tabular}{llccc}
\hline \multicolumn{1}{c}{ Category } & \multicolumn{1}{c}{ Type } & \multicolumn{2}{c}{ Exposure $(\boldsymbol{\mu g} /$ person/day) } \\
& & General population & Children & Infants \\
\hline Mammalian muscle & Sheep and other ovines & 0.1 & 0.1 & $<0.1$ \\
Mammalian offal & Mammalian liver & 6.3 & 2.7 & $\mathrm{~N} / \mathrm{A}$ \\
Mammalian offal & Mammalian kidney & $<0.1$ & $<0.1$ & $\mathrm{~N} / \mathrm{A}$ \\
Mammalian offal & All mammalian offal & $\mathrm{N} / \mathrm{A}$ & $\mathrm{N} / \mathrm{A}$ & 0.8 \\
Mammalian fat & Mammalian trimmed fat & 0.7 & 0.1 & $\mathrm{NC}$ \\
\hline
\end{tabular}

NOTES: N/A = Not applicable, NC = Not consumed.

\section{GEADE}

Residue data for the 95th percentile were not available for derquantel. The GEADE was therefore calculated based on the same concentrations used for the TMDI and GECDE, i.e. the adjusted MRL.

Unlike chronic exposure estimates, fat is one of the major contributors to exposure in the general population. However, liver is still an equal contributor. For children, liver and fat are both major contributors to exposure, but the other tissues are also of importance (Table A3.13).

The GEADE for the general population was $0.58 \mu \mathrm{g} / \mathrm{kg}$ bw / day. For children, the GEADE was $0.48 \mu \mathrm{g} / \mathrm{kg} \mathrm{bw} /$ day. As there is no ARfD established for derquantel, these numbers were not compared against reference values.

Table A3.13. Exposure based on 97.5th percentile consumption by food for the general population and children. The major contributors to exposure are shaded.

\begin{tabular}{llcc}
\hline \multicolumn{1}{c}{ Category } & \multicolumn{1}{c}{ Type } & $\begin{array}{c}\text { Exposure } \\
(\boldsymbol{\mu g} / \mathbf{k g} \text { bw/day) }\end{array}$ & $\begin{array}{c}\text { Children } \\
(\boldsymbol{\mu} \mathbf{g} / \mathbf{k g} \text { bw/day) }\end{array}$ \\
\hline Mammalian muscle & Sheep and other ovines & 0.06 & 0.05 \\
Mammalian offal & Mammalian liver & 0.22 & 0.24 \\
Mammalian offal & Mammalian kidney & 0.07 & 0.07 \\
Mammalian Fat & Mammalian fat & 0.22 & 0.12 \\
\hline TOTAL (GEADE) & & 0.58 & 0.48 \\
\hline
\end{tabular}

\section{Comparison with TMDI estimates}

The TMDI calculations based on the model diet found that the MRL resulted in exposure estimates below the ADI. Similarly, the GECDE calculations found that exposure estimates were below the ADI for all population groups. Mammalian liver was the major contributor to chronic exposure. Fat was a major contributor to acute (GEADE) exposure in the general population, but the liver was also important when estimating overall acute exposure. 


\section{Emamectin benzoate}

\section{Summary of EDI}

In this dietary exposure assessment, fish was the only contributor to dietary exposure. The EDI for emamectin benzoate was calculated based on median residues found in fish muscle. The estimated dietary exposure was $11.2 \mu \mathrm{g} /$ person per day, which is equivalent to $37 \%$ of the upper bound of the ADI of $0-0.5 \mu \mathrm{g} / \mathrm{kg} \mathrm{bw}$ per

Table A3.14. EDI calculations for emamectin based on the median residue associated with the MRLs of $100 \mu \mathrm{g} / \mathrm{kg}$ in muscle and fillet (muscle with adhering skin) for salmon and trout

\begin{tabular}{llc}
\hline & & Exposure (EDI) \\
\hline EDI, general population & $\mu \mathrm{g} /$ person/day & 11 \\
$\mathrm{ADI}$, general population & $\% \mathrm{ADI} /$ person/day & 37 \\
\hline
\end{tabular}
day (or $30 \mu \mathrm{g} /$ person per day) (Table A3.14).

Assumptions for dietary exposure assessment

The following assumptions were used in dietary exposure estimates:

- Residues of emamectin are only found in finfish.

\section{Inputs}

The inputs for the dietary exposure assessment for emamectin are given in Tables A3.15A3.18.

Table A3.15. Reference values for emamectin exposure assessment

\begin{tabular}{lcl}
\hline NOEL & 0.25 & $\mathrm{mg} / \mathrm{kg} \mathrm{bw} / \mathrm{d}$ \\
Safety factor & 500 & \\
ADI & $0-0.5$ & $\mu \mathrm{g} / \mathrm{kg} \mathrm{bw} / \mathrm{d}$ \\
ARfD & 10 & $\mu \mathrm{g} / \mathrm{kg} \mathrm{bw} / \mathrm{d}$ \\
\hline
\end{tabular}

Table A3.16. Foods included in the exposure assessment for emamectin and the associated $\mathrm{MRL}$ and marker residue to total residue ratio

\begin{tabular}{cccc}
\hline Food & $\begin{array}{c}\text { median } \\
\boldsymbol{\mu g} / \mathbf{k g}\end{array}$ & $\begin{array}{c}\text { 95th percentile } \\
\boldsymbol{\mu g} / \mathbf{k g}\end{array}$ & MR:TR \\
\hline Muscle (Fish) & 33.5 & 67.9 & 0.9 \\
\hline NOTES: MR:TR is the ratio of marker residue to total residue.
\end{tabular}

Table A3.17. Consumption of food used in chronic exposure assessment for emamectin

\begin{tabular}{l|c|c|c|c|c|c|c|c|c}
\hline & & \multicolumn{4}{c}{ Consumption $(\mathbf{g})$} \\
Category & Type & \multicolumn{4}{c}{ whole population } & \multicolumn{2}{c}{ children } & \multicolumn{2}{c}{ infants } \\
& & Model diet & Mean & High & Mean & High & Mean & High \\
\hline & & 300 & 27 & 655 & 24 & 226 & 1.3 & 32.5 \\
\hline
\end{tabular}

Table A3.18. Consumption of food used acute exposure assessment for emamectin

\begin{tabular}{l|cccccc}
\hline Category & Type & \multicolumn{3}{c}{ Whole population } \\
& Model diet & 97.5th/person & $\begin{array}{c}\text { 97.5th/kg } \\
\text { bw }\end{array}$ & 97.5th/person & 97.5th/kg bw \\
\hline Fish and seafood & Fish & 300 & 2000 & 27.8 & 345 & 24.9 \\
\hline
\end{tabular}

\section{GECDE}

Using the median residue and fish consumption as inputs, the GECDE for the general population was $24.2 \mu \mathrm{g} /$ person per day $(0.40 \mu \mathrm{g} / \mathrm{kg}$ bw per day), which is equivalent to $81 \%$ of the upper bound of the ADI. The higher exposure estimate compared with the EDI was due to the higher consumption of fish used in the GECDE, $10 \mathrm{~g} / \mathrm{kg}$ bw per day (655 g/person), compared with $300 \mathrm{~g}$ of muscle (fish) per person used in the model diet. The consumption data for fish are based on 1043 consumers from a Brazilian nutrition survey 
and are considered a robust estimate of high-level chronic fish consumption. This estimate is considered conservative for the 97.5th percentile of the global population (Table A3.19).

In children, the GECDE was $0.56 \mu \mathrm{g} / \mathrm{kg}$ bw per day, which represented $111 \%$ of the upper bound of the ADI. This estimate above the ADI was due to a consumption amount of fish (226 g) that was very similar to the model diet being combined with the lower bodyweight of the population group, resulting in a comparatively high exposure on a bodyweight basis. Exposure of infants was estimated to be lower, at $0.24 \mu \mathrm{g} / \mathrm{kg}$ bw per day, because fish consumption in infants is $10 \%$ of that in the model diet.

Table A3.19. Estimated chronic exposure (GECDE) to emamectin for the general population, children and infants based on the corrected MRL and an ADI of $0.5 \mu \mathrm{g} / \mathrm{kg}$ bw/day

\begin{tabular}{|c|c|c|c|c|}
\hline \multirow{2}{*}{ Population } & \multirow{2}{*}{$\begin{array}{c}\text { Bodyweight } \\
\text { kg }\end{array}$} & \multicolumn{2}{|c|}{ GECDE } & \multirow{2}{*}{$\begin{array}{c}\text { ADI } \\
\%\end{array}$} \\
\hline & & $\mu \mathrm{g} /$ person/day & $\mu \mathrm{g} / \mathrm{kg}$ bw/day & \\
\hline General population & 60 & 24.2 & 0.40 & 81 \\
\hline Children & 15 & 8.4 & 0.56 & 112 \\
\hline Infants & 5 & 1.2 & 0.24 & 48 \\
\hline
\end{tabular}

\section{GEADE}

The Committee derived an $\mathrm{ARfD}^{7}$ of $10 \mu \mathrm{g} / \mathrm{kg}$ bw for emamectin residues. Therefore, an estimate of acute dietary exposure was carried out to characterize the risk of dietary exposure. The GEADE was calculated based on the 95th percentile residues, adjusted for the marker to total residue ratio. The GEADE for the general population was approximately $1.97 \mu \mathrm{g} / \mathrm{kg}$ bw per day. For children, the

Table A3.20. GEADE for emamectin for the general population, children and infants, based on the MRL and proposed MRL adjusted for Marker/total ratio

\begin{tabular}{lcc}
\hline \multicolumn{1}{c}{ Population } & \multicolumn{2}{c}{ GEADE } \\
& $\boldsymbol{\mu g} / \mathbf{k g}$ bw/day & \%ARfD \\
\hline General population & 1.97 & 20 \\
Children & 1.80 & 18 \\
\hline
\end{tabular}
GEADE was approximately $1.77 \mu \mathrm{g} / \mathrm{kg}$ bw per day. For the general population, the GEADE represented $20 \%$ of the ARfD. For children, the acute dietary exposure estimate was $18 \%$ of the ARfD (Table A3.20).

\section{Comparison with EDI estimates}

The calculations based on the model diet found that the median residue for emamectin resulted in exposure estimates below the ADI for the general population. Similarly, the GECDE calculations found that exposure estimates were below the ADI for the general population and for infants. However, the GECDE identified children as a population group that may experience high exposure to emamectin residues. This appears to a realistic estimate, in particular in those populations where fish consumption is high on a day-to-day basis. It should be noted that, while the consumption amounts appear reasonable, the assumptions that all fish consumed contains emamectin residues at the median concentration found in trials is highly protective of consumers as emamectin is only used (when required) in the production of some aquacultured species.

${ }^{7}$ The Committee developed an ARfD for emamectin benzoate solely for the purpose of this pilot study. 


\section{Lasalocid sodium}

\section{Summary of the EDI}

The EDI for lasalocid residues was calculated from the median residues found in poultry muscle, liver, kidney and fat. Based on the established model diet, the dietary exposure to lasalocid expressed as the EDI was $80.0 \mu \mathrm{g} /$ person per day. Dietary exposure was estimated to be $26.7 \%$ of the upper bound of the ADI of $0-5 \mu \mathrm{g} / \mathrm{kg}$ bw per day (Table A3.21).
Table A3.21. EDI calculations for lasalocid, based on the median residues associated with the MRLs for chicken tissues

\begin{tabular}{|c|c|c|}
\hline \multicolumn{3}{|c|}{ Exposure (EDI) } \\
\hline EDI, general population & $\mu \mathrm{g} /$ person/day & 80.0 \\
\hline ADI, general population & $\% A D I / p e r s o n / d a y$ & 26.7 \\
\hline
\end{tabular}

\section{Assumptions for dietary exposure assessment}

The following assumptions were used in dietary exposure estimates:

- Residues are only found in poultry.

- Residues are found in muscle, liver and kidney, skin and fat.

- All poultry offal is assumed to be liver (worst case scenario).

- Following the approach set out in the monograph, egg consumption was not included in the exposure assessment.

\section{Inputs}

The inputs used in the dietary exposure assessment for lasalocid are given in Tables $\mathrm{A} 3.22-\mathrm{A} 3.25$.
Table A3.22. Reference values for lasalocid exposure assessment

\begin{tabular}{lcc}
\hline NOAEL & 0.5 & $\mathrm{mg} / \mathrm{kg} \mathrm{bw} / \mathrm{d}$ \\
Safety factor & 100 & \\
ADI & $0-5$ & $\mu \mathrm{g} / \mathrm{kg} \mathrm{bw} / \mathrm{d}$ \\
\hline
\end{tabular}

Table A3.23. Foods included in the exposure assessment for lasalocid and associated residues of lasalocid $(\mu \mathrm{g} / \mathrm{kg})$

\begin{tabular}{lllll}
\hline \multicolumn{1}{c}{ Category } & \multicolumn{1}{c}{ Food } & median residue & p95 residue & MR:TR \\
\hline Poultry & Poultry muscle & 25.0 & 392 & 0.55 \\
& Poultry fat and skin & 41.7 & 561 & 0.52 \\
& Poultry offal (liver) & 123.9 & 1102 & 0.22 \\
\hline
\end{tabular}

NOTES: MR:TR is the ratio of marker residue to total residue. p95 $=95$ th percentile residue concentration.

Table A3.24. Consumption of food used in chronic exposure assessment for lasalocid

\begin{tabular}{|c|c|c|c|c|c|c|c|c|}
\hline \multirow{3}{*}{ Category } & \multirow{3}{*}{ Type } & \multicolumn{7}{|c|}{ Consumption (g) } \\
\hline & & \multicolumn{3}{|c|}{ General population } & \multicolumn{2}{|c|}{ children } & \multicolumn{2}{|c|}{ infants } \\
\hline & & Model diet & Mean & High & Mean & High & Mean & High \\
\hline \multirow[t]{3}{*}{ Poultry } & Poultry muscle & 300 & 118 & 352 & 35 & 207 & 6.3 & 77 \\
\hline & Poultry fat and skin & 50 & 1 & 23 & 0.05 & 3 & - & - \\
\hline & Poultry offal & $100(50)$ & 5 & 188 & 0.4 & 87 & 0.05 & 26 \\
\hline
\end{tabular}


Table A3.25. Consumption of food used in acute exposure assessment for lasalocid

\begin{tabular}{|c|c|c|c|c|c|c|}
\hline \multirow{3}{*}{ Category } & \multirow{3}{*}{ Type } & \multicolumn{5}{|c|}{ Consumption (g) } \\
\hline & & \multirow{2}{*}{ Model diet } & \multicolumn{2}{|c|}{ Whole population } & \multicolumn{2}{|c|}{ Children } \\
\hline & & & 97.5th/person & 97.5th/kg bw & 97.5th/person & 97.5th/kg bw \\
\hline \multirow[t]{3}{*}{ Poultry } & Poultry muscle & 300 & 1120 & 15.4 & 467 & 35.3 \\
\hline & Poultry fat and skin & 50 & 50 & 0.9 & 20 & 1 \\
\hline & Poultry offal & $100(50)$ & 389 & 7.2 & 130 & 5.6 \\
\hline
\end{tabular}

\section{GECDE}

The GECDE for lasalocid was calculated from the consumption of poultry muscle, poultry fat and skin and total poultry offal. Exposure estimates for the general population were $111.3 \mu \mathrm{g} /$ person per day, or $1.86 \mu \mathrm{g} / \mathrm{kg}$ bw per day. The GECDEs for children and infants were 3.37 and $2.99 \mu \mathrm{g} / \mathrm{kg}$ bw per day, respectively. None of the dietary exposure estimates using the new methodology exceeded the upper bound of the ADI; the GECDEs were 37\% (general population), 67\% (children) and 60\% (infants) of the upper bound of the ADI of $5 \mu \mathrm{g} / \mathrm{kg}$ bw per day (Table A3.26).

Table A3.26. Estimated chronic exposure (GECDE) to lasalocid residues for the general population, children and infants based on the MRL and an upper bound of the ADI of $5 \mu \mathrm{g} / \mathrm{kg}$ bw/day

\begin{tabular}{|c|c|c|c|c|}
\hline & \multirow{2}{*}{ Bodyweight (kg) } & \multicolumn{2}{|c|}{ GECDE } & \multirow{2}{*}{$\begin{array}{l}\text { AD } \\
(\%)\end{array}$} \\
\hline & & $\mu \mathrm{g} /$ person/day & $\mu \mathrm{g} / \mathrm{kg}$ bw/day & \\
\hline General population & 60 & 111.3 & 1.86 & 37 \\
\hline Children & 15 & 50.6 & 3.37 & 67 \\
\hline Infants & 5 & 14.9 & 2.99 & 60 \\
\hline
\end{tabular}

For all population groups, poultry offal was the major contributor to estimated dietary exposure from lasalocid residue. Poultry fat and skin contributed only negligible amounts to overall dietary exposure estimates (Table A3.27).

Table A3.27. Estimated exposure of the general population, children and infants (up to 11 months) to lasalocid residues from animal foods. The major contributors to exposure (based on high usual consumers at the 97.5th percentile) are shaded.

\begin{tabular}{llcccc}
\hline \multicolumn{1}{c}{ Category } & \multicolumn{1}{c}{ Type } & \multicolumn{2}{c}{ Exposure $(\boldsymbol{\mu g} /$ person/day) } \\
& & General population & Children & Infants \\
\hline Poultry & Poultry muscle & 5.4 & 1.6 & 0.3 \\
Poultry & Poultry fat and skin & 0.1 & $<0.1$ & NC \\
Poultry & Poultry offal & 105.9 & 49.0 & 14.6 \\
\hline
\end{tabular}

NOTES: NC= Not consumed.

\section{GEADE}

The GEADE for the general population was $39.00 \mu \mathrm{g} / \mathrm{kg}$ bw/day. For children, the GEADE was $42.67 \mu \mathrm{g} / \mathrm{kg} \mathrm{bw} /$ day. As there is no ARfD, these numbers were not compared against reference values (Table A3.28). The GEADE was calculated based on the 95th percentile of lasalocid residues. Like chronic exposure estimates, poultry offal is the major contributor to estimated exposure in the general population and children. Muscle is also a major contributor for both populations. 
Table A3.28. Estimated acute exposure to lasalocid by food for the general population and children. The major contributors to estimated exposure are shaded.

\begin{tabular}{llcc}
\hline \multicolumn{1}{c}{ Category } & \multicolumn{1}{c}{ Type } & \multicolumn{2}{c}{ Exposure $(\boldsymbol{\mu g} / \mathbf{k g}$ bw/day) } \\
& & General population & Children \\
\hline Poultry & Poultry muscle & 7.97 & 18.27 \\
Poultry & Poultry fat and skin & 0.75 & 0.83 \\
Poultry & Poultry offal & 30.28 & 23.55 \\
\hline TOTAL (GEADE) & & 39.0 & 42.67 \\
\hline
\end{tabular}

\section{Comparison with EDI estimates}

The calculations based on the model diet found that the median residues resulted in exposure estimates below the ADI. Similarly, the GECDE calculations found that exposure estimates were below the ADI for all population groups. However, GECDE were higher than the EDI, particularly for children and infants. Poultry offal was the major contributor to both chronic and acute exposure estimates.

\section{Monepantel}

\section{Summary of EDI}

The EDI for monepantel was calculated based on median residues found in muscle, liver, kidney and fat of sheep, determined after a 7-day withdrawal period. The estimated dietary exposure was $443 \mu \mathrm{g}$ / person per day, which is equivalent to $37 \%$ of the upper bound of the ADI of 0

Table A3.29. Calculation of the EDI for monepantel based on the median residues associated with the MRLs for sheep tissues

\begin{tabular}{llc}
\hline & Exposure (EDI) \\
\hline EDI, general population & $\mu \mathrm{g} /$ person/day & 443 \\
ADI, general population & $\% \mathrm{ADI} /$ person/day & 37 \\
\hline
\end{tabular}
$20 \mu \mathrm{g} / \mathrm{kg}$ bw per day (Table A3.29).

\section{Assumptions for dietary exposure assessment for monepantel}

The following assumptions were used in dietary exposure estimates:

- Residues are only found in sheep and other ovines.

- Residues are found only in muscle, liver and kidney and fat.

- For infants, all offal consumed is assumed to be worst case.

\section{Inputs}

The inputs for the dietary exposure assessment are given in Tables A3.30 and A3.31. Food consumption data used were the same as for derquantel (Tables A3.9 and A3.10)
Table A3.30. Reference values for monepantel exposure assessment

\begin{tabular}{lrc}
\hline NOAEL & 1.8 & $\mathrm{mg} / \mathrm{kg} \mathrm{bw} / \mathrm{d}$ \\
Safety factor & 100 & \\
ADI & $0-20$ & $\mu \mathrm{g} / \mathrm{kg} \mathrm{bw} / \mathrm{d}$ \\
\hline
\end{tabular}


Table A3.31. Foods included in exposure assessment and associated residues for monepantel

\begin{tabular}{llcccc}
\hline \multicolumn{1}{c}{ Category } & \multicolumn{1}{c}{ Type } & Median $(\boldsymbol{\mu g} / \mathbf{k g})$ & $\begin{array}{c}\text { 95th percentile } \\
(\boldsymbol{\mu g} / \mathbf{k g})\end{array}$ & MR:TR & $\begin{array}{c}\text { Sulfone } \\
\text { correction }\end{array}$ \\
\hline Mammalian muscle & Sheep and other ovines & 152 & 528 & 1.00 & 0.94 \\
Mammalian offal & Mammalian liver & 1295 & 6666 & 0.66 & 0.94 \\
Mammalian offal & Mammalian kidney & 406 & 1722 & 0.66 & 0.94 \\
Mammalian offal & All mammalian offal & 1295 & 6666 & 0.66 & 0.94 \\
Mammalian trimmed & Mammalian trimmed fat, & 2660 & 13213 & 0.66 & 0.94 \\
\hline fat, skin and added fat & skin and added fat & & & & 0.96 \\
\hline
\end{tabular}

NOTES: MR:TR is the ratio of marker residue to total residue. The marker residue for monepantel is monepantel sulfone.

\section{GECDE}

The GECDE was calculated from the consumption of sheep and other ovine muscle, mammalian liver, mammalian kidney and mammalian trimmed fat. For the general population, exposure was estimated to be $8.01 \mu \mathrm{g} / \mathrm{kg}$ bw per day ( $480.5 \mu \mathrm{g} /$ person per day). The GECDE for children was $13.24 \mu \mathrm{g} / \mathrm{kg}$ bw per day. Exposure of infants was estimated to be $11.46 \mu \mathrm{g} / \mathrm{kg}$ bw per day. The median residue found in liver was assigned to all mammalian offal, because liver consumption and kidney consumption were not reported separately for this population. None of the dietary exposure estimates using the new methodology exceeded the upper bound of the ADI; the GECDEs were $40 \%$ (general population), $66 \%$ (children) and 57\% (infants) of the upper bound of the ADI (Table A3.32).

For the general population, mammalian fat was the major contributor to estimated dietary exposure from monepantel residue. For children, mammalian liver contributed substantially more than fat to exposure. For infants, no consumption of fat was reported. Therefore, almost all of the estimated dietary exposure came from mammalian offal (Table A3.33).

Table A3.32. Chronic exposure (GECDE) to monepantel residue for the general population, children and infants, based on the Median Residue, and MRL and proposed MRL adjusted for Marker:Total residue ratio and correction factor for measurement as sulfone

\begin{tabular}{|c|c|c|c|c|}
\hline \multirow{2}{*}{ Population } & \multirow{2}{*}{ Bodyweight (kg) } & \multicolumn{2}{|c|}{ GECDE } & \multirow{2}{*}{ ADI (\%) } \\
\hline & & $\mu \mathrm{g} /$ person/day & $\mu \mathrm{g} / \mathrm{kg}$ bw/day & \\
\hline General population & 60 & 480.5 & 8.01 & 40 \\
\hline Children & 15 & 198.6 & 13.24 & 66 \\
\hline Infants & 5 & 57 & 11.46 & 57 \\
\hline
\end{tabular}

Table A3.33. Exposure to monepantel residues by food for the general population, children and infants (up to 11 months). The major contributors to exposure (based on high usual consumers at the 97.5th percentile) are shaded.

\begin{tabular}{llccc}
\hline \multicolumn{1}{c}{ Category } & \multicolumn{1}{c}{ Type } & \multicolumn{3}{c}{ Exposure $(\boldsymbol{\mu g} /$ person/day) } \\
& & General population & Children & Infants \\
\hline Mammalian muscle & Sheep and other ovines & 3.0 & 1.9 & 0.1 \\
Mammalian offal & Mammalian liver & 3.7 & 190.0 & N/A \\
Mammalian offal & Mammalian kidney & 0.3 & 0.3 & N/A \\
Mammalian offal & All mammalian offal & N/A & N/A & 57.2 \\
Mammalian fat & Mammalian trimmed fat & 473.6 & 6.4 & NC \\
\hline
\end{tabular}

NOTES: N/A = Not applicable; NC = Not consumed. 


\section{GEADE}

The GEADE for monepantel was calculated based on the 95th percentile of monepantel residues. The GEADE for the general population was $206.28 \mu \mathrm{g} / \mathrm{kg}$ bw $/$ day. For children, the GEADE was $170.55 \mu \mathrm{g} / \mathrm{kg}$ bw/day. As there is no ARfD, these numbers were not compared against reference values (Table A3.34).

Like chronic exposure estimates, mammalian fat is the major contributor to exposure in the general population, and mammalian liver is the main contributor in children, but both tissues are substantial contributors to acute dietary exposure estimates in both population groups (Table A3.34).

Table A3.34. Exposure based on 97.5th percentile consumption by food for the general population and children. The major contributors to exposure are shaded

\begin{tabular}{llcc}
\multicolumn{1}{c}{ Category } & \multicolumn{2}{c}{ Type } & \multicolumn{2}{c}{ Exposure( $\boldsymbol{\mu g} / \mathbf{k g}$ bw/day) } \\
& & General population & Children \\
\hline Mammalian muscle & Sheep and other ovines & 5.51 & 4.81 \\
Mammalian offal & Mammalian liver & 78.80 & 86.40 \\
Mammalian offal & Mammalian kidney & 31.64 & 30.41 \\
Mammalian fat & Mammalian fat & 90.33 & 48.93 \\
\hline TOTAL (GEADE) & & 206.28 & 170.55 \\
\hline
\end{tabular}

\section{Comparison with EDI estimates}

The calculations for monepantel based on the model diet found that EDI resulted in exposure estimates of $37 \%$ of the ADI. The GECDE estimates were very close to the EDI, but it was shown that exposure was higher in children and infants, 66 and $57 \%$ of the ADI of $20 \mu \mathrm{g} / \mathrm{kg}$ bw/day. In summary, none of the chronic exposure estimates exceeded the ADI.

\section{Outcomes, conclusions and further investigation}

\section{Outcomes}

Overall, moving from a model diet-based approach (the EDI or TMDI), to a GECDE and GEADE approach allows dietary exposure assessments of veterinary drug residues to be based on more accurate consumption data, and so provides an improved estimate of dietary exposure. The use of more detailed consumption data and the calculation of exposure on a bodyweight basis across a wider range of population groups increase the breadth and flexibility of the risk assessment process. Care must be taken in the interpretation of chronic dietary exposure information expressed per kilogram of bodyweight in children and infants, as their consumption per kilogram of bodyweight will change over time, and the ADI is based on lifetime exposure.

The outcomes of the chronic dietary exposure assessments (i.e. EDI and GECDE) were generally similar (Table A3.35), i.e. exposure estimates did not exceed the ADI. However, estimates were generally somewhat more conservative using the new approach. As expected, exposures for children were usually higher, reflecting the higher consumption per kilogram bodyweight of this population group. In addition, the high consumption of offal reported for children who are consumers of these foods contributed to higher GECDEs in some cases. As offal is often a major contributor to dietary exposure, a higher level of confidence is required in the consumption of these foods. However, consumer numbers are often small, and deriving a reliable 97.5 th percentile of consumption can be difficult.

Estimates of exposure to emamectin residues in fish were substantially higher using the new method for chronic exposure assessment. This was due to the comparatively low 
consumption amount for fish used in the model diet to calculate the EDI. In contrast, the GECDE is based on more accurate high-level chronic consumption amounts (based on large numbers of consumers), which are more than double the amount used for fish in the food basket. However, it should be noted that the assumptions that all fish consumed comes from aquaculture rather than wild catches, and that all aquacultured fish have been treated with the drug, are highly conservative.

As the Committee derived an ARfD for emamectin benzoate, it was possible to carry out an acute exposure assessment for that compound. The outcome was that the ARfD was not exceeded for any of the population groups. As the assumptions made in the assessment were robust and conservative for both consumption and residue concentration, the exposure assessment should be suitable to assist in formulating MRLs that are sufficiently protective of consumers.

Table A3.35. A comparison of dietary exposure of the general population to five chemical residues estimated using a model diet and GECDE

\begin{tabular}{lcccc}
\hline \multicolumn{1}{c}{ Chemical } & $\begin{array}{c}\text { ADI } \\
(\boldsymbol{\mu} \mathbf{g} / \mathbf{k g} \text { bw/d) }\end{array}$ & EDI (TMDI) & $\begin{array}{c}\text { GECDE } \\
\text { \% ADI }\end{array}$ & $\begin{array}{c}\text { Difference between EDI } \\
\text { (or TMDI) and GECDE }\end{array}$ \\
\hline derquantel & $0-0.3$ & $(38)$ & 39 & none \\
emamectin & $0-0.5$ & 37 & 81 & more conservative \\
lasalocid & $0-5$ & 27 & 37 & more conservative \\
monepantel & $0-20$ & 37 & 40 & slightly more conservative \\
\hline
\end{tabular}

\section{Conclusions}

The following general conclusions were drawn from the pilot of the new approach to carry out dietary exposure assessment:

- The new approach for dietary exposure assessment is preferable to the model diet approach because it moves from a theoretical food basket to consumption amounts derived from surveys. For future meetings of the Committee, the new approach should continue to be used in parallel with the model diet approach until more experience has been obtained in the interpretation of the results with the new approach.

- Like the EDI, the GECDE and GEADE rely on realistic and reliable median and 95th percentile residue data in all foods that are contributors to exposure to a veterinary drug residue. It should be communicated to sponsors and Codex member states that such data form an essential part of the data package needed by the Committee to establish MRLs.

- Global food consumption data change over time. The latest and best quality consumption data available should be used in all dietary exposure assessments.

- Exposure can be estimated for population groups other than the general population, such as children and infants.

- For future assessments, it would be better practice to express dietary exposure on a bodyweight basis rather than a per person basis to allow for easier comparison with the ADI across population groups. Care should be taken in interpreting the comparisons.

- The GEADE approach is suitable for deriving an estimate of acute dietary exposure.

- GECDE and GEADE use higher consumption amounts to calculate exposure to residues of veterinary drugs from fish. This would result in higher estimates of dietary exposure to veterinary drug residues in fish compared with the EDI. 
- In some categories, such as mammalian muscle, the exposure estimates following the new methodology may include residues from more than one species (e.g. from cattle as well as poultry). When estimating the GECDE, there is only a single major contributor to exposure: that food that is the highest contributor to exposure using the chronic 97.5th percentile of consumption. In most cases, this makes it unlikely that including additional foods in the exposure assessment would substantially increase chronic exposure estimates.

\section{Areas for further investigation}

A number of areas were identified that should be investigated further to improve dietary exposure assessment methodology of residues in veterinary chemicals. The Committee recommends that a working group should be set up to investigate the following:

- The EDI, GECDE and GEADE assign residue concentrations to specific tissues. If, for example, the concentration of residues in liver is higher in pigs than in sheep, the higher level is used in the estimate. If later higher residue data are submitted to establish MRLs for additional species, the dietary exposure estimate (and consequently the MRL) that was derived previously may be affected. A process should be elaborated for assessing the need to re-evaluate MRLs.

- Some veterinary drugs (e.g. emamectin benzoate) produce residues that are also found in plant-based agricultural commodities. There is a need to estimate total dietary exposure from all foods. The methods and data requirements for this need to be further explored.

- Finfish, molluscs and crustaceans are different from most other animal products, as they are consumed from wild as well as aquaculture sources. When calculating the GECDE and GEADE, options should be investigated to obtain data from Member countries that would assist in estimating the proportion of farmed fish and other seafood in the food supply.

- The highest contributor of dietary exposure to veterinary drug residues is typically the residues in organ meats (offal). Many of the data for these foods that underpin the GECDE and GEADE are based on small numbers of consumers. Guidance should be elaborated on the use of these figures.

\section{References}

Buck-Louis, G., Damstra, T., Diaz-Barriga, F., Faustman, E., Hass, U., Kavlock, R., Kimmel, C., Kimmel, G., Krishnan, K., Ludere, U. \& Sheldon, L. 2006. Perinciples for evaluating health risks in children associated with exposure to chemicals. WHO Environmental Health Criteria, No. 237. Available at http:/ / www.who.int/ipcs/publications/ehc/ehc237.pdf?ua=1 Accessed 2014-05-27.

FAO. 1967. Specifications for the identity and purity of food additives and their toxicological evaluation: some flavouring substances and non-nutritive sweetening agents (Eleventh report of the Joint FAO/WHO Expert Committee on Food Additives). FAO Nutrition Meetings Report Series, No. 44.

FAO/WHO. 2009a. Report of the Eighteenth Session of the Codex Committee on Residues of Veterinary Drugs in Foods, Natal, Brazil, 11-15 May 2009. Joint FAO/WHO Food Standards Programme, Codex Alimentarius Commission, 2009 (ALINORM 09/32/31). Available at: http:// www.codexalimentarius.org/download/report/726/al32_31e.pdf Accessed 2014-05-14.

FAO/WHO. 2009b. Principles and methods for the risk assessment of chemicals in food. Environmental Health Criteria, 240. World Health Organization, Geneva. Available at: http://www.who.int/foodsafety/chem/principles/en/index1.html Accessed 2014-05-14. 
FAO/WHO. 2010. Request for data on dietary intake (consumption) of standard and non-standard animal tissues and food of animal origin (Issued 26 October 2010). Geneva, World Health Organization (http://www.who.int/foodsafety/chem/JECFA75.pdf).

FAO/WHO. 2011a. Report of the Nineteenth Session of the Codex Committee on Residues of Veterinary Drugs in Foods, Burlington, USA, 30 August-3 September 2010. Joint FAO/WHO Food Standards Programme, Codex Alimentarius Commission, 2011 (REP11/RVDF.) Available at: http://www.codexalimentarius.org/download/report/761/REP11_RVe.pdf

FAO/WHO. 2012b. Joint FAO/WHO Expert Meeting on Dietary Exposure Assessment Methodologies for Residues of Veterinary Drugs, Final Report including Report of Stakeholder Meeting. FAO Rome. Available at: http://www.who.int/foodsafety/chem/jecfa/FAOWHO_exposure_report.pdf Accessed 2014-05-14.

JECFA. 1989. Evaluation of certain veterinary drug residues in food (Thirty-fourth report of the Joint FAO/WHO Expert Committee on Food Additives). WHO Technical Report Series, No. 788. WHO, Geneva. Available at: http:/ /whqlibdoc.who.int/trs/WHO_TRS_788.pdf?ua=1 Accessed 2014-0515.

JECFA. 2000. Evaluation of certain veterinary drug residues in food (Fifty-second report of the Joint FAO/WHO Expert Committee on Food Additives). WHO Technical Report Series, No. 893. WHO, Geneva. Available at: http:/ / whqlibdoc.who.int/trs/WHO_TRS_893.pdf?ua=1 Accessed 2014-0515.

JECFA. 2006. Evaluation of certain veterinary drug residues in food (Sixty-sixth report of the Joint FAO/WHO Expert Committee on Food Additives). WHO Technical Report Series, No. 939. WHO, Geneva. Available at: http://whqlibdoc.who.int/publications/2006/9241209399_eng.pdf?ua=1 Accessed 2014-05-15.

JECFA. 2009. Evaluation of certain veterinary drug residues in food (Seventieth report of the Joint FAO/WHO Expert Committee on Food Additives). WHO Technical Report Series, No. 954. WHO, Geneva. Available at: http://whqlibdoc.who.int/trs/WHO_TRS_954_eng.pdf?ua=1 Accessed 2014-05-15.

JECFA. 2012. Evaluation of certain veterinary drug residues in food (Seventy-fifth report of the Joint FAO/WHO Expert Committee on Food Additives). WHO Technical Report Series, No. 969. WHO, Geneva. Available at: http://whqlibdoc.who.int/publications/2012/9789241209694_eng.pdf?ua=1 Accessed 2014-05-15.

Lewinsohn, P.M., Holm-Denoma, J.M., Gau, J.M., Joiner, T.E. Jr., Streigel-Moore, R., Bear, P. \& Lamoureux, B. 2005. Problematic eating and feeding behaviours of 36-month-old children. International Journal of Eating Disorders 38(3): 208-219.

Marcus, M. \& Kalarchian, M. 2003. Binge eating in children and adolescents. International Journal of Eating Disorders, 34: S47-S57.

WHO. 2013. Global Environment Monitoring System - Food Contamination Monitoring and Assessment Programme (GEMS/Food), modified June 20, 2013; World Health Organization, Geneva. Available at: http://www.who.int/foodsafety/chem/gems/en/ 


\section{Annex 4-Response from JECFA to nine questions posed by CCRVDF 20}

\section{Introduction}

The 20th Session of the Codex Committee on Residues of Veterinary Drugs in Foods (CCRVDF), meeting in San Juan, Puerto Rico (7-11 May, 2012) considered a working paper on the extrapolation of maximum residue limits (MRLs) to additional species and tissues (CX/RVDF 12/20/15). Following discussion, the CCRVDF posed a series of questions to JECFA to better determine whether Environmental Health Criteria (EHC) 240 (FAO/WHO, 2009) provides sufficient guidance for JECFA to develop a scientific framework for extrapolating MRLs between species and tissues (See REP12/RVDF). The JECFA Secretariat responded that an electronic working group of JECFA would be convened "to develop minimum criteria for information upon which to base extrapolation between food animals and commodities".

\section{Procedure for preparation of this document}

The JECFA Secretariat engaged a consultant to prepare a draft working paper to review the background and describe current JECFA practices regarding extrapolation of MRLs from major to minor species by JECFA, to review available guidance from other sources, and to prepare responses to each of the questions forwarded from the 20th Session of the CCRDVF. The working paper was then circulated to an electronic working group of JECFA residue experts for comment and discussion ${ }^{1}$. The nine questions forwarded to JECFA by the 20th Session of the CCRVDF are listed below, with the responses to each question as agreed by the electronic working group.

The JECFA Secretariat has also provided comments, assisted by the electronic working group, in response to the request for JECFA advice on the proposed Risk Analysis Policy on Extrapolation of MRLs of Veterinary Drugs to Additional Species and Tissues, and in response to the request for JECFA advice on the CCRVDF Discussion paper on the policy for the establishment of MRLs or other limits for honey (CX/RVDF 12/20/14).

Further detailed guidance on extrapolation was developed by the 78th session of JECFA, including minimum criteria for information upon which to base extrapolation between food animals and commodities.

\section{Response to the nine questions from the 20th CCRVDF}

\section{Question 1}

EHC 240 does not define "what comparable metabolic profile between species" means. JECFA may wish to consider elaboration of the criteria described in EHC 240 (such as the precise definition of "metabolically comparable").

\section{JECFA Response}

A "comparable metabolic profile between species" implies that the same major metabolites are present in both species and that they are present in similar proportions. When comparing metabolic profiles qualitatively, the same major compounds should appear in the metabolic profile. This may include both parent compound (if available) and one or more metabolites, including bound residues. Quantitatively, the compounds should be present in similar

1 The electronic working group consisted of Drs Joe Boison, Alan Chicoine, Holly Erdely, Lynn Friedlander, Fernando Ramos, Pascal Sanders, Stefan Scheid and Zonghui Yuan. 
proportions, within reasonable limits reflecting measurement uncertainty and biological variability. JECFA has not to this point established precise numerical limits for quantitative comparison of metabolic profiles. This is still subject to interpretation on a case-by-case basis, based on the data provided.

\section{Question 2}

Guidance on the criteria/assumptions to be used for interspecies extrapolations, including minimum data required to support such extrapolation among physiological related species, and extrapolation to additional (unrelated) species.

\section{JECFA Response}

When requested to consider the extrapolation of MRLs to another species, JECFA must address certain issues related to the approved usage of the drug, toxicology of the drug residues and the dietary intake calculations, based on the MRLs, which are used to ensure consumer safety. Issues considered by JECFA include:

- JECFA bases MRL recommendations on the authorized use of drugs (GVP). Without an existing approved use for a drug in a minor species in a member state and provision of a label or equivalent information documenting the approved use, JECFA does not recommend MRLs for the drug in the minor species.

- JECFA will consider a request for extrapolation of MRLs from a major species, which the 52nd JECFA defined as being cattle, sheep, pigs and chickens, when full MRLs have been recommended for one or more major species. JECFA does not generally consider extrapolation of MRLs from a major species to a minor species when only temporary MRLs are recommended for the major species.

- There should not be any metabolites or bound residues of unknown toxicity in the minor species that are not present in the major species. Comparative metabolism in the minor and major species may be shown through available scientific literature sources, through a limited experiment with a minimum number of test animals, or through in vitro methods, as described in VICH guidance.

- When the marker residue is the only residue of toxicological concern, it is not necessary to consider total residues in the dietary intake estimates, thus eliminating one of the issues that must be addressed when considering extrapolation of MRLs. However, when the total residue is considered to be of toxicological concern, then the ratio between marker and total residues (MR:TR ratio) must be considered.

- If the conditions of use are the same or equivalent in the two species, then similar depletion profiles may be deduced from limited pharmacokinetic, metabolism and/or depletion data. If there are differences in pharmacokinetics observed in the two species and very limited data from depletion experiments, or if the conditions of use differ significantly in the two species, the available data may be considered insufficient to warrant extrapolation, requiring submission of additional data to provide a basis for the recommendation of MRLs for the minor species.

- If data from a full residue study in the minor species are provided, MRLs will be derived using that data, which may result in extension of the MRLs already established for a major species to the minor species. This process does not involve extrapolation.

- The relative amounts of the food basket items used in the intake calculation are currently considered suitable to represent the majority of consumers and should, in fact, provide an inflated estimate of the food consumed on a daily basis by most typical consumers. JECFA is considering alternatives to the present dietary intake calculations, but currently applies the same food basket to foods from all species, using the MRLs for each food basket item that yield the highest intake estimate. 
- Analytical methodology should be available for the monitoring of drug residues in the minor species. Preferably, there should be a method that has been validated for food basket items from the minor species, although there may be situations where JECFA experts are satisfied that a method validated for the food basket items from a major species should be applicable to the same items from the minor species.

- The quantity and quality of data available to JECFA when reviewing a request for extrapolation of MRLs from a major to a minor species are quite variable, usually requiring considerable discussion and the application of expert judgement on a caseby-case basis as to whether the data available from all sources are sufficient to support the extrapolation. Thus, it is important that all available information pertaining to the approved use and residues associated with that use in a minor species should be provided to JECFA.

\section{Question 3a}

Possibility of extending extrapolation by JECFA similar to that allowed under the current EU guidelines.

EHC 240 does not allow for the extrapolation of MRLs from muscle of Salmonidae to other finfish, but this is allowable based on European Union guidelines. JECFA should consider extrapolation of MRLs between fish species. If the data required to support such MRL extrapolation is not available, what further work may be required?

\section{JECFA Response}

JECFA must first receive information to confirm that there is an existing approval in a member state for use of the drug in the species of fish for which extrapolation of MRLs is requested, including a label or a statement of the approved conditions of use (GVP). The conditions of approved use (GVP) may differ depending on species of fish and region. However, the water temperature at which a product is used for treatment of fish and at which residue studies have been conducted are major considerations in the recommendation of MRLs for fish. This may result in different MRLs being recommended for different species, based on the GVP established for the use of the drug in one or more fish species in a member state or member states.

\section{Question 3b}

Possibility of extending extrapolation by JECFA similar to that allowed under the current EU guidelines.

Whether MRLs can be extrapolated to all food-producing species when the established MRLs in three different "classes" of major species (ruminant, pigs, and chickens) are similar?

\section{JECFA Response}

JECFA must be provided with evidence of an approved use of the drug (GVP) in a member state for any food-producing species for which extrapolation of MRLs is requested. Since the data available for review differ for each compound and species nominated for extrapolation, review on a case-by-case basis is therefore currently considered more appropriate by JECFA than a blanket policy which would be applied in all cases.

\section{Question 4}

Whether it would be possible for JECFA to consider metabolism and pharmacokinetic data of non-food animals (such as laboratory animals or humans), in addition to the data provided for major food producing species? This might provide further evidence of a common route of metabolism within all mammals for a given compound, and could be used to justify extrapolating MRLs for that compound to all mammalian species. JECFA might also wish to consider the use of in vitro metabolic models for certain compounds. 


\section{JECFA Response}

JECFA typically includes any metabolic and pharmacokinetic data available for laboratory animals and humans in the evaluation of a drug. Requirements for a toxicological evaluation by JECFA specifically include acute and chronic toxicity experiments conducted in laboratory animals. Data generated using in vitro experiments have also been a source of information on comparative metabolism in the review of a number of compounds by JECFA. The preponderance of information, including metabolism and pharmacokinetic studies in laboratory animals and data from use in humans, has been used to recommend MRLs in one or more species for some compounds, particularly those with a long history of use in both veterinary and human medicine.

\section{Question 5}

It is understood that MRL extrapolation would be based on the principles of risk assessment. Whether the risk associated with uncertainties in extrapolation of MRLs to a new species could sufficiently be addressed by the likely lower exposure to residues from tissues of extrapolated species (e.g. tissues of certain species are consumed less frequently and in smaller quantity) and the adequacy of the safety factors already inherent in the establishment of MRLs?

\section{JECFA Response}

JECFA has consistently taken a conservative approach to the estimate of chronic exposure based on food intake, using consumption factors adopted by the 34th Meeting of the Committee and confirmed following a review of data provided by member governments of the Codex Alimentarius to the 40th Meeting of JECFA. A draft version of the Report of the Joint FAO/WHO Expert Meeting on Dietary Exposure Assessment Methodologies for Residues of Veterinary Drugs, issued in response to a request to the FAO and WHO from the 18th and 19th Meetings of the CCRVDF, was considered at the 75th Meeting of JECFA. It was decided that the dietary exposure models proposed in the Report of the Expert Meeting would be further considered at future meetings of JECFA, along with worked examples using the new models.

A primary concern is that the consumption factors used for exposure estimates should reflect the food consumption by what are termed "high level" consumers, typically those who fall in the 97.5th percentile for consumption of the food. In addition, the Expert Meeting observed that currently there are "insufficient data from different world regions to support a regional diet approach". When different MRLs are recommended for different species, JECFA currently takes a conservative approach and bases the intake calculations on residues associated with the highest potential residue consumption associated with an MRL recommended for any tissue, irrespective of species. At this time, it is perhaps premature to state how risk assessment principles might be applied to extrapolation of MRLs using the new dietary models. However, the issue raised is part of the ongoing considerations and will be addressed in any changes in approaches to estimates of dietary exposure that may be adopted in the future by JECFA.

\section{Question 6}

Whether extrapolation could consider group MRLs for therapeutically/chemically related compounds? More sophisticated approaches might need to be developed (e.g. predictive approaches using structure activity relationships or in silico tools to predict ADME properties) for its routine use.

\section{JECFA Response}

In the past, JECFA has considered and recommended group MRLs for therapeutically/chemically related compounds where appropriate. For example, the related compounds, febantel, fenbendazole and oxfendazole, which produce common metabolites, have a group MRL and share a common marker residue. The 58th JECFA recommended 
common MRLs for residues of streptomycin and dihydrostreptomycin, and also group MRLs for chlortetracycline, oxytetracycline and tetracycline residues. In each of these cases, there was an assignment of a group ADI. JECFA will continue to consider and recommend group ADIs and MRLs for chemicals which are therapeutically/chemically related, with a similar toxicological profile, and to harmonize MRL recommendations across species where the data indicate such action is appropriate.

JECFA also continues to assess developing approaches, such as the use of in silico and in vitro approaches for investigation of adsorption, metabolism, excretion and distribution (ADME) and to use data from such studies, when available. For example, data from in silico studies were included in the toxicological evaluation of derquantel by the 75th JECFA. However, caution must be taken in interpretation as in vitro studies may provide very different metabolic profiles from in vivo experiments, as the experimental conditions differ, and this could have marked influences in the observed metabolism.

\section{Question 7}

Whether extrapolation of MRLs from terrestrial species to fish could be considered.

\section{JECFA Response}

JECFA has recommended MRLs in fish without receipt of any metabolism data other than for terrestrial species, but usually based on the availability of residue depletion data. These situations are therefore more in the nature of an extension of MRLs to include the fish species, rather than extrapolation. JECFA will consider the extension or extrapolation of MRLs from terrestrial species to fish when suitable data are available to support such recommendations, such as a common level for allergic response to a residue or the availability of sufficient residue data in a species of fish. Such an extrapolation or extension of MRLs is considered on a case-by-case basis, requiring, first, evidence of an approved use of the drug for one or more species of fish in a member state, with some information on the nature of the residues found in a representative species of fish for which use was approved.

\section{Question 8}

Whether extrapolation of MRLs to honey would be feasible by using the most conservative MRL from terrestrial animal tissues and applying an appropriate factor to account for uncertainties (MR:TR ratio 2:1, likely unsubstantial residue depletion other than some degradation in honey, etc.) in extrapolation and adjusting for food consumption values?

\section{JECFA Response}

It is stated in EHC $240(\mathrm{FAO} / \mathrm{WHO}, 2009)$ that "It is not appropriate to consider honey as a candidate for extension of MRLs from one species to another because of the difficulty in extrapolating from mammals, birds or fish to bees, as the treatment modalities are not comparable." Procedures for the establishment of MRLs for the use of veterinary drugs in the production of honey were discussed at the 70th JECFA, which made a number of recommendations concerning potential approaches to the establishment of such MRLs. Issues to be considered include whether the marker residue identified for monitoring residues of a drug used in treatment of animals is also appropriate for monitoring residues in honey, and the nature of residues found in honey. While typically there is no metabolic pathway in honey, there may be degradation or dilution of residues.

JECFA bases MRL recommendations on residue data produced under GVP conditions of use in one or more member states. A critical consideration in the establishment of MRLs for honey is that the MRL must be consistent with good bee-keeping practice, i.e. the MRL should be high enough to avoid non-compliant residues from use of the substance according to the label instructions under field conditions (GVP use), but not so high as to permit use of the drug without following the withdrawal period required under the GVP approved 
conditions of use. The establishment of MRLs for honey by some form of extrapolation from MRLs previously established for tissues, milk or eggs, in the absence of residue depletion data for honey, poses the risk that MRLs may be established which are not consistent with the approved GVP usage and therefore are not practical.

It may therefore be prudent to await the outcome of a review by a future JECFA of a request to establish an MRL for a veterinary drug used in honey, at which time the practical application of the principles discussed by the 70th JECFA and the CCRVDF working group can be evaluated.

\section{Question 9}

Whether JECFA could evaluate the feasibility of inter-tissue extrapolations within the same species? However, due to limited experience in this area, it might be scientifically challenging.

\section{JECFA Response}

There is currently no scientific basis on which extrapolation of MRLs between different tissues from a species appears warranted in the absence of data that demonstrate the relative concentrations of the residue in the various tissues. Therefore, there are very limited situations in which inter-tissue extrapolation within the same species may be contemplated, such as where there is a common threshold for allergic response or an acute reference dose. The most obvious example where common MRLs are recommended by JECFA for different tissues from the same species is when there are no detectable residues of a drug in two or more tissues. In such situations, JECFA has based MRL recommendations on the limit of quantification (LOQ) of the analytical method ( $2 \times \mathrm{LOQ})$, provided that the method is considered to have a sufficiently low LOQ to ensure that any residues present were indeed at very low concentrations. The same MRL then may be assigned to multiple tissues. While there have been some publications in peer-reviewed scientific journals exploring approaches to model the distribution of residues in various tissues or fluids based on limited data, these models have not yet been validated to the point where they could be routinely applied by regulatory authorities (or JECFA) for the extrapolation of MRLs to various tissues within the same species.

\section{References}

FAO/WHO. 2009. Environmental Health Criteria (EHC) 240, Principles and Methods for the Risk Assessment of Chemicals in Food. Chapter 8: Maximum Residue Limits for Pesticides and Veterinary Drugs. A joint publication of the Food and Agriculture Organization of the United Nations and the World Health Organization. Available at: http:// www.who.int/foodsafety/chem/principles/en/index1.html; accessed March 26, 2013.

REP12/RVDF. Report of the Twentieth Session of the Codex Committee on Residues of Veterinary Drugs in Foods, San Juan, Puerto Rico, 7-11 May 2012. See para. 156. Available at: http: / / www.codexalimentarius.org/download/report/778/REP12_RVe.pdf Accessed 2014-05-15 


\title{
Annex 5 - JECFA Guidelines for the Extrapolation of MRLs to Minor Species
}

\author{
First draft prepared by \\ James D. MacNeil, Rome, Italy
}

\section{Background}

JECFA has clearly stated requirements for data to be provided to support the recommendation of MRLs for foods derived from major animal species. These may be found on the JECFA website in Procedures for Recommending Maximum Residue Limits Residues of Veterinary Drugs in Food (JECFA, 1999). These requirements have been developed over the course of JECFA Meetings and documented in the meeting reports. There are also situations where MRLs are required for use of drugs in minor species. For minor species, there typically are not the same full data packages available as are provided for review of the use of these drugs in a major species. A scientifically sound approach is therefore required to use the available information regarding the use in a minor species, combined with knowledge obtained from data available for major species and laboratory animals, as well as human use of the drug, to determine when MRLs established for one or more major species can be extrapolated to one or more minor species.

The 20th Session of CCRVDF, held in San Juan, Puerto Rico, 7-11 May, 2012, posed a number of questions to JECFA concerning the extrapolation of MRLs from major species to minor species. The FAO JECFA Secretariat appointed an electronic working group of JECFA, consisting of Drs Joe Boison, Alan Chicoine, Holly Erdely, Lynn Friedlander, James MacNeil, Fernando Ramos, Pascal Sanders, Stefan Scheid and Zonghui Yuan, to review existing JECFA policy, previous JECFA decisions and available guidance from other sources. The working group prepared responses to each of the questions on extrapolation forwarded from the 20th Session of CCRDVF. A working paper was then prepared for consideration by the 78th Meeting of the Committee to further develop policy and guidance to be used by JECFA experts when considering requests for the extrapolation of MRLs from major species to minor species.

\section{Evolution of JECFA practices regarding recommendation of MRLs by species}

The 12th Meeting of JECFA, held in 1968, was the first to consider veterinary drug residues in foods. A number of antimicrobial drugs used in the treatment of food-producing animals were evaluated and residue limits were proposed for "meat", milk and eggs (JECFA, 1969 [TRS 430]). The 26th Meeting of JECFA, held in 1982, the next to consider veterinary drug residues in foods, began the development of specific guidance for the evaluation of veterinary drug residues in foods (JECFA, 1982 [TRS 683]). Subsequently, the 27th Meeting of JECFA, held in 1983, continued the development of an evaluation policy for veterinary drug residues and proposed different residue limits to be established for trenbolone residues in "liver" and "other tissues", thus moving to more specific tissue identification than "meat" (JECFA, 1983 [TRS 696]).

The 32nd JECFA, meeting in 1987, was the first convened to respond specifically to issues forwarded from the then recently established CCRVDF (JECFA, 1988 [TRS 763]). It was given tasks that included the establishment of principles for evaluating the safety of residues of veterinary drugs in foods, determining safe levels for residues resulting from use in accordance with Good Veterinary Practice (GVP), determining criteria for appropriate analytical methods to support proposed residue limits and providing advice on other 
matters arising from the CCRVDF report. The 32nd JECFA stated a number of principles to be applied in evaluations, including the need for metabolism and pharmacokinetic data, as well as data on use, toxicology, residue depletion and residue analysis. It also recommended "Acceptable Residue Limits" for trenbolone in liver and kidney, and for zeranol in bovine muscle and liver, thus continuing the trend to be more specific as to the tissue to which residue limits would apply. The subsequent 34th Meeting of JECFA dealing with veterinary drug residues in food informed the CCRVDF that it would adopt the term "Maximum Residue Limit", which had been adopted by the CCRVDF, and also adopted the food basket approach to establishment of MRLs, which included muscle, liver, kidney, fat, milk and eggs (JECFA, 1989 [TRS 788]). The 34th JECFA recommended MRLs on the basis of this food basket and included specified species in these recommendations.

The 36th JECFA, meeting in 1990, made MRL recommendations by tissue, using the food basket approach adopted at the 34th JECFA, but many of these recommendations were for "all species" (JECFA, 1990 [TRS 799]). These recommendations were clarified by the 38th JECFA in 1991, which stated that the designation "all species" only applied to those species for which adequate data on which to base an MRL recommendation had been provided (JECFA, 1991 [TRS 815]). The 38th JECFA also stated that specific species would be named in future MRL recommendations.

The issue of extrapolation of MRLs to minor species has been discussed in the past by JECFA and CCRVDF, but without final resolution. The 52nd JECFA in 1999, for example, noted that "nearly all MRLs established to date by the Committee have been for edible tissues and for milk and eggs of major animal species (i.e. cattle, pigs, sheep and chickens); very few MRLs have been established for minor animal species (such as deer and rabbits)" (JECFA, 2000 [TRS 893]). The 52nd JECFA prepared a working paper for comment by "the next session of the CCRVDF" on guidelines to be used in the establishment of MRLs for minor species and identified major species as "cattle, sheep, pigs and chickens", while deer and rabbits were cited as examples of minor species. The 12th Session of the CCRVDF, in 2000, considered the working paper from JECFA and also a working paper prepared by a CCRVDF Working Group on data requirements for the establishment of MRLs for minor species. After some discussion, these working papers prepared by JECFA and the CCRVDF working group were referred to a new CCRVDF drafting group which would be considering all aspects of risk analysis "for further consideration of such issues as data requirements and extrapolation for incorporation into the general framework of risk analysis" (FAO/WHO, 2000). However, the extrapolation issue has not been addressed in the text of the "Risk Analysis Principles Applied by the Codex Committee on Residues of Veterinary Drugs in Foods" as contained in the 21st edition of the Codex Alimentarius Commission Procedural Manual (FAO/WHO, 2013). In the meantime, JECFA had recommended MRLs for minor species for a number of compounds from the 36th through the 60th meetings of the committee (FAO, 2003).

The extrapolation of MRLs was considered in the work of the Codex Update Project conducted in the last decade, resulting is the guidance included in Environmental Health Criteria (EHC) 240, which is discussed in the next section (FAO/WHO, 2009). While EHC 240 was not published until 2009, the consultation that provided the information used in the drafting of Chapter 8, in which guidance on extrapolation of veterinary drug MRLs is provided, was held in Bilthoven, the Netherlands, in 2005, with a report published in 2006 (FAO/WHO, 2006). Thus, the general principles on extrapolation contained in EHC 240 were available to the 66th JECFA Meeting and referenced in the meeting report (JECFA, 2006 [TRS 939]). The recommendations from the Bilthoven consultation include a recommendation intended for JECFA that:

"Procedures for extrapolation from one species of animal having a full data set and recommended MRLs to another species need to be agreed upon and harmonized guidance documents prepared." 
The 66th JECFA recommended MRLs for colistin and erythromycin in "poultry", based on metabolic data for chickens (JECFA, 2006 [TRS 939]; FAO, 2006). No metabolic data for other poultry species, such as turkeys, were included in the review, but there were data indicating the presence of the marker residue and the availability of a suitable analytical method. MRLs recommended for triclabendazole for sheep were also extended to goats at this meeting, based on metabolic and residue data for two other major ruminant species (cattle, sheep), plus limited metabolic and residue data for goats. This decision was later revoked by the 70th JECFA (FAO, 2009) and that decision was confirmed by the 75th JECFA (FAO, 2011), following a question on the issue posed by the CCRVDF (FAO/WHO, 2010). The 70th JECFA recommended MRLs for avilamycin in turkey and rabbit tissues, based on metabolic data for rats and pigs, plus limited residue depletion data for turkey and rabbits, including a demonstration of presence of marker residue and available analytical methodology (FAO, 2009). The 70th JECFA also recommended MRLs for residues of dexamethasone in horse tissues, based on studies considered by the 42nd JECFA (FAO, 2004; JECFA, 1995 [TRS 851]), plus the presence of the marker residue in the tissues and the availability of an analytical method that the Committee considered could be extended to horse tissues. In addition, the 70th JECFA recommended MRLs for monensin in tissues of goat, turkey and quail, based on the availability of metabolic data for species that included chicken, turkey, goat and other ruminants, the presence of marker residue in tissues and the availability of suitable analytical methodology.

The 66th Meeting of JECFA made the following statement with respect to the use of the term extrapolation (JECFA, 2006 [TRS 939]):

"The Committee concluded that extrapolation may not be the appropriate term, but rather extension of the MRL."

However, this terminology has not been adopted by CCRVDF and the term extrapolation was subsequently used in the report of the 75th JECFA (JECFA, 2012 [TRS 969]).

\section{Sources of guidance on extrapolation}

\section{Guidance in EHC 240}

Some general guidance on the extrapolation of MRLs for residues of veterinary drugs in foods is contained in the FAO/WHO publication Environmental Health Criteria, No. 240, (FAO/WHO, 2009). It is noted in the discussion of extrapolation in this document that:

"JECFA has routinely recommended MRLs in animal species such as cattle, pigs, sheep, chickens and turkeys. JECFA has recommended MRLs for at least 15 substances in some species, including horses, goats, deer and rabbits, on the basis of data from related species (FAO/WHO, 2004). This extension of MRLs from one species with a comprehensive data set to another species without such a data set has been based on considerations such as the choice of a marker residue and how similar the MRLs are for the species for which recommendations on MRLs have already been made based on data.

For the majority of substances with MRLs for more than one species, the same marker residue has been identified. For products such as eggs and milk, the marker residue is not different from those defined for edible tissues, including liver and kidney. The parent drug has been chosen as the marker residue in almost all cases.

The range of variation of the MRLs between species has routinely been a factor of 3 or less (e.g. cattle and pig muscle $300 \mu \mathrm{g} / \mathrm{kg}$, poultry muscle $800 \mu \mathrm{g} / \mathrm{kg}$ ). From the examination of the variations of MRLs between species, most of the differences can be explained by variations in ratios of the marker residue to total residues. When these differences in the ratios exist, harmonization of the MRLs across species could result in the EDI exceeding the exposure to residues permitted by the ADI for those species. JECFA has based its recommendations on two situations: 
- substances with a residue depletion study using unlabelled drug in the specific species in conjunction with data on comparative metabolism or relevant data on metabolism in another species; and

- substances where MRLs were recommended only by extrapolation of information available for another relevant species."

On the subject of extrapolation of MRLs, the following guidance is provided:

"For substances that have no MRLs recommended in any species, a full set of residue data in all relevant species and tissues should be provided so that the most complete set of MRLs can be recommended. For substances that have MRLs recommended in one or more species, MRLs could be extended to a related species provided that the metabolic profile is comparable, the marker residue is present in the species for which the extension is considered at sufficient levels for monitoring by validated analytical methods, and there is an approved use. Extension of MRLs from one species to another may be reviewed on a case-by-case basis."

Some examples of situations where there is potential for the extrapolation of MRLs are provided in an accompanying table (Table 8.8 in EHC 240 -- FAO/WHO, 2009). These include extrapolation from "ruminant (muscle, liver, kidney, fat)" to "all ruminants", "nonruminant mammals (muscle, liver, kidney, fat)" to "all non-ruminant mammals" and "chicken and eggs" to "poultry and poultry eggs".

The CCRVDF working group considering extrapolation of MRLs to minor species for discussion at the 20th Meeting of the CCRVDF concluded that the guidance in EHC 240

"allows flexibility to extrapolate MRLs from one or more species to a physiologically-related species provided that the metabolic profile is comparable, the marker residue is present in the species for which the extension is considered, an analytical method is available, and there is an approved use. No detailed criteria are described, and the guideline recommends extrapolation to be considered on a case-by-case basis"

(FAO/WHO, 2011a).

\section{Guidance from $\mathrm{VICH}$}

VICH (International Cooperation on Harmonisation of Technical Requirements for Registration of Veterinary Medicinal Products) has produced a number of guidelines that elaborate the requirements for experiments to be conducted on veterinary drug products submitted for authorization to national authorities. While VICH membership is currently limited to the European Union, the United States of America and Japan, other countries have observer status and the guidelines reflect a consensus on "best practices" from authorities who have well developed and well documented processes for the scientific evaluation of products intended for veterinary use in food producing animals. Guidance on the conduct of metabolism and residue kinetic studies to determine the quantity and identify the nature of residues (VICH, 2011a), for example, specifies the number of animals required in a study, the nature of formulations to be tested, sacrifice intervals and tests to be conducted on sample materials collected. This guideline notes that:

"There are some national/regional differences regarding the designation of major and minor species, particularly for turkeys and sheep. These differences can affect national/regional data collection requirements and recommendations. In certain instances, the total residue and metabolism data for a drug's use in a major species might be extrapolated to the minor species. When a national/regional authority calls for a total residue and metabolism study for a minor species or for a species considered to be major in one region but not another, the study design outlined in this guidance should be acceptable."

It further states that:

“Ordinarily, a single study can be performed in swine ( 40 to $80 \mathrm{~kg}$ ), sheep ( 40 to $60 \mathrm{~kg}$ ) and poultry. For cattle, a single study in beef cattle ( 250 to $400 \mathrm{~kg})$ could apply to dairy cattle, and vice versa. Generally, the results of a metabolism study in adult cattle and sheep can be extrapolated to calves and lambs, respectively. However, a second study might be appropriate 
for pre-ruminating animals if there is sufficient reason to believe the pre-ruminating animal will have metabolism significantly different from the adults. A separate study should be performed to demonstrate the total residue in milk of dairy cows."

The VICH guideline for marker residue depletion studies also provides detail on the studies to be conducted (VICH, 2011b). It states that the guidance

"encompasses the most common species, namely cattle, pig, sheep and poultry; however, the principles of this guidance can also be applied to related species not mentioned in this core group (e.g. cattle vs. all ruminants)."

The general advice is similar to that given in the studies to characterize the residues:

"Ordinarily, one marker residue depletion study (for tissues) should be performed in swine, sheep and poultry. For cattle, a single study in ruminating beef cattle could be applied to dairy cattle (or vice versa). However, because of differences in ruminant and pre-ruminant physiology, separate studies are recommended when the target species encompasses both adult and pre-ruminating animals. A separate study should be performed to demonstrate the residue depletion profile in milk of dairy animals or in eggs produced by laying hens."

Thus, while these guidelines recognize that there are situations in which extrapolation of MRLs is acceptable, no clear examples are provided other than for beef cattle to dairy cattle or cattle and sheep to calves and lambs (except pre-ruminant). No examples of inter-species extrapolation are provided.

\section{Guidance from European Union agencies}

The Committee for Veterinary Medical Products (CVMP) of the European Commission produced guidance in 1997 for the establishment of MRLs for minor species (EMEA/CVMP, 1997a) and for Salmonidae and other finfish (EMEA/CVMP, 1997b). The guidance included such considerations as the existence of MRLs for a comparable major species, the use of the same dietary intake (exposure) factors, the presence of the same marker residue, the relationship between marker and total residues, and the availability of analytical methodology. Guidance on extrapolation was also contained in EMEA/CVMP/187/00Final, dealing with risk analysis for residues of veterinary drugs (EMEA/CVMP, 2000). A subsequent note, EMEA/CVMP/069/02, reported the extrapolation of MRLs for a number of drugs (EMEA/CVMP, 2002). The CVMP subsequently produced a working paper for comment in 2003 to further address the extrapolation of MRLs (EMEA/CVMP, 2003). The goal of this consultative process was to develop a pragmatic approach to the establishment of MRLs for minor species, which would also guarantee consumer safety. The process resulted in new guidance published in 2005 (EMEA/CVMP, 2005).

On the subject of extrapolation of MRLs, this document states that:

"Where identical or very similar MRLs have been set for three major species from different animal classes (ruminants, monogastrics and poultry), based on specific residue data, confirming a similar exposure situation of the consumer in relation to these species, it can be assumed that the exposure assessment and consequently the risk characterisation on the basis of same/similar MRLs for further species beyond the animal classes concerned would be similar."

The guidance recommends the following as cases where extrapolation may be considered when MRLs have previously been established in a major species:

- major ruminant (meat) to all ruminants (meat);

- major ruminant (milk) to all ruminants (milk);

- major monogastric mammal to all monogastric mammals;

- chicken and eggs to poultry and poultry eggs;

- Salmonidae to all finfish; and

- either a major ruminant or a major monogastric mammal to horses. 
In addition,

"if identical MRLs were derived in cattle (or sheep), pigs and chicken (or poultry), which represent major species with different metabolic capacities and tissue composition, the same MRLs can also be set for ovine, equidae and rabbits, which means an extrapolation is considered possible to all food-producing animals except fish."

When MRLs have been set at different concentrations in several major species, the more conservative MRLs may be used for extrapolation to a minor species. Furthermore,

"if a validated method for major species is available, it is considered not necessary that a fully validated method is also provided for minor species. It may be sufficient to demonstrate that the method developed for the major species is basically applicable in the minor species."

It is, of course, required that the marker residue be common to the major and minor species when extrapolation is considered.

Subsequently, Regulation (EC) No 470/2009 of the European Parliament and of the Council (EEC, 2009), issued in May 2009, contained the following section (Article 5) dealing with extrapolation of MRLs:

"With a view to ensuring the availability of authorised veterinary medicinal products for conditions affecting food-producing animals, the Agency, while ensuring a high level of protection of human health, shall, when carrying out scientific risk assessments and when drawing up risk management recommendations, consider using maximum residue limits established for a pharmacologically active substance in a particular foodstuff for another foodstuff derived from the same species, or maximum residue limits established for a pharmacologically active substance in one or more species for other species."

Overall, the general principles found in the these documents are similar to those provided in EHC 240, but more specifics on implementation of the principles are provided in the European documents.

\section{Guidance from United States Food \& Drug Administration}

The United States Food and Drug Administration (FDA), Center for Veterinary Medicine (CVM), issued revised guidance for industry on the approval of new animal drugs for minor uses and minor species in 2008 (USFDA, 2008). Recommendations contained in the document reflect current thinking in the Agency, except where specific regulatory or statutory requirements are cited. Alternative approaches that satisfy any such legal requirements may therefore also be considered. The document also clearly states that the guidance is not intended to lessen the legal requirements to demonstrate effectiveness and safety for a minor use of a drug. The guidance in the document applies to all minor uses and use in minor species, both species considered as food animals and species usually referred to as companion animals in the United States of America. Various sections of the document provide guidance on avian species, fish, rabbits and other animals. The document also describes requirements related to species and age of target animals, where separate data submissions are required.

On the issue of extrapolation, the document states that "CVM allows interspecies data extrapolation to support minor use applications whenever scientifically justifiable." It also notes that this is of particular importance for food-producing animal species, where "data extrapolation may be utilized in place of some expensive human food safety studies". One of the primary issues mentioned repeatedly in the document is that where the minor use is for a drug that was originally registered by another Sponsor that holds ownership of the proprietary data used for the original approval, written consent from the owner of that data is required before it can be used by CVM in an evaluation of the proposed minor use. This may be less of an issue for JECFA, if a determination can be made from the published JECFA review documents for previous submissions of the compound. For example, JECFA will typically apply an 
established ADI when asked to consider MRLs for tissues, eggs or milk from additional species, even if the request is not from the same original Sponsor. JECFA will also consider pharmacokinetic, metabolism and residue depletion data, and analytical methodology contained in reports of previous meetings that reviewed data submissions for the same drug, even if different sponsors were involved in the data submissions at the previous meetings.

To establish MRLs for edible tissues, milk or eggs for residues of a drug in a minor species under this FDA guidance, the following considerations apply:

- There must be an existing approved use for a major species, with established tolerances (equivalent to MRLs).

- The risk of dietary exposure is considered to ensure that the dietary exposure associated with the use will not exceed permitted limits.

- "Drug metabolism in the minor species may, when scientifically justifiable, be examined on the basis of available data concerning the metabolism of the drug in the most closely related species for which the drug is approved or, preferably, in the minor species for which approval is being sought."

- "If insufficient data exist to determine how an approved major use drug is metabolized in the minor species, the FDA will consider proposals which present known and theoretical metabolic reaction pathways that the drug (and/or drug class of which the parent is a member) could undergo. This information would be used to determine whether or not a unique metabolite(s) of toxicological concern might occur in the minor species."

- There must be evidence of the availability of a suitable analytical method for residues in tissues or other animal-derived foods from the minor species. However, this may not require the method trial in government laboratories mandated for new drugs if the same method has previously been approved for animal-derived foods from other species.

- "The tolerance for monitoring drug residues in the edible tissues of the minor use species will be set, where appropriate, at the level previously established for the approved use in the major species."

- Guidance is provided on the numbers of animals and time-points that should be used when a depletion study is conducted for use of a drug in a minor species. It notes also that a depletion study is generally required to establish a withdrawal period for use of the drug in the minor species.

The last bullet is perhaps the key difference between the role of a national or regional authority in regulating the conditions of use of an animal drug and the role played by JECFA and the Codex Alimentarius Commission in the establishment of MRLs for residues of veterinary drugs in foods. JECFA only considers drugs that have an approved use in a Codex member state. The MRLs established by the Codex Alimentarius Commission, on recommendation from CCRVDF, are based on the approved use in the member state(s). No withdrawal periods are listed with the Codex MRLs, although in rare instances JECFA has provided advice that the MRLs resulting from an evaluation may require extended withdrawal periods that might render use of the drug impractical.

JECFA does not require a depletion study for purposes of establishing a withdrawal period, but rather uses the data to determine if MRLs can be established consistent with the conditions of use in the member state and which can be accommodated within the upper limit of the ADI when the estimated daily intake or other exposure estimate is calculated, based on these MRLs. There is, therefore, a question as to whether JECFA needs depletion data to extrapolate MRLs from a major species to a minor species if they have evidence of an approved use in the minor species, evidence of common metabolism in the major and minor species, evidence that the same marker residue may be used to monitor residue 
concentrations in both species, and evidence that a suitable method of analysis for residues has been validated for the equivalent food products for which MRLs have been established for the major species (muscle, liver, kidney, fat, milk and/or eggs, as appropriate). Establishing a withdrawal period consistent with the MRLs is the role of national authorities, who may request a re-consideration of the MRLs during the comment period in the Codex process if they feel the recommended MRLs are not consistent with the conditions of use (withdrawal period) in their country. In such a situation, JECFA would require a depletion study under those conditions of use to determine if different MRLs can be recommended for the minor species, consistent with the withdrawal period in the member state and the ADI.

\section{Guidance on the criteria/assumptions to be used by JECFA experts for interspecies extrapolations, including minimum data required to support such extrapolation among physiological related species, and extrapolation to additional (unrelated) minor species}

When requested to consider the extrapolation of MRLs to another species, JECFA must address certain issues related to the toxicology of the residues and the dietary exposure calculations, based on the MRLs, used to ensure consumer safety. Basically, it must be determined from the available information whether there is a significant risk that the ADI will be exceeded if the MRLs previously established for the major species are extrapolated to the minor species. It is inherent when considering extrapolation that a complete data package is not available for use of the drug under GVP in the minor species to which extrapolation of MRLs has been requested. The term extrapolation is therefore used to indicate that there has been an evaluation conducted, in the absence of a complete data package, to determine if the MRLs previously established for foods derived from a major species will provide an adequate level of consumer protection if applied to the equivalent foods obtained from a minor species, usually a species that is considered to be physiologically related to the major species.

Past JECFA reports have also used the term extension when making such recommendations, particularly when the recommendation is based on data from a residue depletion study in the minor species. However, in those cases, there have been other gaps in the available data, typically data usually obtained from a radiolabelled study to determine total residues and their relationship to the marker residue. JECFA will continue to use the terms extension and extrapolation to differentiate between those situations where MRLs may be independently derived for a minor species from depletion data for the drug used under GVP in that species. When data from a residue depletion study for the drug used under GVP conditions are available for a minor species, JECFA may recommend the extension of MRLs previously established for a major species to the minor species. In such instances, the available data will usually enable JECFA to ascertain that the extension of these MRLs to the minor species is consistent with the withdrawal period specified. JECFA will therefore use the term extrapolation to refer to the process to consider the application of MRLs previously recommended for a major species to a minor species in all instances where data from a complete residue depletion study are not available for the minor species and JECFA cannot confirm that the extrapolated MRLs are consistent with the approved conditions of use in the minor species (GVP). When a complete data package is available for the minor species, the usual evaluation procedures will be followed to recommend MRLs for the minor species, based on the data for use in the minor species.

The CCRVDF has preferred to use the term additional species in considering extrapolation of MRLs (FAO/WHO, 2011a), while the 52nd Meeting of JECFA has previously distinguished between major and minor species (JECFA, 2000 [TRS 893]). JECFA considers that it should maintain consistency with the terminology used in EHC 240, which 
refers to major and minor species when discussing the extrapolation of MRLs (FAO/WHO, 2009). The minimum requirements identified for extrapolation in EHC 240-which include data on metabolism in the minor species, a common marker residue and the availability of an analytical method suitable for application to foods derived from the minor species-should be satisfied before JECFA will consider extrapolation of MRLs to a minor species. In addition, JECFA experts should then determine if there is a significant risk that the extrapolation will result in a dietary exposure that exceeds the ADI.

The use of the term "additional species" could lead to some confusion in considering requests for extrapolation of MRLs and could be taken to imply that MRLs could be extrapolated between two species currently designated as major species by JECFA, such as cattle and sheep. A review of previous MRL recommendations from JECFA, based on full data sets for cattle and sheep, reveals instances where different MRLs have been proposed for one or more tissues from different major species to reflect differences in the distribution of the residues (Table A5.1).

Additional examples (Table A5.2) demonstrate that the extrapolation of MRLs from a single major species to all species could also result in MRLs that do not reflect the tissue distribution in all of the species, so that MRLs for tissues of some species could not be achieved within the approved withdrawal period in member states.

These results demonstrate the need for some caution and a case-by-case consideration when JECFA considers requests for the extrapolation of MRLs to additional species.

There are two factors used in the dietary exposure calculations that could affect the outcomes of those calculations. First, the MR:TR ratio should be considered to determine if available information suggests a significant risk that the MR:TR ratio in the tissues of the minor species differs significantly from that observed in the major species and whether this could result in a higher estimate of the dietary exposure that could exceed the ADI. There typically is not a large difference in MR:TR ratio in the comparable edible tissues of the various food animal species and it has been suggested that when the information is not available to confirm that the ratios are the same in the major and minor species being compared, the ratio for any other species for which MRLs have been established which will result in the highest estimate of exposure will typically be considered by JECFA. The second factor that has sometimes been used in dietary exposure calculation is a bio-availability factor, which adjusts the exposure to the fractional amount of the residue that may be absorbed during the digestive process, based on experimental data. In the case of triclabendazole, the factor derived from cattle liver was applied to all tissues for all species (cattle and sheep) for which MRLs were recommended (JECFA, 2009 [TRS 959]; JECFA, 2012 [TRS 969]).

The available information on GVP use in the minor species must also be assessed to determine if the extrapolated MRLs are practical; that is, it must be determined if the MRL is 
consistent with the withdrawal period established as a condition of the GVP use in the minor species. When this information is not available, that should be indicated in the risk assessment provided by JECFA to the CCRVDF.

The above issues can be addressed by consideration of the following questions and the information required to satisfy the concerns expressed in these questions.

- Have MRLs previously been established in a relevant major species (i.e., a physiologically related species)? The guidance in EHC 240 and guidance used within the European Union and also by the USFDA recommend that there must first be MRLs established in a major species that is physiologically related to the additional species to which extrapolation of the MRLs is contemplated. Thus, MRLs should already exist in cattle and/or sheep for the consideration of MRLs to another ruminant species; in pigs for the consideration of MRLs to another non-ruminant (monogastric) species; or in chickens for extrapolation to other poultry. In the absence of such MRLs, a data package is required for the species under consideration. If an ADI has not previously been established for the compound, then a full toxicological evaluation is required to establish an ADI.

Table A5.2. Examples where common MRLs for all species would result in MRLs inconsistent with the distribution of residues in the tissues in one or more species

\begin{tabular}{|c|c|c|c|}
\hline \multirow{2}{*}{ Compound } & \multicolumn{3}{|c|}{ MRL $(\mu \mathrm{g} / \mathrm{kg})$} \\
\hline & Cattle & Pig & Chicken/poultry \\
\hline Danofloxacin & $\begin{array}{l}\text { L: } 400 \\
\text { K: } 400 \\
\text { M: } 200 \\
\text { F: } 100\end{array}$ & $\begin{array}{l}\text { L: } 50 \\
\text { K: } 200 \\
\text { M: } 100 \\
\text { F: } 100\end{array}$ & $\begin{array}{c}\text { L: } 400 \\
\text { K: } 400 \\
\text { M: } 200 \\
\text { F/S: } 100\end{array}$ \\
\hline Doramectin & $\begin{array}{l}\text { L: } 100 \\
\text { K: } 30 \\
\text { M: } 10 \\
\text { F: } 150\end{array}$ & $\begin{array}{l}\text { L: } 100 \\
\text { K: } 30 \\
\text { M: } 5 \\
\text { F: } 150\end{array}$ & \\
\hline Ivermectin & $\begin{array}{l}\text { L: } 100 \\
\text { F: } 40\end{array}$ & $\begin{array}{l}\text { L: } 15 \\
\text { F: } 20\end{array}$ & \\
\hline Tilmicosin & $\begin{array}{l}\text { L: } 1000 \\
\text { K: } 300 \\
\text { M: } 100 \\
\text { F: } 100\end{array}$ & $\begin{array}{l}\text { L: } 1500 \\
\text { K: } 1000 \\
\text { M: } 100 \\
F: 100\end{array}$ & $\begin{array}{c}\text { L: } 2400 \\
\text { K: } 600 \\
\text { M: } 150 \\
\text { F/S: } 250\end{array}$ \\
\hline Flubendazole & & $\begin{array}{l}\mathrm{L}: 10 \\
\mathrm{M}: 10\end{array}$ & $\begin{array}{l}\text { L: } 500 \\
\text { M: } 200\end{array}$ \\
\hline Lincomycin & & $\begin{array}{c}\text { L: } 500 \\
\text { K: } 1500 \\
\text { M: } 200 \\
\text { F: } 100\end{array}$ & $\begin{array}{l}\text { L: } 500 \\
\text { K: } 500 \\
\text { M: } 200 \\
\text { F: } 100\end{array}$ \\
\hline Spiramycin ${ }^{1}$ & $\begin{array}{l}\text { L: } 600 \\
\text { K: } 300 \\
\text { M: } 200 \\
\text { F: } 300\end{array}$ & $\begin{array}{l}\text { L: } 600 \\
\text { K: } 300 \\
\text { M: } 200 \\
\text { F: } 300\end{array}$ & $\begin{array}{l}\text { L: } 600 \\
\text { K: } 800 \\
\text { M: } 200 \\
\text { F: } 300\end{array}$ \\
\hline
\end{tabular}

NOTES: $\quad(L=$ liver; $K=$ kidney; $M=$ muscle; $F=$ fat; $F / S=$ fat with adhering skin). Residues are highest in kidney in chicken, but highest in liver in cattle and pigs.

- Do the residues found in the species to which extrapolation of MRLs is under consideration contain any metabolites or bound residues of unknown toxicity which are not present in the major species for which MRLs have been established? This should be addressed by the requirement that the metabolic profiles are comparable in the two species, as discussed above. The requirement therefore may be satisfied by either (i) a minimum set of comparative metabolism data, which might be provided through a limited experiment with a minimum number of test animals; (ii) through in vitro methods, as described in $\mathrm{VICH}$ guidance; or (iii) by a sound scientific argument as to why there should be no expected difference in the metabolic profiles (e.g. based on information available for related compounds).

- Does the marker residue include all residues of toxic concern? When the marker residue is the only residue of toxicological concern, whether it is the parent drug, a major metabolite, a sum of parent drug and/or metabolites, or a compound formed by the chemical reaction of residues of parent compound and/or metabolites, it is not necessary to consider total residues in the dietary exposure estimates. However, when the total residue is considered to be of toxicological concern, then the ratio between marker and total residues must be considered. For an extrapolation of MRLs from a major species to a minor species, when the total residue must be considered in the dietary exposure calculation, data ideally should be provided to demonstrate that the relationship between marker and total residues is the same in each of the food items 
considered in the exposure calculation. If the factors differ in the additional species from those used in the dietary exposure calculation for the species for which the MRLs were originally derived, the new factors must be determined for this additional species. For example, the 58th JECFA recommended MRLs for alpha-cypermethrin in edible tissues of cattle and sheep, with parent drug as the designated marker compound and common factors to be applied for calculation of total residues in both these species (FAO, 2002). Extrapolation of these MRLs to another ruminant species may require data to demonstrate that the same factors to adjust marker residue to total residue could be applied to the additional species. If such data are not available, then the factors previously derived for the representative major species may be considered as surrogates. The 58th JECFA also recommended MRLs for lincomycin in cattle, pigs and chickens, designating parent compound as the marker residue and also noting that it was the only microbiologically active residue (i.e. the only residue of toxicological concern). Therefore, no factors were required to adjust marker residue concentrations to total residue concentrations in the dietary exposure calculation and, for compounds such as lincomycin, conversion of marker residue to total residues should not be a concern if the existing MRLs are extended to other species.

- Is an adjustment factor for bio-availability used in the dietary exposure calculation? When a bio-availability factor has been applied in the dietary exposure estimates previously prepared based on the MRLs recommended for the major species from which MRLs are to be extrapolated to the minor species, then it must be determined if the same factor should also be applied to the minor species. Ideally, there should be data provided to assess the bio-availability of the residues in tissues from the minor species. In the absence of such data, expert judgement should be used to determine if the bioavailability factor(s) applied in the exposure calculation for the tissues from the major species are suitable to also apply to exposure from the consumption of tissues from the minor species.

- Are the dietary consumption quantities used in the dietary exposure calculation appropriate? It is generally assumed that the relative amounts of muscle, liver, kidney, fat, milk, eggs and honey used in the traditional exposure calculation are suitable to represent the majority of consumers and should, in fact, provide an inflated estimate of the food consumed on a daily basis by most typical consumers. However, there may be situations where alternative approaches to dietary exposure need to be considered (FAO/WHO, 2011b). For example, regional consumption of a particular tissue may exceed the quantities used in the standard exposure calculation and, if consumption of the species is primarily regional, it may be necessary to adjust the exposure calculation accordingly to ensure consumer safety. In such a case, the MRLs previously established for the major species may not be considered appropriate by some Codex member states, which may, under Codex rules, establish different MRLs to reflect national consumption patterns of that food. In some situations, it may be appropriate to considering alternatives to the usual approach, the calculation of a Theoretical Maximum Daily Intake (TMDI) or an Estimated Dietary Intake (EDI), when considering the dietary exposure calculations.

- Are data available to demonstrate that the extrapolated MRLs are consistent with the GVP conditions of use (withdrawal period) established for the use of the drug in the minor species? When data from a depletion study conducted in the minor species are available, it can usually be determined if the extrapolated MRLs are consistent with the approved conditions of use (GVP). In the absence of residue depletion data for the minor species, pharmacokinetic data may provide an indication of similarities or differences in rates of absorption and elimination in the major and minor species, which may suggest similarities or differences in depletion rate from tissues. The absence of such data 
should not preclude a recommendation that the MRLs established for the major species may be extrapolated to the minor species, but such a recommendation should include the information that it could not be confirmed that the MRLs are consistent with the withdrawal periods that may have been established by national authorities who have approved the use of the drug in the minor species.

When available, pharmacokinetic data may provide useful insights into the behaviour of drug residues in a minor species and may be used to bridge gaps in data on residue depletion in the minor species. The kinetic behaviour of a drug and its residues in animal tissues and blood after administration is a function of many factors related to animal species and individuals (e.g. strain, sex), drug formulation, drug properties, dosage regimen and route of administration. All of these factors influence the absorption, distribution, metabolism and excretion (ADME) phases. With the development of scientific knowledge, it is possible to identify the major factors driving these processes.

Animal species can be described by major physiological parameters (i.e. weight, type of gastro-intestinal tract, cardiac output, blood flow and tissue volume) and individual variation factors are represented by factors such as age, sex, weight, body composition and metabolism phenotype. The major physico-chemical properties of the drug are molecular weight, pKa, lipid solubility, and chemical structure, which may contribute to physiochemical properties such as tissue:blood partition ratio and biochemical properties (i.e. enzyme affinities, protein binding) which depend also on the animal biochemistry. The extrapolation of residue kinetics from one animal species to another must therefore be based on the identification of the most important characteristics of the drug kinetics.

To support an extrapolation, some of these data must be obtained from experimental in vitro and in vivo studies (Sanders and Anadon, 2011). The necessary experimental studies must provide data from which the essential pharmacokinetic parameters may be derived to indicate similarities or differences in drug behaviour between animal species. MRLs are based on the identification of a marker residue (MR) which is representative of the total residue; the total residue (TR) kinetics are established for the different tissues based on the distribution observed in the tissue during the final phase of elimination. Extrapolation of MRL from one mammal ruminant species to another or from one non-ruminant mammalian to another may thus be considered after analysis of different parameters which include the following (Sanders and Anadon, 2011):

- Chemical properties of compound (e.g. anion/cation/zwitterion; lipophilicity; etc.).

- ADME processes identified in laboratory animals, target animals and humans.

- Total residue and marker residue depletion curves in reference animals and in those where extrapolation is needed (if available).

- Plasma pharmacokinetic profile (i.e. bio-availability, clearance, apparent volume of distribution, elimination half-life) in reference animal and in those where extrapolation is needed.

Extrapolation requires a case-by-case approach, as many variation factors are drugdependent. The following situations may occur (Sanders and Anadon, 2011):

1. For drugs with no or a low metabolic clearance and a limited tissue distribution, mainly in the extra cellular compartment (volume of distribution below 1), the MR:TR ratio will be close to 1 and the MRLs could be extrapolated from a major (reference) species to a minor species. The kinetics should be a function of animal species, breed and age, dosage regimen, drug formulation and route of administration (e.g. low absorption rate and low bio-availability).

2. For drugs with a limited metabolism and a high lipophilicity, which results in storage of residues in fat tissue, the MR:TR ratio will be close to 1 . The MRLs could be extrapolated from a major species to a minor species. The kinetics should be a function 
of animal species, breed and age, dosage regimen, drug formulation and route of administration (e.g. low absorption rate, and low bio-availability).

3. For drugs cleared by metabolism, a comparison should be made between the metabolic profiles of the major species and the minor species. Extrapolation of MRLs from the major species to the minor species is dependant on the tissue distribution, since interspecies variation could occur when residues (ratios of parent drug and metabolites) show an important tissue distribution. In this case, if the volume of distribution of the drug is greater than 1, the extrapolation of MRL from the reference species to another can be performed by analysis of the kinetic tissue depletion of residues in the new species (muscle, live, kidney, fat). The analysis of kinetic tissue depletion may be done using in vitro or in vivo models, or both.

4. For drugs showing a large volume of distribution and limited metabolism as indicated by the apparent body clearance in the major species, the absence of data or limited metabolism data in the minor animal species could be addressed using, for example, in vitro studies. In this case, the kinetics of the drugs is dependant on the tissue blood flow. Plasma concentration-time curves from pharmacokinetic studies in the minor animal species may be used to determine clearance and apparent volume of distribution. However, to extrapolate MRLs from the major species, tissue depletion curves obtained in the minor species are useful for such drugs.

5. In the absence of tissue residue depletion data in the minor species to support the extrapolation of MRLs, integration of all the data provided may be attempted using in silico methods, such as physiologically based pharmacokinetic models (PBPK). This type of approach has been developed in the last 20 years by several research groups exploiting progress in mathematical computation. These new tools require different data related to animals, drugs, protein binding and metabolic pathways. Such an approach requires a high level of scientific expertise and models are currently neither harmonized nor validated. However, progress is ongoing to validate and standardize these tools, which are currently used in medical pharmacology and environmental risk assessment.

6. When only the marker residue is of toxicological concern and there is evidence of similar metabolism or distribution of the marker residue in tissues (and/or milk, eggs) from the major and minor species, the MRLs may be extrapolated from the major species to the minor species.

The available data for the minor species should be assessed using the above criteria when considering a request for the extrapolation of MRLs from one species to another. This review will identify any data required to support the committee in its extrapolation assessment.

Based on the above considerations, the following principles have been established to be applied by JECFA experts considering the extrapolation of MRLs from major species to minor species:

- There should be evidence of approved use of the drug under GVP in the minor species in one or more member states of Codex (label or equivalent information).

- MRLs should already have been established by Codex in one or more animals defined by JECFA as major species relevant for extrapolation of MRLs to the "minor" species (e.g. chicken to turkey; cattle or sheep to goat).

- Information should be available to enable the Committee to determine that the metabolic profile is qualitatively and quantitatively similar in the two species, with parent drug and major metabolites present in edible tissues in similar proportions, although the concentrations of the residues may differ in the two species due to factors such as dosage and pharmacokinetics. 
- Strict numerical limits should not be applied when assessing the quantitative relationships, but the parent compound and major metabolites should be in similar proportions in the species compared to provide some evidence of similar residue distribution and composition in the major and minor species.

- The sum of the minor metabolites and bound residues should constitute equivalent proportions of the total residue in both species.

- The same marker residue designated for the major species should be appropriate for monitoring residues in edible tissues of the minor species.

- When data are not available to establish the relationship between the marker residue and total residues, and total residues are of toxic concern, the MR:TR relationships observed in other relevant species may be considered and used as surrogate values for the minor species. The same considerations may also be applied to bio-availability factors that might be used in the dietary exposure calculations.

- When residue depletion data are incomplete or unavailable for the drug in the minor species, other sources of information, such as data from metabolic and

pharmacokinetic studies, may be used to compare the behaviour of the drug in the major and minor species.

- When residue depletion data are not available for the minor species to confirm that an MRL extrapolated from a major species to a minor species is consistent with the GVP use in the minor species (e.g. the specified withdrawal period where the use is authorized), this should be noted with any recommendations of MRLs for the minor species.

- A validated analytical method used for the determination of residues of the drug in edible tissues of the major species should be considered suitable for extension to the analysis of residues of the drug in tissues of the minor species. When an expert review of the available methodology does not consider such an extension to be likely, a validated analytical method for the determination of residues of the drug in edible tissues of the minor species is required.

Figure A5.1 contains a decision tree for the process to be followed by JECFA experts in determining whether extrapolation of MRLs from a major species to a minor species may be recommended. The risk assessment provided by JECFA to CCRVDF should indicate additional uncertainties associated with the dietary exposure calculations if the MRLs are extrapolated to the minor species (e.g. MR:TR ratio could not be confirmed for the minor species, so the highest MR:TR ratio observed for another species for which MRLs have been established was used) or the data did not enable JECFA to confirm that the MRLs are consistent with the withdrawal period established by a member state(s) for use of the drug in the minor species under GVP. 


\section{References}

EEC. 2009. Regulation (EC) No 470/2009 of the European Parliament and of the Council of 6 May 2009 laying down Community procedures for the establishment of residue limits of pharmacologically active substances in foodstuffs of animal origin, repealing Council Regulation (EEC) No 2377/90 and amending Directive 2001/82/EC of the European Parliament and of the Council and Regulation (EC) No 726/2004 of the European Parliament and of the Council, Official Journal of the European Union, L152: 11-22.

EMEA/CVMP [European Agency for the Evaluation of Medicinal Products/Committee for Veterinary Medical Products]. 1997a. EMEA/CVMP/153a/97-FINAL: Note for guidance on the establishment of maximum residue limits for minor animal species. Committee for Veterinary Medicinal Products, The European Agency for the Evaluation of Medicinal Products. Available at: http://www.ema.europa.eu/docs/en_GB/document_library/Scientific_guideline/2009/10/WC5 00004583.pdf Accessed April 2, 2013.

EMEA/CVMP. 1997b. EMEA/CVMP/153a/97-FINAL; Note for guidance on the establishment of maximum residue limits for Salmonidae and other finfish. Available at: http://www.ema.europa.eu/docs/en_GB/document_library/Scientific_guideline/2009/10/WC5 00004584.pdf Accessed April 2, 2013.

EMEA/CVMP. 2000. EMEA/CVMP/187/00-FINAL: Note for Guidance on the Risk Analysis Approach for Residues of Veterinary Medicinal Products in Food of Animal Origin. Committee for Veterinary Medicinal Products, The European Agency for the Evaluation of Medicinal Products. Available at: http://www.ema.europa.eu/docs/en_GB/document_library/Scientific_guideline/2009/10/WC5 00004534.pdf Accessed March 28, 2013.

EMEA/CVMP. 2002. EMEA/CVMP/069/02: Implementation of the Note for Guidance on Risk Analysis Approach for Residues of Veterinary Medicinal Products in Foods of Animal Origin. Committee for Veterinary Medicinal Products, The European Agency for the Evaluation of Medicinal Products. Available at:

http://www.ema.europa.eu/docs/en_GB/document_library/Scientific_guideline/2009/10/WC5 00004535.pdf Accessed March 28, 2013.

EMEA/CVMP. 2003. Position Paper Regarding Availability of Veterinary Medicinal Products Extrapolation of MRLs, EMEA/CVMP/457/03. Committee for Veterinary Medicinal Products, Veterinary Medicines and Inspections, The European Agency for the Evaluation of Medicinal Products. Available at: http://www.ema.europa.eu/docs/en_GB/document_library/Position_statement/2009/10/WC50 0005164.pdf Accessed March 28, 2013.

EMEA/CVMP. 2005. Establishment of maximum residue limits (MRLs) for residues of veterinary medicinal products in foodstuffs of animal origin. Volume 8: Notice to applicants and Guideline, Veterinary medicinal products. The rules governing medicinal products in the European Union. October 2005. Available at: http:/ / ec.europa.eu/health/files/eudralex/vol-8/pdf/vol8_102005_en.pdf Accessed March 28, 2013.

FAO. 1994. Residues of some veterinary drugs in animals and foods. FAO Food and Nutrition Paper, No. 41/6. (See also monograph on dexamethasone contained in this publication, available at: http://www.fao.org/food/food-safety-quality/scientific-advice/jecfa/jecfa-vetdrugs/en/ Accessed April 2, 2013).

FAO. 2002. Residues of some veterinary drugs in animals and foods. FAO Food and Nutrition Paper, No. 41/14. (See also monographs on alpha-cypermethrin and lincomycin contained in this publication, available at: http://www.fao.org/food/food-safety-quality/scientificadvice/jecfa/jecfa-vetdrugs/en/; accessed April 2, 2013).

FAO. 2003. Residues of some veterinary drugs in animals and foods. FAO Food and Nutrition Paper, No. 41/15. See Annex I.

FAO. 2004. Summary of JECFA evaluations of veterinary drug residues from the 32nd meeting to the present. In: Residues of some veterinary drugs in animals and foods. FAO Food and Nutrition Paper, No. 41/16, Food and Agriculture Organization of the United Nations, Rome. Available at: http://www.fao.org/docrep/007/y5612e/y5612e00.htm; accessed April 2, 2013. 
FAO. 2006. Residue evaluation of certain veterinary drugs. FAO JECFA Monographs, No. 2. Available at: ftp:/ /ftp.fao.org/docrep/fao/009/a0652e/a0652e.pdf Accessed April 2, 2013.

FAO. 2009. Residue evaluation of certain veterinary drugs. FAO JECFA Monographs, No. 6. Available at: ftp:/ / ftp.fao.org/docrep/fao/011/i0659e/i0659e.pdf Accessed April 2, 2013.

FAO. 2011. Residue evaluation of certain veterinary drugs. FAO JECFA Monographs, No. 12. Available at: http://typo3.fao.org/fileadmin/user_upload/agns/pdf/JECFA_Monograph_12.pdf Accessed April 2, 2013.

FAO/WHO. 2000. ALINORM 01/31, Report of the 12th Session of the Codex Committee on Residues of Veterinary Drugs in Foods, Washington, D.C., 28-31 March 2000. Available at: http://www.codexalimentarius.org/meetings-reports/en/?sortingDate=012001 Accessed March 26, 2013.

FAO/WHO. 2006. Updating the Principles and Methods of Risk Assessment: MRLs for Pesticides and Veterinary Drugs. Report of the FAO/RIVM/WHO Workshop: Updating the Principles and Methods of Risk Assessment: Maximum Residue Levels (MRLs) for Pesticides and Veterinary Drugs. Bilthoven, the Netherlands, 7-10 November 2005. Available at: http://www.fao.org/ag/AGP/AGPP/Pesticid/JMPR/DOWNLOAD/bilthoven_2005.pdf Accessed March 29, 2013.

FAO/WHO. 2009. Environmental Health Criteria (EHC) 240, Principles and Methods for the Risk Assessment of Chemicals in Food. Chapter 8: Maximum Residue Limits for Pesticides and Veterinary Drugs. A joint publication of the Food and Agriculture Organization of the United Nations and the World Health Organization. Available at: http://www.who.int/foodsafety/chem/principles/en/index1.html Accessed March 26, 2013.

FAO/WHO. 2010. REP11/RVDF. Report of the Nineteenth Session of the Codex Committee on Residues of Veterinary Drugs in Foods, Burlington, United States of America, 30 August-3 September 2010. Available at: http:/ / www.codexalimentarius.org/meetingsreports/en/?sortingDate=012011 Accessed April 2, 2013.

FAO/WHO. 2011a. CX/RVDF12/20/15. Discussion Paper on Extrapolation of MRLS to Additional Species and Tissues. Report of the CCRVDF Electronic Working Group on Extrapolation of MRLs for Veterinary Drugs to Additional Species and Tissues, prepared by Canada with the assistance of Argentina, Australia, Brazil, European Union, Germany, Ireland, Japan, Mexico, The Netherlands, New Zealand, Norway, South Africa, Sweden, Thailand, United Kingdom, United States of America, JECFA Secretariat and IFAH, December 2011. Prepared for the 20th Session of the Codex Committee on Residues of Veterinary Drugs in Foods.

FAO/WHO. 2011b. Joint FAO/WHO Expert Meeting on Dietary Exposure Assessment Methodologies for Residues of Veterinary Drugs - Final Report. Available at:

http://www.fao.org/fileadmin/user_upload/agns/pdf/jecfa/Dietary_Exposure_AssessmentMet hodologies_for_Residues_of_Veterinary_Drugs.pdf Accessed April 3, 2013.

FAO/WHO. 2012. Joint FAO/WHO Expert Meeting on Dietary Exposure Assessment Methodologies for Residues of Veterinary Drugs. Final report including report of stakeholder meeting. Available at http://www.who.int/foodsafety/chem/jecfa/FAO-WHO_exposure_report.pdf Accessed 201405-29.

FAO/WHO. 2013. Codex Alimentarius Commission Procedural Manual, 21st edition. Joint FAO/WHO Food Standards Programme, FAO, Rome. Available at: ftp://ftp.fao.org/codex/Publications/ProcManuals/Manual_20e.pdf Accessed March 26, 2013.

JECFA. 1999. Procedures for Recommending Maximum Residue Limits Residues of Veterinary Drugs in Food (1987-1999). Joint FAO/WHO Expert Committee on Food Additives. Available at: http://www.fao.org/food/food-safety-quality/scientific-advice/jecfa/guidelines0/en/ Accessed September 19, 2013.

JECFA. 1969. Specifications for the identity and purity of food additives and their toxicological evaluation: some antibiotics. Twelfth Report of the Joint FAO/WHO Expert Committee on Food Additives. WHO Technical Report Series, No. 430. Available at: http://whqlibdoc.who.int/trs/WHO_TRS_430.pdf Accessed March 28, 2013.

JECFA. 683. 1982. Evaluation of certain food additives and contaminants; Twenty-sixth Report of the Joint FAO/WHO Expert Committee on Food Additives. WHO Technical Report Series, No. 683. Available at: http://whqlibdoc.who.int/trs/WHO_TRS_683.pdf Accessed March 28, 2013. 
JECFA. 1983. Evaluation of certain food additives and contaminants. Twenty-seventh Report of the Joint FAO/WHO Expert Committee on Food Additives. WHO Technical Report Series, No. 696, and corrigenda. Available at: http://whqlibdoc.who.int/trs/WHO_TRS_696.pdf Accessed March 28, 2013.

JECFA. 1988. Evaluation of certain veterinary drug residues in food. Thirty-second Report of the Joint FAO/WHO Expert Committee on Food Additives. WHO Technical Report Series, No. 763. Available at: http://whqlibdoc.who.int/trs/WHO_TRS_763.pdf Accessed March 28, 2013.

JECFA. 1989. Evaluation of certain veterinary drug residues in food. Thirty-fourth Report of the Joint FAO/WHO Expert Committee on Food Additives. WHO Technical Report Series, No. 788. Available at: http:/ /whqlibdoc.who.int/trs/WHO_TRS_788.pdf Accessed March 28, 2013.

JECFA. 1990. Evaluation of certain veterinary drug residues in food. Thirty-sixth Report of the Joint FAO/WHO Expert Committee on Food Additives. WHO Technical Report Series, No. 799. Available at: http://whqlibdoc.who.int/trs/WHO_TRS_799.pdf Accessed March 28, 2013.

JECFA. 1991. Evaluation of certain veterinary drug residues in food. Thirty-eighth Report of the Joint FAO/WHO Expert Committee on Food Additives. WHO Technical Report Series, No. 815. Available at: http://whqlibdoc.who.int/trs/WHO_TRS_815.pdf Accessed March 28, 2013.

JECFA. 1995. Evaluation of certain veterinary drug residues in food. Forty-second Report of the Joint FAO/WHO Expert Committee on Food Additives. WHO Technical Report Series, No. 851. Available at: http://whqlibdoc.who.int/trs/WHO_TRS_851.pdf Accessed April 2, 2013.

JECFA. 2000. Evaluation of certain veterinary drug residues in food. Fifty-second Report of the Joint FAO/WHO Expert Committee on Food Additives. WHO Technical Report Series, No. 893. Available at: http:/ /whqlibdoc.who.int/trs/WHO_TRS_893.pdf Accessed March 28, 2013.

JECFA. 2006. Evaluation of certain veterinary drug residues in food. Sixty-sixth Report of the Joint FAO/WHO Expert Committee on Food Additives. WHO Technical Report Series, No. 939. Available at: http:/ /whqlibdoc.who.int/publications / 2006/9241209399_eng.pdf; accessed March 29, 2013.

JECFA. 2009. Evaluation of certain veterinary drug residues in food. Seventieth Report of the Joint FAO/WHO Expert Committee on Food Additives. WHO Technical Report Series, No. 959. Available at: http:/ / whqlibdoc.who.int/trs/WHO_TRS_954_eng.pdf Accessed April 8, 2013.

JECFA. 2012. Evaluation of certain veterinary drug residues in food. Seventy-fifth Report of the Joint FAO/WHO Expert Committee on Food Additives. WHO Technical Report Series, No. 969. Available at: http:/ / whqlibdoc.who.int/publications /2012/9789241209694_eng.pdf?ua=1 Accessed 2014-0515.

Sanders, P. \& Anadon, A. 2011. Working Paper on MRL and kinetics extrapolation, prepared for the 75th Meeting of JECFA, Rome, Italy, 8-17 November 2011.

USFDA. 2008. Guidance for Industry \#61: FDA Approval of New Animal Drugs for Minor Uses and for Minor Species; U.S. Department of Health and Human Services, Food and Drug Administration, Center for Veterinary Medicine, Rockville, MD. Available at: http:/ / www.fda.gov/AnimalVeterinary/GuidanceComplianceEnforcement/GuidanceforIndustry /ucm123821.htm; accessed April 9, 2013.

VICH. 2011a. VICH GL 46 (MRK) - Nature of Residues. Studies to evaluate the Metabolism and Residue Kinetics of Veterinary Drugs in Food-producing Animals: Metabolism Study to determine the Quantity and Identify the Nature of Residues - Final, February 2011. Available at: http: / / www.vichsec.org/en/guidelines2.htm Accessed April 3, 2013.

VICH. 2011b. VICH GL 48 (MRK) - Marker Residue Depletion Studies. Studies to evaluate the Metabolism and Residue Kinetics of Veterinary Drugs in Food-producing Animals: Marker Residue Depletion Studies to establish Product Withdrawal Periods - Final, February 2011. Available at: http://www.vichsec.org/en/guidelines2.htm Accessed April 3, 2013. 
Figure A5.1. Decision tree for extrapolation of MRLs from major species (cattle, sheep, pigs, chickens) to minor species.

There is an approved use for the drug in a minor species in a Codex member State.

\section{YES $\Downarrow$}

An ADI and MRLs for use of the drug in a relevant species have been recommended.

YES $\Downarrow$

\begin{tabular}{|c|}
\hline $\begin{array}{c}\text { Metabolism information for a relevant } \\
\text { species and the minor species are available. }\end{array}$ \\
YES $\downarrow$ \\
\hline $\begin{array}{c}\text { Metabolites and bound residues of toxic } \\
\text { concern are qualitatively and quantitatively } \\
\text { similar. }\end{array}$ \\
\hline
\end{tabular}

YES $\downarrow$

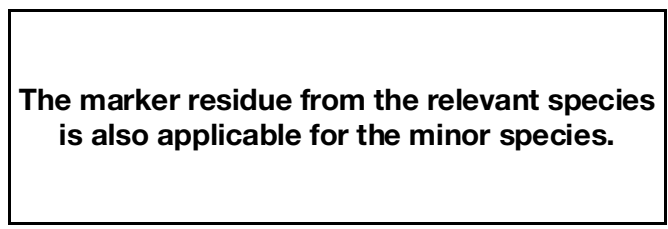

YES $\Downarrow$

A suitable analytical method for the marker residue is available, preferably with data on application to the minor species.

YES $\Downarrow$

Marker residue to total residue relationship and bioavailability is similar in both species or not required for exposure calculation.

\section{YES $\Downarrow$}

Available data indicate similar distribution
and depletion patterns in both species (data
may be from metabolism, pharmacokinetic
and/or residue depletion studies).

YES $\Downarrow$

MRLs may be extrapolated from the relevant species to the minor species.
NO Evidence of an approved use in a Codex member $\Rightarrow \quad$ state must be provided.

$\begin{array}{cc}\text { NO } & \text { A full evaluation to establish and ADI and MRLs } \\ & \text { is required. }\end{array}$

\section{NO Comparative metabolism information must be} $\Rightarrow \quad$ provided for the minor and relevant species.

\begin{tabular}{c} 
No \\
$\Rightarrow \quad \begin{array}{c}\text { Additional toxicological evaluation and a residue } \\
\text { depletion study in the minor species may be } \\
\text { required. }\end{array}$ \\
\hline
\end{tabular}

NO A suitable validated analytical method applicable $\Rightarrow \quad$ to tissues from the minor species is required.

NO

Data to establish marker residue to-total residue relationships and/or bioavailability in edible tissues of minor species may be required when needed in dietary exposure calculations.

\section{NO Additional residue depletion data are required for the minor species.}




\title{
Annex 6-JECFA guidance for the establishment of MRLs in honey
}

\author{
First draft prepared by \\ James D. MacNeil, Rome, Italy
}

\section{Background}

The discussion paper prepared for the Seventieth Meeting of JECFA (FAO, 2008) described the various issues related to the establishment of MRLs for honey and some particular problems associated with the evaluation of residues for the establishment of MRLs. Extensive variability can be observed in the concentrations of the residue found in samples collected from different areas of the same hive or from different hives. For large-scale production, where products from various sources are blended in bulk, samples from multiple hives at multiple locations and times may be required to derive a representative picture for the typical bulk product in international trade. In addition, any reduction in residue concentration is typically a result of dilution or chemical degradation of the parent drug over time from sources such as moisture, heat and light exposure, rather than from metabolic processes. Furthermore, as the depletion pathway in honey is different from the typical metabolic pathways in animals treated with drugs, the marker residue designated for tissues, milk and/or eggs may not be appropriate for honey.

\section{Data requirements}

Honey is generally sold internationally not in small quantities collected from a single hive or producer, but rather as a bulk commodity that contains honey from multiple sources. Thus, MRLs established within the Codex Alimentarius system must reflect residue concentrations expected to be found in bulk honey from multiple producers with hives treated under GVP. The Committee noted that, as stated in EHC 240, MRLs for honey cannot be recommended based on extrapolation from MRLs for tissues, eggs or milk, and considered that MRLs derived using extrapolation may result in MRLs for honey that are not consistent with the approved GVP use in Member States (FAO/WHO, 2009). If practices followed by JECFA in recommending MRLs for veterinary drugs used in honey production are to be consistent with those followed for recommending MRLs for edible tissues, milk and eggs from foodproducing animals treated with veterinary drugs, the following information is required:

- all available information on approved uses in a Codex Member State;

- an existing ADI or the availability of toxicological data to establish an ADI;

- data to establish a marker residue in honey;

- evidence of a validated analytical method for the determination of residues in honey; and

- data on the nature of residues in honey, typical concentrations found and the stability of these residues.

It must be noted that the evaluation of drug residues in honey differs from the evaluation of residues of drugs used in other species of food-producing animals, as there are no pharmacokinetic depletion data or metabolic pathways to consider. The reduction of concentrations of residues in honey is from dilution and/or environmental factors. In addition, the use of veterinary drugs in honey production is usually considered as a minor use in a minor species, and therefore a policy on risk assessment requires some flexibility. Data on the depletion of residues in honey will therefore be considered by JECFA from 
statistically based field trials (which should be conducted according to guidance from VICH when this has become available) or from other sources, such as data from statistically based national monitoring programmes. Three potential situations are envisaged by CCRVDF and JECFA:

1. the establishment of an MRL for honey for substances with an ADI, typically established by JECFA or JMPR, and/or a Codex MRL in a food-producing animal or food commodity;

2. the establishment of an MRL for honey for substances for which an ADI has not previously been established by JECFA or JMPR; or

3. the establishment of an MRL for honey for substances that are not approved for use in food animals.

The manner in which each of these situations may be assessed and the data requirements for such assessments differ, based on the information that is already available from prior evaluations of the safety of the substance.

\section{Substances with an established ADI and/or MRL in a food-producing animal or food commodity}

The main groups of substances that typically leave residues in honey are antibiotics and persistent lipophilic acaricides. Of the products known to be used for treatment of bee diseases, most, but not all, have a national registration and a JECFA or JMPR evaluation with an ADI and/or MRL for either a food-producing animal or other food commodity. The MRLs recommended by JECFA must be consistent with GVP to protect consumer health while ensuring that the veterinary product can be used effectively. It is proposed that the data requirement for compounds with an existing ADI and/or Codex MRLs would be limited to residue depletion studies in honey, which could be used to establish Codex MRLs in honey and by national authorities to also establish withdrawal periods following treatment.

While available information suggests that the parent drug is expected to be the marker residue in honey in most situations, this should be confirmed before residue studies are conducted. Residue studies using the marker residue compound in honey may then be used to provide data for the recommendation of MRLs consistent with GVP, which are therefore practical for monitoring residues in products in international trade. Further details of the factors to consider in developing MRLs relating to the use of veterinary drugs for bees are contained in the report of the 70th Meeting of JECFA (FAO, 2009).

\section{Substances for which an ADI has not previously been established by JECFA or JMPR}

In the case of a new substance not previously considered for registration by national authorities, substances would have to be evaluated as new animal drugs or pesticides and be subject to a full food safety risk assessment. This issue was discussed at the 70th Meeting of JECFA (see Annex 1 of the report - JECFA, 2009 [TRS 954]).

\section{The establishment of an MRL for honey for substances that are not approved for use in food animals}

In the situation in which it has been recommended by the Committee that a substance should not be used in food-producing animals (e.g. chloramphenicol or nitrofurans), no exception for honey would be applied. This issue was also discussed at the 70th Meeting of JECFA (FAO, 2009).

Figure A6.1 illustrates the decision-tree approach to establishing MRLs for veterinary drug residues in honey to be followed by JECFA at future meetings. 
Figure A6.1. Decision tree for establishment of MRLs for veterinary drug residues in honey

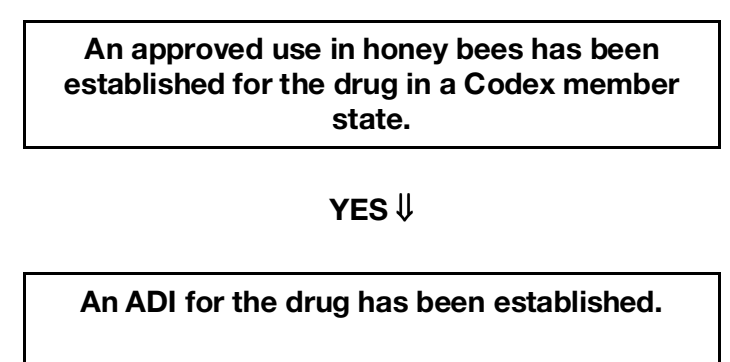

YES $\Downarrow$

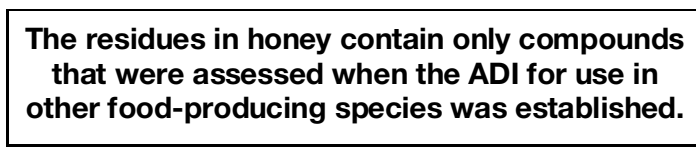

YES $\Downarrow$

Residue depletion data for the approved (GVP) use are available when there is an ADI.

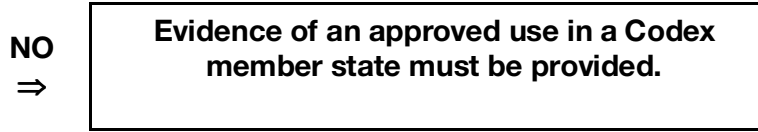

\section{NO A full evaluation to establish and ADI and $\Rightarrow \quad$ MRLs, if required.}

YES $\Downarrow$

The marker residue from the use in other foodproducing animals is also applicable for honey.

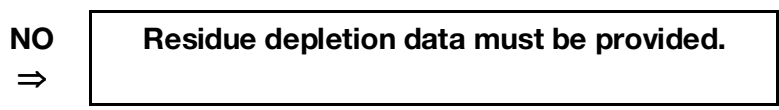

\section{YES $\Downarrow$}

A suitable analytical method for the marker residue is available, preferably with data on application to honey.

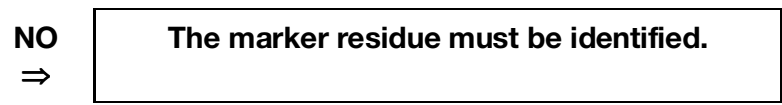

YES $\Downarrow$

MRLs may be established for honey.

\section{Dietary consumption}

A dietary portion size of $50 \mathrm{~g}$ per person per day was recommended for honey by the Twenty-first Session of CCRVDF, consistent with the recommendation of the seventieth meeting of JECFA (FAO/WHO, 2013). This quantity will be used in dietary exposure estimates (EDI or TMDI) performed during risk assessments by JECFA, replacing the $20 \mathrm{~g}$ of honey per person per day used in exposure calculations conducted prior to the current meeting of JECFA. JECFA is currently improving its dietary exposure methodology and may use an updated alternative value based on updated food consumption data. 


\section{References}

FAO. 2009. Residue evaluation of certain veterinary drugs. FAO JECFA Monographs No. 6. Available at: ftp:/ /ftp.fao.org/docrep/fao/011/i0659e/i0659e.pdf Accessed April 2, 2013.

FAO/WHO. 2009. Environmental Health Criteria (EHC) 240, Principles and Methods for the Risk Assessment of Chemicals in Food, Chapter 8: Maximum Residue Limits for Pesticides and Veterinary Drugs. A joint publication of the Food and Agriculture Organization of the United Nations and the World Health Organization. Available at:

http://www.who.int/foodsafety/chem/principles/en/index1.html Accessed March 26, 2013.

FAO/WHO. 2013. Report of the Twenty-first Session of the Codex Committee on Residues of Veterinary Drugs in Foods, Minneapolis, United States of America, 26-30 August 2013. CAC doc. REP14/RVDF. Available at: http:/ / www.codexalimentarius.org/download/ report/802/REP14_RVe.pdf Accessed 2014-05-29.

JECFA. 2009. Evaluation of certain veterinary drug residues in food (Seventieth report of the Joint FAO/WHO Expert Committee on Food Additives). WHO Technical Report Series, No. 954. WHO, Geneva. Available at: http://whqlibdoc.who.int/trs/WHO_TRS_954_eng.pdf?ua=1 Accessed 2014-05-15. 


\section{FAO TECHNICAL PAPERS}

\section{FAO JECFA MONOGRAPHS}

Note: JECFA Monographs are available in English only.

1. Combined compendium of food additive specifications - JECFA specifications monographs from the 1st to the 65th meeting. Vol. 1: Food additives A - D; Vol. 2: Food additives E - O; Vol. 3: Food additives $\mathrm{P}-\mathrm{Z}$; Vol. 4: Analytical methods, test procedures and laboratory solutions.

2. Residue evaluation of certain veterinary drugs - Joint FAO/WHO Expert Committee on Food Additives, 66th meeting 2006

3. Compendium of food additive specifications - Joint FAO/WHO Expert Committee on Food Additives, 67th meeting 2006

4. Compendium of food additive specifications - Joint FAO/WHO Expert Committee on Food Additives -68 th meeting 2007

5. Compendium of food additive specifications - Joint FAO/WHO Expert Committee on Food Additives, 69th meeting 2008

6. Residue evaluation of certain veterinary drugs - Joint FAO/WHO Expert Committee on Food Additives. 70th meeting 2008

7. Compendium of food additive specifications - Joint FAO/WHO Expert Committee on Food Additives, 71st meeting 2009

8. Safety evaluation of certain contaminants in food - Joint FAO/WHO Expert Committee on Food Additives, 72nd meeting 2010. Joint FAO/WHO publication: WHO Food Additives Series No. 63/FAO JECFA Monographs 8

9. Residue evaluation of certain veterinary drugs - Joint FAO/WHO Expert Committee on Food Additives, Meeting 2010 - Evaluation of data on ractopamine residues in pig tissues

10. Compendium of food additive specifications - Joint FAO/WHO Expert Committee on Food Additives, 73rd meeting 2010

11. Compendium of food additive specifications - Joint FAO/WHO Expert Committee on Food Additives, 74th meeting 2011

12. Residue evaluation of certain veterinary drugs - Joint FAO/WHO Expert Committee on Food Additives. 75th meeting 2011

13. Compendium of food additive specifications - Joint FAO/WHO Expert Committee on Food Additives, 76th meeting 2012

14. Compendium of food additive specifications - Joint FAO/WHO Expert Committee on Food Additives, 77th meeting 2013

FAO Technical Papers are available through the authorized FAO Sales Agents or directly from Sales and Marketing Group, FAO, Viale delle Terme di Caracalla, 00153 Rome, Italy. 


\section{RESIDUE EVALUATION OF CERTAIN \\ VETERINARY DRUGS}

Joint FAO/WHO Expert Committee on Food Additives

78th Meeting 2013

This document contains monographs on residue evaluations of certain veterinary drugs, prepared at the seventy-eight meeting of the Joint FAO/WHO Expert Committee on Food Additives (JECFA), which was held in Geneva, Switzerland, from 5 to 14 November 2013. Four substances were evaluated for the first time - emamectin benzoate, gentian violet, lasalocid sodium and zilpaterol hydrochloride. Four additional substances were re-evaluated - derquantel, ivermectin, monepantel and recombinant bovine somatotrophins. The monographs provide information on chemical identity and properties of the compounds, pharmacokinetics and metabolism, residue depletion studies and analytical methods validated and used for the detection and quantification of the compounds. In addition, this document provides an overview of the pilot project to evaluate alternative approaches to estimate daily intakes of residues of veterinary drugs in foods and provides guidance on the extrapolation of MRLs to minor species and for the establishment of MRLs in honey. This publication and other documents produced by JECFA contain information that is useful to all those who work with or are involved with recommending or controlling maximum residue limits for veterinary drugs in foods of animal origin.

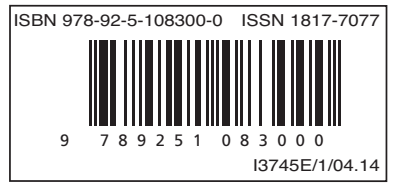

